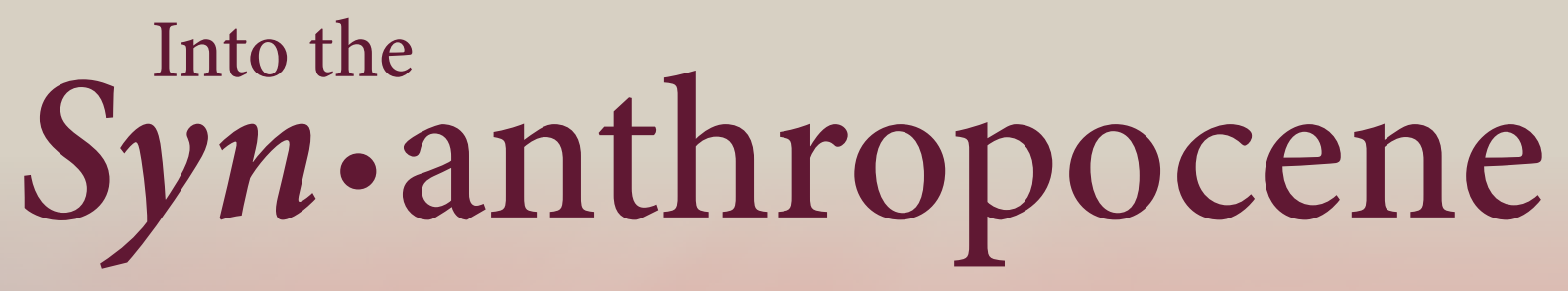

\title{
The Resynchronized Architecture of a Keystone Species
}

Simon Sharon Gordon

Master of Architecture Thesis

Ryerson University

2020 



\title{
Into the Syn-anthropocene: \\ The Resynchronized Architecture of a Keystone Species
}

by

\section{Simon Sharon Gordon}

\author{
Bachelor of Education \\ University of Ontario Institute of Technology \\ 2014 \\ Bachelor of Architectural Studies \\ University of Waterloo
}

2011

\author{
A thesis \\ presented to Ryerson University \\ in partial fulfillment of the \\ requirements for the degree of \\ Master of Architecture \\ in the program of \\ Architecture \\ Toronto, Ontario, Canada, 2020 \\ (c) Simon Sharon Gordon, 2020
}




\section{Author's Declaration}

I hereby declare that I am the sole author of this thesis. This is a true copy of the thesis, including any required final revisions, as accepted by my examiners.

I authorize Ryerson University to lend this thesis to other institutions or individuals for the purpose of scholarly research.

I further authorize Ryerson University to reproduce this thesis by photocopying or by other means, in total or in part, at the request of other institutions or individuals for the purpose of scholarly research.

I understand that my thesis may be made electronically available to the public. 
Into the Syn-anthropocene:

The Resynchronized Architecture of a Keystone Species

Master of Architecture 2020

Simon Sharon Gordon

Architecture

Ryerson University

\section{Abstract}

We share this world with millions of other species. While humans have claimed and transformed vast territories of the planet, our homogenized environments show little regard for the countless birds, mammals, and other creatures that move through these urban jungles. The relationship between culture and nature is ever evolving, and where it goes next is a question at the forefront of architectural discourse. This thesis sets out to explore how architecture can respond to the socio-ecological tensions between wildlife and the built environment. The research identifies a subset of biological subjects that inform a design process which aims to resynchronize architecture with ecological dynamics. The thesis culminates with a proposal for a hybrid eco-cultural hub which celebrates biodiversity and promotes an emerging paradigm shift; it is a step toward redefining humanity as a keystone species - one whose design interventions are aligned with other subjects with whom we share the ecosystem. 


\section{Acknowledgments}

I would like to express tremendous gratitude to Professor Marco Polo for acting as supervisor of my thesis as well as for his role throughout the entirety of my graduate studies at Ryerson University. He shaped the beginning of our graduate studies with the Venice studio - a time characterized by his pedagogical expertise in architecture, his affable rapport, his knack for locating the most interesting parts of our work and driving us forward, and taking our cohort on a once-in-a-lifetime adventure abroad that we will forever cherish. Throughout the entire development process of my thesis, he has been an invaluable guide in providing highly reliable and continual feedback, in sharing distinctive insights from his wealth of knowledge that helped deepen and enrich my work, and in helping me discover the unique moments of meaning in my own project.

I would like to sincerely thank my second reader Professor Terri Peters. It was incredibly useful to have her perspective on the topic, which enabled me to look at my project from other angles. She provided countless sources of information and brought a level of energy to our discussions that helped enliven and boost my work.

I am very grateful to Dr. Leila Marie Farah, the Program Representative on my committee, who helped to effectively bring my work under scrutiny in a very constructive and fruitful way. Her contribution was essential in moving my project forward.

I would like to sincerely thank Scott Sorli for showing great interest in my work during the second studio term and referring me to the work of Sarah Gunawan; this was my first introduction to the notion of the synanthrope - an idea that became a useful catalyst for my thesis.

It was a privilege to have Joyce Hwang as a guest critic during my final thesis defense, whose commendable work at Ants of the Prairie is doing in practice what my thesis process has been testing in theory. Likewise, it was personally meaningful to have Lola Sheppard serve as a guest critic; I greatly respected her as my first studio instructor at the beginning of my undergraduate architecture studies, so it was meaningful to have her input at the end of my graduate degree. 
I would like to thank my classmates; I am very grateful for the bonds and friendships I have made with the students in this cohort. They have been a source of support and insight in all things practical and theoretical. We have been through a lot collectively and I am happy for what we have accomplished here together. I would especially like to thank Bianca Verwaayen, Michael Mazurkiewicz, Alex Caskey, Mitchell Cairns-Spicer, Andres Guzman Romero, and Amir Teyouri for their notable contributions to my thesis.

I want to express appreciation to my group of friends from the University of Waterloo Bachelor of Architecture cohort of 2011, who showed support and attended my final thesis defense. Thank you Leon Lai for our meaningful conversation afterward with respect to my growth and development in this field.

I want to thank my mother for hosting me during the last two months of the thesis at the onset of the pandemic. While we supported each other, it helped to be in a space free of distractions where I could focus on finishing my thesis during this critical part of the process.

Finally, I have to thank my dear friend Dr. Aaron Rosen. We have been through a lot together since high school. Thank you for reading and editing my work, for helping me set up the lighting and organization of my presentation space before the final defense via Zoom, and for providing ongoing support during this entire process. Your friendship has been invaluable these 18 years. 


\section{Dedication}

For my mom.

I know how happy this has made you.

Thank you for everything. 
And for our amazing distant relatives. 


\section{Table of Contents}

Author's Declaration

Abstract iii

Acknowledgments iv

Dedication vi

List of Figures $\quad \mathrm{X}$

List of Appendices $\quad$ xxvi

Lexicon $\quad$ xxix

Preface $\quad$ xxxi

Introduction $\quad 1$

PART 1 | The Anthropocene: A Human Geological Age 5

$\begin{array}{ll}\text { CHAPTER } 1 \text { Socio-Ecological Tensions } & 7\end{array}$

1.1 Chaos \& Order $\quad 9$

1.2 The Socio-Ecological Scene 11

1.3 Benefits from Nature $\quad 15$

CHAPTER 2 The Urban Landscape 21

2.1 Urban Challenges $\quad 23$

2.2 New Opportunities

CHAPTER 3 Contemporary Responses 33

3.1 Precedent Studies $\quad 35$

3.2 Syntax of Boundaries $\quad 59$

3.3 A New Paradigm 
CHAPTER 4 Objective \& Strategy 71

4.1 Objective $\quad 73$

$\begin{array}{ll}4.2 \text { Strategy } & 75\end{array}$

4.3 A Range of Scales $\quad 83$

4.4 Boundary Relationships $\quad 85$

$\begin{array}{lr}\text { CHAPTER } 5 \text { Site Analysis } & 91\end{array}$

5.1 Socio-Ecological Context 93

5.2 Toronto: an Urban Laboratory 99

$\begin{array}{lr}5.3 \text { Wildlife in Toronto } & 105\end{array}$

CHAPTER 6 Biological Subjects 111

6.1 Ecological Dynamics 113

6.2 Animal Compendium 117

PART 3 | The Syn-anthropocene: Resynchronizing Architecture $\quad 139$

CHAPTER 7 An Evolving Architecture 141

7.1 Mutated Forms 143

7.2 Repurposed Scapes 151

$\begin{array}{ll}\text { 7.3 Designed Ecotopes } & 161\end{array}$

CHAPTER 8 A Synanthropic Centre 173

8.1 A Biological Centre 175

8.2 Schematic Design 185

8.3 The Synanthropic Centre 187

8.4 Into the Synanthropocene 221

Conclusion Resynchronized Architecture 223

Epilogue Reflection on Covid-19 227

Appendix 230

$\begin{array}{ll}\text { Bibliography } & 269\end{array}$ 


\section{List of Figures}

Bubbles flow in oil fat with colorful view. 2018. Accessed January 12, 2019.

Cover https://www.freepik.com/premium-photo/bubbles-flow-oil-fat-with-colorfulview 3003372.htm.

I-1a Runge, Veronica. Loggerhead turtle hatchlings make their way to the sea in Juno XXX Beach, Florid. N.d. Accessed March 15, 2020. https://oceanservice.noaa.gov/news/ june15/sea-turtles.html.

I-1b BBC. [Hawksbill turtle hatchling lost in the city streets of Barbados]. In Planet Earth II - Cities. 2016. Television series. United Kingdom. Accessed February 3, 2019. https://www.netflix.com/watch/80195263?trackId=200257858.

\section{Introduction}

I-2a BBC. Planet Earth II - Islands. 2016. Television series, United Kingdom. Accessed February 3, 2019. https://www.netflix.com/watch/80195258?trackId=200257859.

I-2b BBC. Planet Earth II - Jungles. 2016. Television series, United Kingdom. Accessed February 3, 2019. https://www.netflix.com/watch/80195260?trackId=200257858.

I-2c BBC. Planet Earth II - Deserts. 2016. Television series, United Kingdom. Accessed February 3, 2019. https://www.netflix.com/watch/80195261?trackId=200257858.

I-2d BBC. Planet Earth II - Grasslands. 2016. Television series, United Kingdom. Accessed February 3, 2019. https://www.netflix.com/ watch/80195262? trackId=200257858.

I-2e BBC. Planet Earth II - Mountains. 2016. Television series, United Kingdom. Accessed February 3, 2019. https://www.netflix.com/ watch/80195259? trackId=200257858.

I-2f BBC. Planet Earth II - Cities. 2016. Television series, United Kingdom. Accessed February 3, 2019. https://www.netflix.com/watch/80195263?trackId=200257858.

I-3a Reischig, Josef. Microscope image of cells in various stages of mitosis. N.d. Image. Accessed July 3, 2019. https://teachmephysiology.com/basics/cell-growth-death/ mitosis/.

I-3b BBC. Planet Earth II - Cities. 2016. Television series, United Kingdom. Accessed February 3, 2019. https://www.netflix.com/watch/80195263?trackId=200257858.

I-4 Gordon, Simon. The Synanthrope. 2020. Illustration. Toronto.

I-5 Gordon, Simon. The Antithrope. 2020. Illustration. Toronto.

I-6 Gordon, Simon. The threshold between wilderness and human space. 2019. Sketch. Toronto. 


\section{Chapter 1}

1-1 Google satellite image. N.d. Image. Accessed November 12, 2019. https://www. 6

1-2 Goltzius, Hendrick. Apollo Killing the Python. 1589. Engraving. 21.6 x $29.2 \mathrm{~cm}$. Los

Angeles County Museum of Art, Los Angeles. Accessed March 12, 2020. https:// collections.lacma.org/node/688265.

1-3 Fussli, Johann Heinrich. Thor's Battle with the Midgard Serpent. 1788. Accessed March 12, 2020. https://norse-mythology.org/tales/thor-fishing-for-jormungand/ johann heinrich_fussli-thors-battle-with-the-midgard-serpent/.

1-4 Tour Egypt. Tutankhamun Ouroboros - Enigmatic Book of the Netherworld. 1325 BC. Photograph. Accessed March 12, 2020. http://www.soul-guidance.com/ houseofthesun/ouroboros.html.

1-5 Boucicaut Master. The Temptation of Adam and Eve. 1414. Ink on parchment. 42 x $29.6 \mathrm{~cm}$. The J. Paul Getty Museum, Los Angeles. Accessed July 23, 2019. http:// www.getty.edu/art/collection/objects/105151/boucicaut-master-the-story-of-adamand-eve-french-about-1413-1415/.

1-6 Coustou, Nicolas. Gaius Julius Caesar. 44 BC. Marble statue. 242 x 96 x 96 cm. Louvre Museum, Paris. Accessed February 2, 2020. https://www.pinterest.ca/ pin/83035186850198452/.

1-7 Gordon, Simon. Distribution of land, worldwide. 2020. Illustration. Toronto.

1-8 WWF Living Planet Report 2018. The Living Planet Index (LPI) of global biodiversity. 2018. Accessed February 12, 2019. http://www.livingplanetindex.org/ projects? main page project=LivingPlanetReport\&home flag=1.

1-9 WWF International. Benefits from Nature. In WWF Living Planet Report 2018. Gland: WWF, 2018, 18.

1-10 Seeman, Corey. Ann Arbor Arboretum. 2018. Accessed March 12, 2019. https:// www.flickr.com/photos/cseeman/27701380357.

1-11a Pharand-Deschenes, Felix. The Great Acceleration: Socio-Economic Trends. Image. Adapted from The Trajectory of the Anthropocene: the Great Acceleration. Will Steffan, Wendy Broadgate, Lisa Deutsch, Owen Gaffney and Cornelia Ludwig. Accessed December 12, 2019. https://eyeson.earth/blog-ii/2017/2/24/ kuib9wcv02btkombjzxk3h5pcndajv.

1-11b Pharand-Deschenes, Felix. The Great Acceleration: Earth System Trends. Image. Adapted from The Trajectory of the Anthropocene: the Great Acceleration. Will Steffan, Wendy Broadgate, Lisa Deutsch, Owen Gaffney and Cornelia Ludwig. Accessed December 12, 2019. https://eyeson.earth/blog-ii/2017/2/24/ kuib9wcv02btkombjzxk3h5pcndajv 


\section{Chapter 2}

2-1 Urquhart, Eric. New York City. N.d. Photograph. Accessed March 12, 2020. https:// www.twenty20.com/photos/57591820.

2-2a Canadian Architect. Photograph of Downtown Toronto. N.d. Image. Accessed

January 12, 2020. https://www.canadianarchitect.com/community-buildi ng/1002718439-1002718441/.

2-2b Wildlife Rehabilitators Association of Rhode Island. Raccoon Stuck in Sewer

Grate Freed by Animal Clinic. 2017. Photograph. Accessed July 21, 2019. https:// www.necn.com/news/new-england/Raccoon-Sewer-Grate-Rescue-RhodeIsland-442216183.html.

2-2c Lindsey, Robin. Caution, Canada geese crossing. 2011. Photograph. Accessed July 21, 2019. https://westseattleblog.com/2011/05/west-seattle-scene-caution-canadageese-crossing/.

2-2d Young Cat Hunted a Bird. 2018. Photograph. Accessed July 21, 2019. https://www. amusingplanet.com/2018/07/how-single-cat-hunted-to-extinction.html.

2-2e Look After My Bills. Office Building at Night. N.d. Photograph. Accessed July 21, 2019. https://lookaftermybills.com/office-buildings-at-night/.

2-2f Fatal Light Awareness Program. Northern goshawk that mistook a window for open sky. 2002. Photograph in Urban Wildlife Management, Adams, Clark E. (New York: Taylor \& Francis, 2006) 118.

2-2g La Citta Vita. Community Planning. 2010. Photograph. Online. Accessed July 12, 2019. https://commons.wikimedia.org/wiki/File:Community planning (6045997984).jpg.

2-3 Northrop, Robert. Illustration of the loss of core habitat (or interior habitat) caused by road construction cutting through a patch of habitat. 2019. Illustration. http:// blogs.ifas.ufl.edu/hillsboroughco/2019/12/16/urban-natural-areas-2-habitatfragmentation/. 
2-4 Belle, Holl. Hundreds of birds appear to fly into NASCAR Hall of Fame building, killing themselves. 2019. Video frame. Accessed March 8, 2020. https://www. fox46charlotte.com/video/615446.

2-5a Neff, Andrew. American National Insurance building in Galveston, Texas. 2020. Photograph. Accessed March 8, 2020. https:/www.google.com/maps/

2-5b Henderson, Josh. Hundreds of migratory birds were killed after they slammed into a tall building in Galveston, Texas. 2017. Photograph. Accessed March 9, 2020. https:// www.washingtonpost.com/news/animalia/wp/2017/05/10/one-tall-buildingone-dark-and-stormy-night-395-dead-birds/?fbclid=IwAR0L08bFzw7q7N x -B penZGcFrZ1Kvy0LeU1PJ9nPSRSCyQ2sRkGAIZXNo.

2-6 Fatal Light Awareness Program. 2016 FLAP Canada Bird Layout. 2016. Video frame. Accessed January 4, 2019. https://www.smithsonianmag.com/smart-news/ pattern-made-2100-dead-birds-180958379/.

2-7 Bridgman, Lorne. [Ryerson Student Learning Centre by Zeidler Partnership Architects \& Snohetta: Exterior view of the patterned glazing]. N.d. Photograph. Accessed March 8, 2020. https://www.archdaily.com/771491/ryerson-universitystudent-learning-centre-zeidler-partnership-architects-plus-snohetta.

2-8 Bridgman, Lorne. [Ryerson Student Learning Centre by Zeidler Partnership Architects \& Snohetta: Interior view of the patterned glazing]. N.d. Photograph. Accessed March 8, 2020. https://www.archdaily.com/771491/ryerson-universitystudent-learning-centre-zeidler-partnership-architects-plus-snohetta.

2-9 [Plan \& Section of a Pigeonnier]. N.d. Architecture Drawing. Accessed August 12, 2019. https://espritdepays.com/patrimoines-en-perigord/patrimoine-bati-duperigord/colombiers-pigeonniers-perigord/l-architecture-d-un-pigeonnier.

2-10 [Pigeonnier]. N.d. Photograph. Accessed August 12, 2019. https://www.creully. net/2012/09/. 


\section{Chapter 3}

3-1 Gordon, Simon. Precedents. 2019. Illustration. Toronto. 33

3-2 Tschumi, Bernard, and Dereck Revington. The coyote at the edge of digital mass 37 culture. 1999. Image. Accessed August 9, 2019. https://cpb-us-e1.wpmucdn.com/ blogs.uoregon.edu/dist/7/12542/files/2016/03/111019_GSD-2241_PLANTINGSYSTEMS-LECTURE MICHAEL-FLYNN-xuevxi.pdf.

3-3 Tschumi, Bernard, and Derek Revington. Design Overview: Downsview Park Competition. 1999. Image. Accessed August 9, 2019. https://www.pinterest.ca/pin/1 $04427285089552606 /$ ? $1 \mathrm{p}=$ true.

3-4 Sartore, Joel. Trans-Canada Highway wildlife crossings in Banff National Park. 2019. Photograph. Accessed July 28, 2019. https://www.nationalgeographic.com/ animals/2019/04/wildlife-overpasses-underpasses-make-animals-people-safer/.

3-5 Faulkner, Kirsty. Crabs scaling the specially built bridge. 2015. Photograph. Accessed July 28, 2019. https://www.telegraph.co.uk/news/worldnews/australiaandthepacific/ australia/12045930/Crabs-get-their-own-bridge-to-cross-busy-road-on-ChristmasIsland.html.

3-6 Kerr, Doug. Wildlife Crossing - New Jersey. 2017. Photograph. Accessed July 28, 2019. https://mymodernmet.com/wildlife-crossings/.

3-7 British Columbia Ministry of Transportation and Infrastructure. Hello there Badger! 2019. Photograph. Accessed March 30, 2020. https://www.tranbc.ca/2019/04/17/ burrowing-badger-caught-on-bc-wildlife-underpass-cam/.

3-8 Colorado Department of Transportation. Wildife underpasses. 2018. Photograph. Accessed March 30, 2020. https://www.mnn.com/earth-matters/animals/stories/ wildlife-crossings-helping-animals-drivers-colorado.

3-9 Colorado Department of Transportation. Finding the best routes for wildife requires state agencies to work together. 2018. Photograph. Accessed March 30, 2020. https:// www.mnn.com/earth-matters/animals/stories/wildlife-crossings-helping-animalsdrivers-colorado.

3-10 Lane, Steven. The Washington Department of Fish and Wildlife uses a vacuumpowered transport system, aka a salmon cannon, to move chinook salmon to a waiting truck and then to a hatchery on the upper Washougal River. 2019. Photograph. Accessed March 12, 2020. https://www.hakaimagazine.com/article-short/fish-intubes/.

3-11 Video grab of a salmon being transported. 2019. Video frame. Accessed July 15, 2019. https://www.news18.com/news/buzz/whats-the-salmon-cannon-and-why-has-itbecome-internets-latest-obsession-2275891.html. 
3-12 Video grab of a salmon being transported. 2019. Video frame. Accessed July 15, 2019. https://www.news18.com/news/buzz/whats-the-salmon-cannon-and-why-has-itbecome-internets-latest-obsession-2275891.html.

3-13 Studio Gang. Ford Calumet Environmental Center. 2008. Image. Accessed June 27, 2019. https://studiogang.com/project/ford-calumet-environmental-center.

3-14 Studio Gang. Glass Barrier Design. 2008. Image. Accessed June 27, 2019. https:// studiogang.com/project/ford-calumet-environmental-center.

3-15 Studio Gang. A synthesis of environmental systems allows the building to function organically using minimal energy. 2008. Image. Accessed June 27, 2019. https:// studiogang.com/project/ford-calumet-environmental-center.

3-16 Yamchomsuan, Phuchong. The parasitic structure that expands into a new urban fabric. 2016. Image. Accessed January 18, 2019. http://www.evolo.us/the-banyantree-skyscraper-was-designed-to-support-humans-and-wildlife/.

3-17 Yamchomsuan, Phuchong. The ground plane is given over for nature to overtake. 2016. Image. Accessed January 18, 2019. http://www.evolo.us/the-banyan-treeskyscraper-was-designed-to-support-humans-and-wildlife/.

3-18 Boeri, Stefano. Bosco Verticale. 2014. Photograph. Accessed September 22, 2019. https://www.stefanoboeriarchitetti.net/en/project/vertical-forest/.

3-19 [Avis residence and family]. N.d. Photograph. Accessed March 8, 2019. https://www. coenfarm.ca/resources/optimal-human-health-video-series-4-a-permacultureengineers-perspective-on-diet-and-human-health.

3-20 Avis, Rob. Rowan and Naomi picking fresh carrots in the food jungle that is our backyard. 2018. Photograph. Accessed April 12, 2020. https://medium. com/@rob 74123/tire-ponds-urban-swales-growing-food-for-our-family-thetransformation-of-our-urban-home-a5a259a0283f.

3-21 [Home of Rob and Michelle Avis: the Verge Permaculture Homestead]. N.d. Image.

Google Street-view. Accessed Febraury 28, 2019. https://www.google.com/maps/pla ce/227+Fonda+Way+SE,+Calgary,+AB+T2A+4Z7/@51.0467879,-113.9734735,19z/

3-22 Crook, Alex. [Amazon Spheres: man walking along path]. 2018. Photograph. Accessed October 8, 2019. http://seattlemag.com/news-and-features/photo-galleryinside-amazons-spheres.

3-23a Crook, Alex. [Amazon Spheres: path from above]. 2018. Photograph. Accessed October 8, 2019. http://seattlemag.com/news-and-features/photo-gallery-insideamazons-spheres.

3-23b Crook, Alex. [Amazon Spheres: window-frame with organic form]. 2018. Photograph. Accessed October 8, 2019. http://seattlemag.com/news-and-features/ photo-gallery-inside-amazons-spheres. 
3-23c Crook, Alex. [Amazon Spheres: stairway]. 2018. Photograph. Accessed October 8, 2019. http://seattlemag.com/news-and-features/photo-gallery-inside-amazonsspheres.

3-23d Crook, Alex. [Amazon Spheres: seating area]. 2018. Photograph. Accessed October 8, 2019. http://seattlemag.com/news-and-features/photo-gallery-inside-amazonsspheres.

3-23e Crook, Alex. [Amazon Spheres: bird's nest]. 2018. Photograph. Accessed October 8, 2019. http://seattlemag.com/news-and-features/photo-gallery-inside-amazonsspheres.

3-24 Baracco, M., Horwill, C. and Ware, J. Mid-rise, courtyard-focused buildings and wide boulevard streetscapes created through a biodiversity sensitive urban design approach. N.d. Image. Accessed July 11, 2019. https://theconversation.com/heres-how-todesign-cities-where-people-and-nature-can-both-flourish-102849.

3-25 Gordon, Simon. Syntax of Boundaries. 2019. Illustration. Toronto.

3-26 Ogahara, Maria. [In Touch with Nature: Conceptual Parti]. N.d. Image. Accessed September 25, 2019. http://tu-braunschweig-ila.de/projekt/in-touch-with-nature/.

3-27 Ogahara, Maria. [In Touch with Nature: Axonometric of animal habitats embedded in an exterior wall]. N.d. Image. Accessed September 25, 2019. http://tubraunschweig-ila.de/projekt/in-touch-with-nature/.

3-28 Ogahara, Maria. [In Touch with Nature: Species-specific homes in an exterior wall]. N.d. Image. Accessed September 25, 2019. http://tu-braunschweig-ila.de/projekt/ in-touch-with-nature/.

3-29 Blue tit using a Standard bird box; not fully mortard in, allowing box front to be removed for cleaning and monitoring. N.d. Photograph. Accessed April 2, 2020. https://www.birdbrickhouses.co.uk/brick-nesting-boxes/nesting-boxes/.

3-30 Swift box, internal. N.d. Photograph. Accessed April 2, 2020. https://www. birdbrickhouses.co.uk/brick-nesting-boxes/nesting-boxes/.

3-31 Standard nest box, stretcher bond brick fronted. N.d. Photograph. Accessed April 2, 2020. https://www.birdbrickhouses.co.uk/brick-nesting-boxes/nesting-boxes/.

3-32 Gunawan, Sarah. Compost Chimney Section: From Synanthropic Suburbia:

Illustration. Waterloo: Sarah Gunawan, University of Waterloo, 2015. Accessed June 2, 2019. https://uwspace.uwaterloo.ca/handle/10012/9765.

3-33 Ogahara, Maria. [In Touch with Nature: Synanthropic Neighbourhood]. N.d. Image. Accessed September 25, 2019. http://tu-braunschweig-ila.de/projekt/in-touch-withnature/.

3-34 Ogahara, Maria. [In Touch with Nature: Synanthropic Co-habitation]. N.d. Image. Accessed September 25, 2019. http://tu-braunschweig-ila.de/projekt/in-touch-withnature/. 


\section{Chapter 4}

4-1 Gordon, Simon. Parameter considerations. 2019. Illustration. Toronto 70

4-2 Gordon, Simon. Strategy Conceptualization. 2019. Illustration. Toronto 71

4-3 Gordon, Simon. Architecture as landscape. 2019. Idea in a Sketchbook. Toronto. 74

4-4 Gordon, Simon. Hierarchy of Priorities. 2019. Illustration. Toronto. 76

$\begin{array}{lll}\text { 4-5 Gordon, Simon. Urban Network. 2019. Illustration. Toronto. } & 78\end{array}$

4-6 Gordon, Simon. Meanings of "Scape." 2019. Drawing in a Sketchbook. Toronto. 79

4-7 Gordon, Simon. Street Overpass Section. 2019. Illustration. Toronto. 79

4-8 Gordon, Simon. Underpass Sketch. 2019. Illustration. Toronto. 80

4-9 Gordon, Simon. Street Underpass Section. 2019. Illustration. Toronto. 80

4-10a Arana, Usue Ruiz. Dry Meadow: From Rewilding the Gardiner Expressway. 2016.

4-10b Arana, Usue Ruiz. Grassland: From Rewilding the Gardiner Expressway. 2016. Video 82

Frame. Accessed June 6, 2019. https://rewildingthegardiner.com/.

4-10c Arana, Usue Ruiz. Rubble Edge: From Rewilding the Gardiner Expressway. 2016.

Video Frame. Accessed June 6, 2019. https://rewildingthegardiner.com/.

4-10d Arana, Usue Ruiz. Woodland: From Rewilding the Gardiner Expressway. 2016. Video 82

Frame. Accessed June 6, 2019. https://rewildingthegardiner.com/.

4-10e Arana, Usue Ruiz. Embayment Edge: From Rewilding the Gardiner Expressway. 82

2016. Video Frame. Accessed June 6, 2019. https://rewildingthegardiner.com/.

4-10f Arana, Usue Ruiz. Wetland: From Rewilding the Gardiner Expressway. 2016. Video 82

Frame. Accessed June 6, 2019. https://rewildingthegardiner.com/.

4-10g Arana, Usue Ruiz. Map of the Rewilded Gardiner Expressway: From Rewilding

the Gardiner Expressway. 2016. Video Frame. Accessed June 6, 2019. https://

rewildingthegardiner.com/.

4-11 Gordon, Simon. Range of Scales. 2019. Illustration. Toronto. 84

4-12 Villegas, Tim. Inclusion, Exclusion, Segregation and Integration: How are they 85

Different. July 11, 2017. Illustration. Accessed April 25, 2020. https://www.

thinkinclusive.us/inclusion-exclusion-segregation-integration-different/.

4-13 Gordon, Simon. Categories of Boundary Relations. 2019. Illustration. Toronto. 86

4-14 Gordon, Simon. Bat-observation deck on the banks of a river. 2019. Illustration. 87

Toronto.

4-15 Gordon, Simon. Neighbouring Territories. 2019. Illustration. Toronto. 88

4-16a Gordon, Simon. Enclosed scape through buildings - Hydro One building. 2019.

4-16b Gordon, Simon. Enclosed scape through buildings - Eaton Centre. 2019. Illustration. 89

4-17 Gordon, Simon. Blended heterogeneous spaces. 2019. Illustration. Toronto. 90 


\section{Chapter 5}

5-1 The Carolinian Zone. N.d. Image. Accessed March 4, 2020. https://caroliniancanada. ca/about.

5-2 Discovering the beauty of Ontario's southern belle: the Carolinian Forest. 2014.

Photograph. Accessed March 4, 2020. https://www.ontarioparks.com/parksblog/ discovering-the-beauty-of-ontarios-southern-belle-the-carolinian-forest/.

5-3 $19^{\text {th }}$ century estimate of the boundaries of Lake Iroquois. 1893. Map. Accessed March 4, 2020. https://en.wikipedia.org/wiki/Glacial_Lake_Iroquois.

5-4 Almas, Andrew, and Conway, Tenley. Map of the Carolinian Forest Zone in Canada. 2018. Map. Accessed March 4, 2020. https://www.researchgate.net/ publication/323816406 Resident Attitudes and Actions Toward Native Tree Species_A Case Study of Residents in_Four_Southern_Ontario_Municipalities/ figures? $\mathrm{lo}=1$ \&utm source=google\&utm medium $=$ organic. .

5-5 Canada's Forest Regions. 2019. Image. Accessed March 4, 2020. https://www.reddit. com/r/canada/comments/8liu58/canadas forest regions/

5-6 Toronto, Historical: Looking northeast at foot of Parliament. At the left, Gooderham \& Worts and other industries through which the city prospered. N.d. Colour lithograph. Baldwin Room, Metropolitan Toronto Library, Toronto. Accessed March 7, 2020. https://thecanadianencyclopedia.ca/en/article/industrialization.

5-7 The Carolinian forest: highly-prized woodland. May 4, 2018. Photograph. Accessed March 9, 2020. https://www.the-forest-time.com/en/guides-des-pays-et-regions/ canada/the-carolinian-forest-highly-prized-woodland-5ae9c811c.

5-8a [Bird's-eye photograph of Tommy Thompson Park in the year 1967]. 1967. Photograph. Accessed March 8, 2020. https://tommythompsonpark.ca/about/.

5-8b [Bird's-eye photograph of Tommy Thompson Park in the year 1975]. 1975. Photograph. Accessed March 8, 2020. https://tommythompsonpark.ca/about/.

5-8c [Bird's-eye photograph of Tommy Thompson Park in the year 1987]. 1987. Photograph. Accessed March 8, 2020. https://tommythompsonpark.ca/about/.

5-8d [Bird's-eye photograph of Tommy Thompson Park in the year 1998]. 1998. Photograph. Accessed March 8, 2020. https://tommythompsonpark.ca/about/.

5-8e [Bird's-eye photograph of Tommy Thompson Park in the year 2013]. 2013. Photograph. Accessed March 8, 2020. https://tommythompsonpark.ca/about/.

5-9 Baptista, Kyle. Parks of Toronto. N.d. Image. Accessed October 18, 2019. https:// www.blogto.com/city/2014/02/new_map_shows_off_the_massive_park_system in toronto/.

5-10 Gordon, Simon. Discovery Walk sign by Dundas Street and Crawford Street along the Garrison Creek route. 2019. Photograph. Toronto. 
5-11 Gordon, Simon. Garrison Creek's Historical Route. August 19, 2019. Illustration. Toronto.

5-12 Google Maps. Humber River. N.d. Satellite Image. Accessed June 14, 2019. https:// www.google.com/maps/place/Humber+River/@43.6567489,-79.5048964,6588m/

5-13a Gordon, Simon. Tree of cormorants. July 15, 2019. Photograph. Toronto. 106

5-13b Gordon, Simon. Egret Standing. July 15, 2019. Photograph. Toronto. 106

5-13c Gordon, Simon. Turtle on Log. July 15, 2019. Photograph. Toronto. 106

5-14a Google Maps. Toronto Wildlife Centre Patients. 2019. Map data imagery. Accessed 107 August 28, 2019. https://www.torontowildlifecentre.com/what-we-do/wildlifehotline/.

5-14b Greene, Scott. Virginia Oppossum (Didelphis Virginiana). 2017. Photograph. Accessed August 29, 2019. https://www.littlestsimonsisland.com/blog/virginiaopossum-didelphis-virginiana.

5-14c Nicholas, Wayne. Red-eyed Vireo. N.d. Photograph. Accessed August 29, 2019. https://houstonaudubon.org/birding/gallery/red-eyed-vireo.html.

5-14d Wilson, JD. Brown Snake. N.d. Photograph. Accessed August 29, 2019. http:// herpsofnc.org/brown-snake/.

5-14e Toronto Wildlife Centre. Toronto Wildlife Centre Logo. 2019. Image. Accessed August 28, 2019. https://direct.pumprofessionals.org/job/toronto-wildlife-centre60-carl-hall-rd-north-york-on-m3k-2c1-long-term-volunteering-toronto-wildlifecentre-general-volunteer/.

\section{Chapter 6}

6-1 Gordon, Simon. Biological Subjects. 2019. Illustration. Toronto.

6-2 Gordon, Simon. Falcon at Osgoode Hall on Queen Street. 2019. Photograph.

6-3 Gordon, Simon. Symbiotic Relationships. 2020. Illustration. Toronto.

6-5 Harrison, JJ. Mycena interrupta. May 11, 2010. Photograph. Accessed July 12, 2019. https://commons.wikimedia.org/w/index.php?curid=10365439.

6-6 Gordon, Simon. Flyers, Climbers, and Diggers. 2019. Illustration. Toronto. 
6-9 Dinesman, Brad. Loggerhead Shrike eats its prey that it had impaled on barbed wire. 2019. Photograph. Accessed August 23, 2019. http://www.thefieldbrookreserve. com/Birds/Shrikes.asp.

6-10 The IUCN Red List of Threatened Species. Geographical Range of the Loggerhead Shrike. 2016. Image. Accessed August 23, 2019. https://www.iucnredlist.org/ species/22705042/118908179.

6-11 Ritchison, Gary. Loggerhead Shrikes in Kentucky. N.d. Photograph. Accessed March 5, 2019. http://people.eku.edu/ritchisong/shrike.html.

6-12 Staake, Jill. Winter Roosting Sites for Birds. 2011. Photograph. Accessed March 5, 2019. http://www.birdsandblooms.com/blog/winter-roosting-sites-for-birds/.

6-13 Gordon, Simon. Barn Owl Specifications. 2019. Illustration. Toronto.

6-14 Barn owls at church. 2013. Photograph. Accessed March 5, 2020. https://www.

6-15 The IUCN Red List of Threatened Species. Geographical Range of the Common

Barn-owl. 2019. Image. Accessed August 25, 2019. https://www.iucnredlist.org/speci es/22688504/155542941\#habitat-ecology

6-16 Fuller, Robert E. Barn owl nest camera. 2018. Photograph. Accessed August 25, 2019. https://www.robertefuller.com/diary/category/nestcams/barn-owl-nestcamera/

6-17 Gordon, Simon. Barn Owl Nest Box Design Requirements. 2019. Sketch. Toronto.

6-18 Bird Spot. Owl Nest Boxes. N.d. Photograph. Accessed August 25, 2019. https:// www.birdspot.co.uk/bird-boxes/owl-nest-boxes.

6-19 Gordon, Simon. Little Brown Bat Specifications. 2019. Illustration. Toronto.

6-20 Count Duncan Von Trisk. 2012. Image. Accessed March 2, 2020. https://www. dandwiki.com/wiki/Count Duncan Von Trisk (3.5e NPC).

6-21 Bats take flight at sunset. N.d. Photograph. Accessed March 2, 2020. https:// texashighways.com/travel/these-10-texas-nature-conservancy-preserves-offerpublic-access-and-plenty-of-awe-inspiring-sights/attachment/attachment-batstake-flight-at-sunset/

6-22 The IUCN Red List of Threatened Species. Geographical Range of the Little Brown Bat. 2008. Image. Accessed April 2, 2020. https://www.iucnredlist.org/ species/14176/22056344.

6-23a Gaudet, Connie L. Bat roost location in natural environments. N.d. Sketch in Just Bats by M. Brock Fenton. Toronto: University of Toronto Press, 1983, 83. 
6-23b Gaudet, Connie L. Bat roost location in buildings. N.d. Sketch in Just Bats by M. Brock Fenton. Toronto: University of Toronto Press, 1983, 82.

6-24 Gordon, Simon. Bat Roost Requirements. 2019. Sketch. Toronto. 130

6-25 Gordon, Simon. Bat Roost Prototype. 2019. Photograph. Toronto. 130

6-26 Gordon, Simon. Common Raccoon Specifications. 2019. Illustration. Toronto. 131

6-27 Gordon, Simon. Raccoon Mural by Dundas Square in Toronto. 2019. Photograph. 132

6-28 The IUCN Red List of Threatened Species. Geographical Range of the Northern 133 Raccoon. 2008. Image. Accessed May 10, 2019. https://www.iucnredlist.org/ species/41686/45216638.

6-29 Griffin, J. Female raccoon and her young in a chimney. N.d. Photograph. Accessed January 19, 2020. https://www.wildlifeillinois.org/get-help/solve-a-wildlifeproblem/wildlife-in-my-chimney/

6-30 Rea, Micah. Daredevil Raccoon Scales 9 Floors of New Jersey Building. 2018. Frame of a Video. Accessed May 10, 2019. https://www.youtube.com/watch?v=fItgbnuC$\underline{1 \mathrm{E}}$.

6-31a Johnson, Ben. MPR Raccoon: Exploring the Urban Architecture Behind an Antisocial Climber. 2018. Photograph. Accessed May 10, 2019. https://99percentinvisible. org/article/mpr-raccoon-exploring-the-urban-architecture-behind-an-antisocialclimber/.

6-31b Kohlstedt, Kurt. The path of a raccoon that climbed a high-rise building in St. Paul, Minnesota. 2018. Diagram. Accessed May 10, 2019. https://99percentinvisible. org/article/mpr-raccoon-exploring-the-urban-architecture-behind-an-antisocialclimber/.

6-32 Gordon, Simon. Striped Skunk Specifications. 2019. Illustration. Toronto.

6-33 Looney Tunes. Pepe Le Pew. N.d. Frame in a Video. Accessed April 26, 2020. https:// www.youtube.com/watch?v=upEn5msShdk

6-34 The IUCN Red List of Threatened Species. Geographical Range of the Striped Skunk. 2016. Image. Accessed February 7, 2019. https://www.iucnredlist.org/ species/41635/45211301

6-35 Skunks denning in a hollow log. N.d. Photograph. Accessed February 7, 2019. https://moderndogmagazine.com/articles/what-do-about-skunks/93488.

6-36 Den under a sidewalk. N.d. Photograph. Accessed February 7, 2019. https:// duncannonatc.org/category/outdoors/hiking-tips/. 


\section{Chapter 7}

7-1 British Land via Animal Architecture. The Insect Hotel. N.d. London. Accessed

March 14, 2019. https://www.gwarlingo.com/2011/animal-architecture-a-battower-a-bee-folly-a-five-star-hotel-for-bugs/.

7-2 Gordon, Simon. Responsive Architectural Transformations. 2019. Illustration. Toronto.

7-3 Gordon, Simon. Protruding Brick Ladder. 2019. Sketch. Toronto. Accessed March 24, 2020. https://archello.com/story/73326/attachments/photosvideos.

7-4b Spaceshift Studio. Humble Brick House in Bangkok. 2014. Accessed March 24, 2020. https://divisare.com/projects/286993-junsekino-spaceshift-studio-ngamwongwanhouse.

7-4c CAAT Studio. Perforated brick screens act as curtains for Tehran housing by CAAT Studio. May 10, 2016. Accessed March 24, 2020. https://www.dezeen. com/2016/05/10/kahrizak-residential-housing-caat-studio-tehran-iran-perforatedbrick-screens/.

7-10-b Caskey, Alex. Walking through the laneway. September 6, 2019. Photograph. Toronto.

7-11 Gordon, Simon. The Lanescape. 2019. Illustration. Toronto. 
7-17 Gordon, Simon. A set of Ecotopes. 2019. Sketch. Toronto. 162

7-18 Gordon, Simon. Columnar Raccoon Compartments. 2019. Sketch. Toronto. 163

7-19 Gordon, Simon. Observation opportunities. 2019. Sketch. Toronto. 164

7-20 Gordon, Simon. Multiple compartments. 2019. Sketch. Toronto. 164

7-21 Gordon, Simon. Stepping system. 2019. Sketch. Toronto. 165

7-22 Gordon, Simon. Cross-section. 2019. Sketch. Toronto. 166

7-23 Gordon, Simon. Elevation. 2019. Sketch. Toronto. 166

7-24 Gordon, Simon. Owl box at peak. 2019. Sketch. Toronto. 167

7-25 Gordon, Simon. V-shaped compartment. 2019. Sketch. Toronto. 167

7-26 Gordon, Simon. Iterations. 2019. Sketch. Toronto. 168

7-27 Gordon, Simon. Tower sketches. 2019. Sketch. Toronto. 169

7-28 Gordon, Simon. The Obelisk. 2019. Render. Toronto. 171

\section{Chapter 8}

8-1 Gordon, Simon. In Process. Novembver 14, 2019. Render. Toronto. 173

8-2 Cambridge Seven Associates. Downtown Boston Zoo: From Animals and 175

8-3 Perry, Dean, \& Stewart Architects. Franklin Park Zoo: From Animals and 176 Architecture: Architectural Drawing. London: David Hancocks, H. Evelyn, 1971.

8-4 Yeow, Koh Hau. Urban Ecopoesis. 2010. Accessed October 17, 2019. https:// 177 hauyeow.wordpress.com/2010/08/08/urban-ecopoesis/.

8-5 Gordon, Simon. Bickford Centre. January 13, 2019. Photograph. Toronto. 179

8-6 Gordon, Simon. Longitudinal section through Bickford Centre. 2019. Illustration. 179 Toronto.

8-7 Gordon, Simon. Garrison Creek's Historical Route. 2019. Image. Toronto. 180

8-8a Gordon, Simon. Site Photos: Entry plaza. 2019. Photograph. Toronto. 181

8-8b Gordon, Simon. Site Photos: Elevated catwalk towards entrance. January 13, 2019. Photograph. Toronto.

8-9 Gordon, Simon. Existing Plan - Ground. April 12, 2020. Drawing. Toronto. 182

8-10 Gordon, Simon. Existing Plan - Lower Level. April 12, 2020. Drawing. Toronto. 183

8-11a Gordon, Simon. Site Photos: View from Bickford Park. January 13, 2019.

Photograph. Toronto. 
8-11b Gordon, Simon. Site Photos: View of the underpass from the interior courtyard. January 13, 2019. Photograph. Toronto.

8-12 Gordon, Simon. Rededicating the building to wildlife, sketch on trace paper. January 29, 2019. Sketch. Toronto.

8-13 Gordon, Simon. Visualizing the wetland and the building's new enclosed microclimate. February 2, 2019. Illustration. Toronto.

8-14 Gordon, Simon. Conceptual section of the heterogeneous space. February 10, 2019. Illustration. Toronto.

8-15 Gordon, Simon. The Synanthropic Centre acting as a node within a system. April 18, 2019. Illustration. Toronto.

8-16 Gordon, Simon. Ecological network within the building campus. April 18, 2019. Illustration. Toronto.

8-17 Gordon, Simon. Overview. April 18, 2019. Illustration. Toronto.

8-18 Gordon, Simon. Floor Plan - Ground Level. April 18, 2019. Illustration. Toronto.

8-21 Gordon, Simon. Longitudinal section through the main axis of the campus. April 18, 2019. Illustration. Toronto.

8-22 Gordon, Simon. Campus overview. April 18, 2019. Illustration. Toronto.

Toronto.

8-24 Gordon, Simon. Floor Plan - Level Four. April 18, 2019. Illustration. Toronto. 2020. Model. Cardboard, foam, and wood rods. 26 x 14 x $13 \mathrm{~cm}$. Toronto.

8-28 Gordon, Simon. Floor Plan-Boundary Relationships. April 18, 2019. Illustration. Toronto.

8-29 Gordon, Simon. Central Atrium in the Heterogeneous Space. April 18, 2019. Illustration. Toronto.

8-30a Gordon, Simon. Plan depicting classrooms within three sections of the volume, encased by a façade curtain. January 15, 2019. Sketch. Toronto.

8-30b Gordon, Simon. South elevation façade. January 15, 2019. Sketch. Toronto. 
8-33 Gordon, Simon. View from Bloor Street. April 18, 2019. Illustration. Toronto. 215

8-34 Gordon, Simon. Courtyard lab. April 18, 2019. Illustration. Toronto. 216

8-35 Gordon, Simon. Construction process of a bat house. March 6, 2019. Photograph. 216

8-36 Gordon, Simon. Distinct observation spaces in the heterogeneous volume. April 18, 217 2019. Illustration. Toronto.

8-37 Gordon, Simon. Night-time activity of nocturnal creatures. April 18, 2019. Illustration. Toronto.

8-38 Gordon, Simon. Day-time activity and operations. April 18, 2019. Illustration. 220

8-39 Gordon, Simon. Bickford Park in winter. April 18, 2019. Illustration. Toronto. 221

\section{Epilogue}

E.1a A herd of deer decided to rest in a housing estate in Harold Hill, Romford, east

London. 2020. Photograph. SWNS. Accessed April 10, 2020. https://finance.yahoo. com/news/coronavirus-animals-reclaiming-cities-covid-19-pandemic-140503907. $\underline{\text { html. }}$

E.1b Mountain goats roam the streets of Llandudno, Wales. 2020. Photograph. Getty Images. Accessed April 10, 2020. https://finance.yahoo.com/news/coronavirusanimals-reclaiming-cities-covid-19-pandemic-140503907.html.

E.1c Nature is talking back Venice: wildlife returns to tourist free-city. 2020. Photograph. The Guardian. Accessed April 10, 2020. https://www.theguardian.com/world/ video/2020/mar/20/dolphins-and-fish-nature-moves-into-spaces-left-empty-byitalian-coronavirus-quarantine-video.

E.1d Stapleton, Shannon. A coyote stands by the roadside, as the spread of the coronavirus pandemic continues, at Golden Gate Bridge View Vista Point across from San Francisco, April 7, 2020. 2020. Photograph. Reuters. Accessed April 12, 2020. https://abcnews.go.com/International/photos-wildlife-roams-planets-humanpopulation-isolates/story?id=70213431.

E.1e Guerrero, Jorge. Two peacocks walk down a street in Ronda on April 3, 2020 during a national lockdown to prevent the spread of the COVID-19 coronavirus. 2020. Photograph. Getty Images. Accessed April 10, 2020. https://www.cnbc. com/2020/04/10/coronavirus-empty-streets-around-the-world-are-attractingwildlife.html.

E.1f u/Huevosdeoro. Deer running along beach at Bluffers Park. 2020. Video frame. Accessed April 29, 2020. https://www.reddit.com/r/toronto/comments/g566he/ deer_running along beach at bluffers_park/. 


\section{List of Appendices}

A.1

DATA \& RESEARCH

231

A.1-1 World population growth, 1700-2100. June 18, 2019. Graph. Accessed March 8, 2020. https://en.wikipedia.org/wiki/Projections of population growth.

A.1-2 Dimmick, Shane. Minimum Access Area Needed by Common Wild Animal Species Found Around Homes. Retrieved from Wild Neighbors: the Humane Approach to Living with Wildlife. John Hadidian (Washington, D.C: Humane Society Press, 2007) 51.

A.1-3 Dimmick, Shane. Quick Reference to Human Health Concerns in Dealing with Wildlife. Retrieved from Wild Neighbors: the Humane Approach to Living with Wildlife. John Hadidian (Washington, D.C: Humane Society Press, 2007) 19.

\section{A.2 PRECEDENTS}

A.2-1 Robson Square Section. Adapted from Transversal section, Robson Square Provincial Government Complex, Vancouver, British Columbia. Arthur Erickson Architects. 1974-1982. Reprographic drawing. Positive photostat print on paper. $22 \times 28$ cm. Vancouver. Accessed July 12, 2019. https://www.cca.qc.ca/en/search/details/ collection/object/368017.

A.2-2 UBC Public Affairs. Robson Square and its greenery is one of Margolese prize winner Cornelia Oberlander's contributions to the city of Vancouver. N.d. Photograph. Accessed July 12, 2019. https://apsc.ubc.ca/spotlight/research/margolese-prizewinner-advocates-for-sustainable-landscape-design.

A.2-3 Chan, Kenneth. [Sitting by a waterfall at Robson Square]. 2017. Photograph. Accessed July 12, 2019. https://dailyhive.com/vancouver/robson-square-courthouse-cascadingwaterfall-photos.

A.2-4a Radburn, New Jersey. N.d. Map. Accessed November 1, 2019. http://www. fradkinmcalpin.com/project/radburn-new-jersey/.

A.2-4b Radburn, New Jersey. N.d. Map. Accessed November 1, 2019. http://tessellarsociety. blogspot.com/2007/05/protection-from-traffic.html.

A.2-5 Jackson, Lisa. Toronto Overgrown by Nature. 2019. Image. Accessed November 12, 2019. https://moca.ca/calendar/lisa-jackson-and-mathew-borrett-in-conversation/. 
$\begin{array}{llr}A .3 & \text { CONCEPTUAL SKETCHES } & 241\end{array}$

A.3-1 Gordon, Simon. Boolean Overlap. 2019. Illustration. Toronto. 241

A.3-2 Gordon, Simon. Carrying Capacity. 2019. Illustration. Toronto. 242

A.3-3a Gordon, Simon. Intersection. 2019. Sketch. Toronto. 243

A.3-3b Gordon, Simon. Intersection: a closer look at one iteration. 2019. Illustration. Toronto. 243

A.3-4a Gordon, Simon. Surface. 2019. Sketch. Toronto. 244

A.3-4b Gordon, Simon. Surface: creating a stepped form to accommodate wildife circulation. 244

A.3-5 Gordon, Simon. Pan-species Environment. 2019. Illustration. Toronto. 246

$\begin{array}{llr}\text { A.4 } & \text { PHOTOGRAPHS } & 247\end{array}$

A.4-1 Gordon, Simon. Canada Goose at Dundas Street and Bay Street. 2019. Photograph. 247 Toronto.

A.4-2(a-b) Gordon, Simon. Bickford Centre as seen from Christie Pits Park. 2019. Photograph. 248 Toronto.

A.4-3(a-k) Gordon, Simon. Bickford Centre. 2019. Photograph. Toronto. 249

A.4-4(a-k) Gordon, Simon. Bickford Park. 2019. Photograph. Toronto. 251

A.5 PHYSICAL MODELS $\quad 253$

A.5-1 Gordon, Simon. Bat Roost Prototype. 2020. Model. MDF, wood dowels, and plastic 253 mesh. $35 \times 72 \times 9 \mathrm{~cm}$. Toronto.

A.5-2 Gordon, Simon. Classroom Pod in the heterogeneous Space, 1:100 scale. 2020. Model. 255 Cardboard, foam, and wood rods. $26 \times 14 \times 13 \mathrm{~cm}$. Toronto. 
A.6-1 Gordon, Simon. Shared Space. 2020. Illustration. Toronto. 257

A.6-2 Gordon, Simon. View from Bloor Street. 2020. Image. Toronto. 258

A.6-3 Gordon, Simon. Elevation. 2020. Image. Toronto. 258

A.6-4 Gordon, Simon. Overall Scheme (Milestone II). 2020. Image. Toronto. 259

A.6-5 Gordon, Simon. Façade system: horizontal louvers, sliding glass, and storage 261 compartments (Milestone III). 2020. Image. Toronto.

A.6-6 Gordon, Simon. View from Bloor Street (Milestone III). 2020. Image. Toronto. 262

A.6-7 Gordon, Simon. Entrance Lobby Elevation (Milestone III). 2020. Image. Toronto. 262

A.6-8 Gordon, Simon. Process investigation of the façade. 2020. Image. Toronto. 263

A.6-9 Gordon, Simon. Bloor Street Elevatoin. 2020. Sketch. Toronto. 264

A.6-10 Gordon, Simon. Animal Vestibule Section. 2020. Sketch. Toronto. 265

A.6-11 Gordon, Simon. Animal Vestibule. 2020. Sketch. Toronto. 266

A.6-12 Gordon, Simon. Animal Vestibule at the Synanthropic Centre. 2020. Render. Toronto. 266

A.6-13 Gordon, Simon. Final Design - Entry from Bloor Street. 2020. Render. Toronto. 267

A.6-14 Gordon, Simon. Final Design-Sunken Garden. 2020. Render. Toronto. 267

A.6-15 Gordon, Simon. Final Design - Entrance Lobby. 2020. Render. Toronto. 268 


\section{Lexicon}

Animated 1. Containing an essence of life; revived; active.

2. Containing animals or representations of animals.

Anthropocene

Architecture

Ecotope

Keystone

Scape

Synanthrope

Synanthropocene
The contemporary geological age of the Earth, wherein geomorphology is largely impacted by human activity.

The process of environmental modification via the projection of one's consciousness.

A distinct geo-morphological element (composed of biotic and/or abiotic constituents) that exists as a unit within a connected network of such units: an ecosystem. (Examples: river, hill-top, cliff-side, a tree)

1. Biology: A species that is essential to an ecosystem's health and stability.

2. Architecture: The wedge-shaped stone at the peak of an arch, which ensures its structural stability.

1. A condition or state, as in "landscape" and "cityscape"; synonymous with the suffix '-ness'.

2. As pertaining to various areas of study: a shaft, chute, column, stalk, artery, stem, and other such typological elements.

A non-domesticated animal that benefits from living in the midst of humans within their built environments.

A speculative geological age of the Earth, wherein geomorphology is largely impacted by human activity that is more closely in sync with the evolutionary traits of synanthropic biological subjects. 

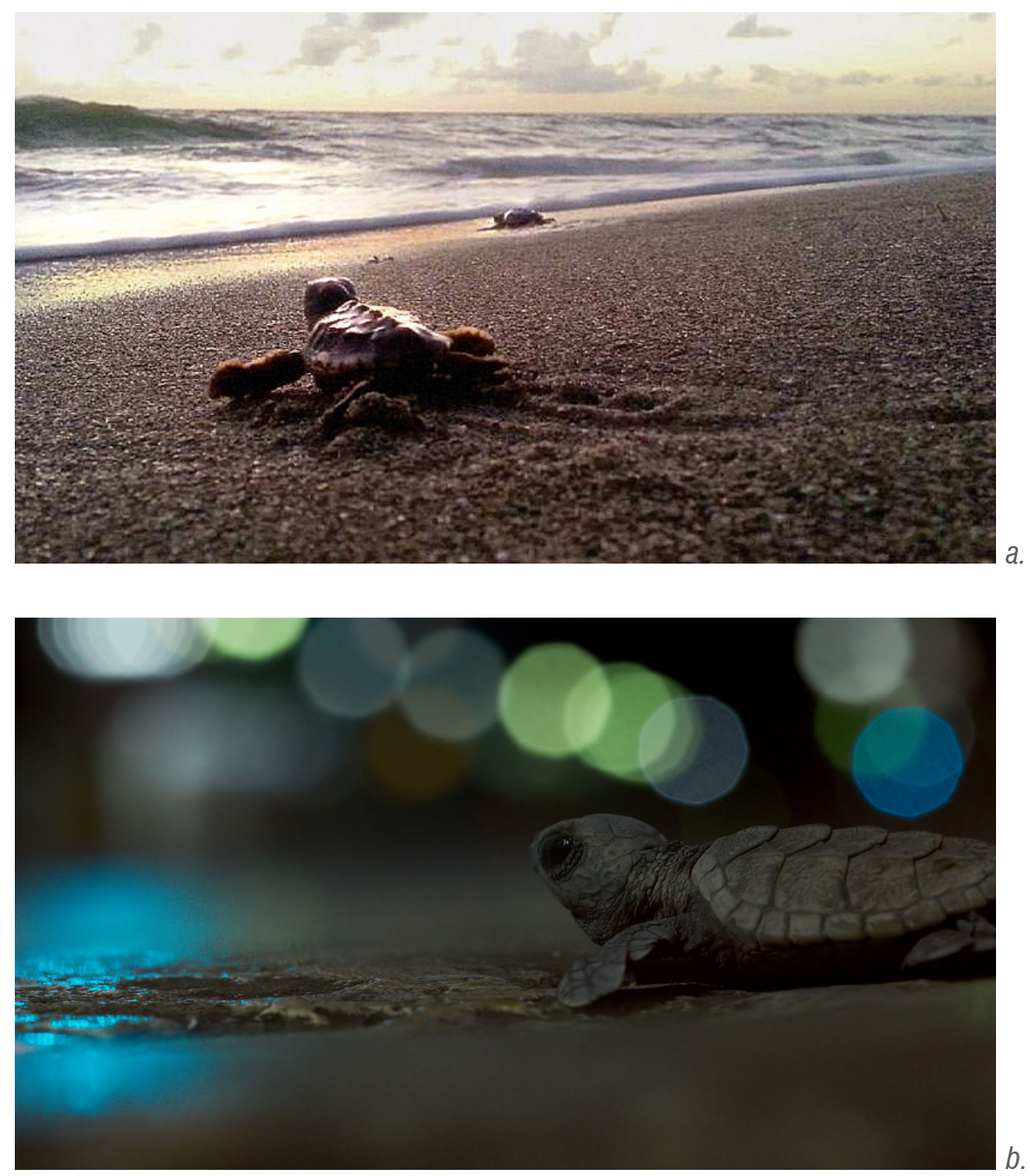

Figure I-1a. A sea-turtle hatchling rushing to water upon emergence from its nest. Figure I-1b. A sea-turtle hatchling lost and dazed by the city lights. 


\section{Preface}

It's a warm evening in Barbados - a cool breeze drifts across the island's sandy shores. The night sky is illuminated by the brightness of the full moon - its light shimmers across the ripples of the water. Slowly, almost imperceptibly, something crawls out from underneath the sand. Newly hatched Hawksbill sea-turtles dig their way out of their burrow, where their mother had laboriously dug and laid them eight weeks prior. As the hatchlings crawl out, instinct kicks in. They are drawn to the bright light - an evolutionary mechanism that compels them to rush quickly into the safety of the waters. Feeling the tropical breeze for the very first time, dozens of turtles hurry off from this single nest. However, many of them slow down. And stop. Confused, they turn in the opposite direction. Although the water is just a few yards away, the turtles begin to trek towards a brighter light-source - the city. Beachfront edifices, streetlights, and a glowing haze in the sky lure the turtles away from their natural habitat and into the callous embrace of the city's maze of cement with its rushing cars and sewer pitfalls. The newly hatched sea-turtles continue to crawl on land, to and fro - following light after light, using up what strength they have. They are easy targets for seagulls. Crabs have even recognized this pattern of behaviour, and have learned to hide beneath light posts and await their feeble prey. As many as $80 \%$ of hawksbill turtles are disoriented by the city lights. They are unlikely to survive the night. 

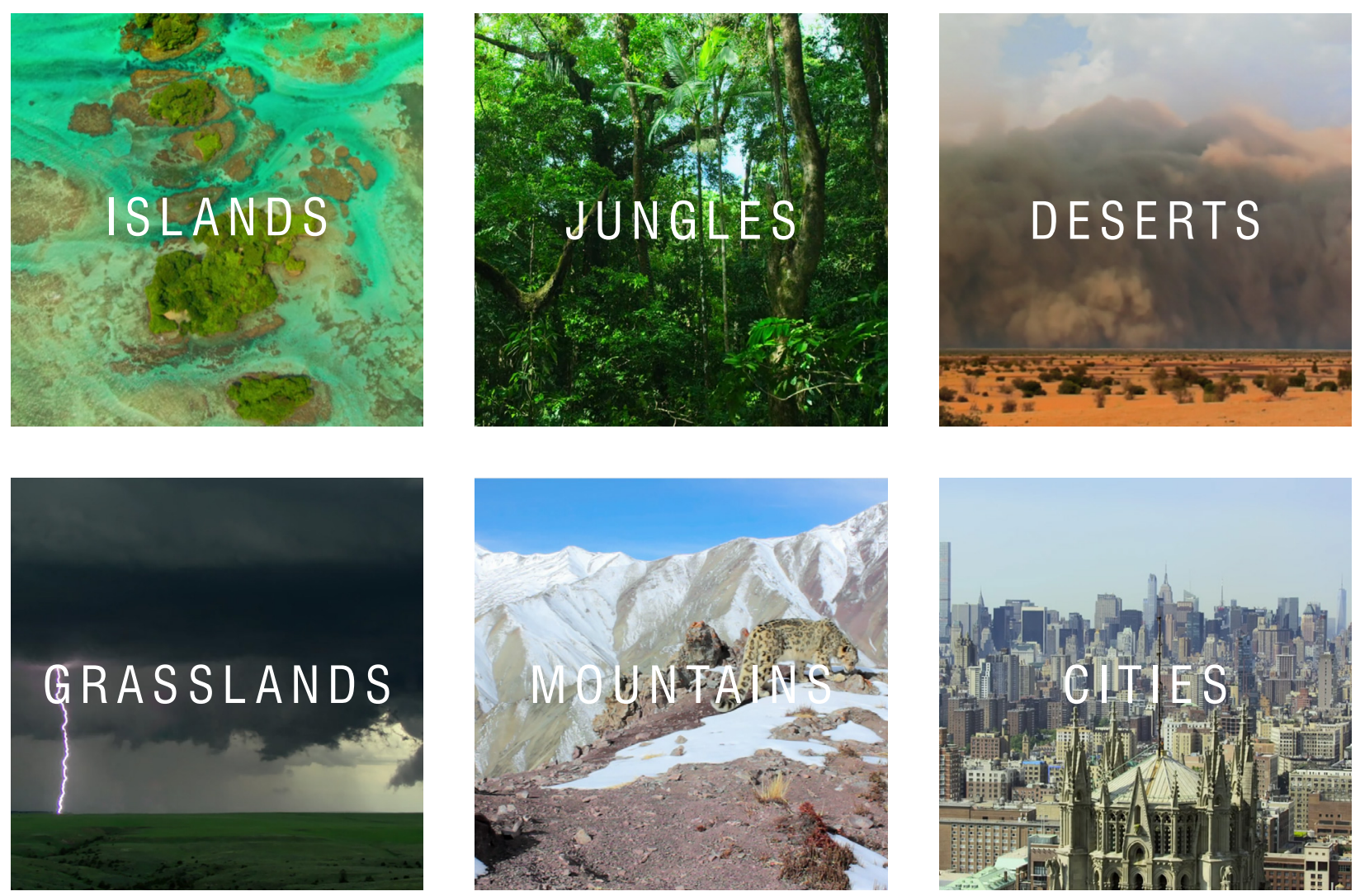

Fig I-2a. Islands.

Fig l-2b. Jungles.

Fig I-2c. Deserts.

Fig I-2d. Grasslands.

Fig I-2e. Mountains.

Fig I-2f. Cities. 


\section{Introduction}

For billions of years, there has been a synchronous dance between 'life' and 'environment.' Biological species evolved at a slow rate in concert with the gradually changing landscapes of their surroundings. Thus, plants and animals have been able to adapt and thrive in the landscapes which they inhabited. Modern cities, however, are a drastically different kind of landscape which, within an evolutionary time-frame, has appeared only very recently and has terra-formed large swathes of the planet. The emergence of cities is
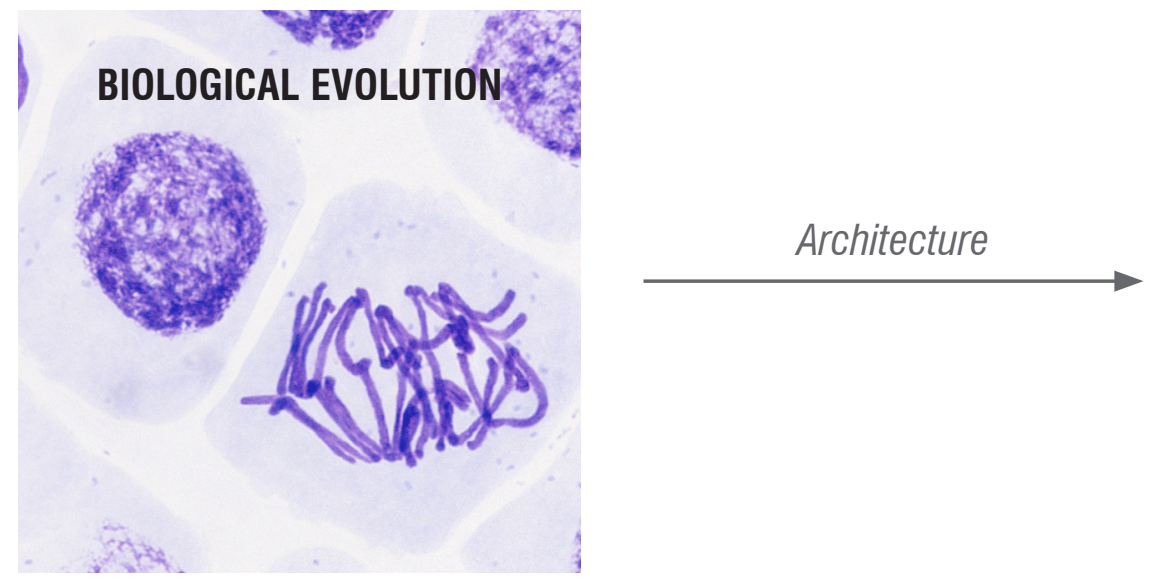

a product of the relatively rapid process of cultural evolution, which is out of sync with the much slower process of biological evolution. The main thrust of this thesis is to explore how architecture can begin to negotiate the lag that exists between these two evolutionary processes.

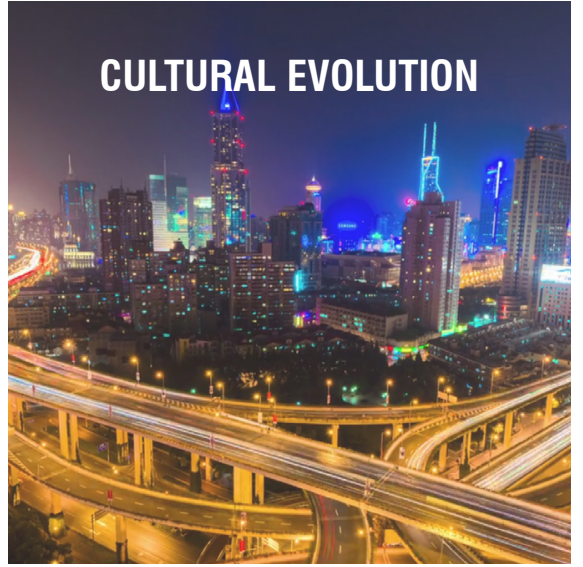

Fig I-3a. Biological Evolution. Fig l-3b. Cultural Evolution. 


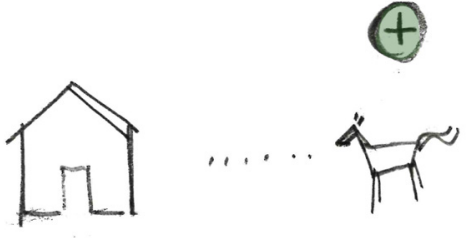

Fig I-4. The Synanthrope.

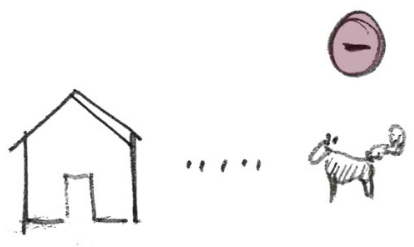

Fig I-5. The Antithrope.
Cities are a radically new type of landscape that constitutes a wealth of opportunities as well as precarious dangers for the animal kingdom. Some animals that venture into this man-made environment thrive from the benefits they are able to reap, while others fall prey to its hazardous traps. Contemporary engagements in this novel discourse have generated a new term: the synanthrope. A composite of the Greek word anthropos (meaning 'man') and the prefix syn (meaning 'together with'), a synanthrope is an undomesticated animal that lives in close association to humans and directly benefits from their built environment and activities.

The idea of the synanthrope bridges the gap of the indistinct notion between the wild and domesticated animal. However, it could be argued that this concept is not entirely complete: synanthropes are understood to benefit from human environments; however, many species of animals come to occupy and engage with the urban fabric at a terrible cost. Many become confused, lured in, trapped, maimed, and killed within the urban maze of the city without having any capacity to avoid these hazards. As such, the discourse presented in this thesis proposes an alternative term to encapsulate the notion that not all animals benefit from the city but, to the contrary, face tremendous challenges by entering it: the antithrope. Architecture - the process of designing human habitats - has built the stage that enabled the conceptualization of synathropes and antithropes; this thesis seeks to unpack this phenomenon and cultivate a resynchronized mode of architecture that would reallocate more species that find themselves in the midst of human environments from the latter category into the former. 


\section{Research Objective}

The objective of this thesis is encapsulated within these nested questions:

1. How can architecture re-synchronize the relationship between wildlife and the built environment?

- How can architecture enable antithropes to become synanthropes?

2. How does the concept of a boundary between humans and wildlife, order and chaos, inside and outside become questioned, and how, then, do boundaries begin to evolve, change, and/or diffuse in order to implement this re-synchroniztation?

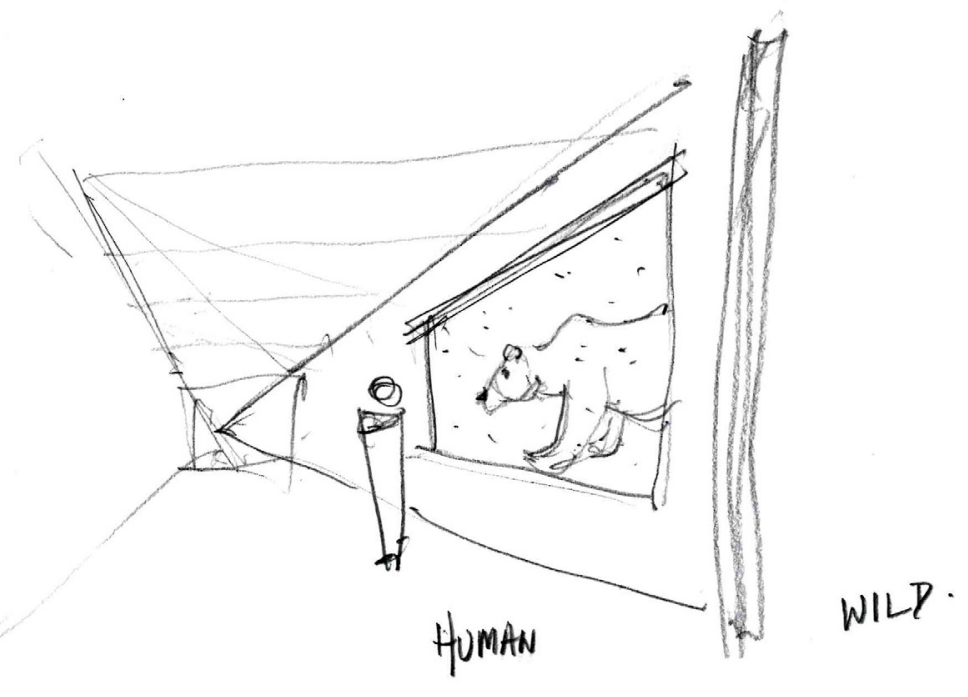

Fig I-6. The threshold between wilderness and human space. 


\section{part I}

\section{The Anthropocene}

\section{A Human Geological Age}

Chapter 1 Socio-ecological Tensions

Chapter 2 The Urban Landscape

21

Chapter 3 Contemporary Responses 
asting

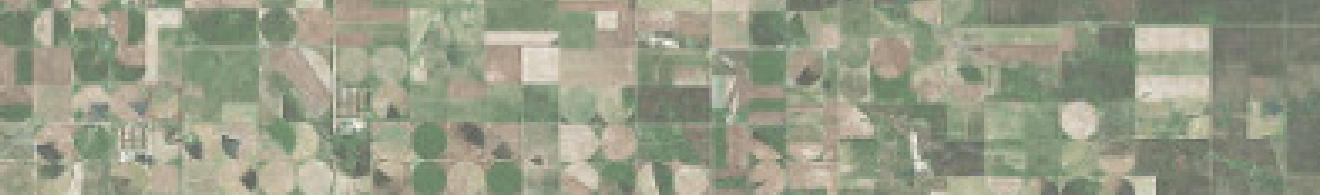
ind

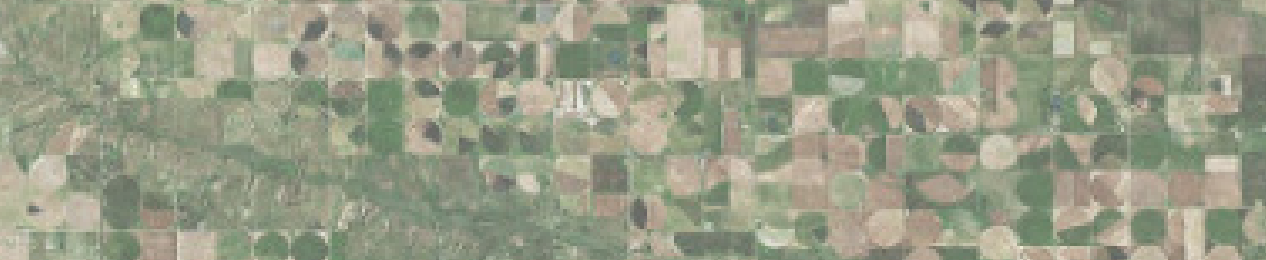

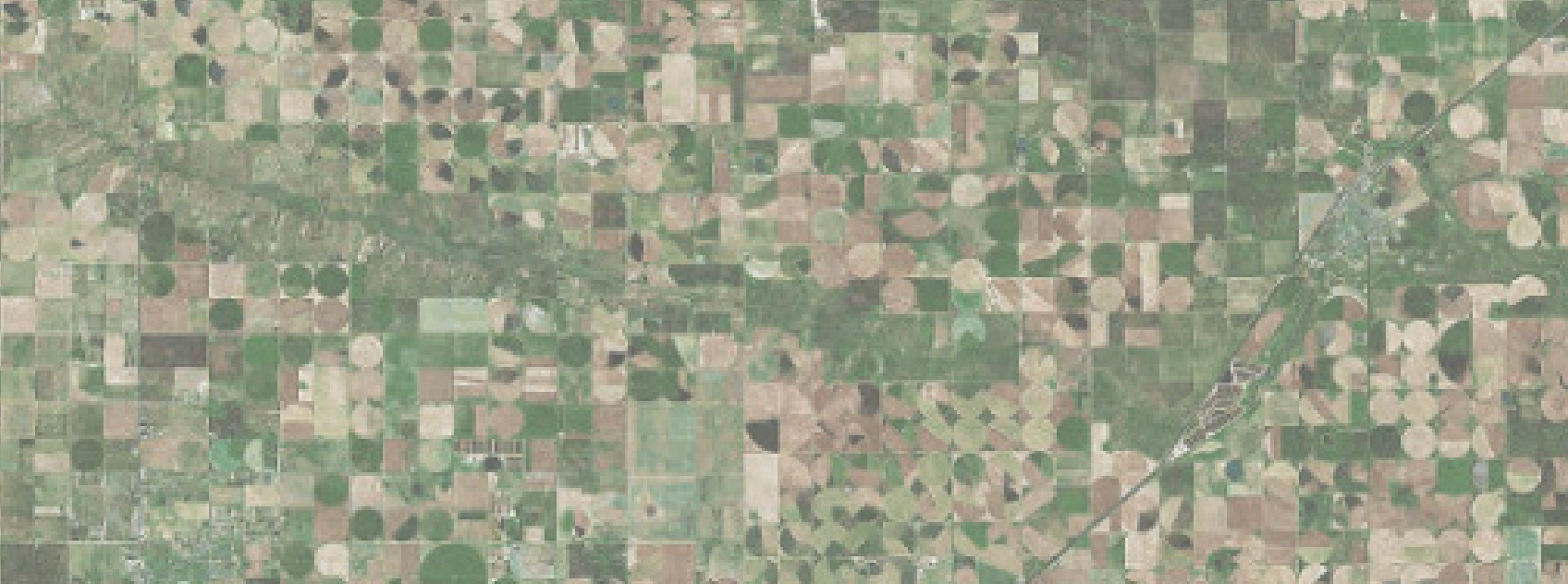

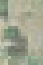

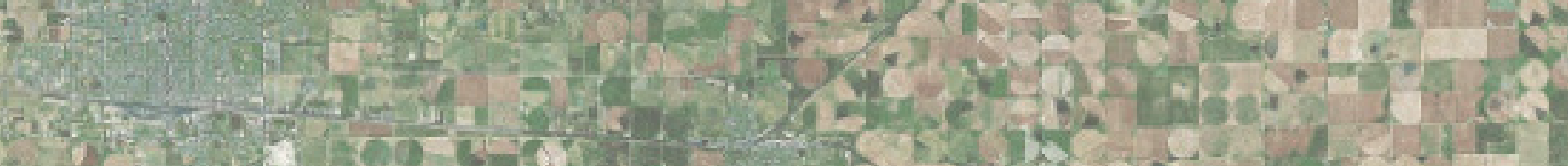

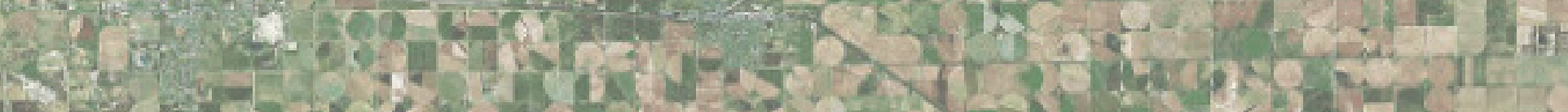

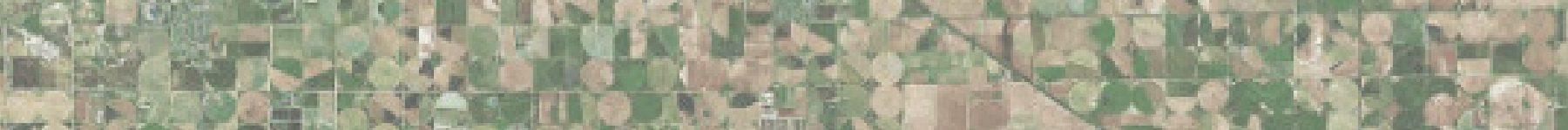

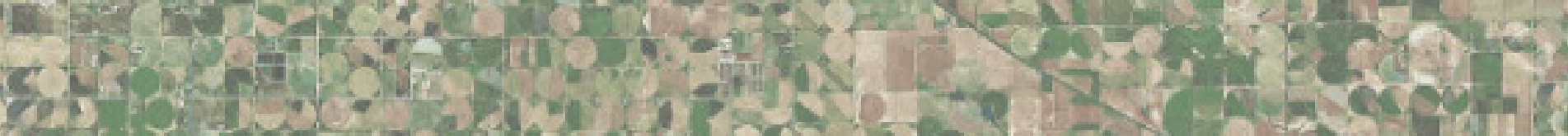
Se.

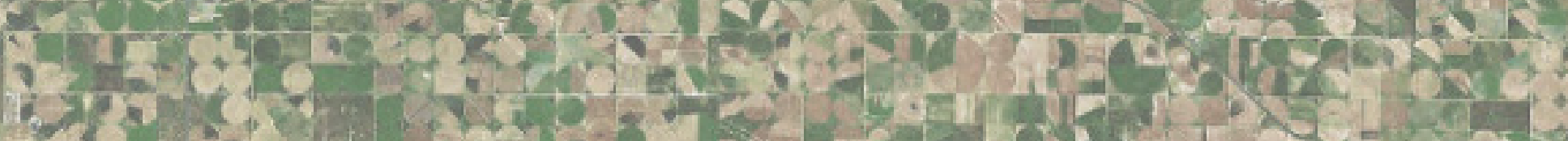

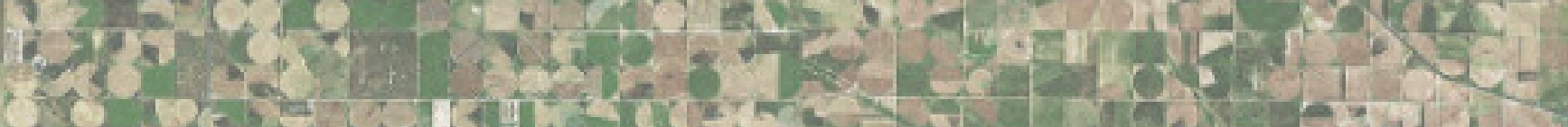

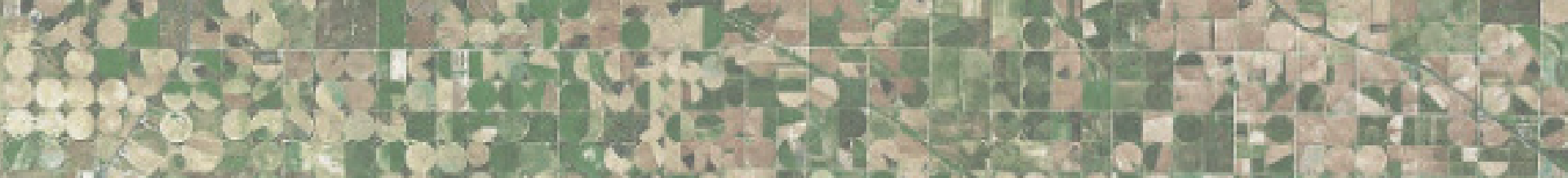

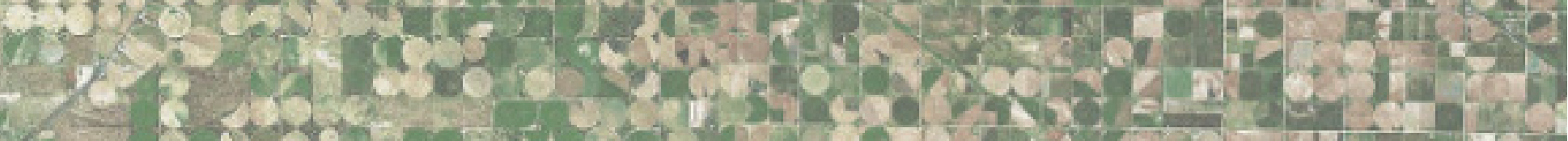

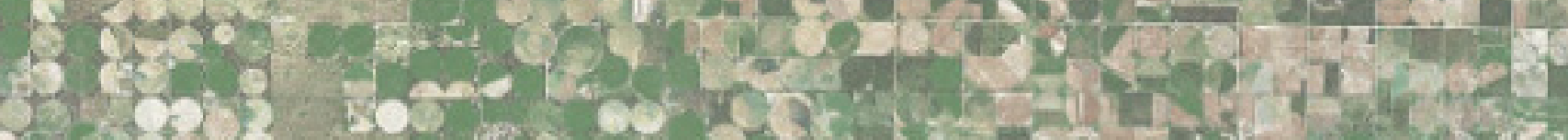

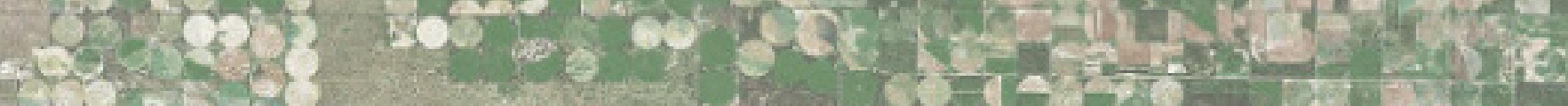

Fig 1-1. Nebraska Farmland Google Satellite. 


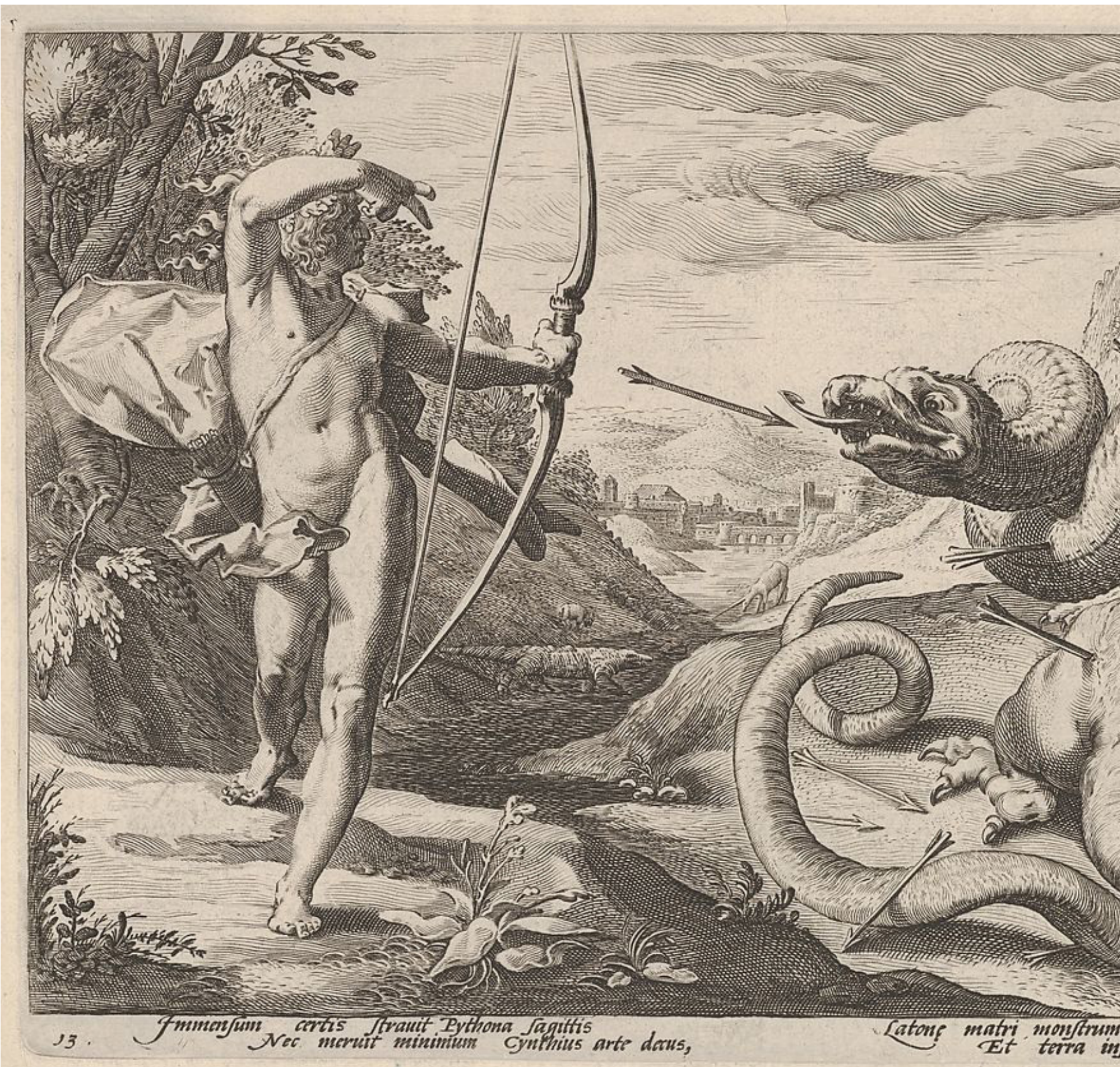




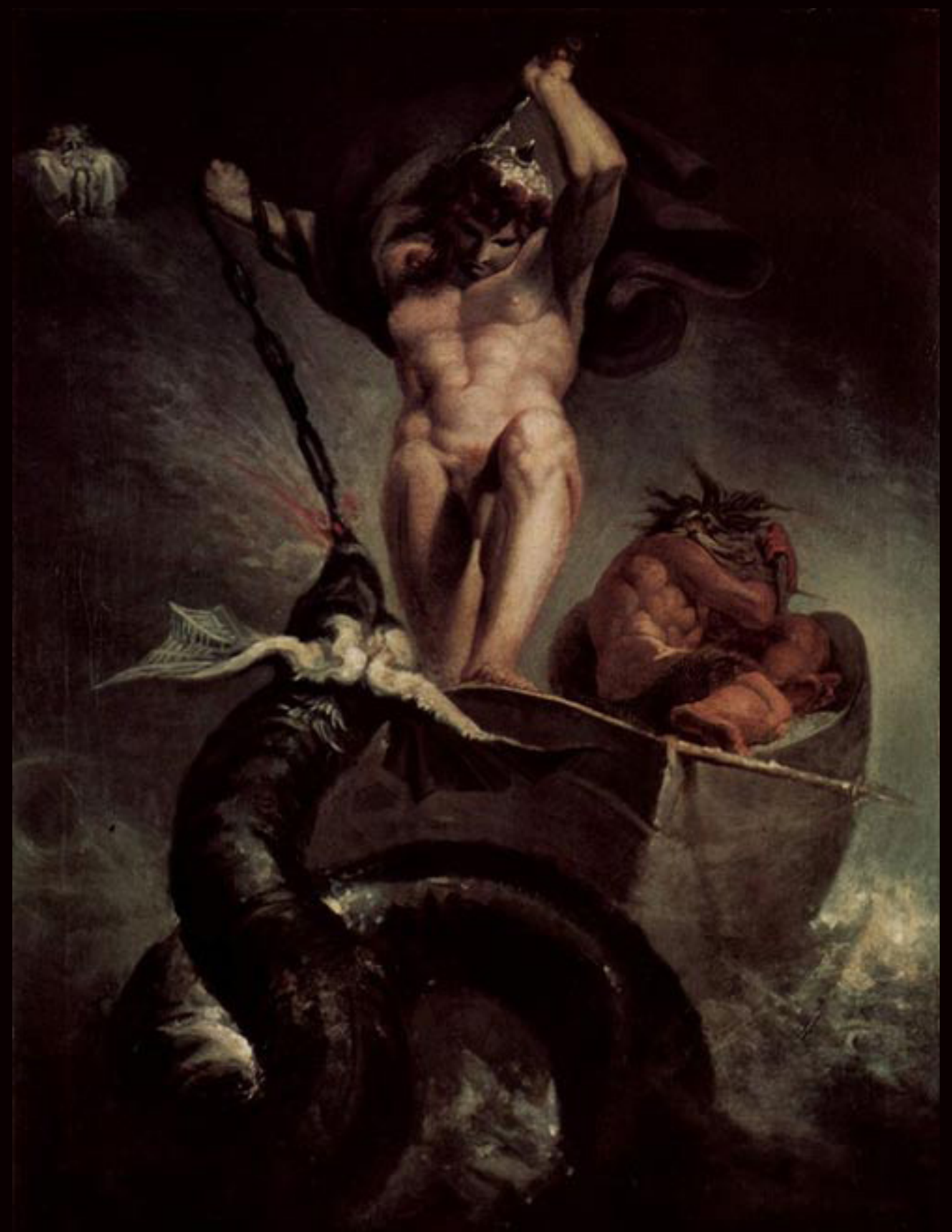

Fig 1-3. Thor Battering the Midgard Sepent by Henry Fuseli (1790). 
1.1

\section{Chaos \& Order}

The Old Norse manuscript of the Gylfaginning tells the chronicles of Loki, God of Chaos, and his three vile offspring. One of the three was Jormungandr, also known as the World Serpent. Odin had cast him out into the depths of the ocean, but the snake grew so large that he could encircle all of Midgard and bite down on its own tail - forming the shape of an Ouroboros. This malevolent serpent that encircles the world is the arch nemesis of Thor. Time and again, the two clash in mortal combat, but each escape to live until their next encounter - an eternal conflict between order and chaos, culture and nature, man and beast.

Their duel closely resembles other cultural lore: Heracles and the Hydra, Apollo and the Python, and Hercules and Achelous, among others. It could be argued that this motif is not just an echoing of a cultural idea, but it is actually a deeply biological one; thousands of generations of humans that have braved and confronted the perils of the wilderness - a motif that has been infused into the human psyche and resurfaced as an archetypal cultural mythos.

While this drive to confront and vanquish the wild was pertinent throughout most of human existence, in the post-industrial age, this force has accelerated beyond the necessity for survival and has led humanity to establish a foothold over the entire planet. Society has constructed a reality - an order - made in its own image - pushing wilderness and the rest of life within it into an ever-diminishing territory.

The Garden of Eden, as depicted in the Boucicaut Master's painting in Fig. 1-5, is an idyllic built environment: an amalgam of human construction and natural growth. However, even in the most exalted and perfect of orderly environments, chaos can surface at any moment - the snake in the tree. This foundational cultural saga embodies the notion that order and chaos are forever intertwined; one will always give birth to the other; neither can ever be vanquished. Rather, an acceptance of the two must be sought - an eternal, balanced, and harmonious dance.

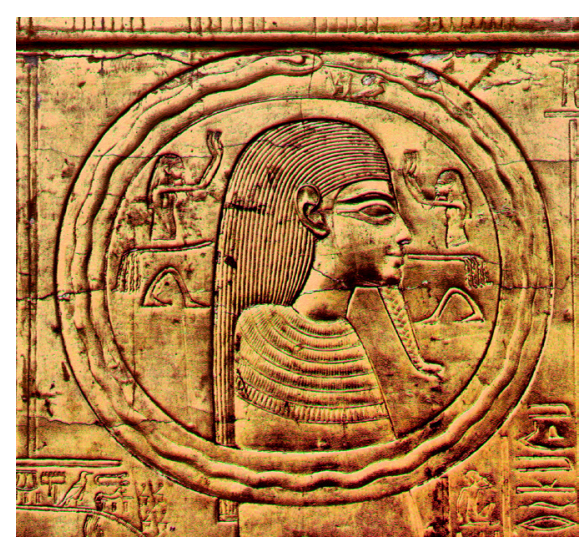

Fig 1-4. An Ouroborous.

The sarcophagus of Tutankhamun depicts the earliest known representation of this symbol (c. 1325 BC).

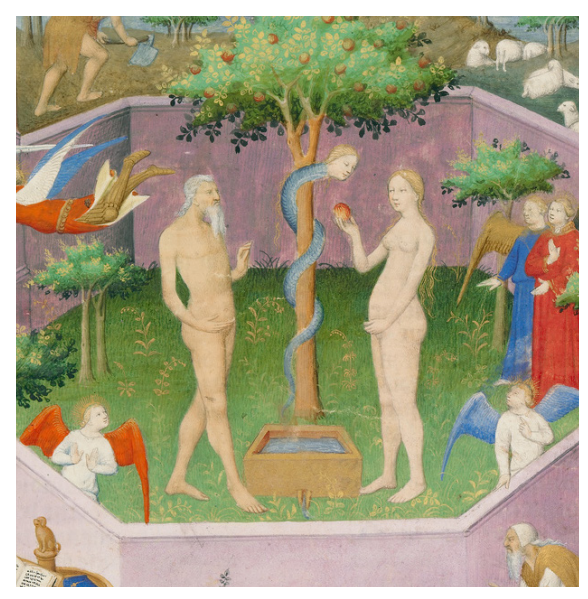

Fig 1-5. The Temptation of Adam and Eve by Boucicaut Master (1415). 
See Appendix Fig A.1-1. Graph of world population growth, 1700-2100.

\section{The Socio-Ecological Scene}

1.2

The current population of the globe (in the year 2020) is 7.8 billion. ${ }^{1}$ This is not the result of a gradual slow increase over the course of millennia, but due to the unprecedented boom of the 20th century where the population more than tripled. It is predicted to rise to 9.7 billion by 2050 and finally plateau at 11 billion by $2100 .^{2}$ The rate of increase has slowed as the global population approaches the world's carrying capacity for a single species (out of the eight million other living species): Homo sapiens. This, however, is a radically new reality for the planet; the human biomass was not always this large and widespread. For most of the Homo sapien's 200,000-yearlong existence (and, in fact, the six million year-long stretch of quasi pre-human species), the global population never amounted to more than a few thousand. Humanity - mostly localised in the savannas of eastern Africa - was a negligible minority in the tapestry of life on Earth.

However, humanity embraced a new form of evolution - not only biological, but also cultural. In his 1976 book The Selfish Gene, evolutionary biologist Richard Dawkins coined the term 'meme' it is a unit of culture which replicates as it is transmitted from one mind to another. ${ }^{3}$ In real time, this form of evolutionary change is orders of magnitude faster than the evolution of biological life by means of natural selection. Words, thoughts, signals, and gestures these are the genetic building blocks that shape larger cultural values, ideas, theories, movements, and motivations. The human species transformed into a civilization and a society - still underpinned by biological impulses, but largely driven by cultural forces.

\footnotetext{
1 “Current World Population,” Worldometer, last modified March 17, 2020, accessed March 17, 2020, https://www.worldometers.info/world-population/.

2 "Growing at a slower pace, world population is expected to reach 9.7 billion in 2050 and could peak at nearly 11 billion around 2100," United Nations, last modified June 17, 2019, accessed March 21, 2020, https://www.un.org/development/desa/en/news/ population/world-population-prospects-2019.html.
}

3 Richard Dawkins, The Selfish Gene, (Oxford: Oxford University Press, 1976), 192. 
Veni, vidi, vici.

In adherence with the infamous words of Julius Caesar, humanity has continued to spread, see, and conquer - a motivation that is grounded by the biological inclination of confronting and vanquishing the external wilderness (the chaos that exists outside the bounds of ordered human life and civilization). In the industrial and post-industrial ages of the last 250 years, humanity has continued to do so at unprecedented scales. Over half of the world's habitable land surface has been terraformed in the image of Man. ${ }^{4}$ These radical changes to the environment have had and continue to have profound

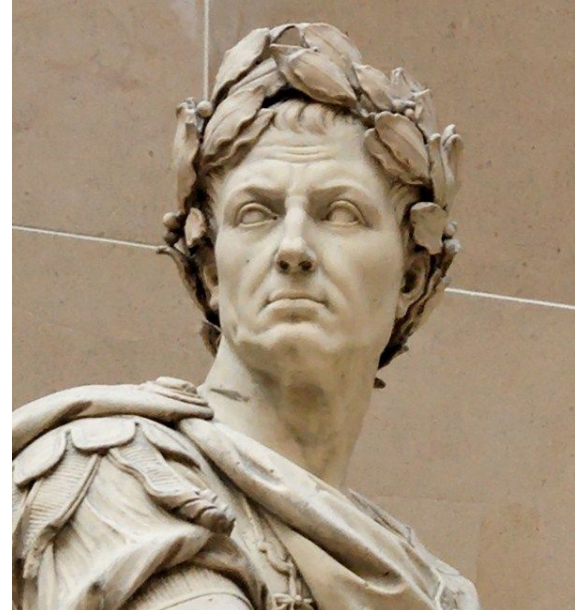

Fig 1-6. Gaius Julius Caesar. impact on global ecologies and, inevitably, humanity itself.
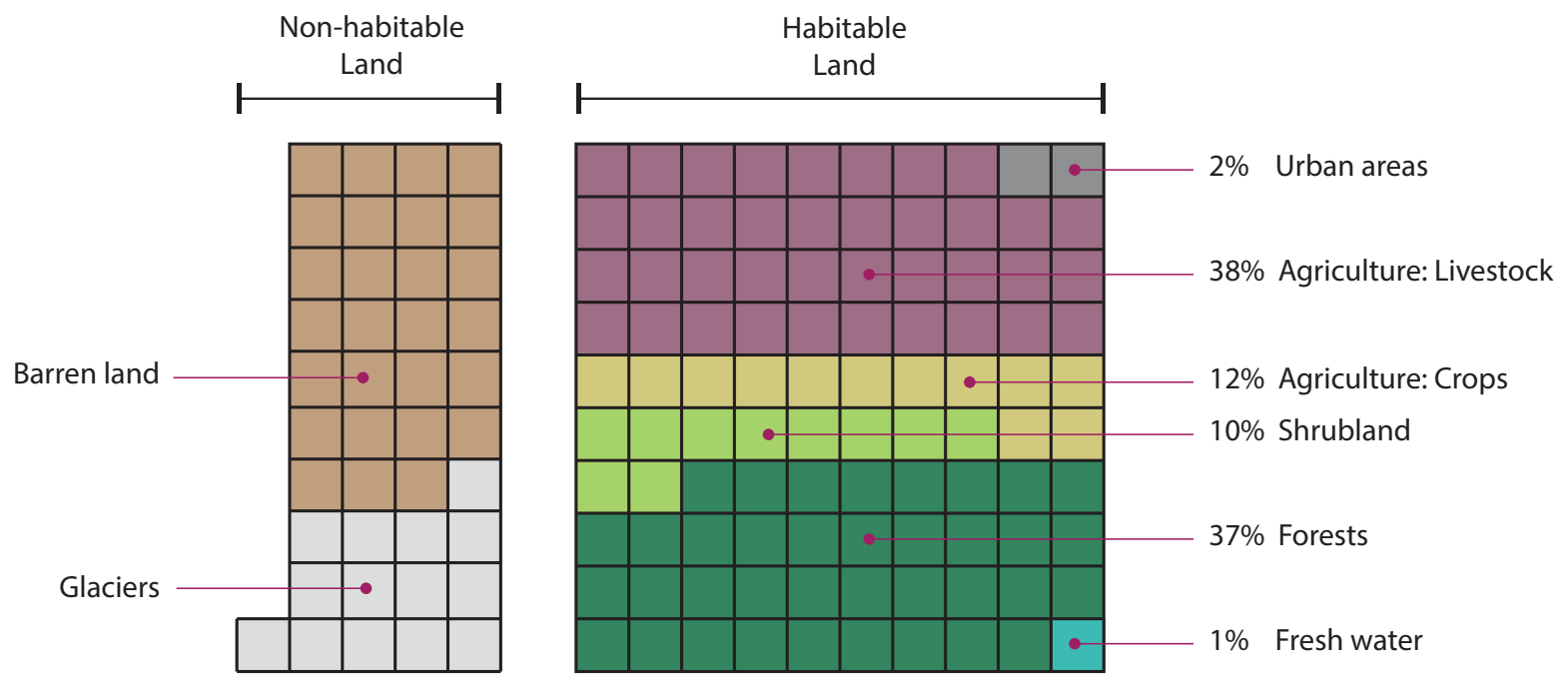

Fig 1-7. Distribution of land, worldwide: the percentage values refer to areas of habitable land on Earth.

4 Hannah Ritchie and Max Roser, "Land Use," Our World in Data, last modified September 2019, accessed January 17, 2019, https://ourworldindata.org/land-use. 


\section{Biodiversity Decline}

Life on this planet has been gradually evolving, adapting, and changing over the last four and a half billion years. While there has always been extinctions of species (what is referred to as the background extinction rate), the contemporary rate of extinction of species is calculated to be 1000 times as fast. ${ }^{5}$ The International Union for Conservation of Nature Red List has assessed over 100,000 different species worldwide and has found that about one third are threatened with extinction. ${ }^{6}$ As well, in a report published by the World Wildlife Fund in 2018, the Living Planet Index shows that since 1970, populations of many species of mammals, birds, reptiles, fish, and amphibians have declined on average by $60 \% .^{7}$ These types of trends are evident in many different regions worldwide. Canada, a country rich in expansive forests and natural landscapes, could be assumed to be faring better with regard to the retention of species. However, an ongoing study since 1970 that has been monitoring 903 vertebrate species in Canada has shown that half of the populations (451 of 903 ) have declined on average by $83 \% .^{8}$

5 Peter Aldhous, "We are killing species at 1000 times the natural rate," NewScientist, last modified May 29, 2014, accessed October 9, 2019, https://www.newscientist.com/article/ dn25645-we-are-killing-species-at-1000-times-the-natural-rate/.

6 "More than 30,000 species are threatened with extinction," The IUCN Red List of Threatened Species, last modified March, 2019, accessed June 22, 2019, https://www. iucnredlist.org/.

$7 \quad$ M. Grooten and R.E.A. Almond, "Living Planet Report 2018: Aiming Higher - Summary," WWF Report 2018, (2018): 18-19, last modified 2018, accessed June 12, 2019, https://wwf.panda.org/knowledge hub/all publications/living_planet report_2018/.

8 WWF-Canada, "Living Planet Report Canada: A National Look at Wildlife Loss Summary,” 2017, (Toronto: WWF-Canada, 2017), 2. 


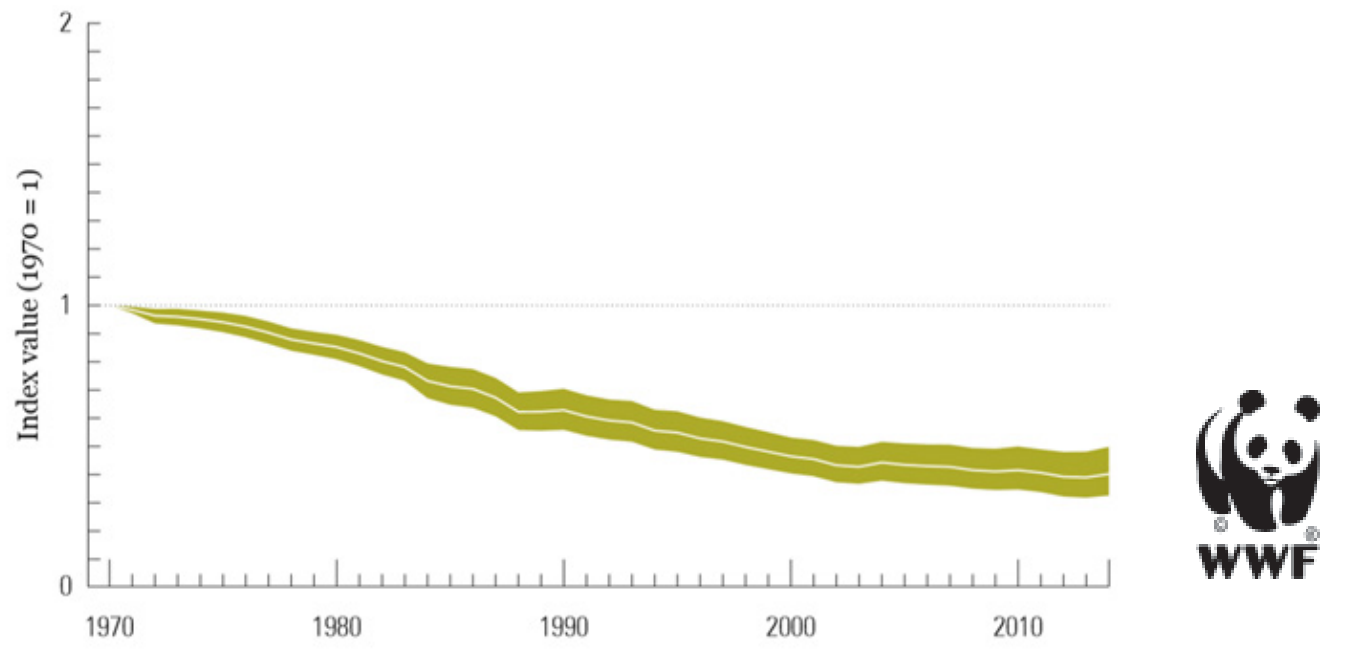

Fig 1-8. Living Planet Index. 


\section{Benefits from Nature}

\section{Ecosystems \& Humans}

The natural environment is composed of ecotopes. These are landscape components that may consist of abiotic as well as biotic constituents. While a cliff-side consists of rock, a hilltop may have grass upon it, and a river may have various biological organisms within it as well. One of the earliest descriptions of this term was made in 1936 by Arthur Tansley, when he wrote that an ecotope is "the particular portion... of the physical world that forms a home for the organisms which inhabit it." ${ }^{\prime 9}$ Ecotopes are, essentially,

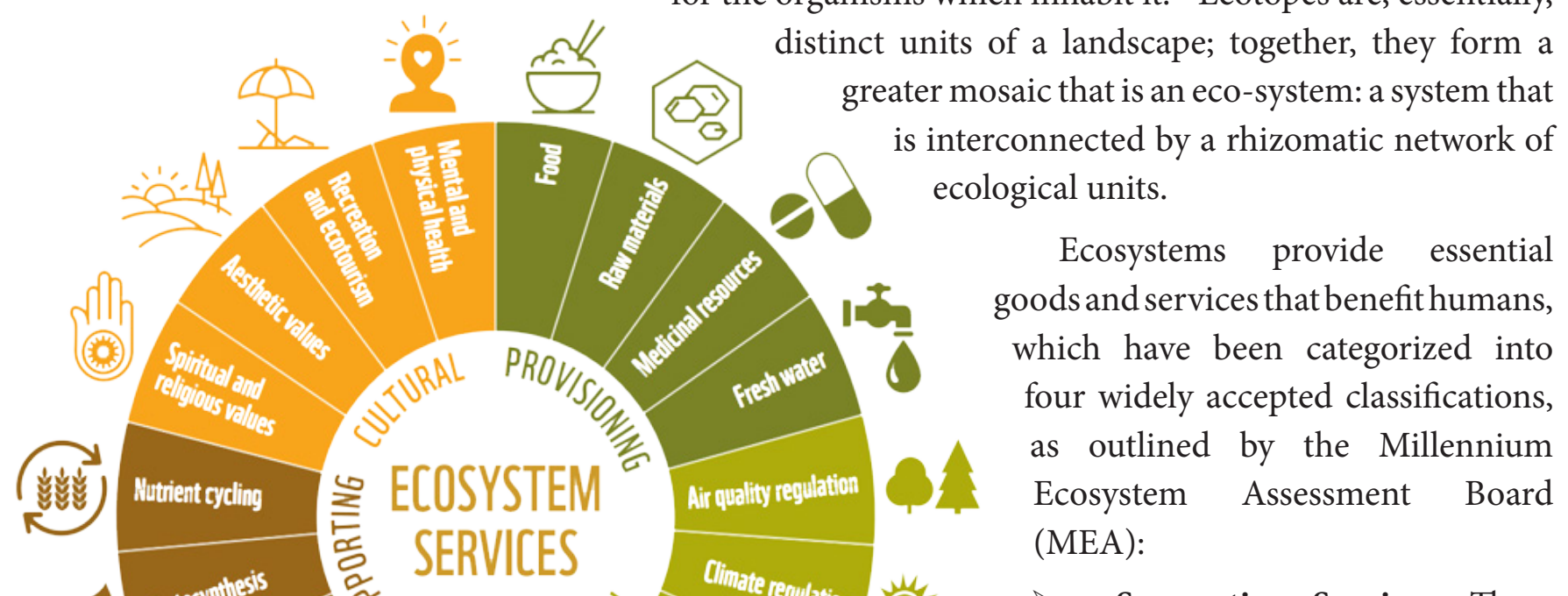

Supporting Services: These form the foundational base processes which support and facilitate the other three categories. These include processes such as soil formation and nutrient cycling.

Provisioning Services: This category encapsulates the range of products that humans

Fig 1-9. Benefits from Nature.
9 “Ecotope," Revolvy, n.d., accessed March 17, 2020, https://www.revolvy.com/page/ Ecotope. 
$>$ Regulating Services: These are sophisticated biochemical processes that regulate various aspects of the environment. Examples include water quality regulation, air quality regulation, carbon sequestration, waste regulation, disease control, pollination, climate regulation, and various others.

$>$ Cultural Services: These are the aspects of ecosystems to which humans attribute cultural value, and which can enhance the human condition in cognitive, psychological, and physiological ways. These include recreational services, educational opportunities, spiritual connectivity, aesthetic influences, etc.

Ecological biodiversity facilitates the resilience of an ecosystem. A decline in biodiversity goes hand-in-hand with the deterioration of the life-supporting processes, resources, and provisions that humans depend on. In essence, it comes at the cost of the future.

When we degrade global ecosystems, either by massive disruption or via the insidious, cumulative impacts of "death by a thousand cuts," we inevitably reduce the potential for them to allow us to lead fulfilled lives, including our economic prospects. ${ }^{10}$

- Mark Everard in

The Business of Biodiversity. 


\subsubsection{Health \& the Environment}

Elaborating further on the cultural services discussed in the previous section, scientific studies have demonstrated a relationship between contact with nature and physiological well-being. A metaanalysis published in the International Journal of Environmental Research and Public Health analyzed the research of fifty peerreviewed studies that exhibit this positive link. ${ }^{11}$ Their findings support the Biophilia hypothesis: the notion that humans have an affinity towards (and derive physiological benefits from) natural environments that resemble the conditions within which humans have adapted throughout evolutionary history. ${ }^{12}$ This particular paper, "Biophilia: Does Visual Contact with Nature Impact on Health and Well-Being?" by Bjorn Grindle and Grete Grindal Patil, uses the term "mismatch" to express an environmental condition that differs from a biophilic one, thus causing "discord" (a negative effect) on human well-being. ${ }^{13}$ The urban environment has been shown to cause increased chronic stress, thus triggering a slew of ailments such as anxiety, mental health issues, and heart disease. ${ }^{14}$ Environmental deterioration and pollution has further health implications, which has been linked to increased risk of asthma and disease transmission. ${ }^{15}$ Mazda Adli, the Senior Physician and Director of the Mood Disorders Research Group expressed that architecture and urban planning should absorb findings from neuroscience in the design of built environments that promote human health and well-being. ${ }^{16}$

11 Bjorn Grindle and Grete Grindal Patil, "Biophilia: Does Visual Contact with Nature Impact on Health and Well-Being?" International Journal of Environmental Research and Public Health, no. 6 (August 2009): 2332, 10.3390.

12 Ibid, 2332.

13 Ibid, 2332.

14 Mazda Adli, "Urban Stress and Mental Health," Urban Age, last modified November, 2011, accessed February 15, 2019, https://urbanage.lsecities.net/essays/urbanstress-and-mental-health.

15 Laura E. Jackson, "The Relationship of Urban Design to Human Health and Condition," Landscape and Urban Planning 64, no. 4 (November 2002) 191-192, doi: 10.1016/S0169-2046(02)00230-X.

16 Mazda Adli, "Urban Stress and Mental Health," Urban Age, last modified November, 2011, accessed February 15, 2019, https://urbanage.lsecities.net/essays/urbanstress-and-mental-health. 
A specific example of one such study that demonstrates this link is "The Cognitive Benefits of Interacting with Nature" by Berman, Jonides, and Kaplan. This particular experiment required two sets of 38 subjects to perform an attention-testing task. After the task, one group was to take a 50-minute walk through a particularly busy area of downtown Ann Arbor, Michigan, while the other strolled through the lush gardens of the Ann Arbor Arboretum. Immediately afterward, the groups repeated the task and those who walked through the park environment scored consistently higher results, suggesting a better cognitive state. ${ }^{17}$

The positive influence of certain natural environments on mental health extends beyond plant life and into other species. A study published in "Biology Letters" in 2007 determined a positive correlation between the richness of biodiversity of birds and butterflies in an urban greenspace and the psychological wellbeing of park-goers. A survey was used to measure the strength of the responses of participants in 15 different parks in the city of Sheffield with respect to their levels of fatigue, emotional states, and opportunities for reflection. ${ }^{18}$ While the park area had a positive impact on the subjects' psychological well-being, the richness of the biodiversity showed a stronger influence.

17 Marc G. Berman, John Jonides, and Stephen Kaplan, "The Cognitive Benefits of Interacting with Nature," Association for Psychological Science 19, no. 12 (December 2008) 1207-1209, doi: 10.1111/j.1467-9280.2008.02225.x.

18 Richard Fuller, Katherine Irvine, Patrick Devine-Wright, Philip Warren, and Kevin Gaston, "Psychological Benefits of Greenspace Increase with Biodiversity," Biology Letters 3, no. 4 (August 2007) 390-394, doi: 10.1098/rsbl.2007.0149.

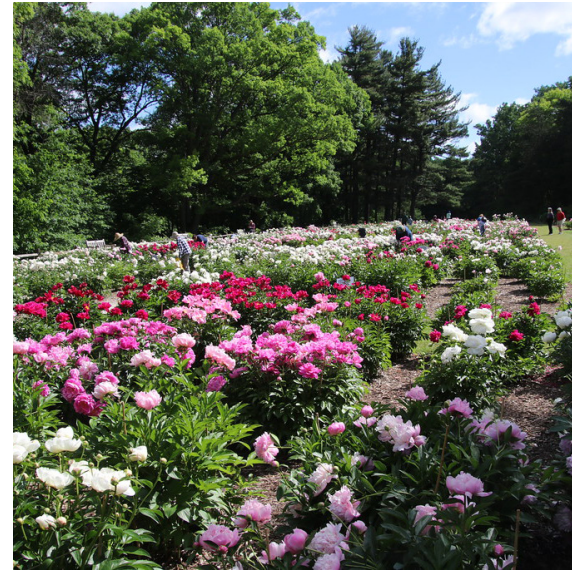

Fig 1-10. Ann Arbor Arboretum. 


\section{The Great Acceleration Graphs}

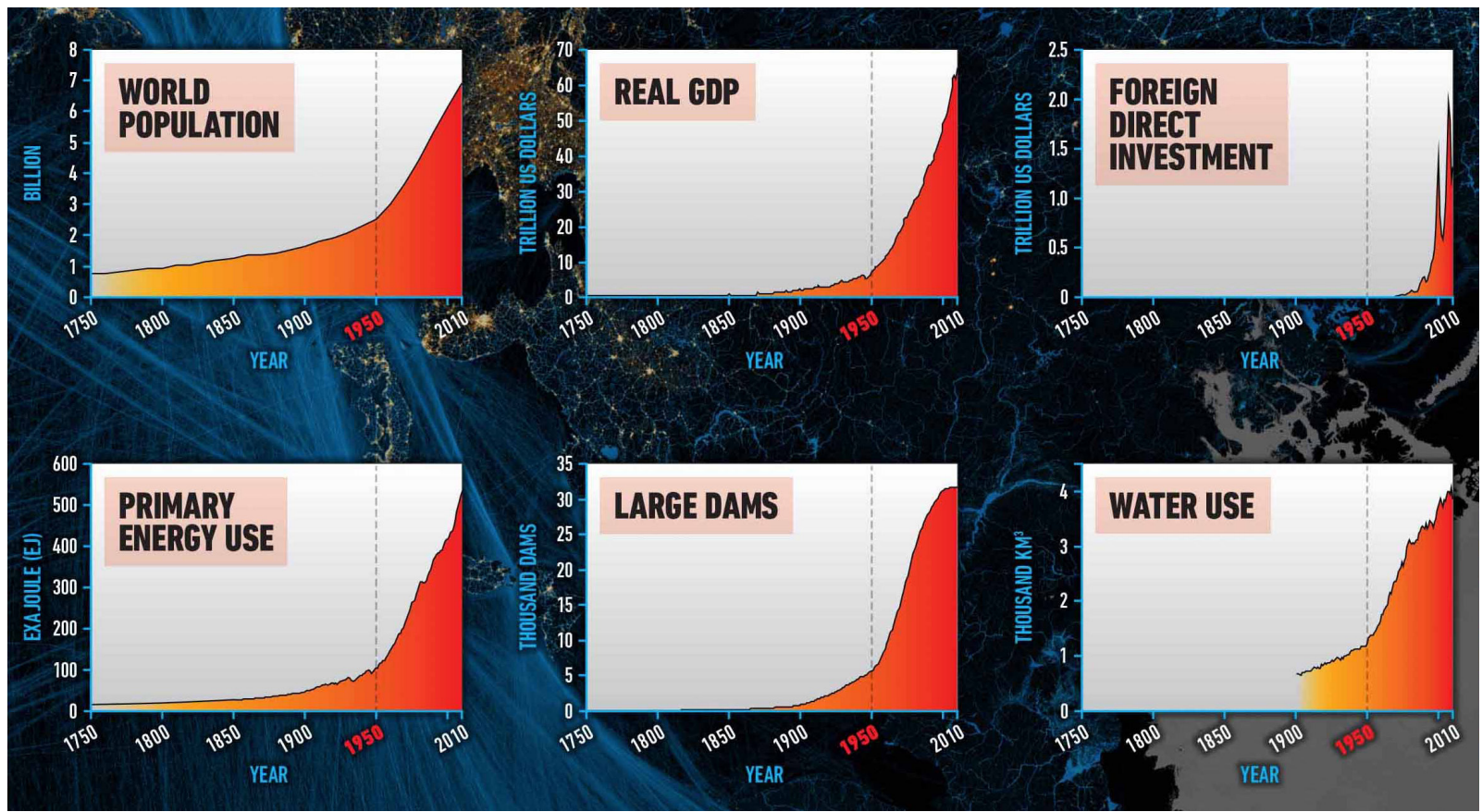

Fig 1-11. Socio-economic Trends.

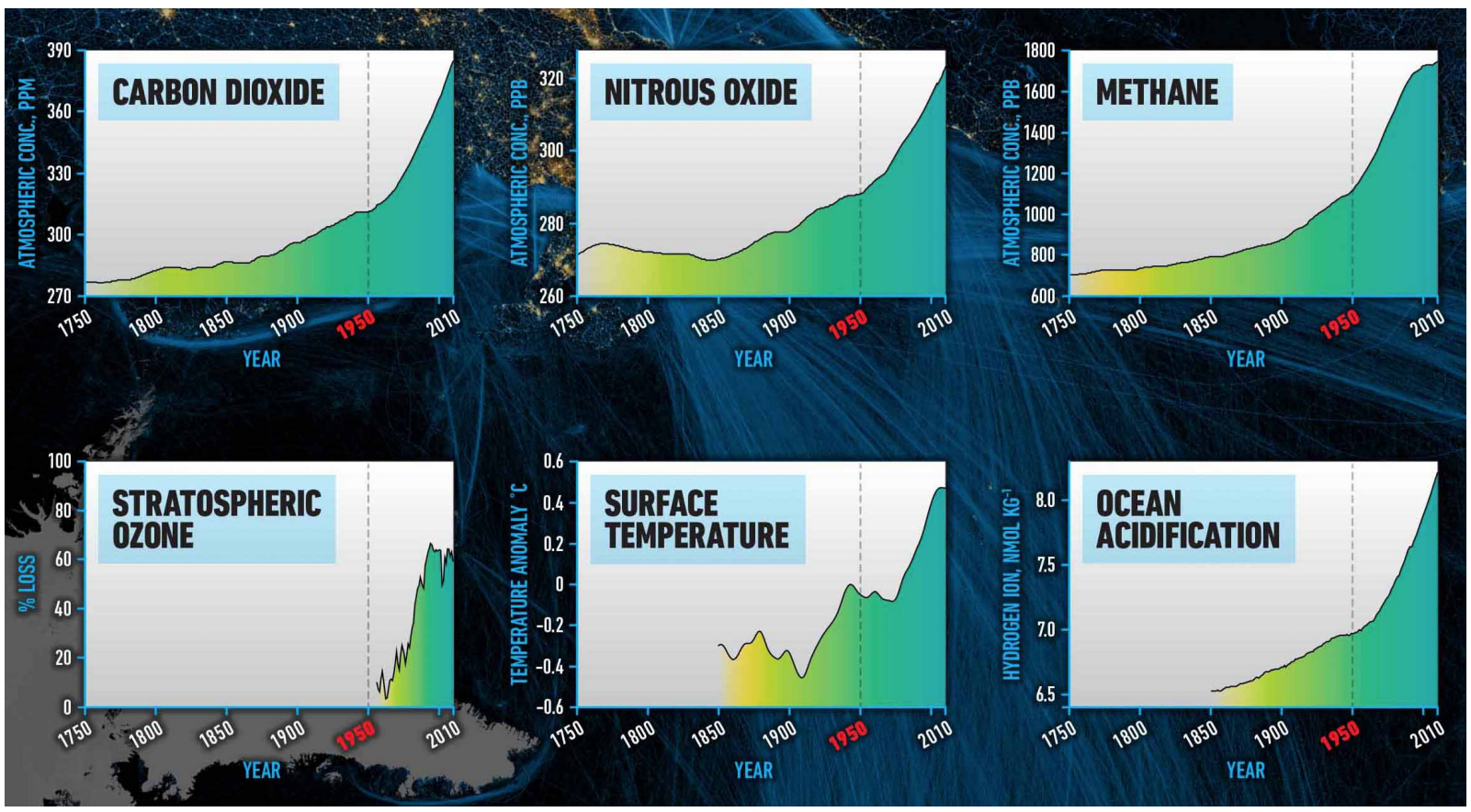

Fig 1-12. Earth Systems Trends. 


\section{Conclusion}

Evidence supports the premise of the biophilia hypothesis that humans have an inherent affinity towards ecotopes of natural ecological systems. A paper published in 2004 titled "The Trajectory of the Anthropocene: The Great Acceleration," presented two critical sets of data, which have become known as The Great Acceleration Graphs. ${ }^{19}$ They showcase the rapid increase of socio-economic activity in the past 250 years, as well as the rapid deterioration of various earth systems within the same timeframe. As the global population increases and moves further into urban environments, natural and ecological systems fall by the wayside. Though Homo sapiens draw benefit from direct contact with nature, the highly urbanized environments that humans build can be largely uninviting to wildlife and natural growth. Chapter 2 examines the various ways in which man-made cities repel biodiversity and present challenges to animals that find their way into these constructed anthropocentric landscapes.

19 Will Steffen, Wendy Broadgate, Lisa Deutsch, Owen Gaffney, and Cornelia Ludwig, "The Trajectory of the Anthropocene: The Great Acceleration," The Anthropocene Review 2, no. 1 (January 2015) 81-98, doi: 10.1177/2053019614564785. 


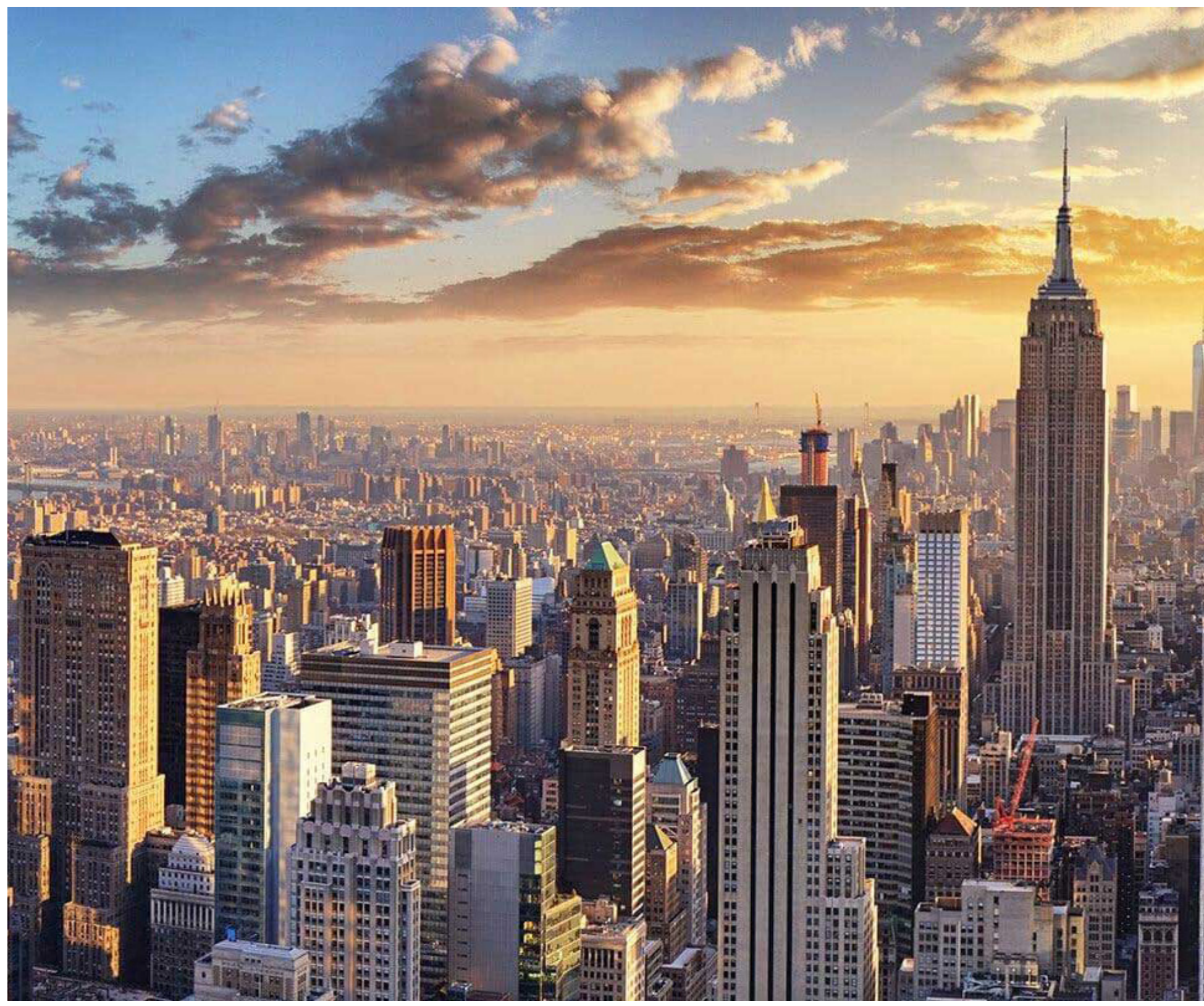

Fig 2-1. New York City. 
Chapter 2

\section{The Urban Landscape}

2.1

2.1.1

2.1.2

2.2
Urban Challenges

23

Habitat Fragmentation

25

Bird-Building Collisions

27

New Opportunities 
2.1

\section{Urban Challenges}

Urban form is an entirely new type of landscape; it is not an environment that is formed by the powerful pressures of natural forces applied over geological time, but rather by the systematic and calibrated interventions of humans. Environmental morphology is no longer governed solely by geological and ecological processes, but now also by cultural forces. Technological advancements facilitate the accelerated evolution of forms, materials, systems, and methods of construction that reshape the landscape. The forms of this novel environment follow the functions desired by its human inhabitants. In a sense, architecture is the process of environmental modification via the outward projection of an internal consciousness within a biological entity. These cityscapes are so finely tuned to the routine behaviours of humans that they are practically divorced from the needs of most other forms of life. Through their morphological design, cities largely inhibit the functions necessary for the survival and well-being of wildlife.

Animals face an assortment of challenges in the urban environment, such as false perceptions of materials, improper circulation that leads to road collisions, and lights that disrupt bird migration patterns. Their inability to comprehend this artificial landscape puts their lives at great risk. 

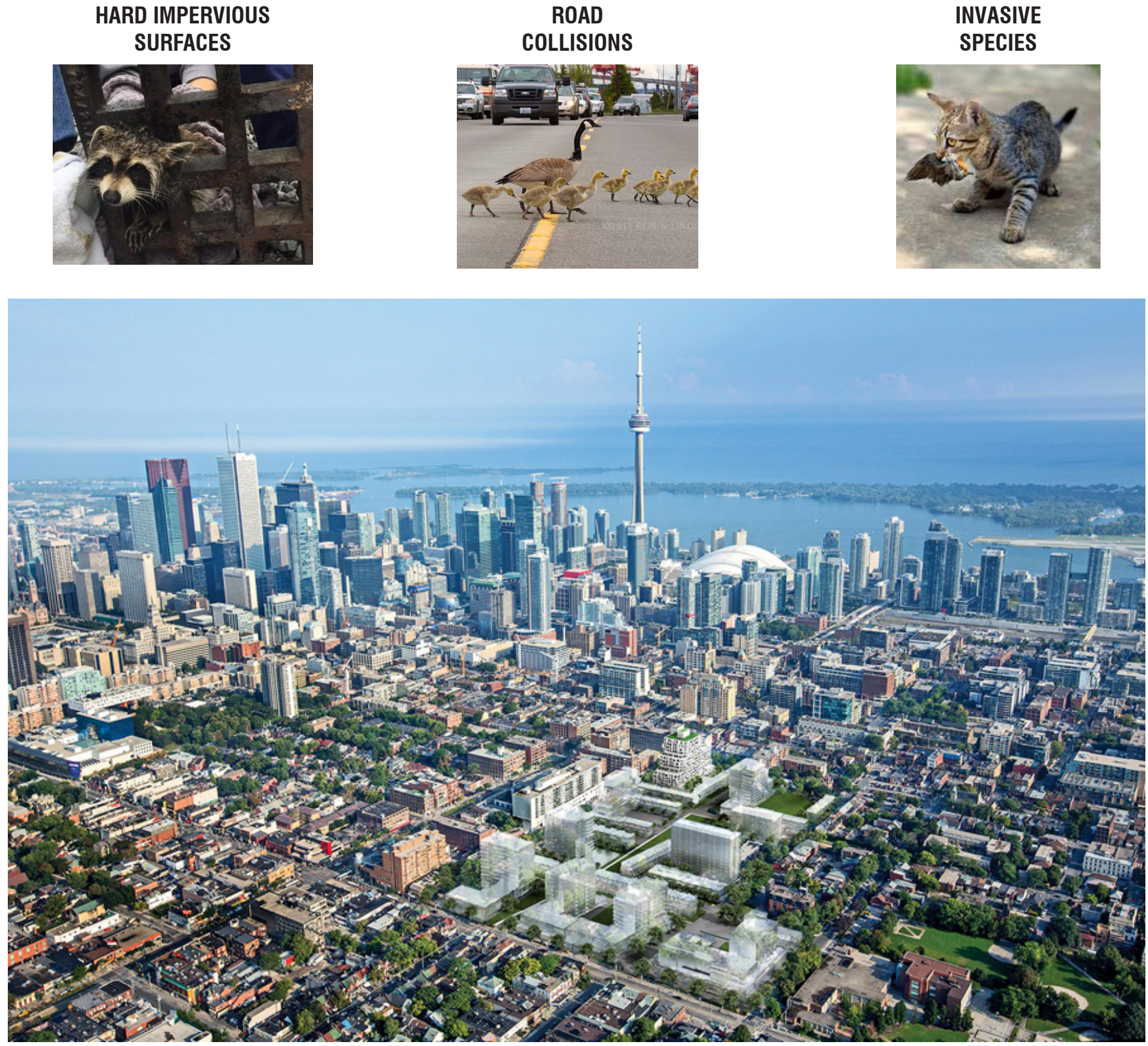

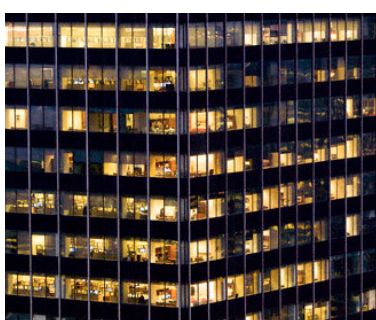

LIGHT POLLUTION

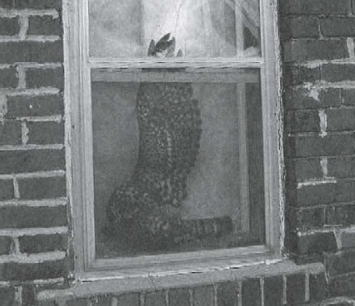

TRANSPARENT GLASS

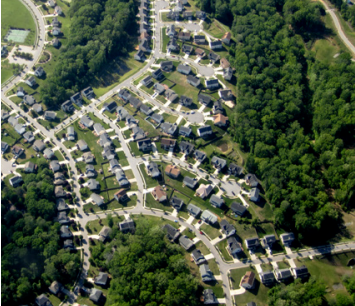

HABITAT

FRAGMENTATION

Fig 2-2. Qualities of the Urban Landscape. 


\subsubsection{Habitat Fragmentation}

Urban development is a primary cause of habitat fragmentation which endangers animal as well as plant life. Fragmentation occurs when habitats are displaced by various anthropomorphic topologies such as farmland and suburban sprawl, or bisected by constructed barriers such as highways and traintracks. Ecosystems are dynamic environments that consist of a mosaic of interconnected territories and ecotopes; severing these connections impedes wildlife movement, instigating multiple detrimental effects:

\section{Patch-Size Effect:}

Smaller patches of land would be unsuitable habitats for certain animals that require larger territorial ranges. Many species depend on contiguous areas with access to different specialized sites depending on the required behavioural activity. Some conditions are better suited to foraging, others to forming social groups, courting, mating, rearing, hunting, resting, amidst a plethora of other essential functions. Reduced available lands impedes the ability of wildlife to engage in critical ecological behaviours and limits their likelihood to survive.

\section{Isolation Effect:}

Biological populations depend on the continual flow of individuals with which to interact for various purposes. Secluding populations and limiting the genetic variability available to its individuals can lead to the group's localized extinction through inbreeding. Some symbiotic species, such as plants that rely on pollinating butterflies and birds, may also be at risk if they are unreachable by their biological partners. 


\section{Edge Effect:}

Bisecting a habitat produces multiple smaller habitats and increases the amount of perimeter conditions that are created as a result. These perimeter edges are highly unfavourable to certain species for multiple reasons. These exposed regions are likely to have higher wind speeds and greater levels of sunlight; they may also be at greater risk of having predators and various invasive species. ${ }^{1}$ When abutting a road, these areas are also prone to wildlife collisions and noise pollution. The risks of edge conditions drive animals to move further into the safer depths of their habitat. As continual fragmentation adds further perimeters conditions, suitable habitats continue to rapidly decline.

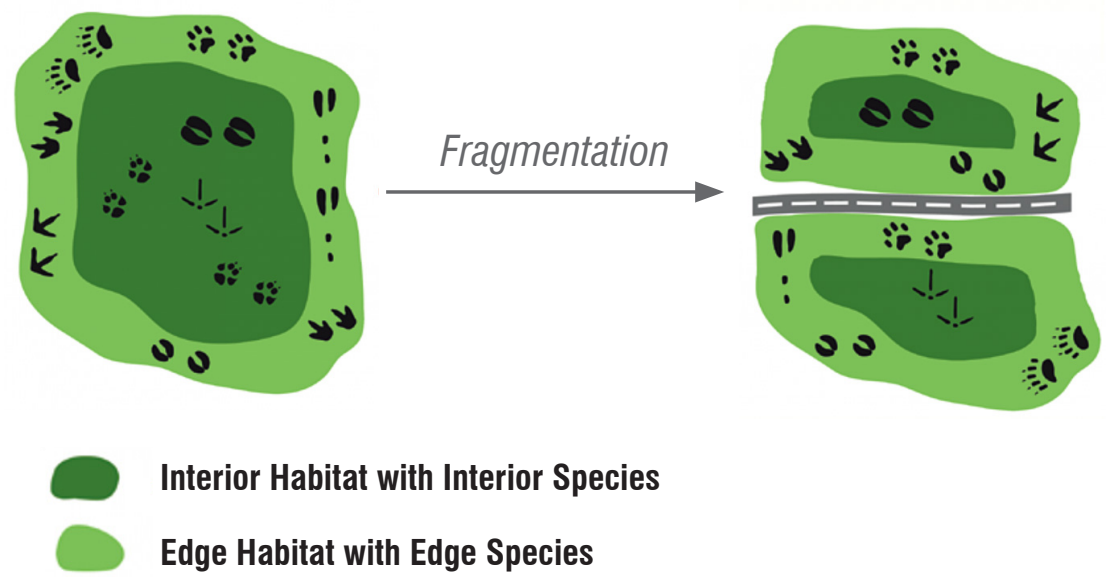

Fig 2-3. Habitat reduction by fragmentation.

1 "Wildlife Habitat Fragmentation - Fact Sheet," The Wildlife Society, n.d., accessed March 3, 2020, https://wildlife.org/. 


\subsubsection{Bird-Building Collisions}

The morning following a dark stormy night in early May of 2017, Josh Henderson of the Galveston Police Department in Texas was called onto a grisly scene - hundreds of birds lay dead at the foot of the 23 storey American National Insurance building. Henderson, supervisor of animal services at GPD, collected the birds for examination; among them, three were still alive. Arranging the deceased birds onto an autopsy bed, the body count read as follows:

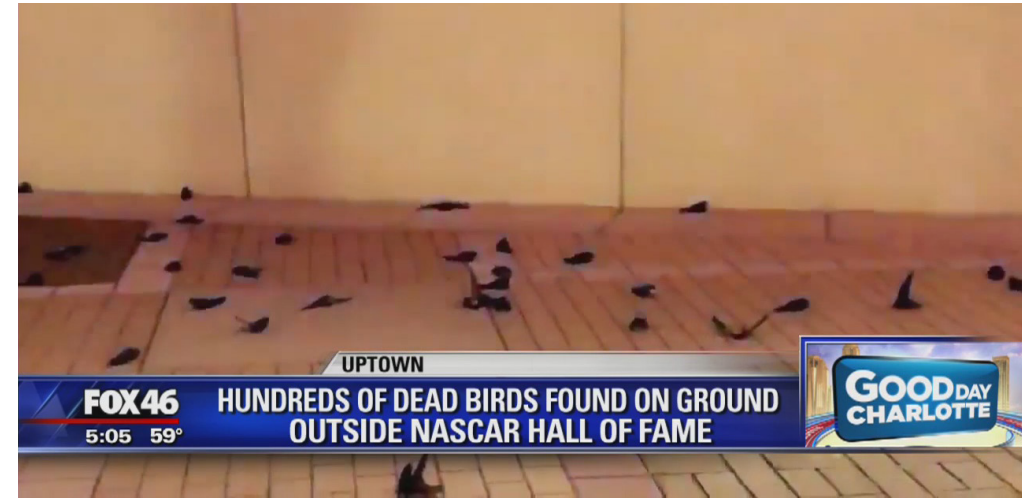

Fig 2-4. Birds that struck into the NASCAR Hall of Fame in Charlotte, North Carolina.
- 90 Nashville warblers

- 60 Blackburnian warblers

- 42 chestnut-sided warblers

- 41 ovenbirds

- 29 yellow warblers

The list went on for a sum total of 395 migratory birds - the casualties of a single tall building. This, however, is not an uncommon occurrence. On October 15 of 2019, about 300 birds slammed into the NASCAR Hall of Fame building in Charlotte, North Carolina. ${ }^{2}$ On this occasion, according to Carolina Waterfowl Rescue, about 100 of the birds were "severely injured with broken wings, legs or other fractures." ${ }^{3}$ With the prevalence of urban sprawl and the development of high-rise buildings in downtown cores of cities across all continents, the skies themselves are no longer safe. Estimates of the number of annual bird fatalities due to collisions with buildings in North America

2 Mark Price and Joe Marusak, "Rescuers rush to save birds that hit NASCAR Hall of Fame, as theories emerge on cause." The Charlotte Observer, last modified October 17, 2019, accessed January 28, 2019, https://www.charlotteobserver.com/news/local/ article236350023.html.

3 Ibid. 


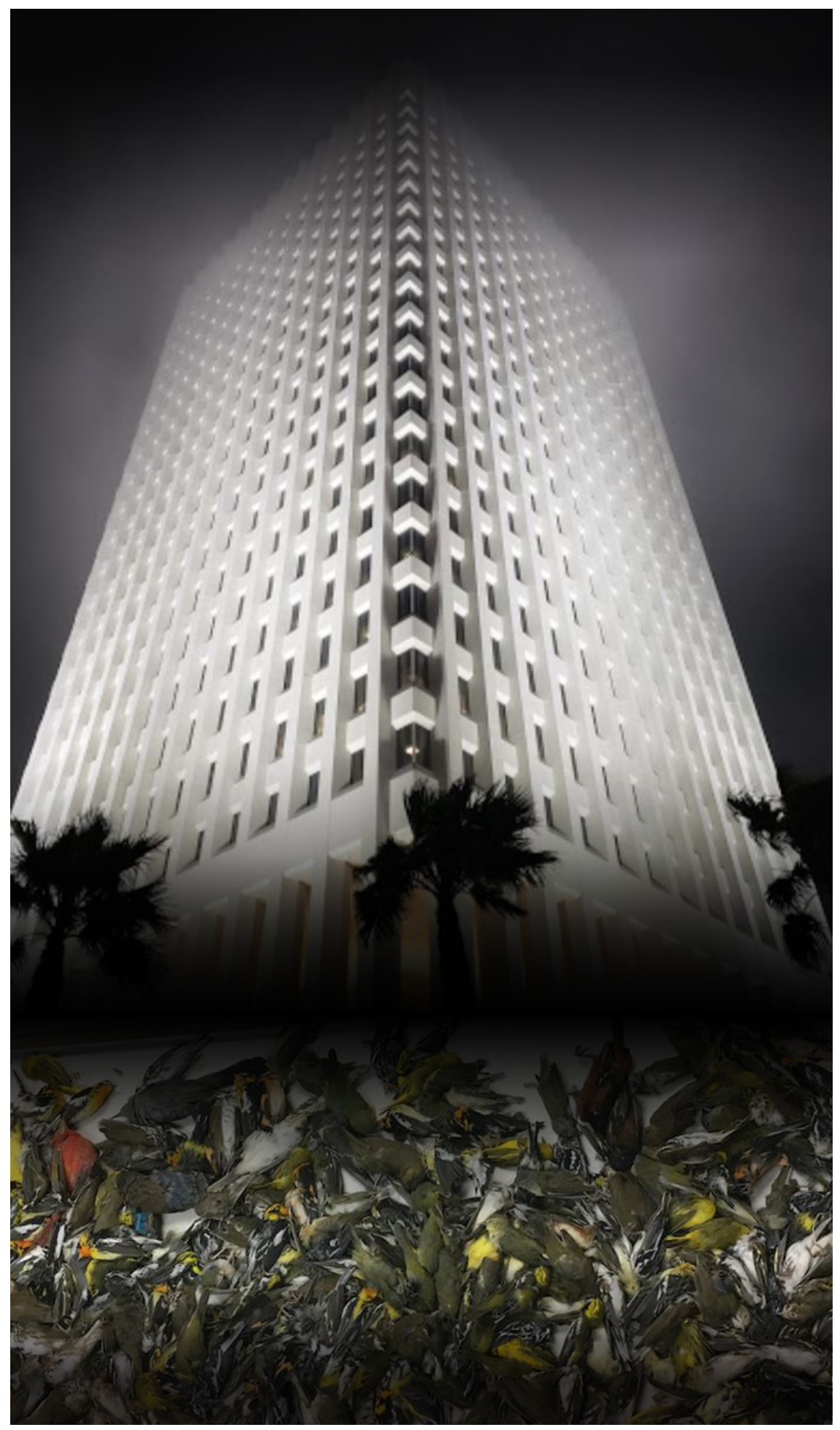

Fig 2-5. The American National Insurance Building and the 395 dead birds that were found at its base. 


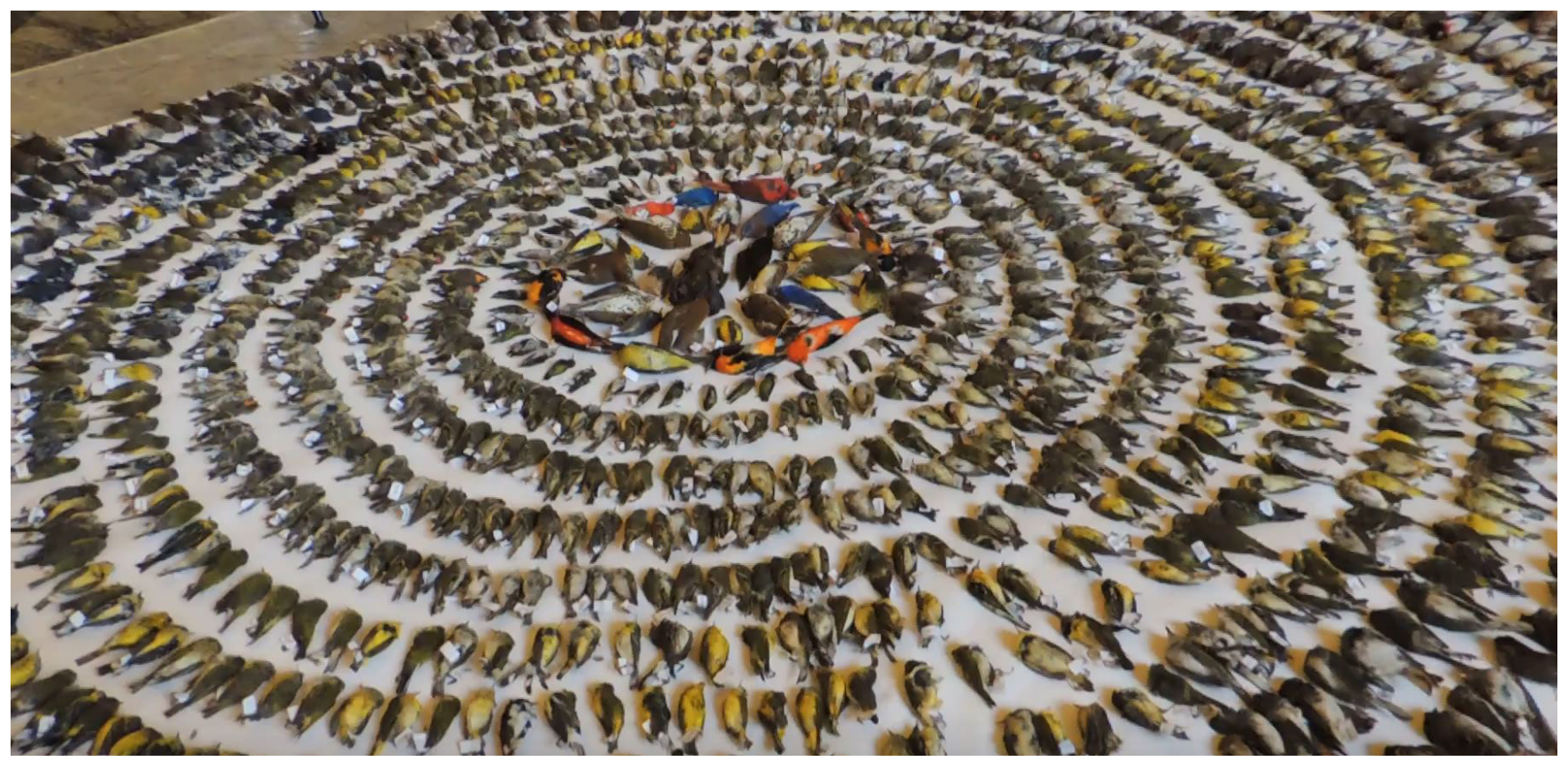

Fig 2-6. FLAP Display.

range from 100 million $^{4}$ to one billion. ${ }^{5}$ In Canada alone, the estimated figure is above 25 million birds every year. ${ }^{6}$ In the grand scheme of things, according to an article published in Science in 2019 by Rosenberg et al., the population of birds in North America has declined by 3 billion from a grand total of roughly 10 billion in $1970{ }^{7}$

4 Clark E. Adams, Kieran J. Lindsey, and Sara J. Ash, "Special Habitat Considerations: Gray Spaces," in Urban Wildlife Management (New York: Taylor \& Francis Group, 2006) 117.

5 Karin Brulliard, "One tall building. One dark and stormy night. 395 dead birds," The Washington Post, last modified May 15, 2017, accessed January 2, 2020, https://www.washingtonpost.com/news/animalia/wp/2017/05/10/one-tall-buildingone-dark-and-stormy-night-395-dead-birds/?fbclid=IwAR0L08bFzw7q7N x-B penZGcFrZ1Kvy0LeU1PJ9nPSRSCyQ2sRkGAIZXNo.

6 “About," FLAP Canada, last modified 2019, accessed March 3, 2020, https://flap. org/about/.

7 Jim Daley, "Silent Skies: Billions of North American Birds Have Vanished," Scientific American, last modified September 19, 2019, accessed March 3, 2020, https:// www.scientificamerican.com/article/silent-skies-billions-of-north-american-birds-havevanished/. 
An organization in Toronto strives to raise awareness of this issue and promote strategies by which to address it. The Fatal Light Awareness Program assembled this particular arrangement of birds collected from the foot of high-rise buildings in Toronto in 2016 (Fig. 2-6).

\section{Bird-friendly Glazing \& Building Design}

Glass is the primary cause of death of birds in the urban environment. Birds are unable to truly understand the properties of glass and, instead, are confused by its presence in multiple ways. Transparent glass can be imperceptible, thus birds fly into it at high velocity, not understanding that a solid structure is in the way. ${ }^{8}$ Glass can also reflect the sky or nearby vegetation; birds may strike the glass thinking there is clear sky ahead in the former situation, and places of rest in the latter. ${ }^{9}$ Finally, windows can create a "black hole" effect wherein birds perceive them as dark caverns into which they can fly to find refuge. ${ }^{10}$

The Bird-friendly Building Design guidelines were published by the Standards Council of Canada in 2019. This document outlines the challenges that birds face with perceiving glazing and offers strategies for building design to mediate these issues. The façade of the Student Learning Centre at Ryerson University follows these types of guidelines; the result is a dynamic aesthetic that adds character to the interior space as well as to the outward appearance of the building, while serving a vital ecological function.

\footnotetext{
8 City of Toronto, Bird-friendly building design, (Toronto: City of Toronto, City Planning, 2019), 11.

9 Ibid.

10 Ibid.
}

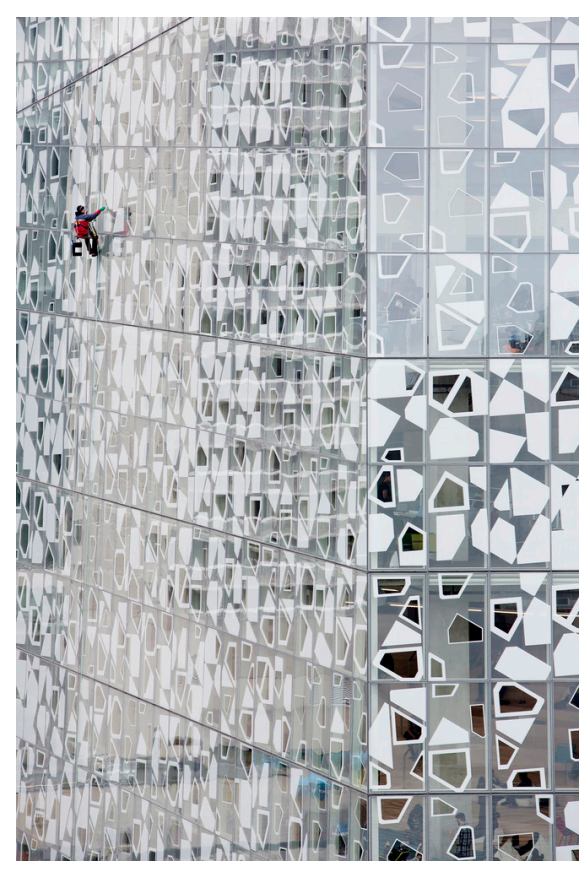

Fig 2-7. Exterior facade of the Ryerson University Student Learning Centre.

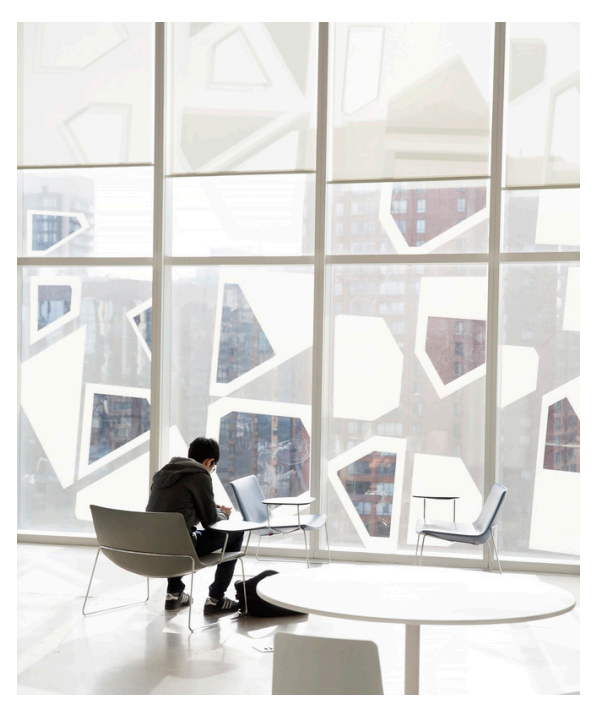

Fig 2-8. SLC's glazing fritted pattern. 


\section{New Opportunities}

While the anthropic landscape poses challenges to many species whose biological nature is not attuned to this recently formed artificial environment, the characteristics of some species happen to fit with it well. The cliff-like qualities of metropolitan cities like New York have attracted peregrine falcons that nest in high places from which they can catch winds at high speeds. ${ }^{11}$ Urban raccoons have developed stronger problem-solving skills than their rural cousins, and have been able to adapt to the built environment. ${ }^{12}$ Rodents have also lived among humans for centuries due to the abundance of food available to them as well as some of the underground networks wherein they're able to find refuge. Centuries ago, people held their relationship with pigeons to be valuable for the communication service that they were able to provide, building tall and intricate pigeonniers wherein to house, organize, and access these precious birds. Some creatures, it seems, are true synanthropes - benefiting from the urban landscape that people have constructed. However, many species are antithropic and do not manifest behavioural and biological properties that coincide with the qualities of the urban landscape. The process of architectural design, at a fundamental level, is the thoughtful configuration of built form to suit the needs of biological subjects. Where architecture begins to change is when this definition extends beyond humans and domesticated animals and into urban wildlife: what can architecture do to incorporate the synanthropes that interact with urban fabric? The next chapter showcases some architectural projects that tackle the relationship between architecture and wilderness and, in one way or another, address this question that informs the development of the thesis.

11 "Peregrine Falcon Program," New York State Department of Environmental Conservation, n.d., accessed February 12, 2019, https://www.dec.ny.gov/animals/7059. $\underline{\mathrm{html}}$.

12 "City Raccoons: Smarter than their rural counterparts," Meta Filter, 10 October, 2014, accessed February 12, 2019, https://www.metafilter.com/143479/City-RaccoonsSmarter-than-their-rural-counterparts. 


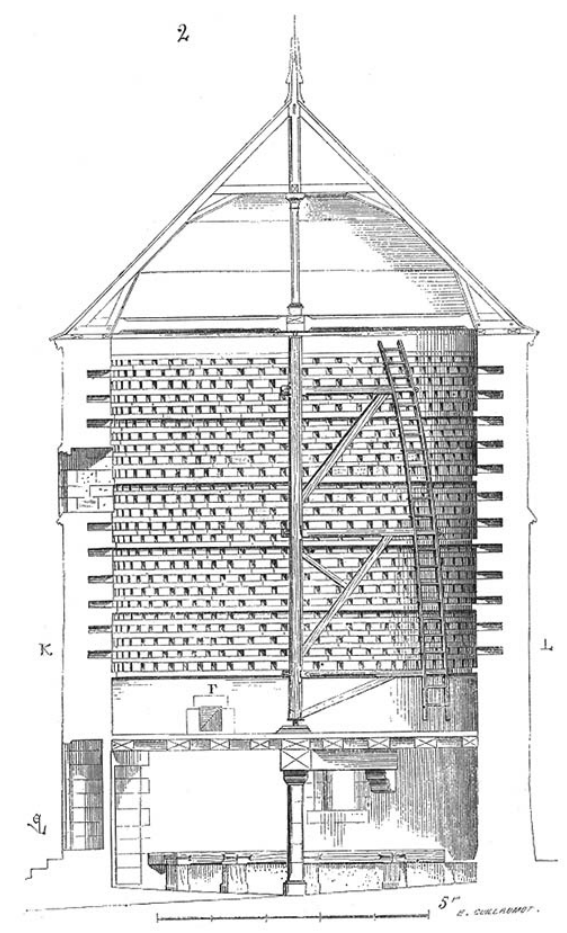

Fig 2-9. Pigeonnier plan and section.
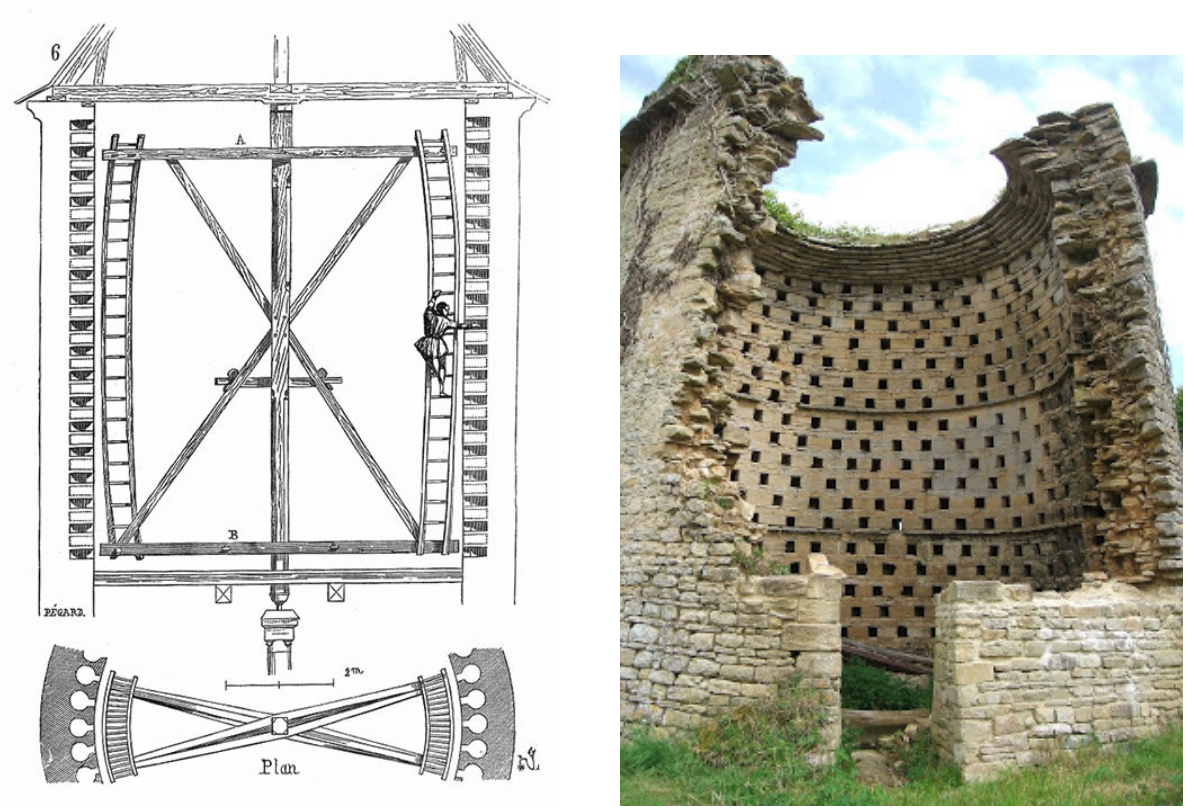

Fig 2-10. Pigeonnier.

Could it not be possible to build cities more in harmony with nature?

How, and whether we decide to invite the wildlife back, is up to us.

- David Attenborough

Planet Earth II: Cities. ${ }^{13}$ 


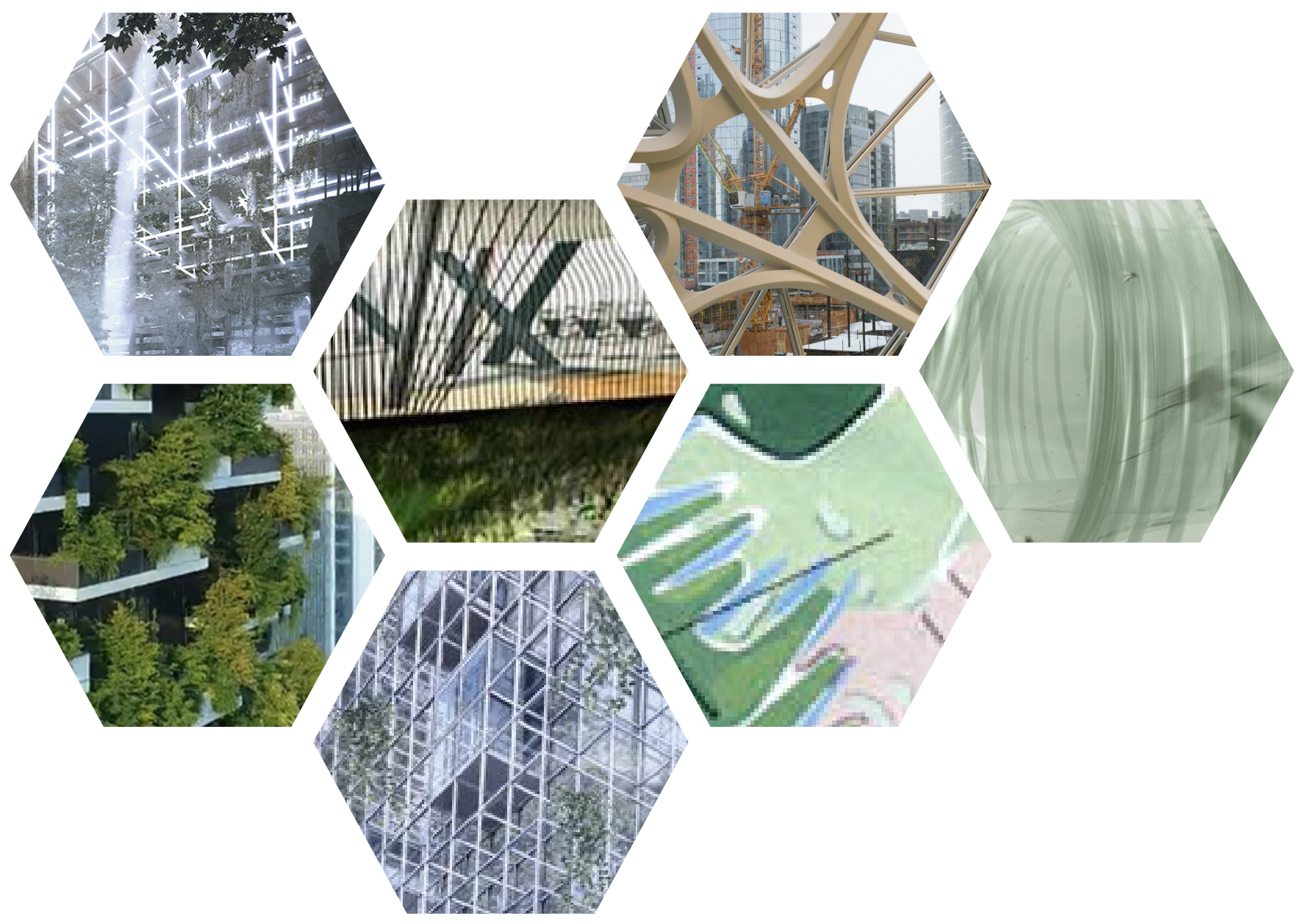

Fig 3-1. Precedents. 


\section{Chapter 3}

\section{Contemporary Responses}

3.1

3.1.1

3.1 .2

3.1.3

3.1.4

3.1 .5

3.1.6

3.1.7

3.1.8

3.2

3.3
Precedent Studies

The Digital \& The Coyote

Wildlife Crossings

Ford Calumet Environmental Center

Banyan Tree Skyscraper

Bosco Verticale

Permaculture

Amazon Spheres

Biodiversity-Sensitive Urban Design

Syntax of Boundaries

A New Paradigm
35

37

39

45

49

51

53

55

57

59

61 
CHAPTER THREE 


\section{1}

\section{Precedent Studies}

In seeking to address some of the issues that emerge from tackling the thesis question, an array of relevant precedent projects have been studied. While they range in intent, approach, program, form, and scale, they all provide unique insights that inform the development of the thesis research and design process.

This chapter highlights some key projects that have informed the thesis and discusses their individual insight. Collectively, these projects have contributed to the development of a syntax of boundaries; this set of boundary conditions is summarized in Section 3.2. The final section of Chapter 3, which also brings Part I of the thesis to a close, discusses the emergence of a paradigm shift in architectural discourse - the neoteric idea of synanthropic architecture. 


\subsubsection{The Digital and the Coyote}

\section{9 | Downsview Park International Design Competition}

Design Team: Bernard Tschumi Architects, Dereck Revington Studio,

Sterling Finlayson Architects

Location: Toronto

Fig 3-2. The coyote at the edge of digital mass culture.
This design was one of the winning proposals for the redevelopment of a former Canadian Forces Base in Toronto (which closed in 1994) into an urban recreational green space. Nearing the turn of the century, the ambition of the design competition for Downsivew Park was to create "an urban park that sets the 21st Century standard for excellence in landscape and architectural design and urban recreational planning." Occupying a high point in the city, this 644-acre site provides distant views of the cityscape while also serving as a watersheds that feeds Toronto's two major river systems: the Humber to the west and the Don to the east. ${ }^{2}$

1 Marco Polo, "Environment as Process," Canadian Architect. 2001, 15.

2 Ibid, 14. 
This design for Downsview Park in Toronto proposed an adjacency between a cultural strip and a landscape of field conditions. The range of intended natural environments included a variety of wooded forests, tall grass savannahs, meadows, and wet landscapes. ${ }^{3}$ In the context of this project, the term "digital" referred not to an electronic aspect, but to the formal use of finger-like eco-zones that interlaced with interstitial public domains - meant to maximize the perimeter of engagement between the coupled regions.

The main contribution of this project is the blurring of boundaries between the wild and the civil (nature and culture, chaos and order). While there exists an enclosed program within the cultural strip, the fields consist of areas into which the wilder digits bleed; this permits all manner of wildlife (ie. coyotes) to travel more freely from within their untamed zones of habitation and into the more manicured areas which people may traverse. This raises a core consideration within the scope of the thesis which poses the question: how close is too close? What levels of comfort and lack-there-of are acceptable? (Chapter 4 begins to deal with these questions, laying out a set of priorities such as safety within the scope of a design strategy). This line of thought further challenges existing paradigms and assumptions about the human position in relation to nature. 


\subsubsection{Wildlife Crossing}

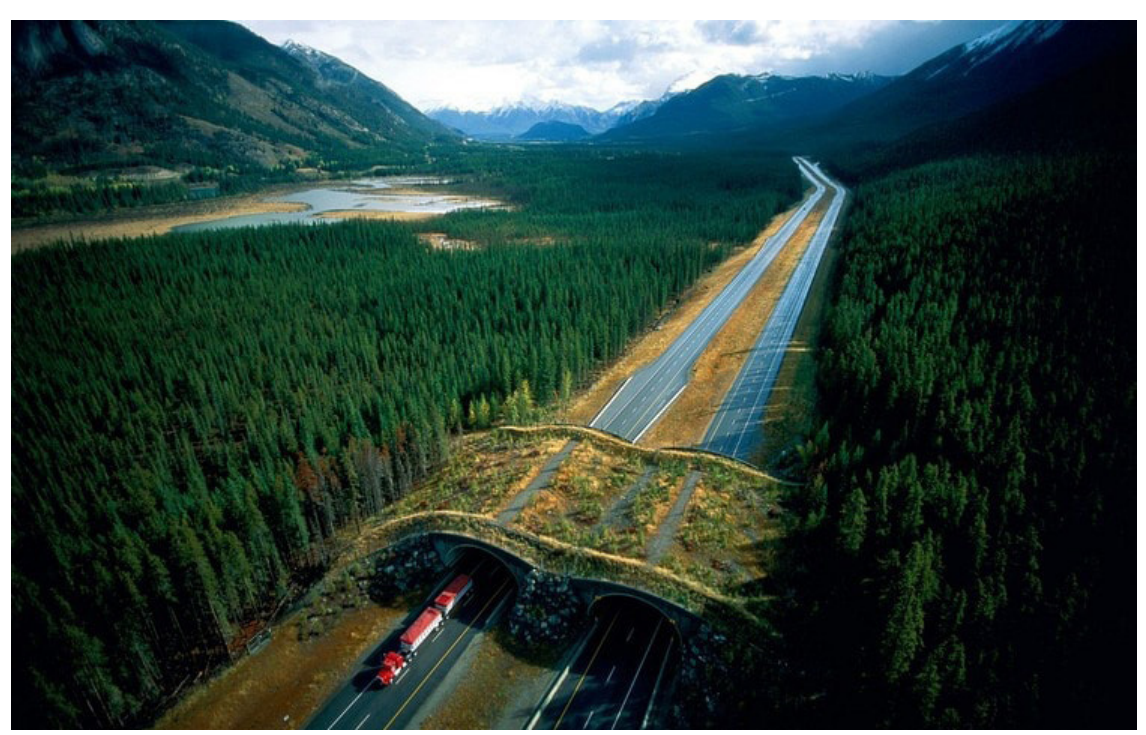

Fig 3-4. Wildlife Crossing - Banff National Park.

Although cities account for a lower percentage of land coverage, paved roads wind through entire continents like the veins and arteries that reach the furthest extremities of an organism. These paved stretches of high-speed traffic not only endanger animals with fatal vehicular collisions, but also highly disrupt valuable migratory paths - enabling habitat fragmentation that destabilizes the ecosystem. Collisions put humans at risk as well, potentially causing injuries, death, and costly property damage. Deer-car collisions can cost upwards of $\$ 8,000 .{ }^{4}$ Collisions with larger animals like elk and moose can cost around $\$ 25,000$ and $\$ 45,000$ respectively. ${ }^{5}$ These costs are associated with the time-consuming and expensive procedures that must follow collisions: towing, vehicle repair, accident investigation by local authorities, and carcass disposal. According to the road ecology program manager at the Western Transportation Institute at

4 Marcel Huijser, John Duffield, Anthony Clevenger, Robert Ament, and Pat McGowen, "Cost-Benefit Analyses of Mitigation Measures Aimed at Reducing Collisions with Large Ungulates in the United States and Canada: a Decision Support Tool," Ecology and Society 14, no. 2, (September 2009): 1.

5 Ibid. 
Montana State University, wildlife-vehicle collisions have increased by $50 \%$ over the past 15 years. ${ }^{6}$ An estimated one to two million animals are killed annually in this manner, some of which belong to endangered species that are directly jeopardized by the threat of the road. ${ }^{7}$

An effective solution to counter-act this phenomenon has been the implementation of wildlife crossings. Building overpasses and digging underpasses that animals can traverse have been significant in saving lives of humans and animals alike, as well as saving on the expensive costs of collisions. These passages have been incorporated in multiple places worldwide and their positive impact can be quantified. A study of a 2-mile stretch along the Trans-Canada Highway, where a wildlife-crossing has been built, demonstrated an annual reduction in vehicular collisions with animals by $79 \% .^{8}$ Further study and observation of these passages elicit new findings about various animals and their respective behaviours in relation to these bridge formations. Some animals, like coyotes and deer, have been found to be more readily adaptive and accustomed to human structures, thus being among the first animals to venture unto these bridges and walk across. ${ }^{9}$ Other animals have shown to be more "shy" in this regard. However, the initial "pioneers" are essential in leaving tracks and paths which the "less enthusiastic" animals may follow, thus promoting accelerated use of the crossing. Other findings

6 Starre Vartan, "How Wildlife Bridges over Highways Make Animals - and people - safer," National Geographic, last modified April 16, 2019, accessed August 25, 2019, https://www.nationalgeographic.com/animals/2019/04/wildlife-overpasses-underpassesmake-animals-people-safer/.

7 Ibid.

8 Tracy Lee, Anthony Clevenger, and Robert Ament, "Highway Wildlife Mitigation Opportunities for the TransCanada Highway in the Bow Valley," Report to Alberta Ecotrust Foundation, August 2012, 31.

9 Starre Vartan, "How wildlife bridges over highways make animals - and people safer," National Geographic, last modified April 16, 2019, accessed October 13, 2019, https://www.nationalgeographic.com/animals/2019/04/wildlife-overpasses-underpassesmake-animals-people-safer/.

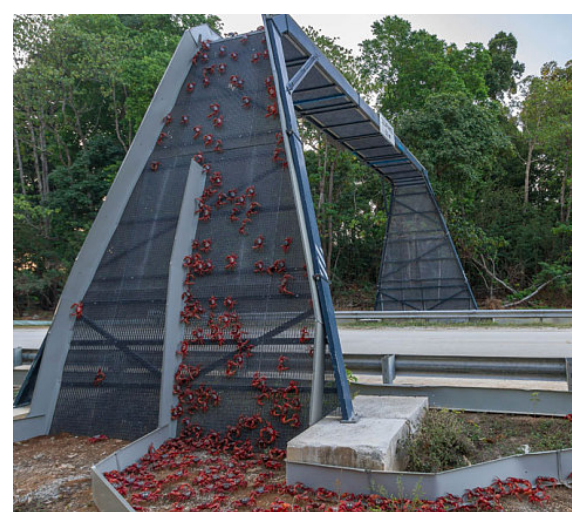

Fig 3-5. Red Crab migration crossing Christmas Island.

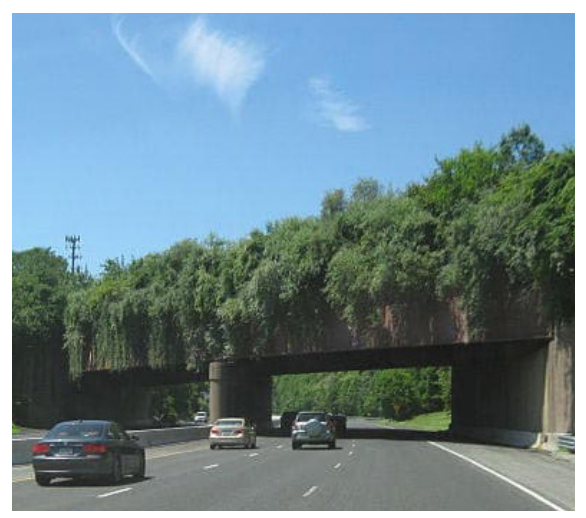

Fig 3-6. Wildlife Crossing - New Jersey. 


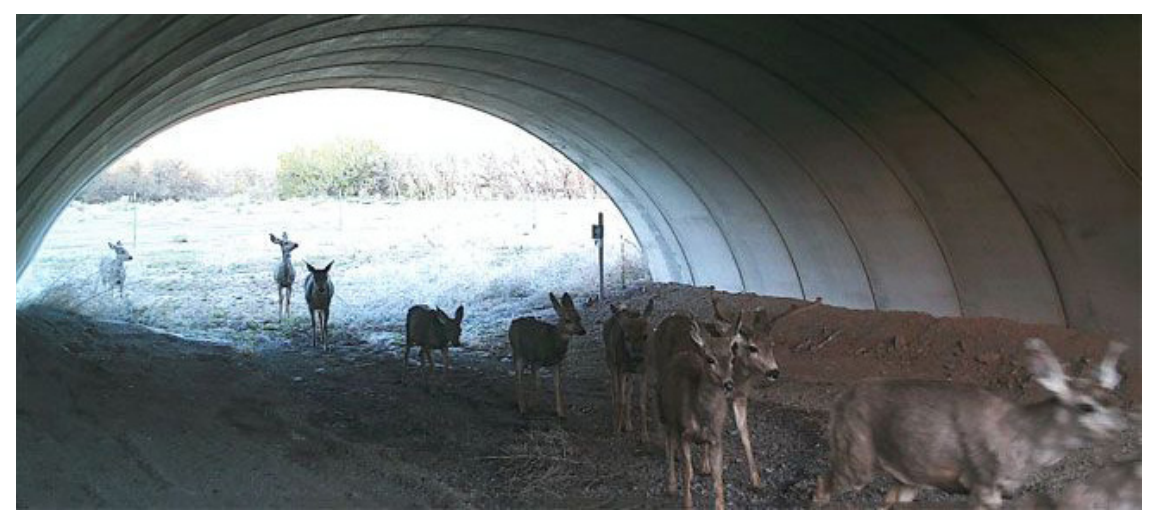

Fig 3-8. A family of deer using an underapss.

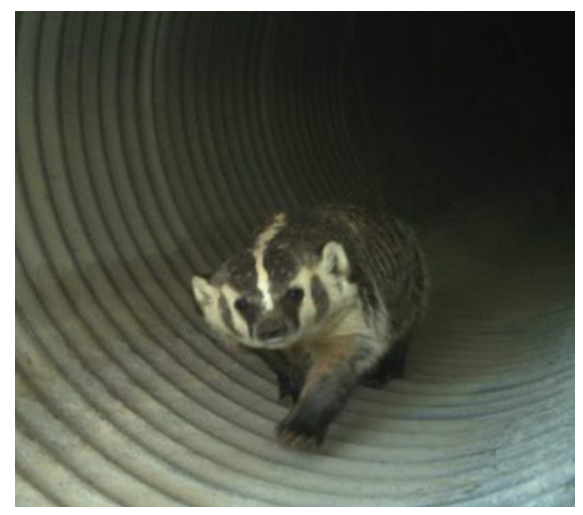

Fig 3-7. A badger using an underpass. demonstrated that some animals have preferences with respect to physical conditions; namely, some harbour affinity for wide, open and lit spaces that resemble the conditions of meadows, while others prefer darker, more constricted and protected conditions that resemble the qualities of denser foliage or caves. ${ }^{10}$ There are even observable preferences of which type of passage to use depending on the animal's gender. ${ }^{11}$ Taking these observations into consideration, some of the crossings in Banff incorporate a variety of landscape conditions - some more open, some more densely vegetated - to accommodate the varied preferences of wildlife. ${ }^{12}$ Patty GarveyDarda, a wildlife biologist, expressed with regards to the construction of such crossings: "we don't want to just connect animals - we want to create ecosystems." ${ }^{13}$ Creating safe crossings that weave a network of ecotopes together allows for permeability, mobility, and mixing of genetic material, thus safeguarding the stability and health of a species and preventing it from being trapped in fragmented habitats

\footnotetext{
10 Ibid.

11 Ibid.

12 Ibid.

13 Ibid.
} 
with the threat of localized extinction by inbreeding. ${ }^{14}$ It is evident that certain human interventions can have positive impacts on the environment, even being mutually beneficial. Within the scope of the thesis, it is critical to consider the circulatory needs of animals and the varied types of conditions and forms that would facilitate that function.

Fig 3-9. Wildlife underpass in Colorado. 


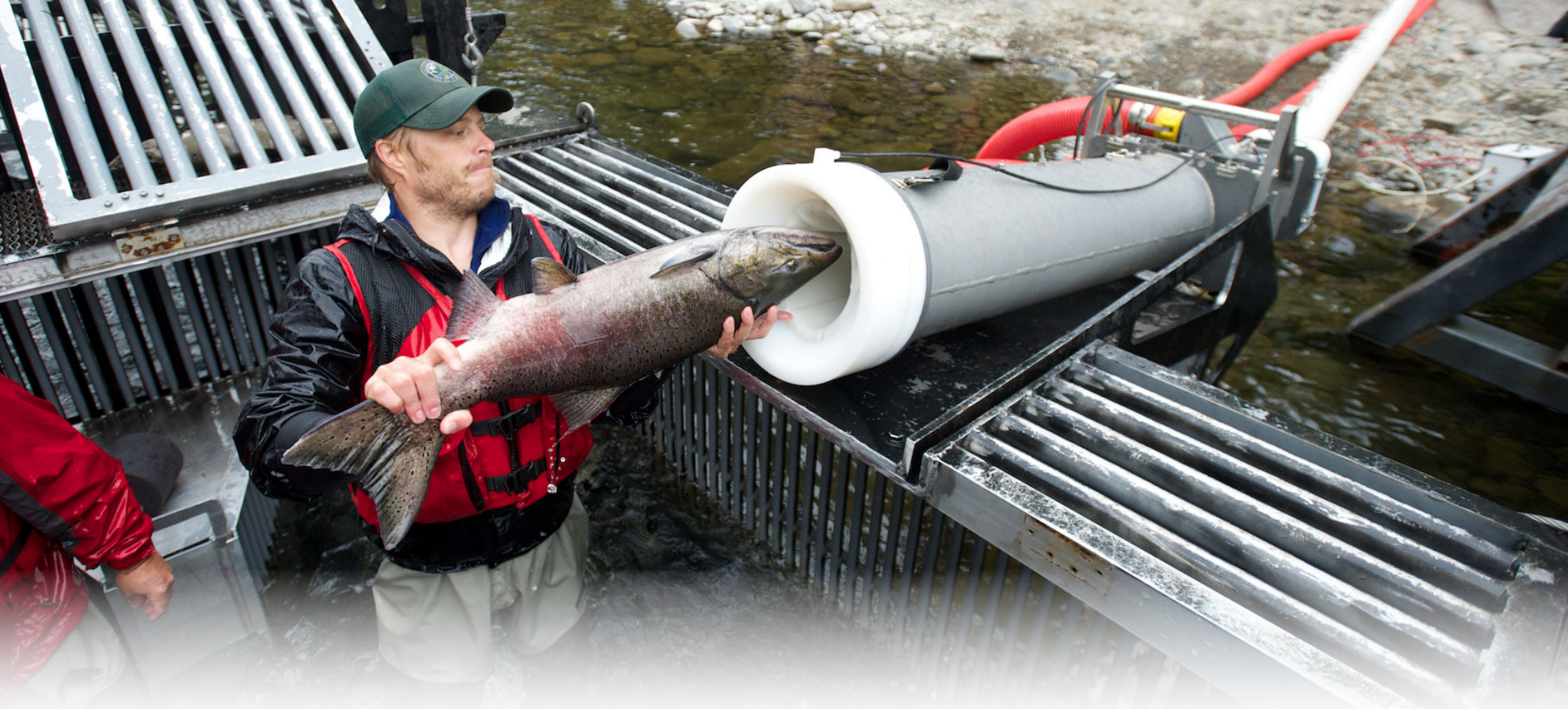

Fig 3-10. The salmon cannon at the Washougal River used by the Washington Department of Fish and Wildlife.

\section{Salmon Cannon}

While roads are a man-made constructs that can be traversed with bridges, other artificial obstacles require more sophisticated technological and procedural strategies. To help fish navigate across hydroelectric dams, this vacuum-powered transport system (also referred to as a salmon cannon) was constructed. ${ }^{15}$ It delivers salmon from one body of water to an adjacent one above. This demonstrates that if humans are to modify the natural environment while aiming to maintain some of its ecological processes, there need to be intricate systems implemented to counter the potential negative ramifications of any such interventions.

15 Amorina Kingdon, "Fish in Tubes," Hakai Magazine, last modified March 13, 2019, accessed July 7, 2019, https://www.hakaimagazine.com/article-short/fish-in-tubes/. 


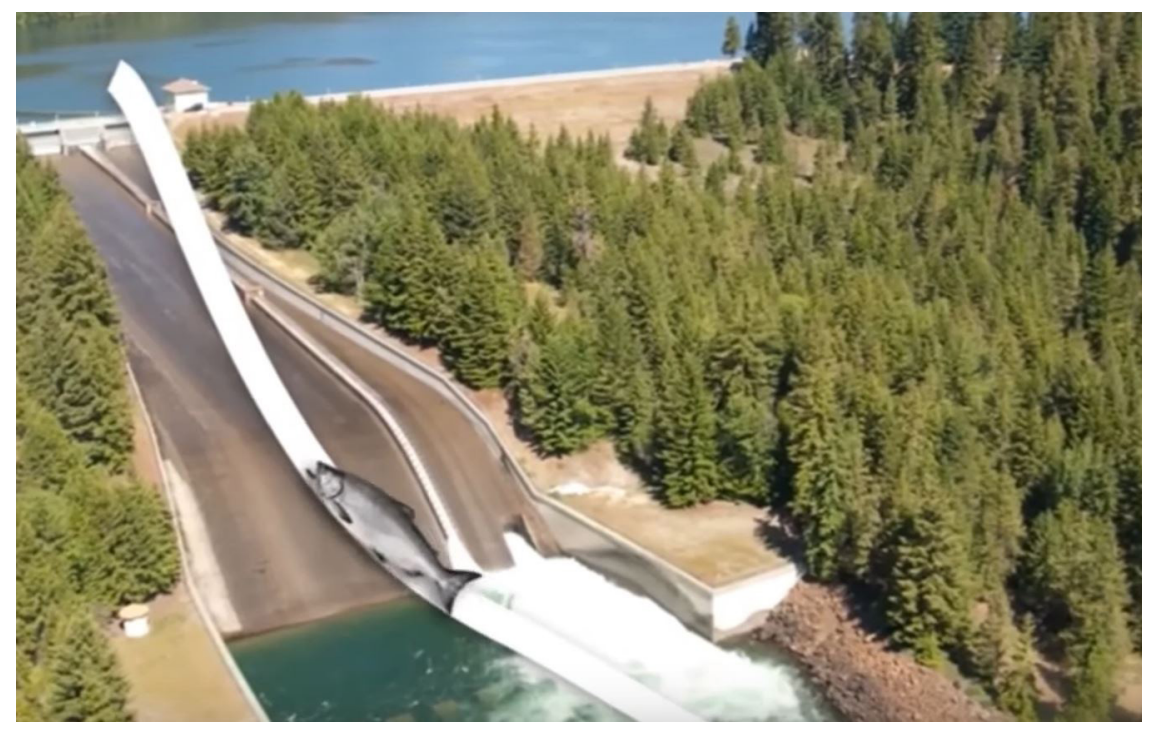

Fig 3-11. Salmon Cannon Concept.

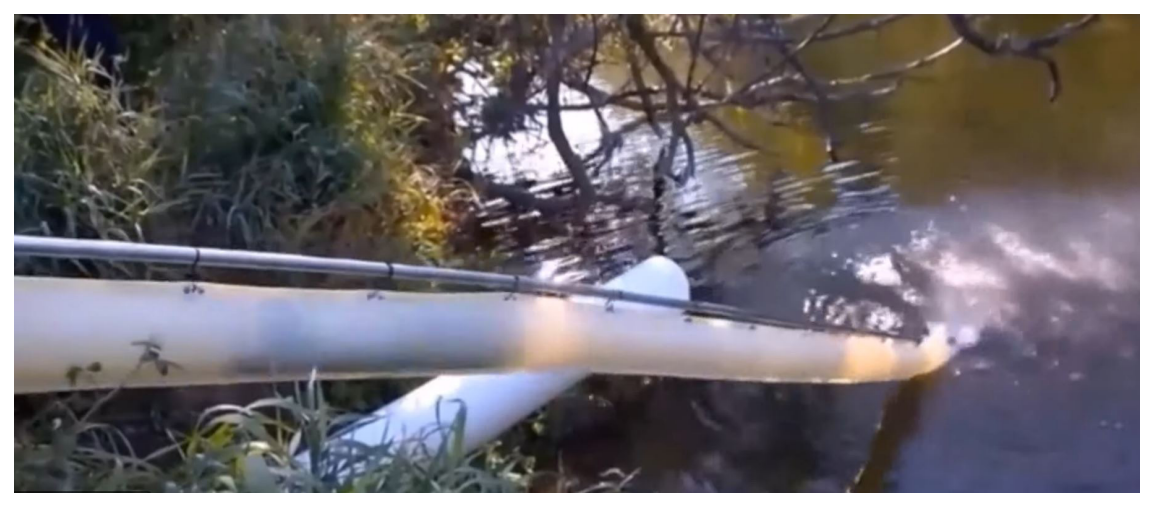

Fig 3-12. Salmon Cannon 


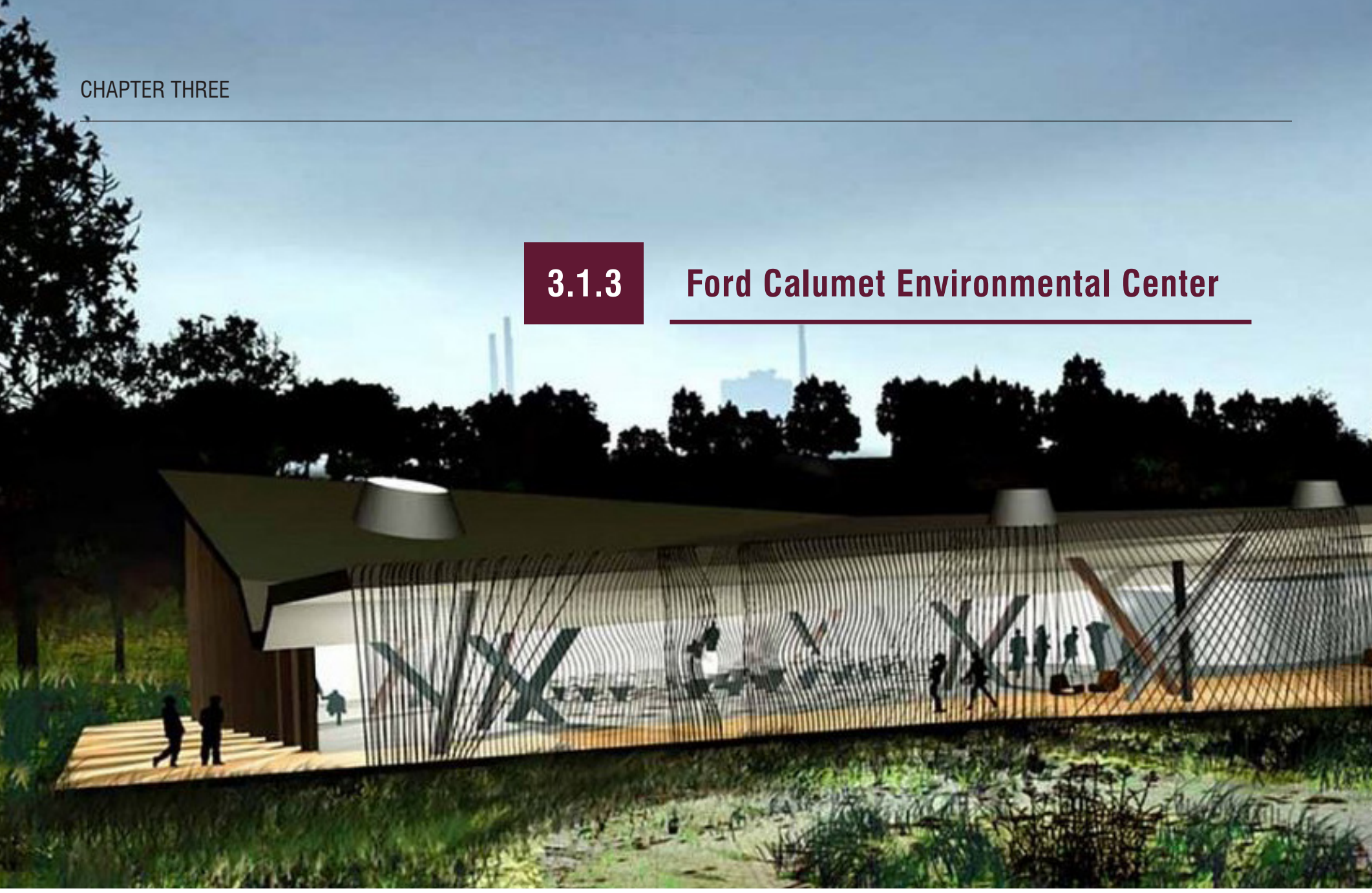

Fig 3-13. Ford Calumet Environmental Center.

\section{8}

Design Team: Studio Gang

Location: Chicago, IL

This project embodies a host of design strategies that informed the thesis work in various ways. The initial contribution of this project was its approach for designing an architecturally expressive, bird-friendly exterior layer. Made of salvaged steel bars, this wiremesh pattern creates a didactic space wherein visitors can occupy and look out into the surrounding wilderness, while protecting birds from colliding with the glass layer behind the steel framework. ${ }^{16}$ However, the project aligns with the thesis work on a deeper level and shares various strategies with the eventual design proposal in Chapter 8.

16 "Ford Calumet Environmental Center," Studio Gang, n.d., accessed September 12, 2019, https://studiogang.com/project/ford-calumet-environmental-center. 


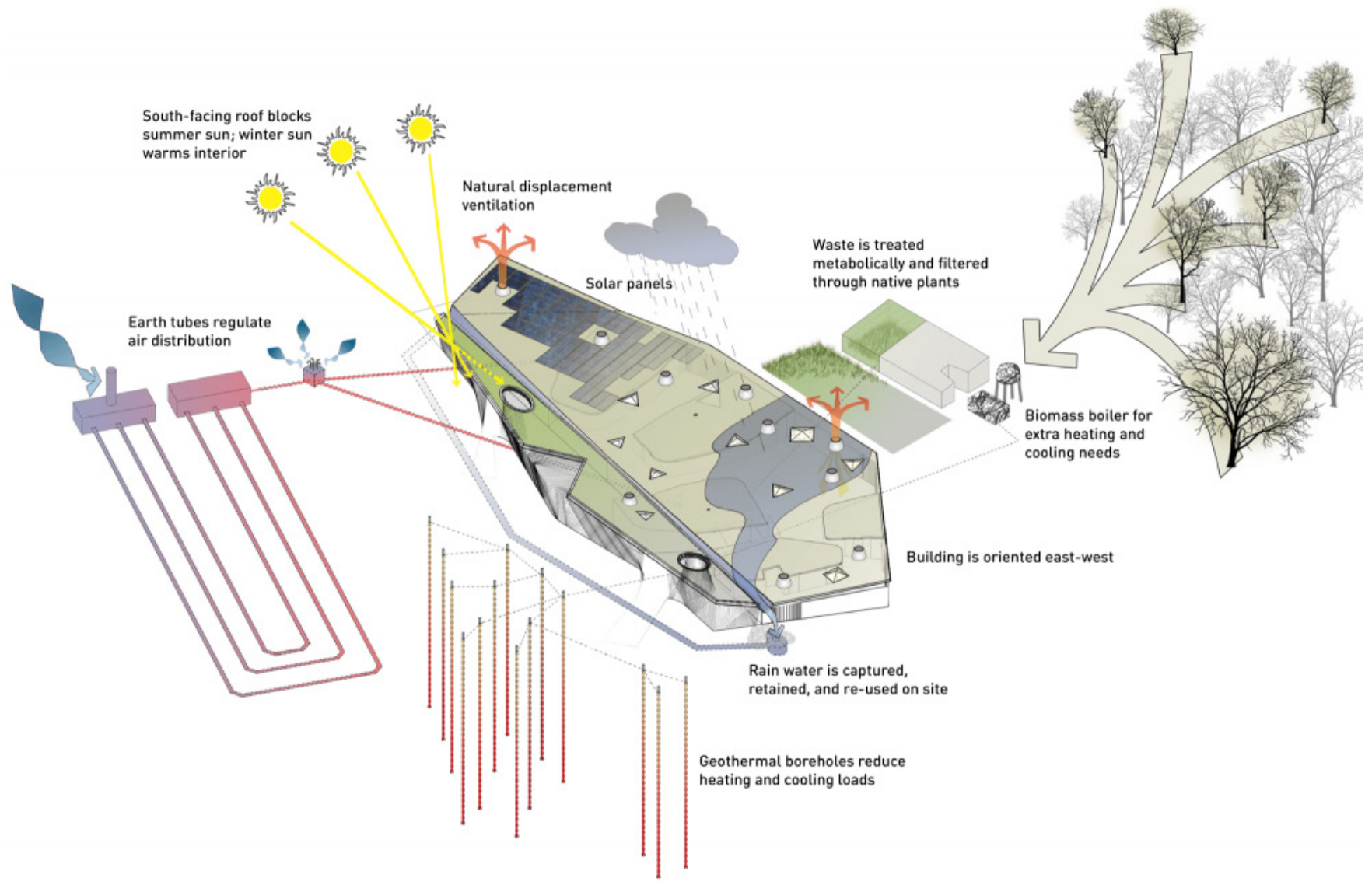

Fig 3-15. Synergy of Systems. 
The Calumet region had once been a major site for the steel production industry, leaving behind many byproducts that can be reused. ${ }^{17}$ The area is also a resting stop for migratory birds. ${ }^{18}$ Drawing from the process of nest-making, the project adopts a model of salvaging recycled materials local to the area, including rebar, glass bottles, slag, reclaimed wood barrels, etc. ${ }^{19}$ The building design also incorporates functional systems that work in concert with the local environment and ecological dynamics - aiming at using minimal energy and exemplifying a building model that operates organically with its surrounding local ecosystem.

Programmatically, the building doubles as an educational and cultural hub. ${ }^{20}$ Teaching programs offer training in environmental restoration and conservation, including activities that develop green-job-specific skill-sets. The south porch acts as meeting area for visitors, providing views into the landscape as well as opportunities to observe scientists conducting lab work. Overall, the project demonstrates a dynamic synergy and coexistence between cultural endeavours and environmental systems.

17 Ibid.

18 Ibid.

19 Ibid.

20 "Ford Calumet Environmental Center," Architizer, n.d., accessed March 28, 2020, https://architizer.com/projects/ford-calumet-environmental-center/. 


\subsubsection{Banyan Tree Skyscraper}

\section{6 | Skyscraper Design Competition}

Design Team: Phuchong Yamchomsuan, Boonjira Phaisitwanichkul, Warut Duangkaewkart.

Location: Thailand

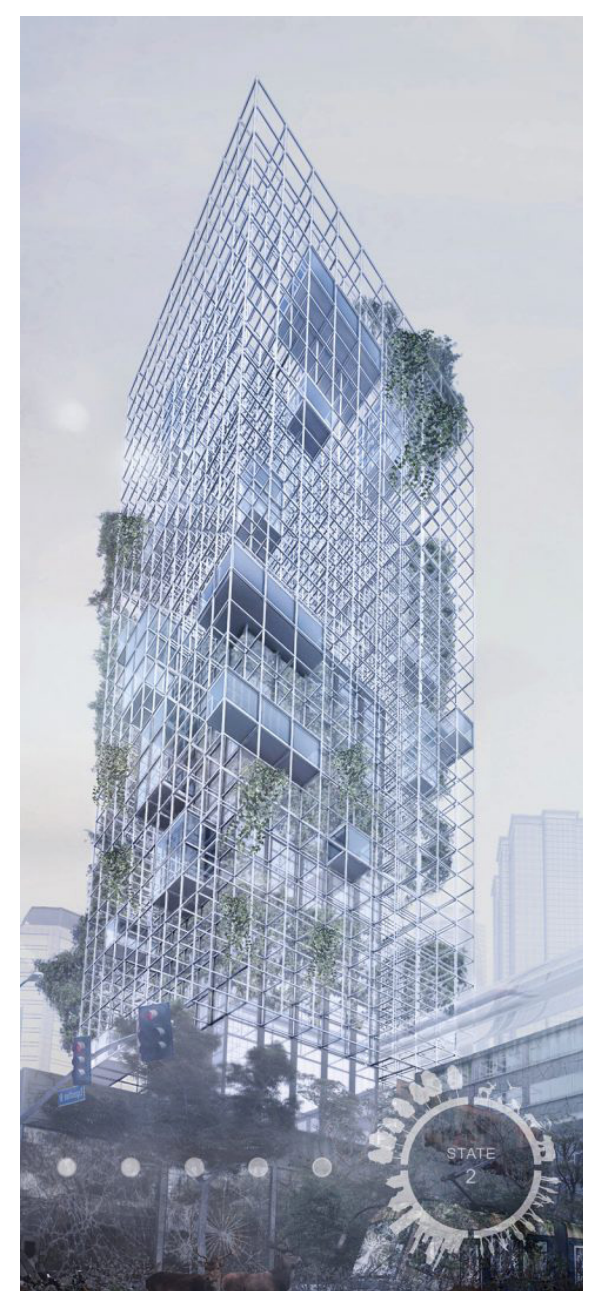

Fig 3-16. The parasitic structure that expands into a new urban fabric.
The design of this architectural system is modelled after the growth model of a Banyan tree; it is actually a parasitic organism that latches onto existing trees and kills them..$^{21}$ Though it overtakes other trees and produces its own limbs, roots, and structure, it provides food and habitat for many species of wildlife..$^{22}$ The design of this project operates by a similar strategy and aims to create habitat for humans and wildlife simultaneously. ${ }^{23}$ The premise of the design is that a matrix structure is latched onto existing buildings and skyscrapers, which had been abandoned to allow nature to take over. In this futuristic scenario, humans have moved upwards to more suitable livable platforms, while the ground plane is returned to wildlife and natural growth. ${ }^{24}$ The structural spaceframe is light, in contrast to the highly dense skyscrapers onto which it has been attached. This allows sunlight and fresh air to permeate through. In order to ensure that the ground plane remains dedicated to wilderness, horizontal circulation between communities is facilitated by elevated platforms and underground tubular transport. ${ }^{25}$

21 "The Banyan Tree Skyscraper was Designed to Support Humans and Wildlife," eVolo, last modified July 11, 2016, accessed January 18, 2019, http://www.evolo.us/the-banyantree-skyscraper-was-designed-to-support-humans-and-wildlife/.

$\begin{array}{cc}22 & \text { Ibid. } \\ 23 & \text { Ibid. } \\ 24 & \text { Ibid. } \\ 25 & \text { Ibid. }\end{array}$ 
This work incites a complete turn-around of conventional paradigms, nearly inverting the relationship between humans and nature, forfeiting much of the existing urban fabric to wilderness. Rather than going one way or the other, this thesis work aims at engaging in constant negotiation between the two and understanding that compromises need to be made. The project offers effective strategies that made their way into the emergent design in the thesis: the implementation of a spaceframe, elevated platforms, and the rededication of the ground plane. However, instead of creating segregated zones between humans and wildlife, the thesis questions the notion of boundaries and considers opportunities that allow greater interactivity and interplay.

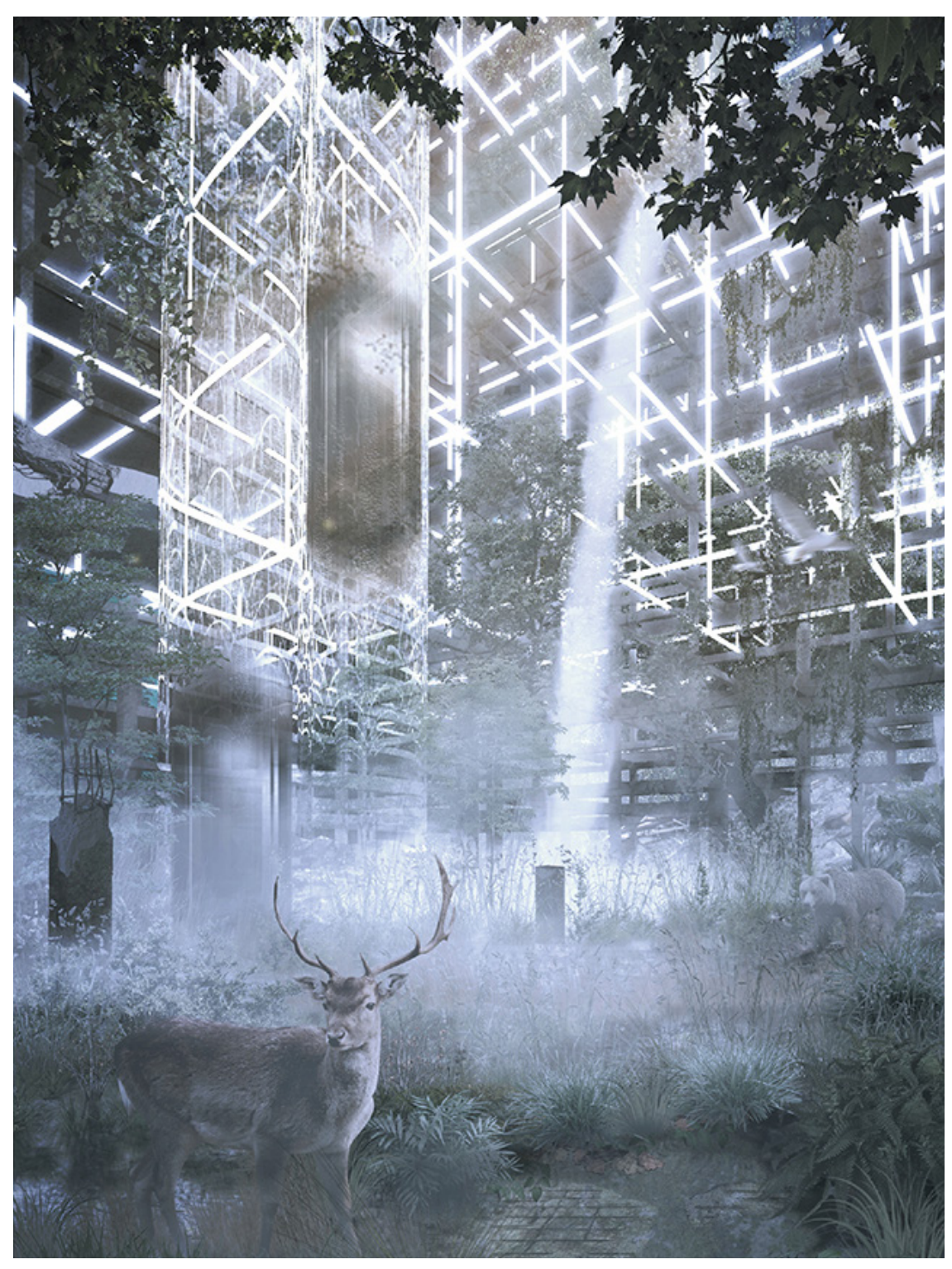

Fig 3-17. The ground plane is given over for nature. 


\subsubsection{Bosco Verticale}

\section{7-2014}

Design Team: Stefano Boeri Architetti.

Location: Milan, Italy.

Bosco Verticale is claimed by its designers, Boeri Studio, to be the first "Vertical Forest" to be built in Milan. Two residential towers, 76 and 110 metres respectively, were built within the city centre to house an overgrowth of greenery. This vertical "densification of nature" consists of 15,000 plants, 4,500 shrubs, and 800 trees (at approximate heights of 3,6 , and 9 metres). ${ }^{26}$ They've estimated that this urban ecological structure is equivalent to 20,000 square metres of typical forest floor. Since its construction, Boeri Studio have designed multiple other buildings with the same kind of ambition which is drawn from their Manifesto. The Urban Forestry Manifesto is a condenser of research on the relationship between urban activity and the natural ecosystem, which informs the design decisions of the architecture firm: ${ }^{27}$

- By $2030,60 \%$ of the world's human population is projected to live in urban areas.

- Cities consume $75 \%$ of the world's natural resources.

- Cities account for $70 \%$ of global $\mathrm{CO}^{2}$ emissions.

- Trees worldwide are at risk of erosion.

- Forests and trees absorb $40 \%$ of yearly fossil fuel emissions (largely produced by cities).

\footnotetext{
26 "Vertical Forest," Stefano Boeri Architetti, n.d, accessed February 12, 2019, https:// www.stefanoboeriarchitetti.net/en/project/vertical-forest/.

27 "Urban Forestry - Manifesto," Stefano Boeri Architetti, n.d., accessed February 12, 2019, https://www.stefanoboeriarchitetti.net/en/urban-forestry/.
} 
This precedent's purpose is twofold. It offers an abundance of relevant research on the impact of urbanization on the surrounding ecosystem. Furthermore, Bosco Vertical exhibits the capacity to apply principles of ecological remediation within the scope of a relatively unprecedented architectural project. Namely, it demonstrated the possibilities of incorporating significant ecological strategies into architecture and exploring the potential of a mutual relationship between humans and the surrounding biological context.

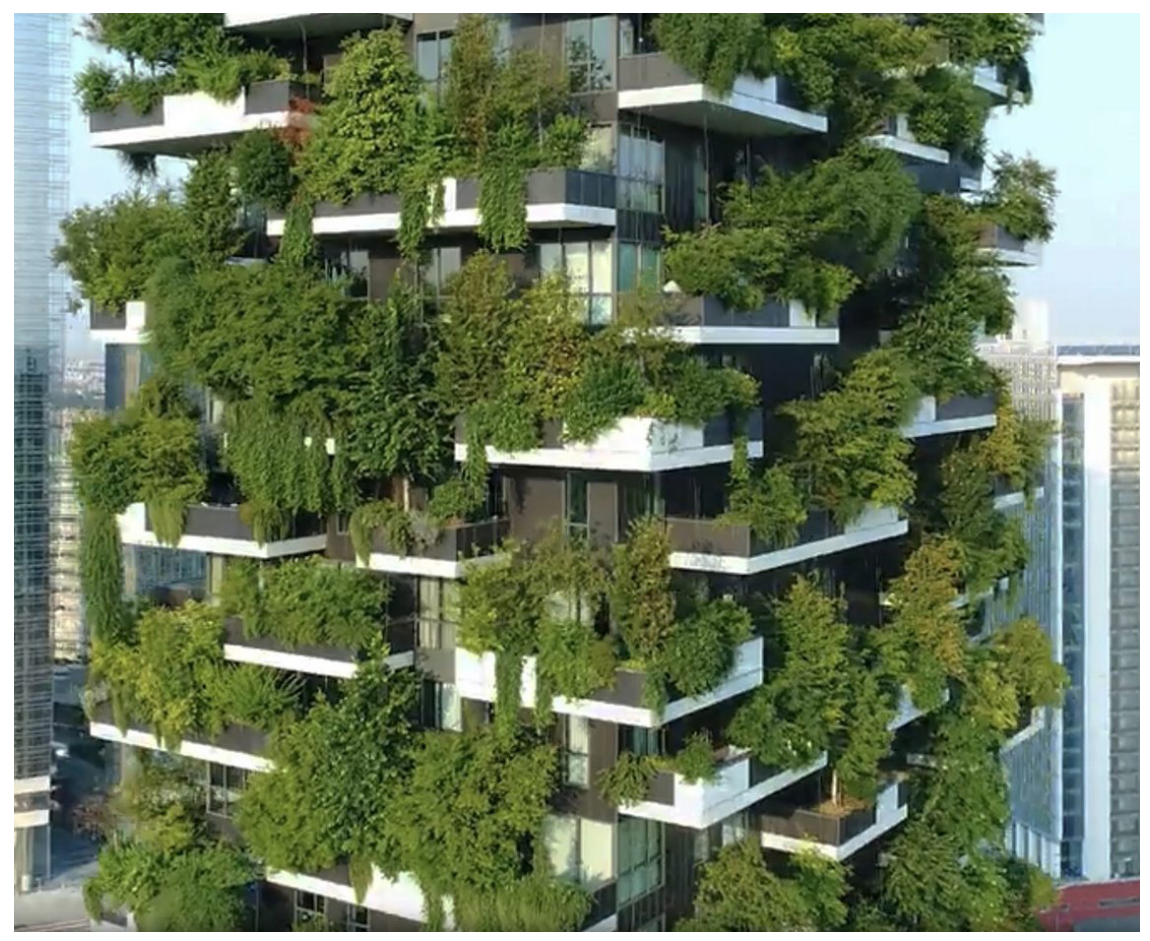

Fig 3-18. Bosco Verticale. 


\subsubsection{Permaculture}

At the Eco-Design Symposium in Toronto on January 19, 2019, multiple speakers from the architecture and engineering community discussed their work on the subject of Re-wilding the urban fabric. ${ }^{28}$ Rob Avis, an engineer from Calgary, Alberta, elaborated on his frustrations with the oil industry and humanity's impact on the environment, which led him on a path to reconfigure his lifestyle and relationship with nature. ${ }^{29} \mathrm{He}$ and his wife, also an engineer, researched methods for pursuing more sustainable activities and espoused the principles and philosophy of an emergent movement - Permaculture. A combination of the words "permanent" and "agriculture," the term was coined in 1978 by Bill Mollison, an ecological researcher, and David Holmgren, a writer. ${ }^{30}$ Permaculture embodies agricultural

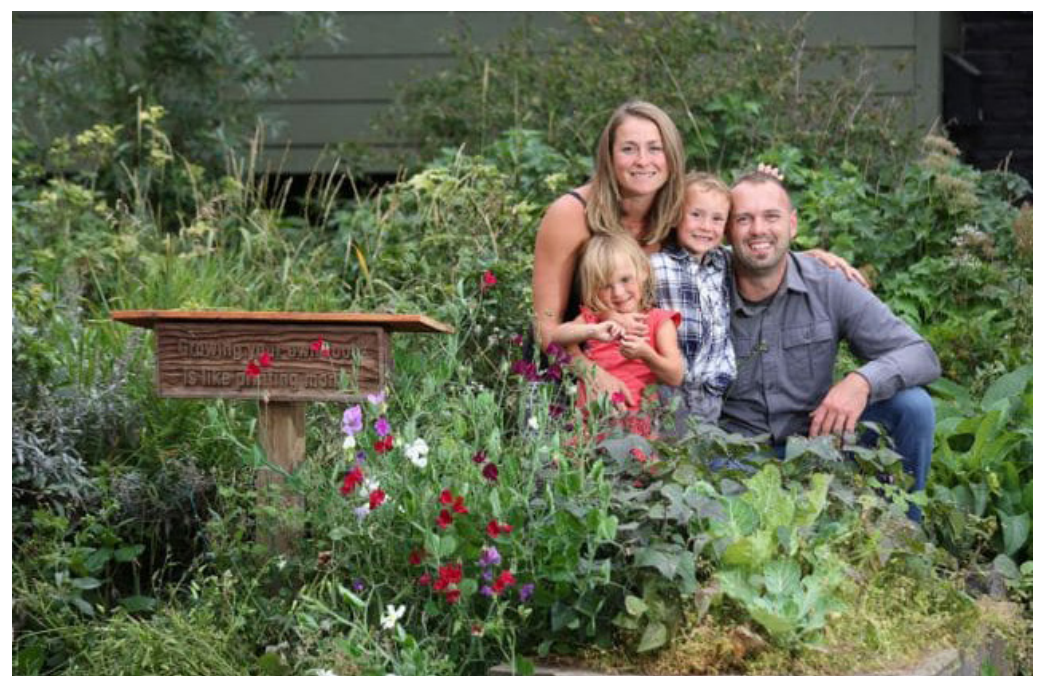
practices using strategies that work in synergy with nature rather than against it. $^{31}$ Understanding the cyclical nature of growth and decay, a permaculture garden would incorporate layers of different plants whose temporal activity is thoughtfully considered. ${ }^{32}$ As some plants die, they feed into the soil and enrich it with nutrients. The garden would produce an abundant source of food, which may invite occasional visitations by wildlife and promote biodiversity.

Fig 3-19. Avis Residence.

28 “Eco Design Symposium," Design TO Festival, last modified, accessed January 15, 2019, https://ecodesignsymposium.ca/.

29 Michelle Avis and Rob Avis, "Rob \& Michelle Avis," Verge Permaculture, n.d., accessed November 12, 2019, https://vergepermaculture.ca/meet-our-team/.

30 Nan Fischer, "What is Permaculture? And How to Apply it to Your Garden," Nature's Path, last modified August 7, 2018, accessed November 12, 2019, https://www. naturespath.com/en-ca/blog/what-is-permaculture/.

31 Ibid.

32 Ibid. 
Though initially Rob endured considerable push-back and hesitation with respect to pursuing this type of transformation to his own property, it ended up being productive and fruitful. Though his lot is a typical and modestly-sized suburban plot of land, it has become densely packed with a rich variety of trees, flowers, shrubs, vegetables, and various fruit-bearing plants. Unlike its neighbouring lots, this re-wilded micro-forest is thriving hub for ecological activity.

This serves as a powerful critique of the conventional model of the suburban home. Rather than promoting the status quo of manicured, presentational lawns that make diminished ecological contributions, an alternative is possible. Even small properties have the potential to generate tremendously productive and lush environments. They can support the growth of an abundance of food, both for its residents and local animals and pollinators. This reconsideration of how to live can allow people to become more self-reliant within their own biome while also creating an important ecological contribution to the surrounding ecosystem at large.

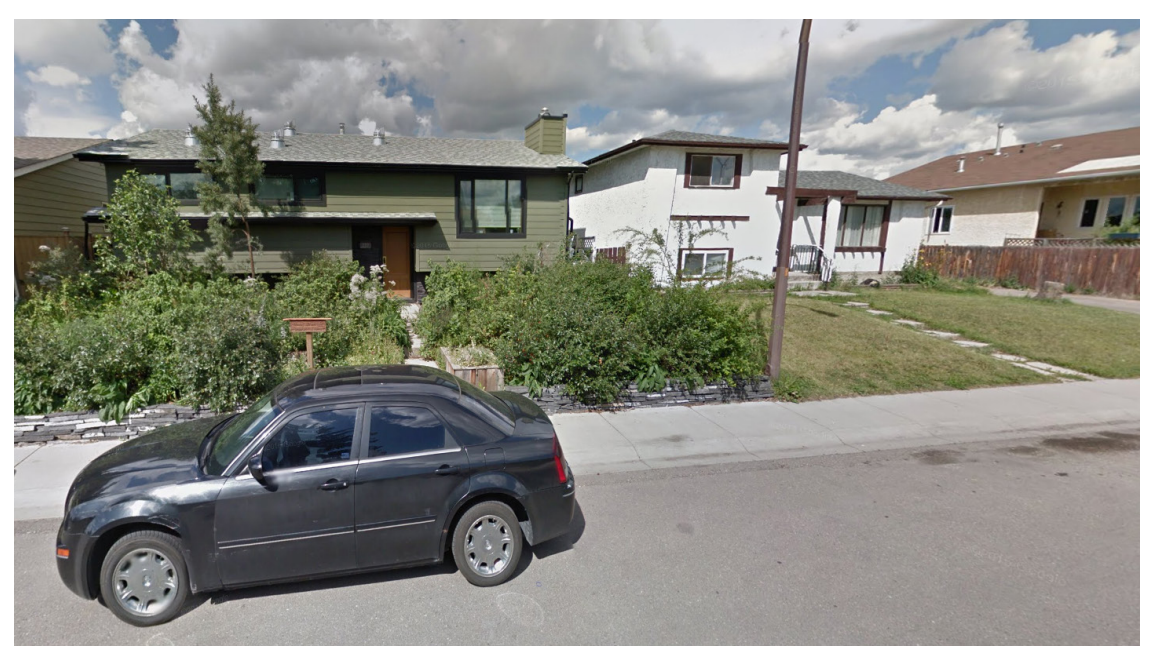

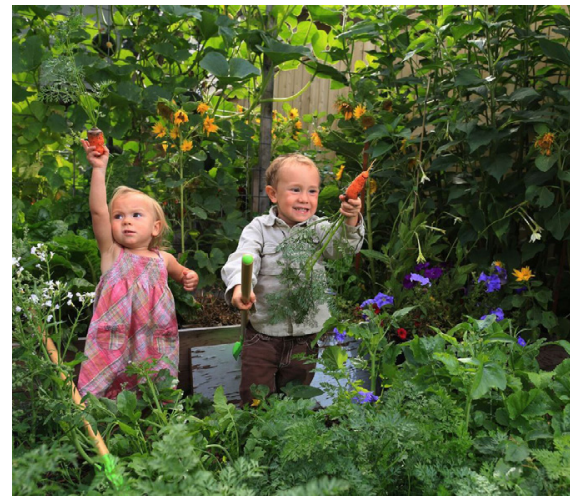

Fig 3-20. Growth at Avis Homestead.

Fig 3-21. Home of Rob \& Michelle Avis: The Verge Permaculture Homestead. 


\subsubsection{Amazon Spheres}

\section{8 | Amazon Headquarters}

Design Team: NBBJ

Location: Seattle, Washington

The design of the Amazon headquarters was highly influenced by ideas of biophilia and the relationship to nature. Given that certain natural environments improve people's well-being and even productivity, this project aims to create a hybrid space where lush growth permeates the built context. This environment is highly calibrated to emulate a "cloud forest" climate. The facility houses roughly 40,000 individual plants and maintains specific levels of atmospheric humidity. ${ }^{33}$ There are some species of frogs housed in this building as well. The importance of this precedent is that this design took the further step of bringing nature and architecture into a more blended and intimate

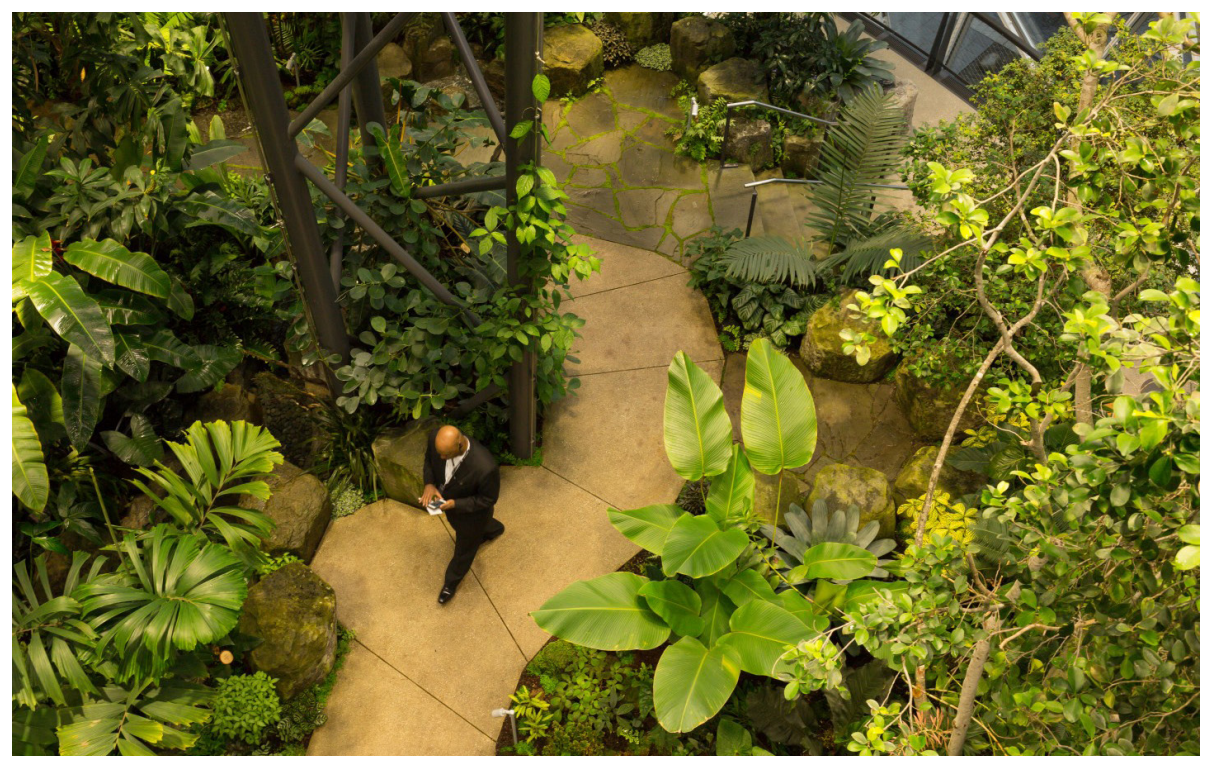
relationship. It tests out the possibilities of architecture as a framework to house a biome of life. Though it consists mostly of plants and has only a few innocuous amphibians, one could imagine that this sort of space would have the potential to support a greater variety of wildlife.

Fig 3-22. Hybrid environment.

33 Sarah Anne Lloyd, "Inside the Amazon Spheres: The plants, the architecture, and a transforming city," Curbed Seattle, last modified January 30, 2018, accessed November 12, 2019, https://seattle.curbed.com/2018/1/30/16947838/amazon-spheres-seattlearchitecture-photos. 

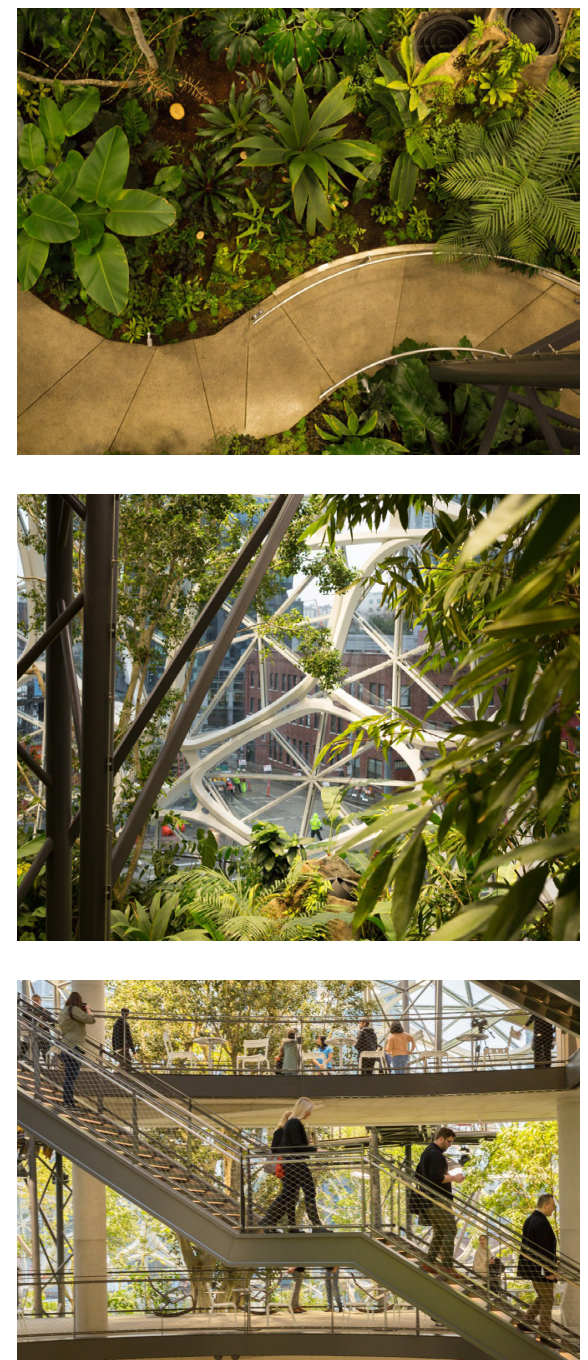

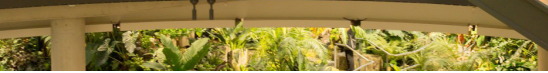

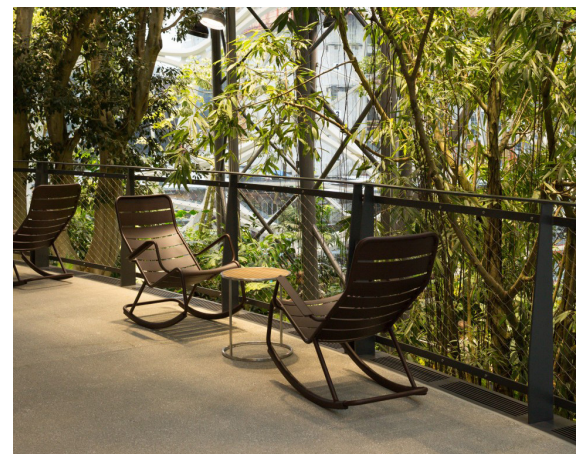

Fig 3-23. Inside the Amazon Spheres.

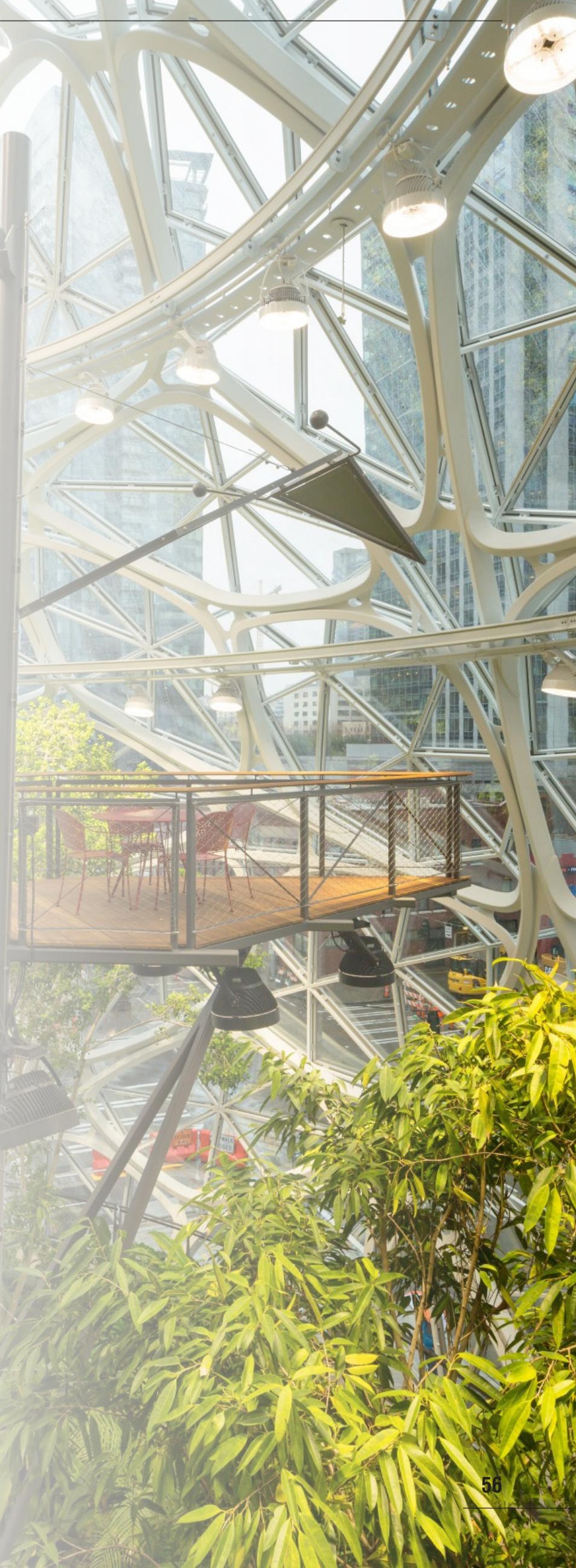




\subsubsection{Biodiversity-Sensitive Urban Design}

Research on Biodiversity-Sensitive Urban Design (B.S.U.D.) was presented in 2017 in "Conservation Letters: A Journal of the Society for Conservation Biology" by Gorgia E. Gerrard, Nicholas S. G. Wiliams, Luis Mata, Jordan Thomas, and Sarah A. Bekessey. This paper, spearheaded by a collaborative team of researchers from the School of Global, Urban and Social Studies in RMIT University and the School of Ecosystem and Forest Sciences in Melbourne, Australia, puts forth an over-arching strategy that can be implemented into the decision-making process of design in order to promote local biodiversity. This system implements quantitative analysis and empirical data in order to demonstrate a net positive effect on the local ecosystem as a consequence of the proposed design intervention. This framework is "applicable across a range of urban development types and densities" as it is meant to act as a systematic guide throughout the design process. ${ }^{34}$ BiodiversitySensitive Urban Design is a structured system devised to promote biodiversity within an urban context. The system uses quantitative methods of assessment at various stages to ensure an empirically positive net result. These are the principles of biodiversity-sensitive urban design:

- Maintain and introduce habitat. ${ }^{35}$

- Facilitate dispersal. ${ }^{36}$

- Minimize threats and anthropogenic disturbances. ${ }^{37}$

- Facilitate natural ecological processes. ${ }^{38}$

- Improve potential for positive human-nature interactions. ${ }^{39}$

34 Georgia E. Gerrard, Nicholas S. G. Williams, Luis Mata, Jordan Thomas, and Sarah A. Bekessy, "Biodiversity Sensitive Urban Design," Conservation Letters: A Journal of the Society of Conservation Biology 11, no. 2 (April 2018): 1.

35 Ibid, 3.

36 Ibid, 3.

37 Ibid, 3.

38 Ibid, 3.

39 Ibid, 4. 


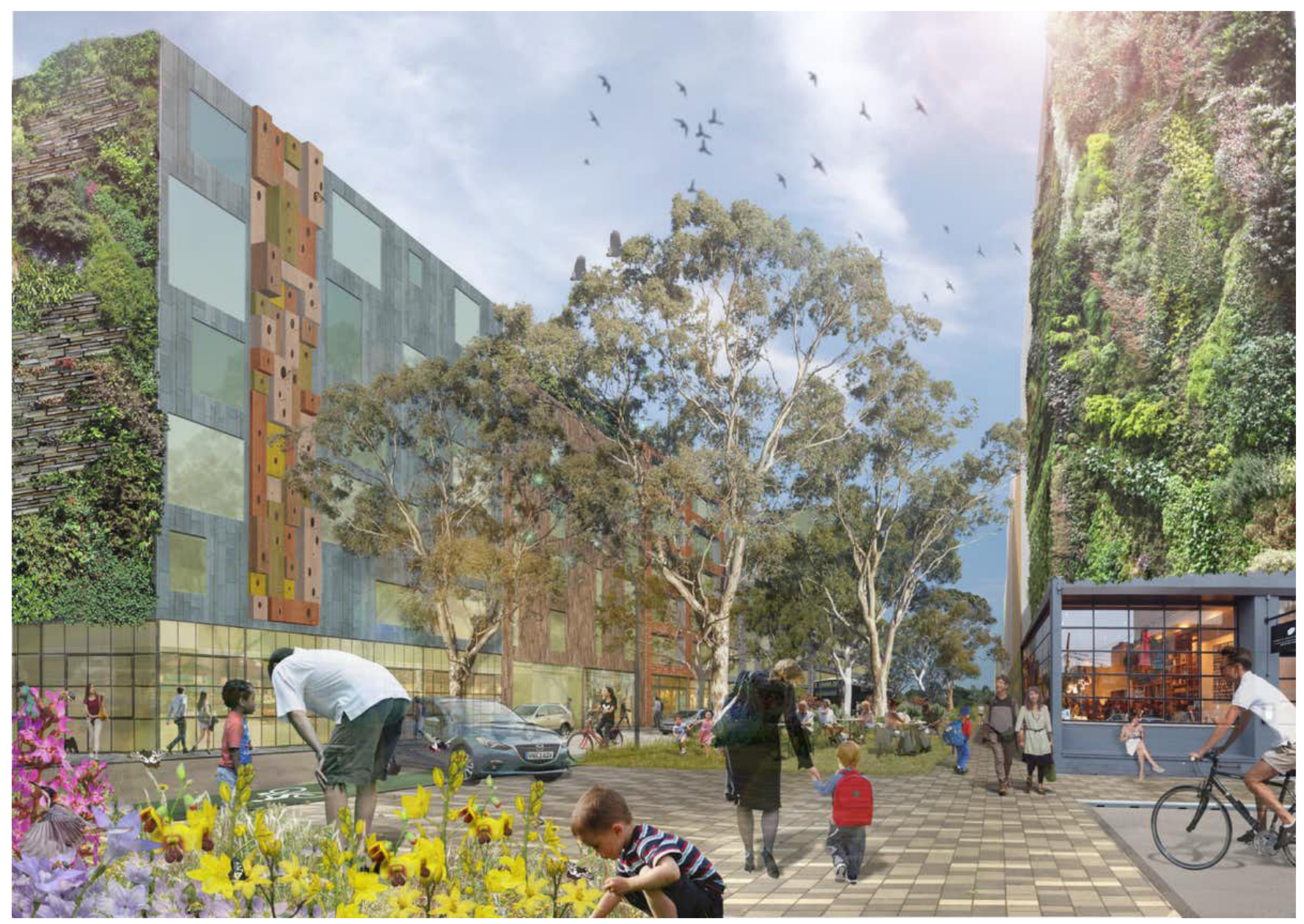

This systematic approach to urban design necessitates the Fig 3-24. Biodiversity-Sensitive Urban Design. formulation of a strategic response to local ecology and the safeguarding of biodiversity. Inherent in this process is an understanding that compromises between the objectives for urban development and ecological biodiversity need to be made; therefore, decisions are informed by an evaluated set of priorities. The various ecological and developmental requirements are assessed with empirical methods. After the formulation of a plan of action and its implementation, a post-construction analysis takes place. This assessment measures the impact of the intervention and evaluates whether the particular goals have been met. The cases presented in the research paper demonstrated the benefits of incorporating these empirical evaluation strategies to ensure the safeguarding of local ecosystems as a result of biodiversity-sensitive urban design. 


\section{2}

\section{Syntax of Boundaries}

The precedent studies have demonstrated unique individual strategies for responding to contemporary socio-ecological tensions. However, many of these precedents also contribute to addressing one of the core research questions of the thesis: the conceptualization of the boundary condition between humans and animals - culture and nature - chaos and order. On the next page, various states are depicted next to their opposing counter-states. These ideas have been diluted and extracted from some of the precedent studies discussed earlier in the chapter. Informed by the case studies, this preliminary syntax of boundary conditions expresses various ways to treat boundaries in order to allow or negate wildlife, and promote or deter a relationship between "us" and "them." 
STATE

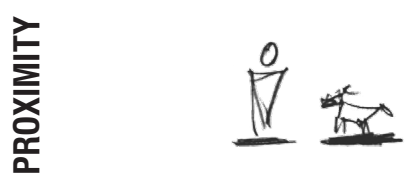

岕岕

을

忘
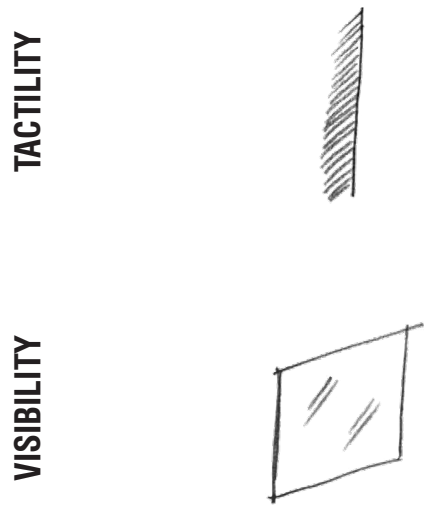

点
COUNTER-STATE
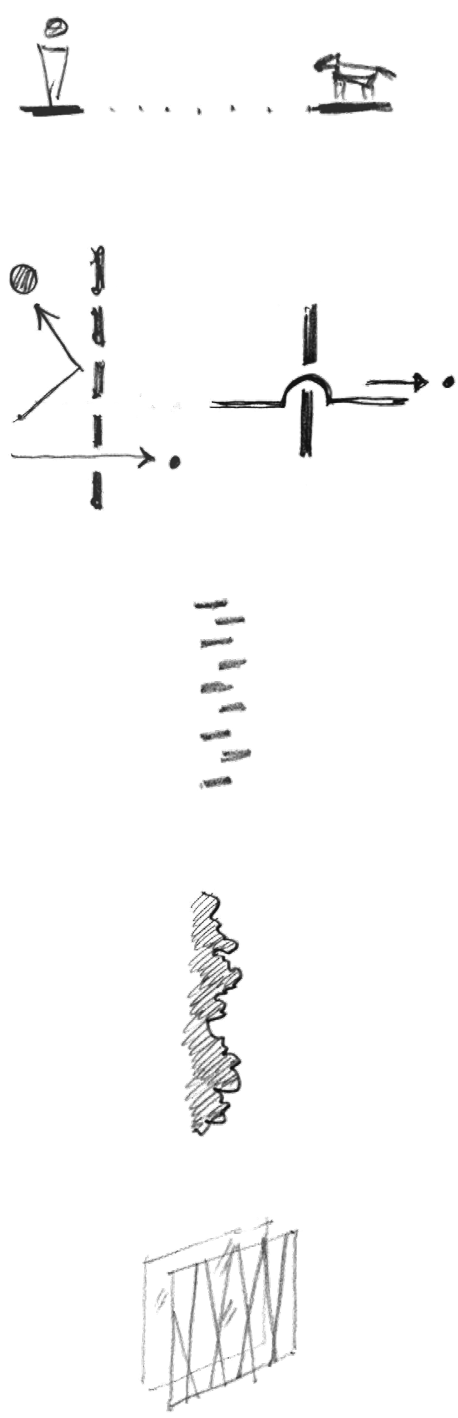

3)))

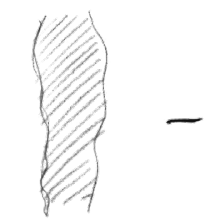

PROJECTS
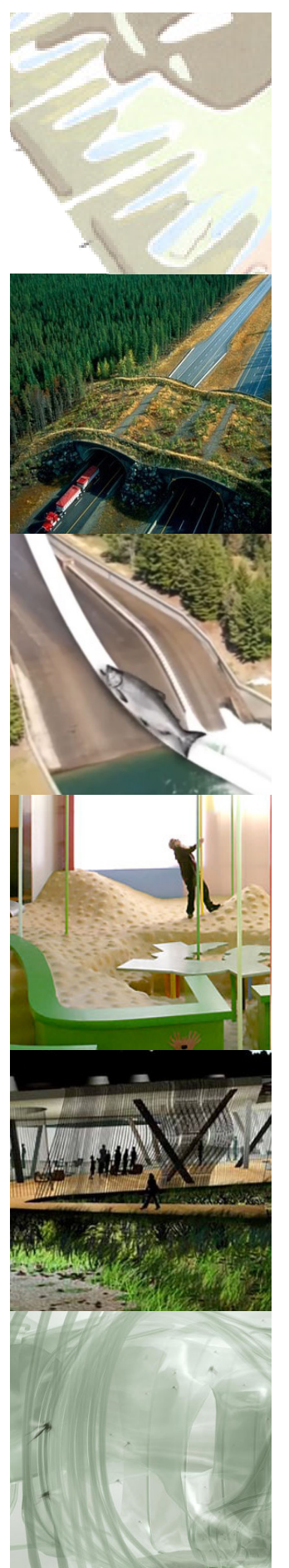

Fig 3-25. Syntax of Boundaries. 


\section{A New Paradigm}

The case studies presented in this chapter represent some of the ways in which designers are responding and providing alternative strategies for addressing socio-ecological tensions. People are beginning to recognize the impact that human activity is having on ecological processes, as is evident by the Great Acceleration Graphs (see page 19). However, rather than framing the issue as "us" versus "them" - "culture" versus "nature" - an alternative paradigm has begun to emerge - one that reframes the two entities as a hybrid. Emergent ideas in architectural discourse entertain the capacity of cultural and natural systems, not to work in opposition and exclude one another, but to work in concert in a state of synergy. As the case studies in this chapter have demonstrated, human intervention exists on a scale - it can act to disrupt ecosystems or, through appropriate design considerations, enable and bolster them.

\section{Synanthropic Architecture}

Architectural explorations of this sort manifest in professional practice as well as in research and academia. Emergent within the context of these explorations is the idea of the synanthrope: a nondomesticated and wild animal that lives in the midst of man-made environments. Terms such as synanthropic architecture as well as habitecture have begun to define such design explorations that aim to develop environmental conditions wherein the functional necessities of humans as well as local wildlife are considered and integrated. 


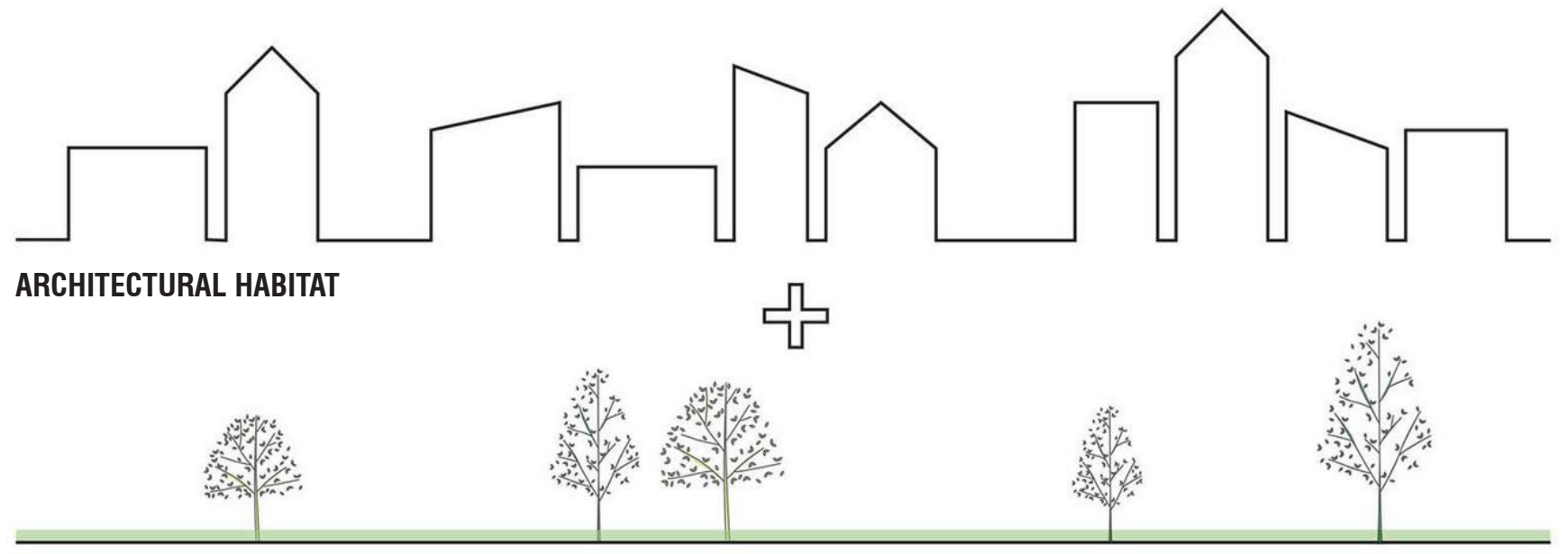

NATURAL HABITAT<smiles>C1CCCC1</smiles>

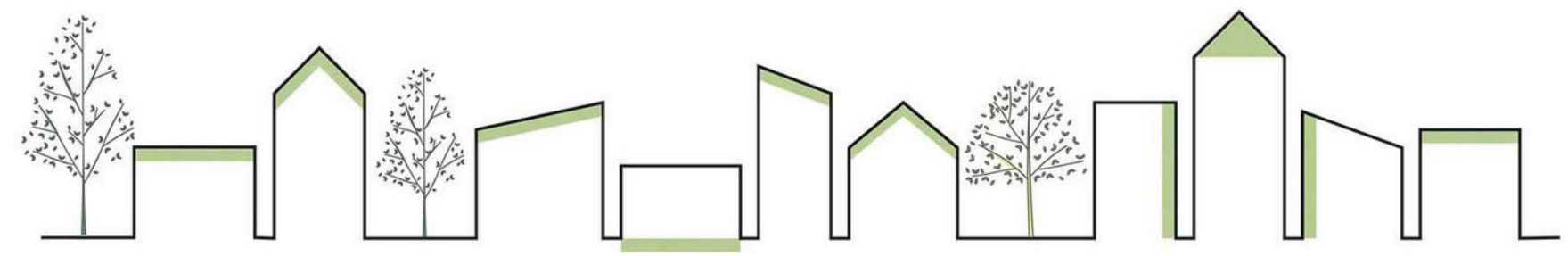
HABITECTURE

Fig 3-26. "In Touch with Nature" by Maria Ogahara Department Architektur Institut für Landschaftsarchitektur. 


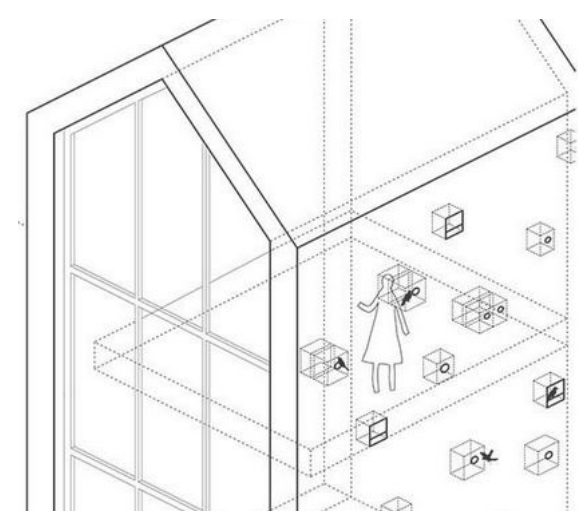

Fig 3-27. Axonometric of Animal Habitats.
Some of the work of students at the Architecture Department of the Technische Universität Braunschweig in Germany is centred on synanthropic architecture. ${ }^{40}$ The project by Maria Ogahara clearly illustrates and emphasizes the idea of integration as opposed to displacement; through mindful design strategies, the functional attributes of an ecological environment can be woven into a constructed landscape. There may be questions as to how successful this might be; however, even a small measure of positive impact is better than the total disruption caused by the existing, conventional approach of displacement.

This project in particular, envisions strategies for modifying human homes to include embedded, wildlife dedicated spaces within their outer layer. Some of the species of animals accounted for are starlings, sparrows, bats, and hedgehogs. Cavities of appropriate dimensions are incorporated into the outer wall, some of which produce formal conditions that impact the interior face of the wall. These formal decisions begin to influence the relationship between humans and wildlife, bringing them into closer proximity, and facilitating greater overlap between them. This type of shared environment starts to questions preconceived notions of "the human" as being separate from nature: that "the wild" is somewhere out there, and "the human environment" is here. This no longer allows human imagination to dictate what animals and wildlife might be like in the chaotic wilderness; it brings animals closer and allows people to experience their behavior in real time, enabling people to learn and understand animals better for what they actually are (and not what the human imagination might make them out to be in their absence).

40 Maria Ogahara, "In Touch with Nature," Institut fur Landschaftsarchitektur, last modified 2019, accessed September 21, 2019, http://tu-braunschweig-ila.de/projekt/intouch-with-nature/. 


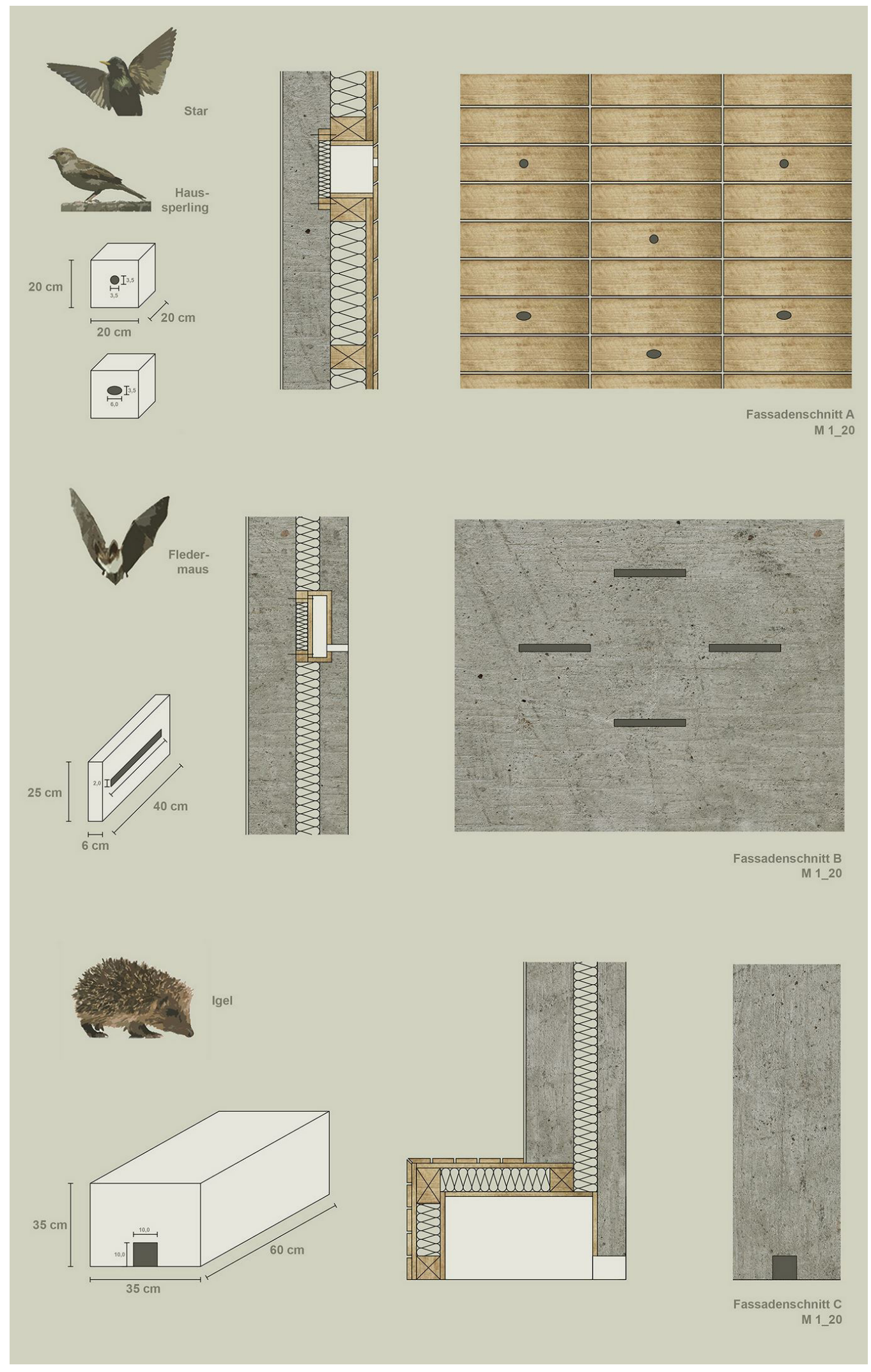

Fig 3-28. Speciesspecific Homes in an Exterior Wall. 


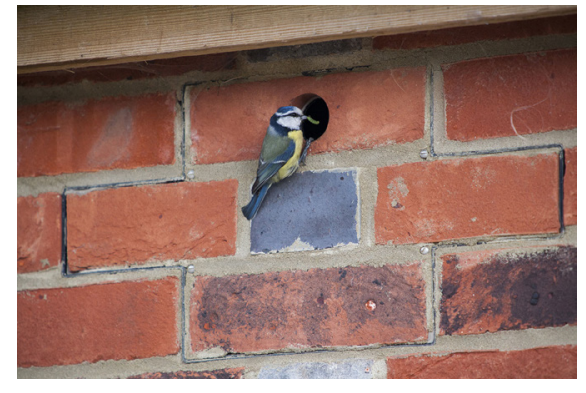

Fig 3-29. Bird box inset into a brick wall.

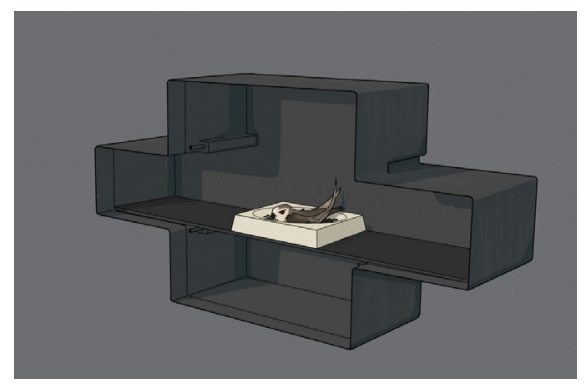

Fig 3-30. Interior space of a bird box.
Bird Brick Houses is a company in the UK that has begun to implement these types of synanthropic systems into construction. ${ }^{41}$ These designs aim to facilitate animal cohabitation by providing solutions that can be incorporated seamlessly into standard practice. The design work of Sarah Gunawan at the University of Waterloo adopts a similar approach of embedding animal-specific systems onto the exterior boundaries of suburban homes. In some instances, as with the Compost Chimney design, ${ }^{42}$ the intervention promotes an interactive relationship between the human and the synanthrope: food-waste and various organic products are transferred into the compost mechanism; raccoons are then able to activate the digestion process by turning an external rotating gear; they are then rewarded with decomposed processed nourishment that is released outwards.

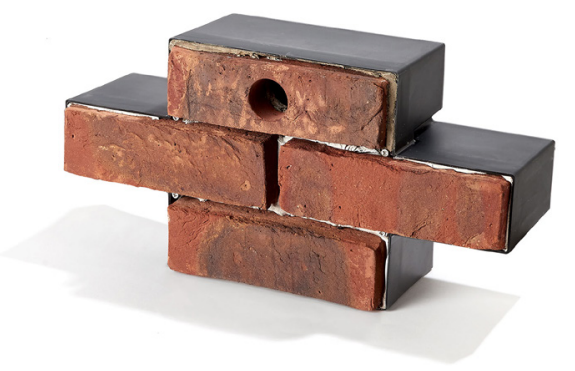

Fig 3-31. Standard removable Brick Bird House.

41 “Bird Brick Houses,” Bird Brick Houses Ltd. n.d., accessed March 31, 2020, https:// www.birdbrickhouses.co.uk/.

42 Sarah Gunawan, Synanthropic Suburbia, (Waterloo: University of Waterloo, 2015), 134. 


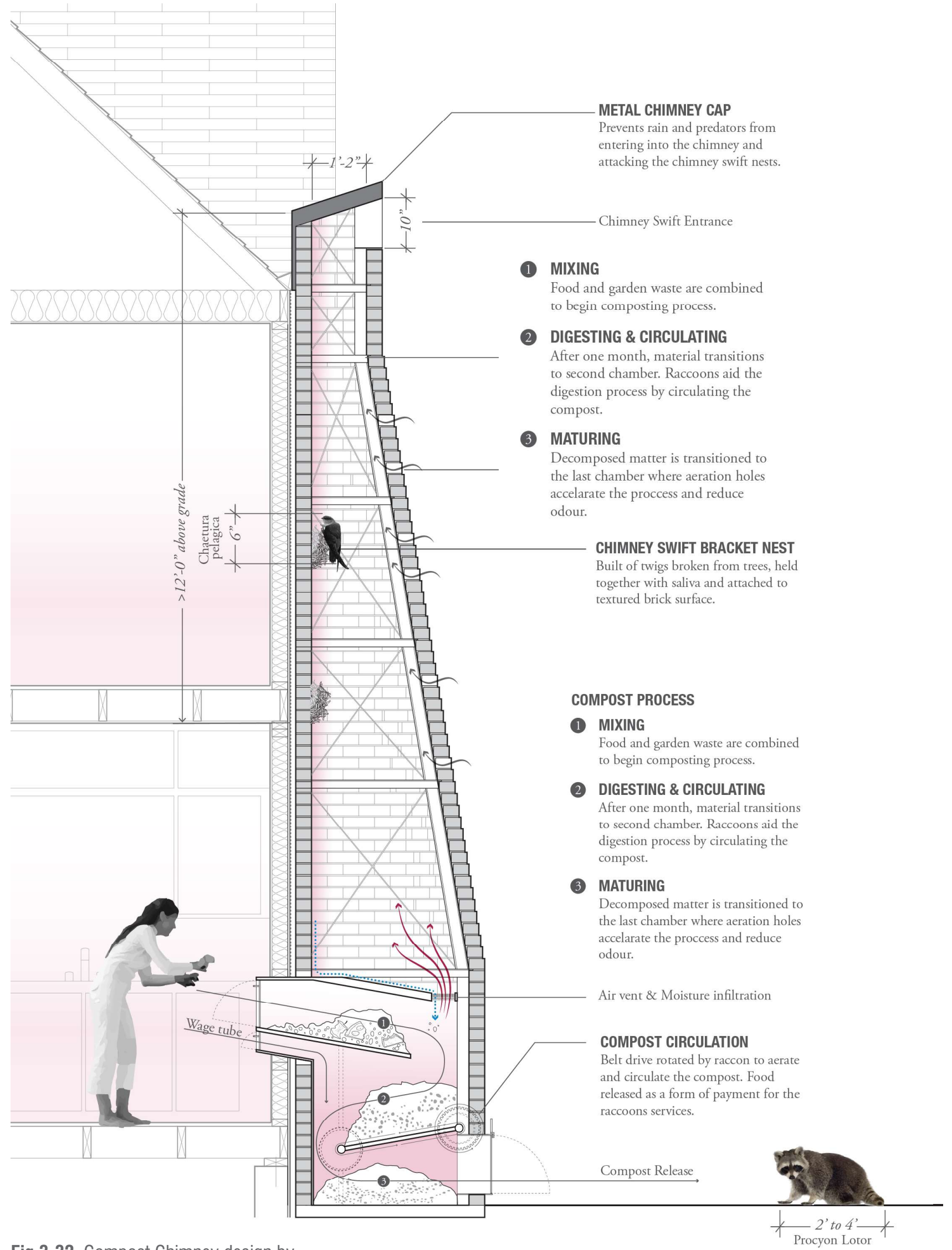

Fig 3-32. Compost Chimney design by 
Fig 3-33. Synanthropic Neighbourhood

"In Touch with Nature" by Maria Ogahara.

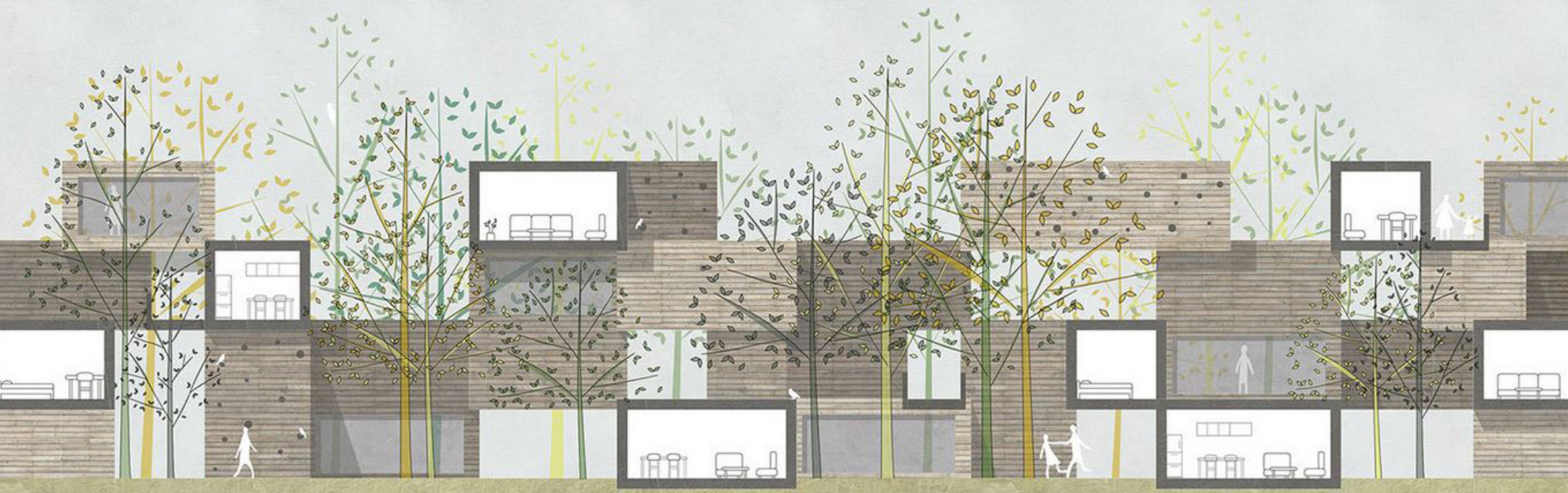

Fig 3-34. Synanthropic Co-habitation

"In Touch with Nature" by Maria Ogahara.
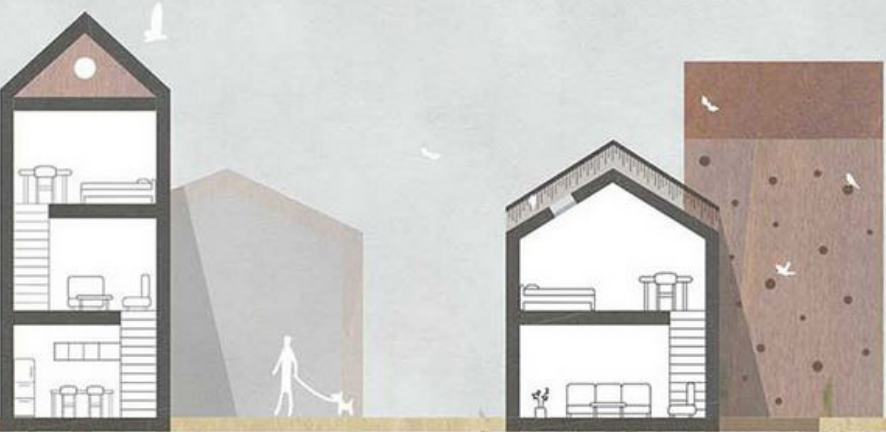
These design investigations at the frontier of architectural discourse are a part of a transforming socio-cultural paradigm - one that critiques the existing hierarchal relationships between culture and nature. This thesis is driven by a similar spirit of envisioning an alternative relationship between architecture and the plethora of life-forms to which it may relate. Having established various tensions that exist between animals and the built environment in part I, the thesis continues onward to envision and embrace an alternative mode of design - a synanthropic architecture - wherein these tensions are addressed. Projections into the Anthropocene warn of the dire consequences that human activity may have on Earth's ecological systems, should trends continue along the current path. A paradigm shift in design and human activity can potentially re-orient humanity into a benevolent as opposed to a destructive force: a keystone species, one that contributes to the health of the local ecology and enables surrounding creatures to thrive within its constructed habitat. This mode of anthropogenic behavior can bring about an alternative reality: the syn-anthropocene, a novel geological age of the Earth defined by the impact of human activity, wherein that impact is driven by a strategy to bolster the surrounding ecosystem and the creatures living within it. Moving forward, part II of the thesis focuses on a particular geographical region wherein the principles of this approach can be applied, and outlines the various parameters that inform the process of design. 


\section{part II}

\section{A Framework for Design}

Chapter 4 Design Intent

Chapter 5 Toronto: an Urban Laboratory 91

Chapter 6 Biological Subjects 


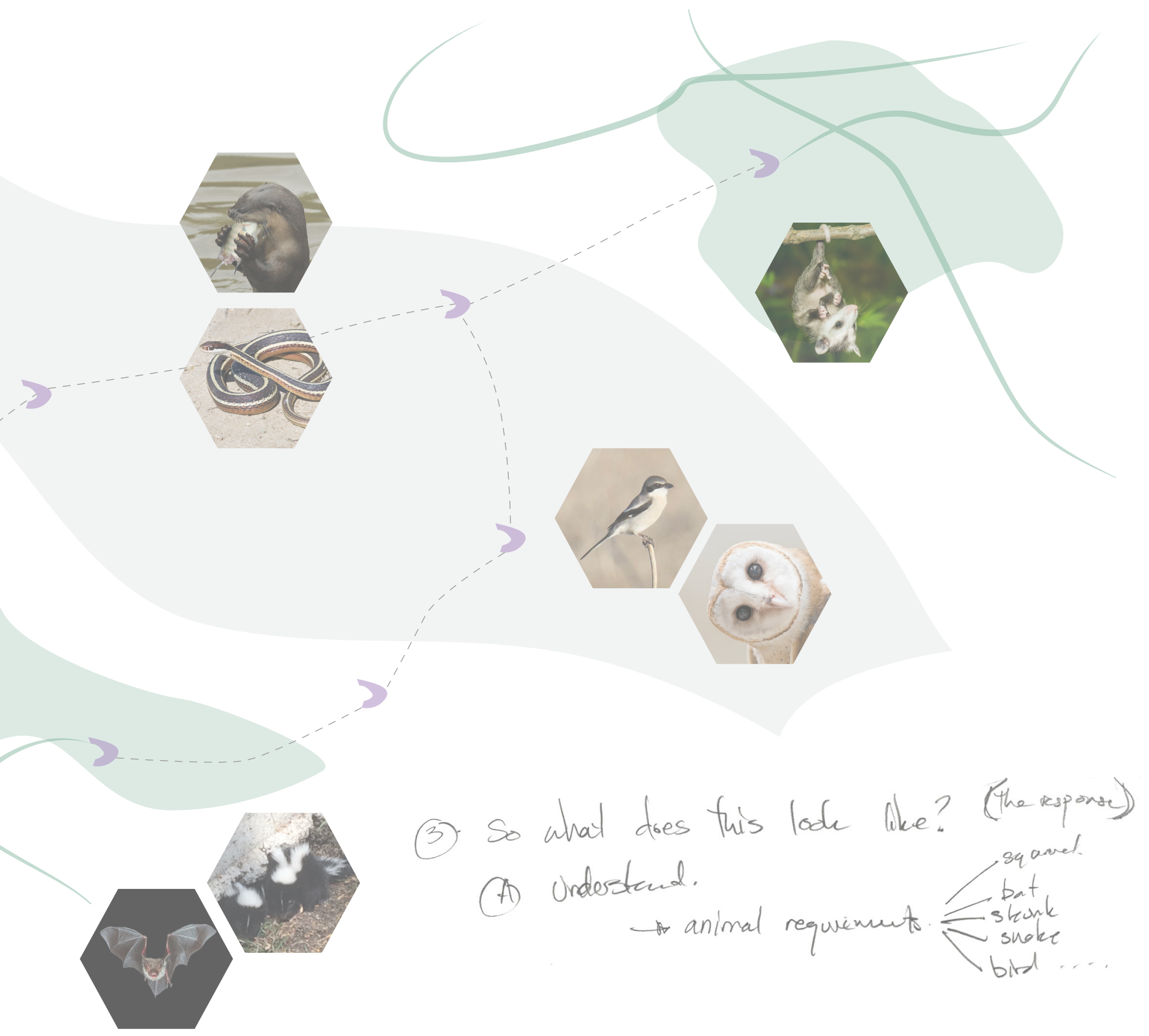

Fig 4-1. Parameter considerations. 


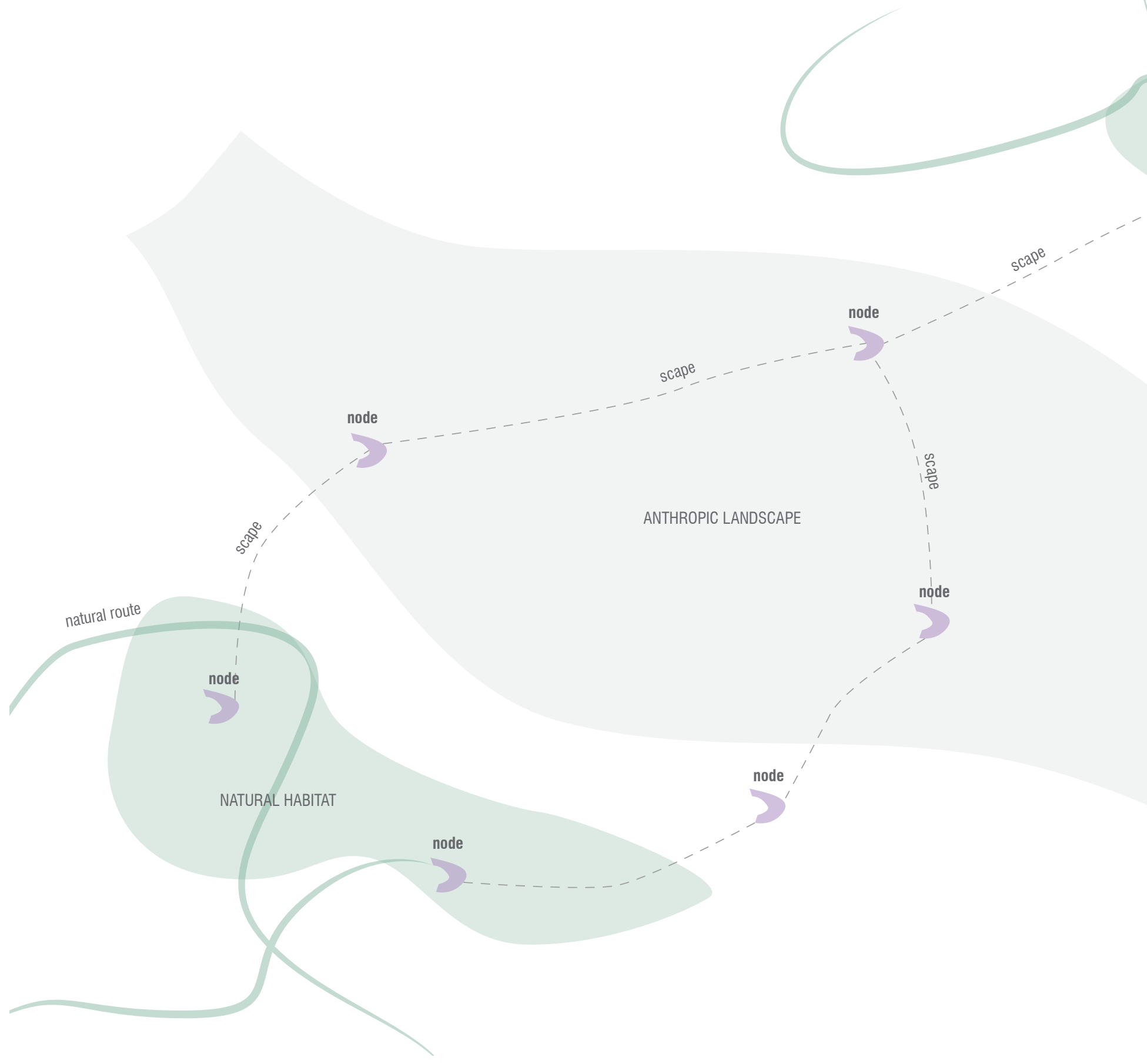

Fig 4-2. Strategy Conceptualization. 


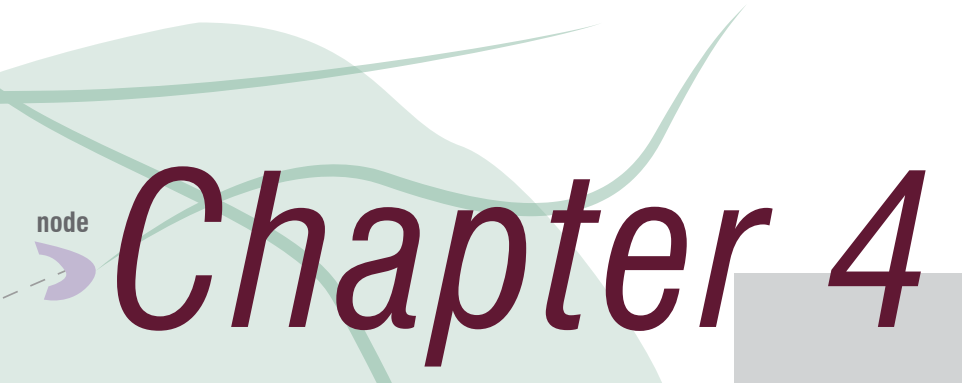

NATURAL HABITAT

\section{Objective \& Strategy}

4.1

4.2

4.2.1

4.2.2

4.3

4.4

4.4.1
Objective

73

Strategy

75

Circulation Scapes

Habitat Nodes

A Range of Scales

Boundary Relationships

Phase of Eco-Cultural Evolution
77

81

83

85

87 
4.1

\section{Objective}

Having established a theoretical foundation of an emerging paradigm in part I, this section of the document lays out a framework wherein the design objective and strategy of the thesis can be applied.

\section{Intent}

The design objective proposes a counter-narrative to conventional paradigms in architecture, and begin to explore a systematic strategy to meet the socio-ecological objectives of synanthropic architecture.

\section{Topology vs Iconography}

Architecture needs to be re-envisioned. Currently, cultural iconography is a central form of communication that manipulates the biological bodies of humans: traffic lights direct people to stop or move; signage along buildings indicates where people may enter; societal laws delineate private and public property. These are but a few of the cultural constructs which are suffused into the built environment and regulate human behaviour within it. These cultural elements are effectively invisible to animals; all that is perceived by them is the physical urban form. Irresponsive to human laws and cultural norms, these animals are, thus, wild. Consequently, in order for animals to be re-synchronized as synanthropes in the urban environment, architecture needs to act not only on a cultural dimension, but also on a topological one. 


\section{Architecture as Landscape}

The idea behind megastructures in the 60's was that of constructing "architecture as landscape" by building it at a similar scale. This design exploration envisions an architecture that can be complex enough to also facilitate a similar function.

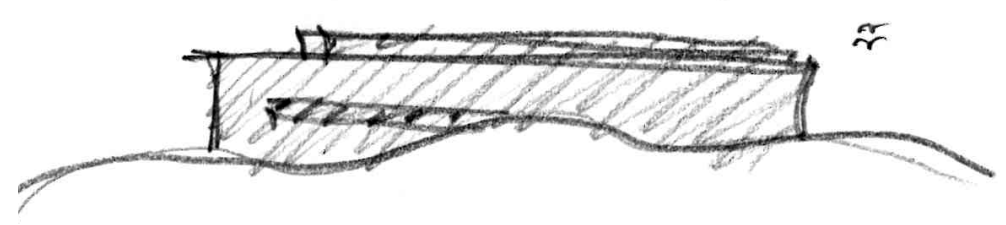

SIMILAR SCALE

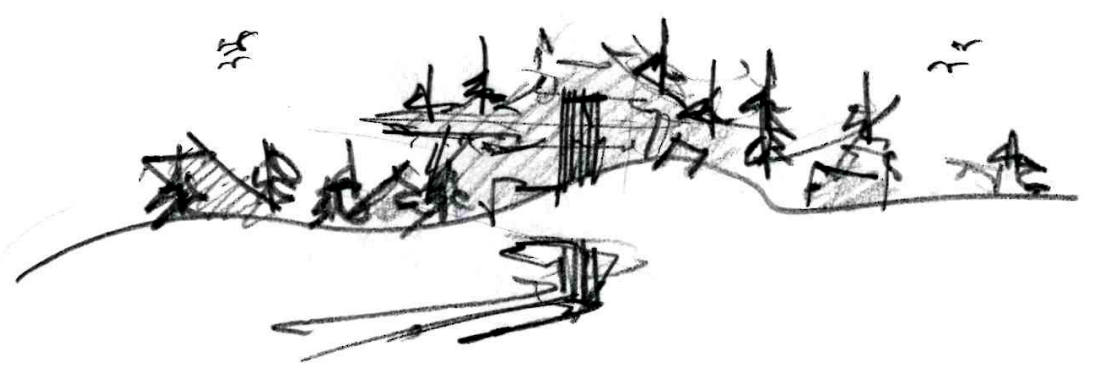

SIMILAR SCALE \& FUNCTION

Fig 4-3. Architecture as landscape. 


\section{Strategy}

\section{Hierarchy of Priorities}

The strategy for incorporating wildlife into the urban fabric involves a hierarchy of priorities. As these separate biological groups come together, there may be conflicting tensions where they overlap. It is therefore pertinent to establish a hierarchy of priorities that the pursuit of this design strategy aims to achieve. For the purpose of this thesis, human safety remains of primary importance; the functional needs of animals in the city are of also high priority. The purpose of the design development in this thesis work is to strive to achieve those goals while safeguarding mutual safety and well-being. That being said, this framework still elevates the ecological concerns of wildlife into the architectural design process, which are infrequently considered in conventional architectural practice.

The goal for the design strategy being developed in this work aims to enrich the urban fabric with biodiversity by integrating systems that also accommodate the biological characteristics of animals. These systems will enable wildlife circulation and create habitation zones within the urban fabric. Weaving ecological entities and processes together, the city would aim to facilitate ecological processes. Creating an environment where a plethora of biological subjects are able to thrive, there would be potential for greater instances of interactivity among them; this may bolster human health and well-being as an outcome of experiential connectivity to biodiversity. 


\section{Humans | Wildlife}

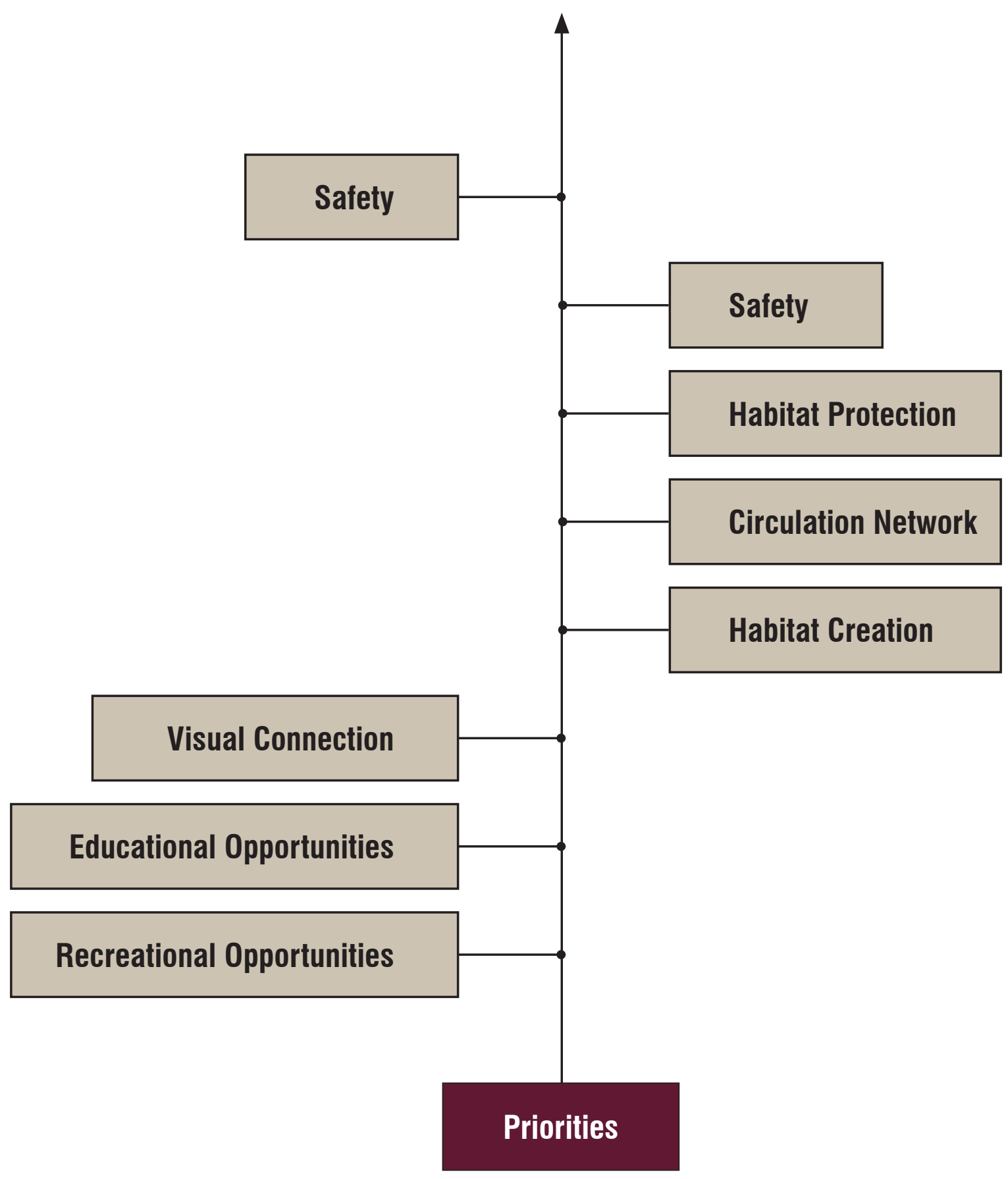

Fig 4-4. Hierarchy of Priorities. 


\subsubsection{Circulation Scapes}

\section{Urban Weaving Network}

Animals move differently than humans. We are biological subjects that vary in shape, mass, and skill-sets. While humans operate according to societally-defined cultural norms, animals do not engage with the built environment based on these parameters. Animals perceive built edifices as landscape like any other, stripped of any socio-cultural attachments humans have attributed to it.

This opens up a plethora of possibilities to create circulation routes dedicated to animals throughout the city; they need not resemble the familiar characteristics of streets, roads, and corridors. These structures can potentially weave more unconventionally throughout the city fabric.

One criticism of this may be the challenging burden of needing to allocate dedicated space for these new routes. However, one only needs to look around the city to see a vast expanse of unutilized "real estate" - countless barren walls, wide open rooftops, and elevated spaces; they need only slight modification in order to become functional as usable circulation paths for wildlife. Treating a wall to have more grip, spanning a light material at an elevated height to act as a bridge for light-weight animals, and connecting rooftops to other circulation pathways; these types of minor alterations can have a significant impact on the ability of wildlife to navigate safely across the urban fabric, which is otherwise fraught with danger. 


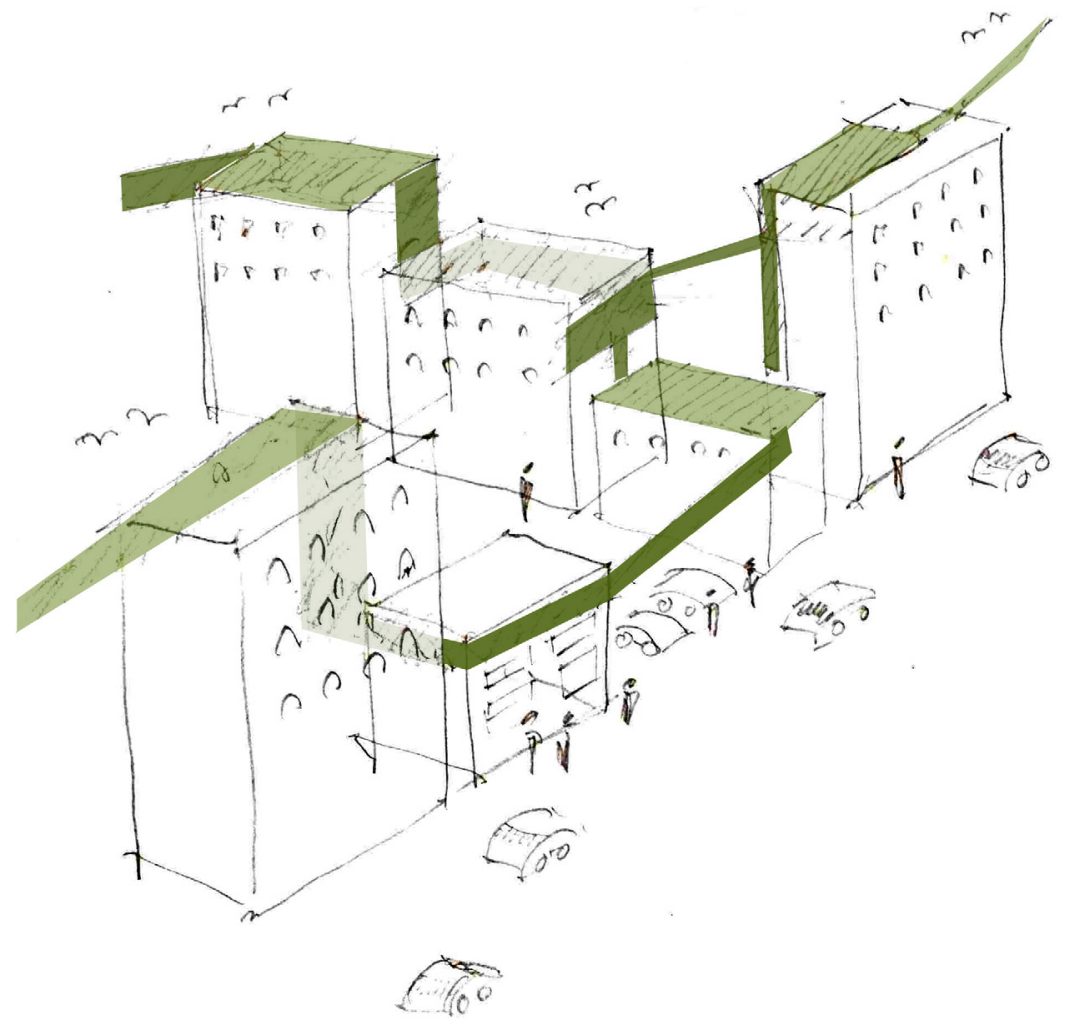

Fig 4-5. Urban Network. 


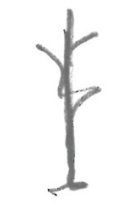

PEDUNCLE

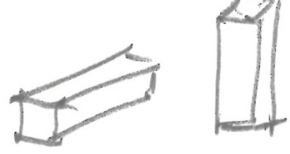

COLUMN

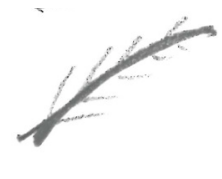

SHAFT
Fig 4-6. Meanings of "Scape."

\section{Scapes}

Throughout the development of the thesis work, the term scape has made its way into the discourse. It is an umbrella term to describe the variety of circulation paths that would be used by animals, irrespective of their diverse manifestations (be they overhead bridges, underground tunnels, narrow, or wide, etc). It is reminiscent of terms such landscape and cityscape, intended to describe a terrain that consists of continuous circulation paths within a redesigned environment. Further investigation of the term's etymology reveals its suitability. It has slightly different meanings depending on the disciplinary context, but they all convolve around a similar definition:

- Botany: a leafless peduncle rising from the ground.

- Zoology: a stem-like part, as the shaft of a feather.

- Architecture: the shaft of a column.

- Entomology: the stem-like basal segment of the antenna of certain insects.

Thus, a central facet of this thesis work is to develop the concept of animated scapes - circulation paths throughout the city fabric that enable the movement of biological subjects to various essential nodes such as habitation areas, hunting grounds, and sources of food. These nodes will be discussed in the next section.

Fig 4-7. Street Overpass Section.

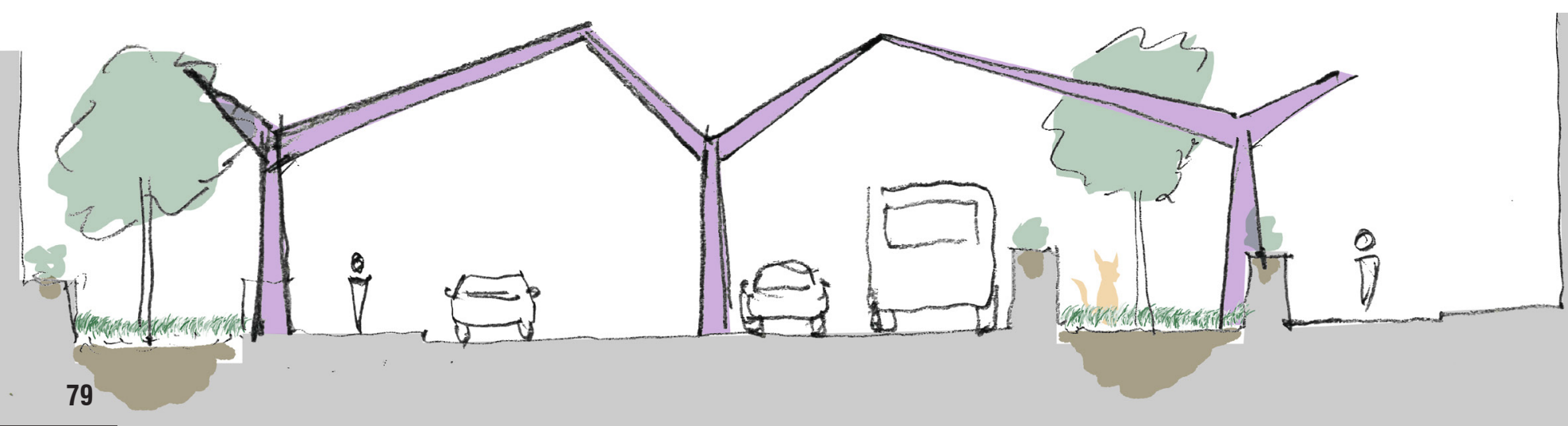




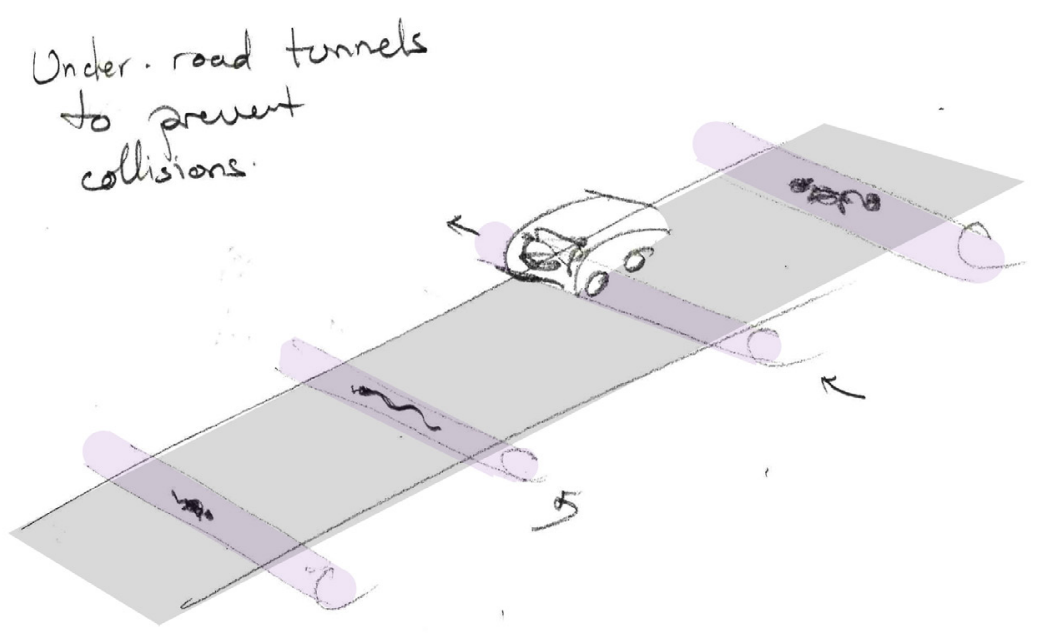

Fig 4-8. Underpass Sketch.

Fig 4-9. Street Underpass Section.

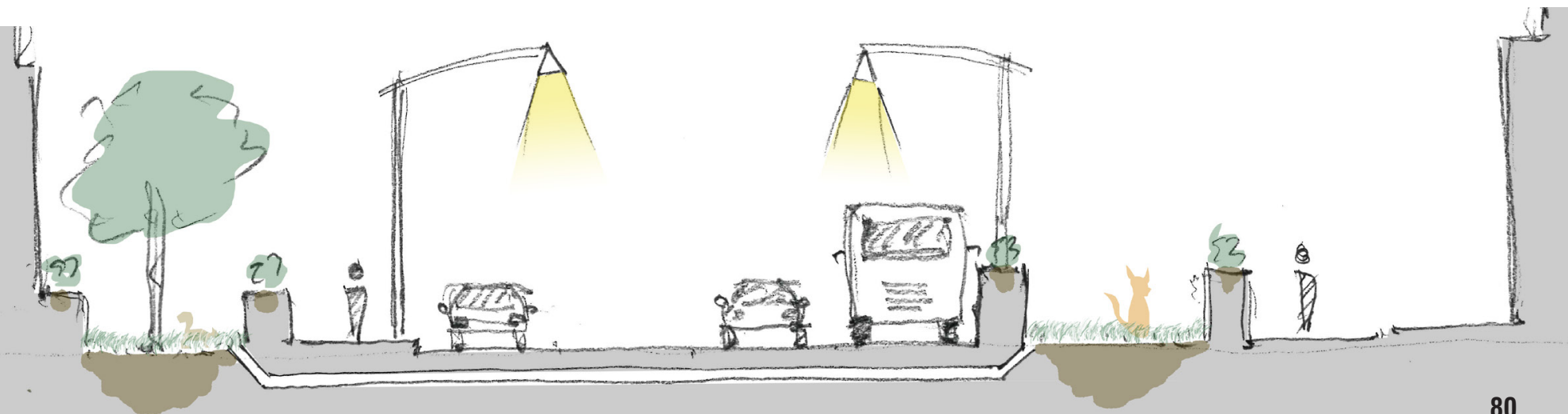




\subsubsection{Habitat Nodes}

Part of the strategy for this systematic approach of creating an urban ecology for wildlife involves the development of key points or zones that facilitate critical functions. These can be resting grounds, foraging areas, nesting sites, and other places of sanctuary for animals. The urban context could facilitate emulations of different ecological conditions as was proposed in the 2016 project "Rewilding the Gardiner Expressway" by Usue Ruiz Arana. ${ }^{1}$ A diversity of habitats with different kinds of biological growths and topological conditions could meet the needs and preferences of different species of animals. In addition to this strategy, actual constructed forms could be incorporated and embedded within the urban context to facilitate functional needs such as perching, roosting, denning, and other essential requirements for wildlife. These different strategies offer animals valuable sites within the urban context; working in concert with the migratory routes provided by the animated scapes, a holistic ecological system begins to form as a woven layer within the city fabric.

1 Usue Ruiz Arana, "Rewilding the Gardiner Expressway," Rewilding the Gardiner Expressway, last modified 2016, accessed January 4, 2019, https://rewildingthegardiner. com/. 
Fig 4-10. Rewilding the Gardiner Expressway, 2016 Usue Ruiz Arana (00BE).

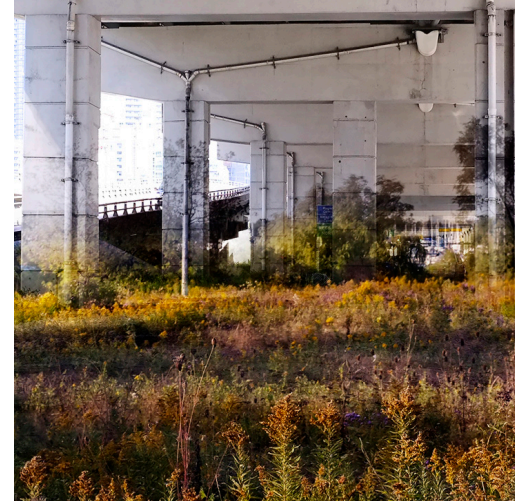

DRY MEADOW

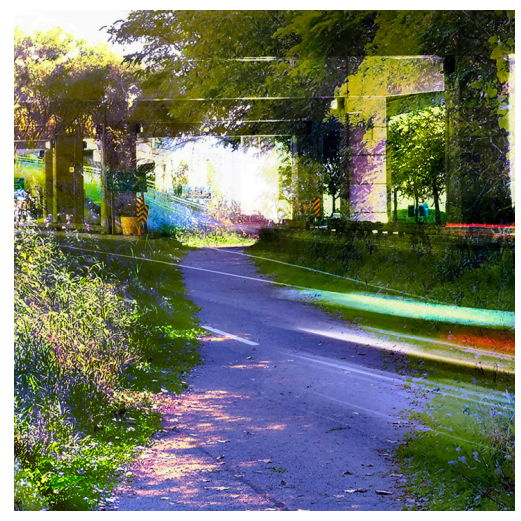

WOODLAND

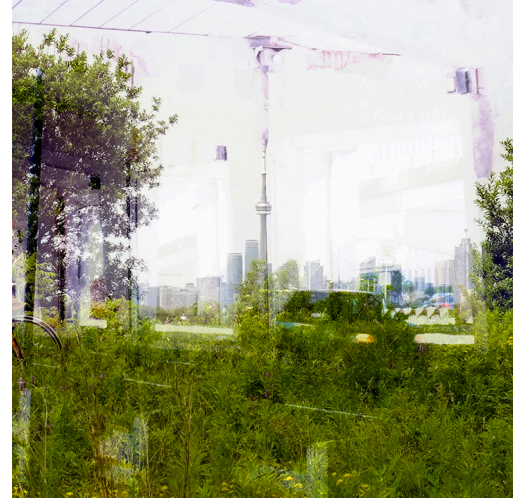

GRASSLAND

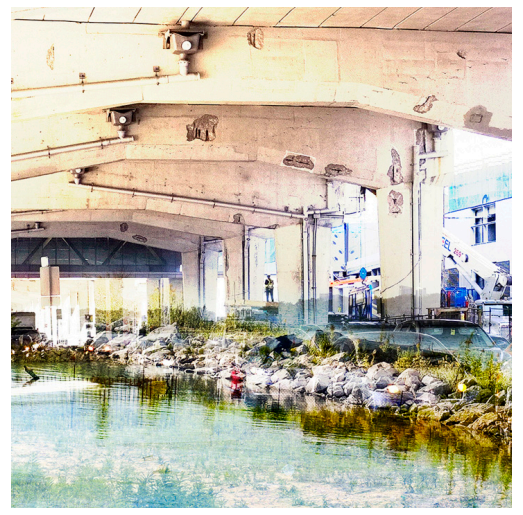

EMBAYMENT EDGE

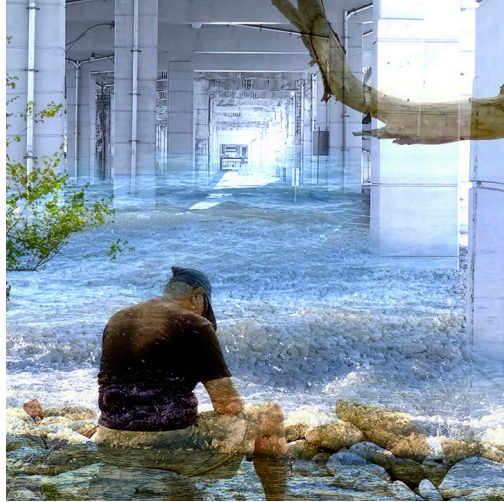

RUBBLE EDGE

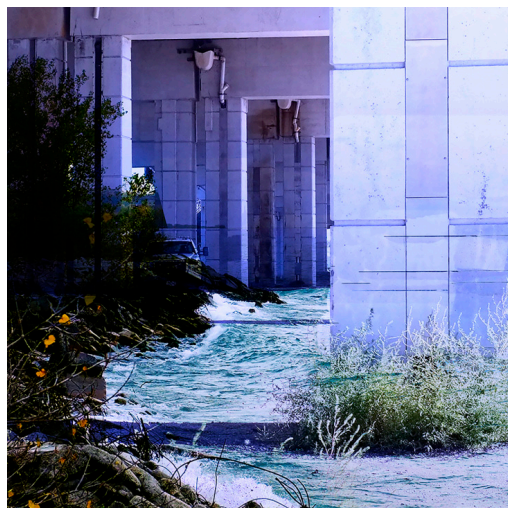

WETLAND

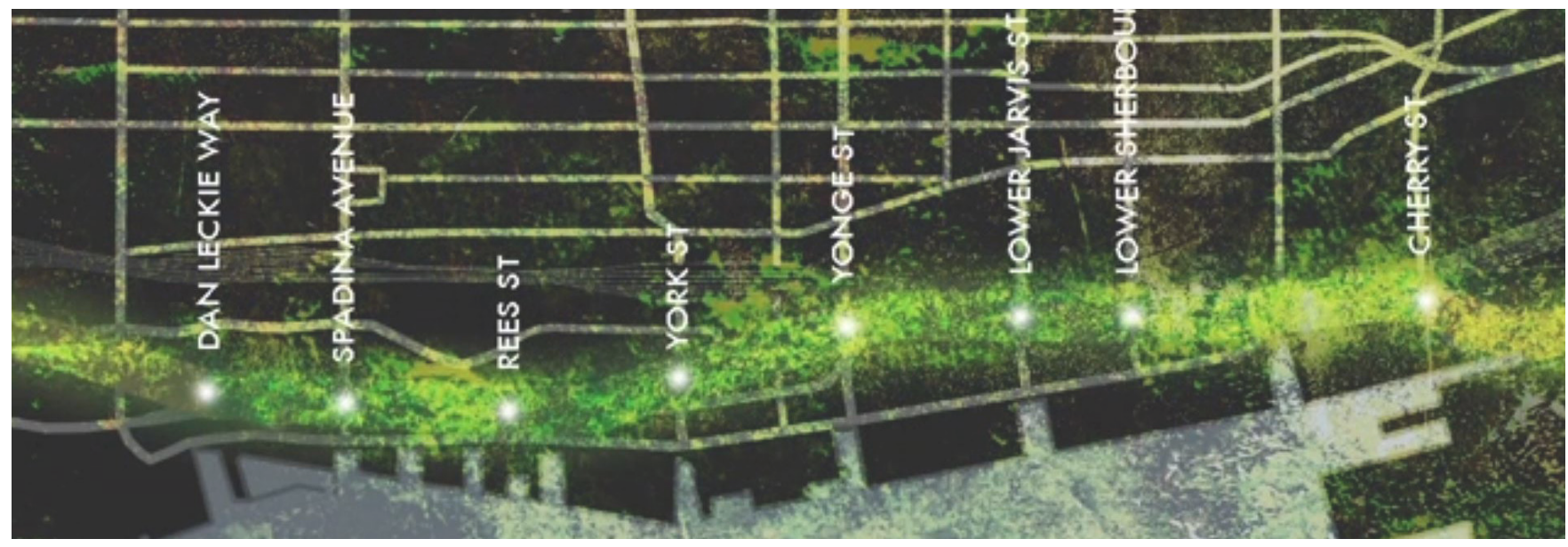




\section{3}

\section{A Range of Scales}

The development of this systematic design needs to operate simultaneously across a range of scales. Interventions at the micro level consist of ecological units with which animals directly interact; these can be thought of as ecotopes (discussed earlier in section 1.3). The mezzo level considers the how such nodes are accessible through a continuous connective tissue of scapes. This strategy ensures that areas of habitat are not isolated in secluded pockets, but connect through an uninterrupted network. At the macro level, this strategy considers how the system relates to the greater areas of the city, its arrangement of parks and green spaces, and its outer boundaries. The three scales can be summarized in this way:

- Micro: artefact, material, and ecotope.

- Mezzo: neighbourhood, landscape, and connected habitat.

- Macro: city and region. 


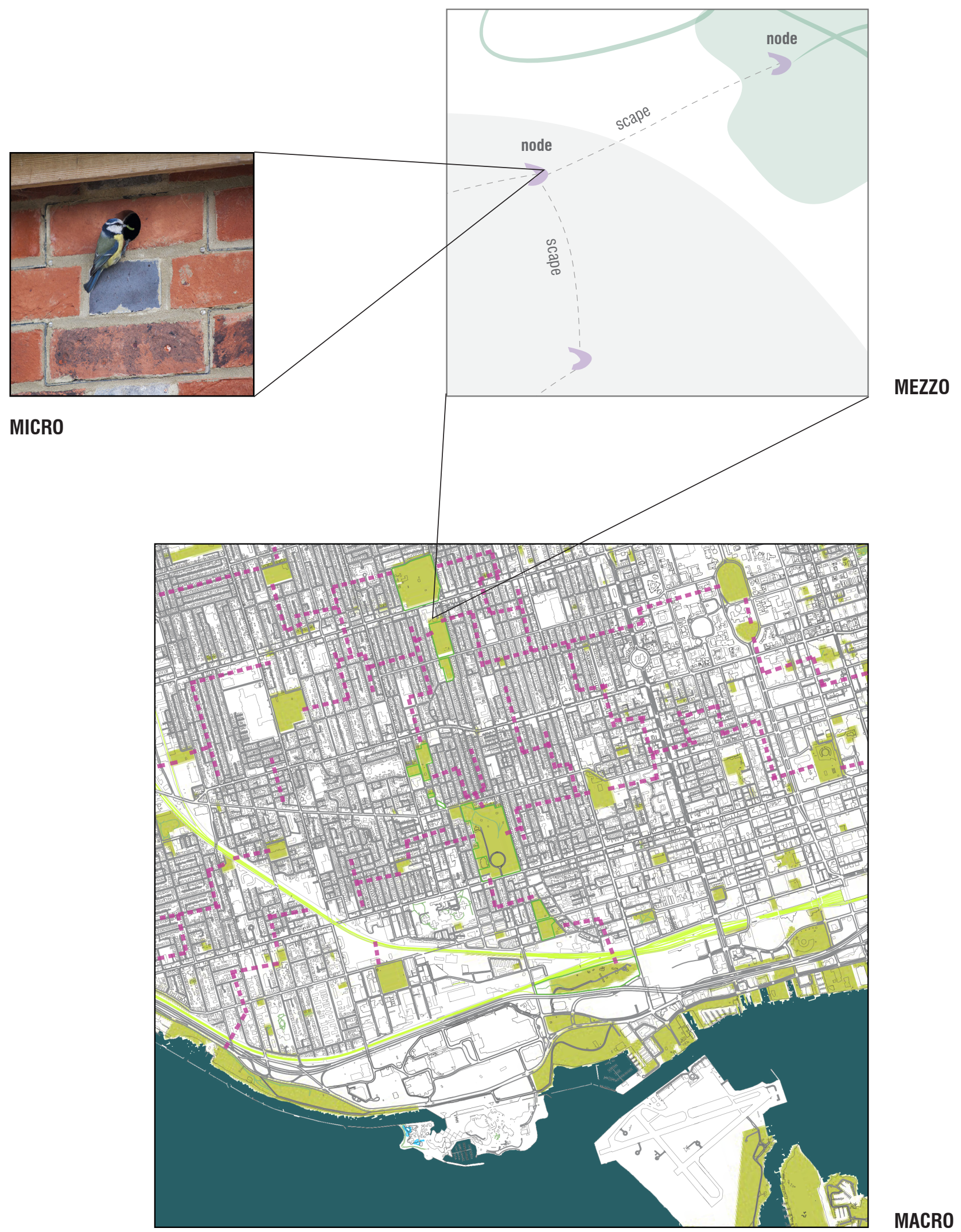




\section{Boundary Relationships}

In researching design interventions that address the relationship between humans and wildlife, four broad categories of boundary conditions became apparent that speak to increasing levels of intensity. The terminology developed to express these four conditions was as follows: isolation, adjacency, intersection, and blending.

Before unpacking these terms (even though their meanings are straightforward enough to deduce), it could be fruitful to relate them to another anecdotal idea. An image with an unknown source has circulated online; while its precise intent is not explicit, it has been largely interpreted as a cultural statement with regard to issues of
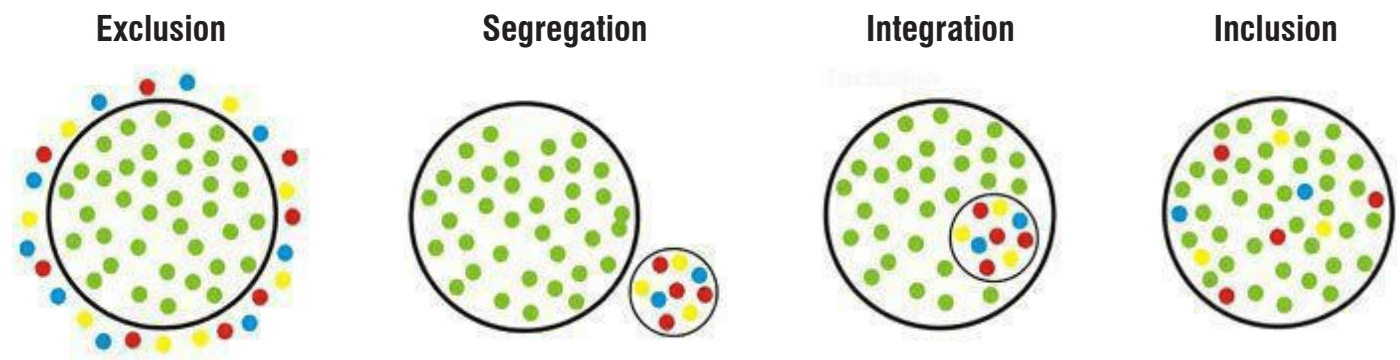

Fig 4-12. Categories of "us" vs "them."

social inclusion. ${ }^{2}$ The image depicts four states wherein the "other" group is either excluded, segregated, integrated, or included. This formulation strongly assists in conveying the conceptual understanding of these categorizations.

2 Tim Villegas, "Inclusion, Exclusion, Segregation and Integration: How are they Different?" Think Inclusive, last modified July 11, 2017, accessed March 30, 2020, https:// www.thinkinclusive.us/inclusion-exclusion-segregation-integration-different/. 


\section{Separation}

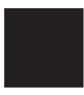

Adjacency

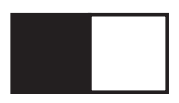

Intersection

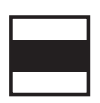

Blending

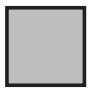

The first categorization treats humans and wildlife as being entirely separate groups that rarely if ever have an opportunity to intermingle. This approach expresses the philosophical notion that each of the two groups has their own territories wherein they reside; humans are allocated to cities, and wildlife is meant to remain in natural environments.

This type of boundary condition brings the two groups and their territories into closer proximity. A physical boundary remains to separate the two, however the level of proximity facilitates new qualities to the relationship between the two; visual connectivity and the carrying of sounds now imbue the relationship with different characteristics.

This type of condition allows animals to travel through humandedicated spaces within some type of boundary. A far more intimate approach, this may elicit feelings of discomfort as human space seems to be "invaded" by wilder constituents.

The furthest extreme possible, the relational mode proposes a condition wherein humans and animals cohabit a shared space. This raises issues of safety, as some animals may be dangerous to be in proximity with. However, there are a subset of less risk-provoking animals that people can afford to have nearby without major cause for concern.

Fig 4-13. Categories of Boundary

Relations. 


\subsubsection{Phases of Eco-Cultural Evolution}

The aforementioned boundary relationships escalate in intensity as wildlife is brought into greater proximity with anthropic space. There may be tremendous push-back against the design of environments wherein wildlife intermingle with humans too closely. Therefore, a socio-political strategy that occurs in phases can gradually change people's understanding of and outlook on animals, and potentially bring about a greater degree of acceptance. The four boundary relationships speak to four possible phases that can bring about this cultural shift:

\section{Phase 1: Separate Environments}

Architectural structures embedded in natural wilderness can provide opportunities to draw people out into a setting where they're able to experience wildlife. This design of a bat observation deck is situated on the banks of a river. People can observe from a distance as bats engage in their nightly hunt for insects and mosquitos above bodies of water. This intervention can shed light on the activities of animals and help strengthen the relationship between humans and synanthropes through an immersive experience.

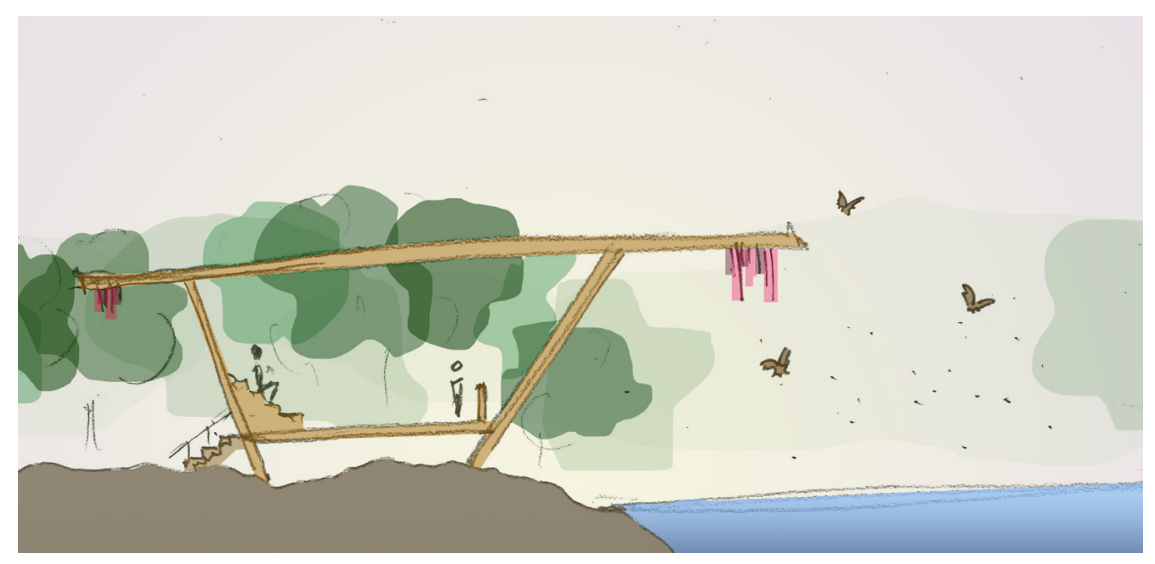

Fig 4-14. Bat observation deck on the banks of a river. 


\section{Phase 2: Adjacent Environments}

Once a level of understanding has been established, certain areas near the urban environment can be reallocated to wildlife. Rewilded green corridors can bring a richer diversity of animals closer to urban communities. In this phase, humans and animals begin to share territory, developing a greater sense of being neighbours within a communal biome.

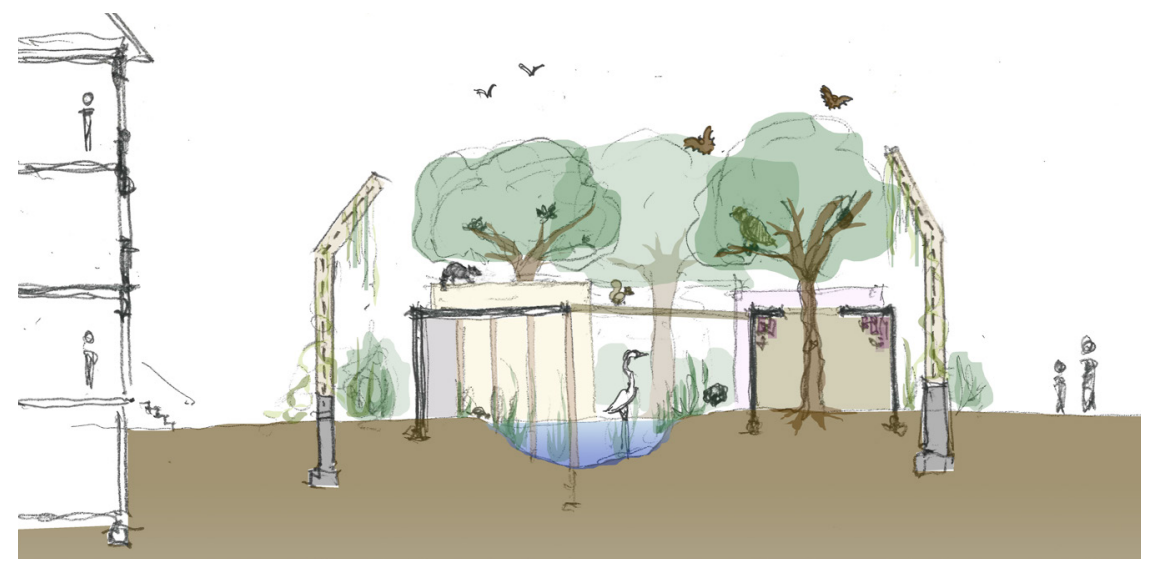

Fig 4-15. Neighbouring territories. 


\section{Phase 3: Intersectional Environments}

Having developed a greater sense of familiarity and comfort with wildlife, their agency becomes further incorporated into standard practices. Ecological principles are more commonly introduced into architectural design, creating urban forms that respond with greater sensitivity to local biodiversity. As such, dedicated environments for wildlife become woven into urban forms, addressing significant ecological issues in the city such as the prevention of habitat fragmentation.
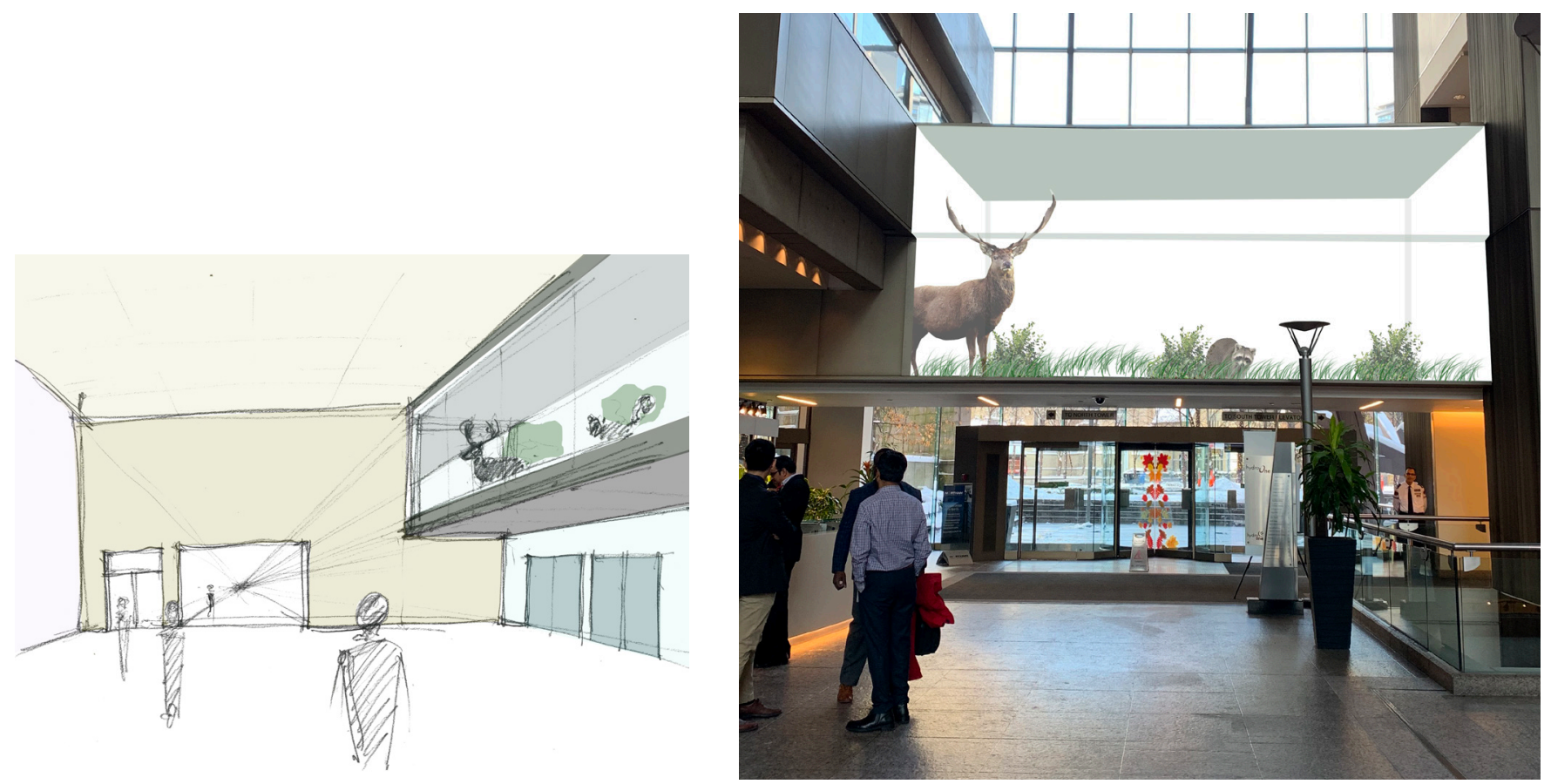

Fig 4-16. Interseting re-wilded corridors through buildings. 


\section{Phase 4: Blended Environments}

With networks of wildlife circulation and habitat weaving seamlessly through the urban fabric, the next phase takes a further step and allows animals to permeate into shared spaces with humans. Arguably the most extreme of the options presented here, this assumes highly sophisticated architectural systems that manage permeability, offering access to certain animals and excluding other more dangerous ones. At the same time, it assumes a tremendous cultural shift wherein humans have developed a greater bond with synanthropes, founded in a gradually phased process that fostered understanding, acceptance, and appreciation.

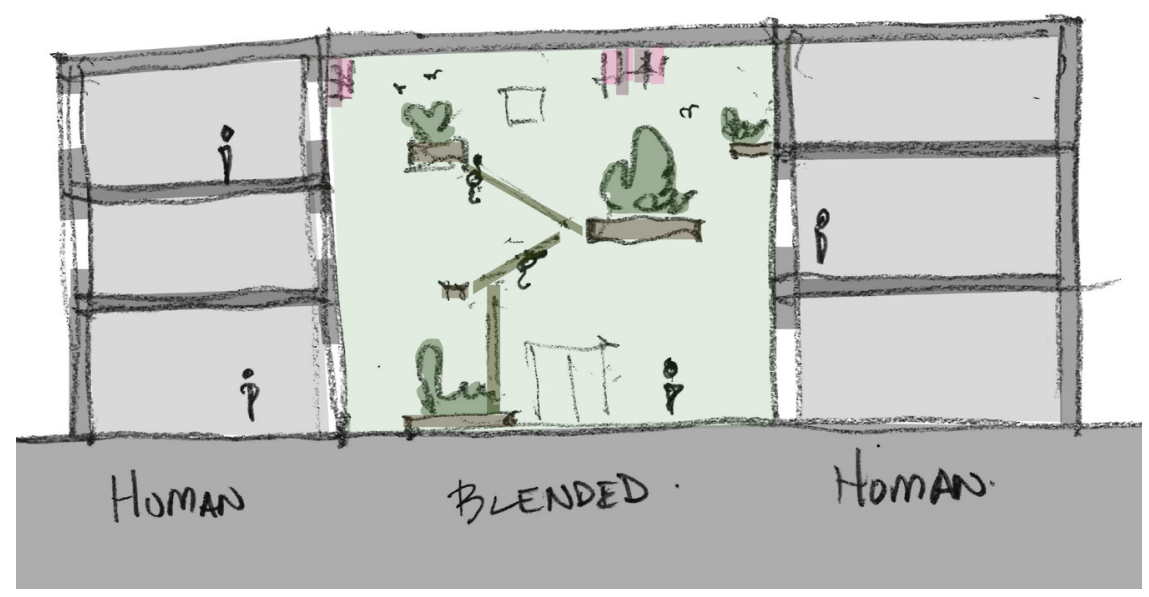

Fig 4-17. Blended heterogeneous spaces. 


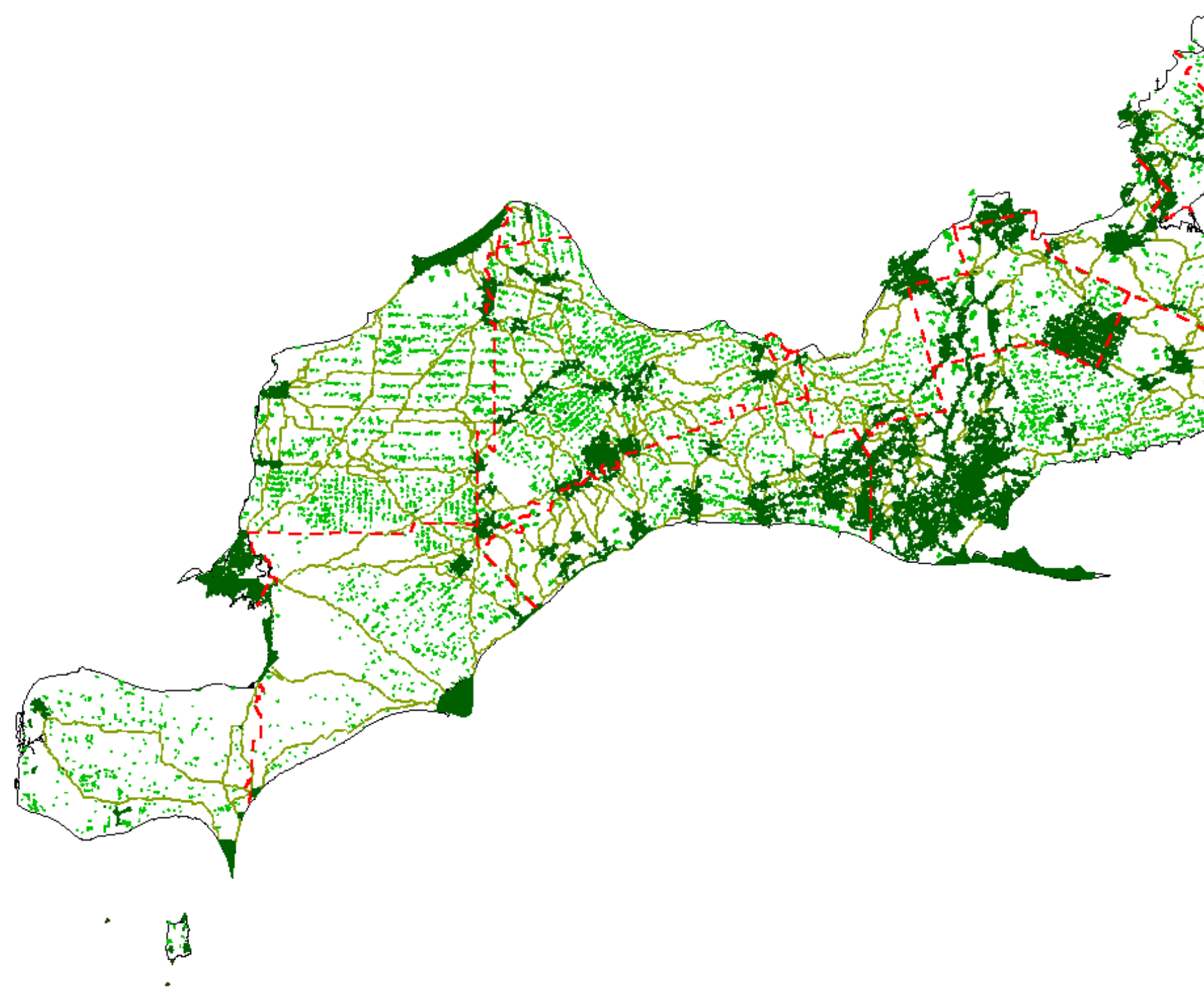

Fig 5-1. The Carolinian Zone. 
Ghapter 5

\section{Site Analysis}

5.1

5.2

5.3
Socio-Ecological Context

Toronto: An Urban Laboratory

Wildlife in Toronto
93

99

105 
south of its current shoreline. ${ }^{5}$ Over the course of millennia, the melting of ice, the flow of waters, and the shifting of soils revealed an expanse of fertile earth within the regions of southern Ontario. The interplay of these dramatic geological changes gave rise to a new environment whose properties are unique from any other in the greater surrounding region: the Carolinian Zone. ${ }^{6}$ Warmed by the neighbouring bodies of water, this area experienced higher

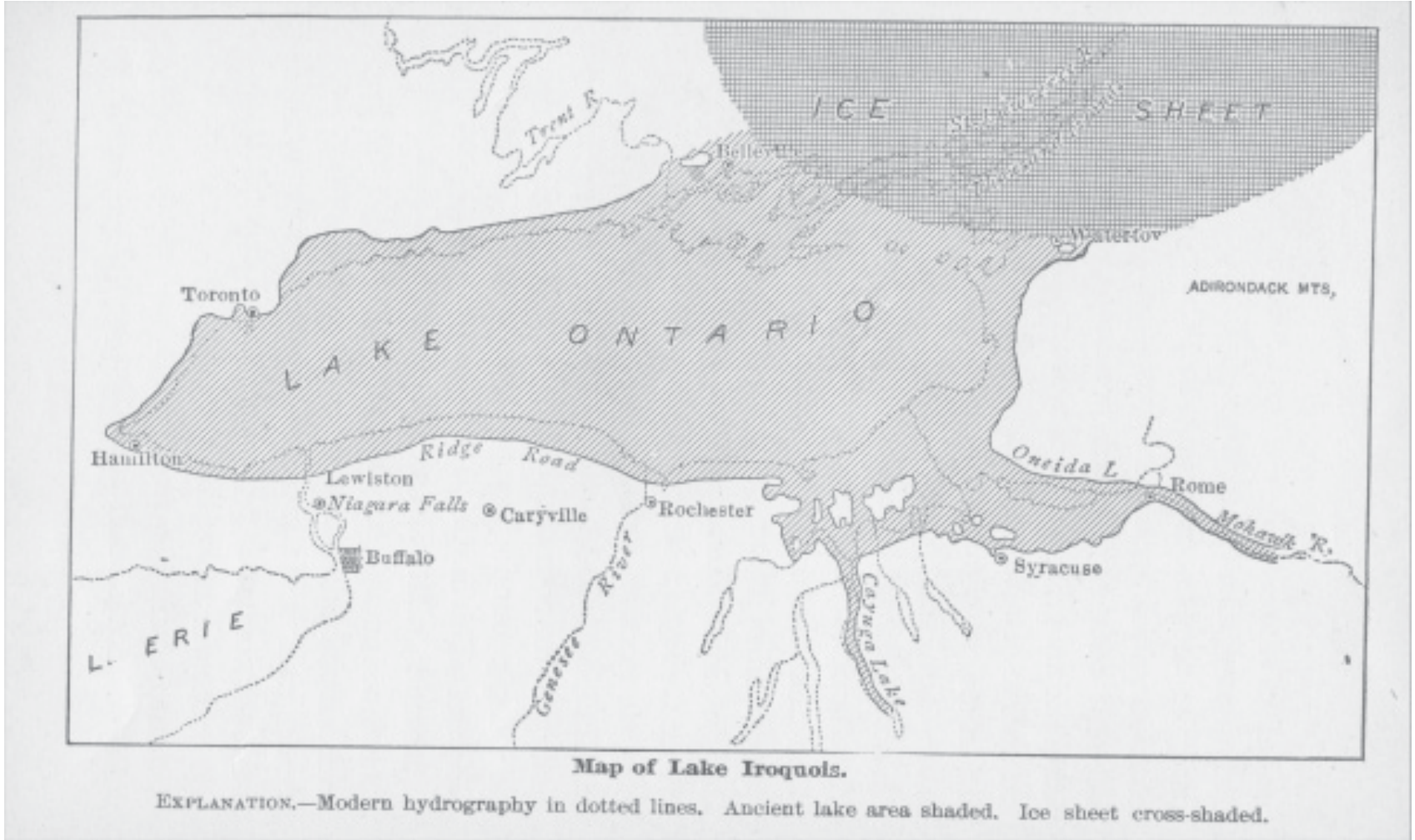

5 “First Peoples," City of Toronto, n.d., accessed March 4, 2020, https://

Fig 5-3. The Ancient Lake Iroquois 13,000 years ago.

web.archive.org/web/20150416111209/https:/www1.toronto.ca/wps/portal/ contentonly?vgnextoid=dd058d577e312410VgnVCM10000071d60f89RCRD.

6 Mark Cullen, "We live in a very special ecosystem - and it needs our help," The Star, last modified August 2, 2019, accessed March 3, 2020, https://www.thestar.com/life/ homes/2019/08/02/residents-of-the-gta-live-in-a-very-special-ecosystem-and-it-needsour-help.html?fbclid=IwAR1A7vuAVvL61AYozFqAtrJJoazaxiHQ47x4xsrsG5t5Ndhc fy6UQLPRXo. 
average annual temperatures and shorter frost-ridden seasons. ${ }^{7}$ These grounds grew lush with deciduous forests extending out from the regions to the south, and promoted a thriving ecology of plant and animal biodiversity. In the wake of the abundance of animals that migrated and thrived in this region, so too came humans who pursued them, hunting caribou, mammoths, mastodons, as well as smaller game. ${ }^{8}$ As waters rose and the climate warmed, conditions in the area began to resemble those of today. While certain animals had migrated or gone extinct, others, like the white-tailed deer, had

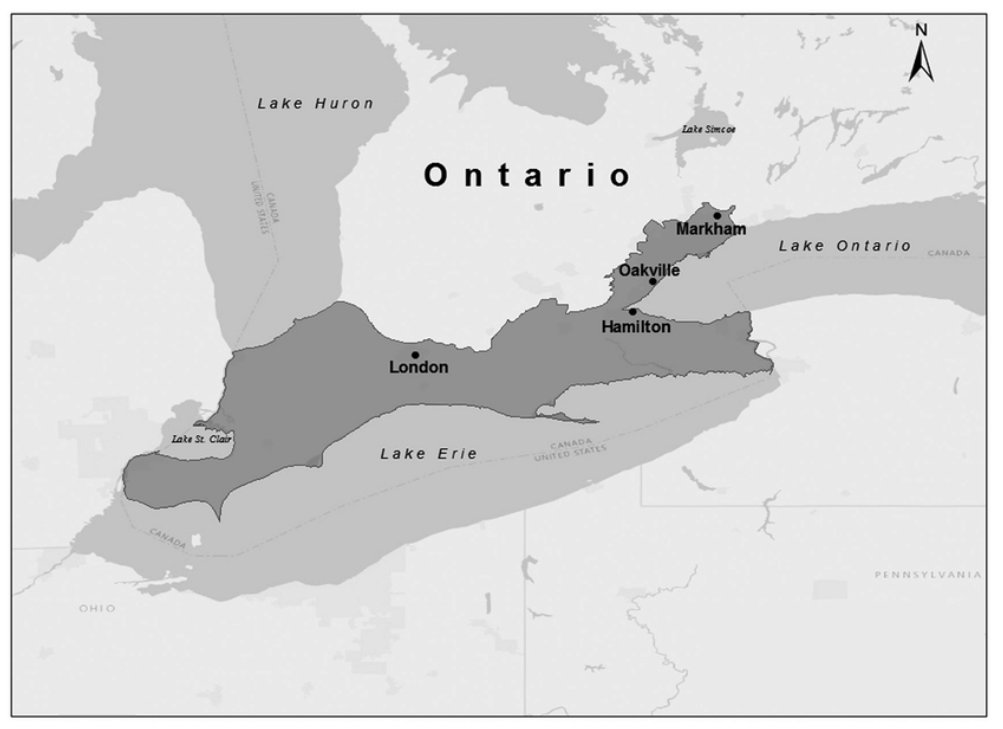

Fig 5-4. The Carolinian Zone. come to take their place. ${ }^{9}$ Indigenous communities of a few hundred people had formed around the ravines, engaging in hunting, fishing, and planting crops. Over the course of thousands of years, this environment maintained a thriving richness of biodiversity.

To this day, this pocket of land known as Carolinian Canada - remains ecologically distinct from any other in the country. While it makes up only $1 \%$ of Canada's total area, it harbours some of the greatest abundance of flora and fauna. ${ }^{10}$ Over 2,200 species of plants are distributed within the boundaries of

7 “The Uniqueness of Carolinian Canada," Carolinian Canada Coalition, last modified June 1994, accessed March 4, 2020, https://caroliniancanada.ca/legacy/FactSheets CCUniqueness.htm.

8 "First Peoples," City of Toronto, n.d., accessed March 4, 2020, https:// web.archive.org/web/20150416111209/https://www1.toronto.ca/wps/portal/ contentonly?vgnextoid=dd058d577e312410 VgnVCM10000071d60f89RCRD.

9 Ibid.

10 "The Uniqueness of Carolinian Canada," Carolinian Canada Coalition, last modified June 1994, accessed March 4, 2020, https://caroliniancanada.ca/legacy/ FactSheets_CCUniqueness.htm. 
this region, 500 of which are considered rare. ${ }^{11}$ Nearly 400 species of birds have been recorded in this landscape, accounting for roughly half the bird species in all of Canada. ${ }^{12}$ One third of Canada's rare, threatened, and endangered animal species inhabit this ecological haven. ${ }^{13}$ In comparison to the rest of the country, the total area of Carolinian Canada is very small, but due to its extraordinary ecological value, it is highly precious.

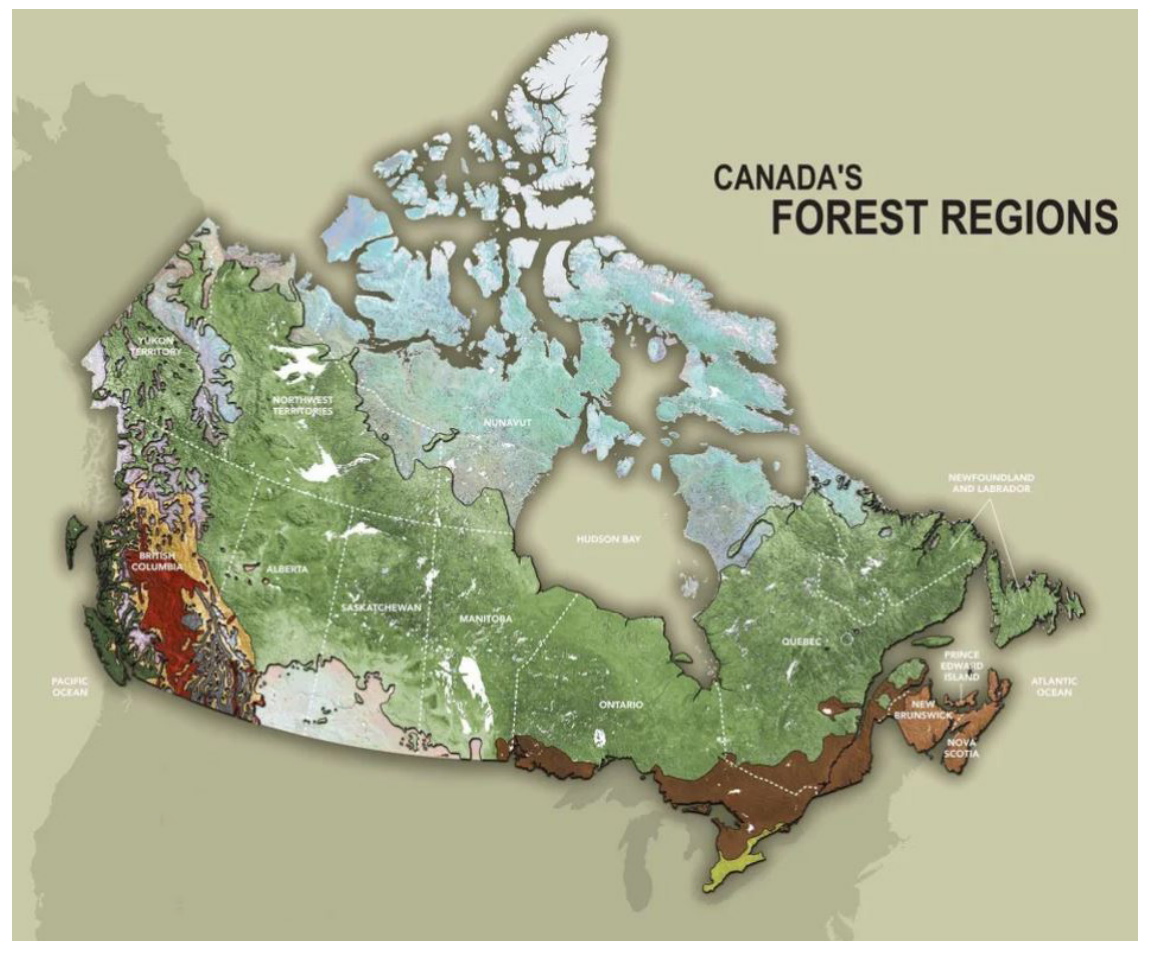

Fig 5-5. Canada's Forest Regions.

As one of the densest concentrations of biological diversity in Canada, it's the emergency room for many species at risk.

- Peter Ewins

Species conservation specialist at WWF Canada ${ }^{14}$

\footnotetext{
11 Ibid.

12 Ibid.

13 Ibid.

14 Mark Cullen, "We live in a very special ecosystem - and it needs our help," The Star, last modified August 2, 2019, accessed March 3, 2020, https://www.thestar.com/life/homes/2019/08/02/residents-of-the-gta-live-in-a-very-special-ecosystem-and-it-needs-our-help.html.
} 


\section{Remnants of a Legacy}

The region of southern Ontario has experienced a radical transformation during the colonial era of the past few centuries. Natural habitats had been appropriated to make way for urban spaces, factories, and farms of the Canadian economic engine. Towns were built along the shorelines of lakes and the banks of ravines, using them for trade and fishing, becoming highly polluted by the industrial waste that accompanies urbanization. ${ }^{15}$ Wetlands that once covered $26 \%$ of the region have since diminished to cover only $5 \%$ of the area. ${ }^{16}$ Southern Ontario became home to the province's manufacturing industry and its agricultural belt. ${ }^{17}$ Nearly the entire region of this invaluable ecosystem has been claimed by civilization; $95 \%$ of the land of the Carolinian Zone is privately owned. ${ }^{18}$ Those species of animal- and plant-life that remain, now occupy only the margins of this anthropogenic landscape.

15 "Discovery Walks: Garrison Creek," City of Toronto, n.d., accessed January 19, 2020, https://www.toronto.ca/services-payments/streets-parking-transportation/walking-intoronto/walking-tours/etobicoke-walking-tours/.

16 Mark Cullen, "We live in a very special ecosystem - and it needs our help," The Star, last modified August 2, 2019, accessed March 3, 2020, https://www.thestar.com/life/ homes/2019/08/02/residents-of-the-gta-live-in-a-very-special-ecosystem-and-it-needsour-help.html?fbclid=IwAR1A7vuAVvL61AYozFqAtrJJoazaxiHQ47x4xsrsG5t5Ndhc fy6UQLPRXo.

17 Ibid.

18 Ibid. 


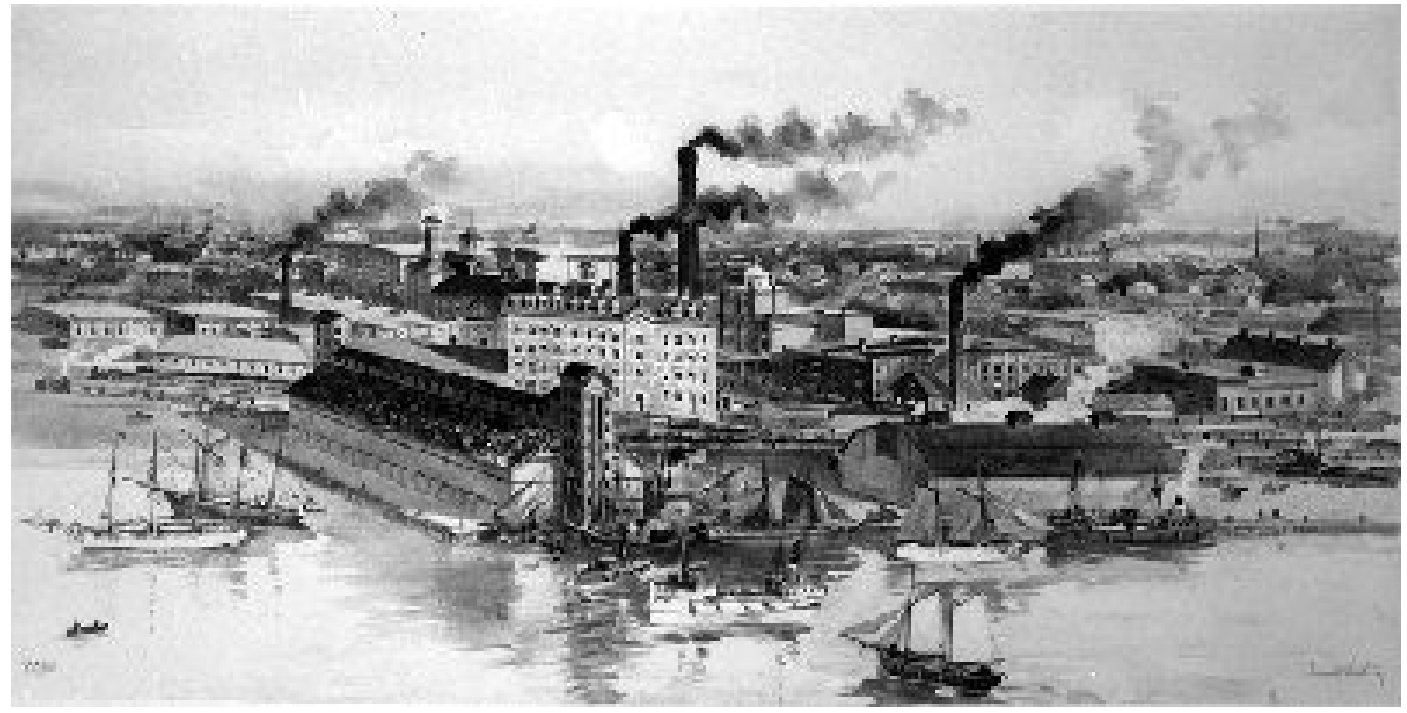

Fig 5-6. Toronto, Historical: looking northeast at foot of Parliament. 


\section{2}

\section{Toronto: An Urban Laboratory}

The City of Toronto has expanded to cover an area of $630 \mathrm{~km}^{2}$, and its population is approximately 2.7 million (based on figures from 2016). Meanwhile, the entire Greater Toronto Area encapsulates an estimated $5,906 \mathrm{~km}^{2}$ with a total population of roughly 6.4 million. ${ }^{19}$ The extensive reach and overabundance of the urban fabric has contributed greatly to habitat fragmentation in the region. Consequently, the Carolinian Zone no longer compares to the fecundity of its vibrant ecological past. However, the levels of growth and wildlife in the region remain quite substantial. Nature, it seems, is loath to abandon this idyllic ecosystem and manages to make do wherever possible - even in the most unexpected of places.

The Leslie Street Spit is an artificial peninsula of rubble, concrete, and urban debris that extends about five kilometres into Lake Ontario. ${ }^{20}$ Situated at the lip of the Port Lands in a highly

19 “Capital Facts for Toronto, Canada," World's Capital Cities, n.d., accessed March 2, 2020, https://www.worldscapitalcities.com/capital-facts-for-toronto-canada/.

20 “About Tommy Thompson Park," Tommy Thompson Park: Toronto's Urban Wilderness, n.d., accessed March 3, 2020, https://tommythompsonpark.ca/about/.

Fig 5-7. Toronto. 
industrialized area, this peninsula's original purpose was meant for "port-related activities. ${ }^{21}$ " However, this necessity was abandoned as the years went by. Instead, as natural growth had been spontaneously populating the peninsula, the site was repurposed in the 1970s and rebranded as Tommy Thompson Park. ${ }^{22}$ Having formed a unique lagoon environment, this ecological safe-haven accommodates a rich biodiversity of plant life, migrating birds, various mammals, amphibians, and insects. ${ }^{23}$

\section{Green Spaces}

Despite being highly urbanized, the city of Toronto is dotted with an abundance of greenspaces. The map in Fig. 5-9 illustrates the many parks, green corridors, ravines, and various other nodes of greenery that exist within the city. In the context of a systematic design moving forward, these areas can serve as a foundational starting point for an over-arching macro network. Reconnecting these micro-territories would begin a process of counteracting the drawbacks of habitat fragmentation in the city.
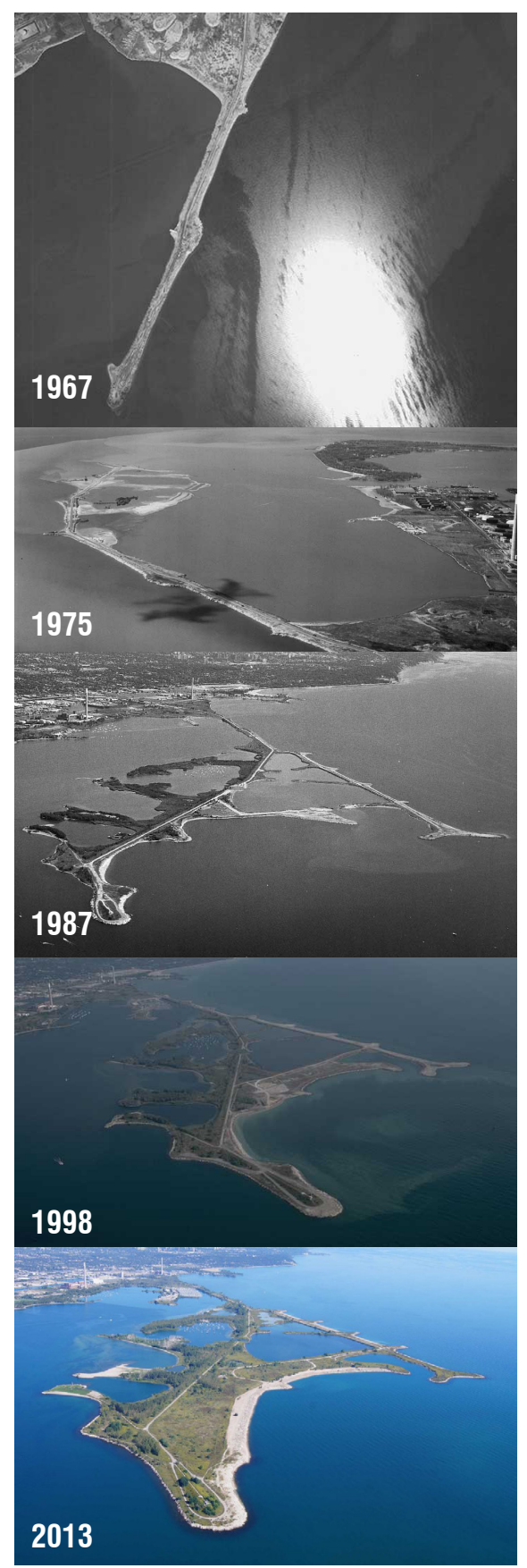

Fig 5-8. The gradual development of Leslie Street Spit, also known as Tommy Thompson Park. 


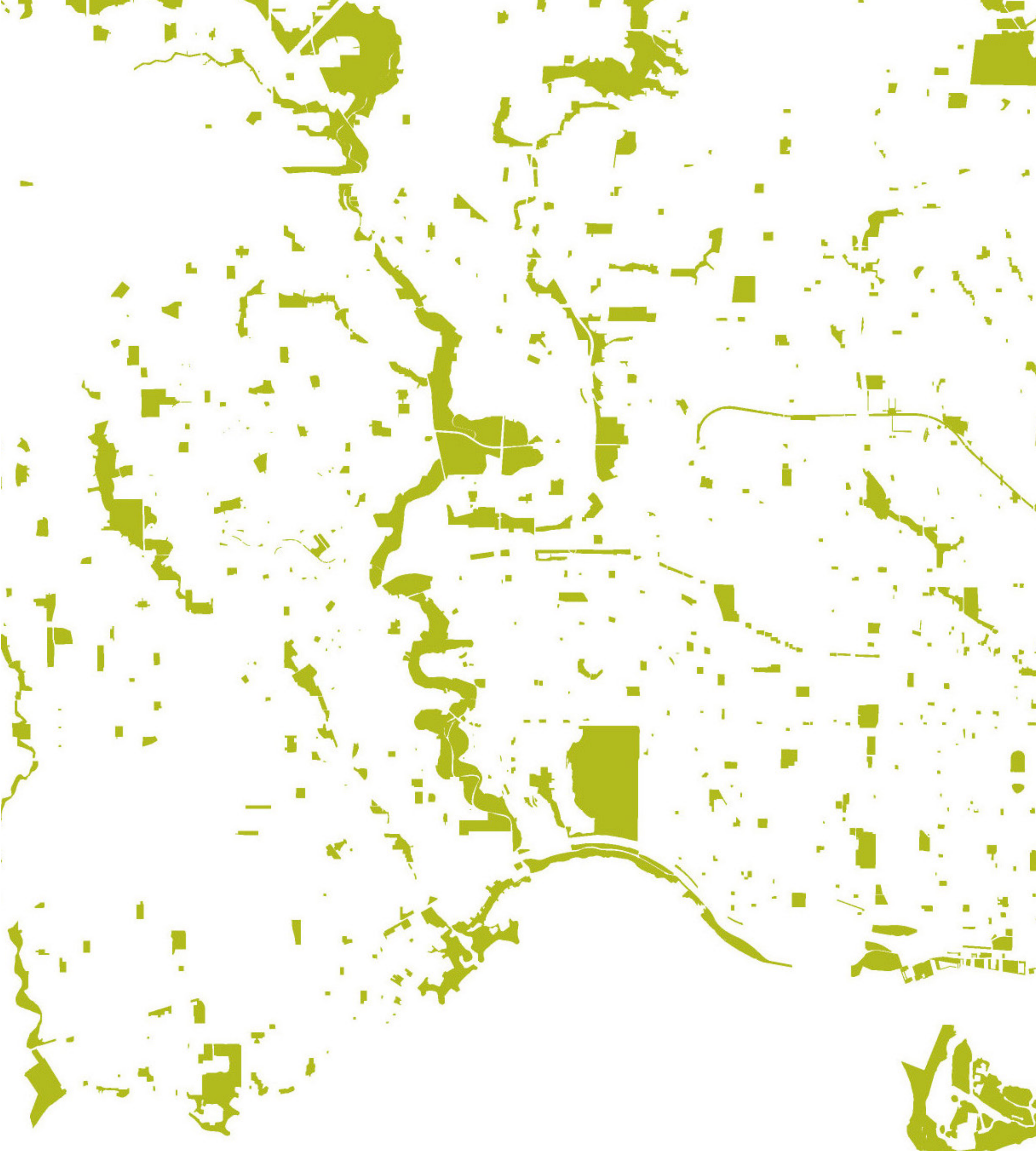





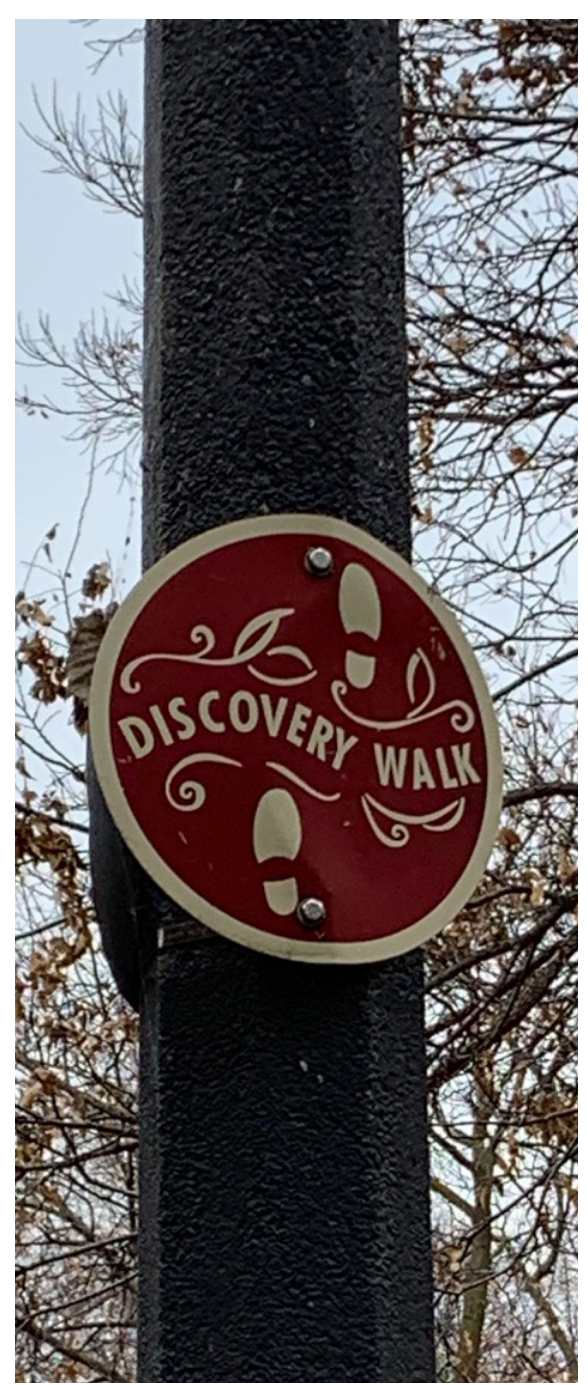

Fig 5-10. Self-directed maps with historical information are made available online by the City of Toronto as part of the "Discovery Walks" program.

\section{Garrison Creek: One of the Buried Ravines}

The City of Toronto offers a program with a series of self-guided tours throughout the city called Discovery Walks. Among them is a suggested route through a series of parks, streets, and paths that trace the historical meandering of the Garrison Creek ravine, which present-day continues to flow underground through a sewer system. During the early days of settlement in the Town of York (now Toronto) in the late 1700s, Garrison Creek was a lush ravine whose clean waters supported salmon. In the process of a century'sworth of continued urban development and infringement on this green corridor, the ravine's water became so heavily polluted that, in the late 1880's, it was decided that the ravine should be buried and redirected into underground sewers. ${ }^{24}$ What remains is an urbanized region of low-rise housing and a collection of parks whose soil is inadequate for construction developments. As an animated scape begins to reconnect with this series of parks and serve an ecological purpose, the emergent infrastructure pays homage to the cultural memory of the ravine below both in form and in function.

Page over:

Fig 5-11. Garrison Creek's Historical

Route.

24 "Discovery Walks: Garrison Creek," City of Toronto, n.d., accessed January 19, 2020, https://www.toronto.ca/services-payments/streets-parking-transportation/walking-intoronto/walking-tours/etobicoke-walking-tours/. 


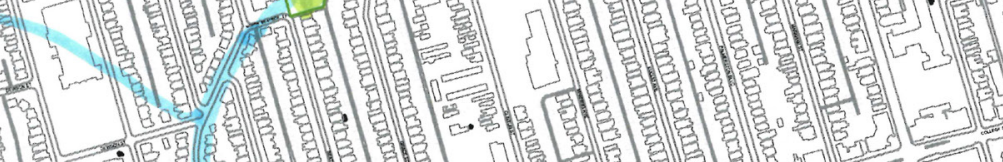

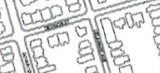

\section{I.}

H.

.

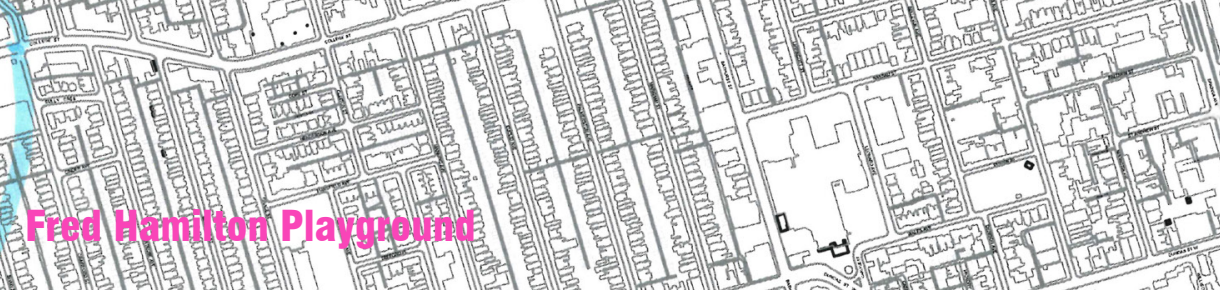

I.

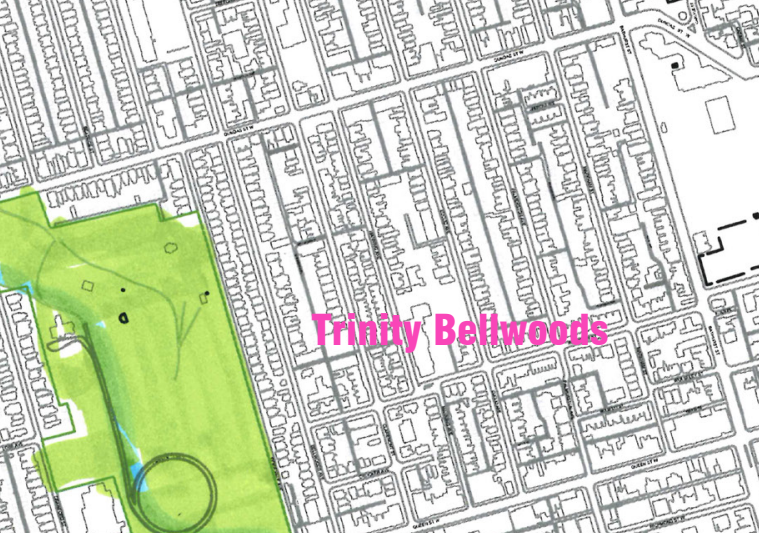

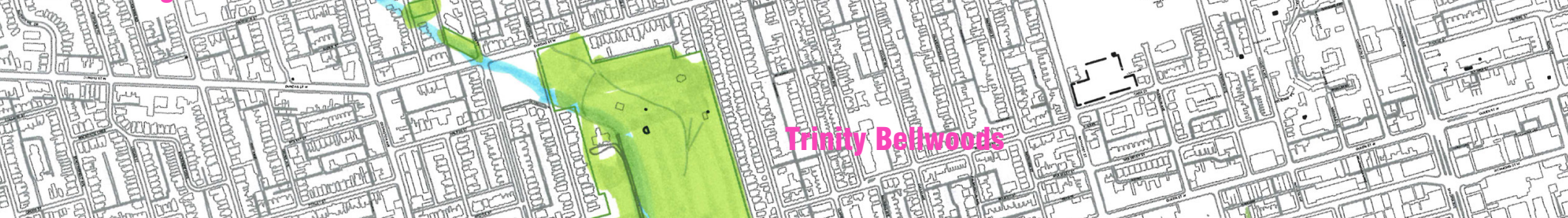
(1) SE 
5.3

Wildlife in Toronto

\section{The Humber River}

An on-site visit to the Humber River on July 15, 2019 revealed an astounding diversity of creatures that benefit from this wetland corridor. Canoeing down the river, one is perplexed by the juxtaposition of the lush and serene wetland and the backdrop of apartment buildings in the general vicinity. The riverbanks of this ravine look onto the backyards of private properties, so they are not subject to heavy traffic. This weaving stream feeds gently into adjacent pools, populated with tall reeds, floating lily pads, and an abundance of animals. It is a surreal experience to get off at a TTC subway station and, within 20 minutes, be in sights of turtles, several egrets, whizzing dragonflies, a host of ducks, and a thriving nest of cormorants from the seat of a canoe. It is evident that even in the midst of a highly urbanized setting, wildlife can find opportunities to thrive given the appropriate environmental conditions. While this lush corridor acts as a safe haven for wildlife, the encroaching urban fabric has some disruptive effects. According to a 2017 report prepared for the Toronto Wildlife Centre, the proximity of high buildings to ravines and to large parks can be potentially detrimental to some birds (particularly Canada geese); they tend to find the roofs of these buildings to be attractive nesting sites, which can lead to a situation whereby the newborn goslings fall off from dangerous heights. Perhaps a mode of construction that is more sensitive to biodiversity could suffuse the urban fabric with qualities that are more compatible with the behaviours of the local wildlife. 


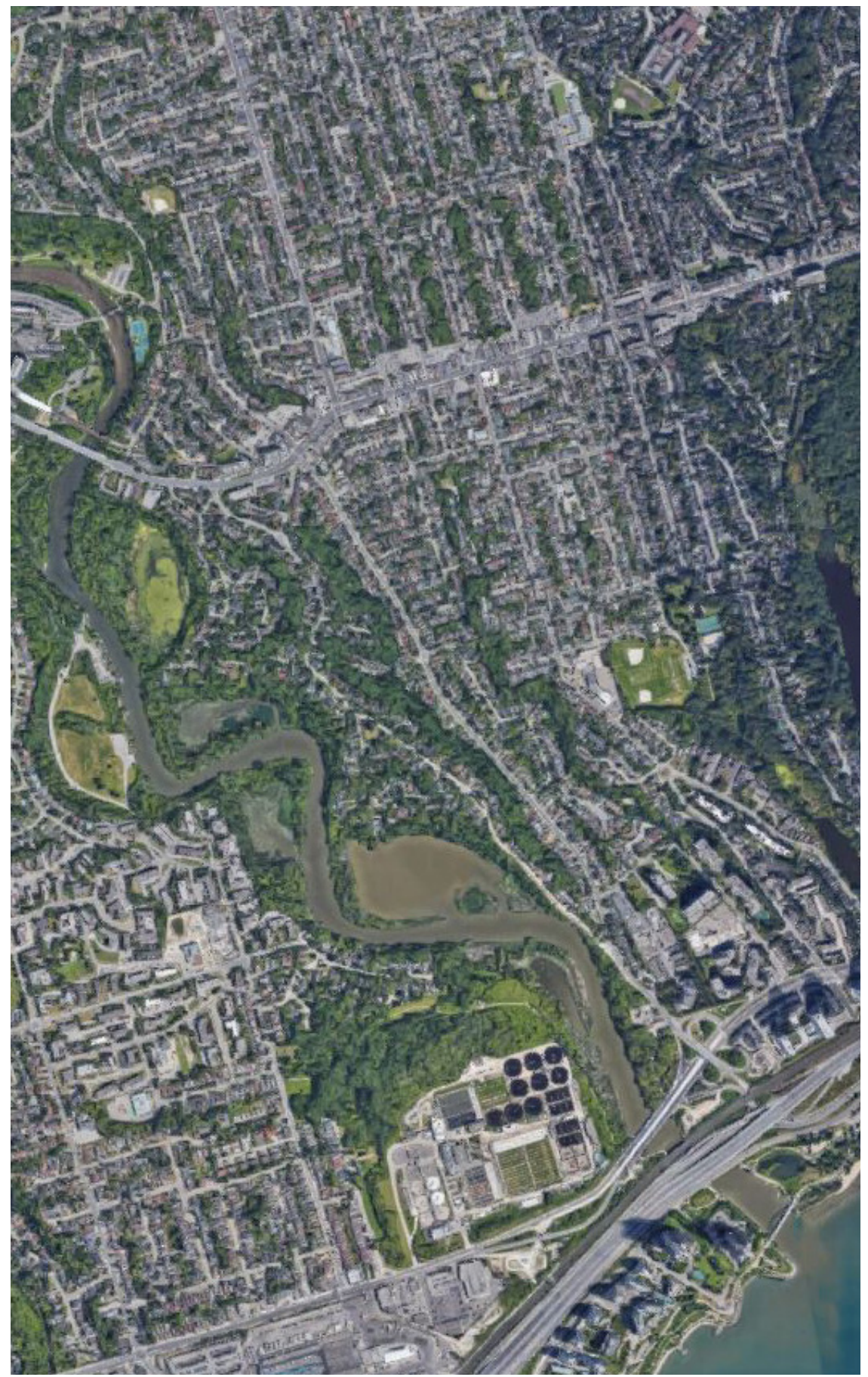

Fig 5-12. Humber River.
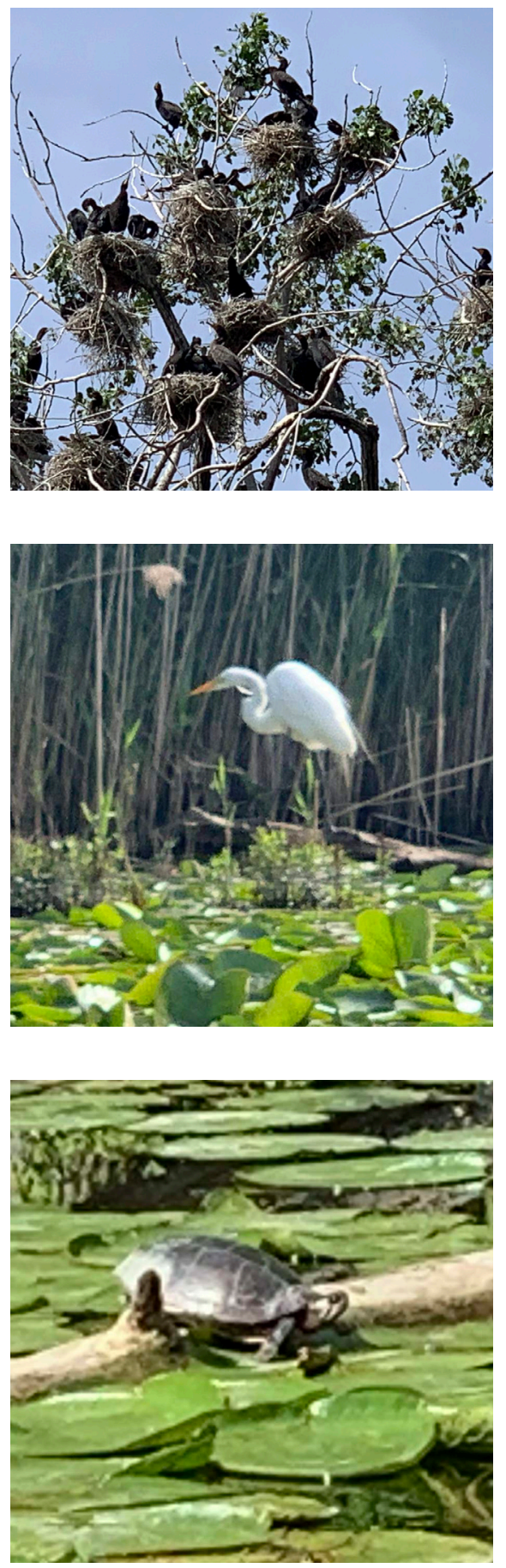

Fig 5-13. Photographs:

a. Cormorants.

b. Egret.

c. Turtle. 


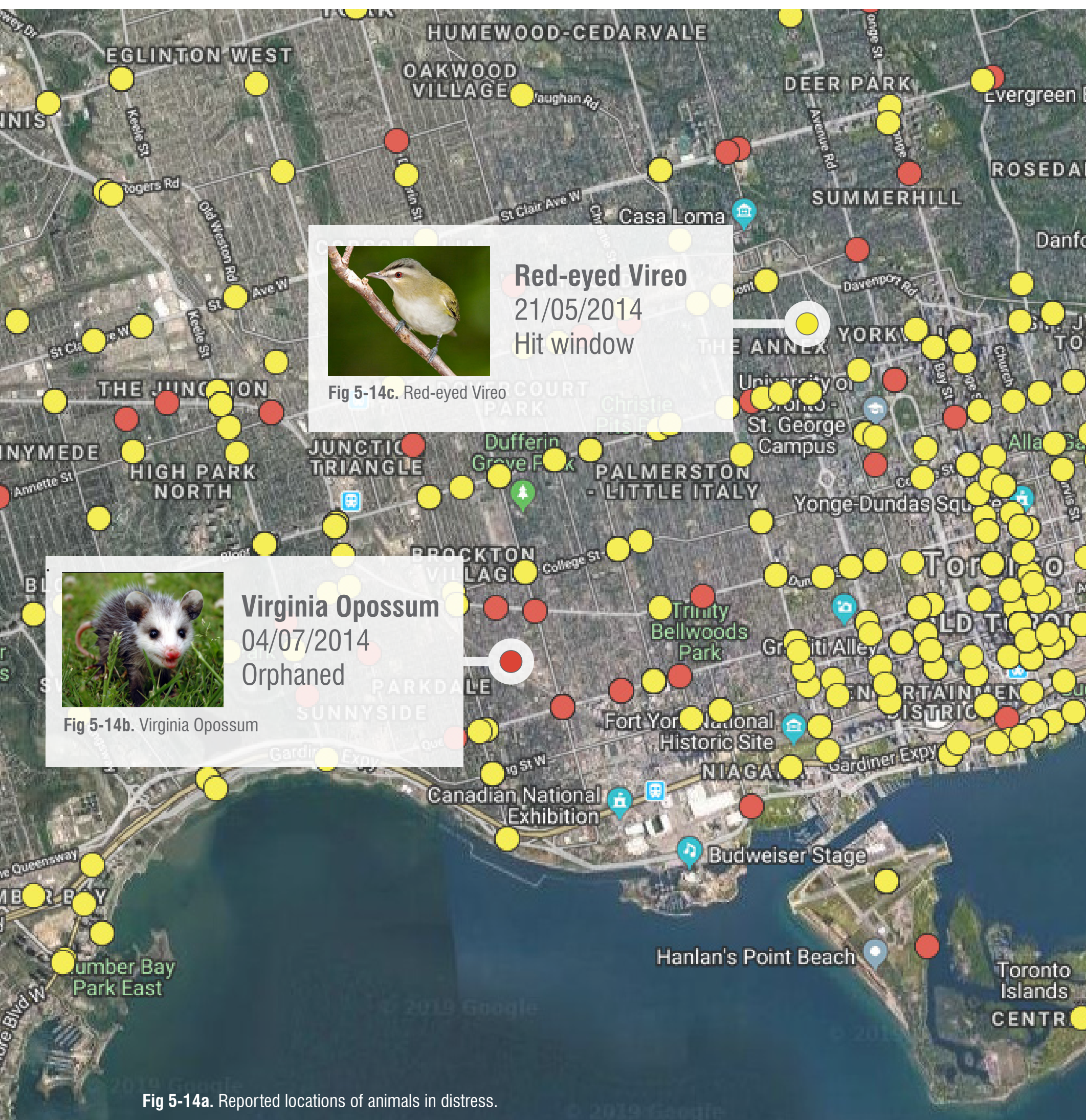




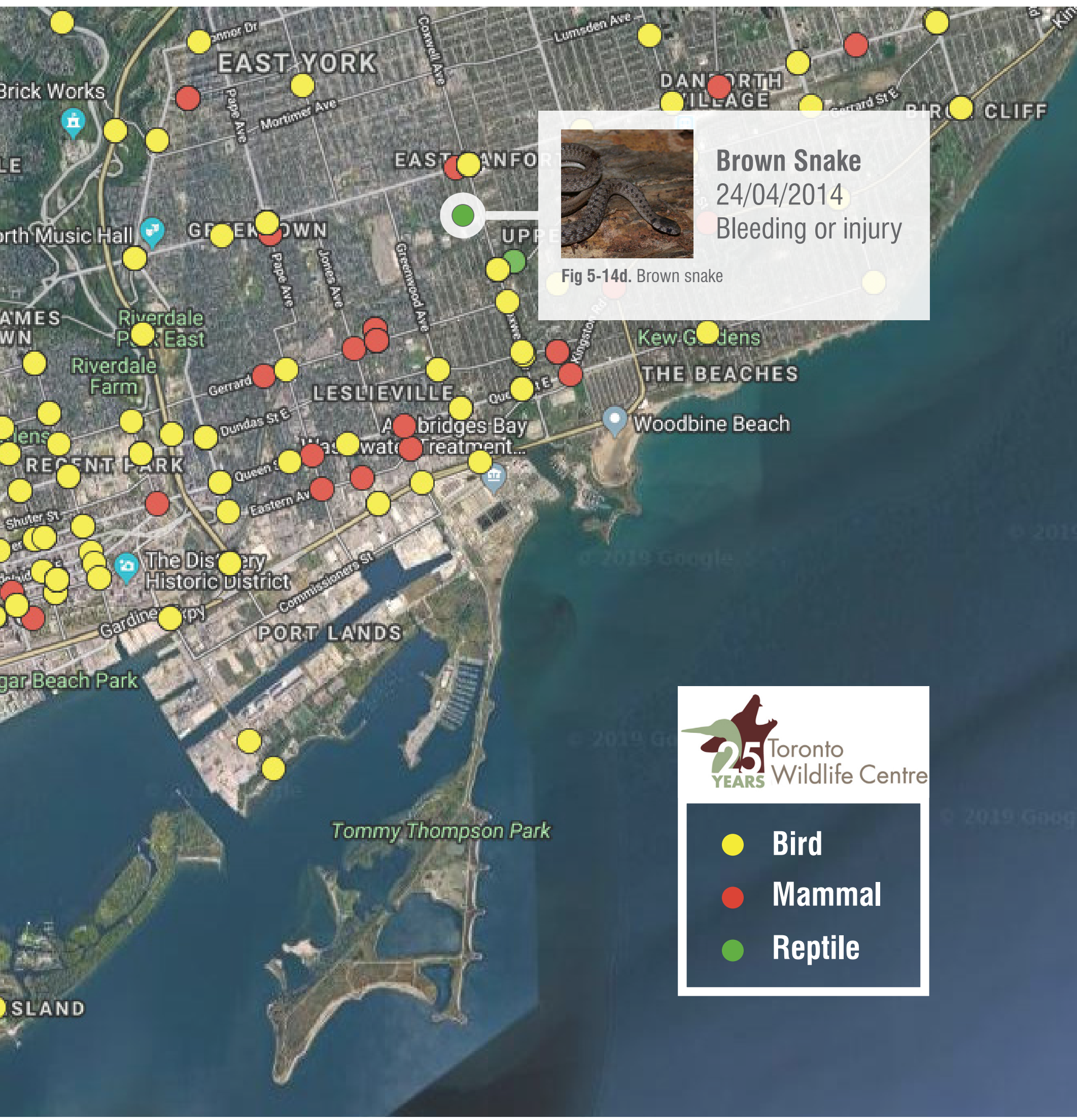




\section{Plight of the Animals}

Situated at the edge of the Carolinian Forest and on the banks of one of the Great Lakes, Toronto has a rich biodiversity, which can largely go unnoticed within the sprawling urbanization. This dense urban fabric poses many challenges for the many species of wildlife living in the margins of this city. The map on pages 105-106 is taken from the Toronto Wildlife Centre Rescue Database. It is a dynamic platform that records all the instances in which the centre was called to respond to an animal in distress. The map is populated by a vast variety of mammals, birds, and reptiles that encounter all sorts of hardships with urban structures and vehicles. Searching through this database, it is almost incredible to discover the kinds of species that are found in this urban setting - animals that one might think don't "belong" in this environment. However, perhaps it is the misunderstanding of animals and their predilections for where to inhabit and how to behave that needs to be addressed. In order to create an urban environment that is more suited to the patterns of animals, it is essential to investigate what those patterns are. Chapter 6 focuses on specific species found locally in the region and delves deeper into their characteristics, preferences, and relationship to the anthropic landscape. Unpacking the nature of these biological subjects begins to formulate a set of parameters that can operate in the process of designing an emergent synanthropic architecture. 


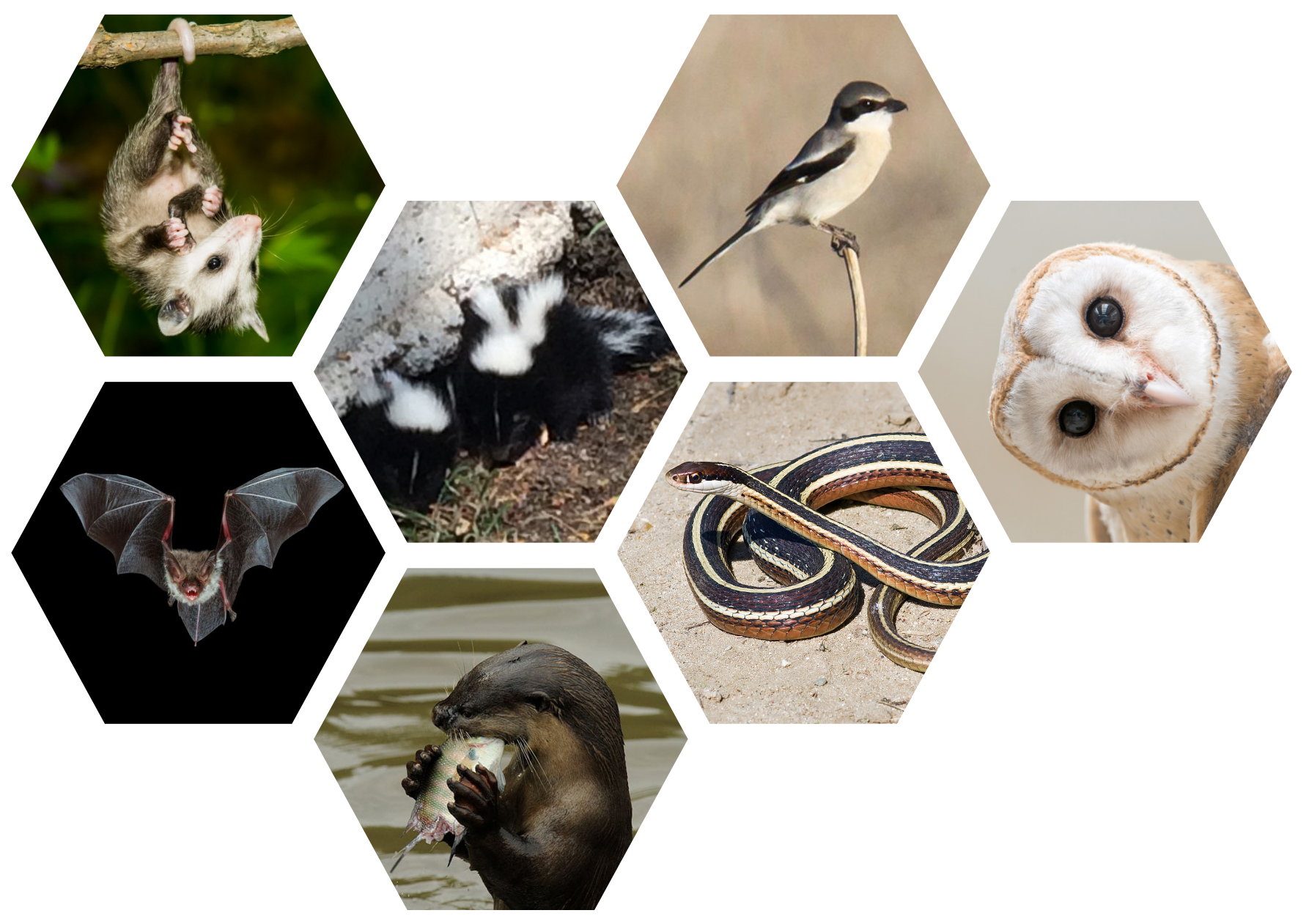

Fig 6-1. Biological Subjects. 


\section{Chapter 6}

\section{Biological Subjects}

6.1

6.2

6.2.1

6.2 .2

6.2 .3

6.2 .4

6.2 .5
Ecological Dynamics 113

Animal Compendium 117

Loggerhead Shrike

119

Barn Owl

123

Little Brown Bat

127

Common Raccoon

Striped Skunk
131

135 


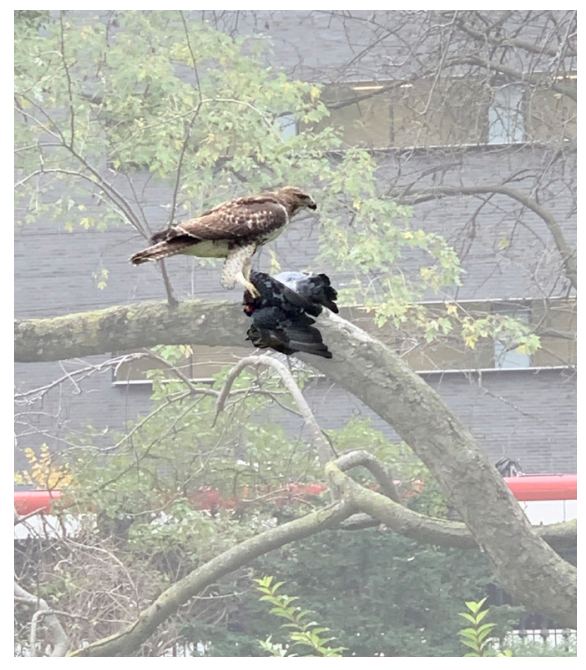

Fig 6-2. Falcon at Osgoode Hall on Queen Street, Toronto.

\section{1}

\section{Ecological Dynamics}

Pursuing design work that constitutes a variety of biological subjects in addition to humans requires a consideration of ecological dynamics. Humans and non-humans are largely governed by similar environmental requirements (ie. the need for shelter, air to breathe, a livable temperature range, a source of nourishment, etc.). In addition to biophysical factors, human activity is also largely dictated by cultural influences. Regulations, by-laws, societal norms, signage, property delineations, architectural typologies - these are all cultural constructs that communicate information on how to behave in certain environments. Anthropic environments depend on their sentient biological subjects complying with the rules of behaviour according to the cultural ideas affiliated with those particular spaces. Animals, however, instinctively disregard these ideas as they are entirely unaware of them. The design of synanthropic architecture needs to consider the parameters defined by the behavioural characteristics of animals and the ecological dynamics that govern them.

\section{Symbiotic Relationships}

An important consideration with respect to designing for multiple biological subjects are the various types of relationships that exist outside of inter-human relations. Human societies have developed cultural norms, government-enforced laws, rules, and expectations within a societal structure. Various behaviours are compartmentalized into prescribed spaces and may be ill-received in others; there is a time and a place for everything. Not subjected to [human] cultural controls, wild animals behave independently 
of them; their survival at times necessitates engaging in violent and displeasing behaviours wherein they subdue their prey. The integration of synanthropes into the human environment requires an acceptance of the range of symbiotic interactions that various species have with each other. These natural relationships serve as critical connections within their respective ecosystems and it should be noted that humans should refrain from interfering with them. Certain animals prey on others and although it may be an emotionally difficult experience for humans to witness, it is an integral component of ecological dynamics.

\section{Species A}

\section{Species B}

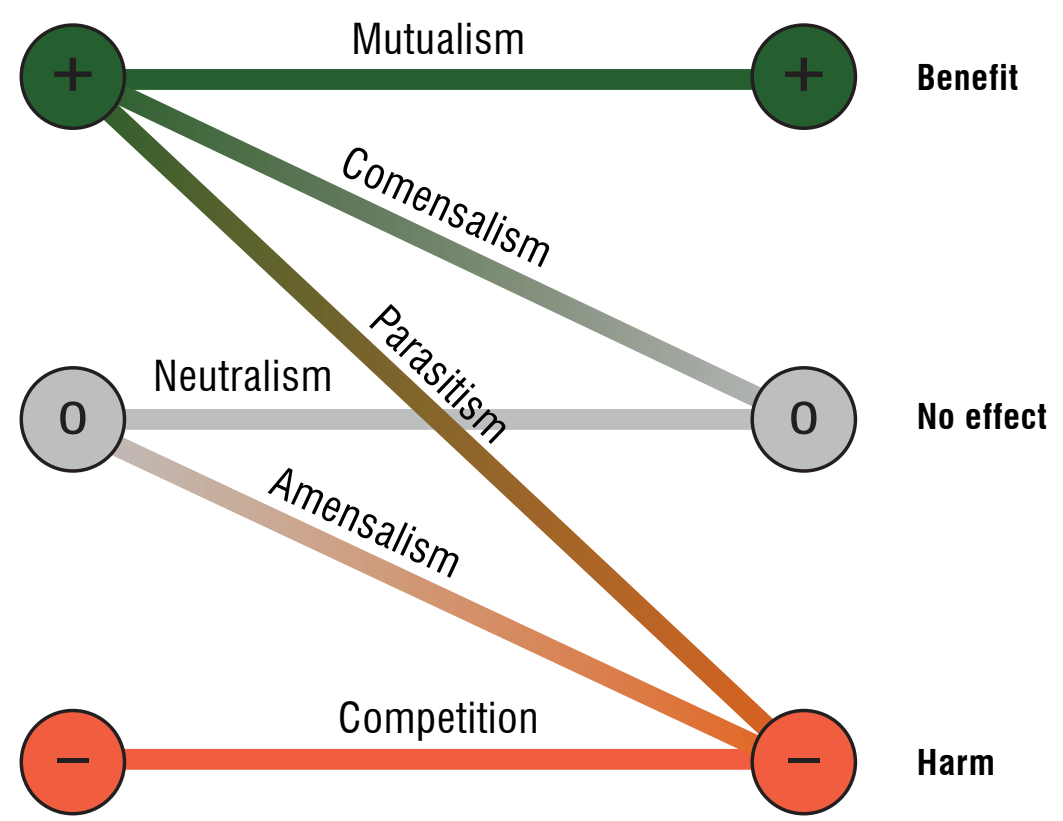

Fig 6-3. Symbiotic Relationships. There are six types of symbiotic relationships between species: mutualism, commensalism, neutralism, amensalism, competition, and parasitism. These relationships are defined by the type of outcome that is bestowed upon each of the species engaged in this relationship be it a benefit, harm (sometimes death), or no effect. 


\section{Trophic Levels}

Pursuing architecture as an ecological enterprise requires an understanding of the biological and chemical dynamics of an interconnected ecosystem. First and foremost, the predation and consumption of one animal by another is a necessary process within this framework. This seemingly violent event is a requisite aspect of ecology that would need to be addressed, or at the very least accepted, within the development of an integrated architecture. The connectivity of animal species, through this process of consumption, can be structured into a hierarchy of trophic levels:

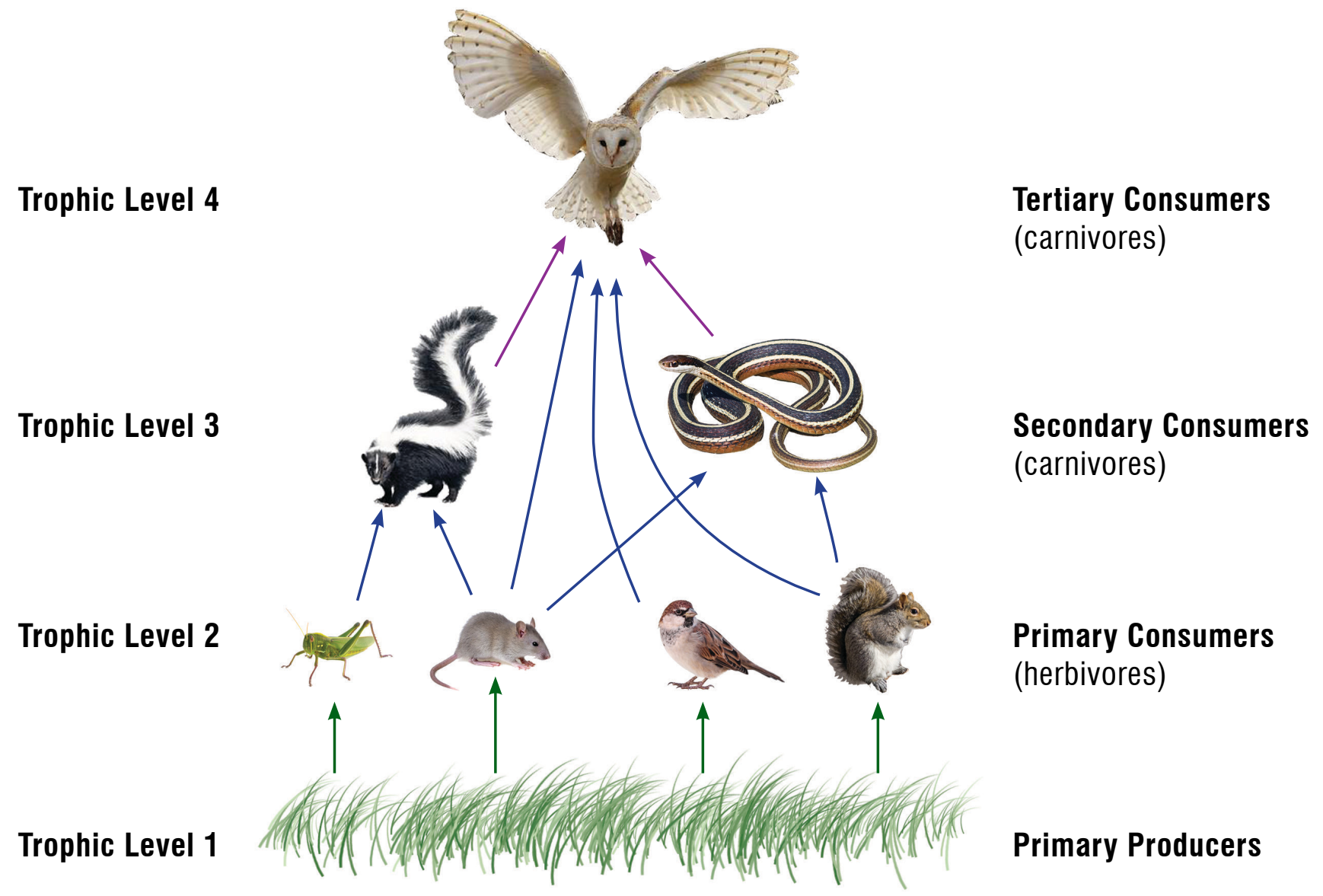

Fig 6-4. Trophic Levels of a Food Web. 
Producers (or primary producers) are species of plants and algae that use photosynthesis to synthesize sugar molecules within which to store energy derived from sunlight. These molecules are used by producers to energize their biological functions (other animals can also harness this energy by consuming the producers). These species are also referred to as primary producers, since they are situated effectively at the start of the energy cascade within the food web pyramid. Producers occupy the first trophic level, or the base, of this pyramid.

Consumers are animals that are unable to produce their own energy and need to consume other animals or plants to acquire sustenance. Primary consumers are animals that absorb energy from eating plants and are therefore known as herbivores. Secondary consumers eat the primary consumers; thus, they are carnivores. Tertiary consumers and beyond are animals that are similarly situated further up the food chain and make up the upper tiers of the pyramid. The efficiency of energy transfer from one tier to the next is approximately $10 \% .{ }^{1}$ Consequently, animals of a higher trophic level are fewer in number than those closer to the base.

Decomposers are various species that break down organic waste and dead matter into chemical components that can be reutilized by other organisms.

1 "Energy Flow and Primary Productivity," Khan Academy, n.d., accessed February 8, 2020, https://www.khanacademy.org/science/high-school-biology/hs-ecology/trophiclevels/a/energy-flow-and-primary-productivity.

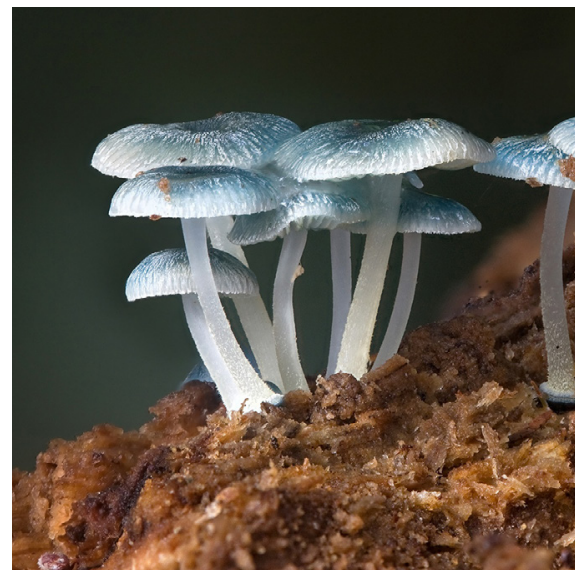

Fig 6-5. Fungi serve as decomposers in an ecosystem. 


\section{2}

\section{Animal Compendium}

Having unpacked the regional site context in chapter 5, this compendium elaborates on a select number of resident species to ascertain parameters that would direct the design process. While various species of mammals, reptiles, and birds have been explored, the thesis work hones in on five specific animals:

- Loggerhead Shrike

- Barn Owl

- Little Brown Bat

- Raccoon

- Striped Skunk

These selected animals are meant to serve as broader representatives of other creatures with similar characteristics. The three broad categories of biological subjects are flyers, climbers, and diggers (or crawlers). The remainder of this chapter will examine these specific animals in greater detail, discussing their unique characteristics, behaviours, diet, geographical range, habitat requirements, ecological status, and relationship with humans. This particular selection consists of animals that, each in their own way, have a unique relationship with man-made environments. More than other creatures, these animals have found ways to interact with the contemporary constructed landscape. However, even with their relatively successful adaptation, they still face tremendous challenges and some are even endangered. Examining these species can be an initial step in understanding how some animals interface with the urban fabric, and seeing what lessons can be derived from this process. The body of research and analysis developed in this section will form part of the foundation for the design proposal in the third and final part of the thesis. 


\section{FLYERS}
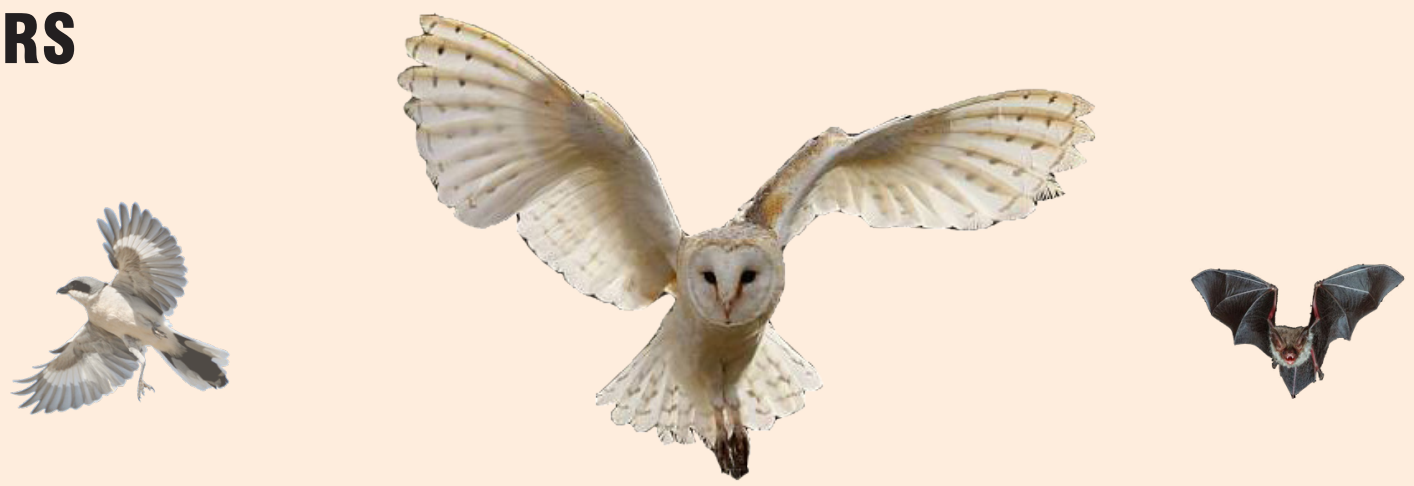

\section{CLIMBERS}

\section{DIGGERS / CRAWLERS}
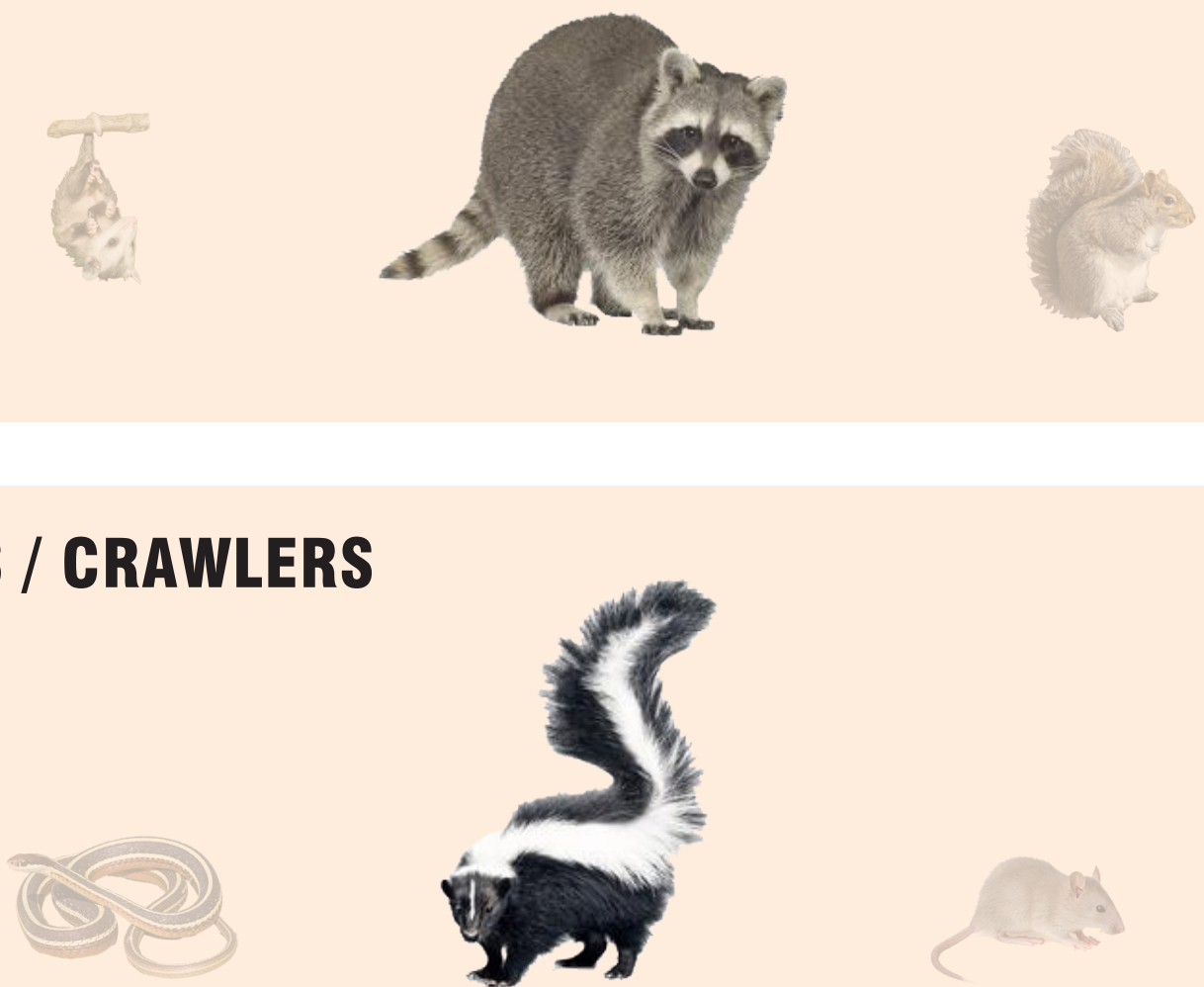

Fig 6-6. Categories of Synanthropes. 


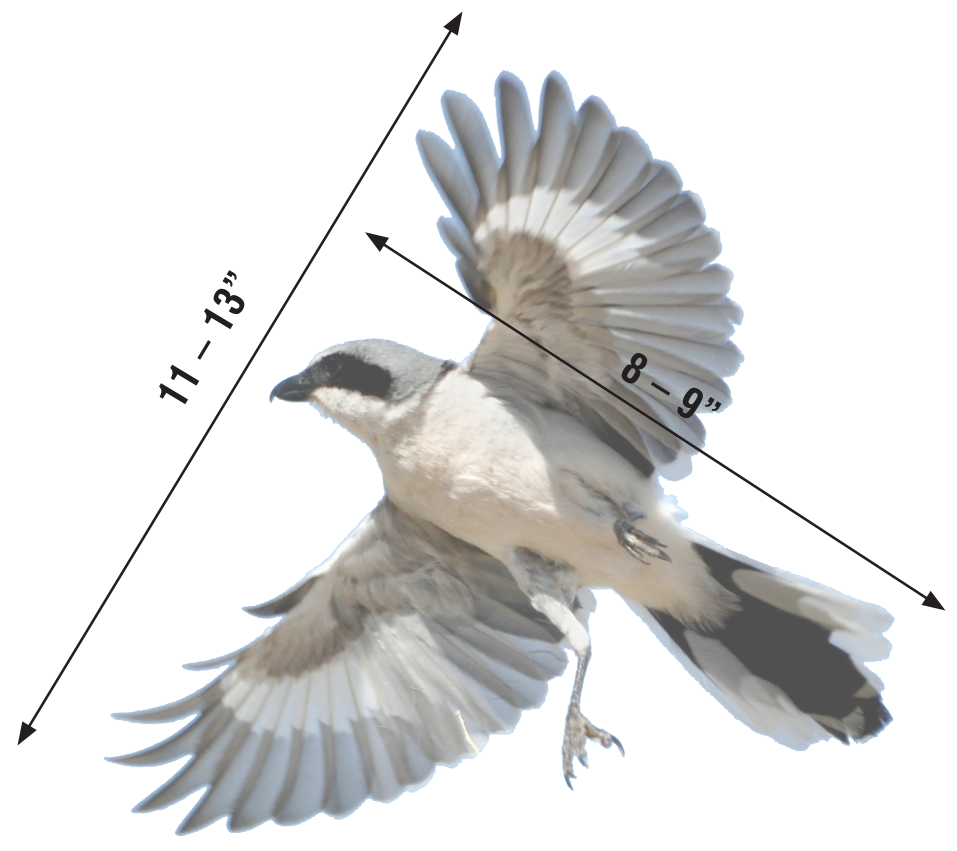

Lanius ludovicianus

Fig 6-7. Loggerhead Shrike. 


\subsubsection{Loggerhead Shrike}

The Loggerhead Shrike is a robin-sized bird that has been chosen to serve as a representative of other species given the many issues that birds face in the urban environment. This particular songbird, however, also has unique characteristics that sets it apart. Its diet consists not only of insects but of rodents, lizards, snakes, and other birds as well. ${ }^{2}$ Unlike larger raptors, the Loggerhead Shrike lacks powerful talons or an overpowering body mass to subdue its prey. Instead, it employs a more creative strategy - piercing its victims onto sharp thorns or barbed wire. Its diet even consists of some poisonous insects, like the lubber grasshopper. ${ }^{3}$ This intelligent bird leaves these toxic insects to dry for days, allowing the poison to break down until the meaty grasshopper is safe to consume. The Loggerhead Shrike tends to build up a private collection of killed prey from which to feast on - a grisly display of its vanquished trophies. Its pattern of behaviour has conferred upon this innocent-looking songbird a fitting name in Latin - Lanius, meaing "butcher."

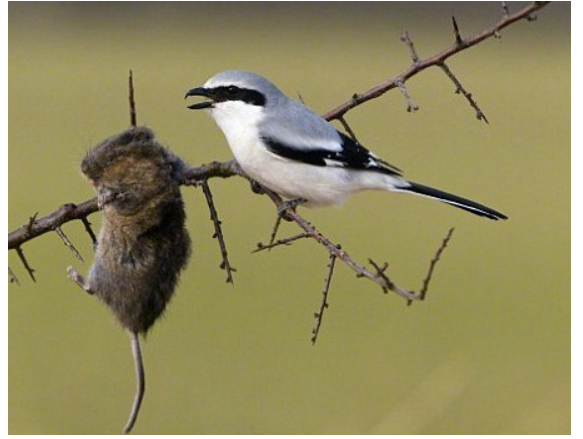

Fig 6-8. Loggerhead Shrike spearing its prey onto sharp thorns.

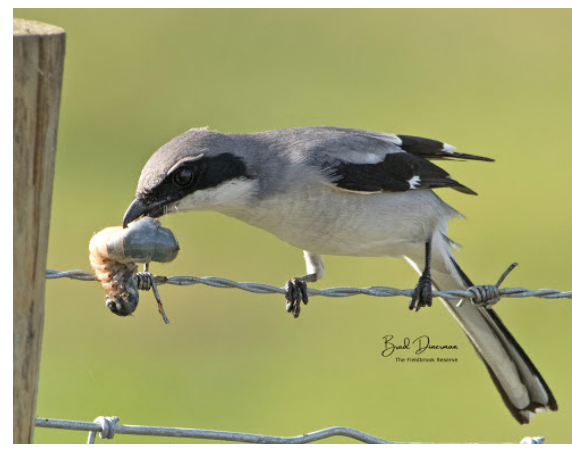

Fig 6-9. Loggerhead Shrike impaling its prey on barbed wire.

2 “Loggerhead Shrike," All About Birds, last modified 2019, accessed December 15, 2019, https://www.allaboutbirds.org/guide/Loggerhead_Shrike/id.

3 "Butchering Bird," National Geographic, last modified October 8 2013, accessed December 15, 2019, https://www.youtube.com/watch?v=okQYO10MT3c.

4 Ibid. 


\section{Habitat}

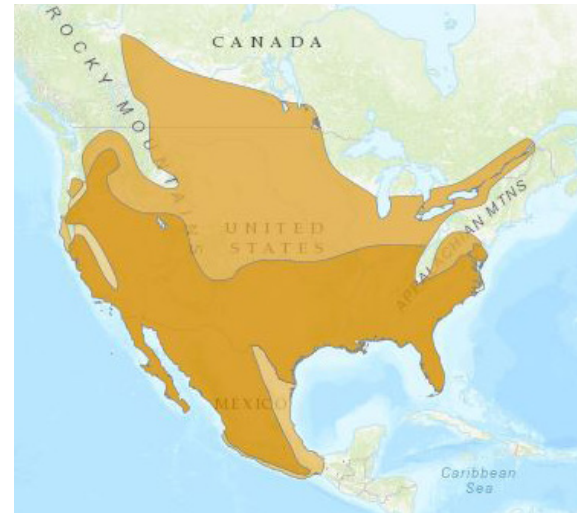

Fig 6-10. Geographic Range of the Loggerhead Shrike.

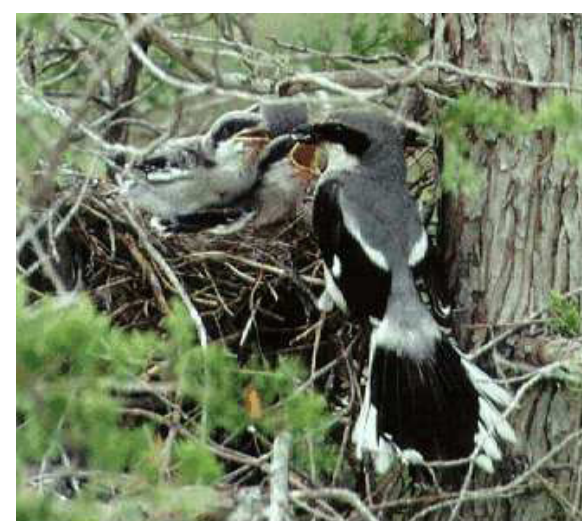

Fig 6-11. Nest of a Loggerhead Shrike.
The Loggerhead Shrike has a preference for grasslands and open fields with shrubs and low trees where it can seek out its prey. ${ }^{5}$ Its habitat range includes southern Ontario and other parts of northeastern North America. However, the species is declining in the province. A 1992 survey found 52 breeding pairs in Ontario; in 2009 , there were only 31 confirmed pairs. ${ }^{6}$

Loggerhead Shrikes construct their nests at a height range of 2.5-4 feet. ${ }^{7}$ The nest is a well-insulated construction of structural twigs and soft materials such as flowers, grass, feathers, and string. Roughly 6" in diameter and 3" deep, the nest contains about 5-6 eggs. Their incubation period is $15-17$ days, followed by a nesting period of 16-20 days.
5 "Loggerhead Shrike," The Ministry of Environment, Conservation and Parks, last modified May 8, 2019, accessed December 15, 2019, https://www.ontario.ca/page/ loggerhead-shrike.

6 Ibid.

7 "Loggerhead Shrike - Life History," All About Birds, n.d. accessed March 3, 2020, https://www.allaboutbirds.org/guide/Loggerhead_Shrike/lifehistory. 


\section{Status: Endangered ${ }^{8}$}

Human activity poses a great threat to birds like the Loggerhead Shrike. As outlined in Chapter 2, collisions with buildings is a major contributor to the decline of bird populations. The Loggerhead Shrike further suffers from habitat loss as suitable grasslands have been degraded. ${ }^{9}$ As the shrike tends to perch on fences and low cables, vehicle collisions are another threat to this bird. ${ }^{10}$

Due to diminishing habitat, bird houses can serve as an adequate strategy to allow the shrike and other birds to find nesting opportunities. Additionally, bird-friendly building design strategies that follow appropriate guidelines, as discussed in section 2.1.4 could also help mitigate the threats that the urban fabric poses to birds.

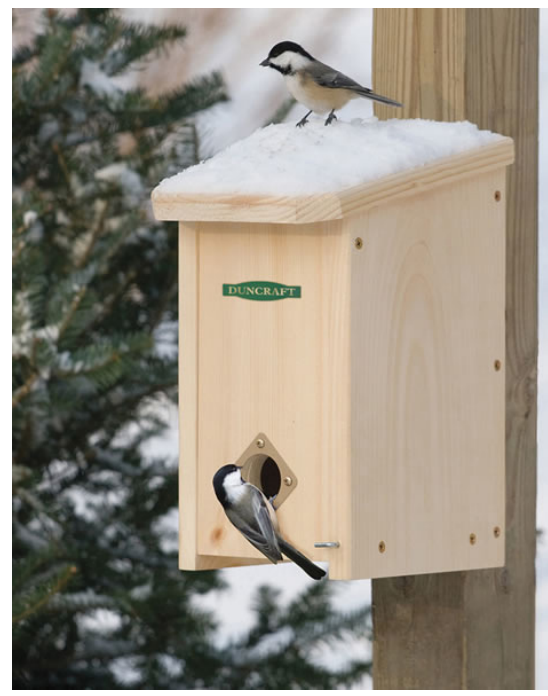

Fig 6-12. Bird-house of a Loggerhead Shrike.

8 “Endangered Species Reserve Fund," Toronto Zoo, n.d., accessed January 4, 2020, http://www.torontozoo.com/tz/reserve.

9 "Eastern Loggerhead Shrike Captive Breeding," Toronto Zoo, n.d., accessed January 5, 2020, http://www.torontozoo.com/tz/els.

10 Ibid. 


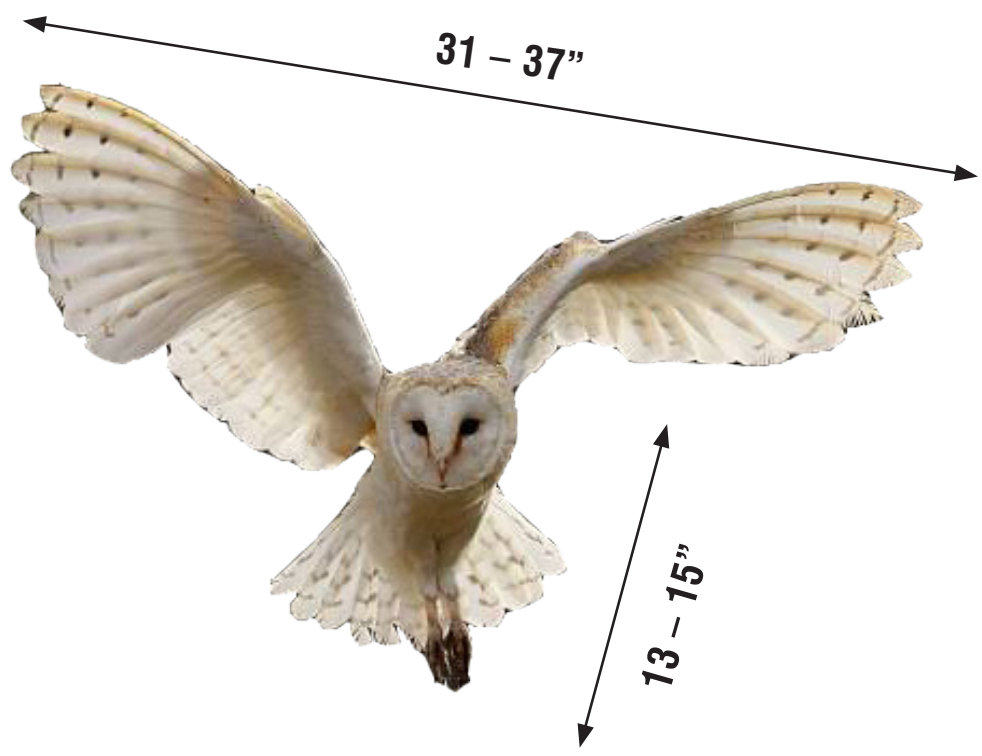

\section{Tyto alba}

Fig 6-13. Barn Owl. 


\subsubsection{Barn Owl}

Beautiful, majestic, ominous, and mysterious; Barn Owls have a unique place in culture and have had a mixed relationship with humans throughout history. Their nightly screeches, ghostly appearance, and the habit of roosting in church steeples and bell towers has led to certain sinister connotations with the Barn Owl - causing fear and misunderstanding. While some have driven them away out of a misplaced sense of peril, others have recognized their value and their usefulness in controlling rodent and insect populations.

The Barn Owl is one of eighteen owl species in North America, ${ }^{11}$ and are more nocturnal than any other owl species. While their territories can overlap with those of hawks and eagles, there is little if any conflict between them since unlike the other raptors, the owls are mostly active at night. ${ }^{12}$ Barn Owls can also overlap as much $100 \%$ of each other's territories without conflict, and may even share the spoils of the hunt. Preying on rodents, small mammals, as well as some birds and insects, the Barn Owl may fly between 10-15 miles in a night to hunt. ${ }^{13}$ The feathers on the front edge of its wings are softer, silencing its flight and allowing the owl to catch its prey by surprise. Unlike other raptors, the owls' eyes are in the front of their heads, allowing binocular vision, even at close range. ${ }^{14}$ Their impeccable sight is about 100 times more sensitive than that of humans. ${ }^{15}$ Their eyes, however, are fixed; in order to look around, their head can swivel within a $270^{\circ}$ range of motion. ${ }^{16}$ This simple turn of the head is one of the owl's strangely fascinating and unique characteristics

\footnotetext{
11 Diana Landau and Shelley Stump, Living with Wildlife: How to Enjoy, Cope with, and Protect North America's Wild Creatures Around Your Home and Theirs (San Francisco: Sierra Club Books, 1994) 191.

12 Ibid, 191.

13 Ibid, 194

14 Ibid, 192.

15 Ibid, 192

16 Ibid, 192.
}

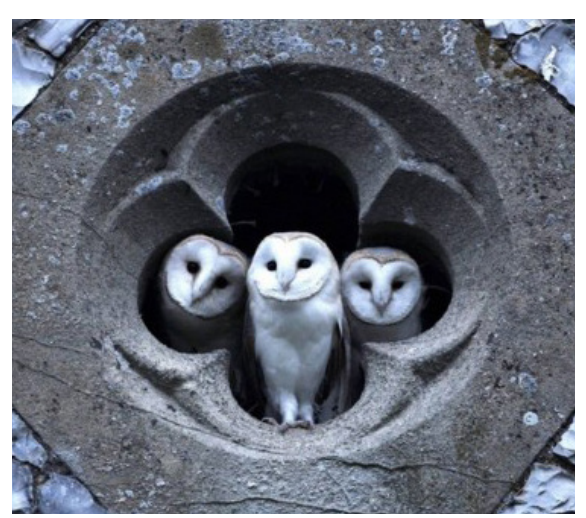

Fig 6-14. Barn Owls roosting in a church. 


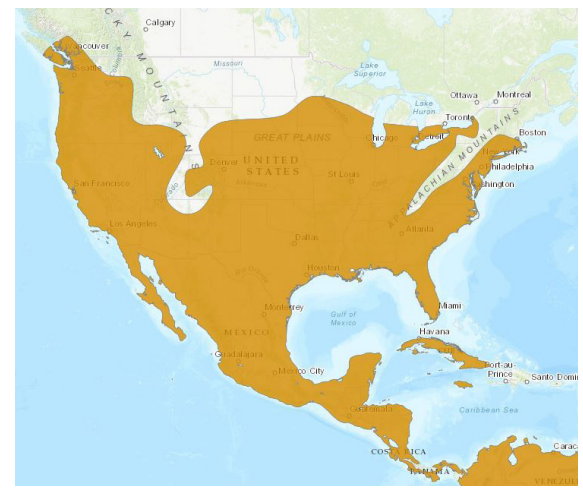

Fig 6-15. Barn Owl Range.

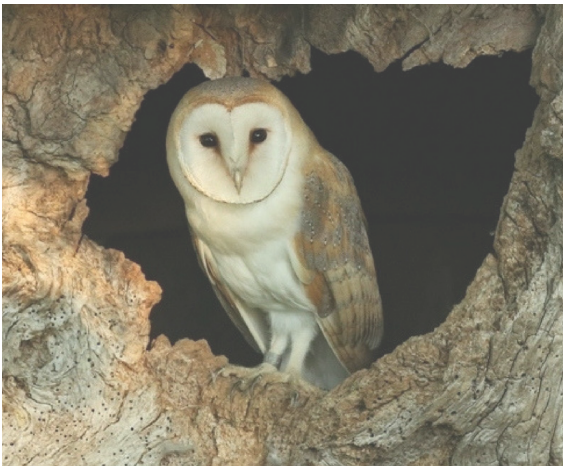

Fig 6-16. Barn Owl Nest. that distinguishes this animal from other birds. While their eyesight is extraordinary, owls rely highly on their exquisite hearing ability to locate their prey. Having the largest eardrum of any bird and feathers on the head that can move and channel sound, owls are able to sense the most minute air vibrations. ${ }^{17}$ These characteristics allow the Barn Owl to detect its prey and capture it in total darkness - executing a swift, decisive, and silent kill.

\section{Habitat}

Barn Owls prefer to forage in relatively open conditions found in fields, pastures, orchards, farmland, streams, and at the margins of roads. They tend to have multiple sites where they would rest throughout the night while they hunt. In terms of roosting and nesting, they prefer warm, dry, and dark conditions. These include caves and hollow trees, as well as man-made structures such as barn lofts, abandoned houses, dry wells, bridge structures, and nest boxes. ${ }^{18}$ Since they do not tolerate colder climates, the territory of Barn Owls doesn't extend past the southern region of Ontario. ${ }^{19}$

\section{Status: Endangered}

Today, there are fewer than five pairs of Barn Owls in Ontario. ${ }^{20}$ Grasslands where owls can forage have diminished due to urbanization. With a declining habitat, there is also a decline in the population of prey. Nesting sites are also scarcer as traditional farm buildings have been replaced by "bird-proof" designs. ${ }^{21}$ Finally, many owl species are endangered by collisions along roadways during nighttime flights, which cause thousands of owl deaths every year. ${ }^{22}$

17 Ibid, 192.

18 "Barn Owl” National Audubon Society, n.d., accessed April 12, 2020, https://www. audubon.org/field-guide/bird/barn-owl.

19 "Barn Owl," The Ministry of Environment, Conservation and Parks, last modified May 8, 2019, accessed January 5, 2020, https://www.ontario.ca/page/barn-owl.

20 Ibid.

21 Ibid.

22 Landau and Stump, Living with Wildlife, (San Francisco: Sierra Club Books, 1994) 195. 


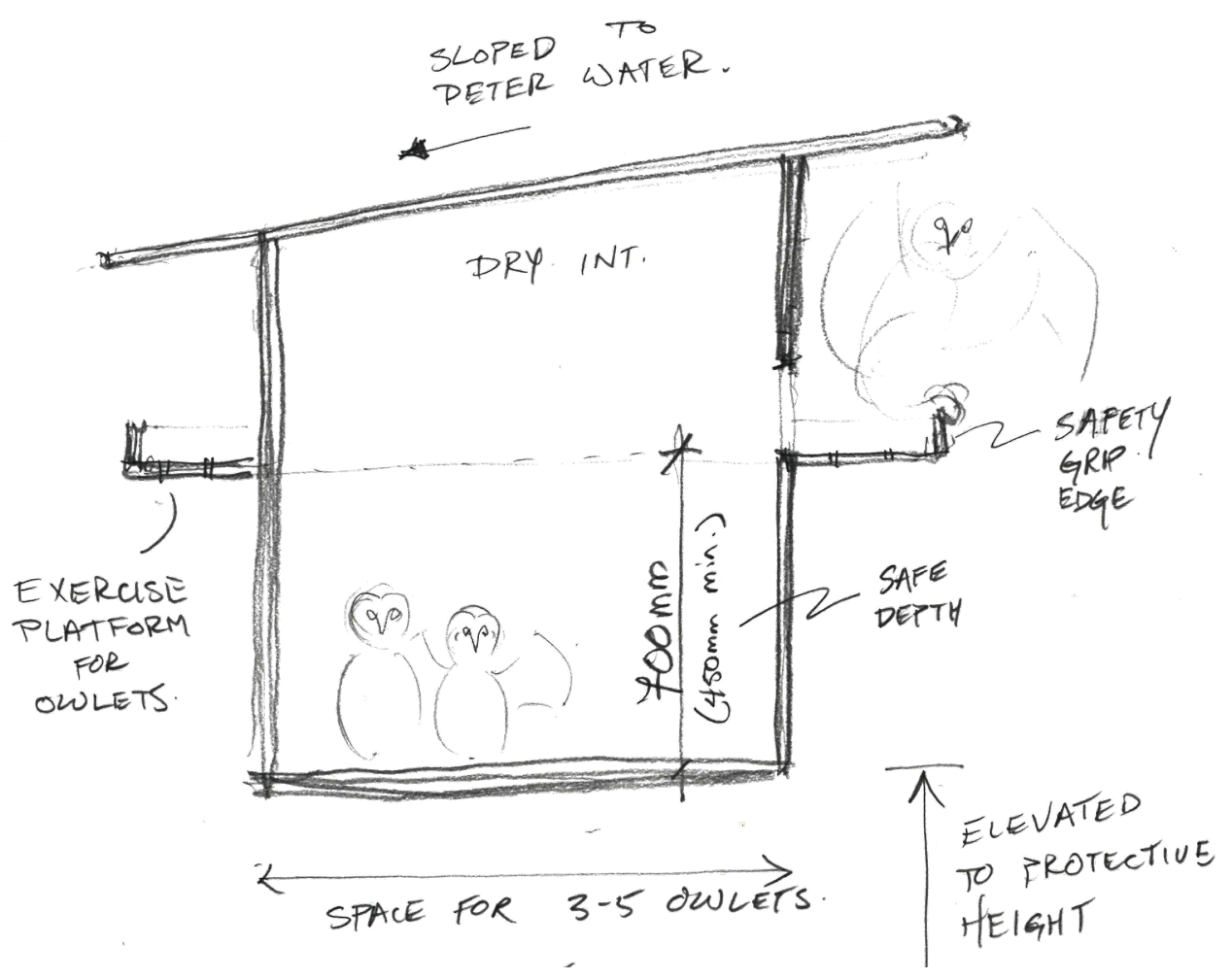

Fig 6-17. Nest Box Design.

\section{Nest Box Design}

A successful nest box has multiple design features that ensure the safety and comfort of a brood of owlets. The nest box needs to be fixed at an elevated height where owls can feel protected from potential predators. The interior needs to be dry, warm, and furnished with soft material such as dry leaves and feathers. ${ }^{23}$ At 18 days, owlets can begin to walk and they require enough space inside the box to move around and practice flapping their wings. While they're developing, they'll be able to jump up to small heights with the aid of their wings, but won't be able to fly until they're 56 days old. For this reason, the opening of the box should be about $450-700 \mathrm{~mm}$ above its base. ${ }^{24}$ At the foot of the opening, a wide exercise platform should be fixed; this allows owls to move around and not be pushed over by other owlets jumping up from behind. If they fall out, they might be neglected by their parents and starve. ${ }^{25}$

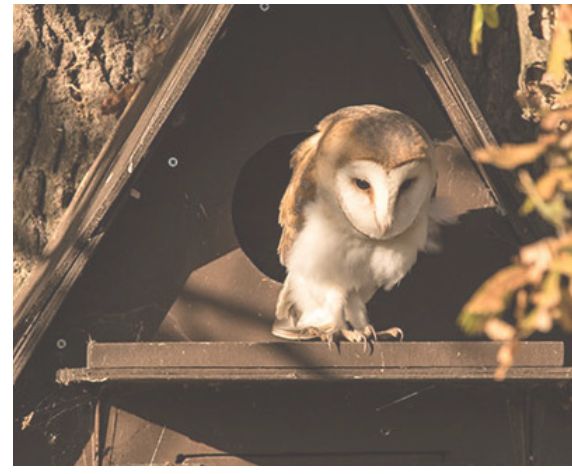

Fig 6-18. Nest Box.

23 "How to Choose the Best Barn Owl Nestbox Design," Youtube, last modified October 9, 2017, accessed June 15, 2019, https://www.youtube.com/watch?v=zr8qLyAFl_k.

24 Ibid.

25 Ibid. 


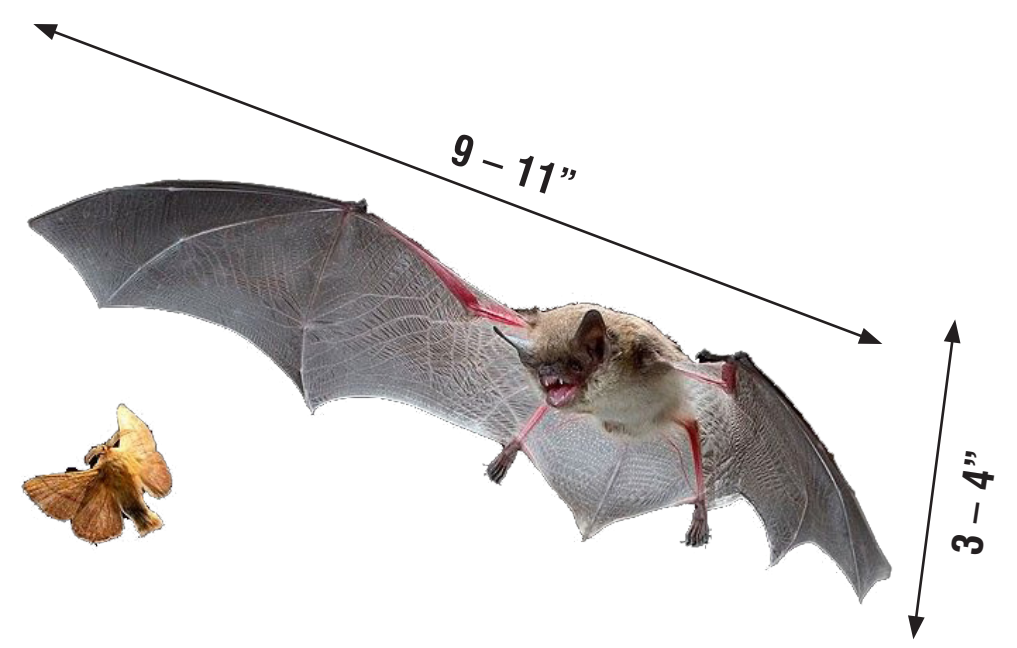

Myotis lucifugus

Fig 6-19. Little Brown Bat. 


\subsubsection{Little Brown Bat}

Dark, looming, chaotic, and menacing; for centuries, bats have been associated with cultural narratives potent with ideas of evil malice and frightful danger. These include Hallowe'en, blood-thirsty vampires, witches, and even Batman (a fear-provoking hero). ${ }^{26}$ Although there are many disconcerting notions about bats, there are also many misconceptions. While there are 1,000 different species of bats world-wide, only three are blood-eaters. ${ }^{27}$ The rest rely on a diet of insects, fruit, and other smaller animals. There is also a fear of contracting rabies. ${ }^{28}$ However, $99 \%$ of the deaths caused by this disease are attributed to dogs - roughly 30,000 deaths per year worldwide. Meanwhile, in the United States, there are only 0-2 annual deaths due to bats. ${ }^{29}$ Though they have suffered from some negative imagery, delving into their characteristics and understanding them further can potentially enhance the relationship between humans and these unique synanthropes.

Bats are grouped into two major suborders: Microchiroptera and Megachiroptera. The former are smaller bats with small eyes and complex ears (about 700 species), and the latter are larger bats with larger eyes and ears that lack echolocation capabilities (about 150 species). ${ }^{30}$ They are the only mammals capable of true flight. The lack of feathers make them less efficient flyers than birds, however, their anatomical differences account for their atypical flight patterns and their distinct manoeuverability at close range. ${ }^{31}$ Hunting and eating about 1,000 insects in one hour, their diet consists of a rich variety of bugs including moths, beetles, mayflies, and mosquitos. ${ }^{32}$

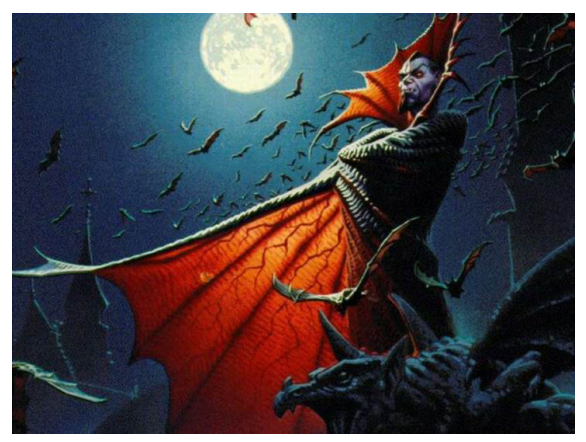

Fig 6-20. Vampire Lord, Count Duncan Von Trisk.

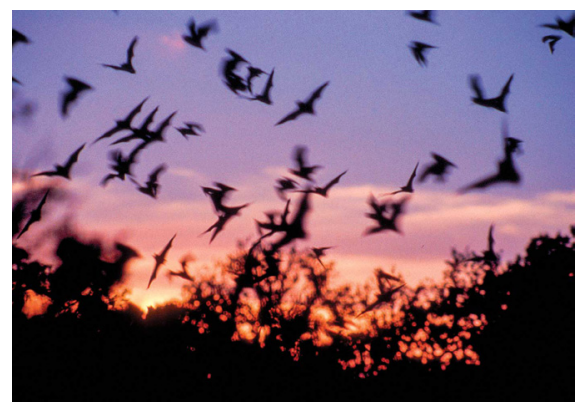

Fig 6-21. Bats in flight at dusk.

\footnotetext{
26 M. Brock Fenton, Just Bats, (Toronto: University of Toronto Press, 1983), 3.

27 Ibid, 149.

28 "Rabies Info," Bat World Sanctuary, last modified 2012, accessed February 16, 2019, https://batworld.org/rabies-info/.

29 Ibid.

30 Fenton, Just Bats, (Toronto: University of Toronto Press, 1983), 7.

31 Ibid, 18.

32 "Little Brown Bat," Canadian Wildlife Federation, n.d., accessed March 12, 2019, https://cwf-fcf.org/en/resources/encyclopedias/fauna/mammals/little-brown-bat.html.
} 


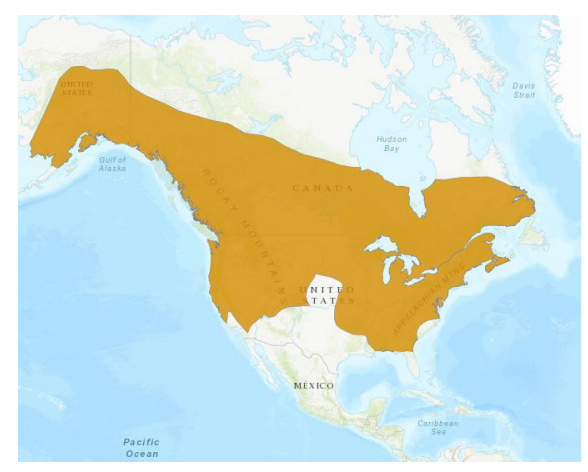

Fig 6-22. Little Brown Bat Range.
Their insect population control contributions have been estimated in the billions of dollars. In order to hunt buzzing insects at night, bats use their extraordinary echolocation capabilities. After emitting high-frequency squeaks, they're able to hear the returning sounds from objects within a few inches of them by sensing the time delays of a thousandth of a second. ${ }^{33}$ The entire process - from detection, pursuit, to capture - lasts about one second. ${ }^{34}$ Contrary to popular belief, bats are not blind. Though their hunting relies primarily on echolocation, their eyesight is quite good and they rely on it for recognizing landmarks at long distances during migration.

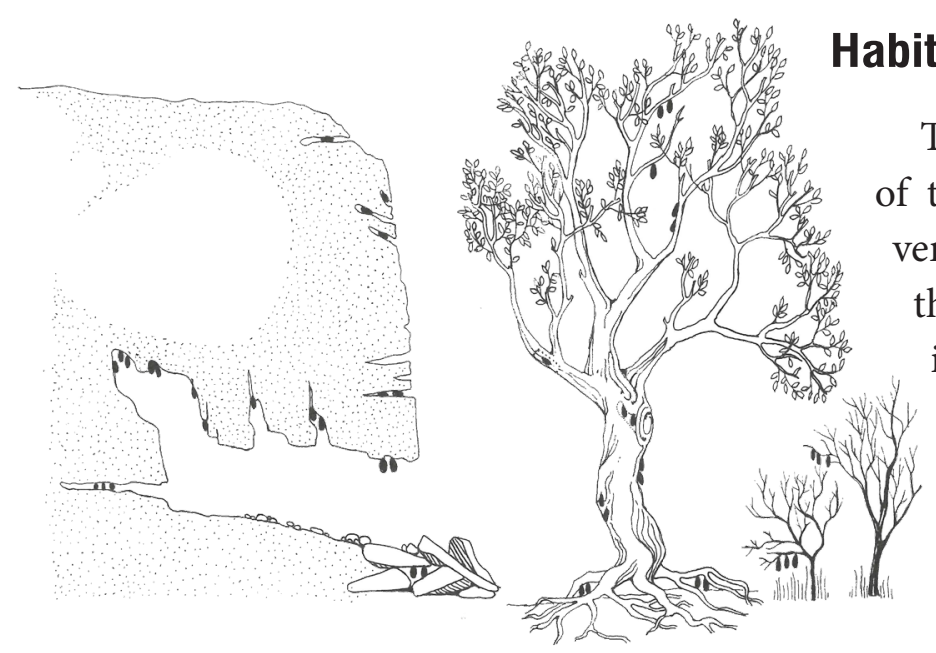

The Little Brown Bat is the most common species out of the 19 found in Canada, and it is the most likely to venture into man-made environments. ${ }^{35}$ Squeezing into the safety of tight crevices and niches, bats find security in the hollow spaces of trees, caves, and various locations within buildings. They roost within two miles of a body of water where they are more likely to find abundant prey. In towns, they may hunt around lamps and other light sources that attract various insects at night. ${ }^{36}$ The Little Brown Bat is also the only migratory species in the region, leaving Canada during the winter when

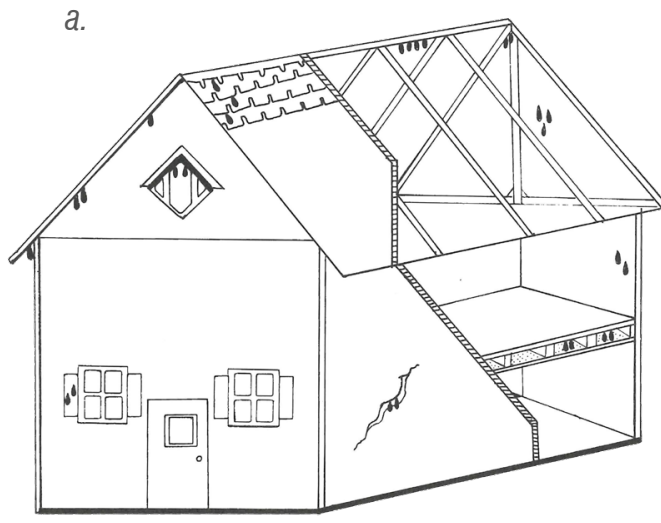

$b$.

Fig 6-23. Roosting locations in natural and built environments. insects are not scarce. During this season, they hibernate in secluded caves or other places referred to as hibernacula. Lowering their body temperatures to below freezing and slowing their heart rate tenfold, they rely on their fat stores to see them through this period. ${ }^{37}$ Disturbing bats during this time can be fatal since they require nearly 20-30 days-worth of food to recalibrate their physiology into a post-hibernation state. ${ }^{38}$

33 Landau and Stump, Living with Wildlife, (San Francisco: Sierra Club Books, 1994) 91.

34 Ibid.

35 "Little Brown Bat," Canadian Wildlife Federation, n.d., accessed March 12, 2019, https://cwf-fcf.org/en/resources/encyclopedias/fauna/mammals/little-brown-bat.html.

36 Landau and Stump, Living with Wildlife, (San Francisco: Sierra Club Books, 1994) 91.

37 “Little Brown Bat," Canadian Wildlife Federation, n.d., accessed March 12, 2019, https://cwf-fcf.org/en/resources/encyclopedias/fauna/mammals/little-brown-bat.html.

38 Landau and Stump, Living with Wildlife, (San Francisco: Sierra Club Books, 1994) 92. 


\section{Status \& Threats}

The Little Brown Bat is considered endangered in Canada and in Ontario. Its predators consist of raccoons, hawks, owls, snakes, and others. Wind turbines also contribute to a significant number of bat deaths per year - between 600,000 to a million bats in North America. ${ }^{39}$ However, the greatest problem that bats have been facing is white-nose syndrome - this is a bat-specific fungal disease that began in eastern Canada in 2010 and has continued to spread ever since. $^{40}$ By disrupting their sleeping patterns, reducing their fat stores, and phasing them out of hibernation too early, this disease has caused the death of $94 \%$ of bats throughout central and eastern Canada within three years of the outbreak. ${ }^{41}$ The disease is expected to spread to the rest of Canada's range by $2028 .{ }^{42}$

\section{Bat Roost}

A properly designed roost box can invite bats and promote various ecological benefits. The box requires an area where bats can land and cling to. The entrance to the roost should be about $3 / 4$ " wide, allowing bats to squeeze through but keeping out predators. ${ }^{43}$ The interior needs to be lined with a mesh or engraved with grooves for the bats to hold on to. A sloped roof and caulking-sealed edges prevent water from entering the box, ensuring a dry environment. While warmer air rises up into the box, a 1/4" ventilation gap keeps air flowing through the roost. ${ }^{44}$ These roosts should be located about 15 feet ( 5 metres) above the ground and face the south to absorb the warmth of the sun throughout the day while the bats sleep inside.

39 Rebecca Boyle, "Wind Turbines Kill More than 600,000 Bats a Year: What Should We Do?” Popular Science, last modified November 19, 2013, accessed February 12, 2019, https://www.popsci.com/blog-network/eek-squad/wind-turbines-kill-more-600000bats-year-what-should-we-do/.

40 WWF-Canada, "Living Planet Report Canada: A National Look at Wildlife Loss Summary," (Toronto: WWF-Canada, 2017), 4.

41 Ibid, 4.

42 Ibid, 4.

43 Rob Mies, "How to Build a Bat House," YouTube, last modified September 19, 2014, accessed August 12, 2019, https://www.youtube.com/watch?v=V8CheVXf7YY.

44 Ibid.

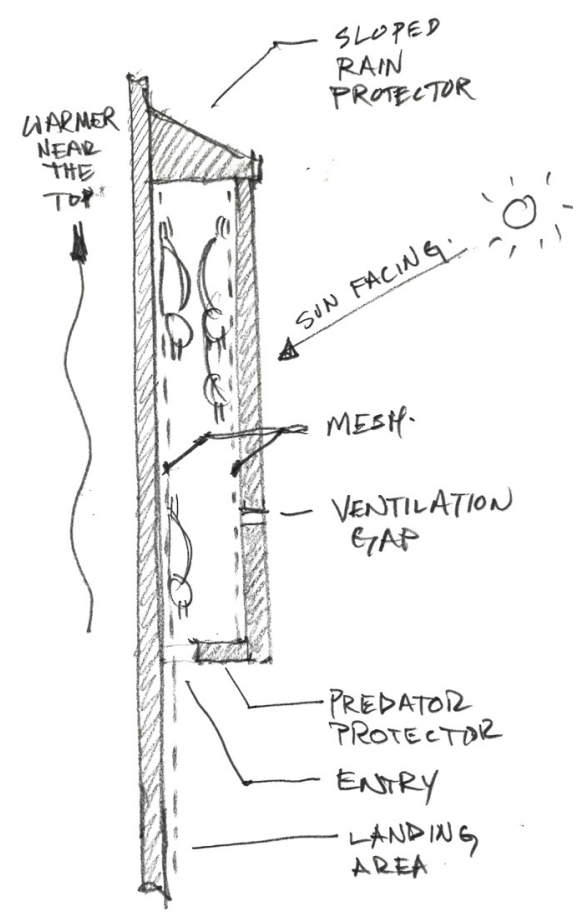

Fig 6-24. Bat Roost Requirements.

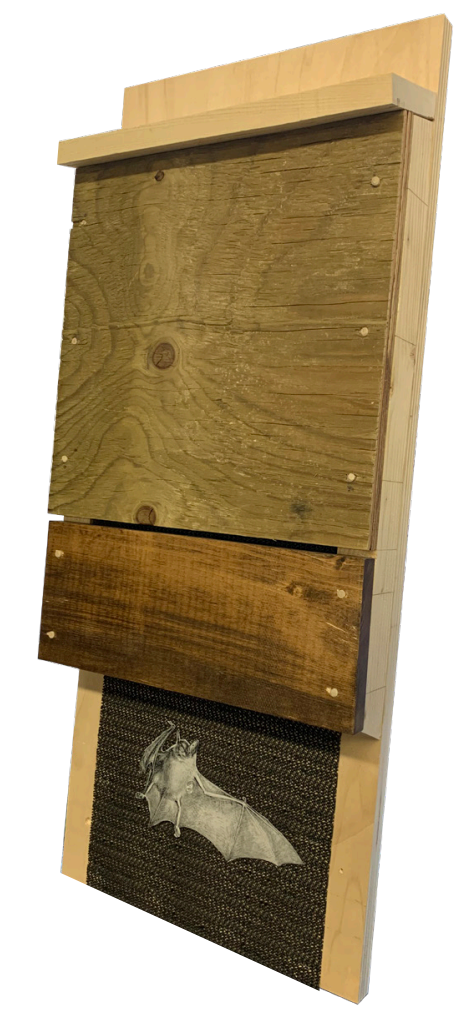

Fig 6-25. Bat Roost Prototype, 1:1 scale, built by Simon Gordon. 


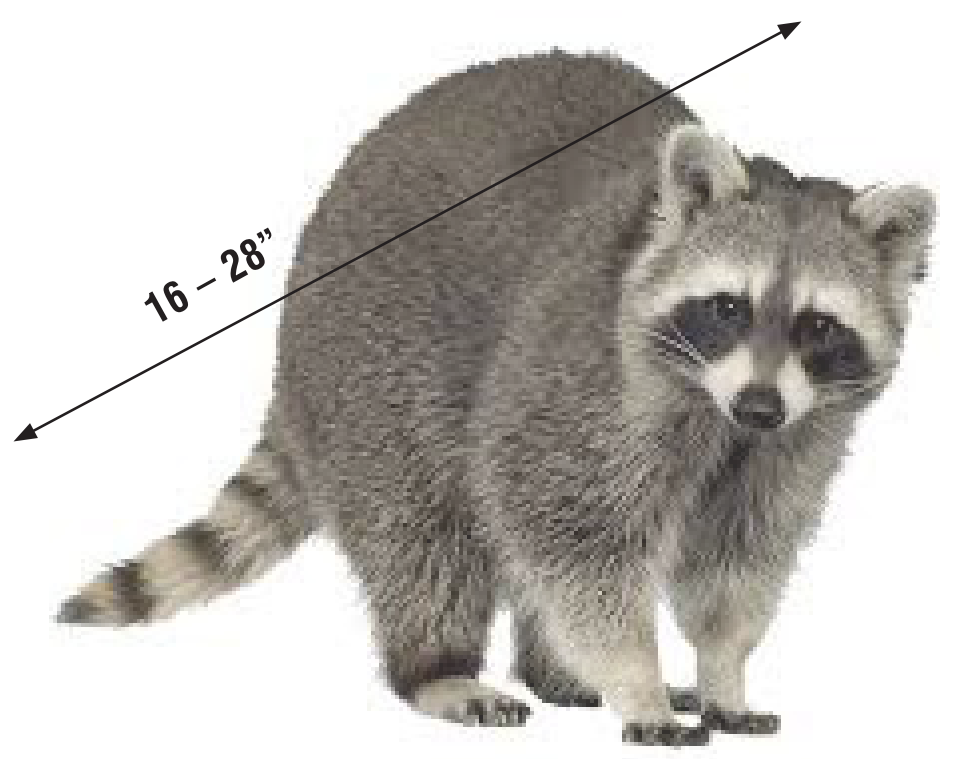

\section{Procyon lotor}

Fig 6-26. Common Raccoon. 


\subsubsection{Common Raccoon}

Cunning, skillful, opportunistic, and brave; the raccoon is one creature that appears to belong more in an urban environment than in the wild. Cultural narratives, such as the mural at Dundas Square, depict raccoons as urban hooligans. That being said, raccoons are indigenous to North America. Their name comes from the Algonquian word arahkunem, meaning "he scratches with the hands." ${ }^{45}$ Raccoons are highly agile, intelligent, and adaptable. After humans urbanized their native environments, the remaining raccoons managed to thrive in them. Psychologist Suzanne MacDonald of York University points out that they are neophilic rather than neophobic, meaning that they do not shy away from new and unknown developments; when objects and novel environments present themselves, raccoons demonstrate a motivation to explore and interact with them. ${ }^{46}$ Unlike other animals with more selective diets, raccoons are omnivores. In rural areas, their diet may consist of insects, nuts, worms, frogs, shellfish, fish, small mammals, birds, eggs, grubs, snakes, and fruits; in agricultural lands, the diet could include corn crops, poultry, and orchard vegetables; in cities, raccoons can find all the food they need in garbage bins and within households and restaurants - as long as they can figure out how to access them. ${ }^{47}$ After a litter is born, the kits remain with their mother for several months until they are ready to separate and mate at about one year of age. During this time, they are taught by their parent the skillsets required to manoeuver and interact with their environment. They have demonstrated an ability to learn from their mistakes and recall solutions to problems for up to three years. In Toronto, \$31 million was spent on proofing garbage bins against raccoons - a technological innovation which they ended up overcoming.

45 "Raccoon," Online Etymology Dictionary, n.d., accessed February 12, 2020, https:// www.etymonline.com/word/raccoon.

46 Adrian Cheung, Julia Whalen, and Victoria Valido, "Is Toronto the raccoon capital of Canada?" CBC News, last modified July 15, 2019, accessed November 7, 2019, https:/www. cbc.ca/news/canada/toronto/is-toronto-raccoon-capital-canada-1.5208580.

47 Landau and Stump, Living with Wildlife, (San Francisco: Sierra Club Books, 1994) 54-55. 


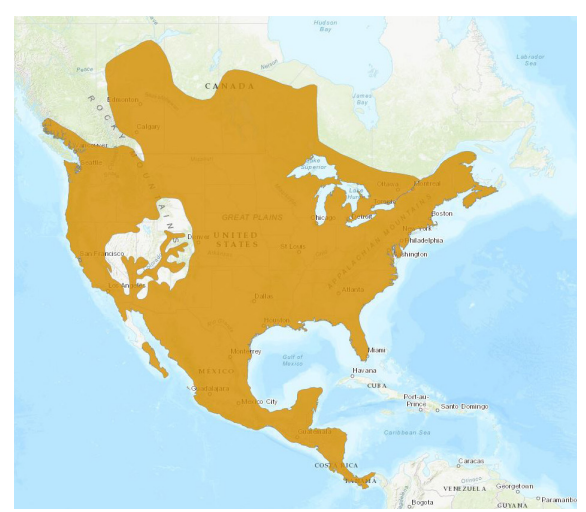

Fig 6-28. Raccoon Range.

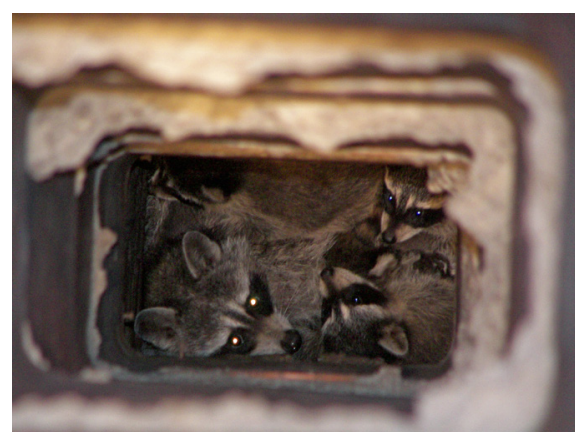

Fig 6-29. Raccoon denning in a chimney.

\section{Habitat}

Their native habitats include deciduous and mixed forests, however, raccoons prove to be adaptable to various ecosystems as long as they have access to food, water, and shelter. In rural areas, their territories could span about $50 \mathrm{~km}^{2}$; in urban areas, however, it would be about a tenth of single square kilometre. ${ }^{48} \mathrm{~A}$ study tracking the movement of raccoons in cities showed that they don't move more than $0.5-1.5$ miles in a night; they take their time to slowly forage through the city, finding sufficient food within this narrow range. Cities also have a much higher density of raccoons than rural areas - Toronto has about 100 individuals per square kilometre ${ }^{49}$ (other cities range between 30-200 individuals $/ \mathrm{km}^{2}$ ). ${ }^{50}$ While their territories can overlap, they seldom engage in conflicts that actually break out into fights. ${ }^{51}$ Within their territories, they usually establish multiple dens. An adequate place for nesting would ideally be warm, dry, dark, and reasonably protected. Such dens could include hollow trees, logs, rocky caverns, as well as drainpipes, basements, crawl spaces, chimneys, and attics. ${ }^{52}$

48 Tobi McIntyre, "Raccoon Fact File," Canadian Wildlife Federation, n.d., accessed February 12, 2020, https://cwf-fcf.org/en/resources/encyclopedias/fauna/mammals/ hinterland-whos-who-raccoon.html.

49 Adrian Cheung, Julia Whalen, and Victoria Valido,"Is Toronto the raccoon capital of Canada?" CBC News, last modified July 15, 2019, accessed November 7, 2019, https://www. cbc.ca/news/canada/toronto/is-toronto-raccoon-capital-canada-1.5208580.

50 Stanley Gehrt, Urban Carnivores: Ecology, Conflict, and Conservation, (Baltimore: The Johns Hopkins University Press, 2010), 37.

51 Adrian Cheung, Julia Whalen, and Victoria Valido, "Is Toronto the raccoon capital of Canada?” CBC News, last modified July 15, 2019, accessed November 7, 2019, https://www. cbc.ca/news/canada/toronto/is-toronto-raccoon-capital-canada-1.5208580.

52 Landau and Stump, Living with Wildlife, (San Francisco: Sierra Club Books, 1994) 54. 


\section{Status \& Threats}

Raccoons are considered to be a species of least concern by the IUCN Red List. ${ }^{53}$ Their natural predators in the wild include coyotes, pumas, bobcats, wolves, and great horned owls. ${ }^{54}$ Urban threats consist of dog packs, automobiles, and various traps. ${ }^{55}$ While raccoons are highly adept and seem to conform well to the urban environment, this artificial landscape was not designed for them. Some raccoons find themselves trapped by various objects, or fall from great heights after losing their grip on vertical walls. The tectonics of cities can be designed with more consideration for the many climbing creatures that make this landscape their home (as it had been long before it was transformed by humans).

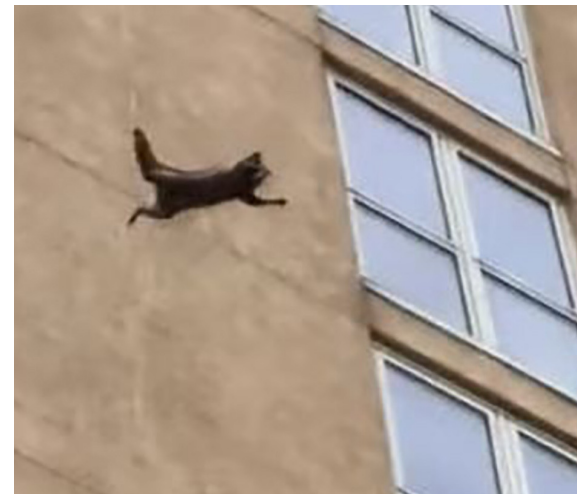

Fig 6-30. Raccoon falling after climbing nine storeys of a New Jersey apartment building.
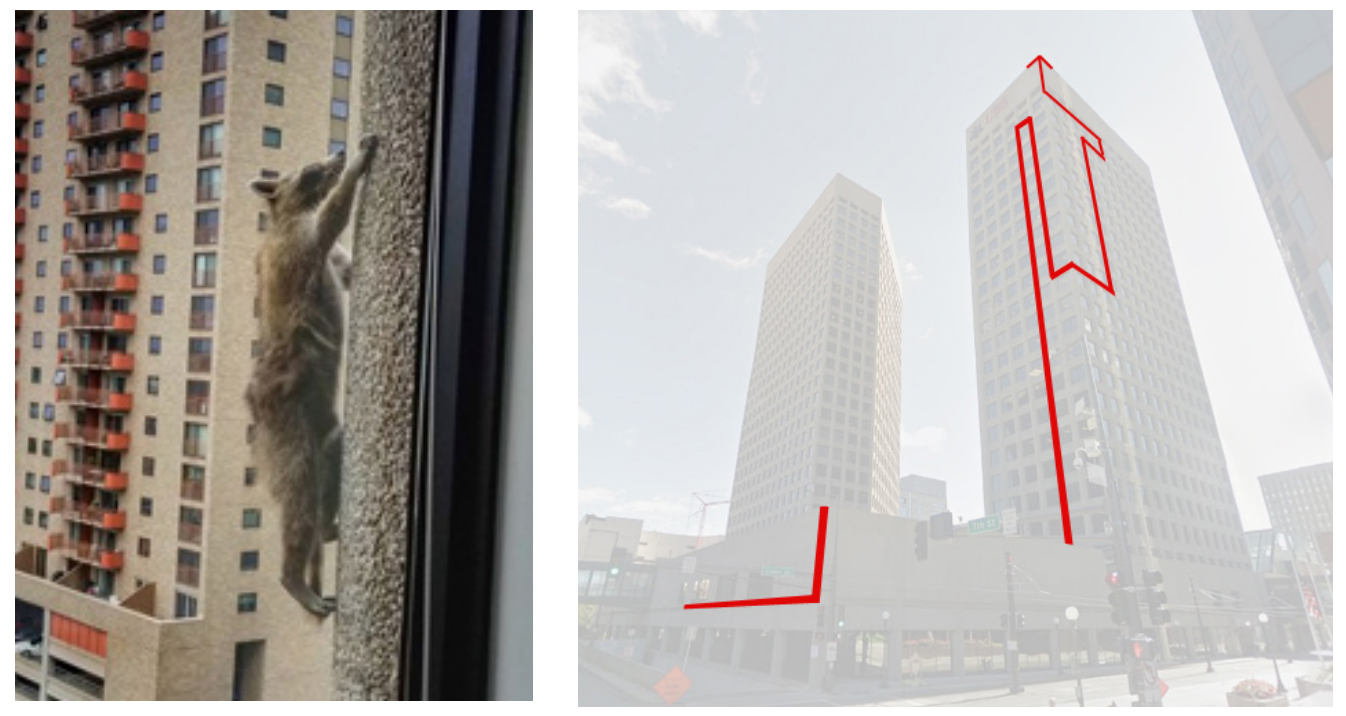

Fig 6-31. The path of a raccoon that climbed a highrise in St. Paul, Minnesota.

53 "Northern Raccoon," IUCN Red List, last modified March 1, 2015, accessed February 14, 2020, https://www.iucnredlist.org/species/41686/45216638.

54 Tobi McIntyre, "Raccoon Fact File," Canadian Wildlife Federation, n.d., accessed February 12, 2020, https://cwf-fcf.org/en/resources/encyclopedias/fauna/mammals/ hinterland-whos-who-raccoon.html.

55 Landau and Stump, Living with Wildlife, (San Francisco: Sierra Club Books, 1994) 55. 


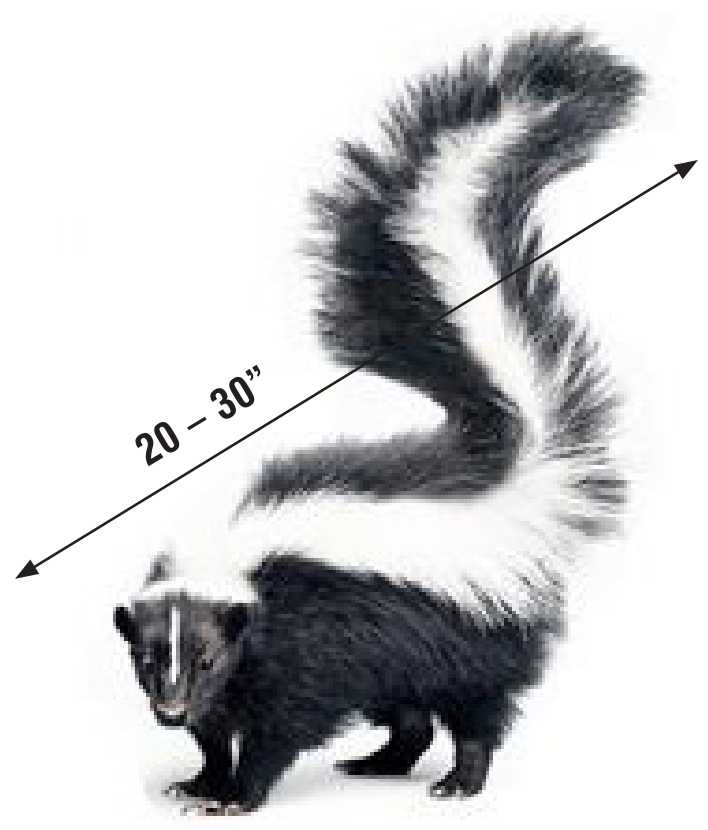

Mephitis mephitis

Fig 6-32. Striped Skunk. 


\subsubsection{Striped Skunk}

Small and fluffy but unpleasantly daunting, skunks are most notorious for their foul and hard-to-remove scent. This is a creature that people want very little to do with, but seems to have made its home rather comfortably in urban settings. While having proximity to skunks may be unnerving, they play a useful ecological role and are highly beneficial to humans. ${ }^{56}$ They greatly contribute to pest and rodent control, and $70 \%$ of their diet consists of insects that are harmful to humans. ${ }^{57}$

Belonging to the weasel family, there are four skunk species in North America: hooded skunk, spotted skunk, hognosed skunk, and the most common one - striped skunk. ${ }^{58}$ Skunks have strong forefeet and long nails, making them effective at digging. However, they're slow movers and not very good climbers. ${ }^{59}$ These nocturnal creatures emerge at sunset to forage. With their black fur and sensitivity to light, they tend to avoid hot, sunny days. ${ }^{60}$ Foraging at night, these omnivores travel about 5-10 miles in search of food. ${ }^{61}$ Their diet consists of mice, lizards, frogs, birds, eggs, garbage, acorns, fruits, beetles, larvae, earthworms, and other insects. ${ }^{62}$

56 “Striped Skunk," Canadian Wildlife Federation, last modified 2020, accessed March 9, 2020, https://cwf-fcf.org/en/resources/encyclopedias/fauna/mammals/striped-skunk-1. html.

57 Landau and Stump, Living with Wildlife, (San Francisco: Sierra Club Books, 1994) 63.

Ibid, 63.

59 Ibid, 63.

60 Ibid, 63.

61 Ibid, 63.

62 "Striped Skunk," Canadian Wildlife Federation, last modified 2020, accessed March 9, 2020, https://cwf-fcf.org/en/resources/encyclopedias/fauna/mammals/striped-skunk-1. $\underline{\mathrm{html}}$.

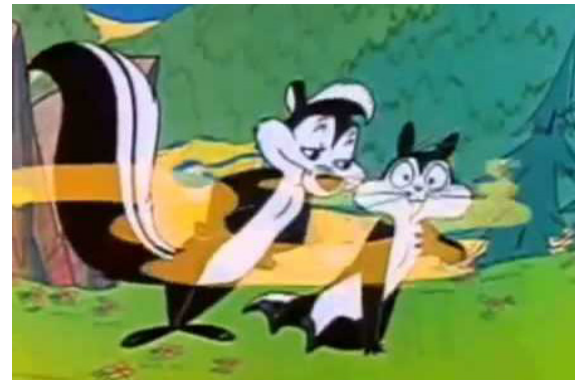

Fig 6-33. Pepe le Pew courting Penelope the cat. 


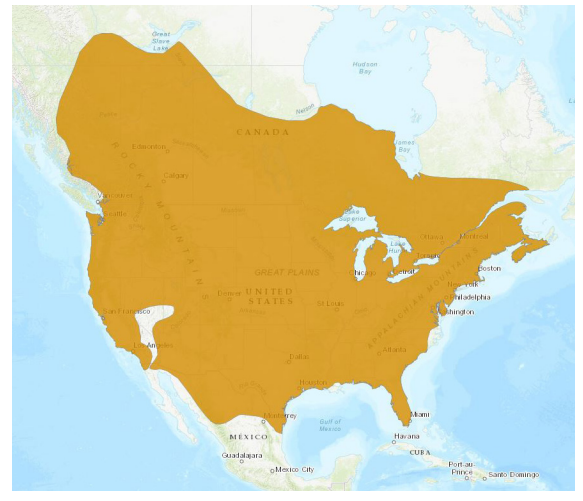

Fig 6-34. Striped Skunk Range.

\section{Habitat}

Skunks tend to prefer semi-open areas of mixed forest and grasslands where they can forage. ${ }^{63}$ Their territories can range between 30-40 acres. ${ }^{64}$ They choose dens that are warm, dry, dark, and defensible, and usually within two miles of a water source. ${ }^{65}$ These tend to be hollow logs, burrows, and abandoned dens of other animals. ${ }^{66}$ They're able to dig their own warrens about one foot underground and furnish it with well-hidden entrances. ${ }^{67}$ Skunks have little fear of humans and find suitable denning conditions beneath buildings: decks, crawl spaces, porches, etc. ${ }^{68}$ Toronto has a skunk population density of 2-7 skunks / square kilometre. ${ }^{69}$ They don't mind sharing dens intermittently with other groups of skunks. However, during their longer winter naps, a den may have many females and only one male.

\footnotetext{
63 Ibid.

64 Landau and Stump, Living with Wildlife, (San Francisco: Sierra Club Books, 1994) 63.

65 Ibid, 63.

66 "Striped Skunk," Canadian Wildlife Federation, last modified 2020, accessed March 9, 2020, https://cwf-fcf.org/en/resources/encyclopedias/fauna/mammals/striped-skunk-1. html.

67 Landau and Stump, Living with Wildlife, (San Francisco: Sierra Club Books, 1994) 63.

68 “Striped Skunk," Canadian Wildlife Federation, last modified 2020, accessed March 9, 2020, https://cwf-fcf.org/en/resources/encyclopedias/fauna/mammals/striped-skunk-1. html.

69 Stanley Gehrt, Urban Carnivores: Ecology, Conflict, and Conservation, (Baltimore: The Johns Hopkins University Press, 2010), 100.
} 


\section{Status \& Threats}

The main threats facing these creatures that stay close to the ground are automobiles and predators such as the great horned owl. ${ }^{70}$ Skunks seldom attack unless provoked or feel the need to defend their young. ${ }^{71}$ They may attempt to ward off threats first by growling, fluffing their fur, stamping on the ground, standing on their hind legs, and spitting. ${ }^{72}$ If the threat persists despite these warnings, they will use their spray, consisting of a sulfuric compound: N-bulymercaptan. ${ }^{73}$ The spray is discharged in a fanlike pattern up to a range of 15 feet. $^{74}$

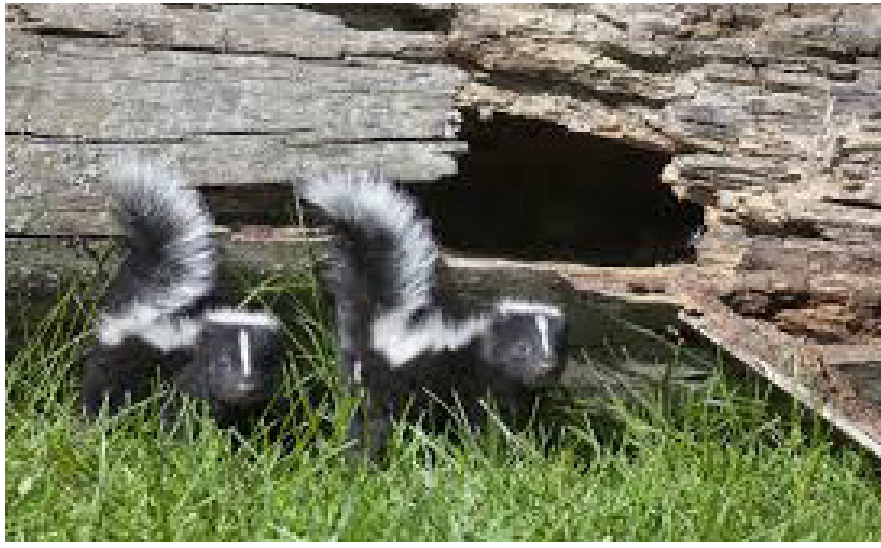

Fig 6-35. Skunks denning in hollow logs.

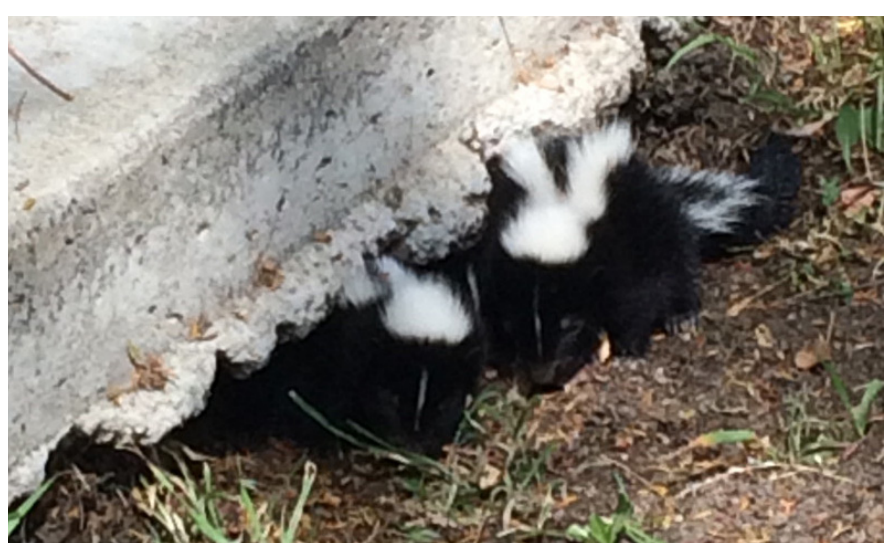

Fig 6-36. Skunks burrowing underneath man-made structures.

70 Landau and Stump, Living with Wildlife, (San Francisco: Sierra Club Books, 1994) 64.

71 Ibid, 64.

72 Ibid, 64.

73 Ibid, 64.

74 Ibid, 64. 


\section{part III}

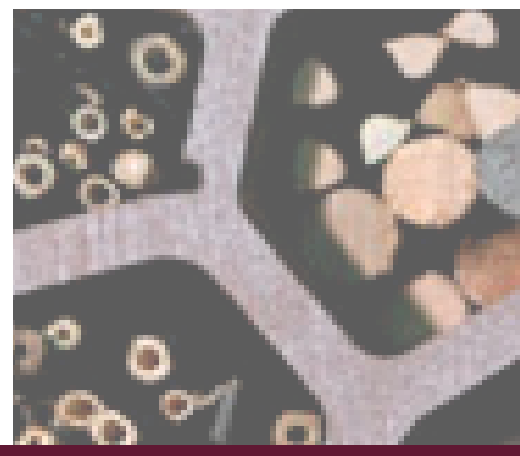

\section{The Syn॰anthropocene}

\section{Resynchronizing Architecture}

Chapter 7 An Evolving Architecture

Chapter 8 A Synanthropic Centre

173

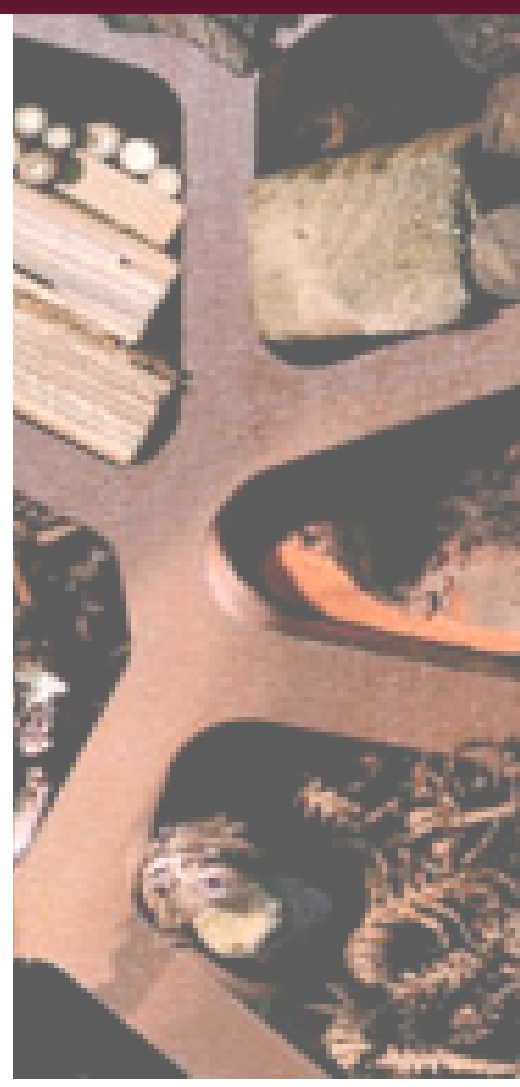


5x: on 7,1

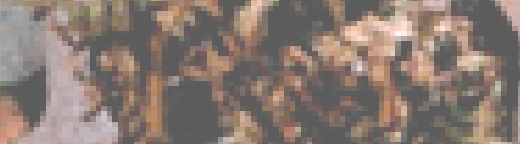

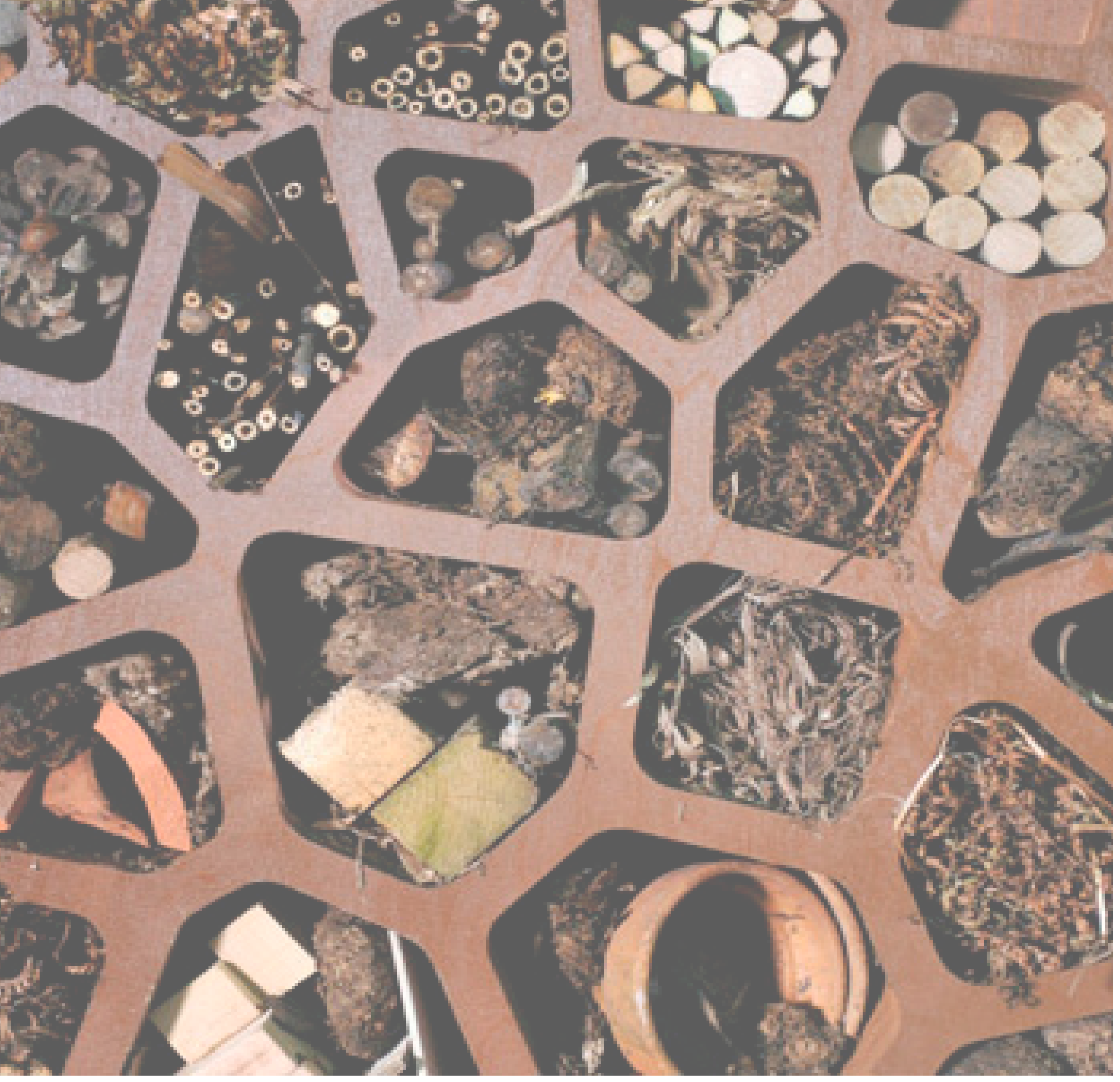

Fig 7-1. Insect Hotel. 


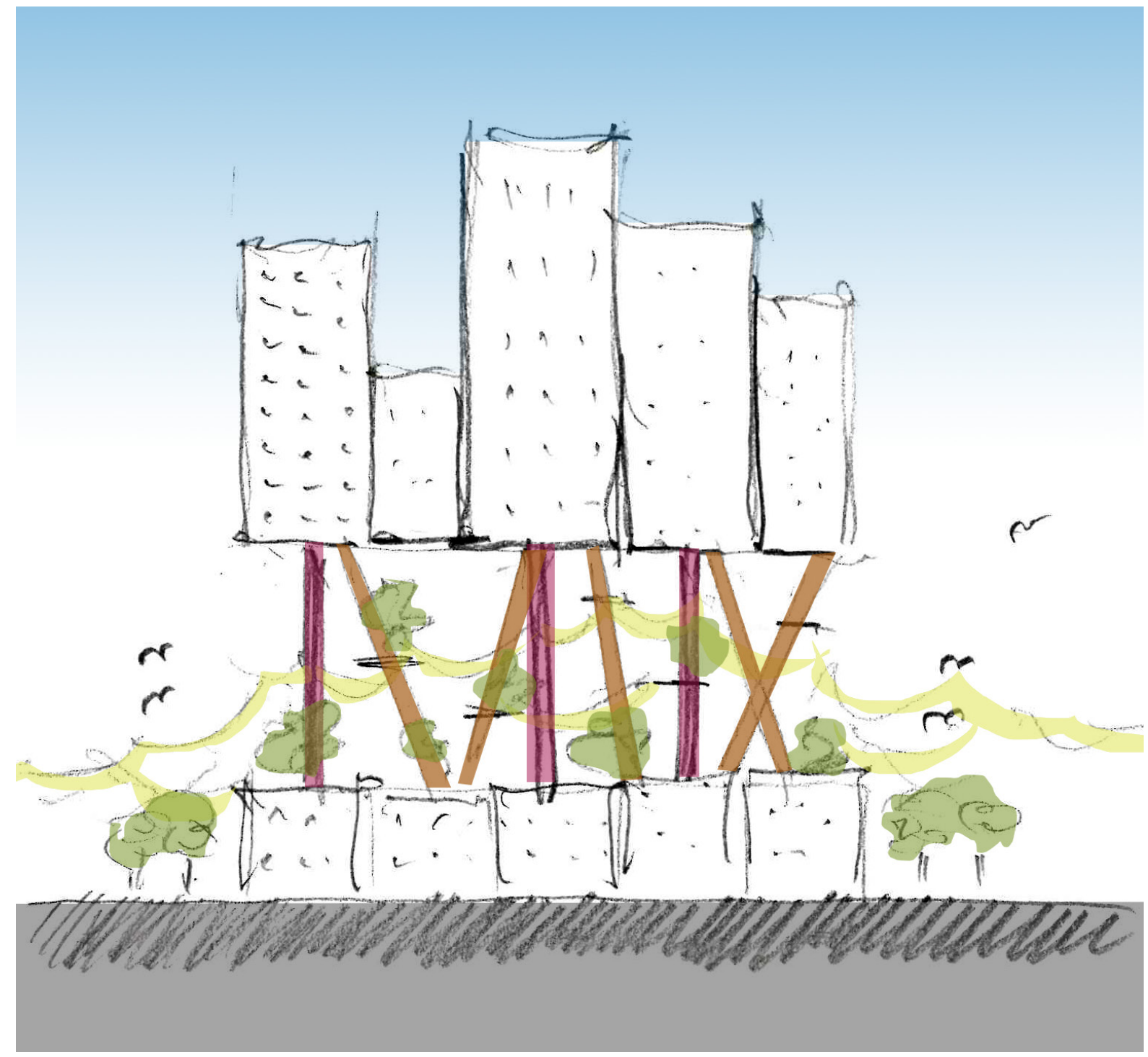

Fig 7-2. Responsive architectural transformations. 


\section{Chapter 7}

\section{An Evolving Architecture}

7.1

7.2

7.3

7.3.1
Mutated Forms 143

Repurposed Scapes 151

Designed Ecotopes 161

The Obelisk

172 


\section{1}

\section{Mutated Forms}

\section{A Subtle Change}

Conventional architectural design is geared mainly to the purposes of human beings, facilitating societal functional needs, as well as people's requirements for health and well-being. To pursue building projects dedicated entirely to animals can appear to be too immense of a task. However, there need not be massive interventions to create considerable impact; subtle changes in design can be manageable enough while making meaningful ecological contributions.

The inception of this idea was first realized by modifying the design of a typical brick wall. Allowing bricks to make minor protrusions from the surface would provide nooks and plateaus that are easier to grasp onto. Wildlife that tend to climb would be able to do so more effectively and safely than relying on the ability of their claws to cling to the bumpy surface of bricks (and support their entire body weight in the process).

Fig 7-3. Protruding Brick Ladder.

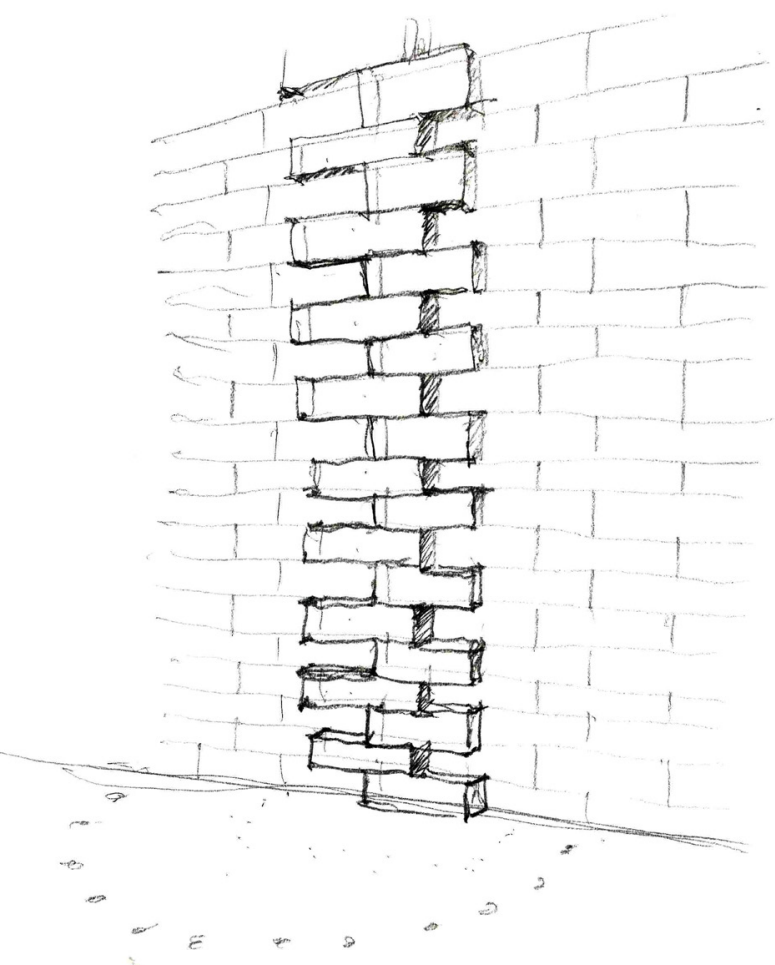


There are existing examples for laying bricks in this way. Implementing this type of strategy would be a feasible pursuit. Creating these kinds of urban ladders would greatly assist wildlife to navigate through different parts of an urban landscape. This would be in stark contrast to the typical urban conditions where animals are obstructed by the vertical walls of buildings that form enormous obstacles in their path.

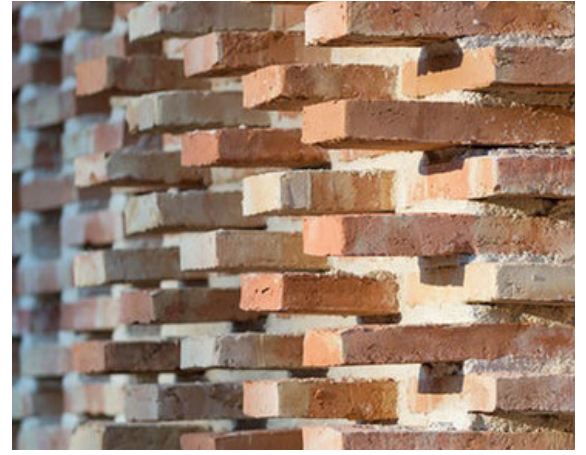

a.

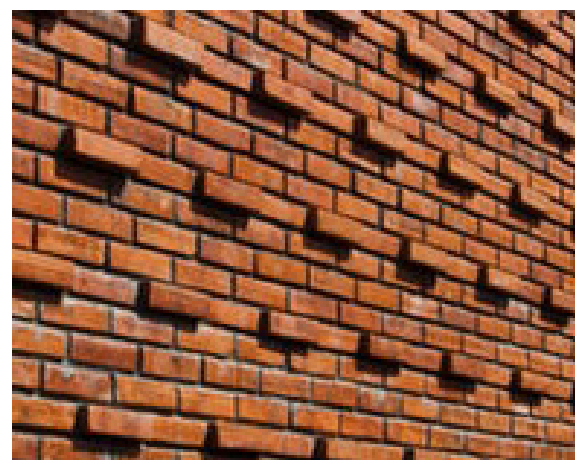

$b$.

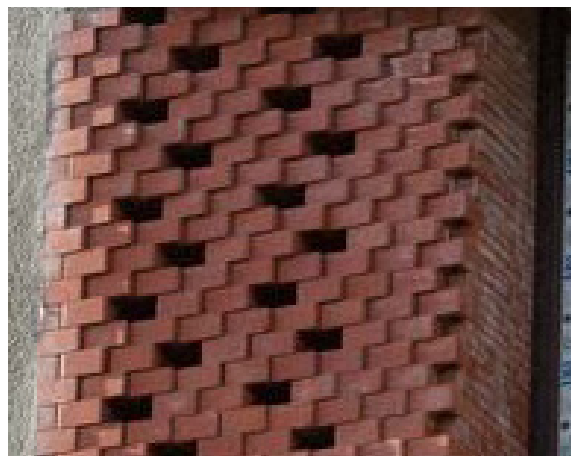

C.

Fig 7-4. Protruding Bricks. 


\section{Evolution}

A minor mutation would create a subtle difference between one condition and its related variant. These subtle differences create a situation where one element is slightly more fit and preferable for a particular function. In this scenario, animals would be more likely to climb the wall with protrusions or one with a slight incline than entirely vertical walls that are harder to scale. While it cannot be definitively determined that animals will not climb the vertical ones, it is possible to posit that they would have a greater preference for the alternative. Implementing these two opposing topologies unto a building creates two distinct zones: one that is more

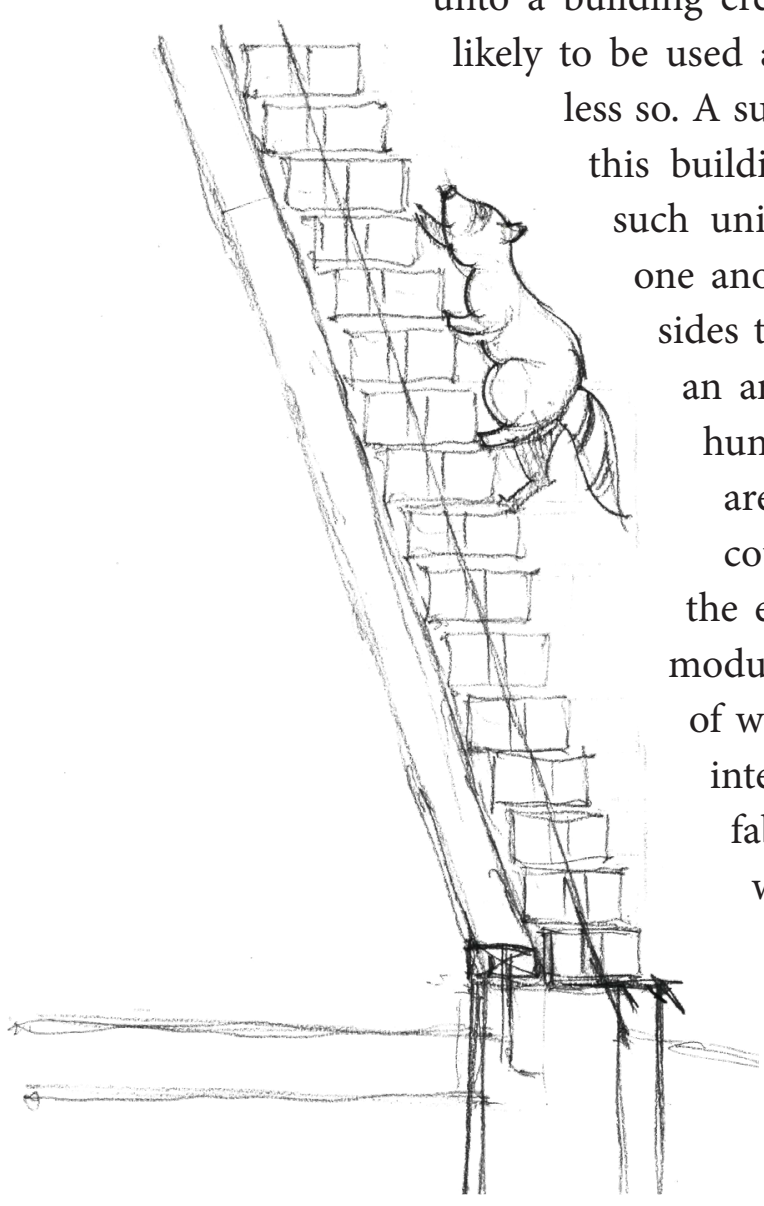

less so. A subsequent step to this would be to consider this building as a module within a multiplicity of units. By orienting 'like' conditions towards ne another, an enclosure can be formed; having ides that are less likely to invite animals creates an area that would be more suitable to enable human circulation; meanwhile, the areas that are more likely to have wildlife circulation could be connected by a bridge element. In the end, the systematic multiplication of these modules can facilitate continuous circulation of wildlife as well as humans as their paths are interwoven in layers within the emergent urban fabric. The city is abundant with vertical walls and other surfaces, spaces, and areas that could have tremendous impact with minor modification - these are places of untapped potential. Architecture can evolve to create urban landscapes that are more inclusive of wildlife.

Fig 7-5. Inclined Brick Wall. 


\section{MODULE}

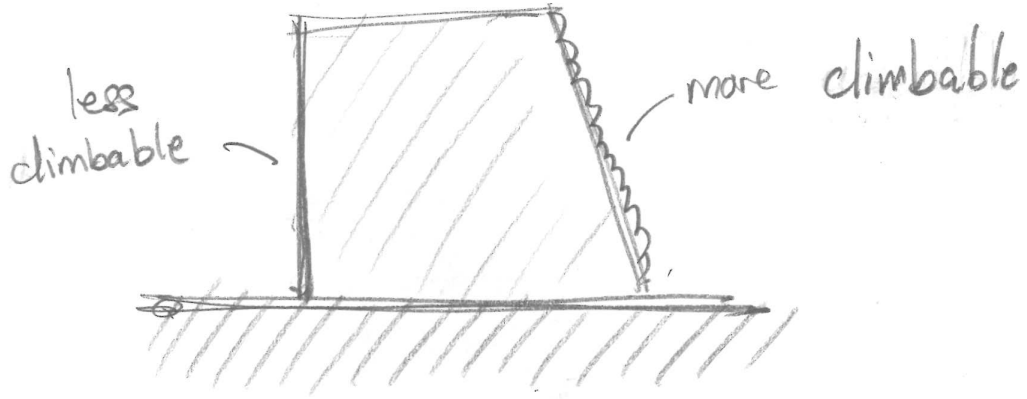

\section{ORIENTATION}

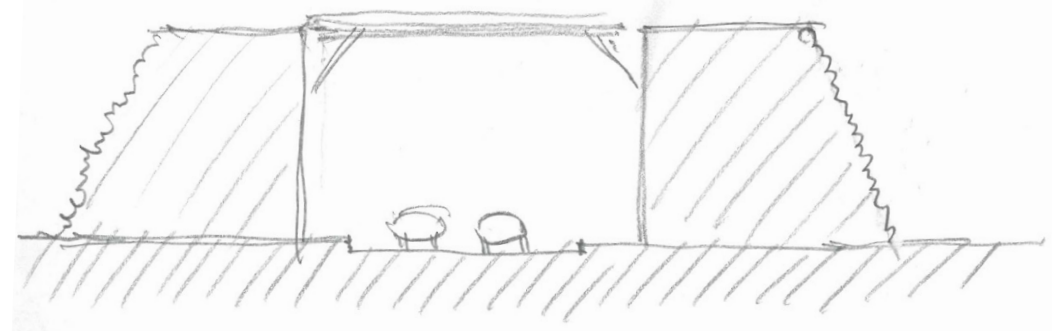

\section{SYSTEM}

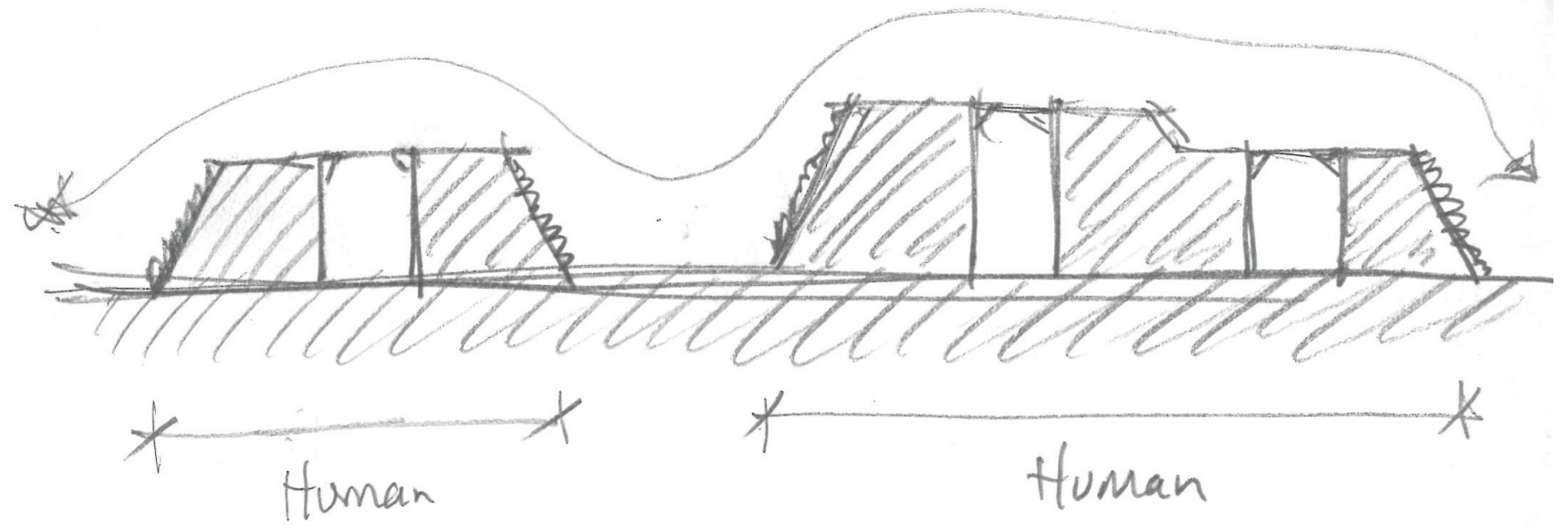

Fig 7-6. Module, Orientation, and System. 


\section{Incorporating Habitats}

Conventional urban fabric can incorporate strategies that enable co-habitation with local wildlife. One design exercise explored the possibility of integrating bat habitat within the exterior walls of typical houses. The aim was to explore how standard construction methods can facilitate a mutation that result in integration of wildlife.

This design for a bat roost aims to be inserted almost seamlessly into the typical structure of a wood-frame building. Following the design parameters of the bat roost from section 6.2.3, this design involves a tall bat box that is adhered between wood studs that follow a typical 16 " or 24 " spacing. Wood siding of a house can utilize a custom siding board that facilitates entry into the bat roost; this board would have a notched opening for bats to enter the roost, as well as grooved surface to serve as a landing pad. Bats can benefit from this form of roosting as the house would provide their nook with the warmth that they require. As a custom designed roost, this preferred and dedicated space could prevent bats from inhabiting elsewhere in parts of the house which would be undesirable to its residents. Bat habitation would promote positive ecological outcomes such as increased pollination and the control of undesirable insects, such as mosquitos. 

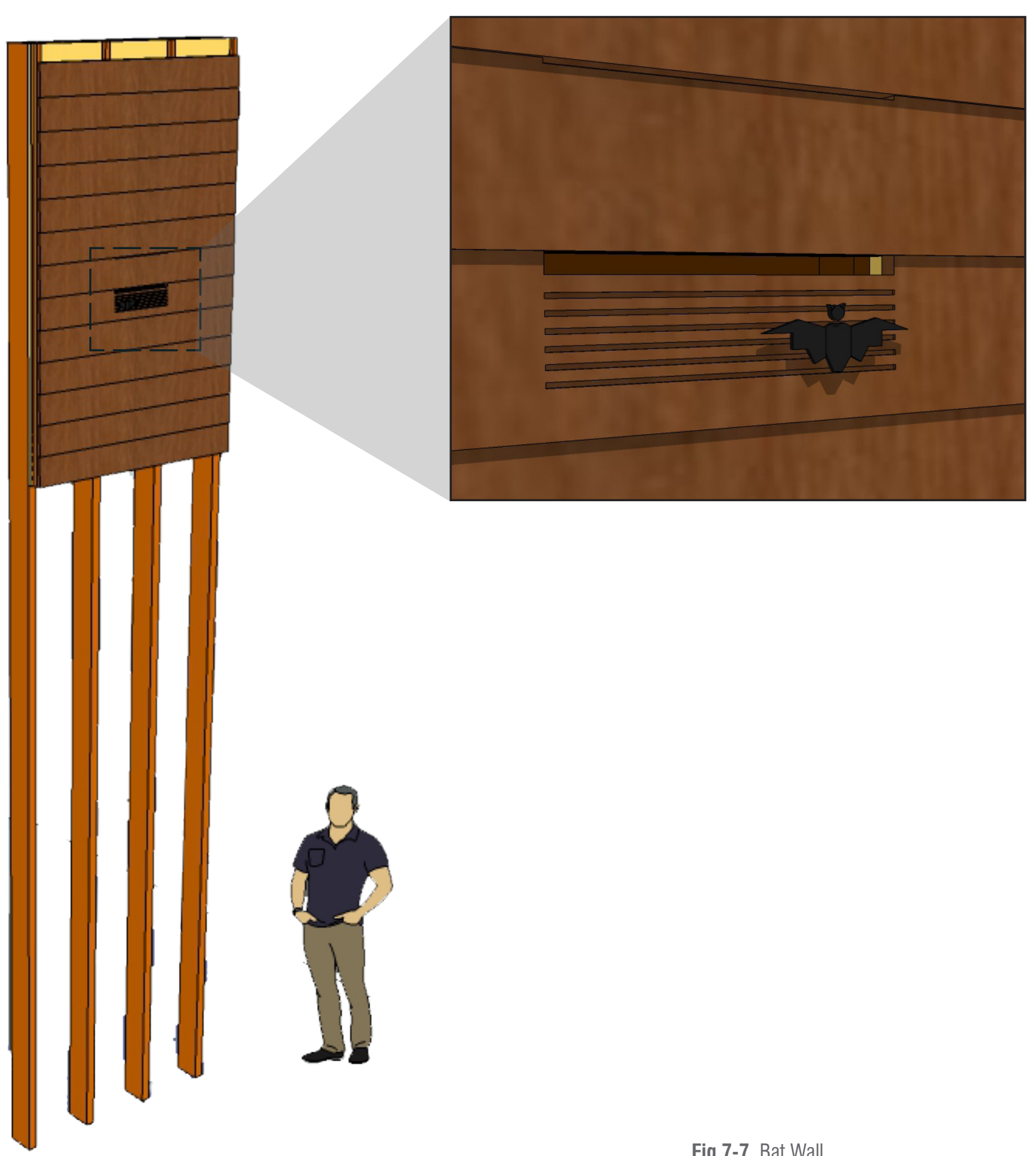

Fig 7-7. Bat Wall. 


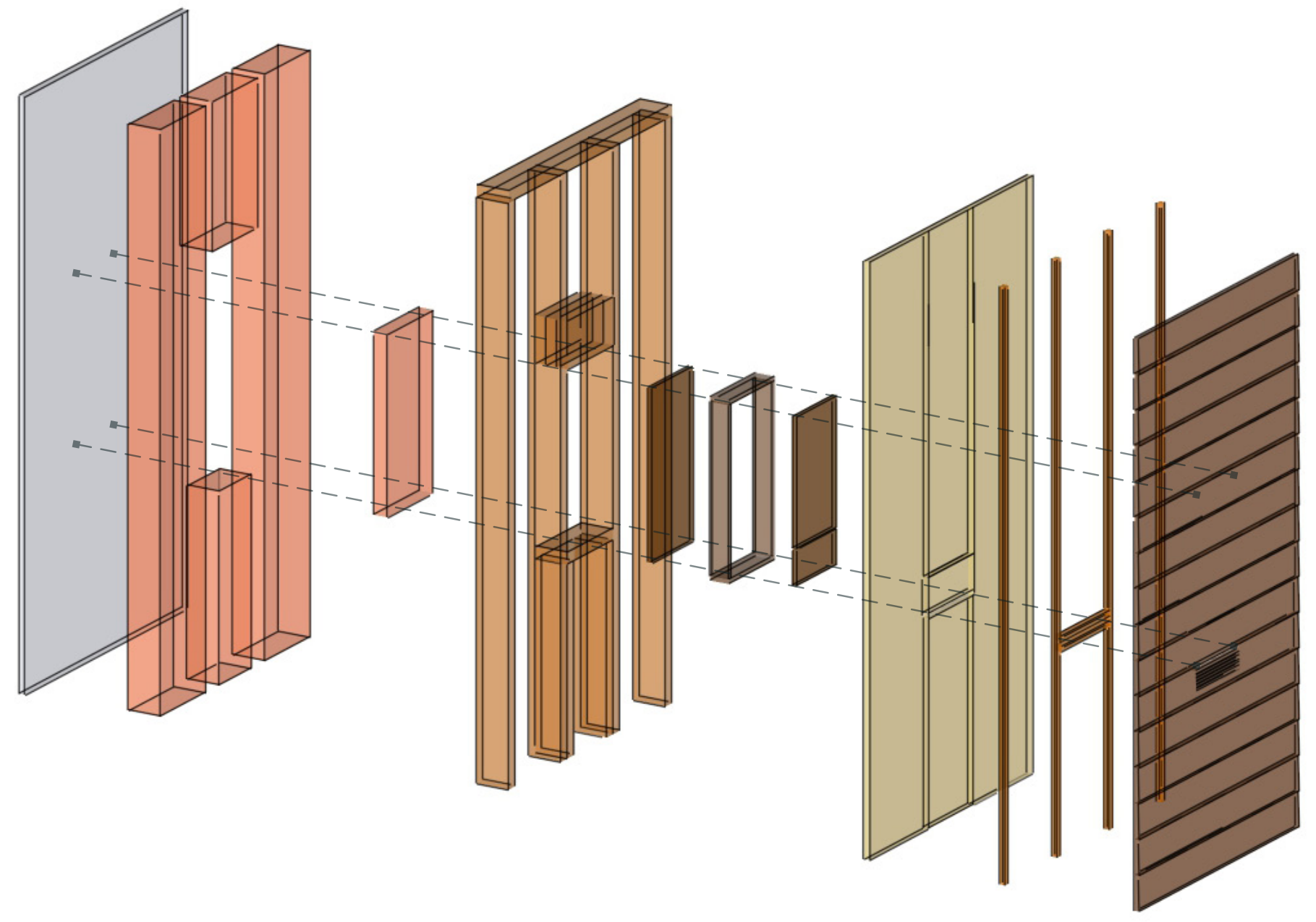

Fig 7-8. Layers of the bat wall system. 

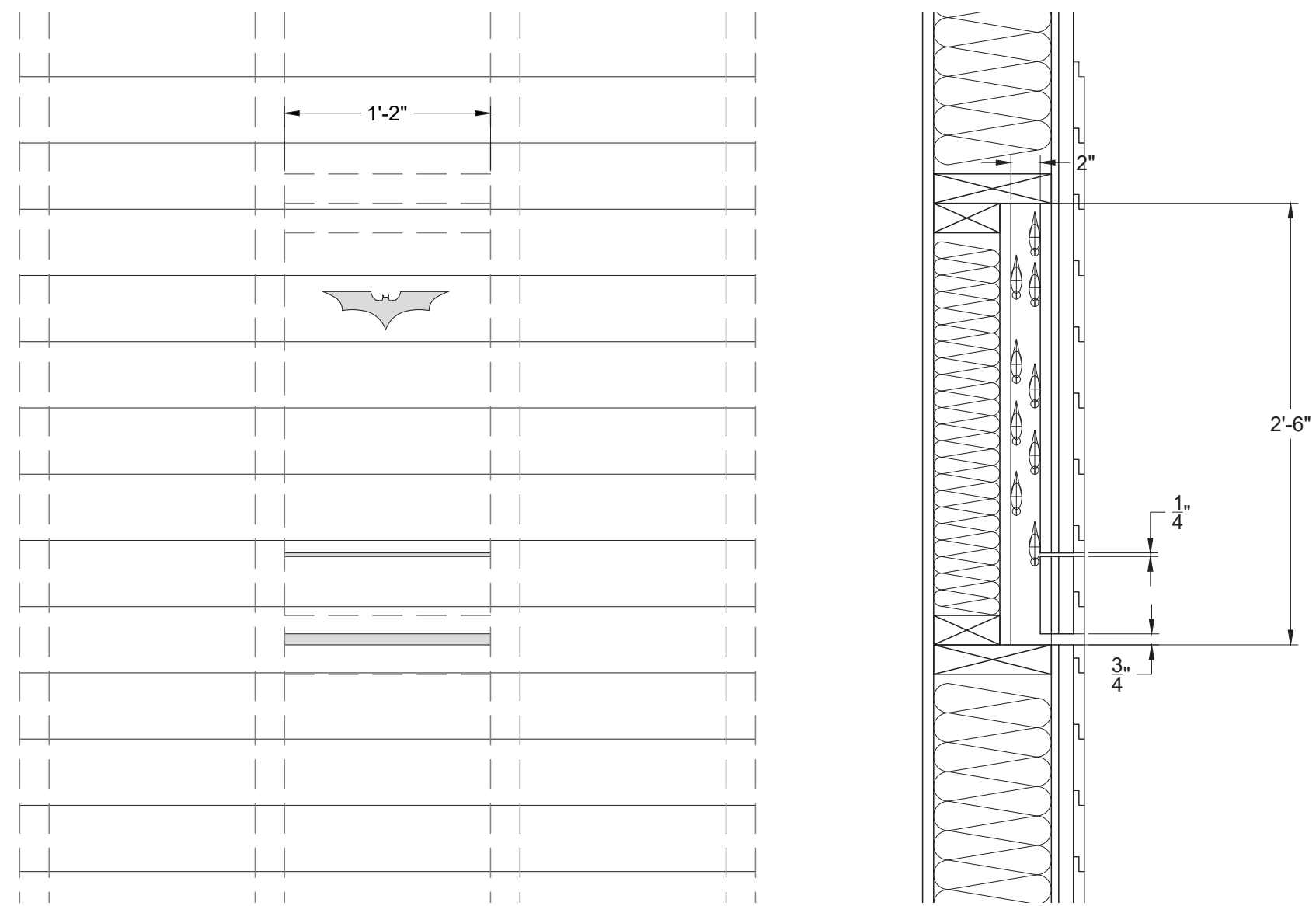

Fig 7-9. Section \& Elevation. 


\section{2}

\section{Repurposed Scapes}

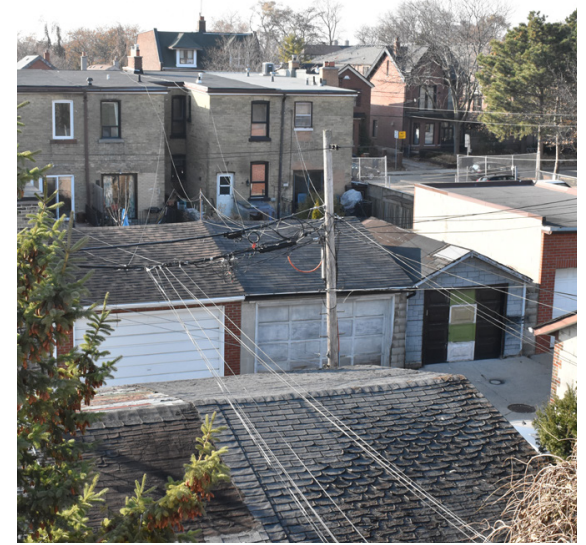

a.

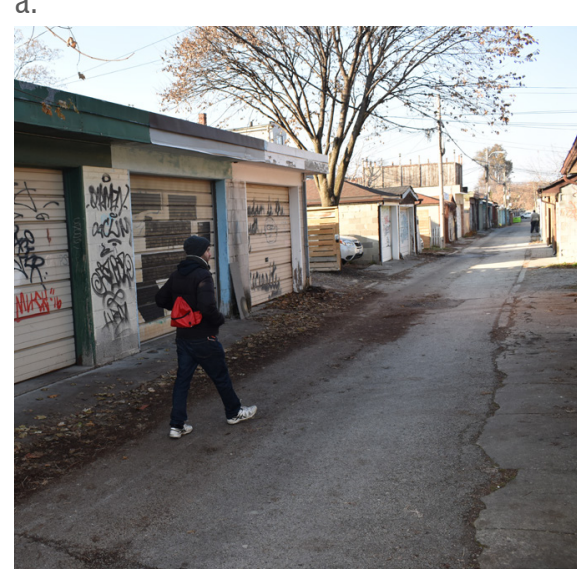

b.

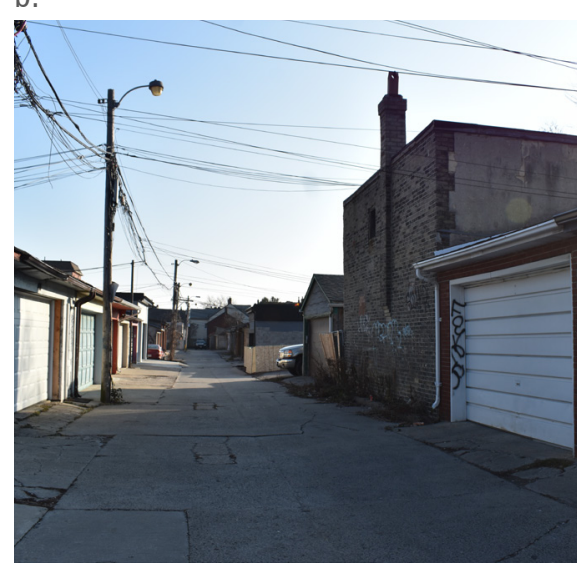

C.

Fig 7-10. Backlanes, photographed by Simon Gordon and Alex Caskey.
A step beyond implementing miniature mutations to an existing fabric is enacting more drastic transformations to repurpose entire areas. This form of intervention can occur at a later stage of a multiphase process (refer to the discussion in section 4.5.1 Phases of EcoCultural Evolution); assuming a gradually shifting cultural paradigm, this intervention dedicates greater territory for wildlife and weaves circulation networks for animals in a more intimate fashion within the urban fabric.

This phase considers the transformation of back lanes of lowdensity neighbourhoods in Toronto into re-wilded territories. Currently, there are multiple series of these lanes that run parallel to the city streets. Though at some point in the past, these garages may have been typically used to house cars, this has started to change. Neighbourhoods such as the Annex, Trinity-Bellwoods, and Cabbagetown, have seen an increase in cycling as a preferred mode of transportation by as much as 34\% from 2006 to $2016 .{ }^{1}$ As fewer people in downtown Toronto rely on cars, these garages end up simply being used as storage spaces. The resultant environment consists not of an active laneway, but a quiet, vacant, and narrow stretch of pavement, flanked by scarcely used garages. These areas can be repurposed and revivified with lush corridors of green growth, bustling with biodiversity. Creating parallel ecological avenues that interconnect over a vast area can create a resilient overarching ecosystem.

1 Sarah Bradley, "Major increase in Torontonians biking to work: up to 34\% in some neighbourhoods." Cycle Toronto, last modified December 1, 2017, accessed March 2, 2020, https://www.cycleto.ca/news/major-increase-torontonians-biking-work-34-someneighbourhoods. 


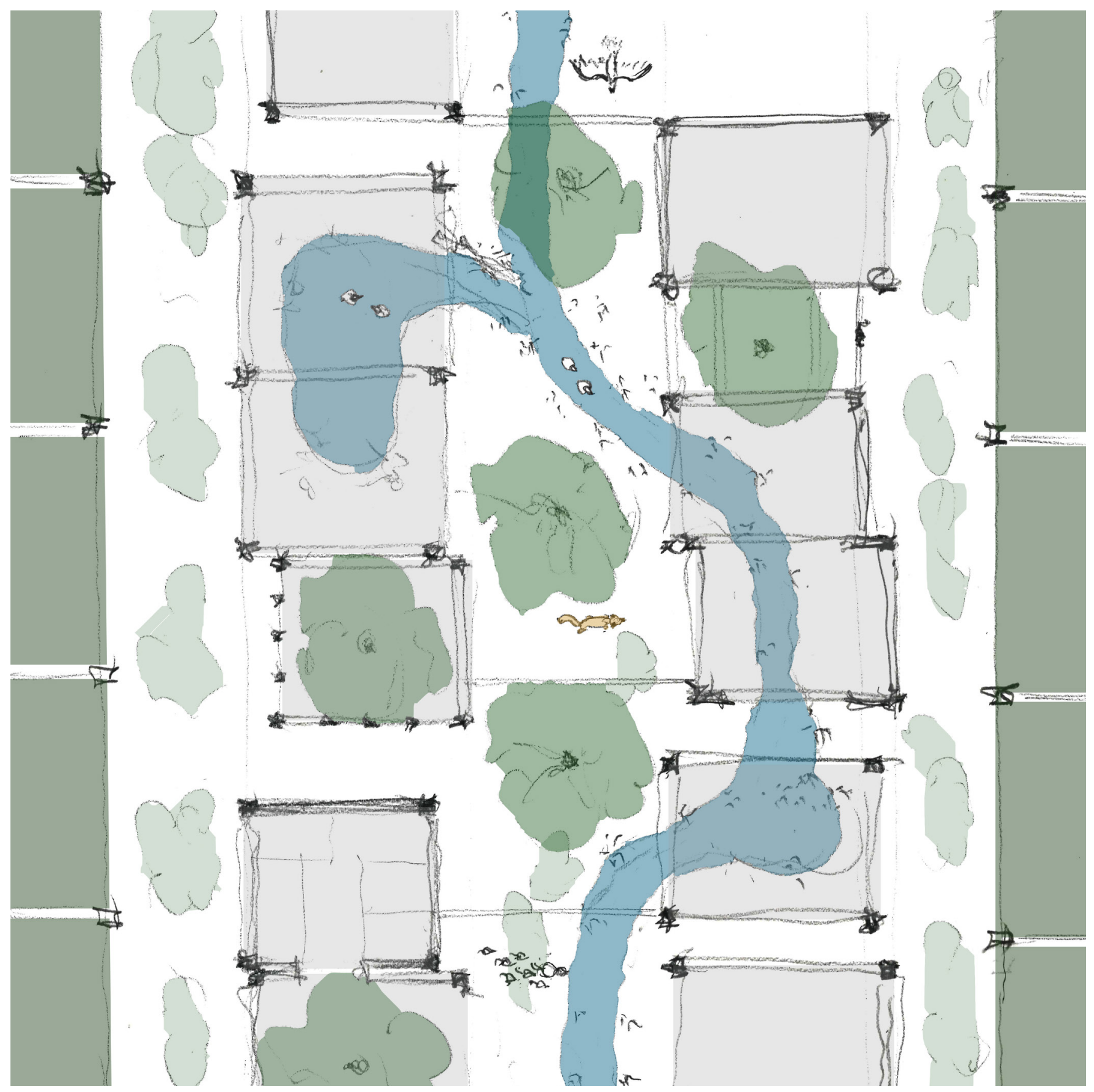

Fig 7-11. The Lanescape. 


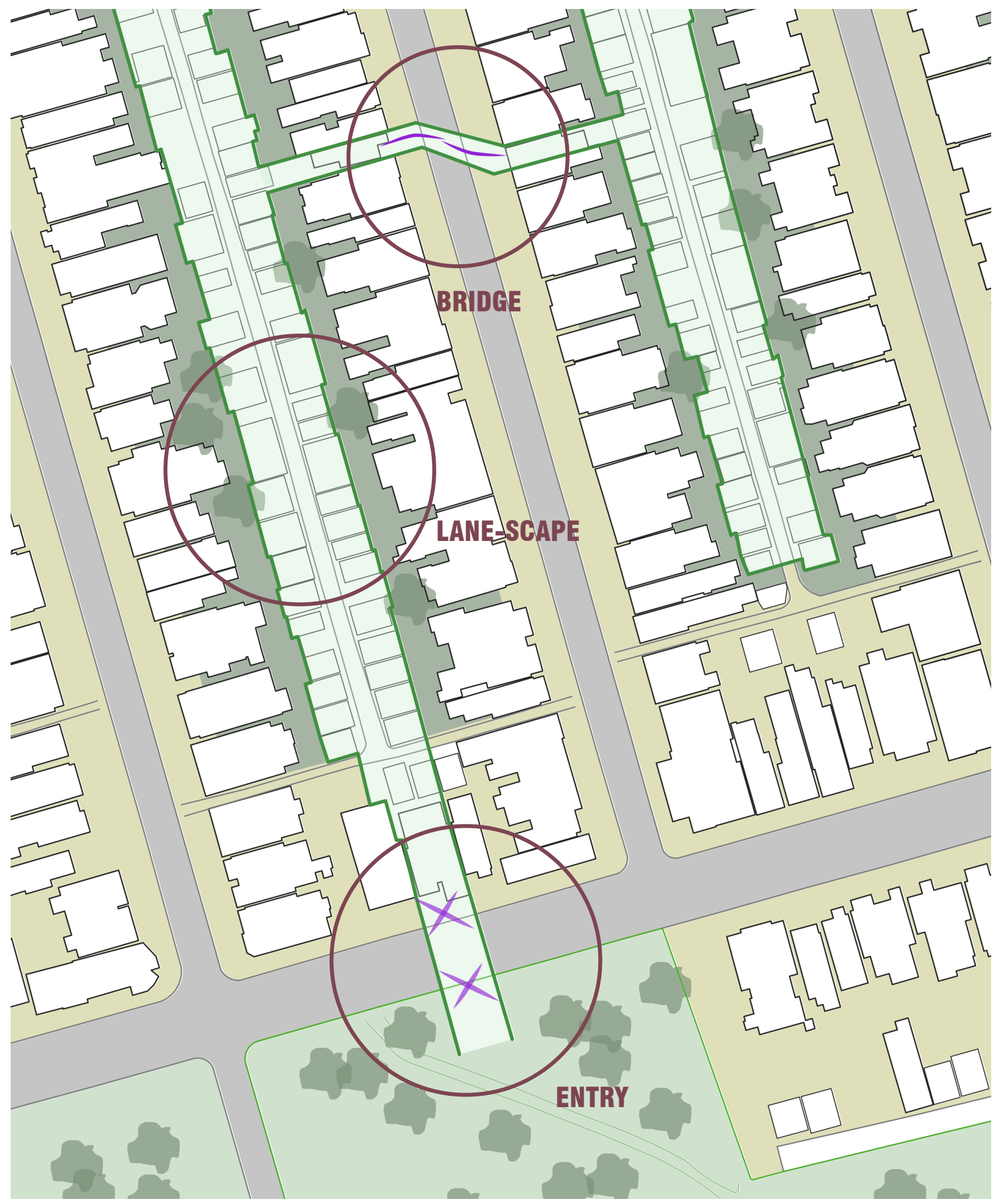

Fig 7-12. Connections to the lanescape. 
The transformed lanescapes would be interconnected with one another, as well as with local parks and green spaces. This strategy of weaving connections within the urban fabric ensures that habitat fragmentation is prevented. Wildlife crossings can connect animals between parks and lanescapes in the form of overhead bridges above streets. Semi-permeable gates can be implemented at the mouths of these crossings that allow animals to pass but obstruct human movement.

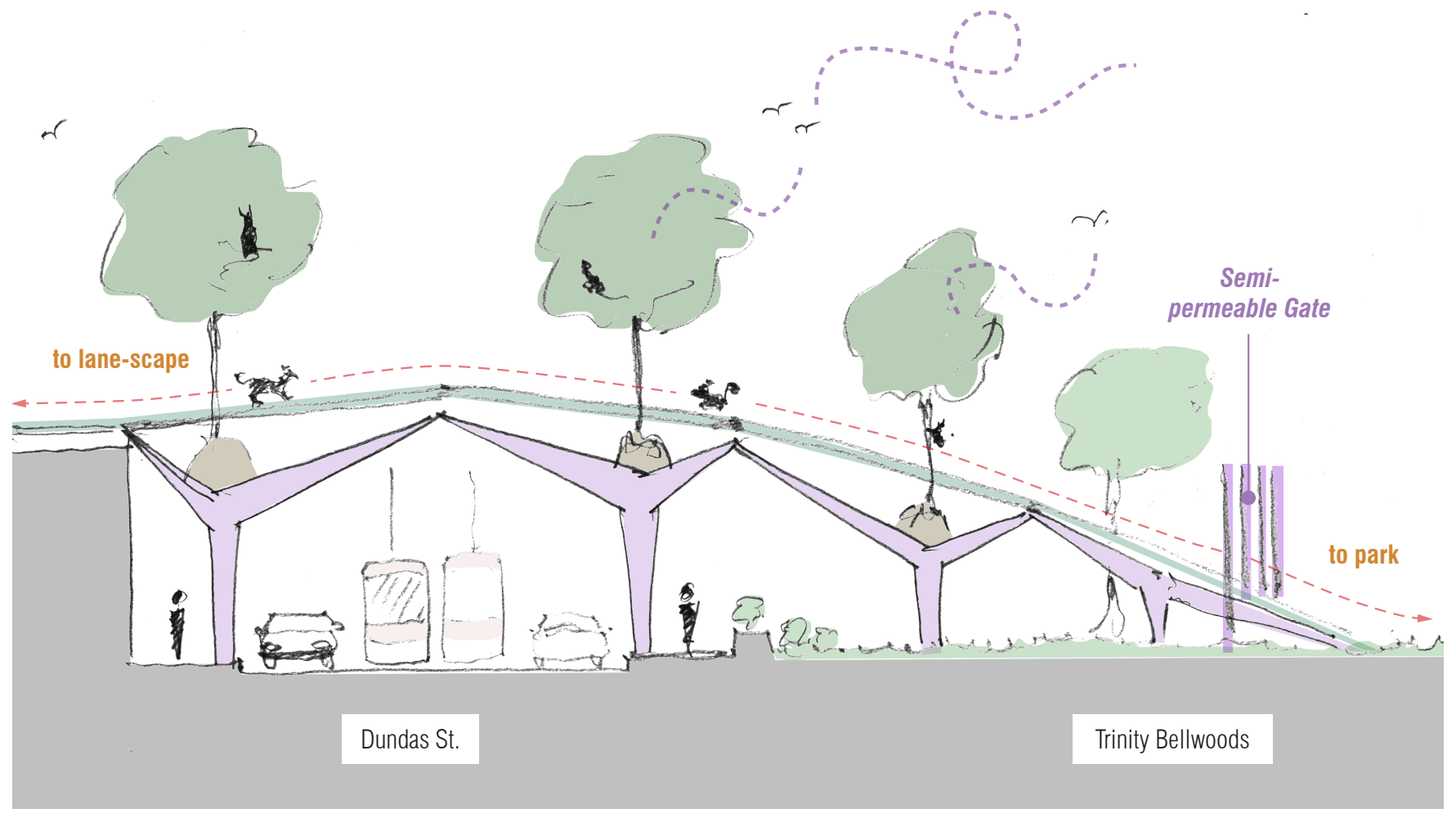

Fig 7-13. Wildlife Crossing. 
Fig 7-14. Longitudinal Section.

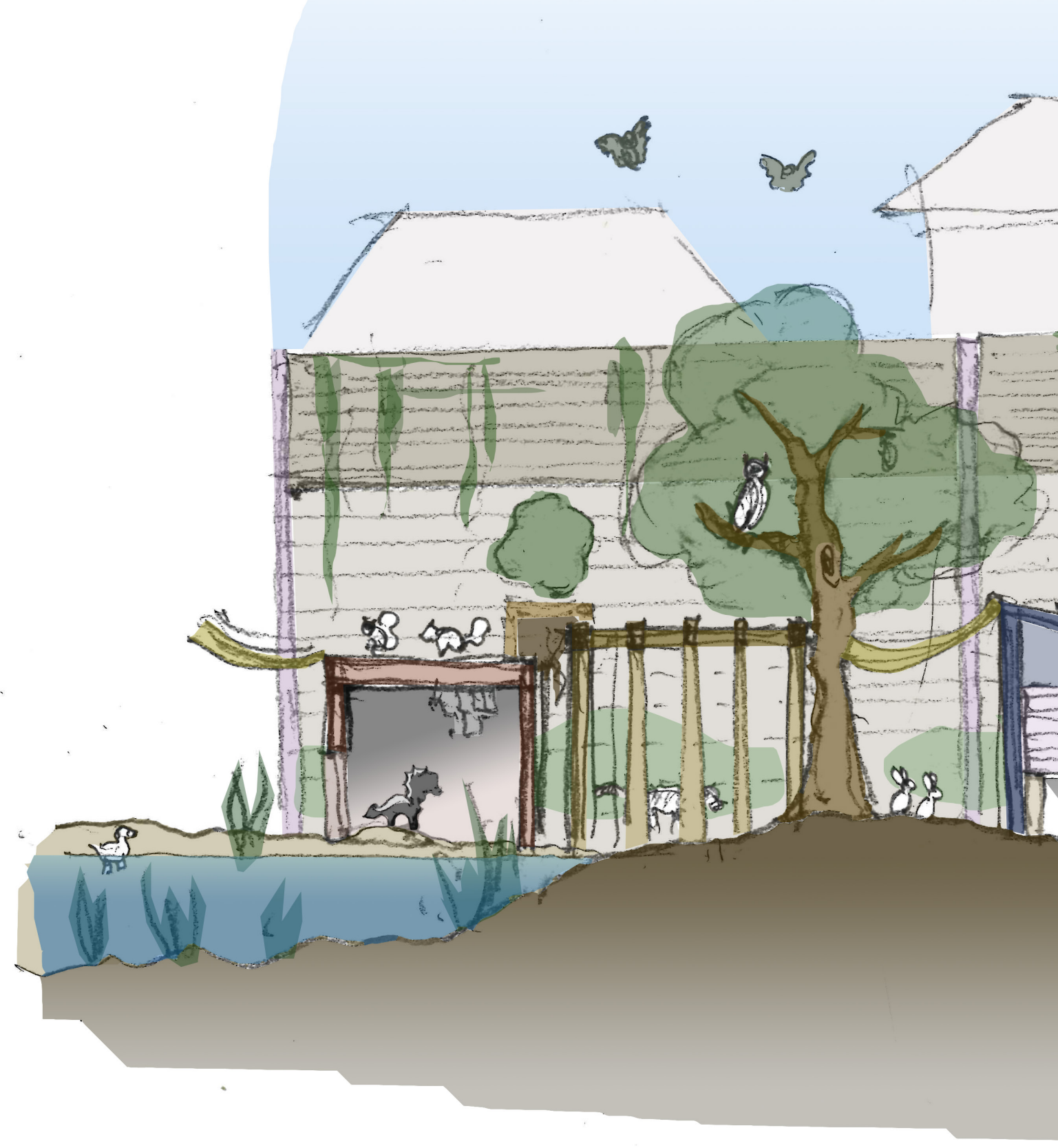




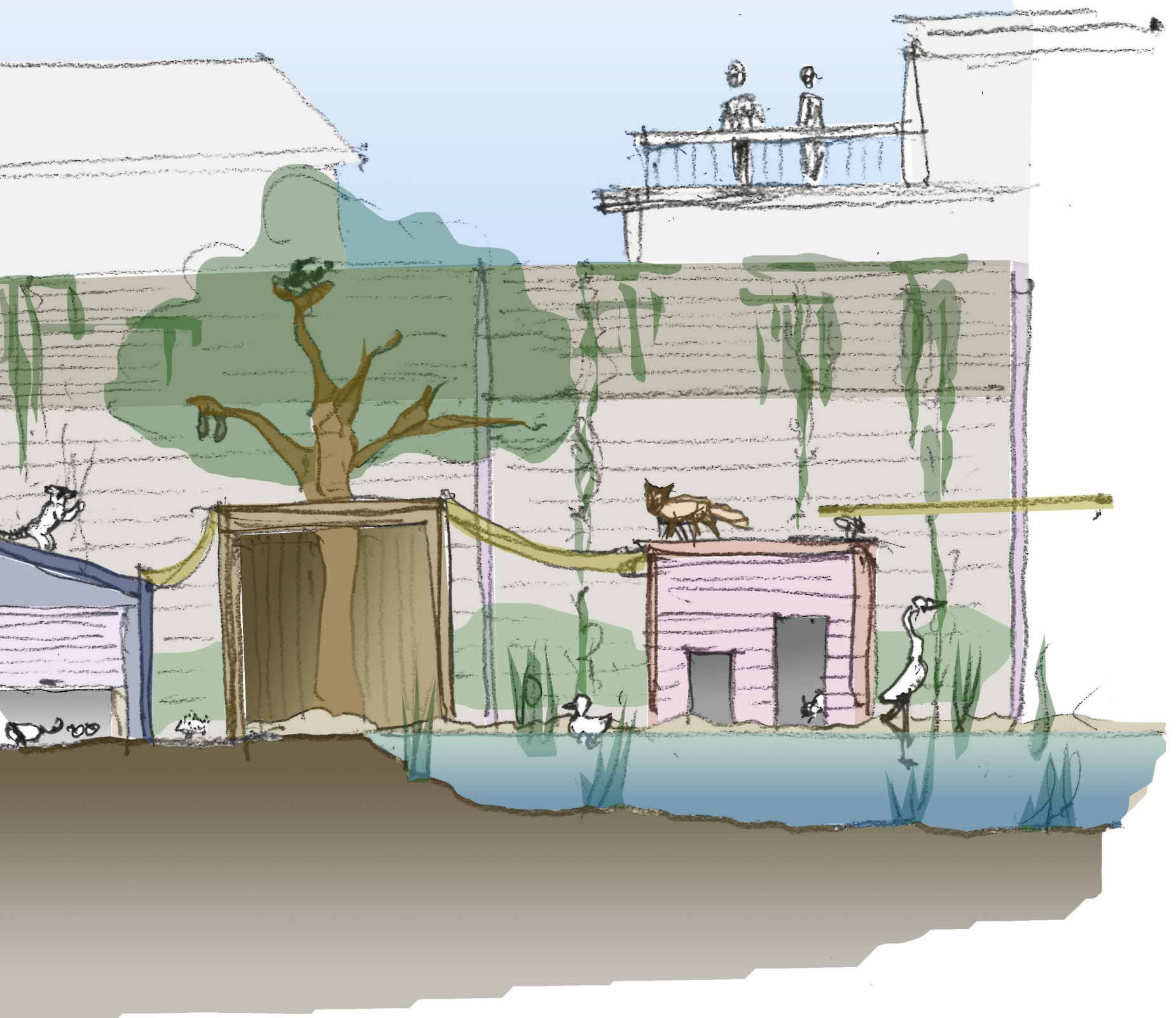


Fig 7-15. Cross-section.

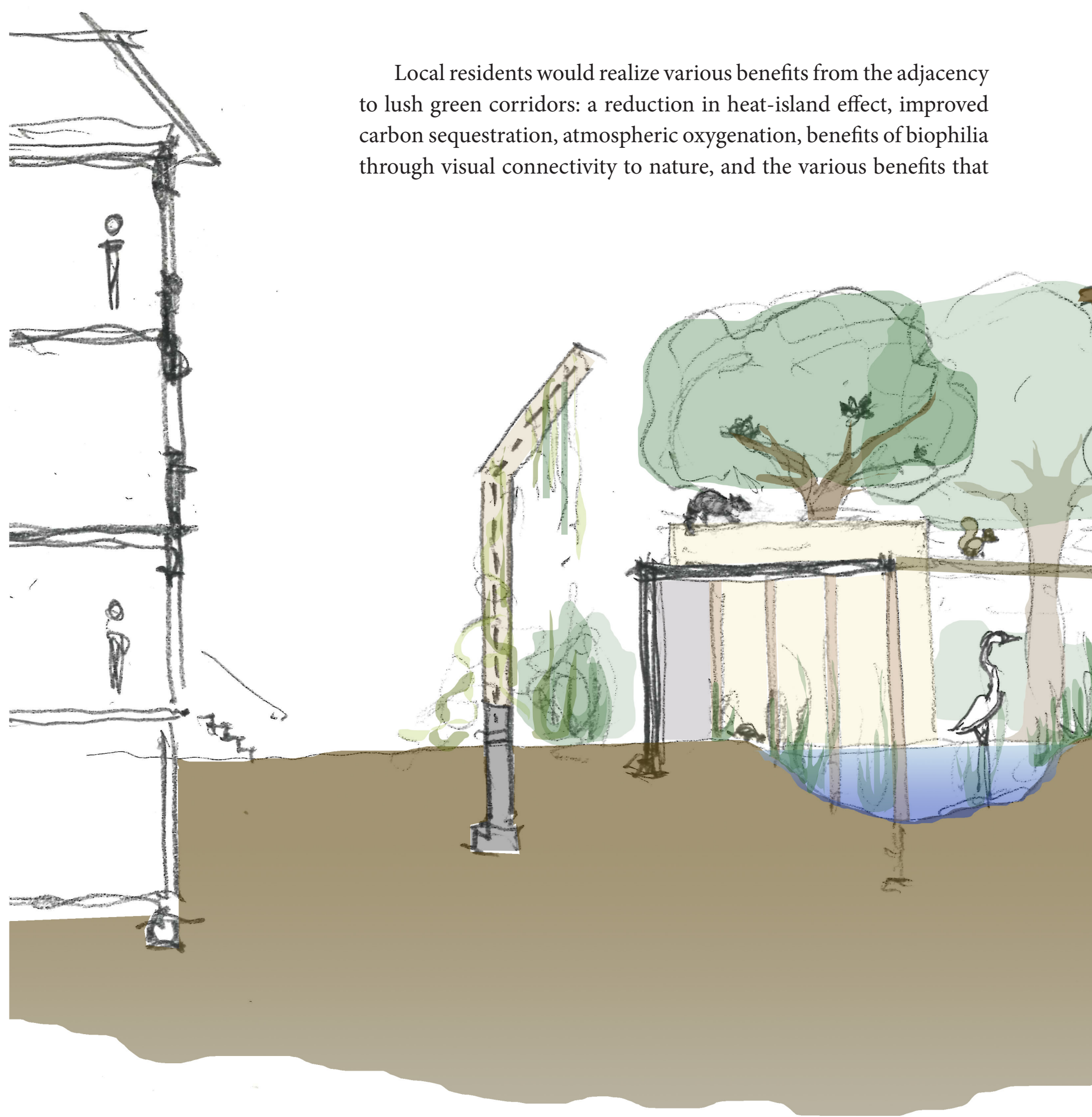


certain animals bring. At the same time, some animals could pose some risk to the safety of people and pets. For this reason, this design incorporates a fencing strategy. These structures have a concave design and constitute tightly spaced slats in order to prevent animals in the size category of coyotes and foxes to pass through.
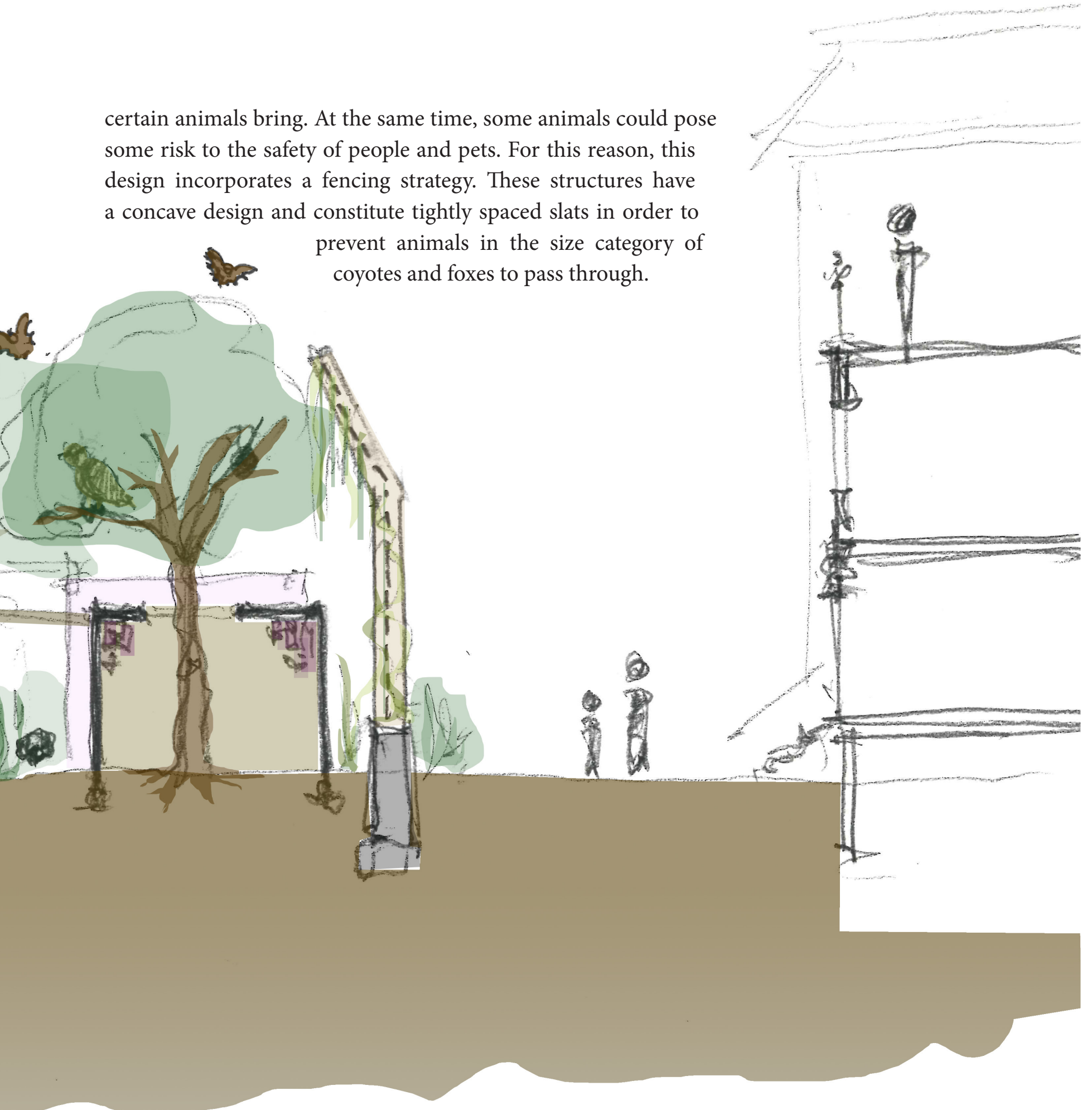




\section{3}

\section{Designed Ecotopes}

Sections 7.1 and 7.2 explored design interventions that constitute the mutation and repurposing of the existing urban fabric of Toronto. This chapter's final section explores the design of entirely new constructions that would be dedicated specifically to certain species. It is unlikely that there is a "one-size-fits-all" solution in designing a new type of built habitat due to the vast variation in species and the issue of clashes between them. However, a variety of such ecotopes can be postulated: a series of structures, each supporting different kinds of synanthropes. These structures would act as habitation nodes that are interconnected within a broader ecological network ecotopes within an ecosystem.

While these structures would host a diversity of inhabitants, there can be unifying resemblance in their architectural expression; form, materiality, and relationship with the environment are some of the qualities that these objects can share while maintaining some necessary variation.

An added consideration would be the relationship that these structures might have with humans. While these ecotopes would priorotize providing habitats for synanthropes, they could have a secondary function of facilitating a visual and educational experience for human observers. To quote Sir David Attenborough: "No one will protect what they don't care about, and no one will care about what they have never experienced." Bringing humans and synanthropes closer together can begin to shed misconceptions about wildlife and strengthen the bonds between these interconnected biological subjects.

2 Jil Carrara, "Sir David Attenborough's Best Quotes," Eco-Age, last modified May 12, 2018, accessed March 13, 2020, https://eco-age.com/news/david-attenboroughs-bestquotes. 


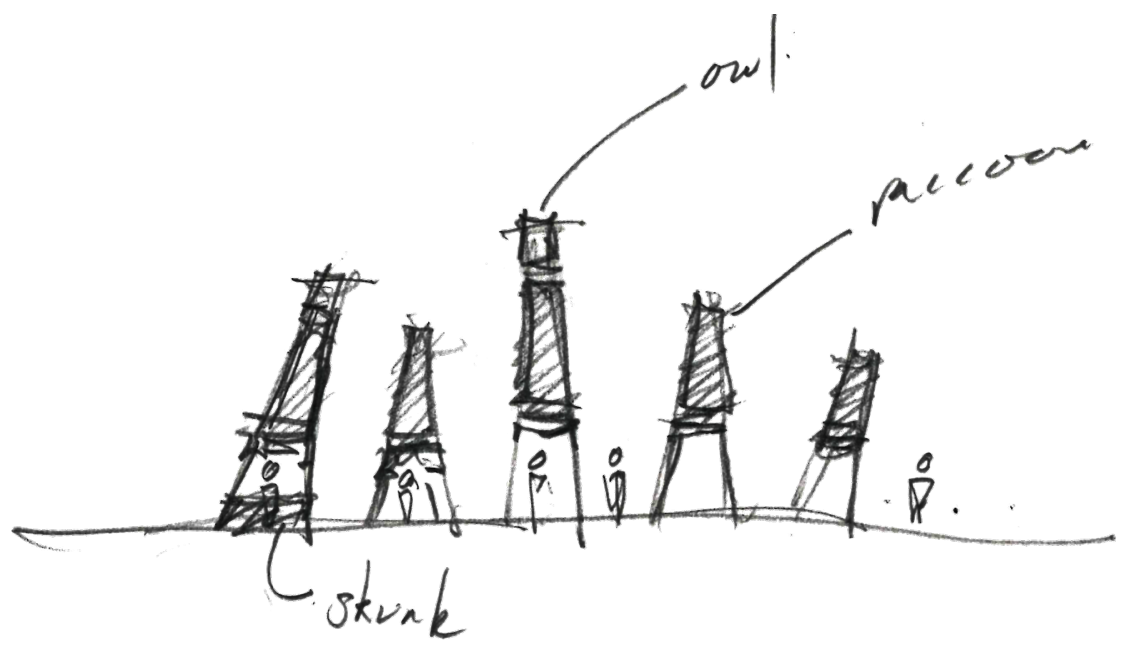

Fig 7-17. A set of ecotopes. 


\section{Raccoon Ecotopes}

A starting point for designing a habitat for raccoons was inspired by their predilection to inhabit chimneys. These tall compartments should be designed to their preferences of a warm, dark, and dry. Creating an entrance at the top of this hollow column allows this space to be somewhat more secure. An ever so slight incline of the walls could allow the raccoon to climb up and down this structure with greater ease. This is especially helpful for when the young first leave the den and are only beginning to learn how to use their claws to cling to surfaces and support their own body weight. The entrance to the shaft should be just narrow enough to allow raccoons to slip through but prevent larger animals from entering. Once inside, the interior would be fashioned with stepping elements that facilitate climbing with even greater ease.
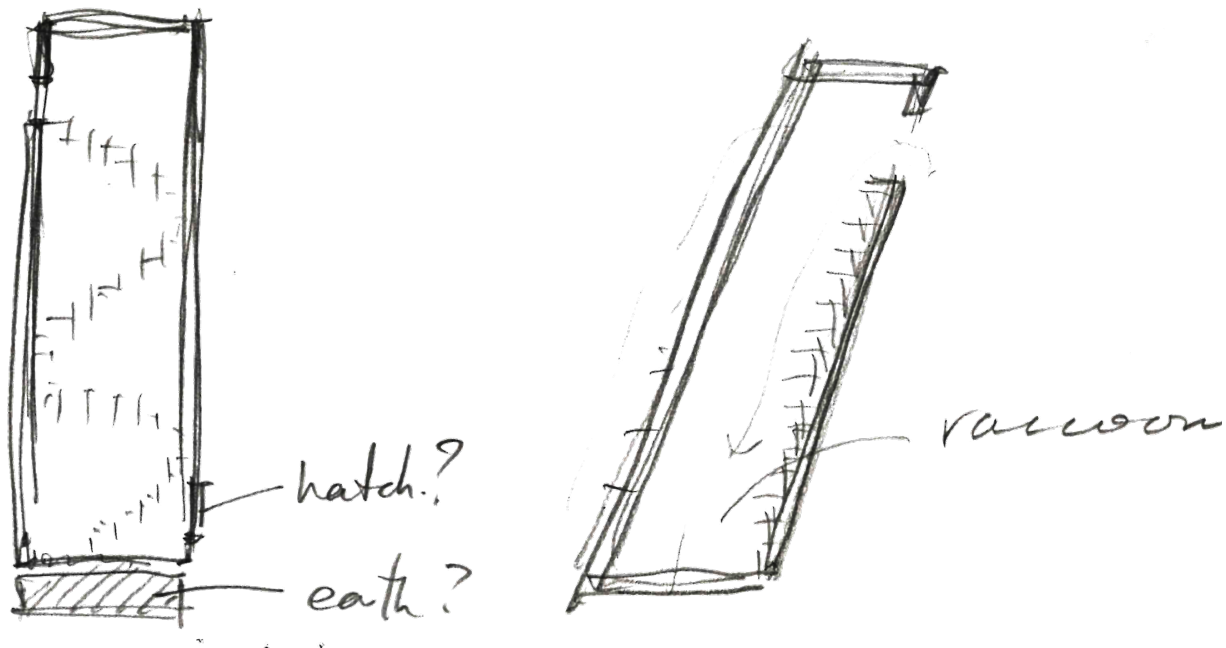

Fig 7-18. Columnar Raccoon compartment. 
Raising this columnar structure even higher would increase its level of security. Furthermore this may create opportunities for other types of compartments to be introduced underneath; these may be either places of observation for humans or perhaps other types of habitats for different animals.

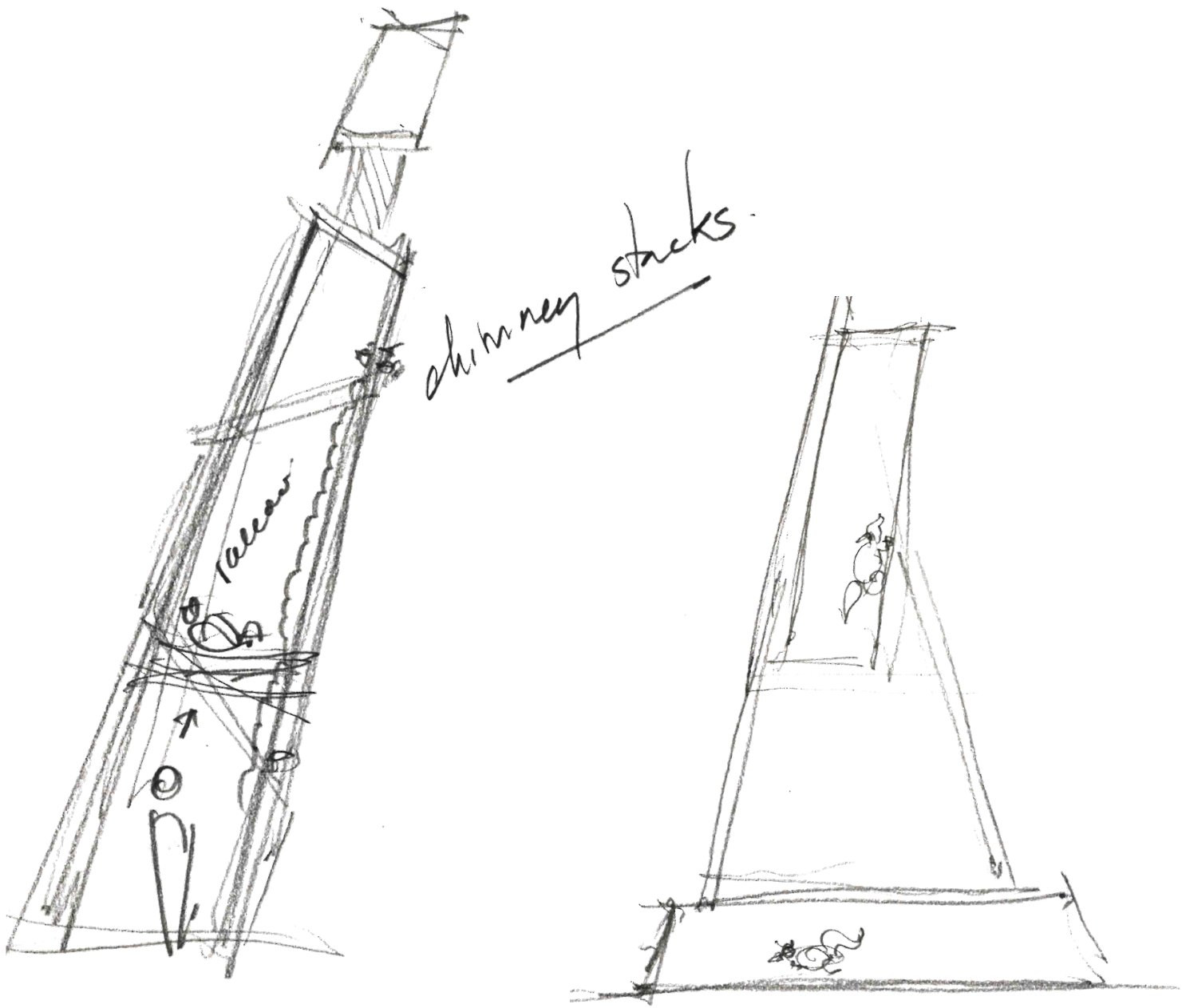

Fig 7-19. Observation opporunities.

Fig 7-20. Multiple compartments. 
As these structures become further articulated, the question of materiality needs to be considered. Using concrete to form the structure would ensure its stability and relative permanence. Alternatively, a wood or steel frame clad in wood could also be suitable. It may be not as cold as concrete and would be able to repaired and modified more easily if needed. To allow maintenance and cleaning, a hatch at the bottom of the raccoon compartment could also be implemented.

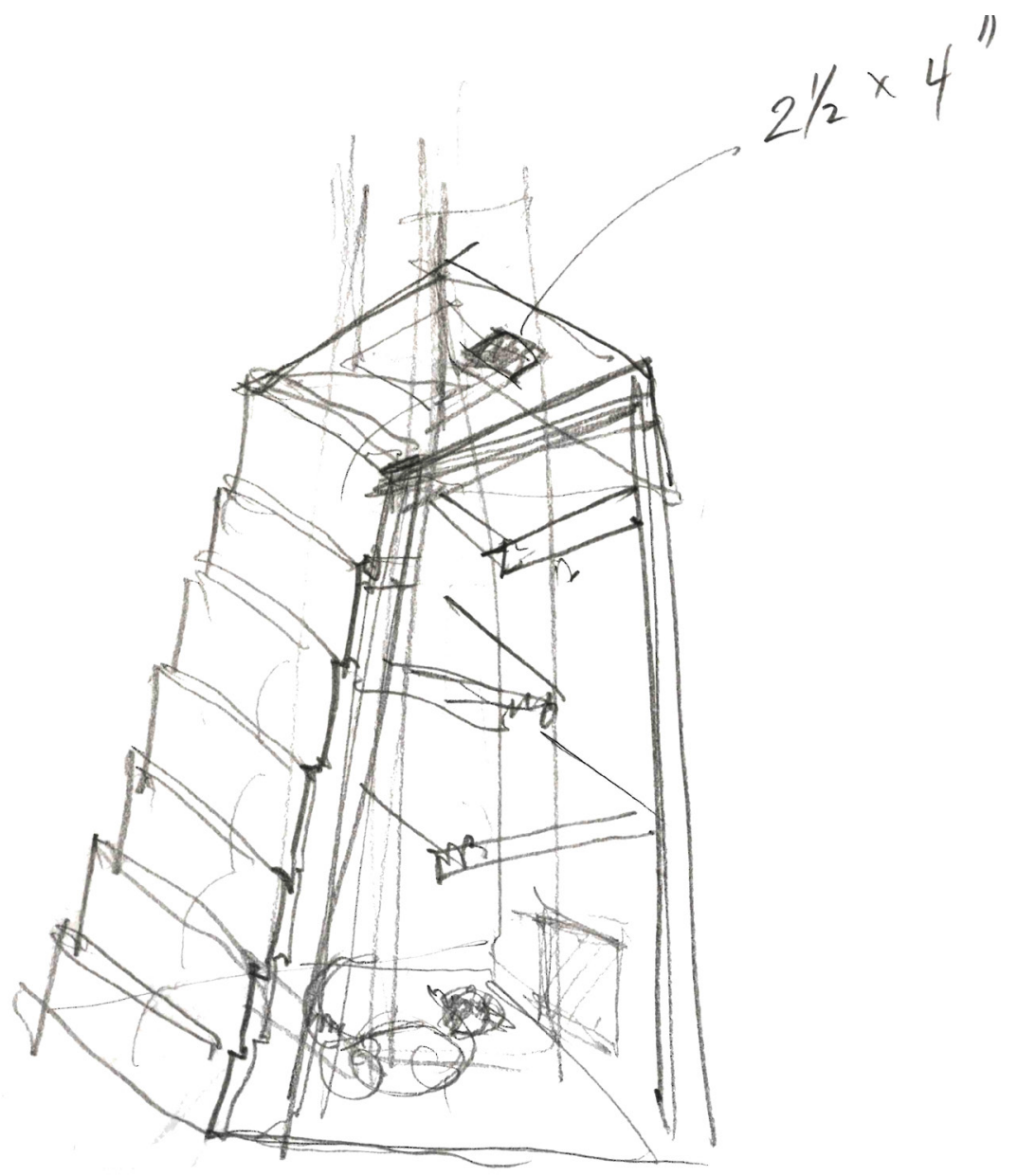

Fig 7-21. Stepping system. 


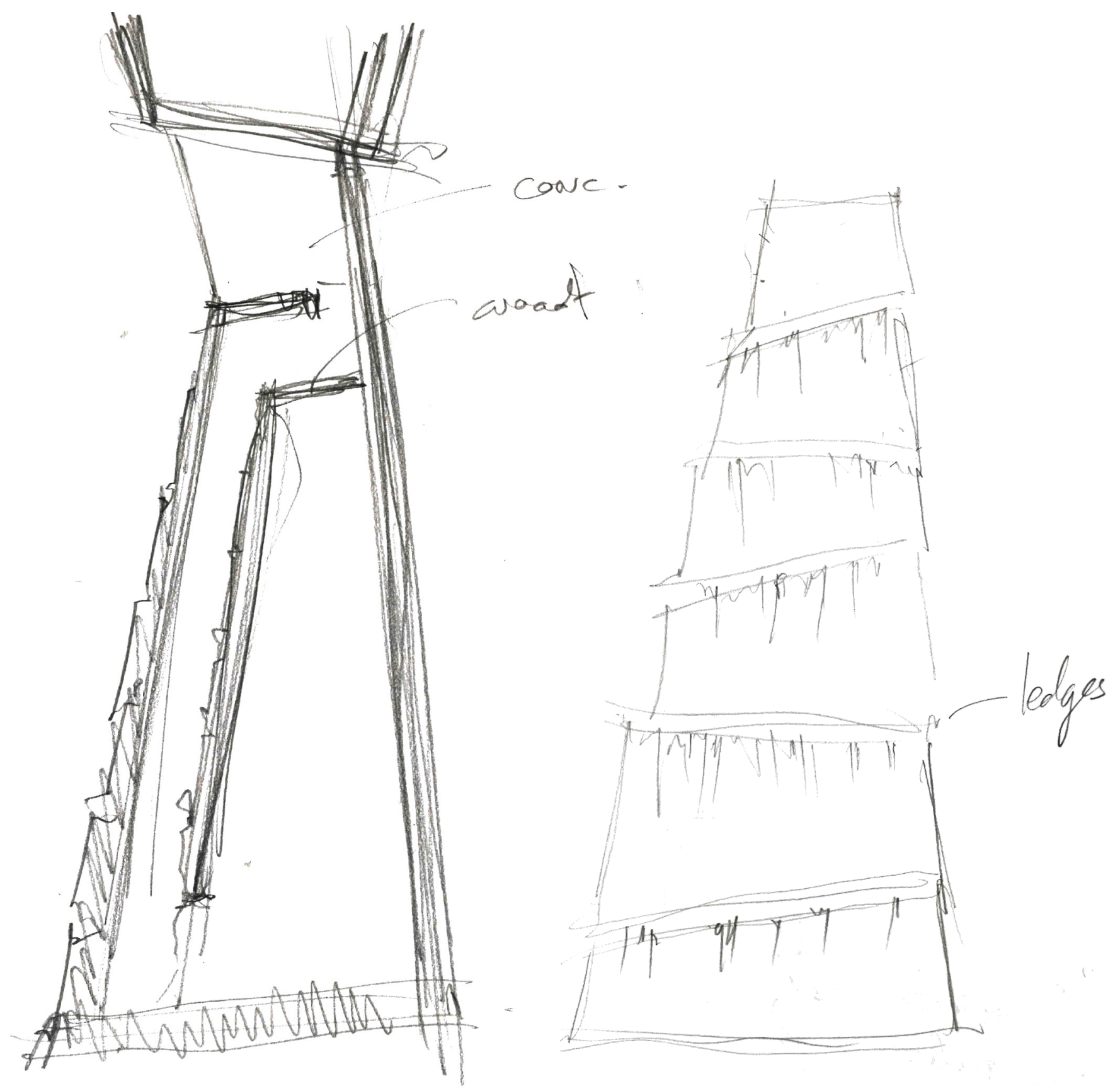

Fig 7-22. Cross-section.

Fig 7-23. Elevation. 


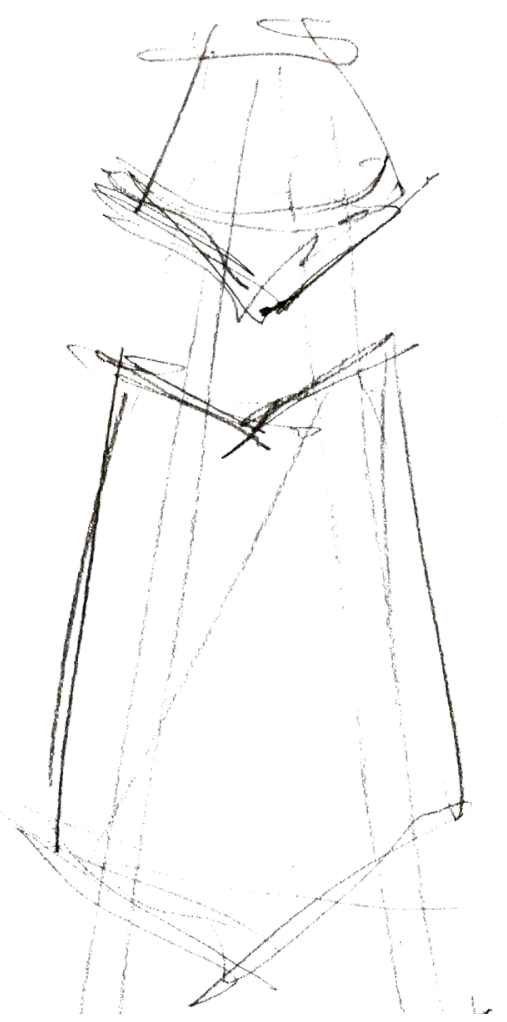

Fig 7-24. Owl Box at peak.

\section{Barn Owl Ecotopes}

Having a tall tower could provide opportunities to create habitats for flyers. Design parameters emerging from the research on Barn Owl boxes (see section 6.2.2) were incorporated into the structure. Some design tactics are considered to ensure some separation between the owls and the animals in the lower part of the structure. One idea was to have physical separation of the barn owl compartment from the structure below while keeping it supported by narrow struts. Another was to have an outward incline to this portion of the structure, making climbing that much more difficult. Finally, treating the surface to be finely finish would deter animals from being able to cling to it at all.

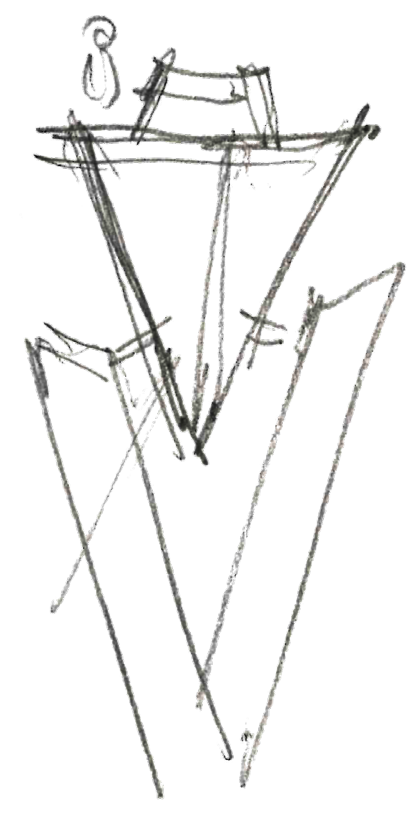

Fig 7-25. V-shaped compartment. 

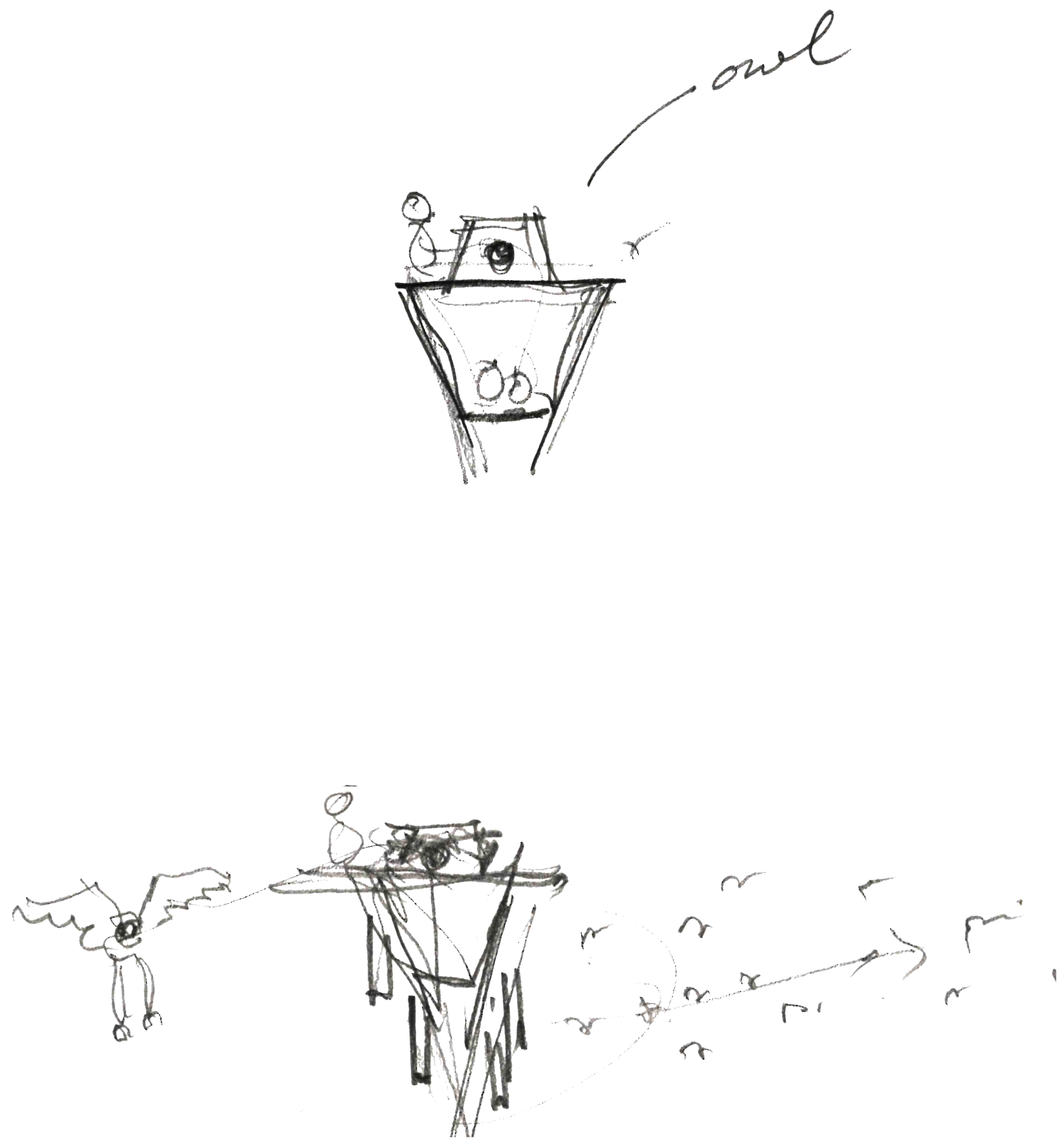

Fig 7-26. Iterations. 
Fig 7-27. Tower sketches.
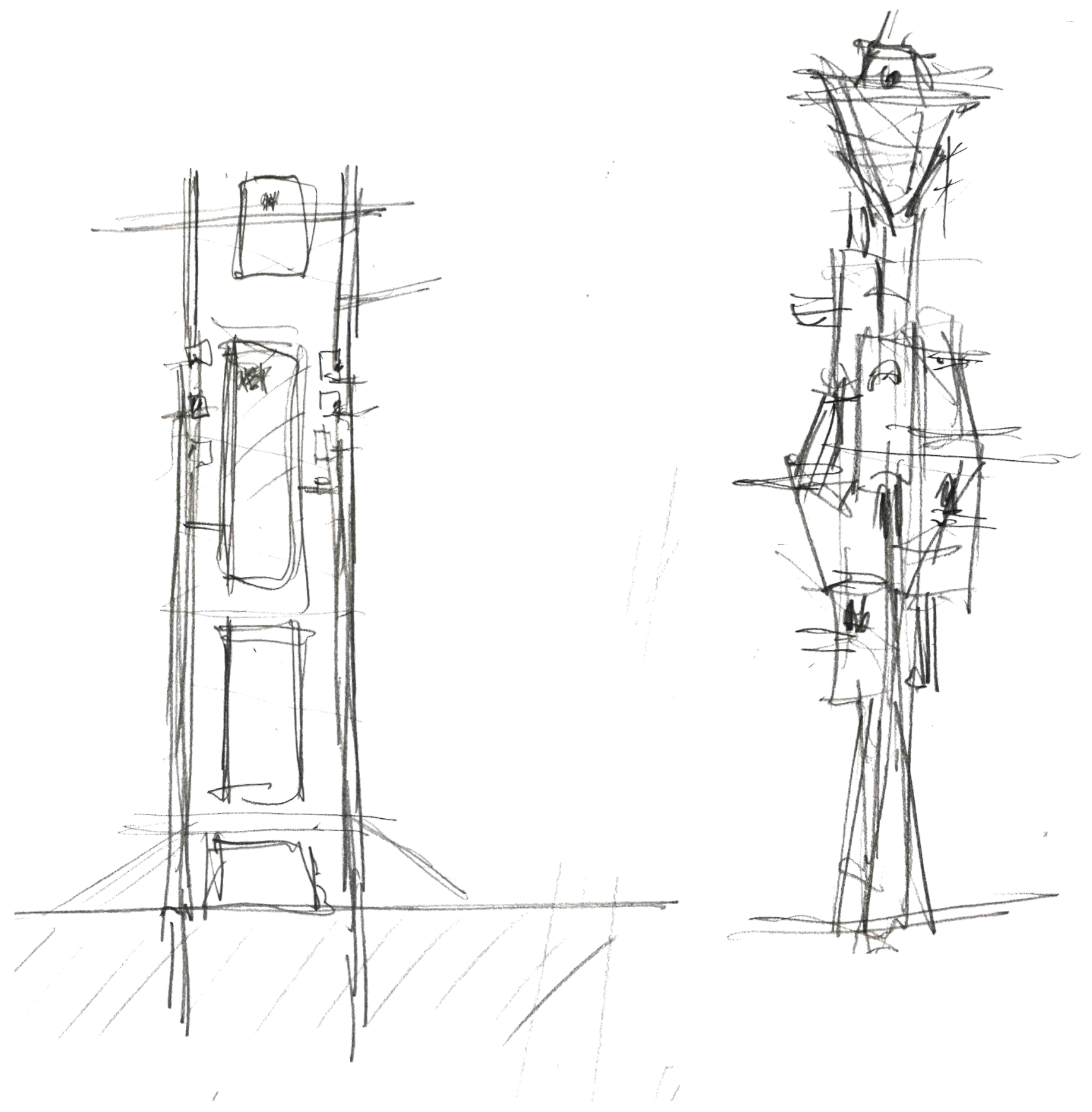


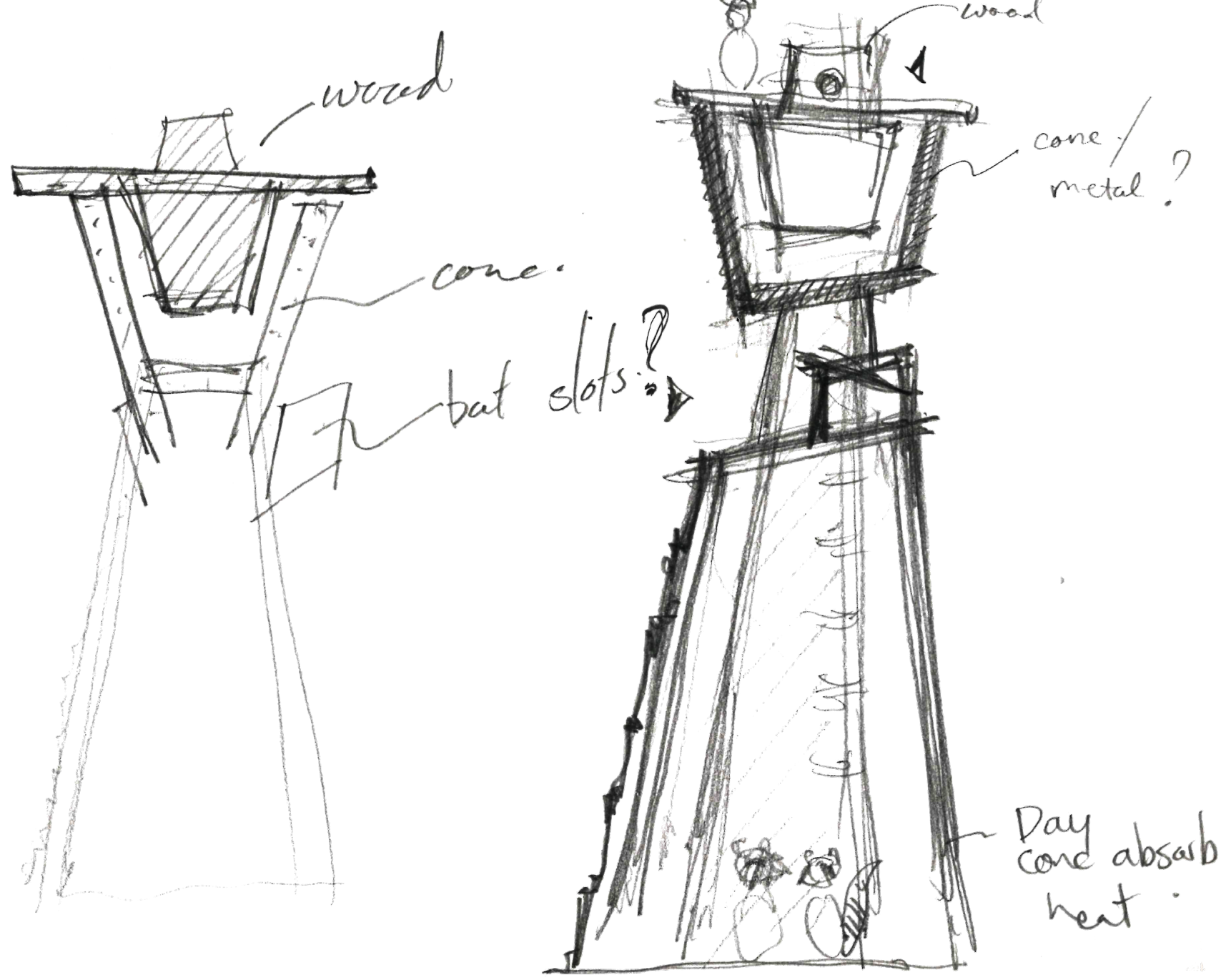





\subsubsection{The Obelisk}

The emergent form is a dedicated constructed ecotope for synanthropic creatures. This obelisk becomes one of a multiplicity of similar forms that perform the ecological function of providing habitat for animals within the urban environment. This could have ongoing ecological benefits in the long-run, strengthening the resilience of the urban ecosystem as a whole.

This also begins to portray an alternative experience that would be characteristic of the syn-anthropocene: a reality where human interventions vividly support the surrounding ecology. In this sense, humans take on the role of a keystone species, allowing their neighbouring wildlife to thrive.

The focus on the animals themselves is almost visibly apparent in the articulation of the towering obelisk itself. It presents itself as a closed-off mass that does not conform to human parameters; instead, distinctive penetrations are created, which are only suited specifically to particular species. This totemic structure further propels a cultural discourse - one that critiques the existing paradigm with respect to the relationship between humans, animals, and architecture.

The final chapter of this thesis continues on this trajectory and investigates the relationship between these actors. It explores the architectural conditions of a point of hyper intersection, considering the possibilities and limitations of symbiosis within the context of a synanthropic cultural paradigm.
See Appendix Fig A.1-2.

Minimum Access Area Needed by Common Wild Animal Species Found Around Homes

Page Over:

Fig 7-28. The Obelisk. 


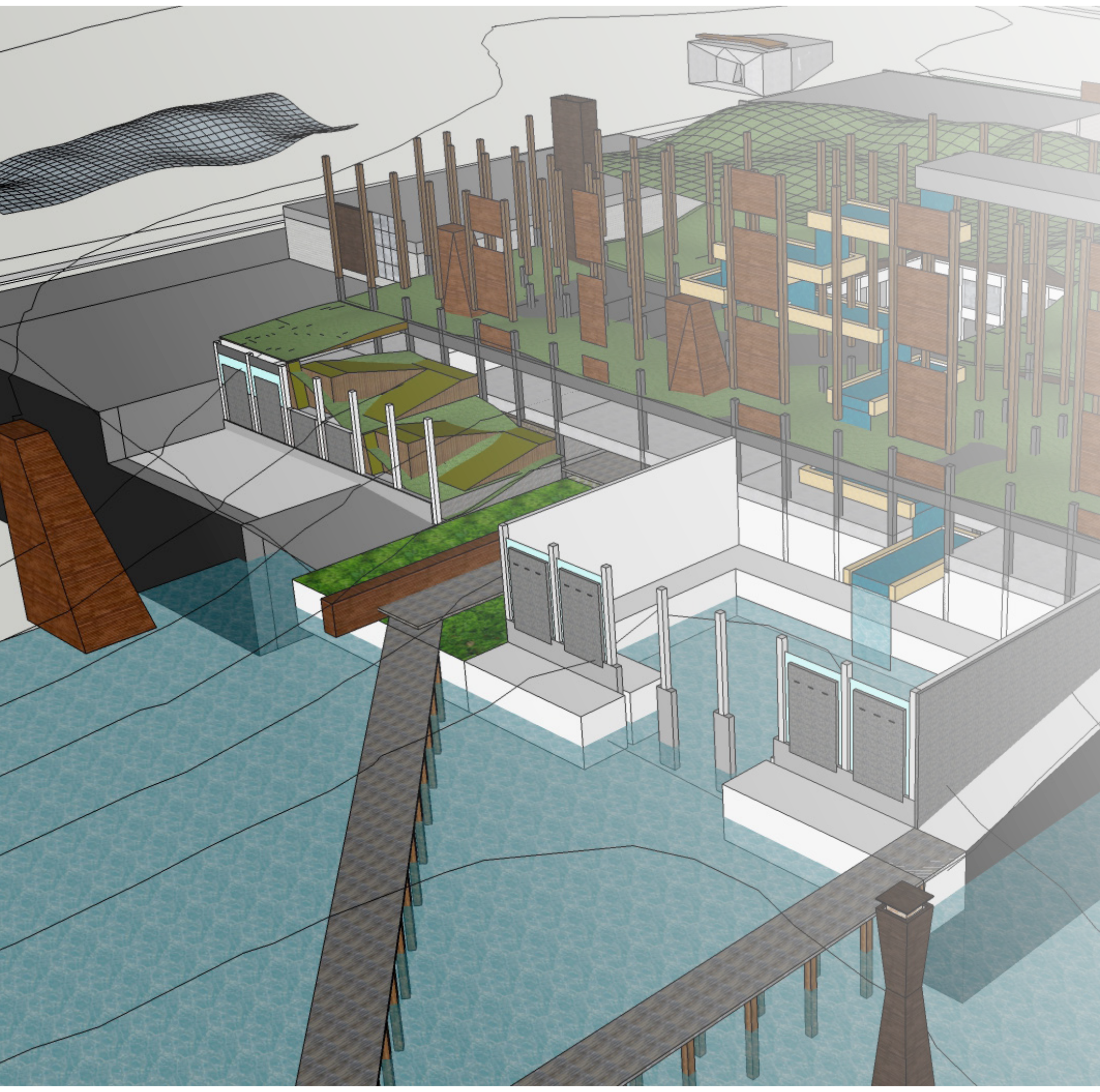




\section{Chapter 8}

\section{A Synanthropic Centre}

8.1

8.1.1

8.2

8.3

8.3.1

8.3.2

8.3.3

8.4
A Biological Centre

Site Selection

Schematic Design

The Synanthropic Centre

Heterogeneous Space

Envelope

Immersion

Into the Synanthropocene
175

179 185 187 199 211 217

221

Fig 8-1. In Process. 


\section{1}

\section{A Biological Centre}

In his 1971 book Animals and Architecture, David Hancocks discussed the evolving relationship that humans have had with the animal kingdom. He explored architectural works (such as the zoo complexes depicted in Fig. 8-2 and Fig. 8-3) that infused animal subjects into their design in various ways. The book concludes with a final discussion of a postulated symbiotic environment - a built facility that celebrates the ecological connectivity between all forms of life - a Biological Centre.

"The proposal to establish a Biological Centre has been based on the conviction that a better understanding of the biological environment, and of our relationship to the rest of the biological world, is vital for our future well-being. "'

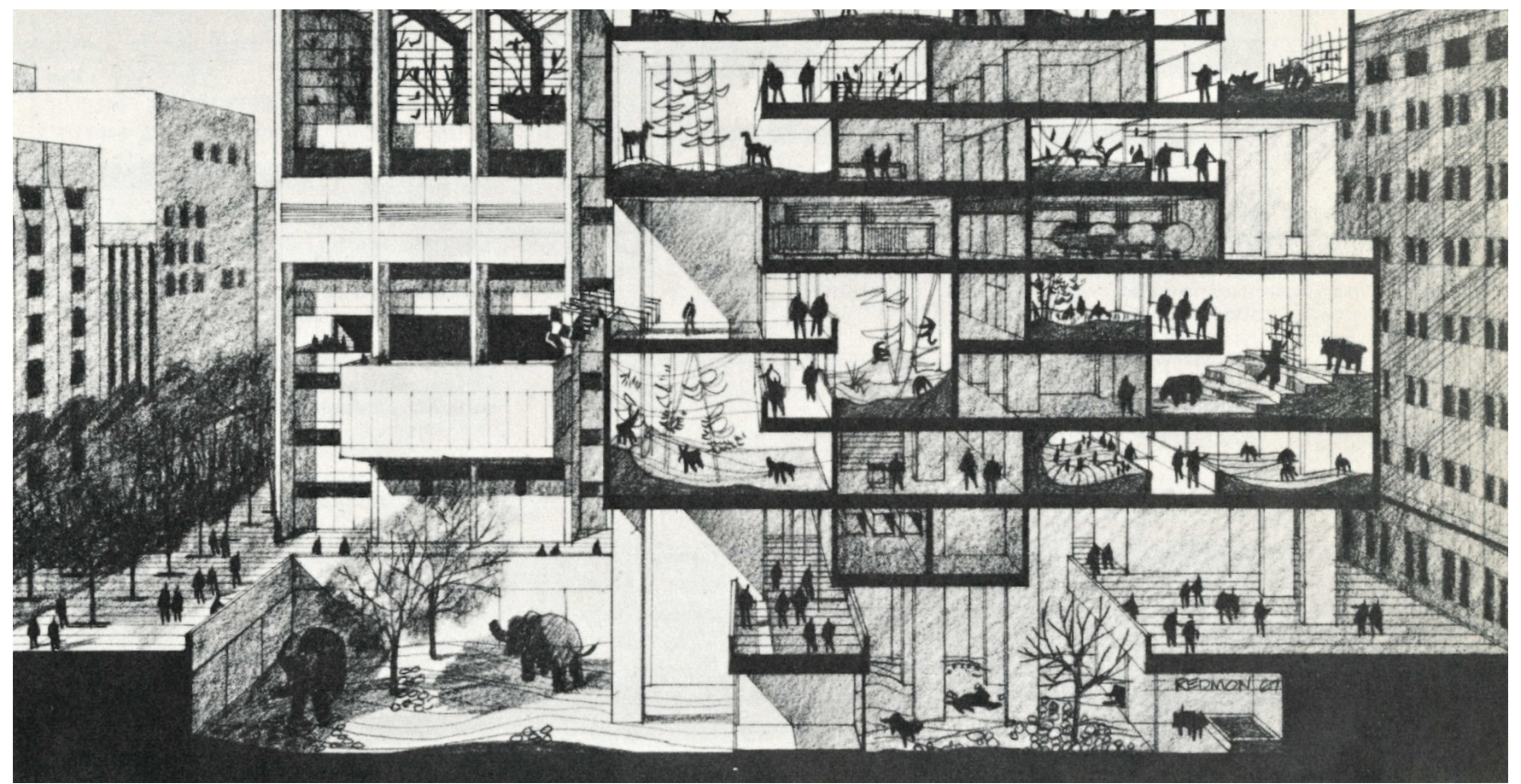

Fig 8-2. Downtown Boston Zoo by Cambridge Seven Associates.
1 David Hancocks, Animals and Architecture, Excursions into Architecture (London: H. Evelyn, 1971), 193. 
The author went on to highlight that this type of place aims to re-orient people's perspectives with respect to their relationship to their surroundings:

"Instead of being an observer the visitor would then see himself as a participant in the biological scene, and the Biological Centre would realise to the full the need to provide a recreational and educational service to its community. ${ }^{2 "}$

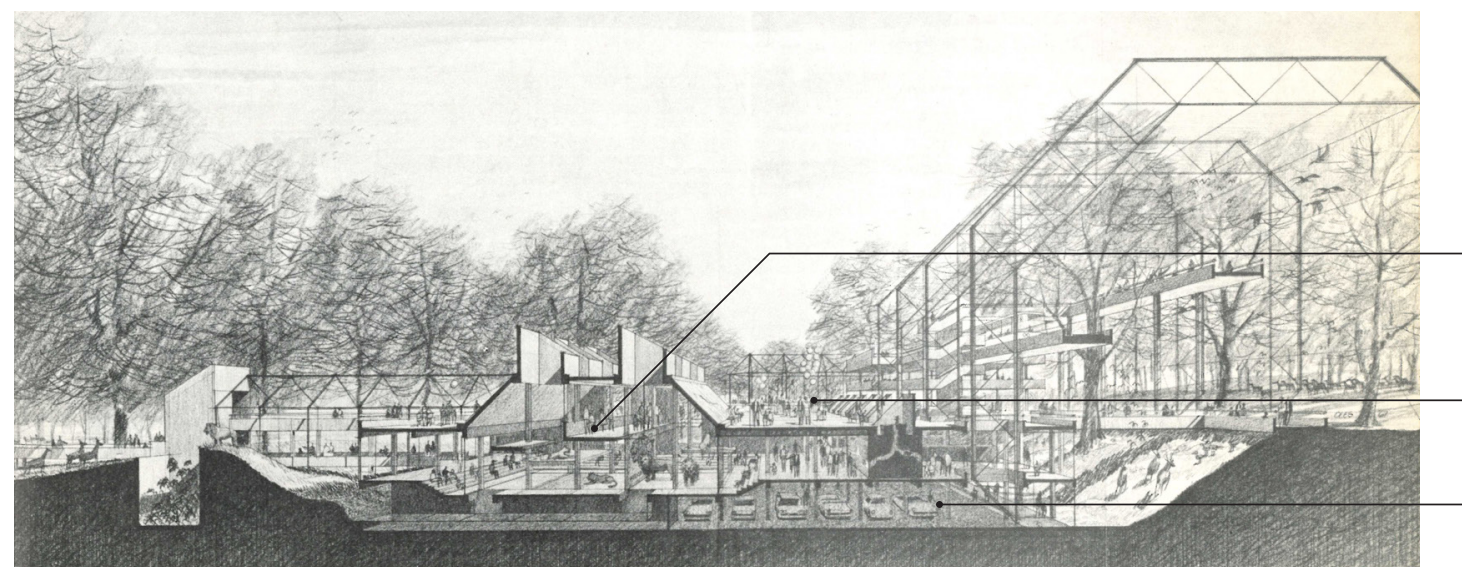

SHARED SPACE FOR ANIMALS \& VISITORS SUMMER CONCOURSE SERVICES

This facility was envisioned not as a zoo that exhibits captive animals on display, but as a hybrid natural/built environment that communicates ideas. ${ }^{3}$ Animals are not considered as presentational objects but rather as genuine autonomous subjects within the shared built environment. ${ }^{4}$
Fig 8-3. Franklin Park Zoo by Perry, Dean \& Stewart Architects.

2 Hancocks, 193.

3 Hancocks, 190.

4 Hancocks, 191. 
This idea is echoed in another theoretical work from 2010. Urban Ecopoesis, an award-winning thesis project by Koh Hau Yew, was designed as an ecological Green-school with a focus on outdoor environmental education in Singapore. ${ }^{5}$ This design aimed to create a hybrid natural/artificial form that would link nearby forest patches while creating a cultural connection between the public to biodiversity. ${ }^{6}$ Similarly, The Ford Calumet Environmental Center (described in section 3.1.3) promoted an ecological program through workshops and training activities. These types of places create an immersive environment that communicates a mutual relationship between communities and their local ecology.

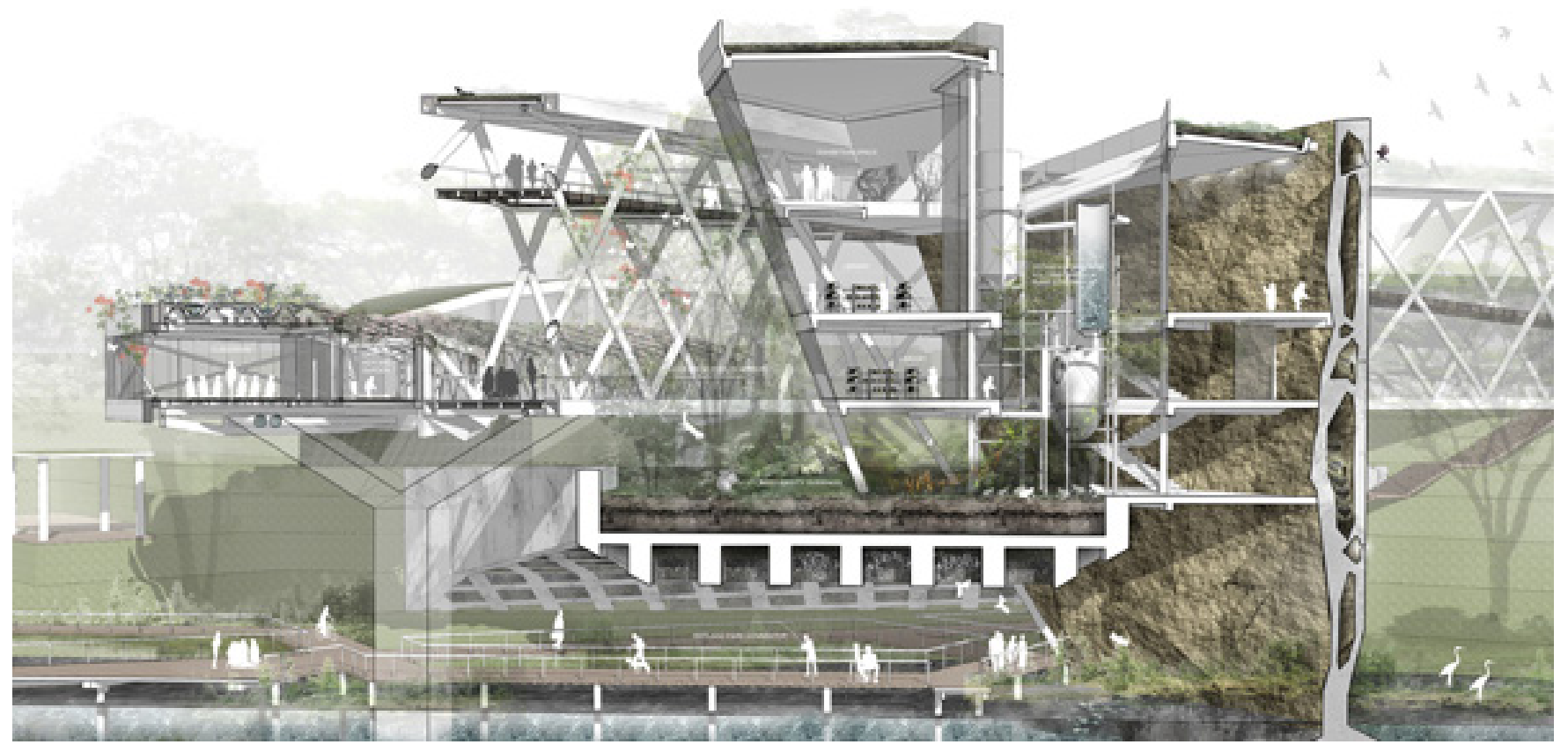

Fig 8-4. Urban Ecopoesis by Koh Hau

Yeow, 2011 Animal Architecture Award.

5 Hau Yeow, "Urabn Ecopoesis," Koh. Hau. Yeow, last modified August 8, 2010, accessed November 11, 2019, https://hauyeow.wordpress.com/2010/08/08/urban-ecopoesis/.

6 Ibid. 


\section{A Vehicle for Design}

This thesis culminates in the development of a synanthropic centre that tests out the intersection of wildlife with human space. Acting as a node within a broader system, this facility would accommodate animal inhabitation and movement through the urban landscape. The centre would be formulated in a way that promotes a paradigm shift toward an ecological perspective as opposed to an anthropic one. Educational programming and experiential opportunities would deepen people's understanding of urban wildlife and strengthen their relationship to the surrounding ecosystem. This centre would be one of several such loci that act as catalysts in a socio-ecological evolutionary process that carries humanity into the synanthropocene. 



\section{Existing Plan | Ground} Scale 1:500

$\mathbf{N}$

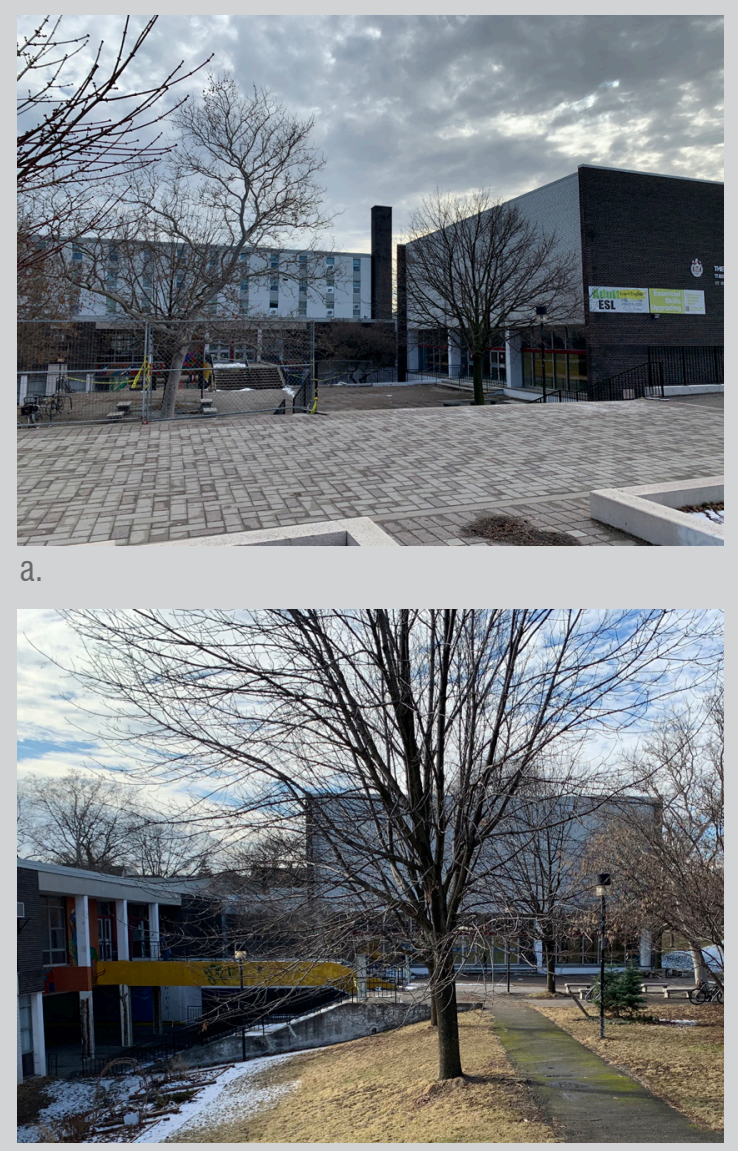

b.

Fig 8-8. Site Photos:

a. Entry plaza.

b. Elevated catwalk towards entrance.

\section{CHRISTIE PITS PARK}

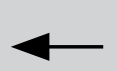

Fig 8-9. Existing Plan - Ground.

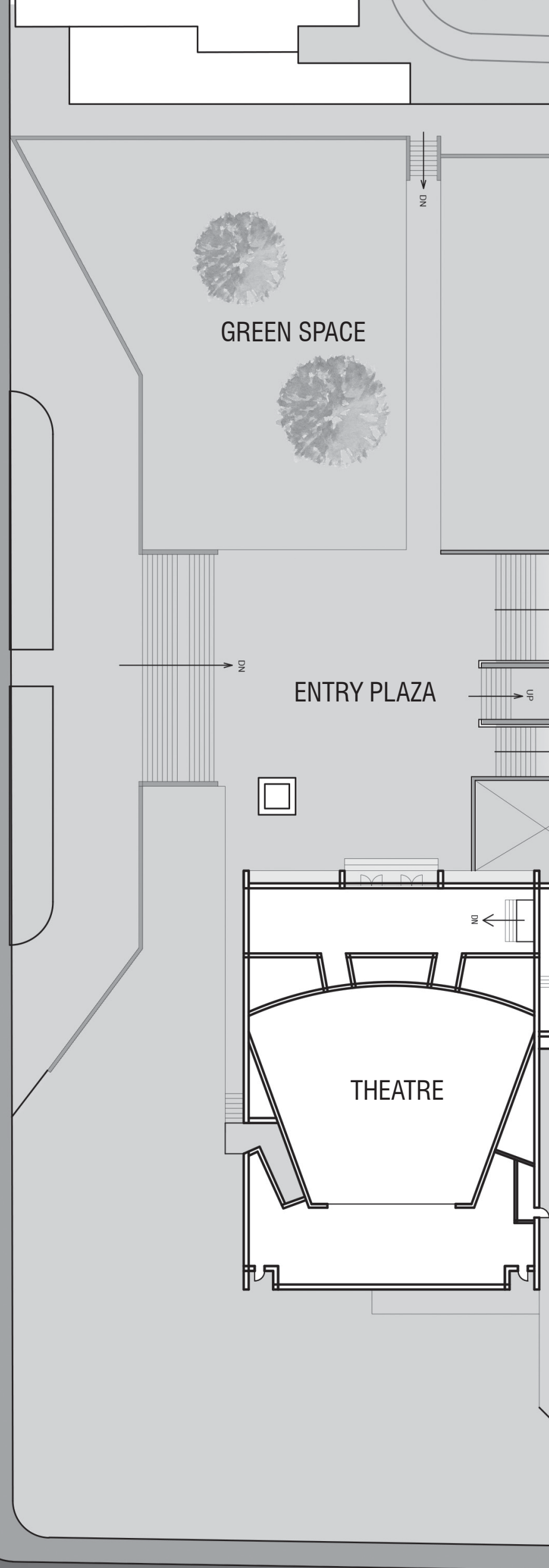




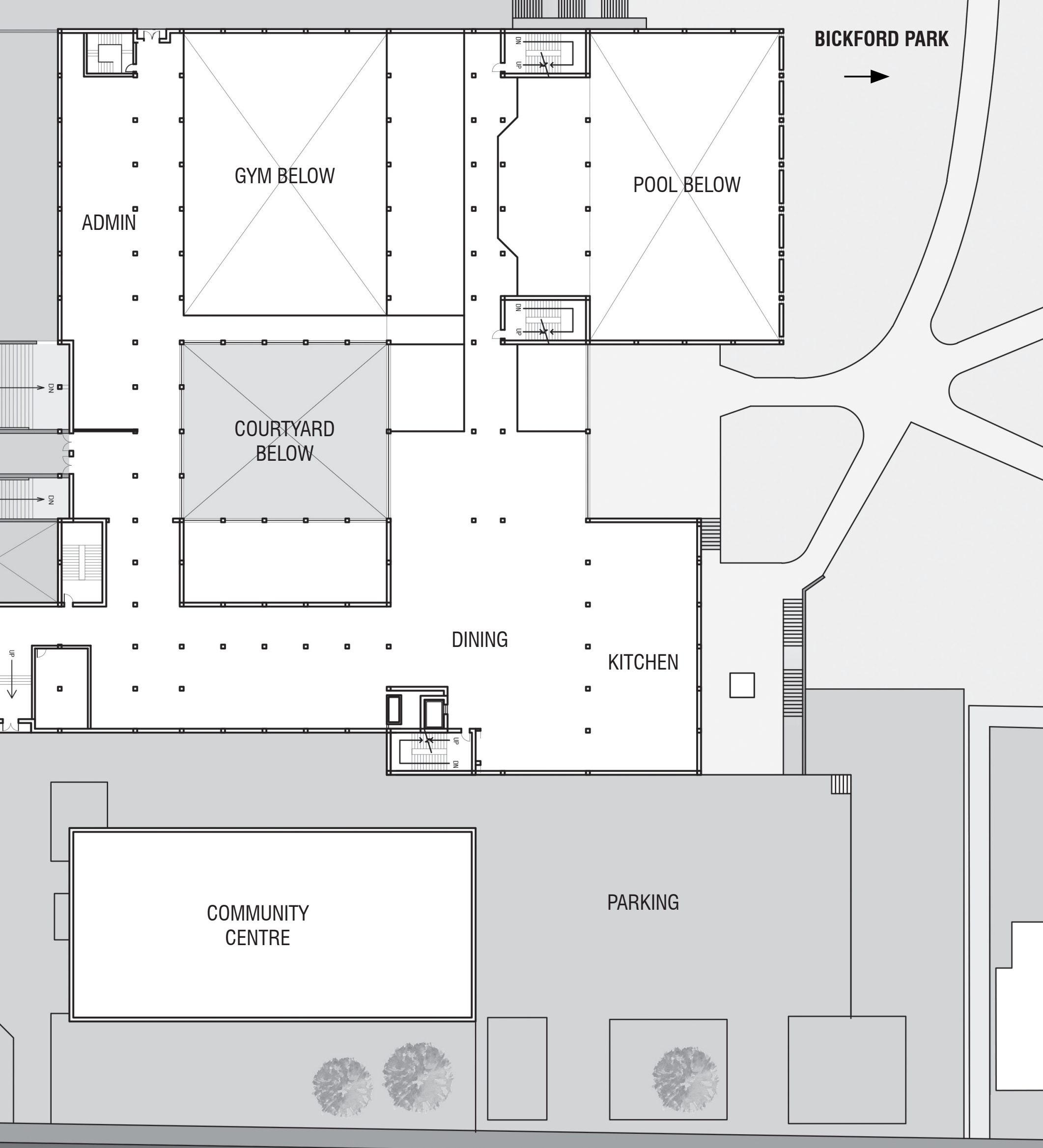




\section{Existing Plan | Lower Level}

\section{Scale 1:500}
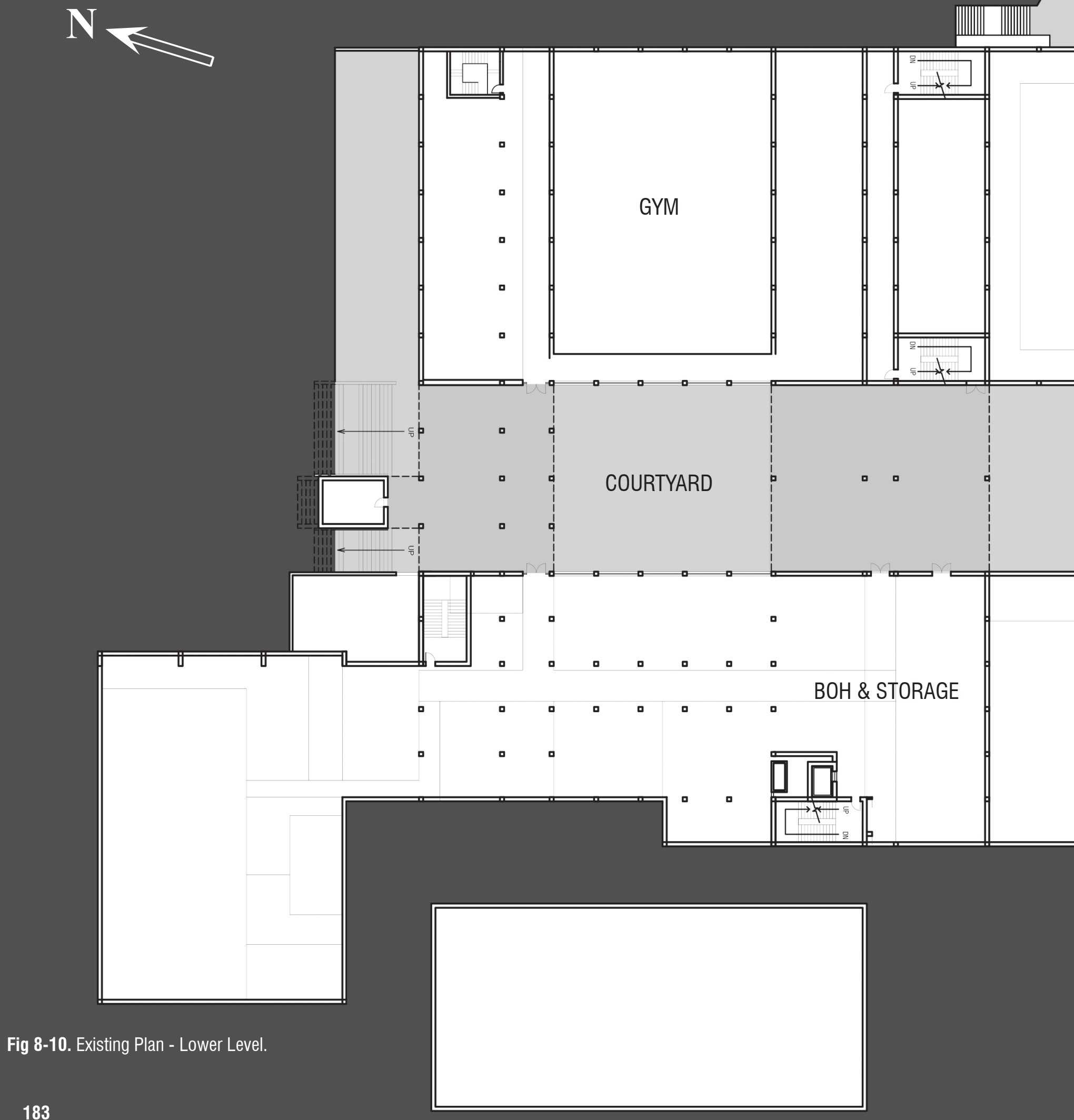

Fig 8-12. Rededicating the building to wildlife, sketch on trace paper.

\section{$=$}
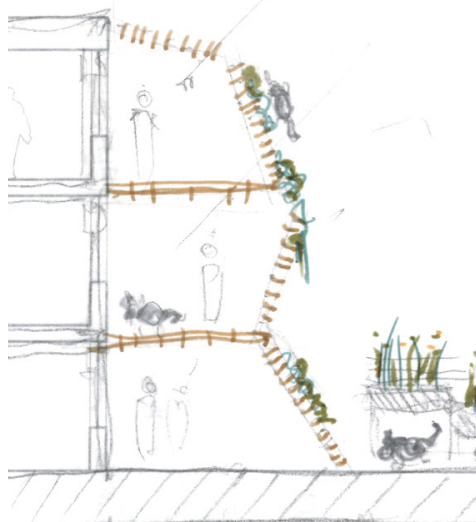

\section{Schematic Design}

From the outset, the intent for the project was to integrate the built-form of the building into the local landscape of the site. Portions of the building would be modified to facilitate this extensive re-integration: walls would be altered so that animals would be able to climb them, and the pool would be opened up into the park to create a more substantial wetland environment. This merging of natural and constructed elements would create a hybrid architectural environment that raises various questions; the most prominent of these is how would the boundary condition between humans and wildlife be addressed in this setting?

The sketch below depicts two potential ways to formulate this boundary. On the level below, a barrier does not allow animals to enter the building, but people inside are able to look into the wetland. The level above considers an interstitial space - an area that is shared between humans that have entered from a more private space within and animals that have permeated the envelope from the outside.

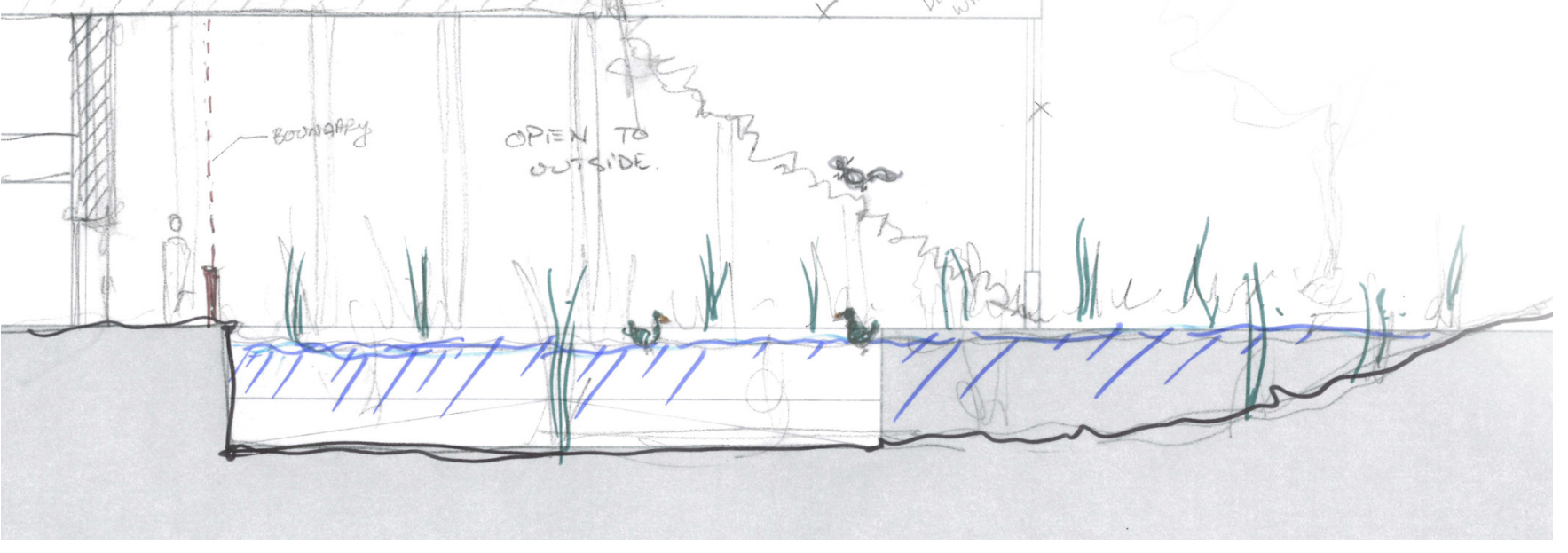




\section{A Beacon}

The design evolved to create an architectural proposal that acts as a socio-ecological catalyst. The building is meant to exemplify and demonstrate the possibilities of an architectural design that responds to the ecological dynamics of local wildlife. The building façade adopts the requirements of bird-friendly guidelines and creates a membrane that prevents birds from colliding with the building's glazing. The semi-transparent façade would allow vague visibility into the interior space beyond. Inside, a substantial portion of the building would be dedicated to the design of an environment that is intended to be shared by animals and humans. The intent for this design is to investigate how architecture can facilitate a hybrid ecocultural environment as well as envision the experiential qualities of this intersectionality. The building is meant to serve as a beacon of synanthropic activity - a place that embraces a paradigm that values co-existence with the fullness of the local biome.

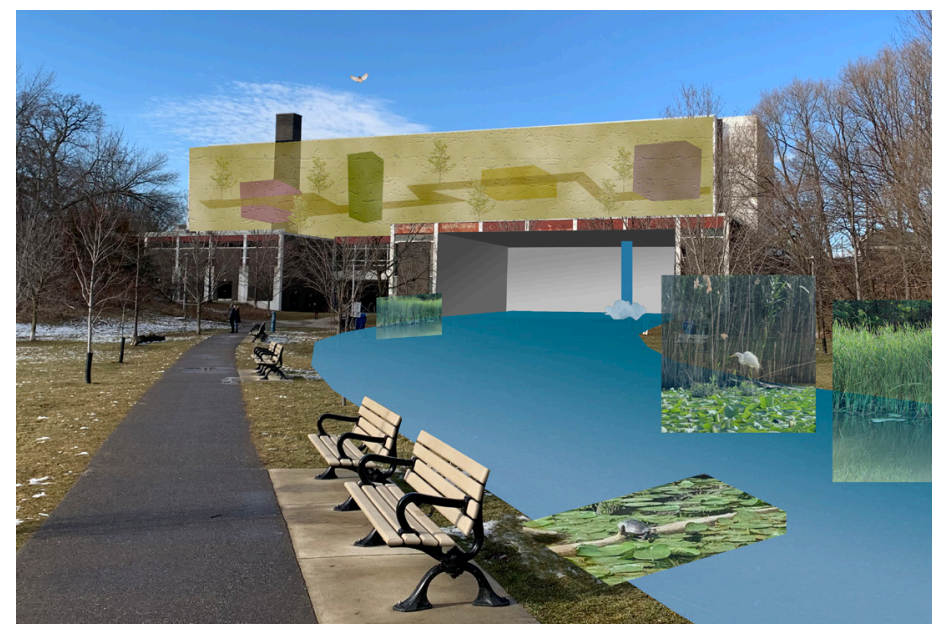

Fig 8-13. Visualizing the wetland and the building's new enclosed micro-climate.

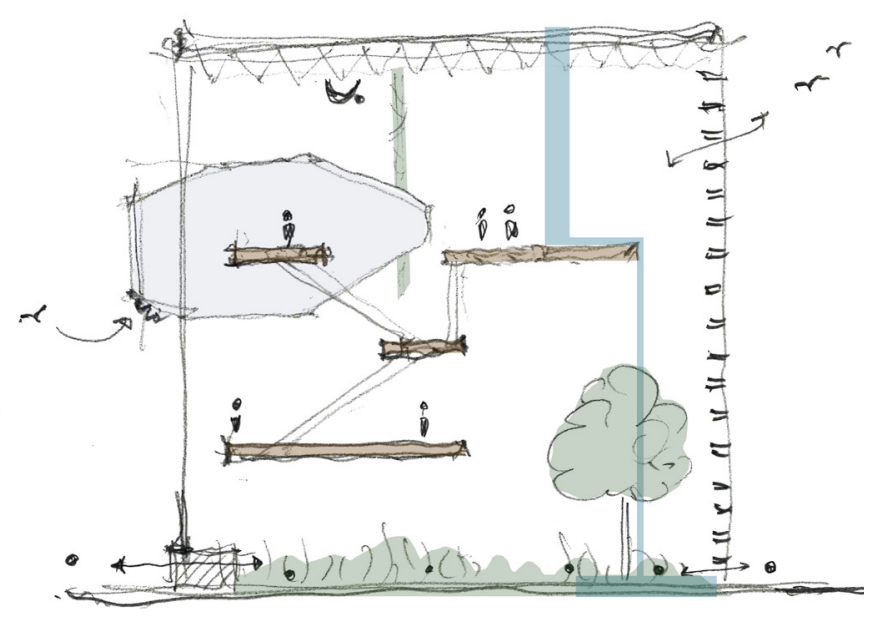

Fig 8-14. Conceptual section of the heterogeneous space.
See Appendix Section A.6. Synanthropic Centre (DD) 
Fig 8-15. The Synanthropic Centre acting

as a node within a system.

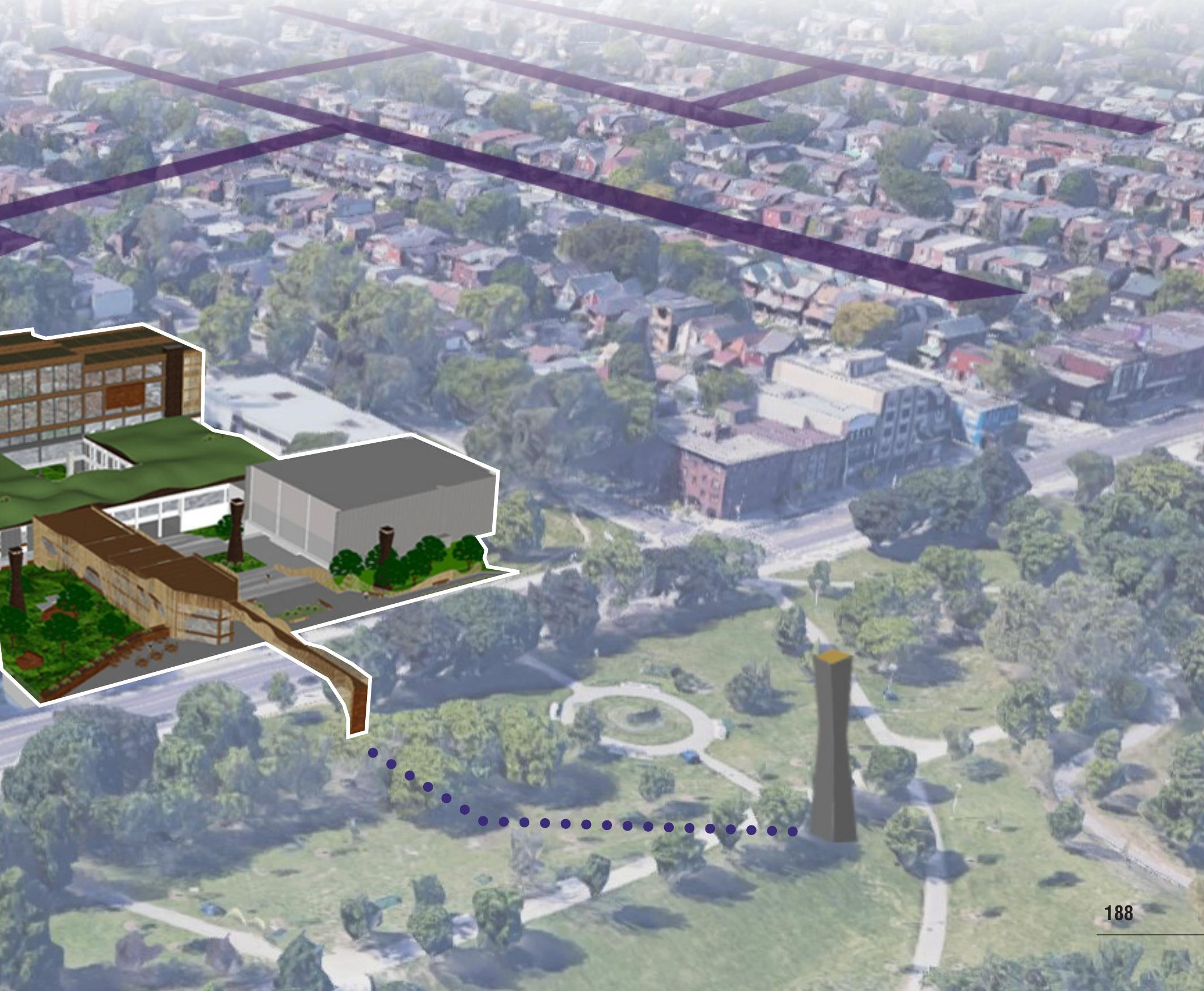




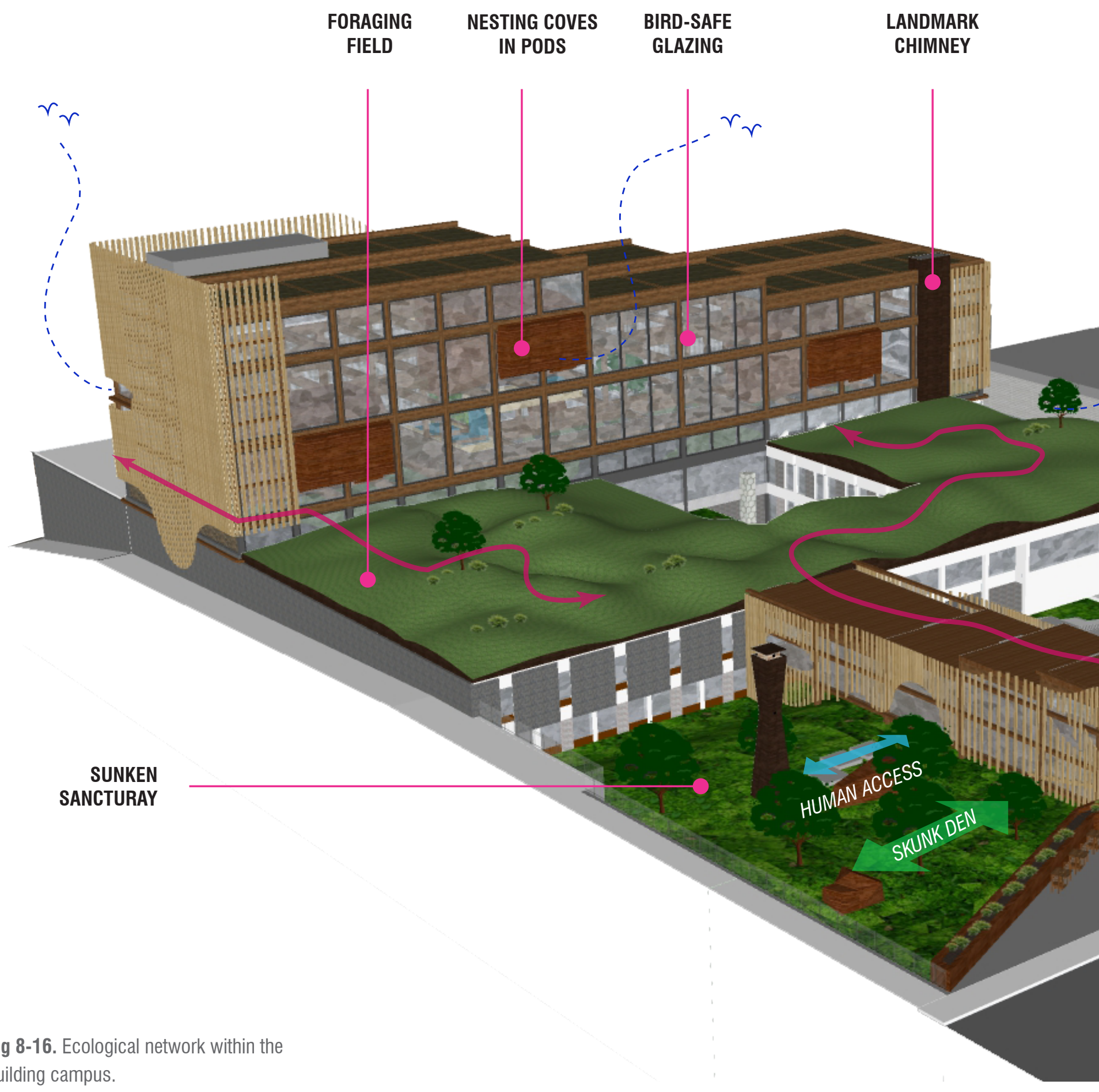




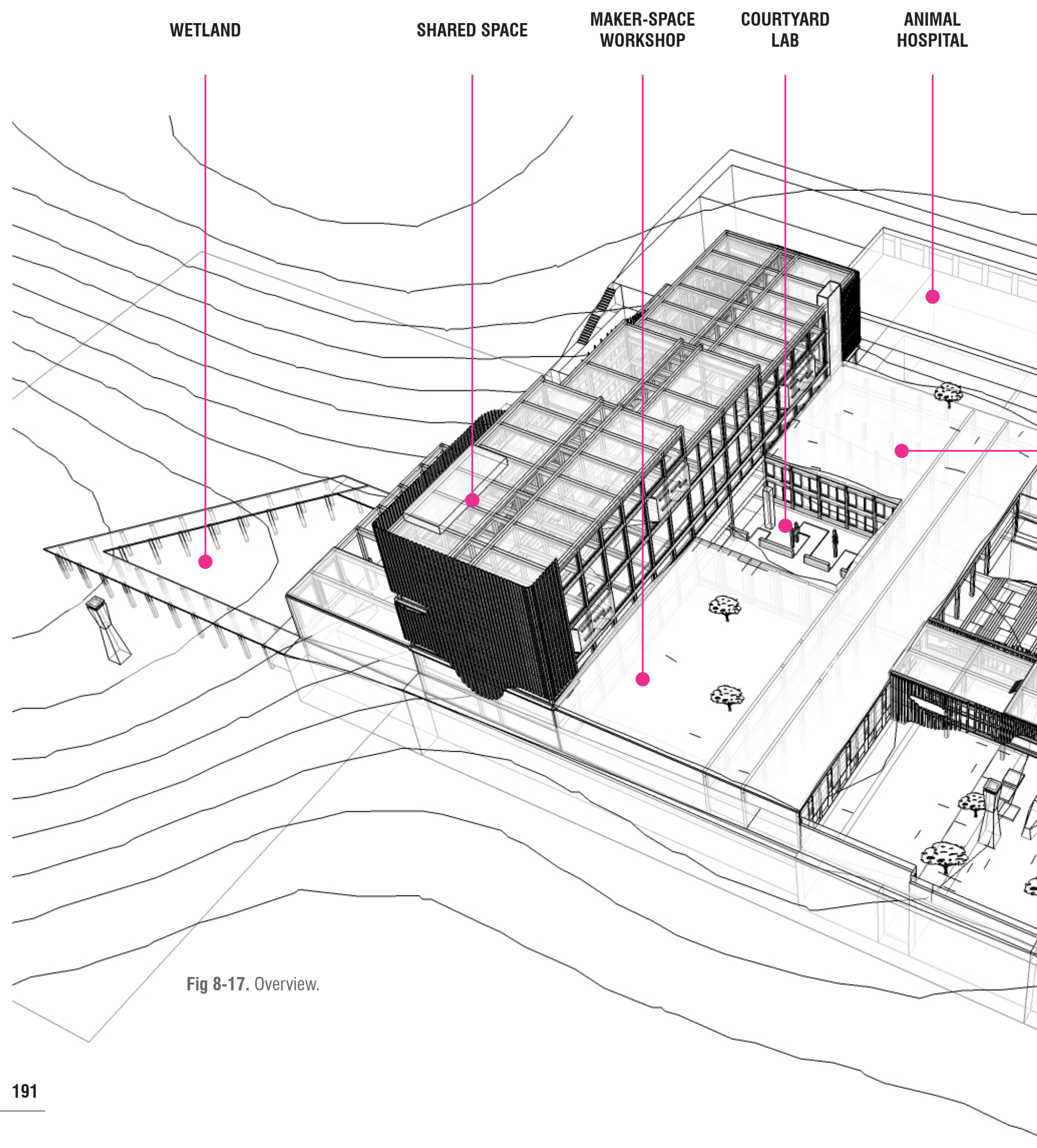


Floor Plan | Ground

Scale 1:500

$\mathrm{N} \approx$

\section{CHRISTIE PITS PARK}

\section{||||||||||||}

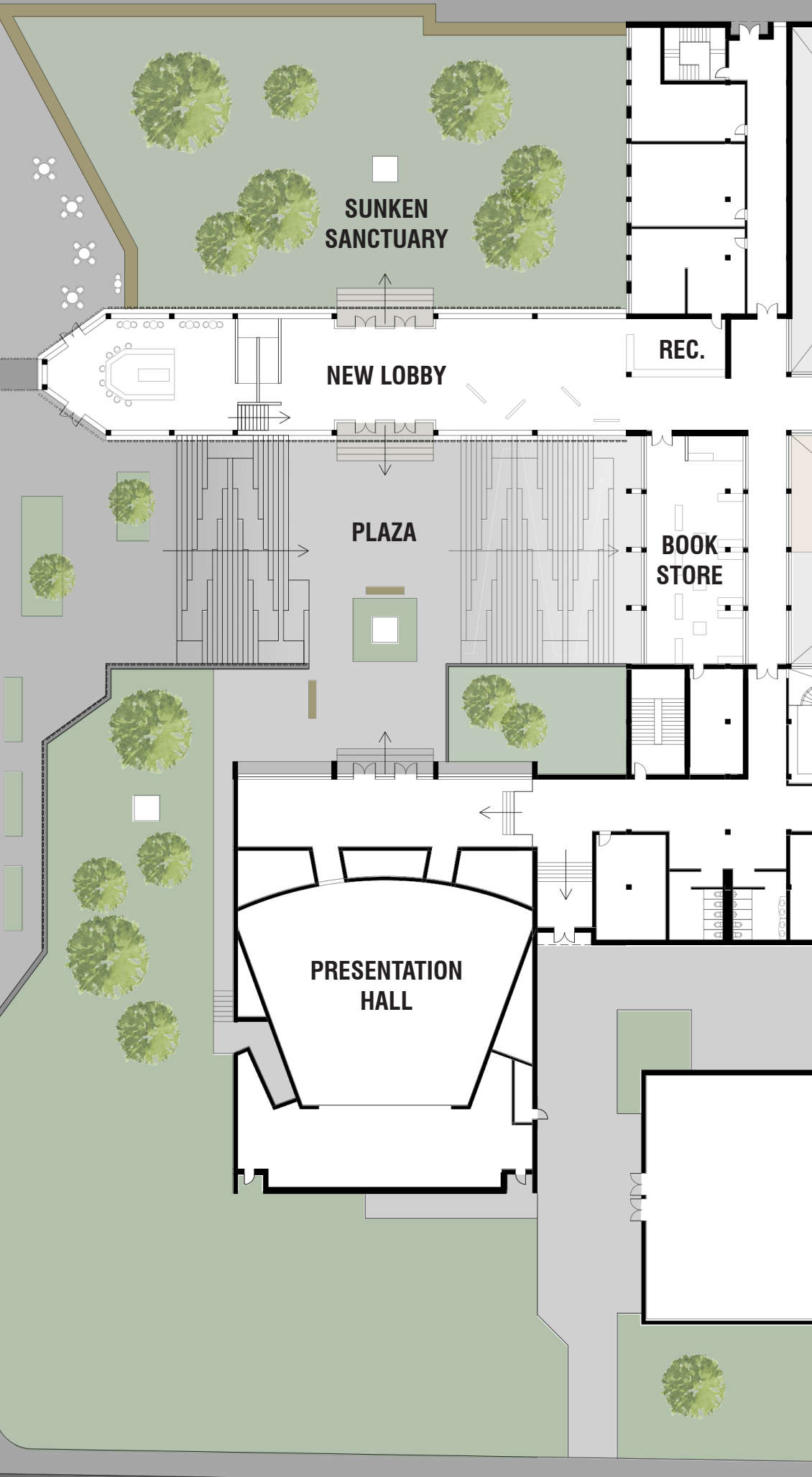

MI

Fig 8-18. Floor Plan - Ground Level. 
Floor Plan | Lower Level

Scale 1:500

$\mathbf{N}$

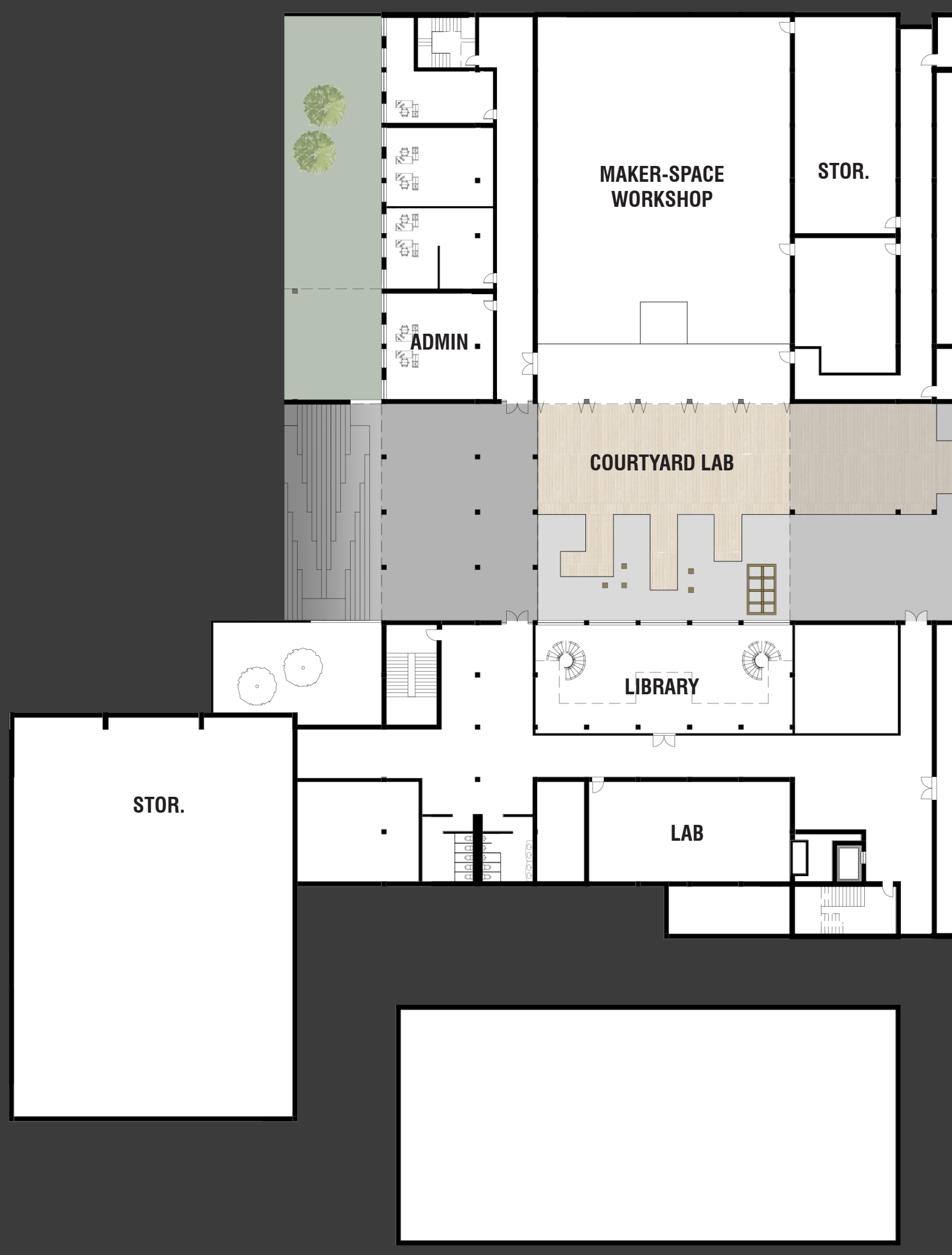




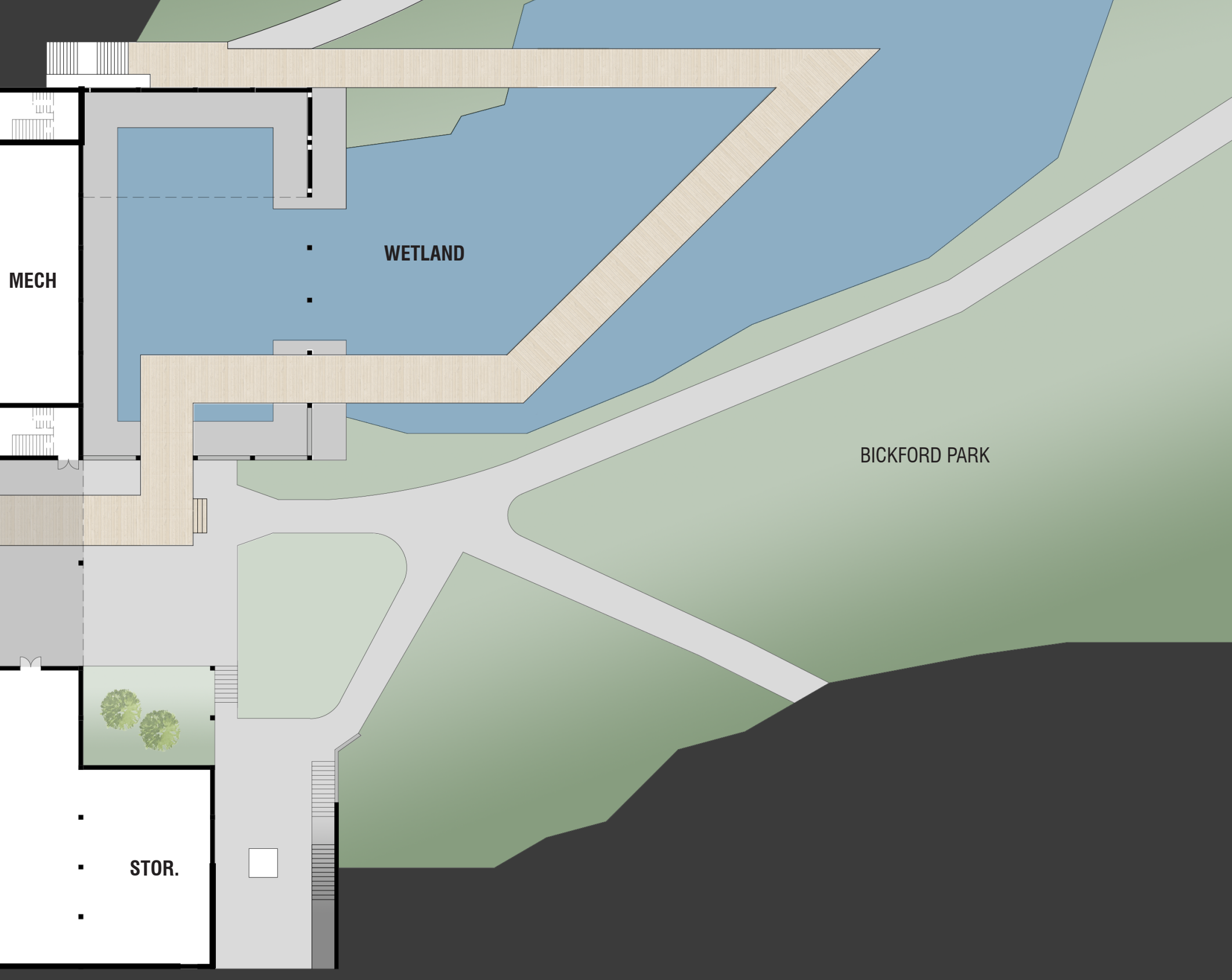

Fig 8-19. Floor Plan - Lower Level. 


\section{Main Axis}

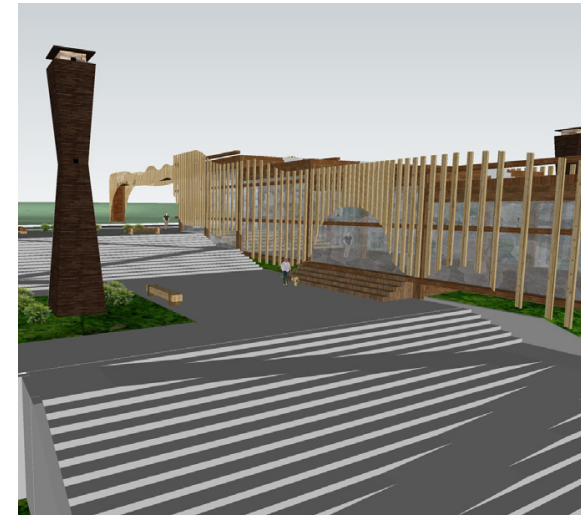

Fig 8-20. Entry plaza with redeveloped stair-ramp.
The project maintains and accentuates the central North-South axis of the building where an underpass forms a link between Bloor Street and Bickford Park. The catwalk to the existing entrance is removed, clearing space for a more open and prominent stairway with an integrated ramp. The main entrance is relocated to a new addition that extends from the building onto the street level on Bloor. The new addition frames this axis and forms an interior corridor through the building that runs parallel to the exterior underpass. Overhead, animals move along the rooftop and across the wildlife crossing that extends from the addition. This axis links the opposite ends of the site and provides circulation for people and animals along its trajectory.
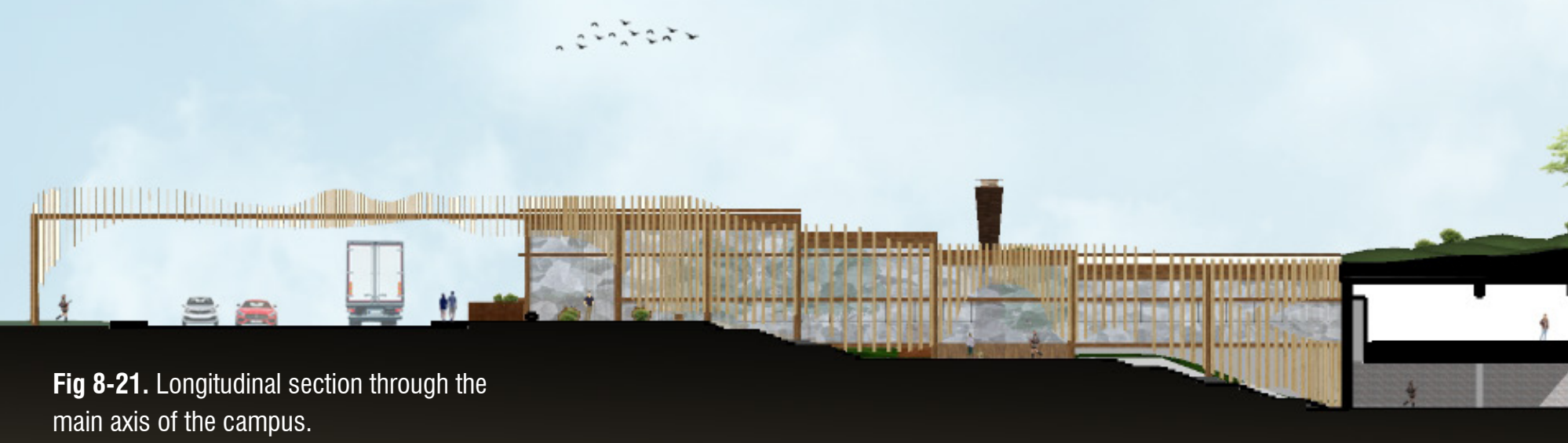
Scale 1:150

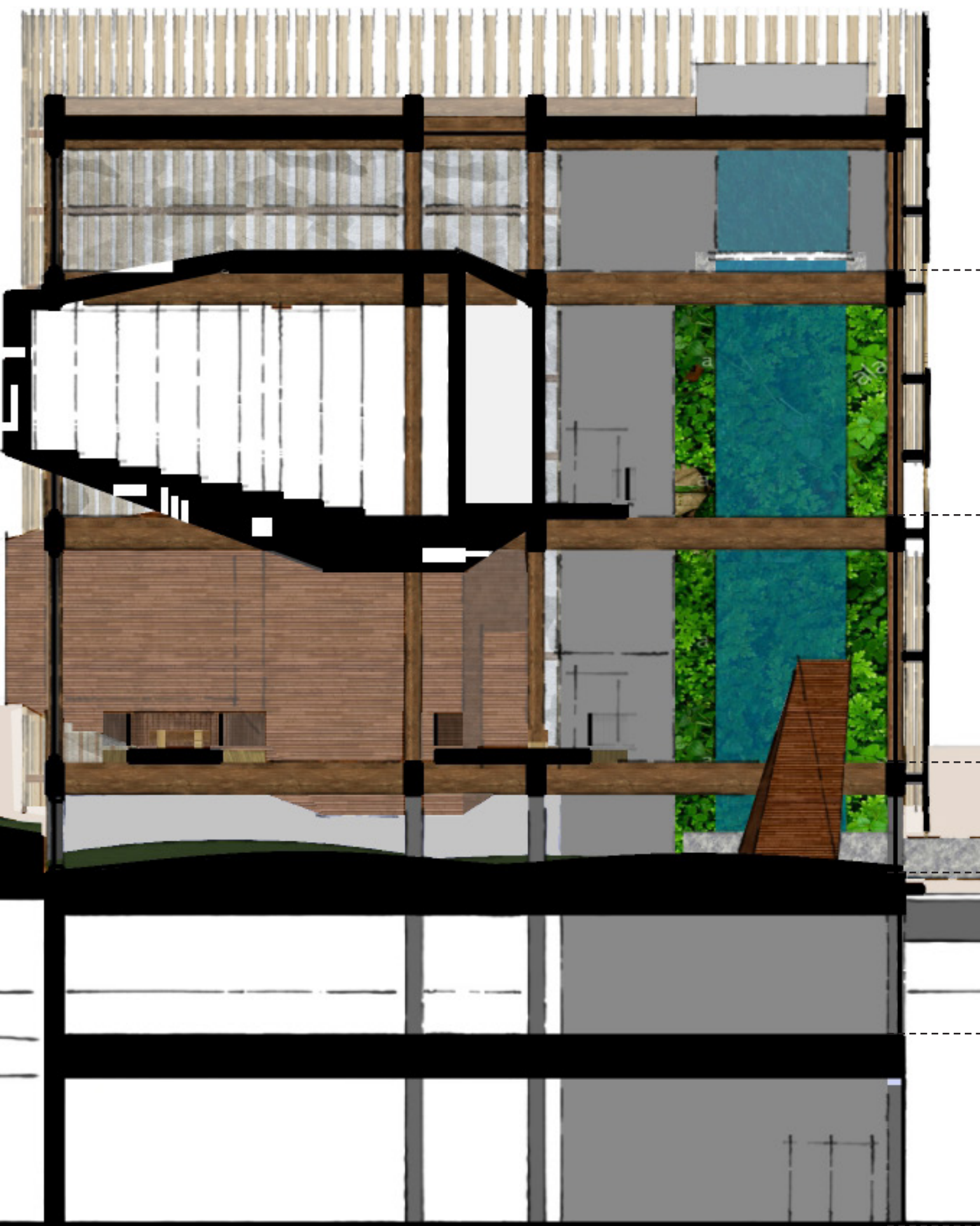




\subsubsection{Heterogeneous Space}

Level 8

Level 6

Level 4

Level 3 - Wildlife Landscape

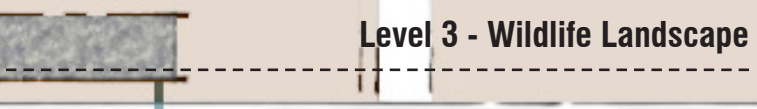

The three-storey block at the south of the facility would be gutted and expanded into a larger volume. This space aims to provide an enclosed environment that is shared by both humans and wildlife - a heterogenous space. Inspired by the Amazon Spheres in Seattle (see section 3.1.7), this space cultivates a rich environment of natural growth. Animals can enter the space from the outside through various dedicated vestibules and window openings. The exterior façade also forms pockets where animals can circulate and reside. While the bottom floor is given over entirely to wildlife, people can navigate this space using elevated walkways. Classroom pods penetrate the north façade; their thick exterior walls provide habitation for animals. Various vertical elements such as columns and green walls provide abundant opportunities for animals to climb and move through the building. The entire space becomes a microecosystem of lush activity that blurs the boundaries between human and synanthropes.

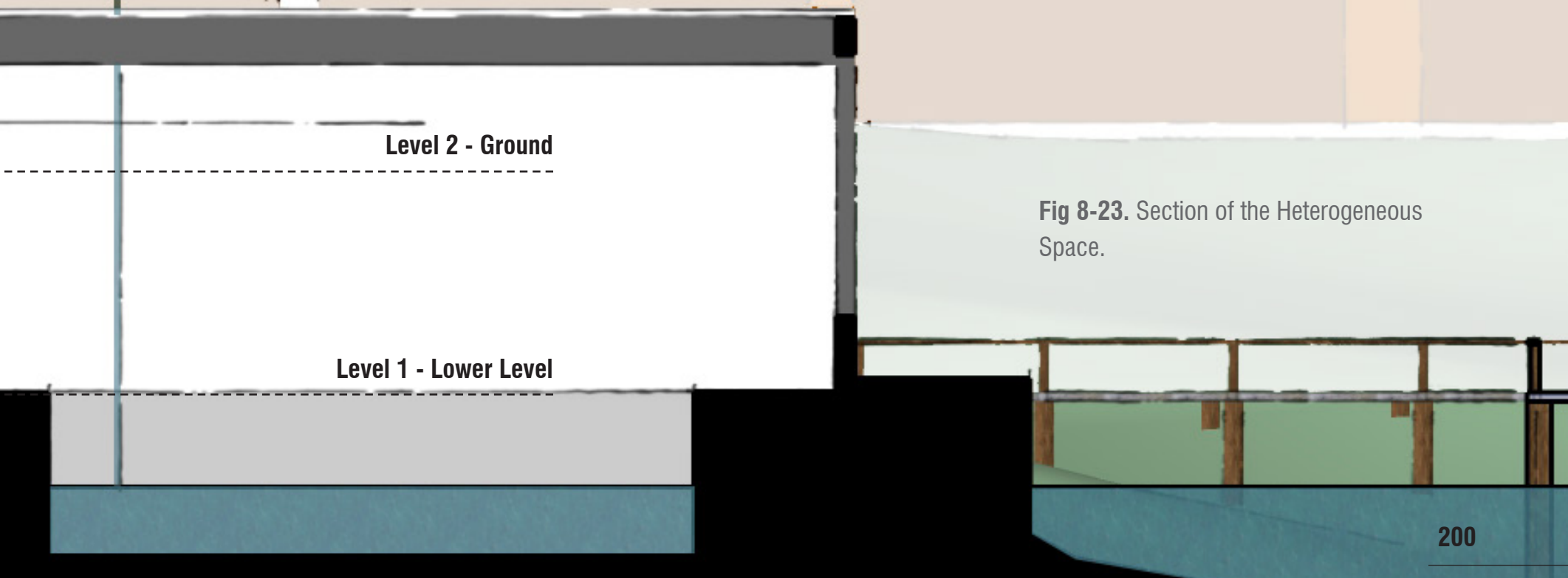



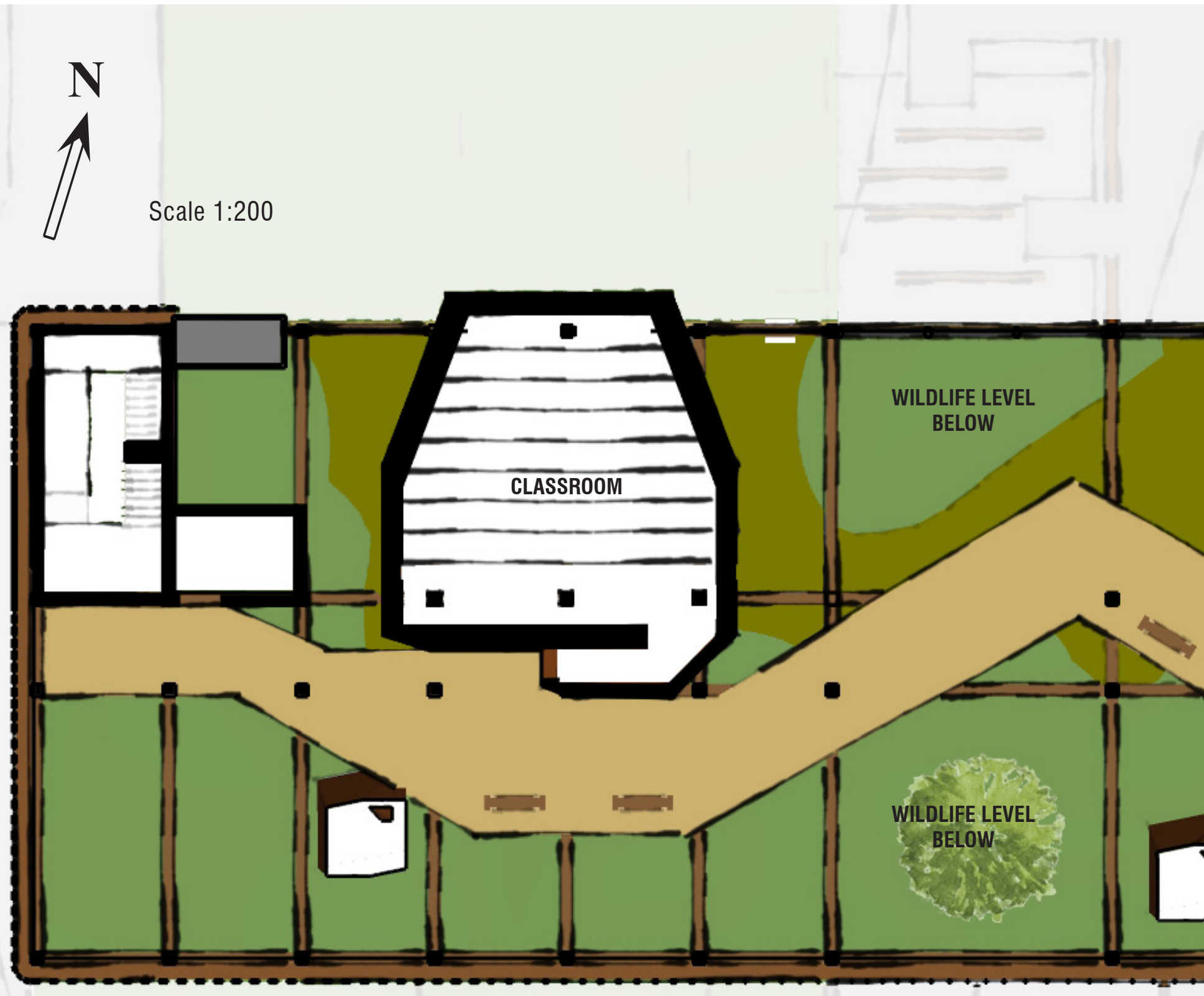


\section{Level Four}

People can enter this space from the central spiral stair or the two emergency stairs at the East and West ends of the block. The stairwells are entirely enclosed, so that animals may not permeate through into deeper parts of the building. The stairwells skip over the third floor (which is dedicated to vegetated growth and wildlife inhabitation) and leads people to an elevated walkway on the fourth floor. This path meanders around various focal points in the overall space, such as a pool, obelisk formations, micro gardens, and a central atrium space. The path also connects to classrooms, which are closed-off to animals.

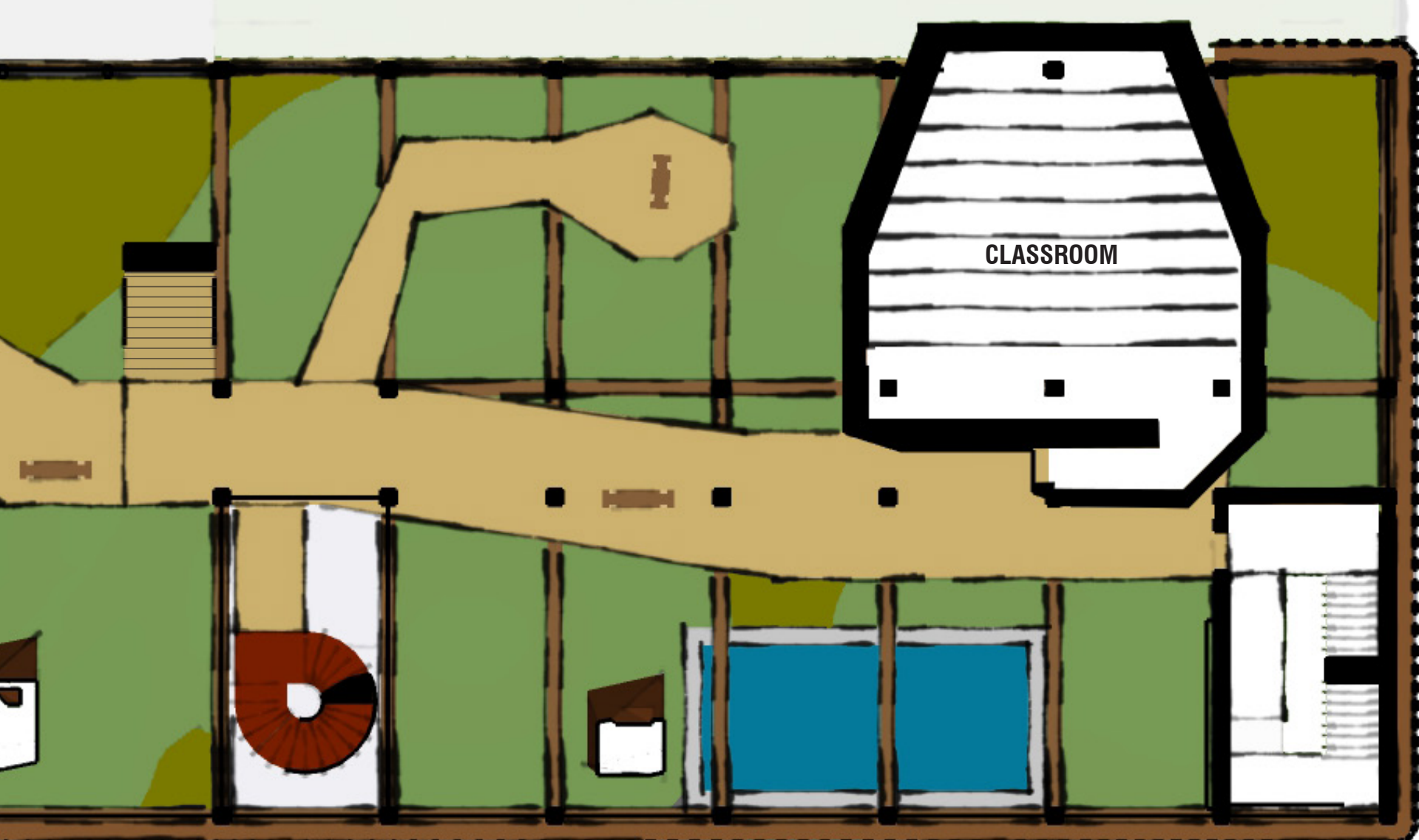

Fig 8-24. Floor Plan - Level Four. 

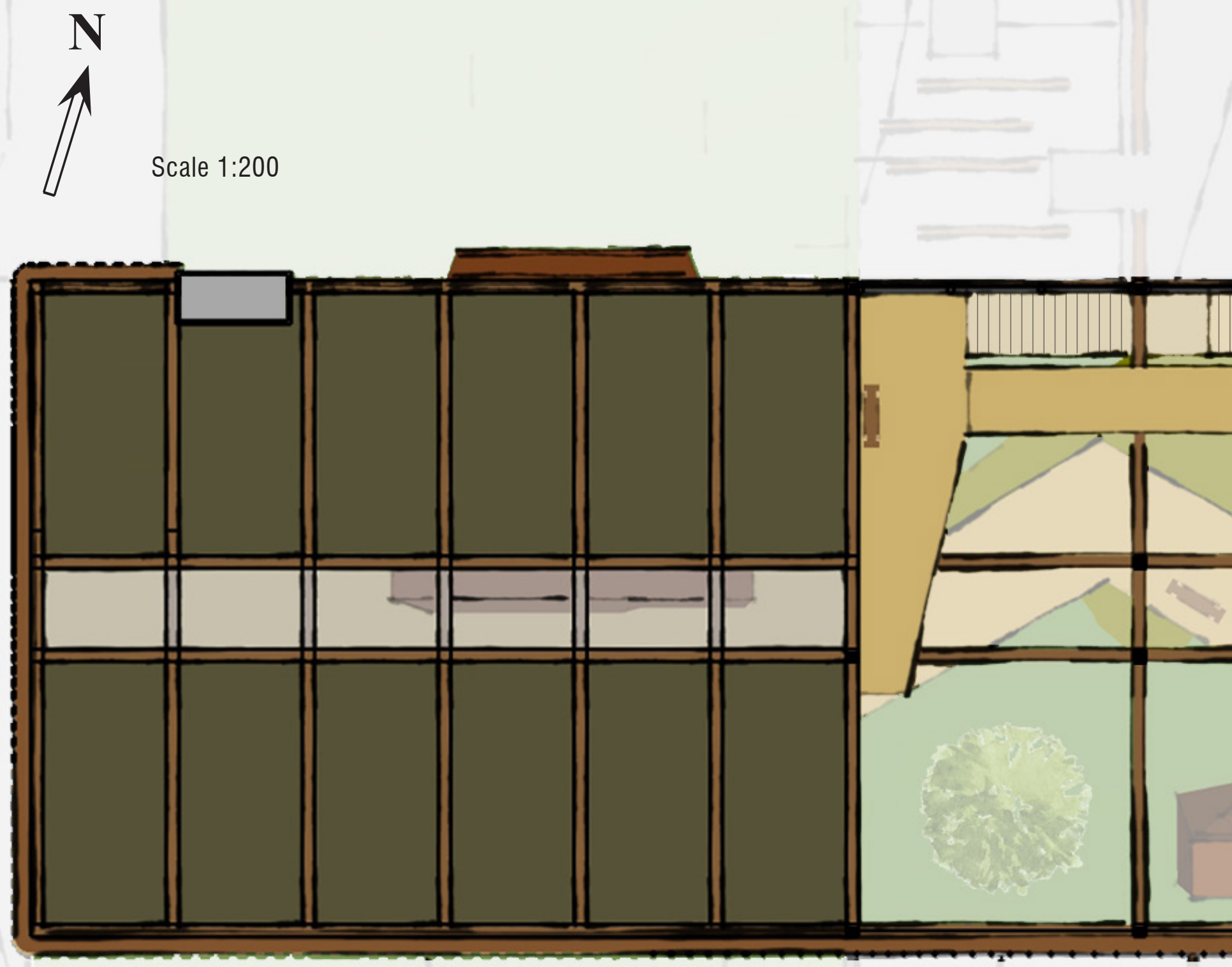


\section{Level Six}

Higher parts of the space provide access to the upper portions of some classroom pods. The elevated walkways broadly circle around the atrium space to create more open views into it. A skylight across the east-west centreline of the structure allows natural light to enter deeper parts of the space.

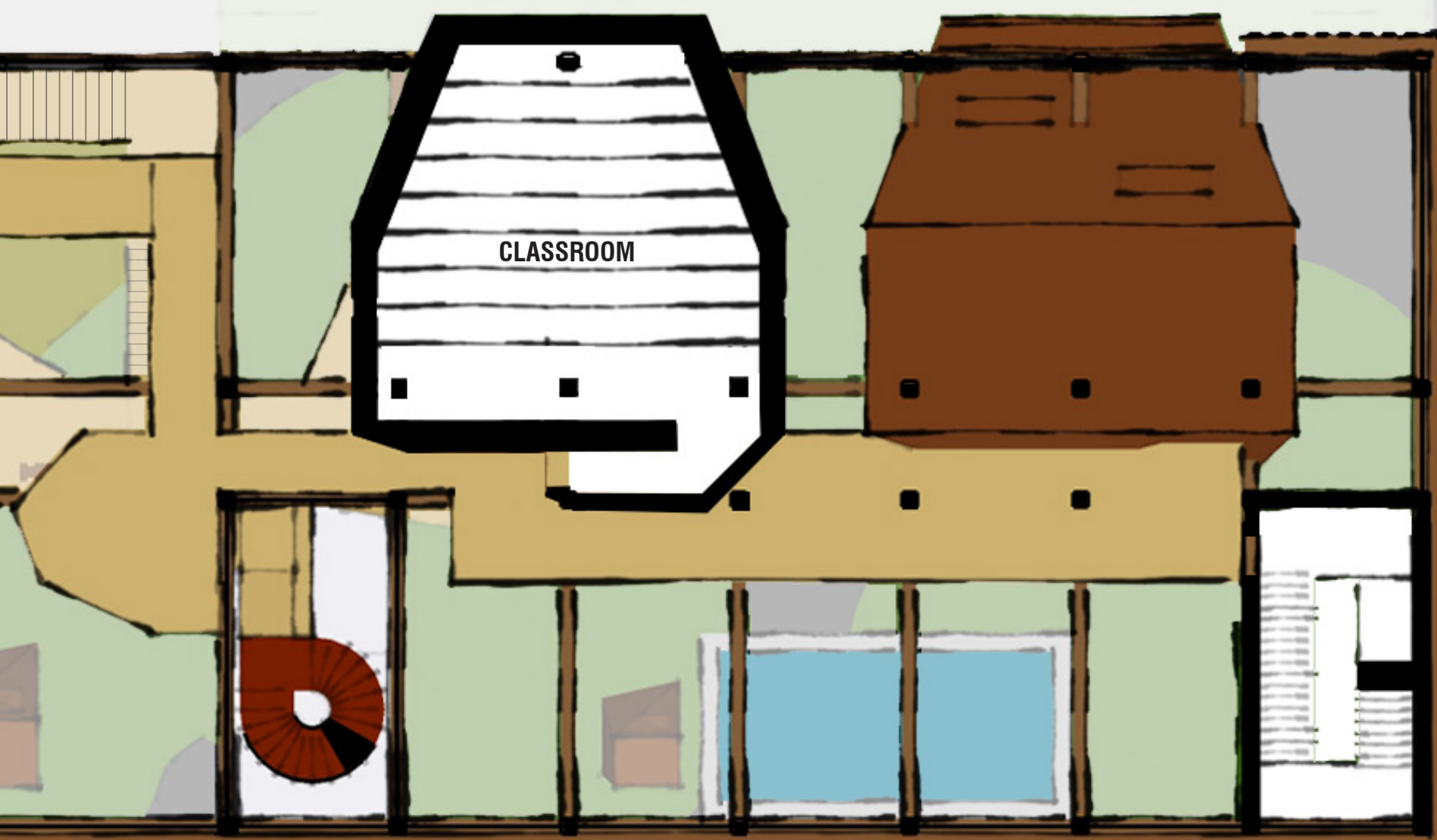

Fig 8-25. Floor Plan - Level Six. 
See Appendix Fig A.5-2.

Classroom pod in the Heterogeneous Space, study model, 1:100 scale.

\section{Classroom Pods}

This 1:100 study model and sectional sketch illustrate the intentions for the classroom pods and their relationship with the surrounding space. While the classrooms provide a controlled interior environment for educational activities, their exterior walls support animal functions. Nooks and notches would allow smaller birds to nest and bats to roost; depressions in the roof could facilitate resting areas for larger animals; and crevices along the sides create a more tectonic surface for quadrupedal animals to climb. The resultant expressive form adopts cliff- and rock-like features, including a cavelike entrance that leads to its doorway. The materiality and form of these structures bear a resemblance to the obelisks discussed in section 7.3. Collectively, they constitute a family of related forms that serve a common socio-ecological ambition and are expressed by a shared architectural vocabulary.

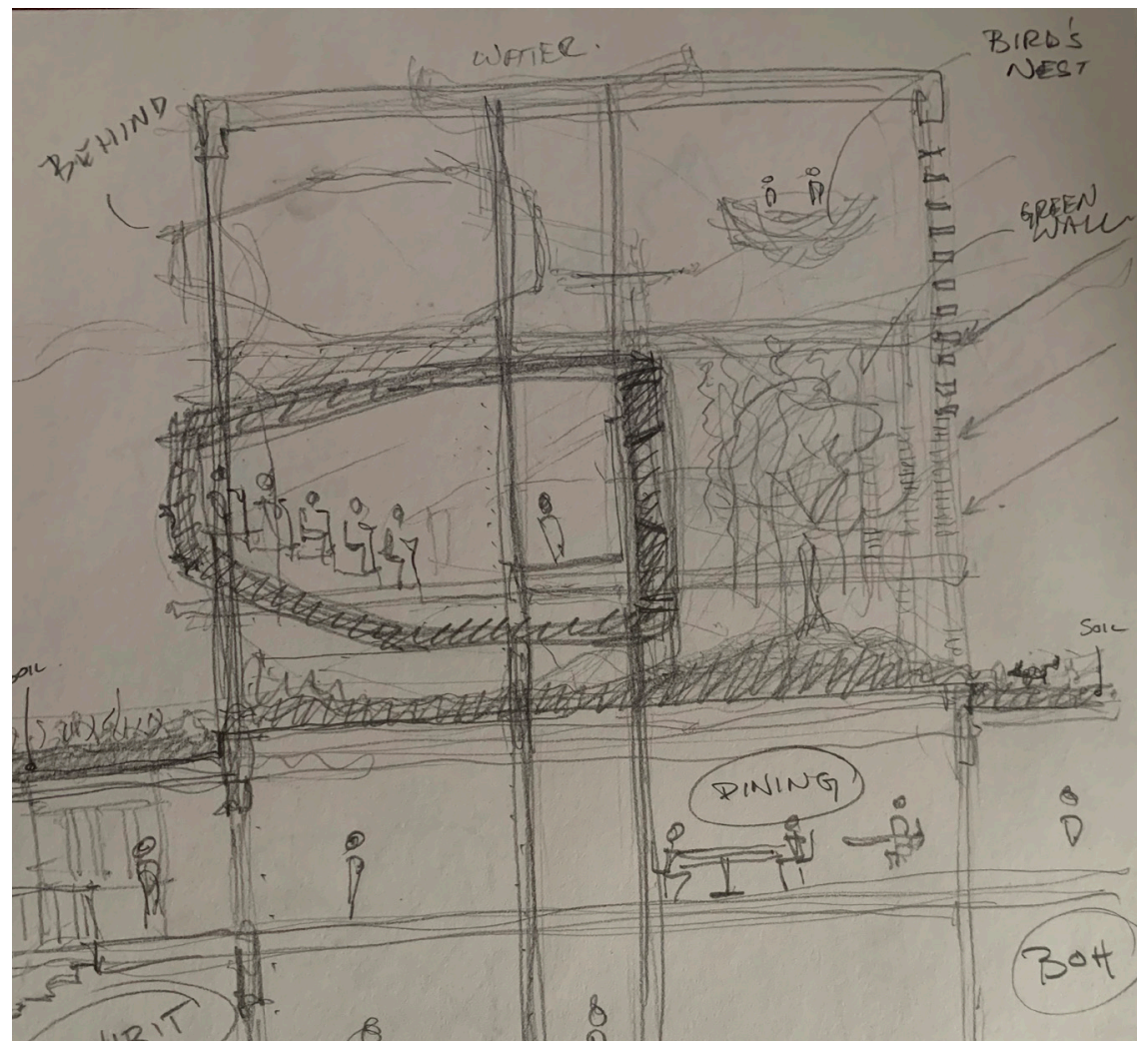

Fig 8-26. Section through classroom. 


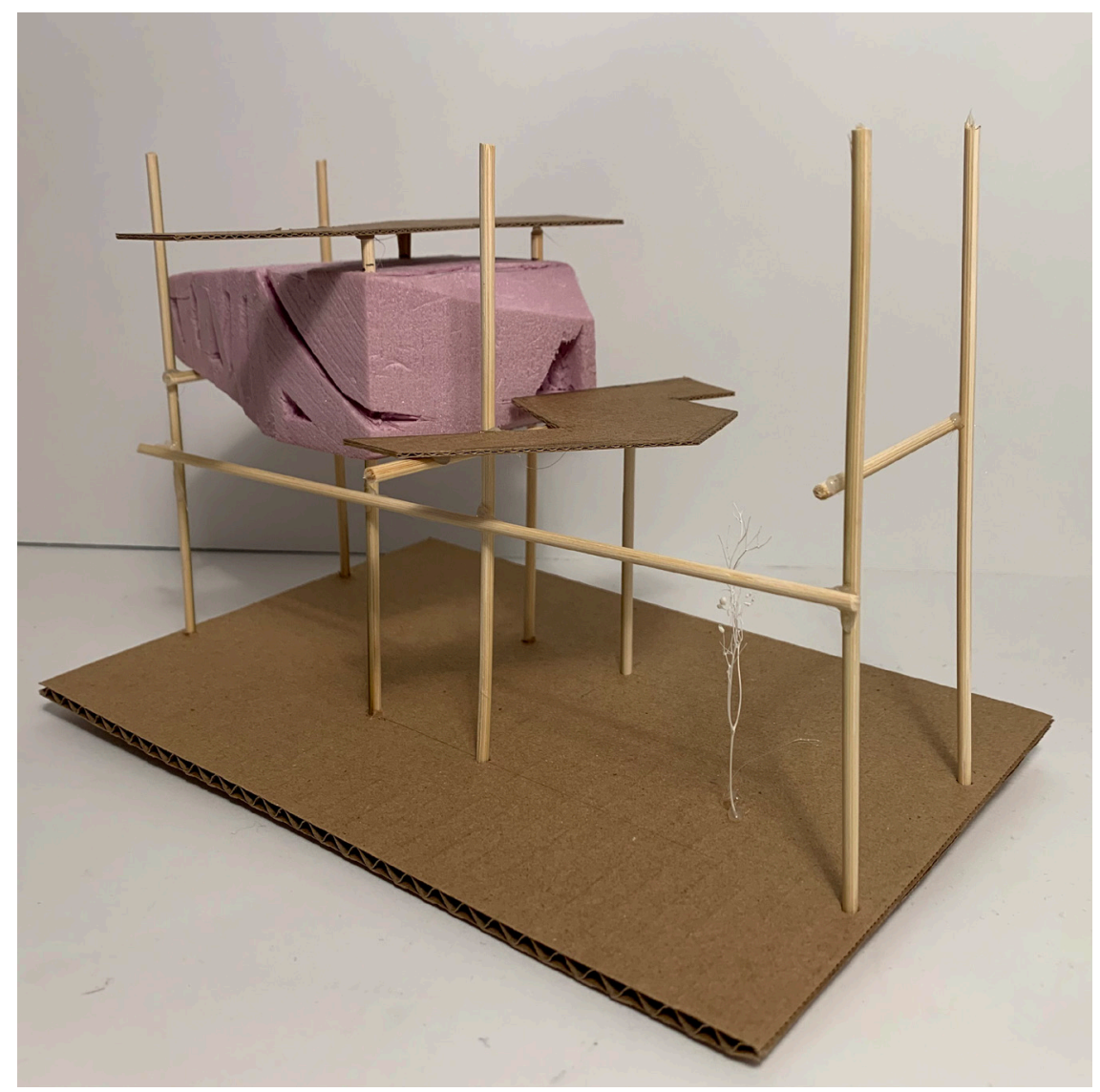

a.
Platforms lead up to the entrance while also maintaining a considerable distance from other areas around the classroom; this ensures that there remains an appropriate distance between the animals populating the pods exterior nooks and the people observing from the edge of the platforms. The spatial gaps and height differentiations allow opportunities for people and animals to co-habit a shared space and foster a meaningful experiential relationship.

Fig 8-27. Sketch model classroom and platforms, 1:100 scale.

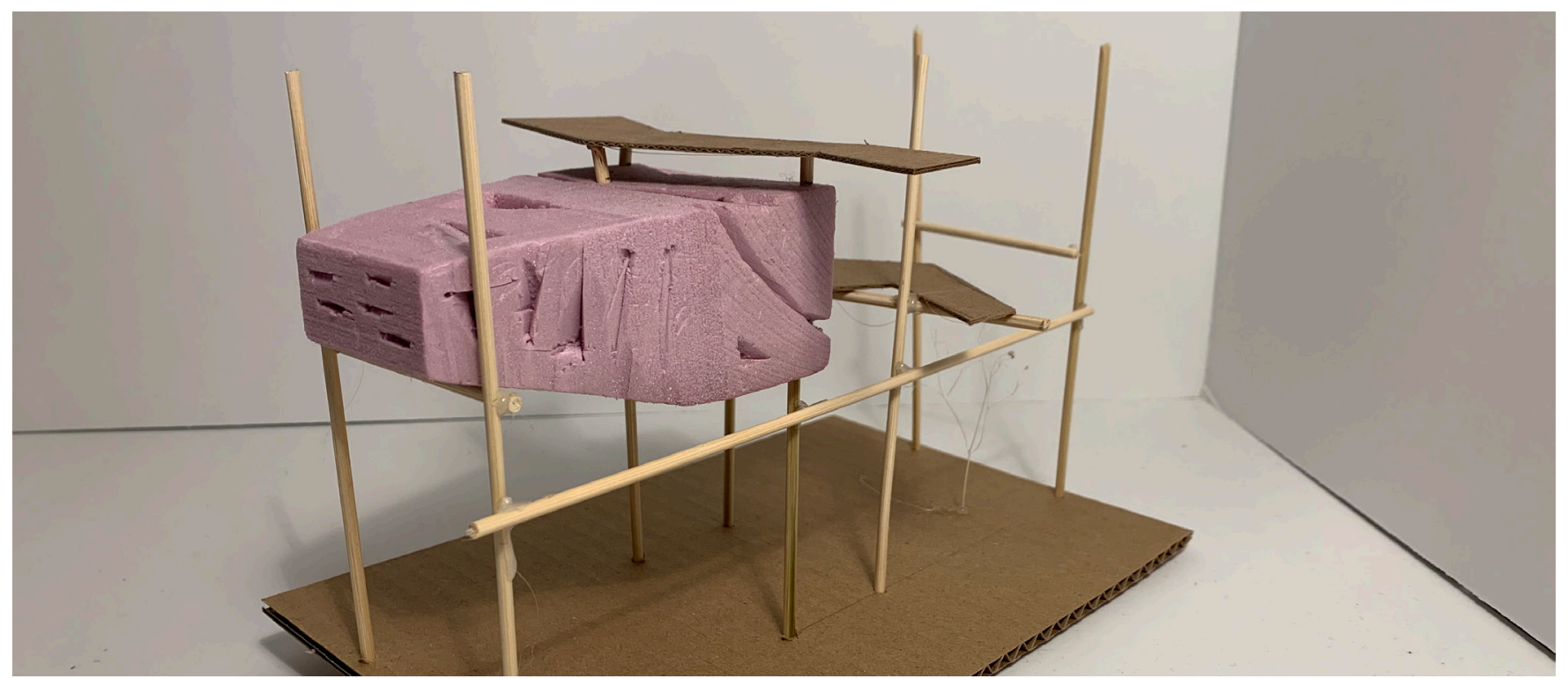

$b$. 


\section{Human-Animal Relationships}

The overall space has dedicated zones for human (marked in blue) and animal (marked in green) activity and circulation. Enclosed classrooms and vertical circulation spaces ensure that animals do not enter further into the building. Certain obelisk structures and other nesting pockets are dedicated to animal inhabitation. The entire space, however, is otherwise free for all biological subjects to move about. Thus, while the elevated pathways are devoted to humans, animals may occasionally traverse across them as well (this mixed zone is marked in violet). The Biodome in Montreal achieves a similar effect to that of this space. Though the animals in that zoo are contained and do not exit the building freely, many interior spaces are shared between humans and the resident animal life.

\section{Floor Plan | Level Four}

Scale 1:250

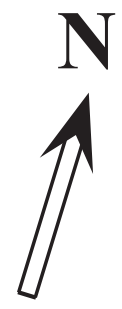

Fig 8-28. Floor Plan - Boundary Relationships.

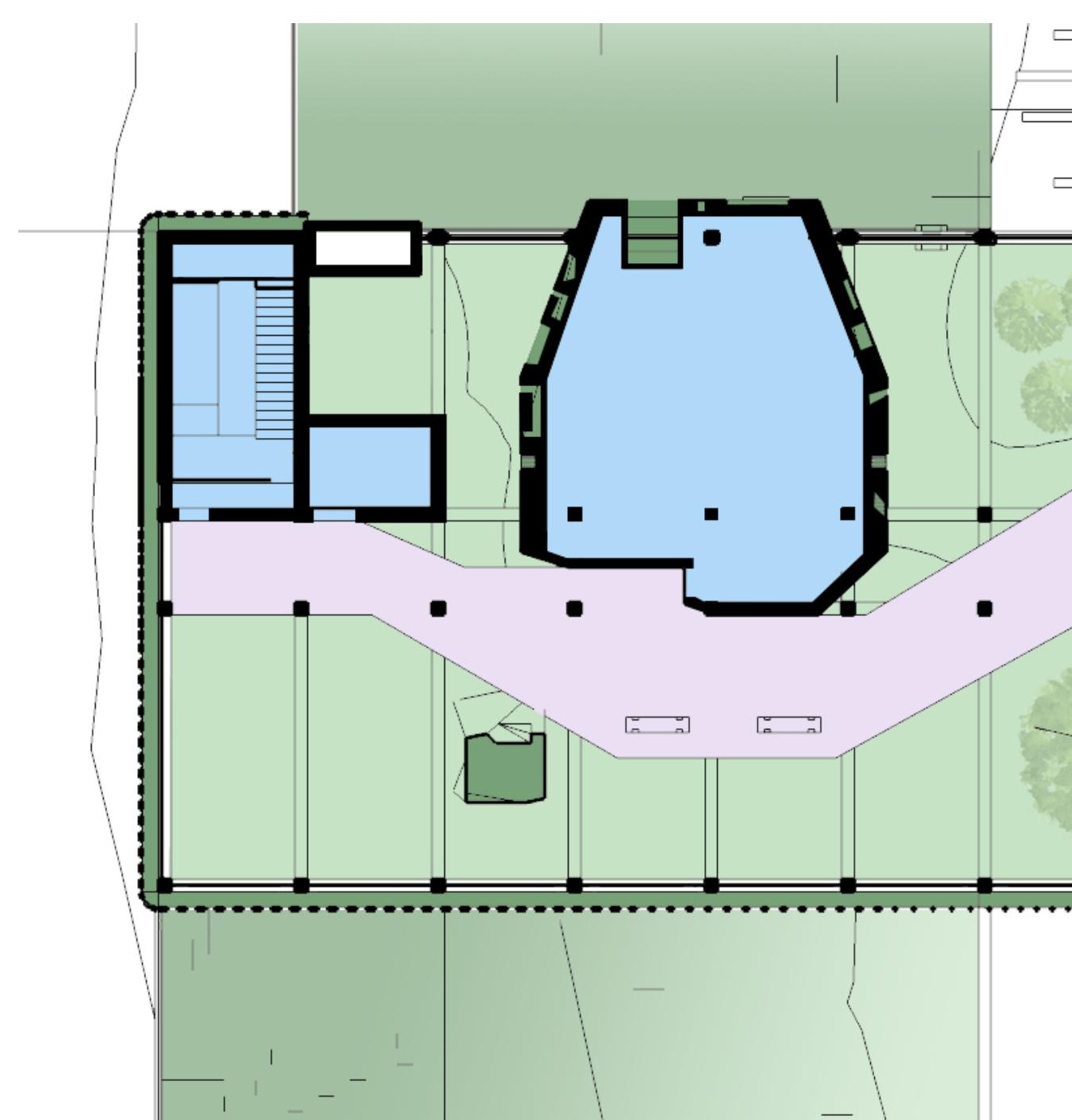




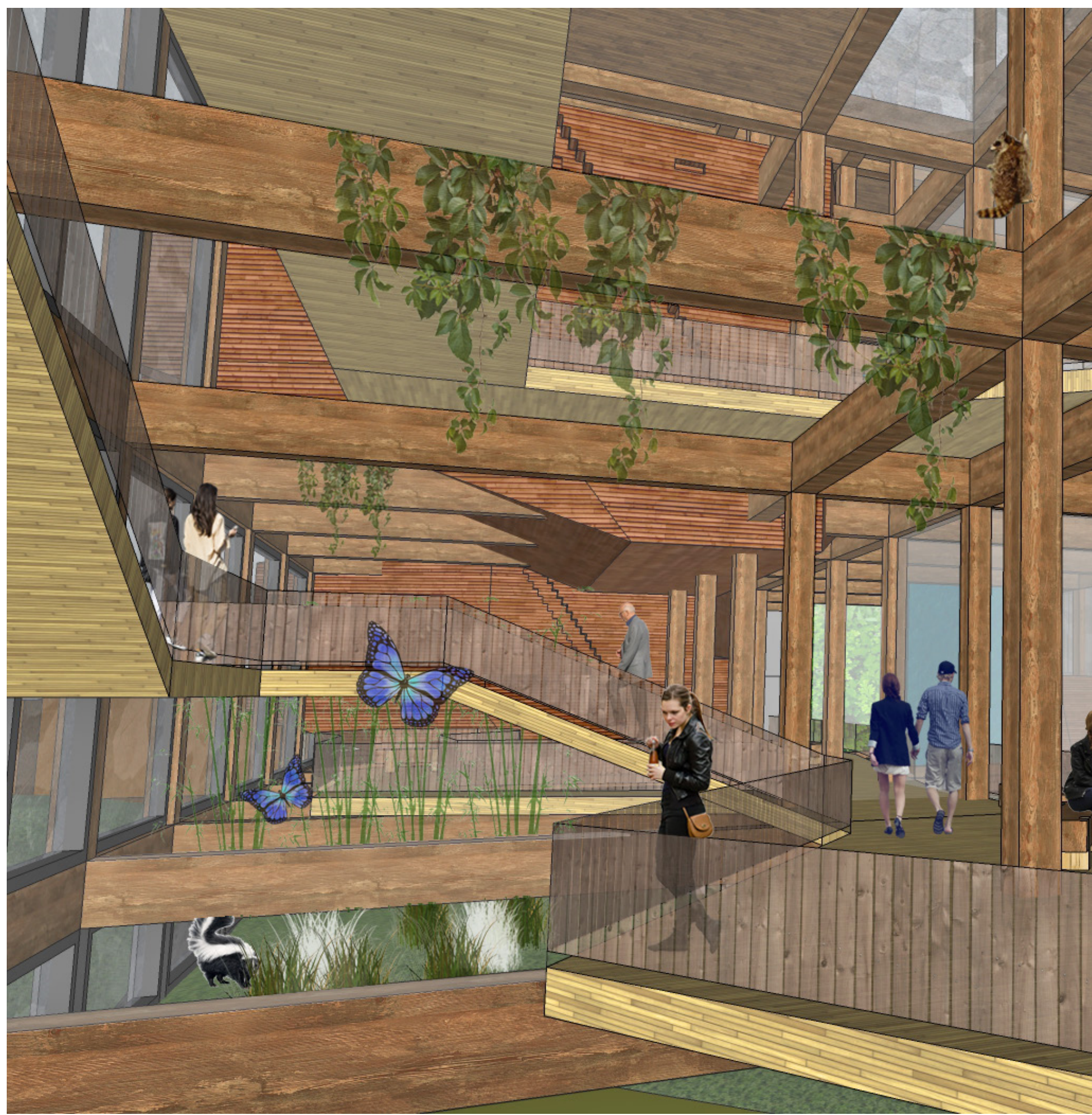


Fig 8-29. Central Atrium in the

Heterogeneous Space.

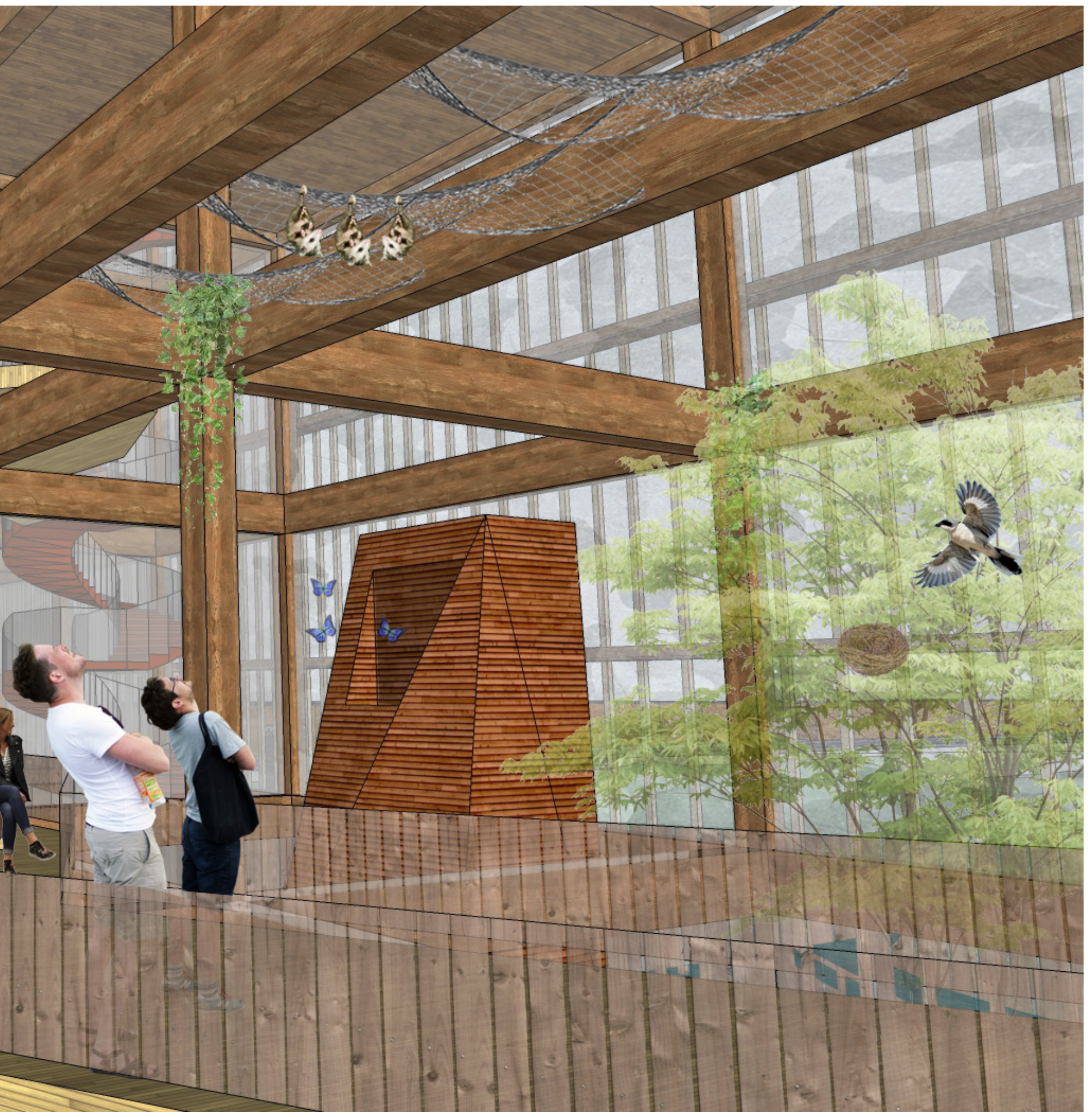




\subsubsection{Envelope}

The design of the envelope incorporates a layer of vertical wooden slats that encase the heterogenous volume, save the north façade where the classroom pods protrude through the glazing. The curvilinear contours of the façade echo the form of the surrounding landscape and contrast the orthogonal geometry of the building's structure - expressing the tension between the artificial and the organic. The façade lifts and dips to facilitate entrances of variable

Fig 8-30a. Plan depicting classrooms within three sections of the volume, encased by a facade curtain.
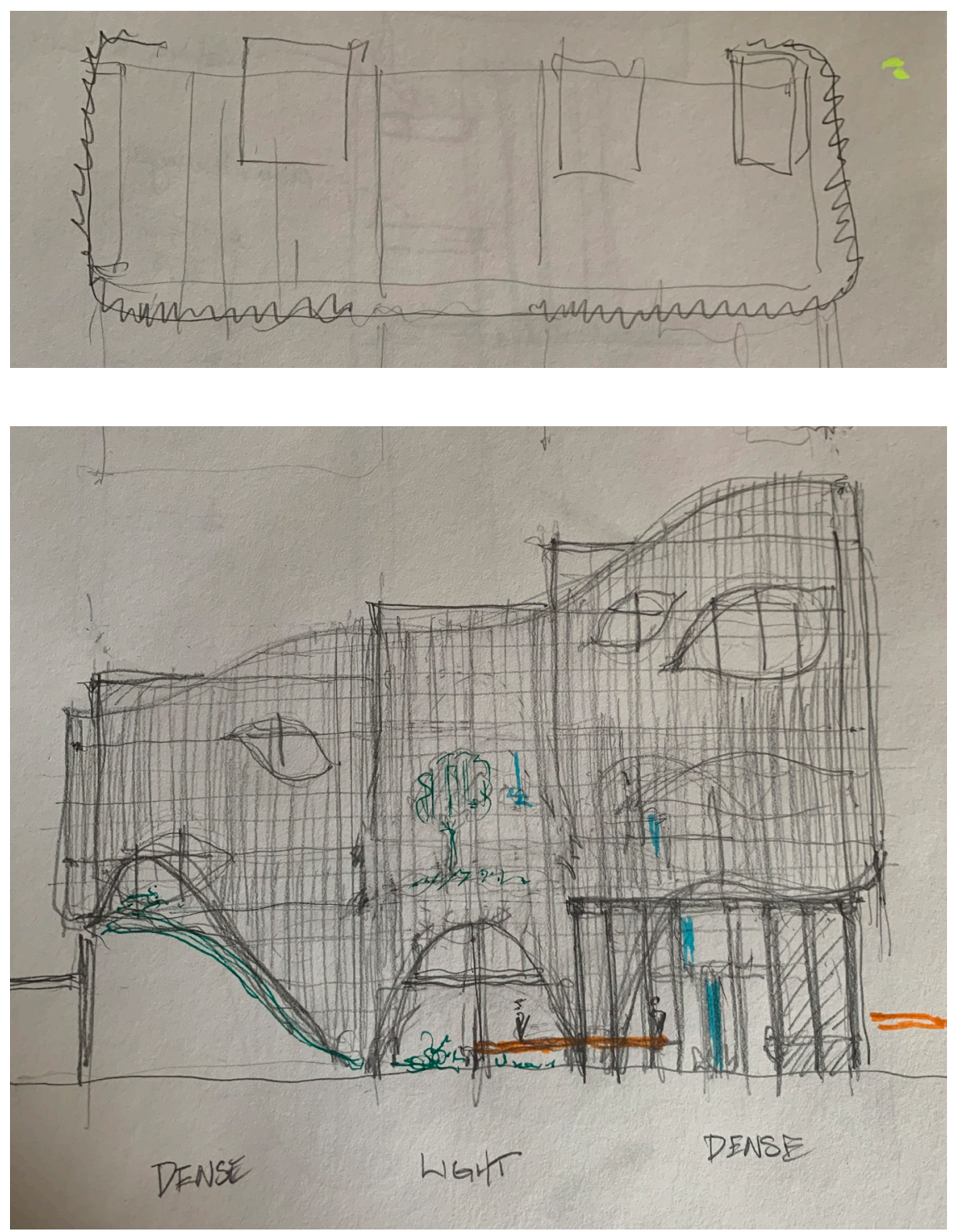

Fig 8-30b. South elevation facade. 
sizes to accommodate different biological subjects: larger gaps for people and smaller ones for wildlife. Punctures through the façade communicate opening toward which birds could fly to find points of entry. Furthermore, the horizontal struts that support this façade can accommodate nesting areas for birds as well as circulation pathways that allow animals to move around the entire building. Finally, the vertical wooden slats are arranged as a dense gradient that thins out towards the middle, allowing greater levels of sunlight and visibility into a central open atrium space within the volume.

This didactic strategy speaks to the inherent tensions of the project that exist on multiple levels between opposing binary entities: the curvilinear contours that negate the orthogonal structure; the encasing, nearly opaque façade that opens up on the north face of the building; the voids created by the punctures on the south contrasted by the solid pods protruding on the north face. These polarities resonate with the greater conceptual oppositions in the project of chaos and order, positive and negative, animal and human, nature and culture.
Fig 8-31. Testing the facade curtain in the model space.

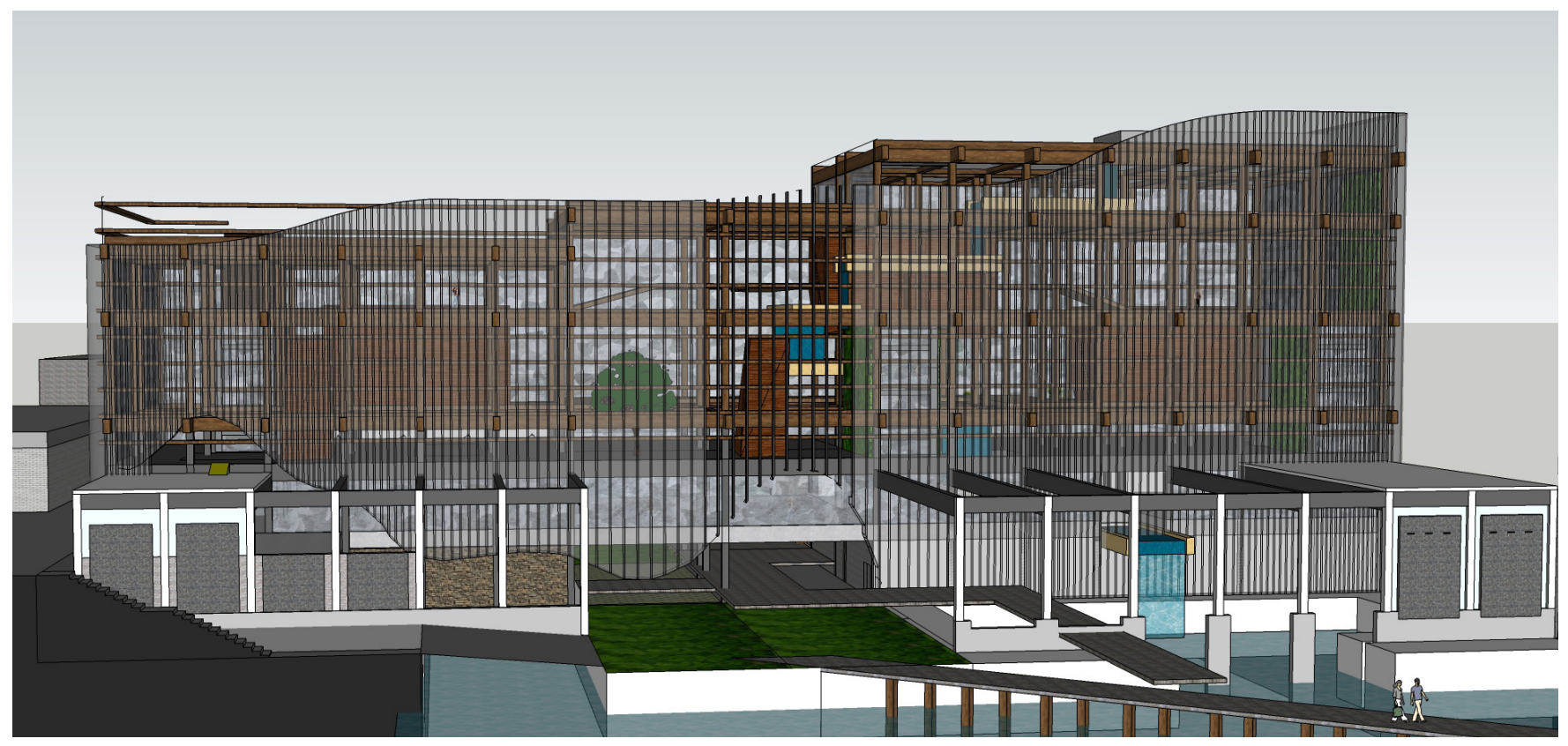




\section{Wetland}

The wetland environment amplifies the local ecology, providing habitat and a source of water for the surrounding wildlife. It also pays homage to the historic Garrison Creek that had flowed through this landscape for thousands of years until it was buried in the $19^{\text {th }}$ century. This wetland functions as a habitat for local wildlife while celebrating the memory of one of Toronto's buried waterways.

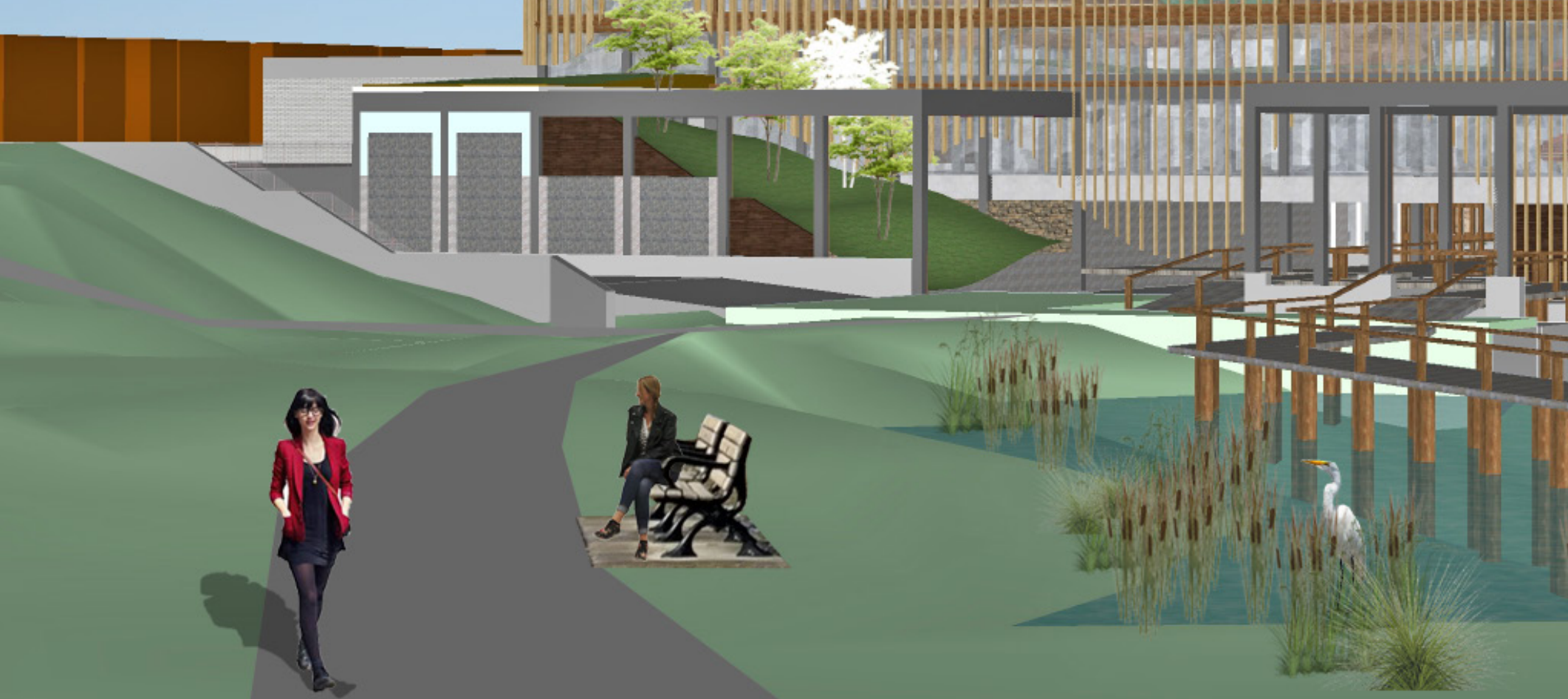

Fig 8-32. Wetland environment. 

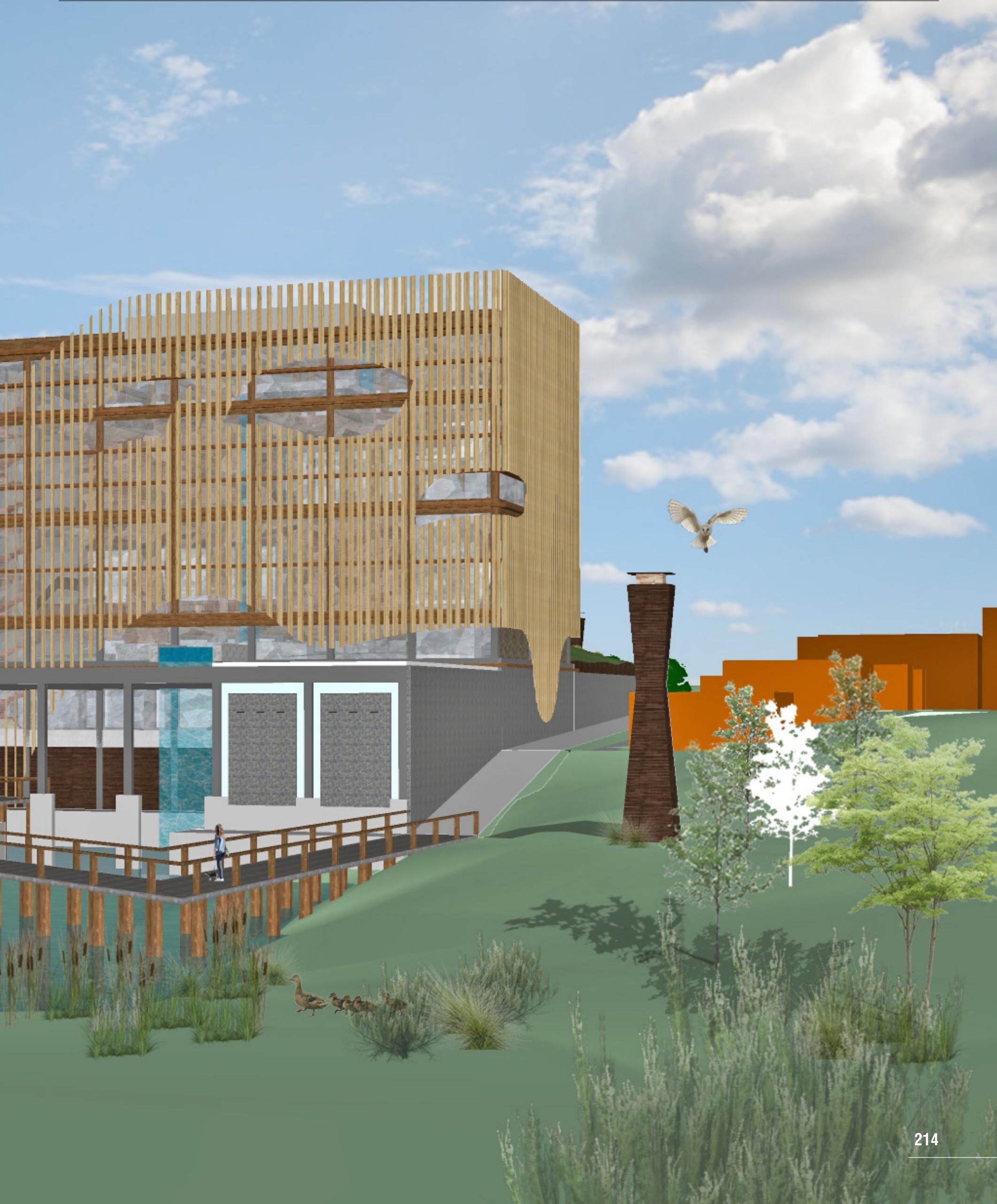

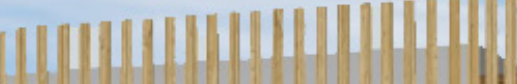


See Appendix Fig A.6-13 to 15. Additional Renders of the Final Design.

\section{Public Realm}

The wood slats that wrap around the building stop on the north side. From Bloor Street, passers-by can peer into this hub of activity, seeing the blurry motion of vague shapes in behind the semitransparent glass. This street-facing side, with solid pods penetrating through the glazing, is a polar opposite to the park-facing side that has voids in the façade.

The façade strategy developed for the heterogeneous volume echoes in other areas of the campus, expressing a consistent architectural vocabulary. Enveloping the new entrance lobby, the undulating vertical slats communicate entry points in areas where their contour lifts from the ground. The new entry addition frames

Fig 8-33. View from Bloor Street.

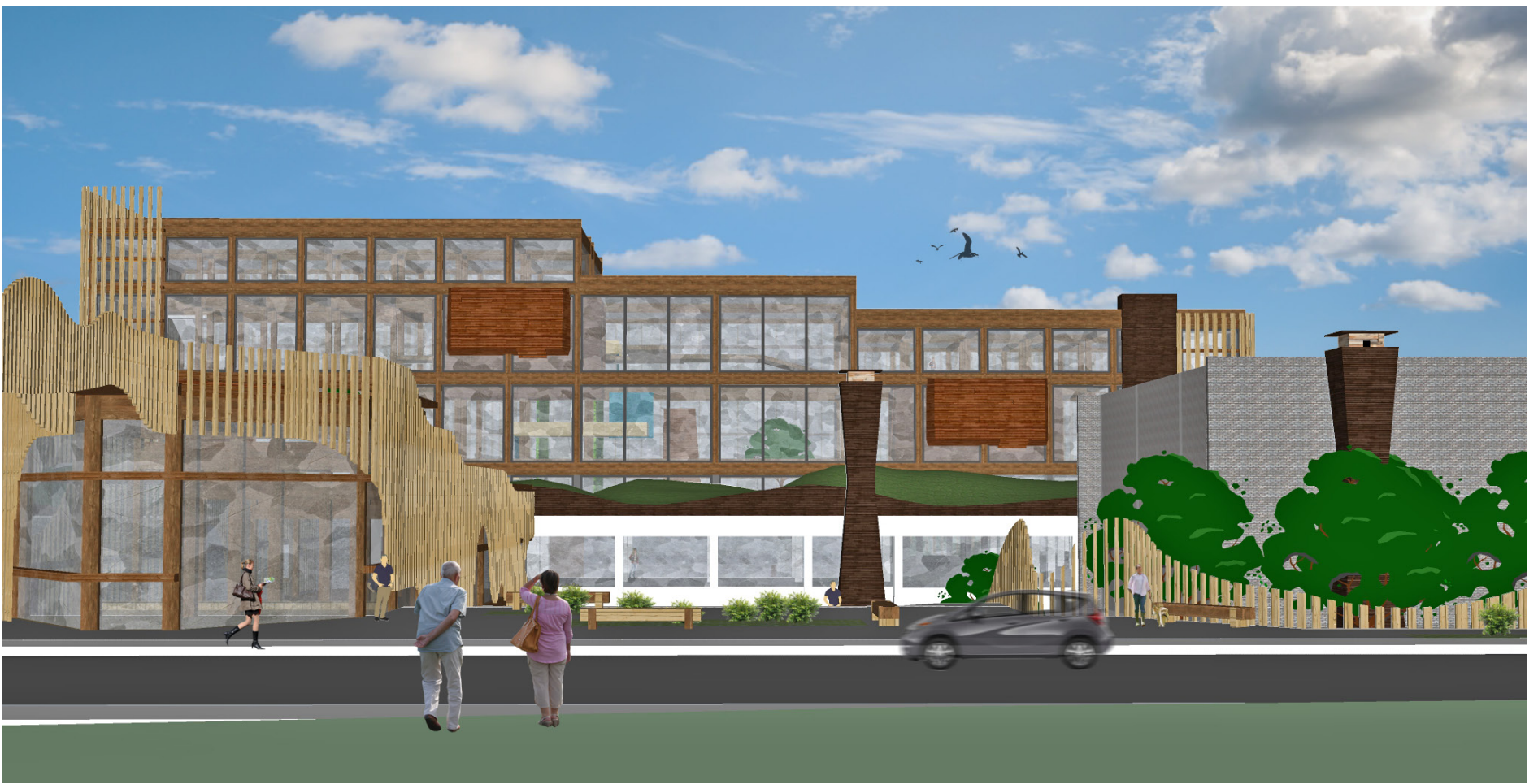


the plaza opposite the theatre. An obelisk in the plaza communicates a place of significance, drawing people in from the street, and alludes to the synanthropic qualities of the facility at large. At this point, people may either enter and explore the building, or continue along the underpass to observe it externally. An interior courtyard is continually populated with constructed habitation artefacts which have been built in the adjacent maker-space workshop. This area acts as an outdoor experimental laboratory and exhibition space which can be explored in person or observed from adjacent spaces in the building.

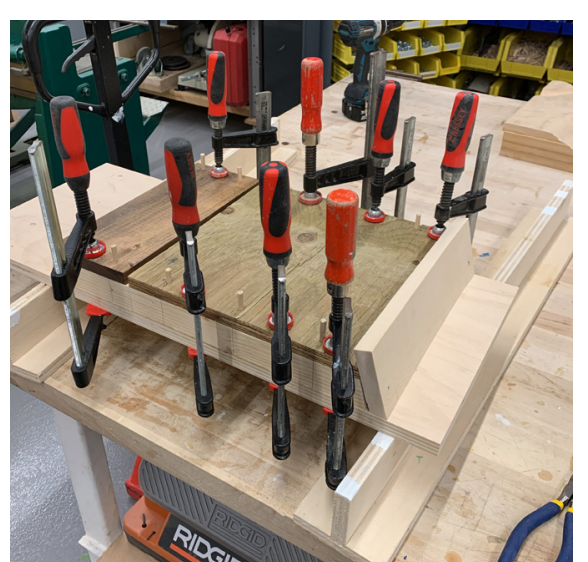

Fig 8-35. Construction process of a bat house.

See Appendix Fig A.5-1.

Bat Roost Prototype.

Fig 8-34. Courtyard lab.

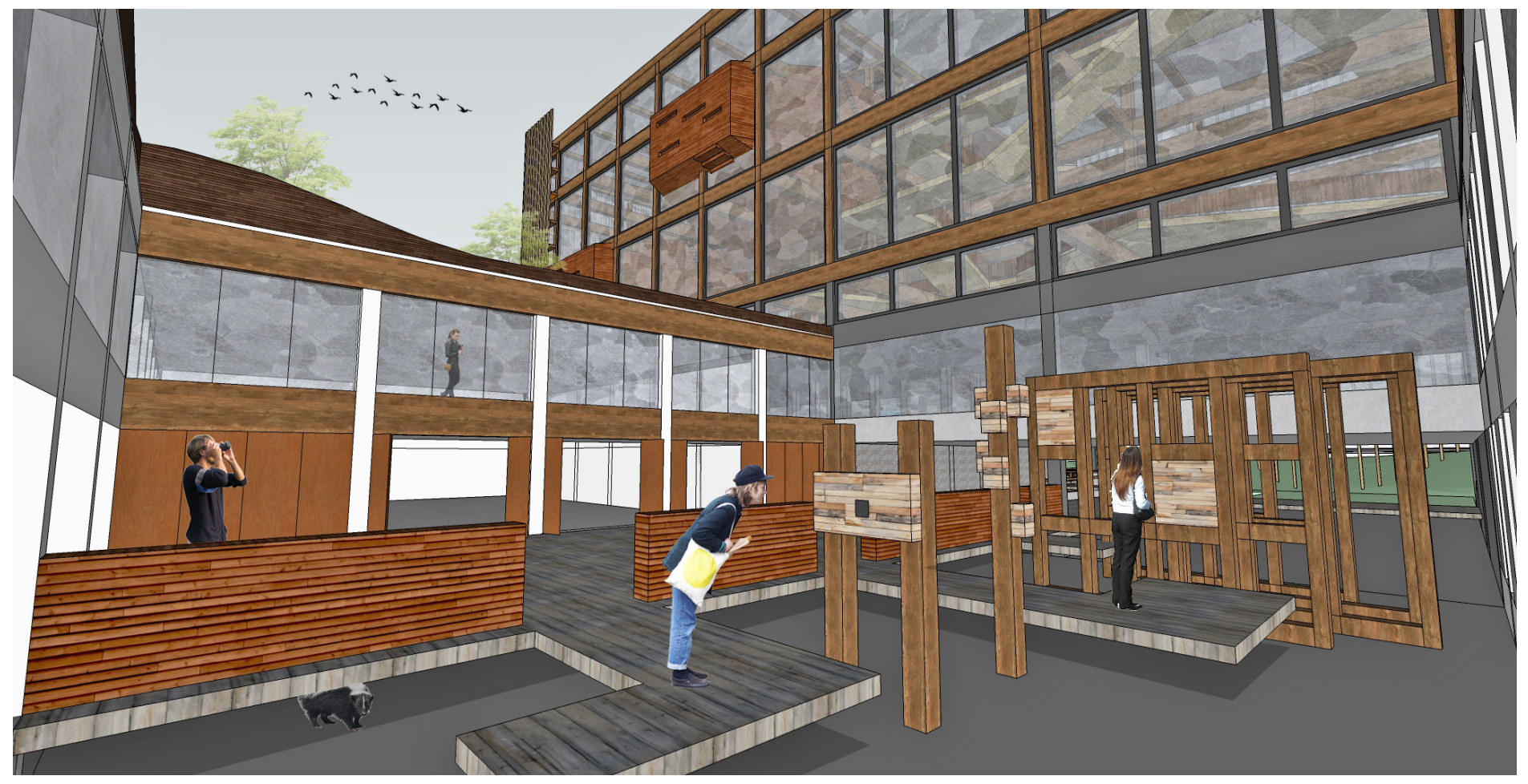




\subsubsection{Immersion}

The facility provides a range of educational activities and an immersive environment bustling with ecological activity. It supports a program where people are not only observers but learn how to be active participants in their own biosphere.

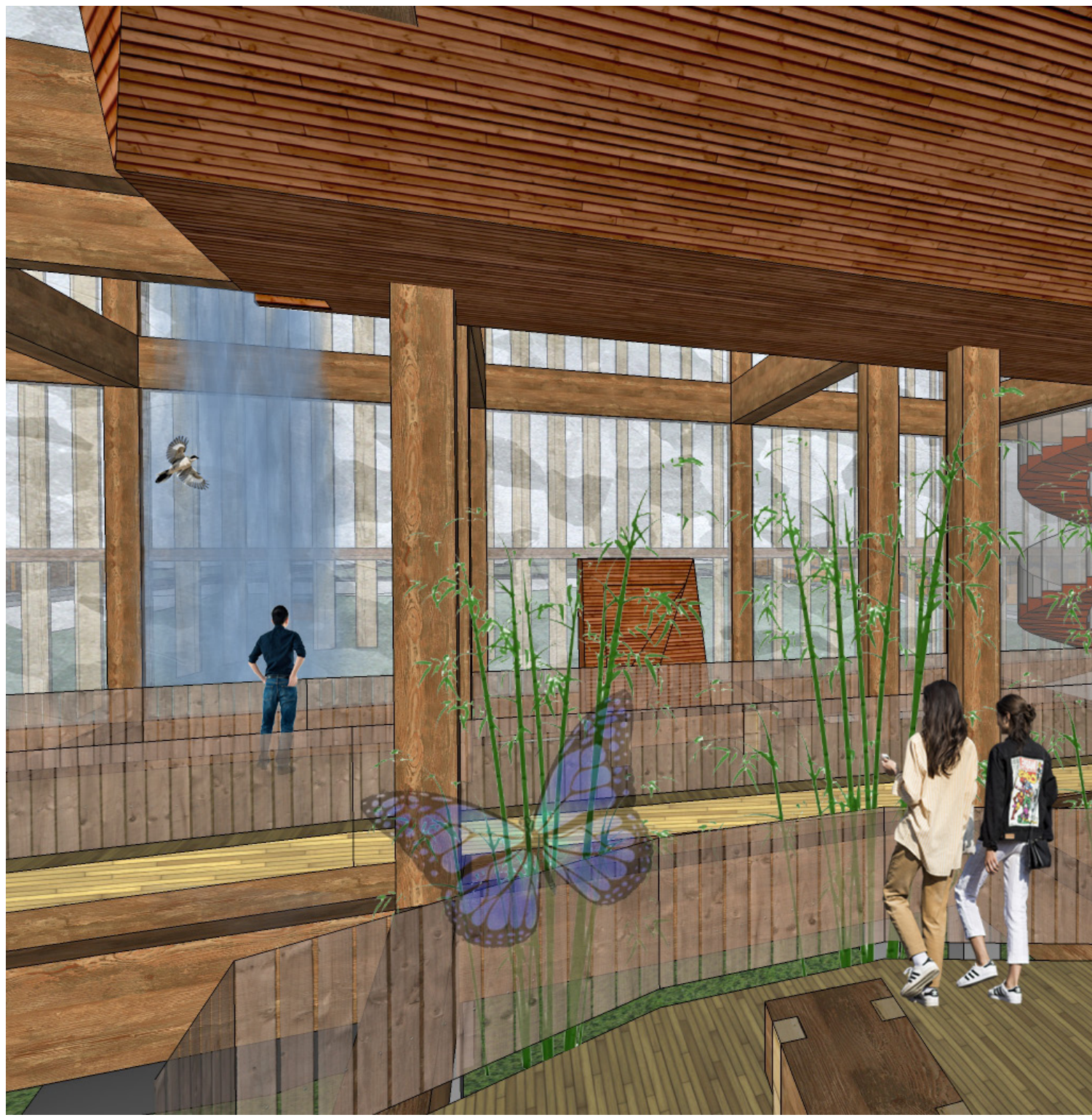


Weather permitting, animals are able to permeate through this space day and night. In places low and high, animals can forage, move about, and find nesting sites. This multi-storey block is built as a large wood-frame structure overtop the existing column grid, which supports the various natural elements and built structures within this spacious framework. This structure forms a lattice

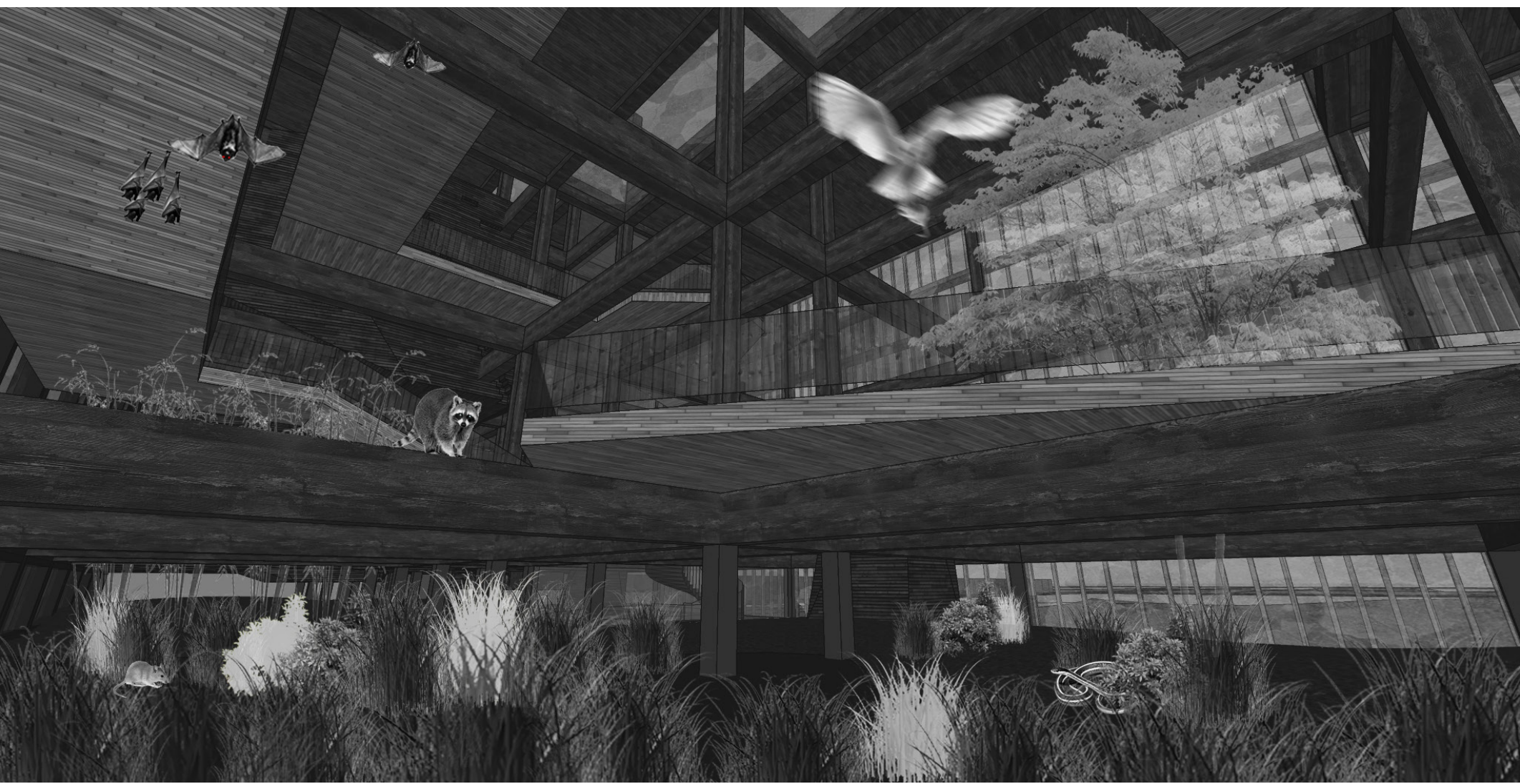

Fig 8-37. Night-time activity of nocturnal creatures. 
spaceframe, similar to the design of the Banyan Tree Skyscraper (see section 3.1.4), that supports platforms, pods, vertical walls, a waterfall feature, habitats, and circulation pathways for animals. This central atrium is a hub of activity characterized by the heterogeneous mixture of people and wildlife.

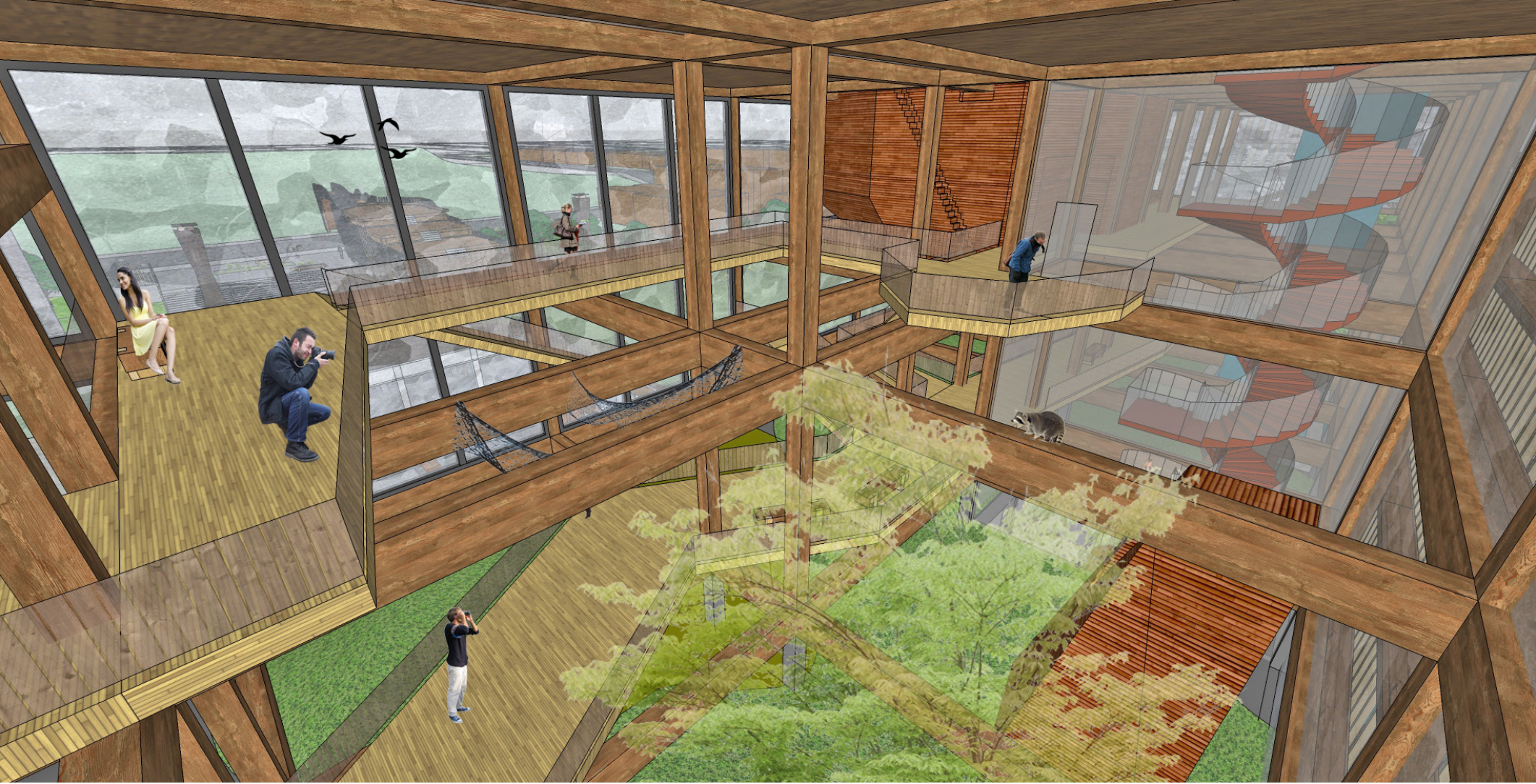

Fig 8-38. Day-time activity and operations. 


\section{4}

\section{Into the Synanthropocene}

The Synanthropic Centre embodies an intersectional node of culture and nature. It is designed as an inclusive environment that responds to a diversity of biological subjects. It demonstrates what architecture could be like if it was literally "environmentallyfriendly"; a quality not determined by its economic, energy-saving properties, but by the nature of its relationship to local biological

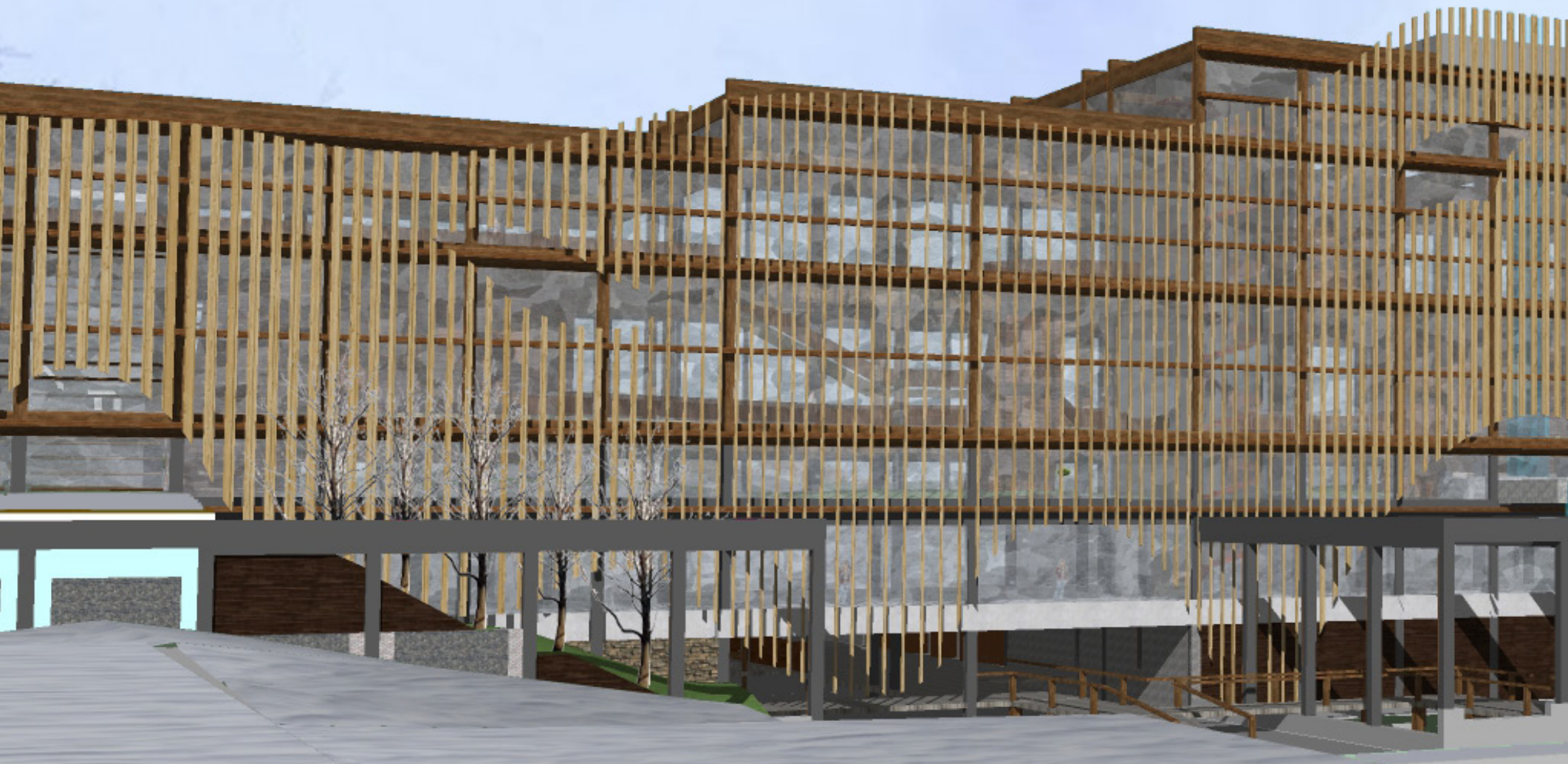

Fig 8-39. Bickford Park in winter. 
subjects. The Synanthropic Centre creates an experience that brings people into closer proximity to the other actors in their biome by incorporating dedicated spaces of habitat. This ecological campus is the architectural product of a cultural paradigm shift. However, perhaps it is the architecture itself that promotes an alternative mode of being.

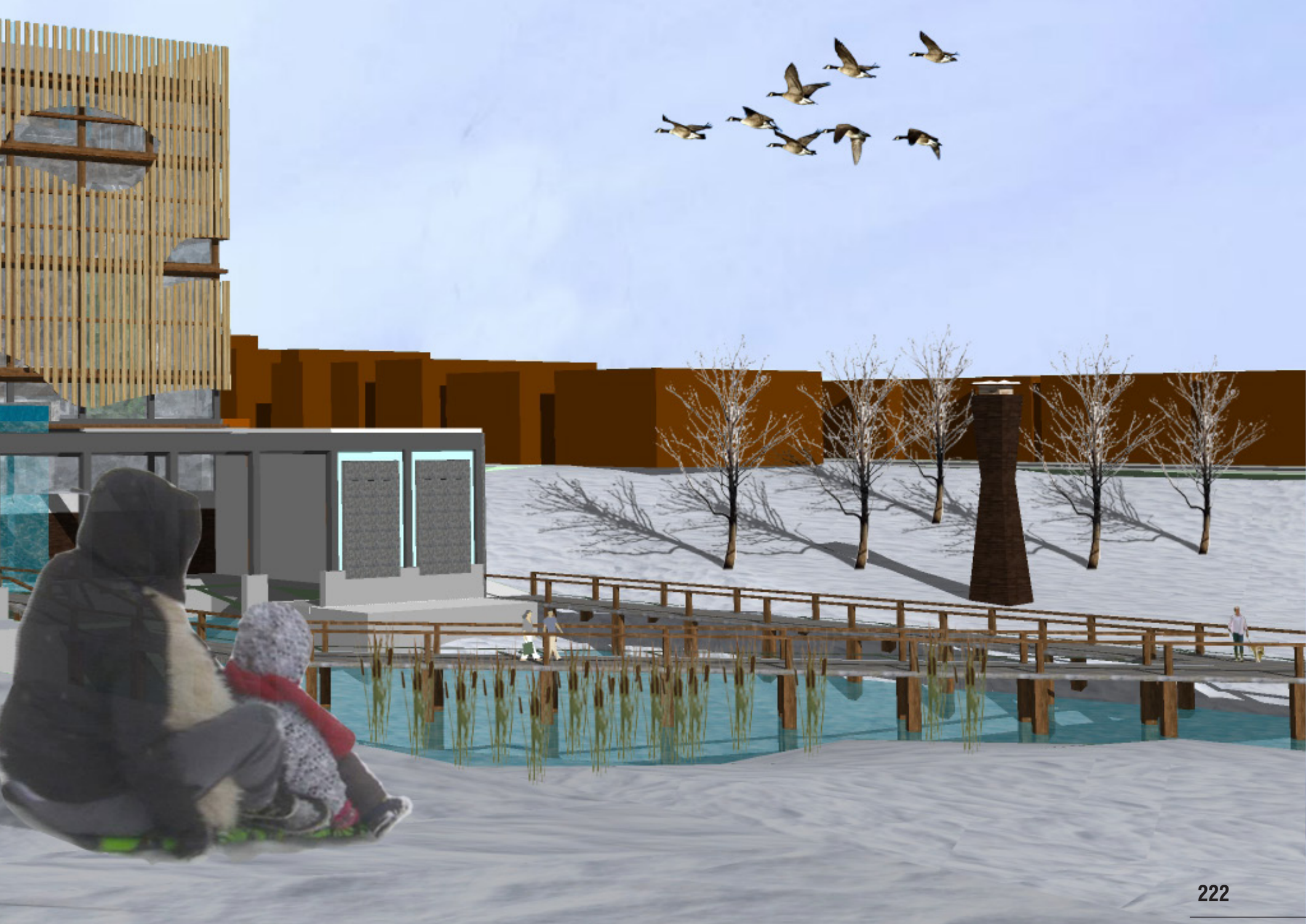




\section{CONCLUSION}

\section{Resynchronized Architecture}


The inspiration for this thesis sparked from a feeling of oddity and discomfort that arose while watching the documentary series Planet Earth II with David Attenborough. Each of the six episodes focused on a different type of natural environment, showcasing the distinct species that live in those landscapes. What caused a sense of awkwardness and revulsion was that the final episode focused on cities. It seemed as though this topic should not belong in a "nature" documentary. However, what soon became clear is that cities are in fact a widespread artificial landscape that has tremendous impact on wildlife and the environment in many respects. Though it may not seem "natural," there are many animals living in the margins of urban environments (often unbeknownst to its human inhabitants), and they are facing a plethora of challenges negotiating a concrete landscape to which their biological instincts are not attuned. It became clear that architecture could be an active force in changing this relationship. Design is the process of assessing requirements and formulating solutions in response. The potential of design is arguably limitless - it need only be explored. This thesis provided an opportunity to explore the potential of architecture to follow this trajectory. What would architecture be like if it responded not only to humans, but also to the animal biodiversity that chooses to reside in, or migrate through, the urban landscape? This proved to be an extremely challenging question. It is hard enough to design for one species, let alone eight million. The process of doing this thesis work demonstrated that the potential of exploring this trajectory is nearly limitless. Taking into consideration the vast interconnectivity that exists within an ecosystem, the problem becomes much more complex (this isn't to say that one should lose heart in tackling this issue - only that it requires considerable effort due to its immense scope). 
This process also demonstrated the flexibility of architecture, and its ability to be a responsive vehicle even for such seemingly unusual subject-matter as the issues facing non-human biological life. Through research and design, I was able to see how architecture and biology co-relate, and what realities could be made possible. The unique opportunity in this exploration was the process of designing from an entirely different perspective. It made me review conventional architectural practices and methods and aim to redesign them in response to other beings. It was necessary to consider how animals might respond to various formal conditions they had become the actors for design. Having encountered the term synanthrope, it served as a useful catalyst that framed the relationship between humans and urban wildlife.

What became interesting is circling back to a human perspective. How does the pursuit of synanthropic architecture influence (and perhaps redefine) the human condition? Does this type of architectural discourse facilitate a paradigm shift? Does it provoke people to question their relationship to the environment, and the amount of value that is attributed to its non-human subjects? Can humans and animals co-exist? And if so, how? How close can the boundaries between them approach, and under what conditions can they disappear? How does human behaviour need to change, and is it reasonable to expect it to?

One of the most interesting ideas at the heart of the thesis is that the smallest modifications in the design of urban form can potentially cascade into an overwhelmingly positive ecological impact for the wildlife that interact with it; perhaps the smallest changes in architecture can create a difference in people as well. 


\section{EPILOGUE}

\section{Reflection on Covid-19}

The onset of Covid-19 has forced us into a lockdown and will undoubtedly have an impact on how we approach architectural design. It has also revealed the extent of biodiversity that has been living in the margins of our cities. Rather than returning to a future where animals continue to be pushed back, what if there was another way? Perhaps urban environments can be designed with an alternative strategy that considers wildlife and genuinely integrates them into what would be a shared synanthropic landscape. 


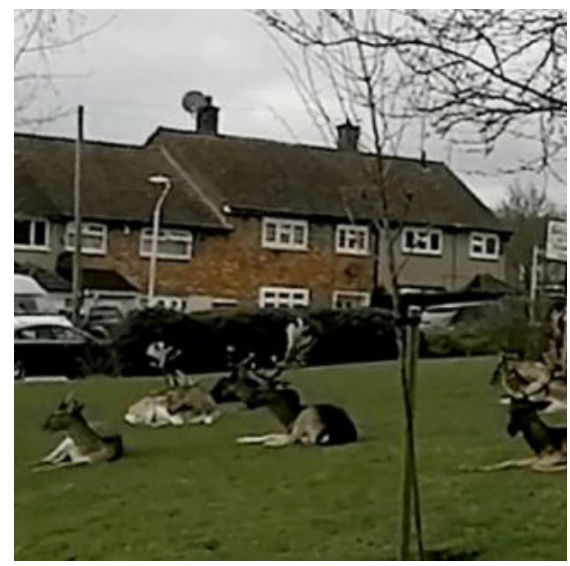

Fig E.1a. A Herd of Deer

Romford, UK.

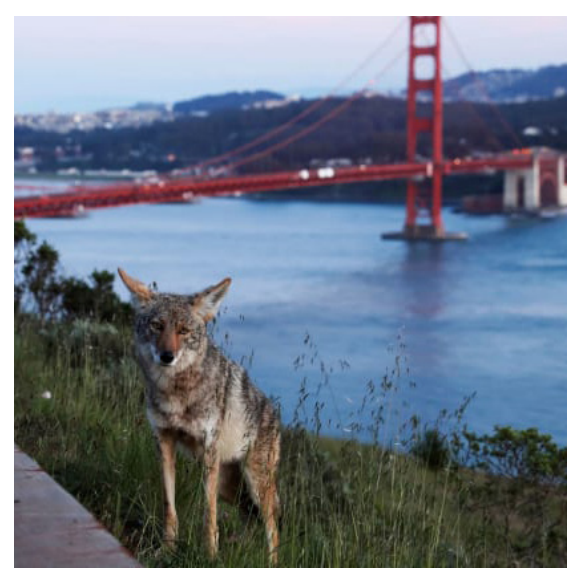

Fig E.1c. Coyote

San Francisco, USA.

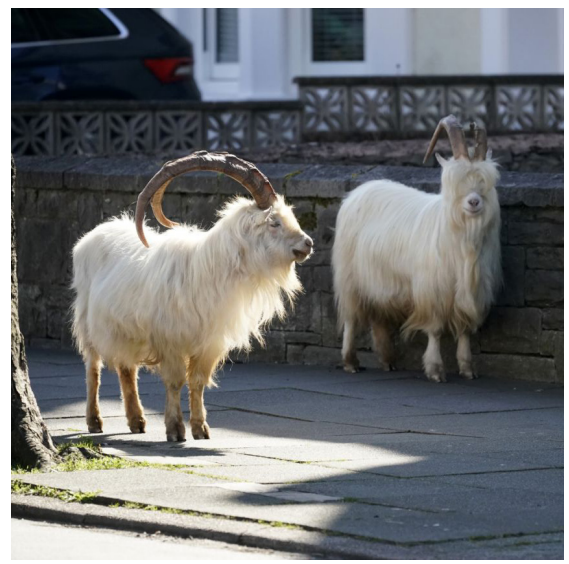

Fig E.1b. Mountain Goats Llandudno, Wales.

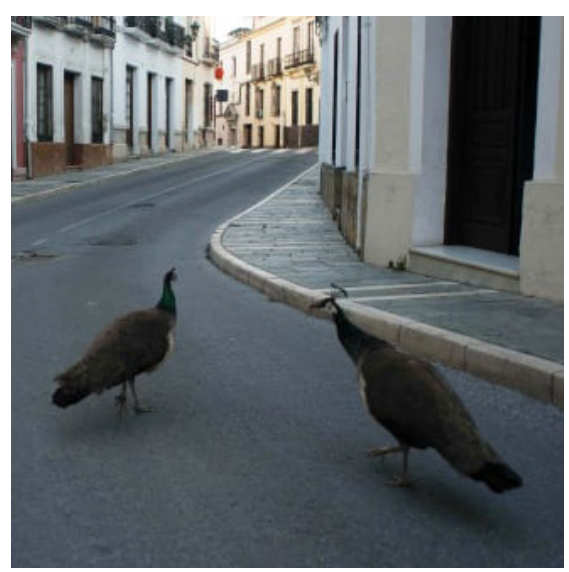

Fig E.1e. Peacocks.

Ronda, Spain.

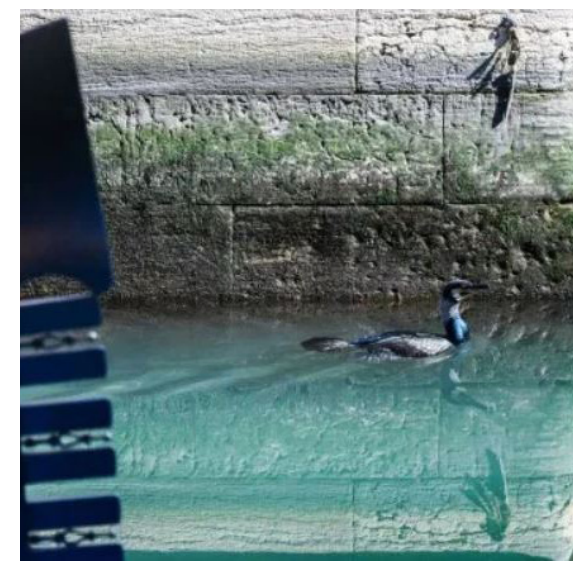

Fig E.1c. Seabird Venice, Italy.

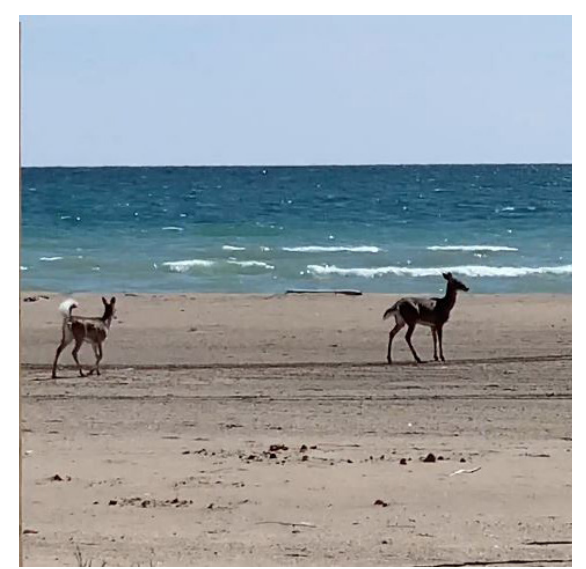

Fig E.1f. Deer

Toronto, Canada. 


\section{Appendix}

A. 1

A. 2

A.3

A. 4

A.5

A. 6
Data \& Research 231

Precedents 235

Conceptual Sketches 241

Photographs 247

Physical Models 253

Synanthropic Centre (DD) 257 
A.1

Data \& Research 
Fig A.1-1.

World population growth, 1700-2100.

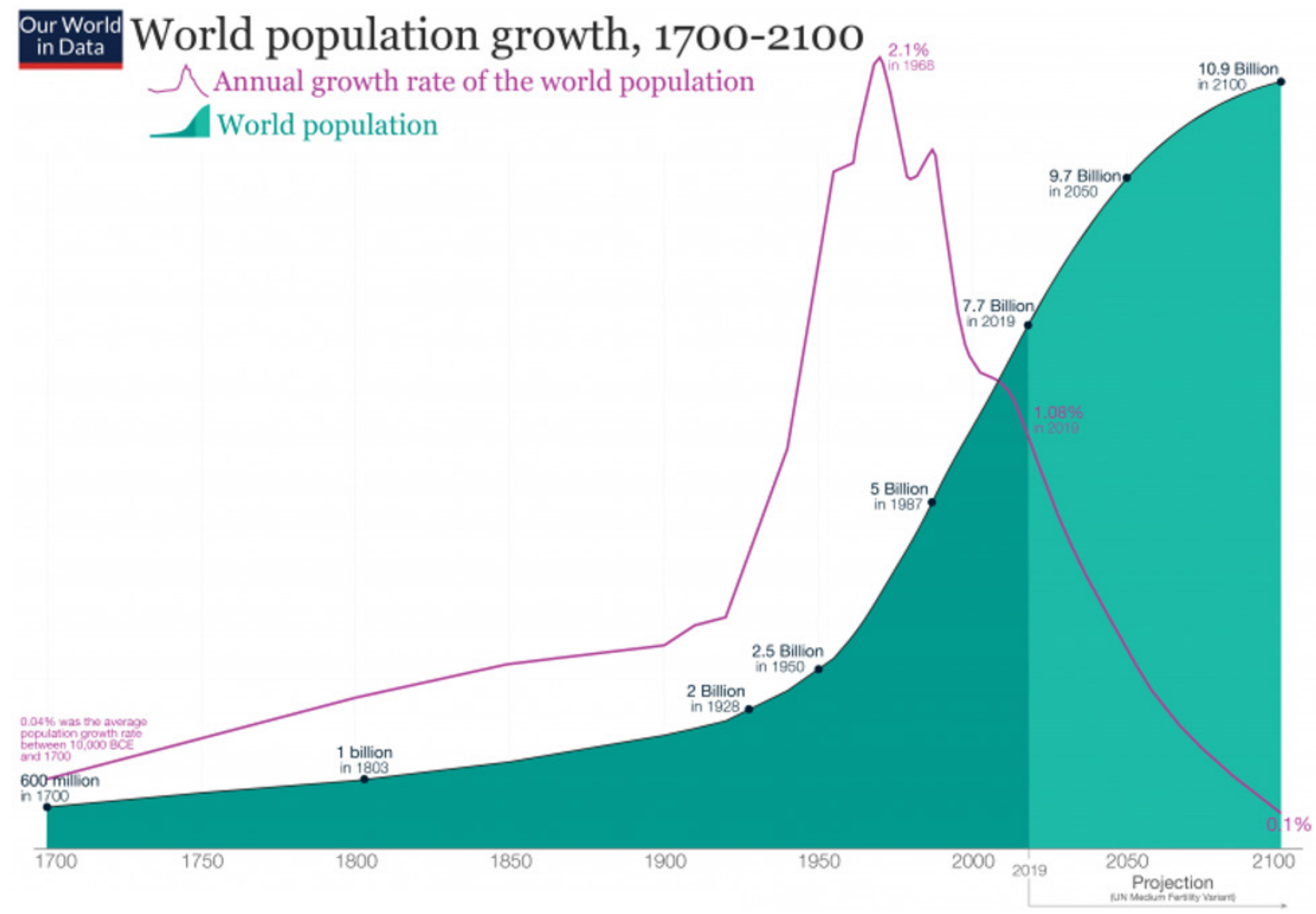


Fig A.1-2.

Minimum Access Area Needed by Common Wild Animal Species Found Around Homes.

\begin{tabular}{|c|c|c|}
\hline SPECIES & OPENING (IN INCHES) & COMMENTS \\
\hline BATS (MOST SPEGIES) & $1 / 4 \times 1 / 2$ & $\begin{array}{l}\text { Usually gain access through } \\
\text { gaps where materials join, } \\
\text { such as siding and soffit. }\end{array}$ \\
\hline FOXES (RED AND GRAY) & $4 \times 4$ & Gray foxes are good climbers. \\
\hline HOUSE SPARROWS & $3 / 4 \times 3 / 4$ & $\begin{array}{l}\text { Adept at gaining access } \\
\text { to clothes dryer, range, } \\
\text { and bathroom vents. }\end{array}$ \\
\hline MICE & $1 / 4 \times 1 / 2$ & $\begin{array}{l}\text { Can fit through openings } \\
\text { the size of a dime. }\end{array}$ \\
\hline RACCOONS & $21 / 2 \times 4$ & $\begin{array}{l}\text { Can fit through surprisingly } \\
\text { small openings; heavier } \\
\text { material required to exclude } \\
\text { because of greater strength. }\end{array}$ \\
\hline RATS & $1 / 4 \times 1 / 2$ & $\begin{array}{l}\text { Can fit through openings } \\
\text { the size of a quarter. }\end{array}$ \\
\hline SNAKES & $1 / 4 \times 1 / 2$ & $\begin{array}{l}\text { Some snakes fit through } \\
\text { smaller openings; if the snake } \\
\text { can get his head into the } \\
\text { opening, he can get his body in. }\end{array}$ \\
\hline STARLINGS & $1 \times 1$ & $\begin{array}{l}\text { Clothes dryer and exhaust fan } \\
\text { vents are a favorite; starlings } \\
\text { can lift flaps and get in. }\end{array}$ \\
\hline TREE SQUIRRELS & $2 \times 2$ & $\begin{array}{l}\text { Entry often occurs through } \\
\text { screening behind attic vents } \\
\text { and deteriorated louvers; may } \\
\text { require very heavy exclusion } \\
\text { matcrials becausc of gnawing } \\
\text { ability. }\end{array}$ \\
\hline WHITE-TAILED DEER & $12 \times 24$ & $\begin{array}{l}\text { Deer prefer to crawl under } \\
\text { obstructions rather than jump } \\
\text { over; a 9-inch or lower wire } \\
\text { is recommended on either } \\
\text { electric or nonelectric fencing } \\
\text { because the animals may } \\
\text { crawl under higher wires. }\end{array}$ \\
\hline WOODCHUCKS & $3 \times 4$ & $\begin{array}{l}\text { Under decks and porches; the } \\
\text { characteristic mound of carth } \\
\text { in front of a hole is an indicator } \\
\text { of woodchucks. }\end{array}$ \\
\hline
\end{tabular}


Fig A.1-3.

Human Health Concerns Dealing with Wildlife.

\begin{tabular}{|c|c|c|c|}
\hline DISEASE & $\begin{array}{l}\text { WILDLIFE } \\
\text { HOST(S) }\end{array}$ & $\begin{array}{c}\text { PRIMARY MODE } \\
\text { OF TRANSMISSION }\end{array}$ & PREVENTION \\
\hline BUBONIC PLAGUE & $\begin{array}{l}\text { Prairie dogs, } \\
\text { ground squirrels }\end{array}$ & $\begin{array}{l}\text { Flea infestations, } \\
\text { inhalation }\end{array}$ & $\begin{array}{l}\text { Public education, } \\
\text { rodent population } \\
\text { control }\end{array}$ \\
\hline CHLAMYDIOSIS & $\begin{array}{l}\text { Birds (csp. pigcons, } \\
\text { mallards) }\end{array}$ & $\begin{array}{l}\text { Contact with } \\
\text { feces, inhalation }\end{array}$ & $\begin{array}{l}\text { Good hygicne, } \\
\text { protective clothing }\end{array}$ \\
\hline GIARDIASIS & $\begin{array}{l}\text { Widespread, } \\
\text { esp. aquatic }\end{array}$ & Ingestion & $\begin{array}{l}\text { Good hygiene, espe- } \\
\text { cially hand washing }\end{array}$ \\
\hline HANTAVIRUS & Rodents & Inhalation or bite & $\begin{array}{l}\text { Public education, } \\
\text { habitat modification/ } \\
\text { exclusion }\end{array}$ \\
\hline HISTOPLASMOSIS & $\begin{array}{l}\text { Soil (esp. roosting } \\
\text { areas) exposed } \\
\text { to birds, bats }\end{array}$ & Inhalation & $\begin{array}{l}\text { Avoid known } \\
\text { roosting areas }\end{array}$ \\
\hline LEPTOSPIROSIS & Numerous mammals & $\begin{array}{l}\text { Ingestion, } \\
\text { broken skin }\end{array}$ & $\begin{array}{l}\text { Avoid handling and } \\
\text { exposure to urine, } \\
\text { practice good hygiene }\end{array}$ \\
\hline LYME DISEASE & $\begin{array}{l}\text { White-footed mouse, } \\
\text { white-tailed deer }\end{array}$ & Tick vector & $\begin{array}{l}\text { Avoid tick-infested } \\
\text { areas, wear protective } \\
\text { clothing }\end{array}$ \\
\hline RABIES & $\begin{array}{l}\text { Primary carriers: } \\
\text { raccoons, skunks, bats, } \\
\text { foxes, coyotes }\end{array}$ & Animal bite & $\begin{array}{l}\text { Avoid contact; treatment } \\
\text { regimen if bitten }\end{array}$ \\
\hline $\begin{array}{l}\text { RACCOON } \\
\text { ROUNDWORM }\end{array}$ & Raccoons & $\begin{array}{l}\text { Exposure to feces or } \\
\text { contaminated soil }\end{array}$ & $\begin{array}{l}\text { Avoid exposure } \\
\text { to feces or likely } \\
\text { infected areas }\end{array}$ \\
\hline $\begin{array}{l}\text { ROCKY MOUNTAIN } \\
\text { SPOTTED FEVER }\end{array}$ & $\begin{array}{l}\text { Rabbits, rodents, } \\
\text { opossums }\end{array}$ & Tick vector & $\begin{array}{l}\text { Avoid tick-infested } \\
\text { areas, wear protective } \\
\text { clothing }\end{array}$ \\
\hline SALMONELLOSIS & $\begin{array}{l}\text { Widespread: reptiles, } \\
\text { birds, mammals }\end{array}$ & Ingestion & Hygiene, disinfection \\
\hline TULAREMIA & Rabbits, rodents & $\begin{array}{l}\text { Tick, biting fly, or } \\
\text { contaminated water }\end{array}$ & $\begin{array}{l}\text { Good hygiene, avoid } \\
\text { contaminated areas }\end{array}$ \\
\hline WEST NILE VIRUS & $\begin{array}{l}\text { Primary reservoirs: } \\
\text { birds }\end{array}$ & $\begin{array}{l}\text { Mosquito or arthropod } \\
\text { vector, accidental } \\
\text { human-to-human }\end{array}$ & $\begin{array}{l}\text { Control mosquito } \\
\text { breeding, wear } \\
\text { protective clothing }\end{array}$ \\
\hline
\end{tabular}




\section{A. 2}

\section{Precedents}

\section{Fig A.2-1. Robson Square.}

Robson Square was one of the precedents that informed the design of a hybrid architectural-landscape environment. The implementation of sloped formations, resting areas, and vegetation create an experience that allows people to traverse higher elevations with greater ease. This section of Robson square has been re-coloured.

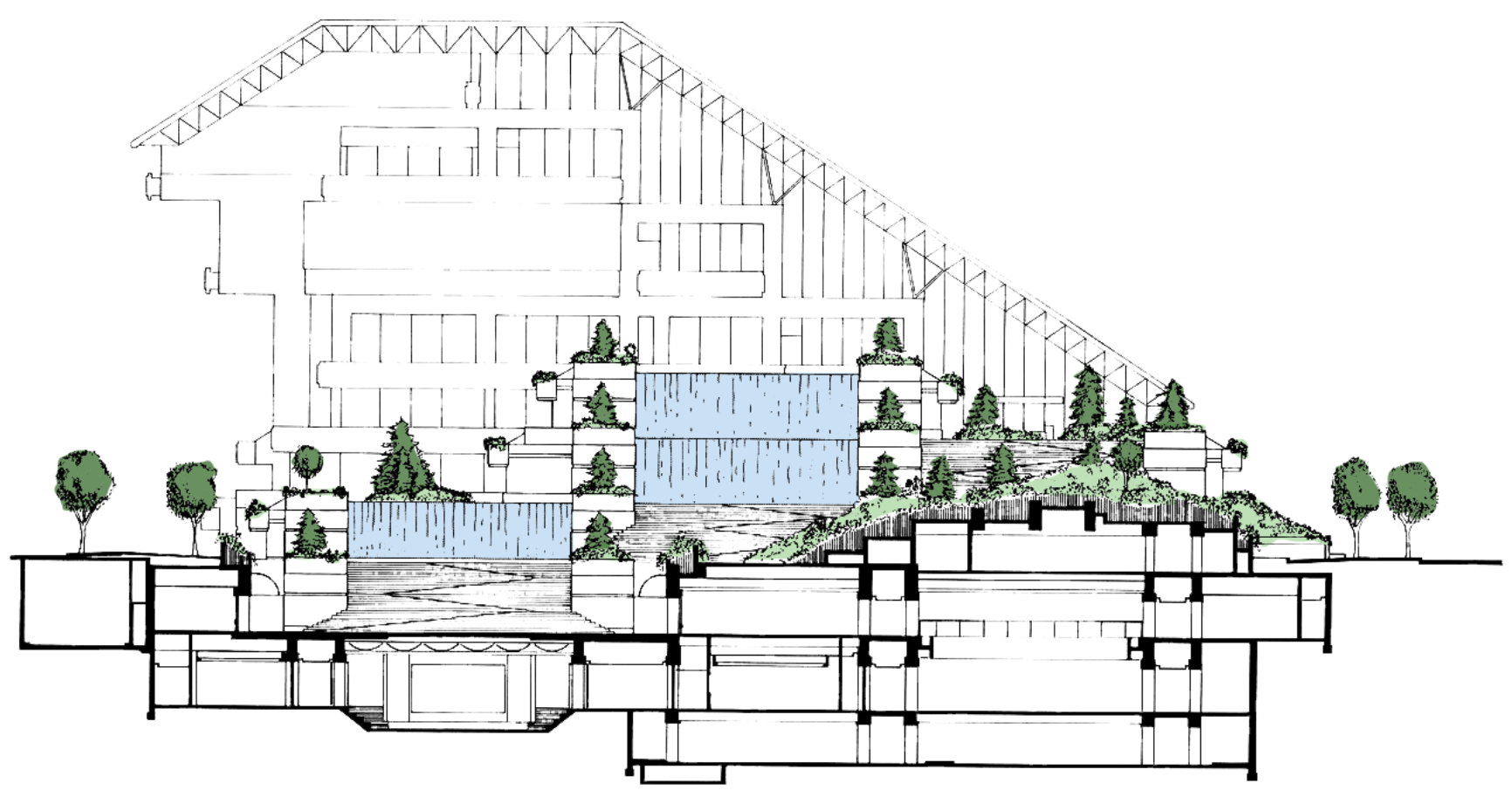


Fig A.2-2. View from Above.

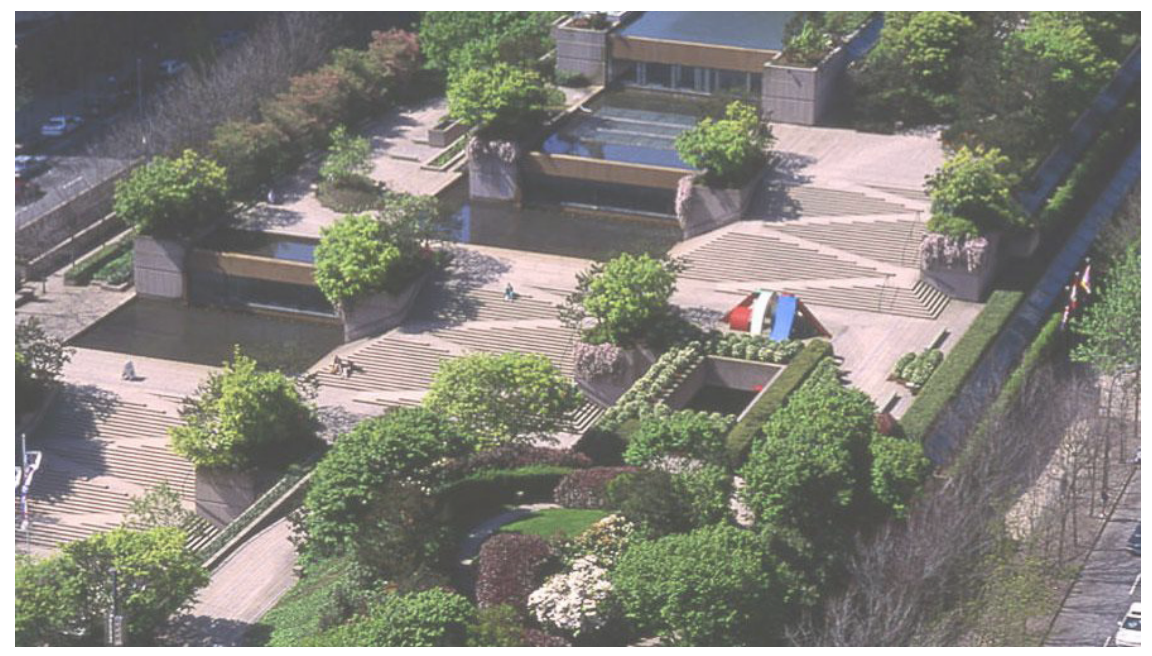

Fig A.2-3. First-person perspective.

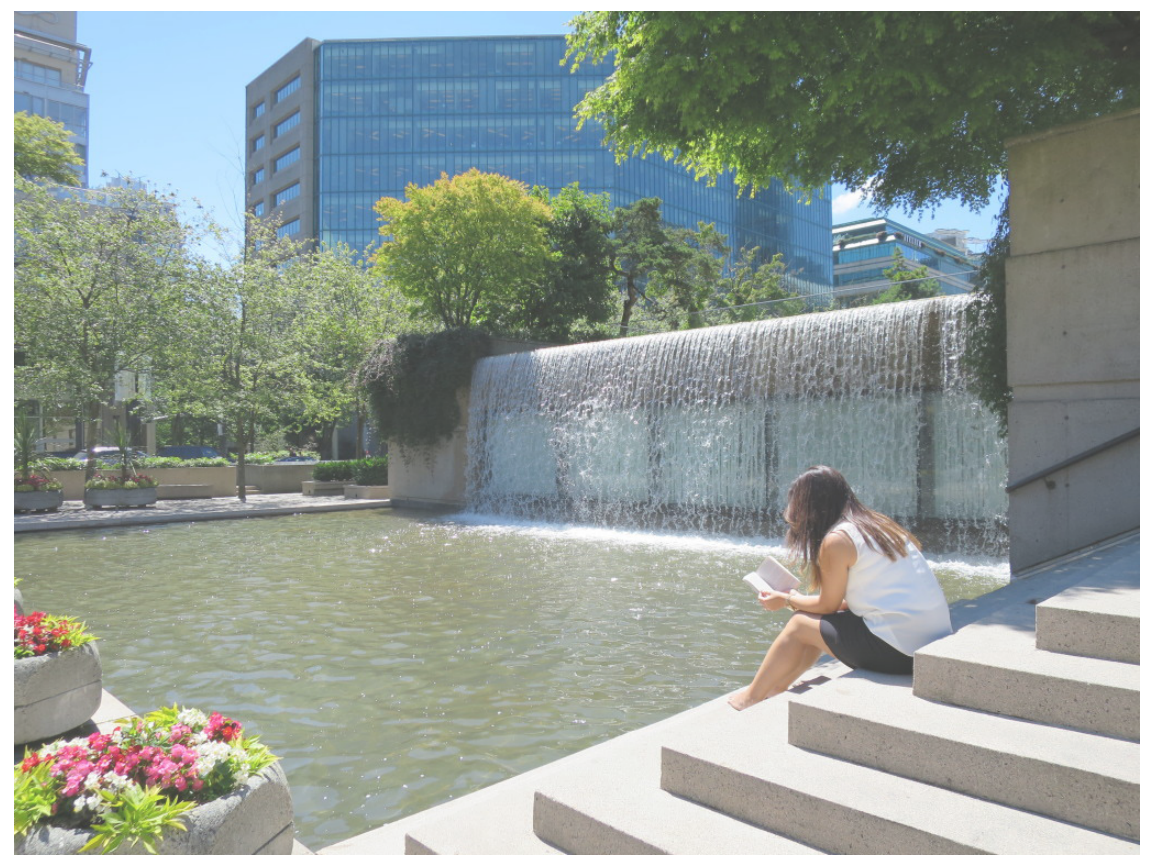




\section{Fig A.2-4. Radburn, New Jersey.}

This planning project implemented zones of safe travel for school children in a local neighbourhood. These pedestrian areas are separated from streets in the neighbourhood that see vehicular traffic. This masterplan incorporates two opposing circulation networks that rarely intersect. This strategy informs the design of weaving a circulation network for wildlife within the urban fabric.

a.

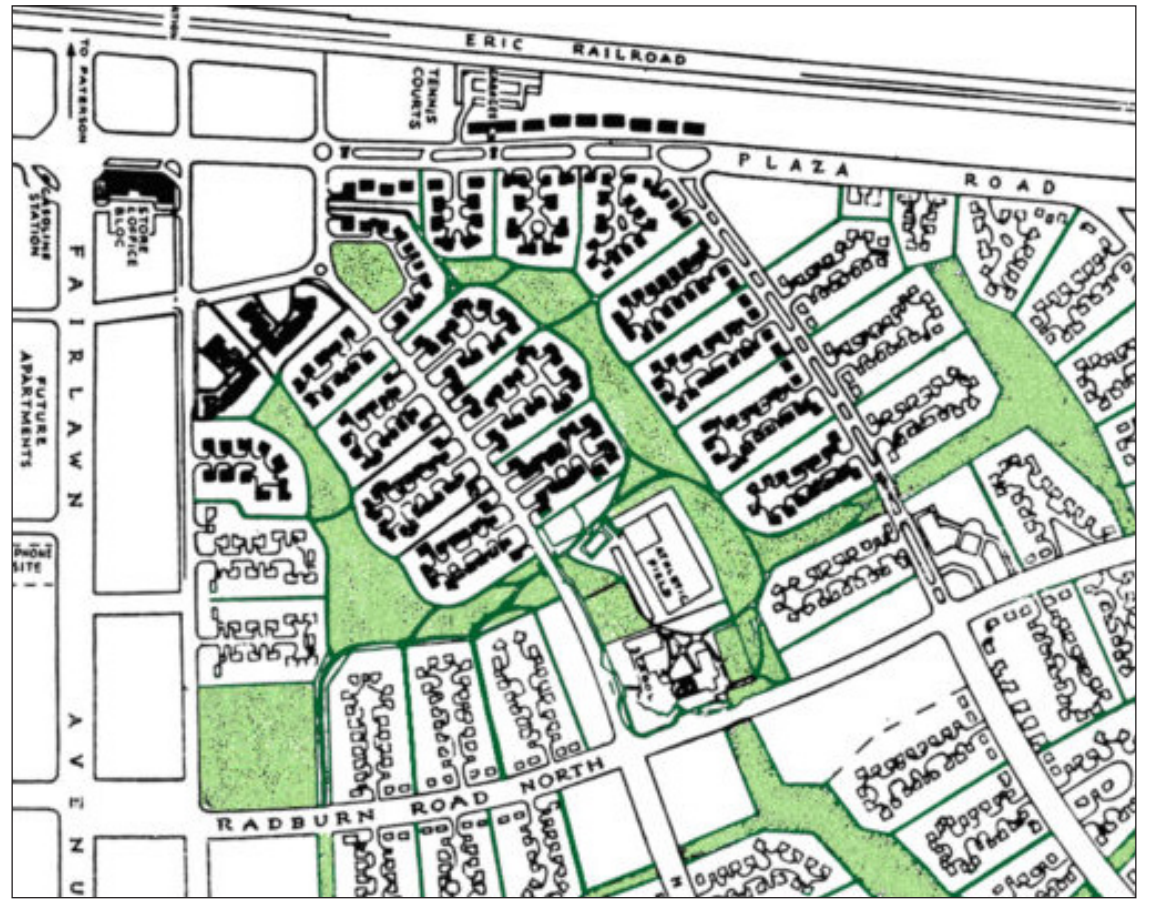


b.

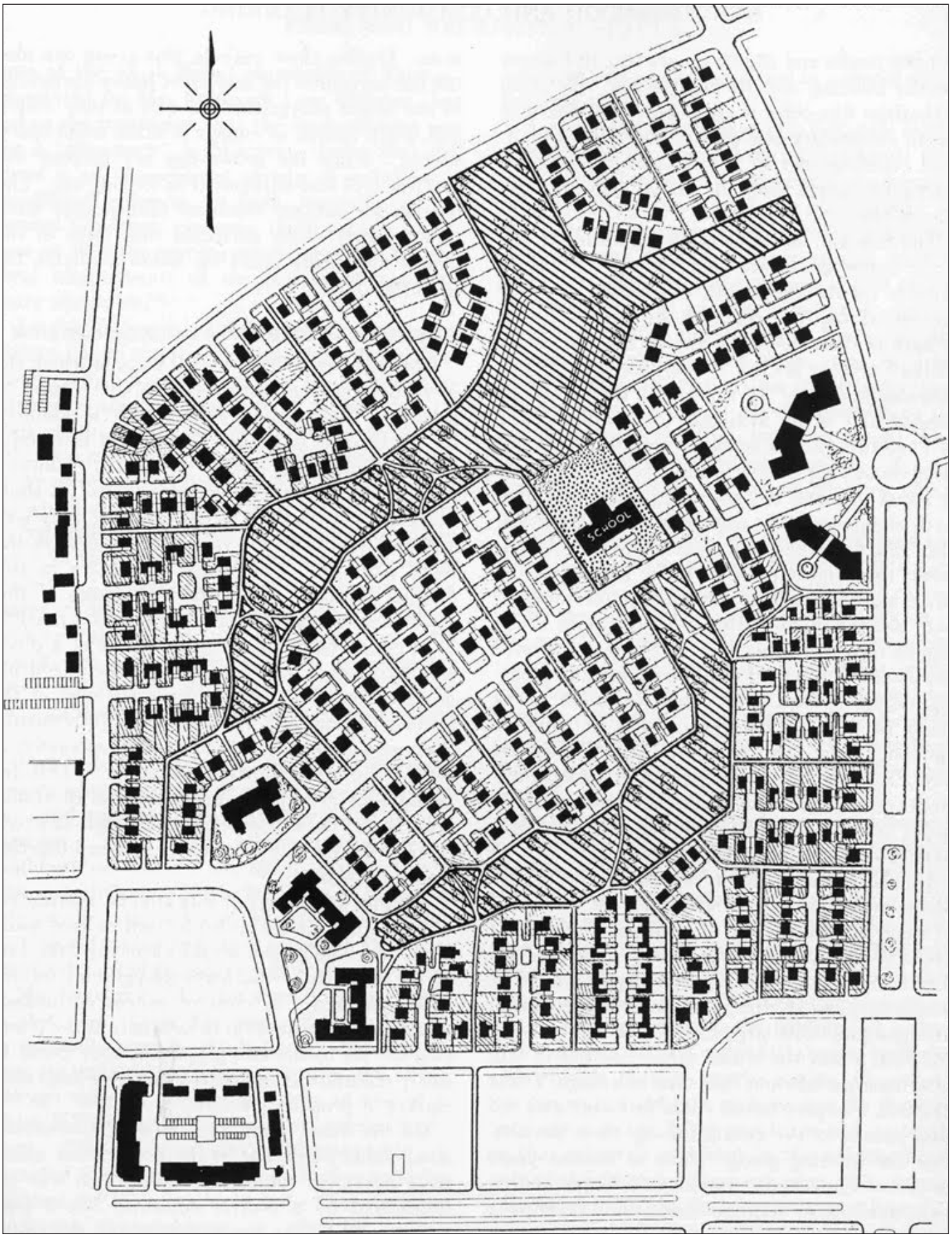




\section{Fig A.2-5. Toronto Overgrown by Nature.}

Lisa Jackson.

This visualization of Toronto overtaken by nature is an extreme scenario. Using this as a point of reference, the thesis work aimed to achieve a more balanced relationship between the forces of culture and nature.

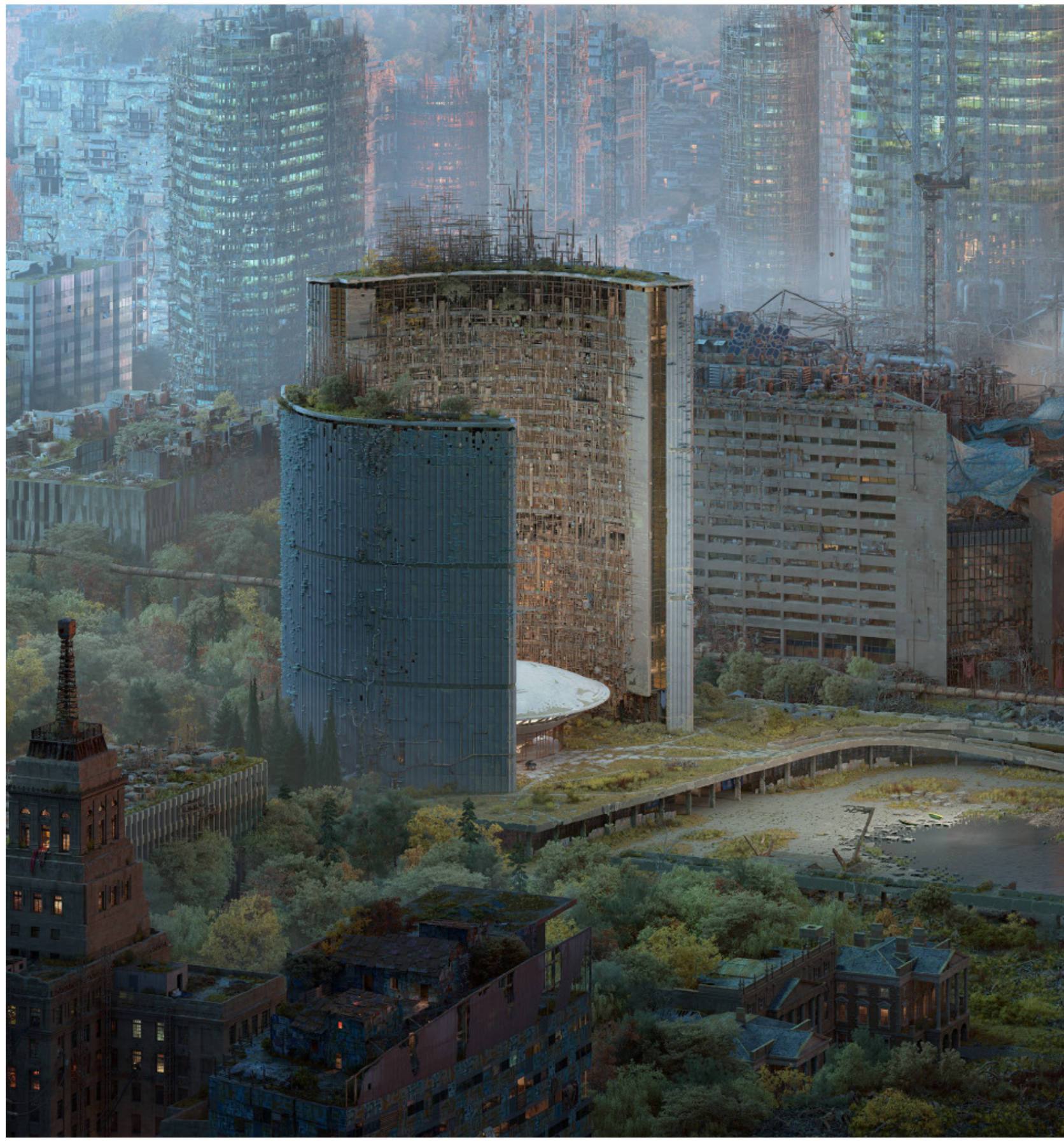




\section{A.3}

\section{Conceptual Sketches}

\section{Fig A.3-1. Booelan Overlap.}

This sketch encapsulates the idea of carving and intersecting dedicated zones for wildlife based on known parameters. For example, clearing certain heights from physical obstructions prevents potential bird collisions. These voids can then be populated by other wildlife circulation and program elements. Meanwhile, these areas would accomodate vertical human circulation as well as observation areas of the emergent hybrid environment.

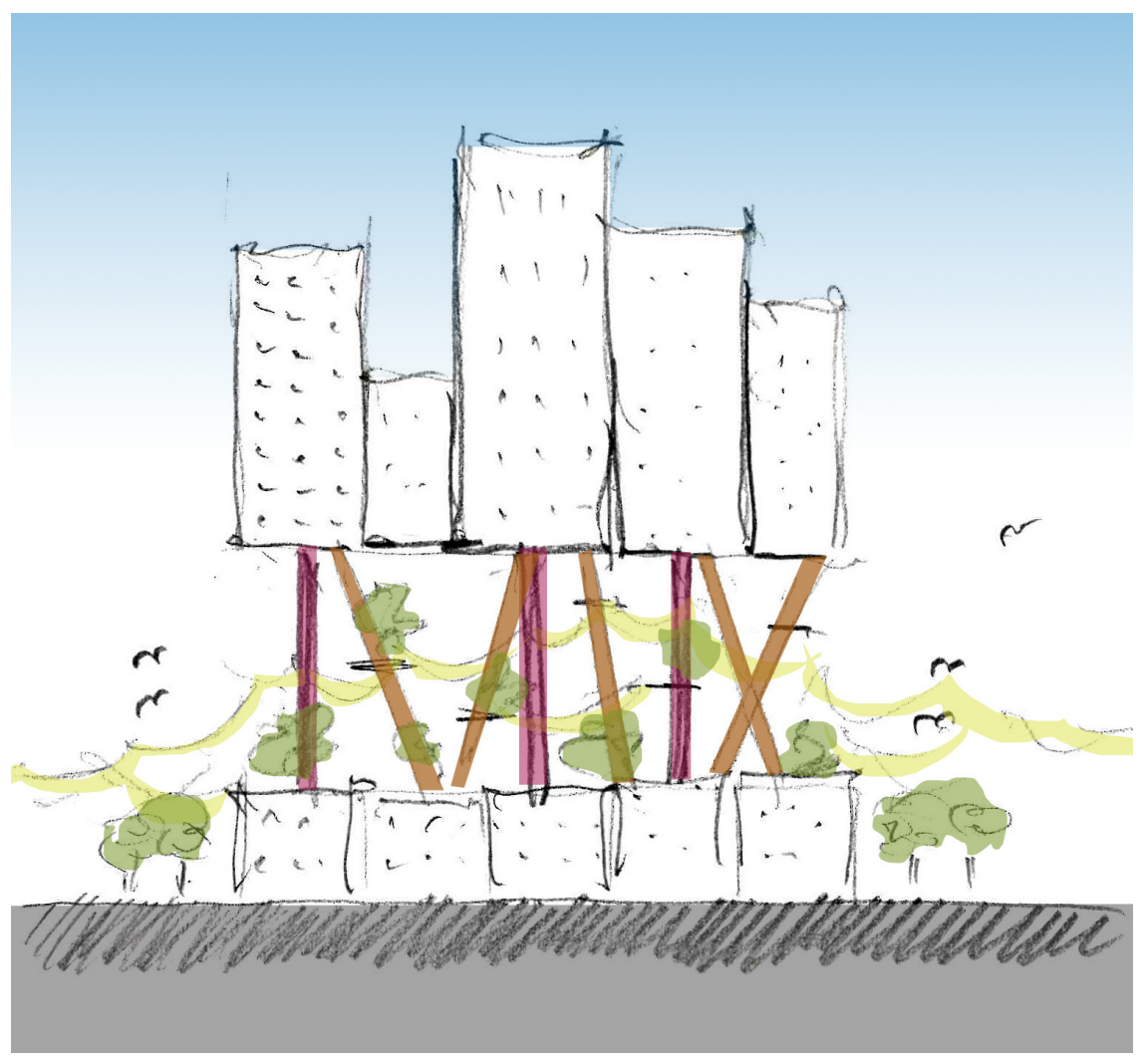




\section{Fig A.3-2. Carrying Capacity.}

Another idea is that rather than building cities so excessively, certain limits can be instituted to building heights, volumes, and overall distribution based on something like an analysis of carrying capacity for the city. The resultant in-between spaces will be dedicated to other wildlife.

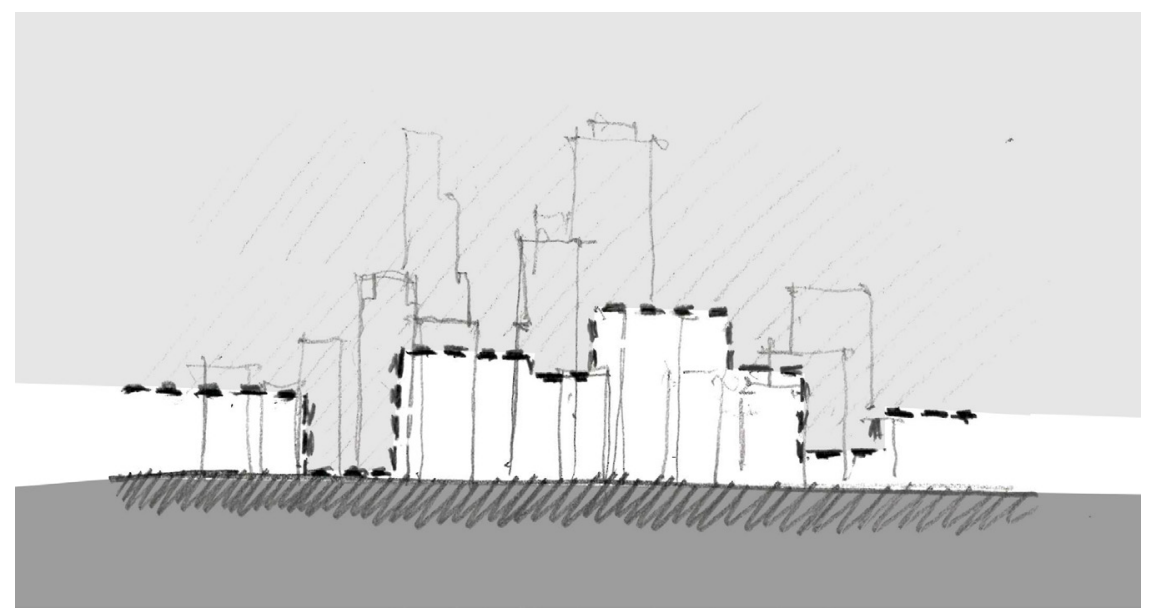


a.

Fig A.3-3. Intersection.

This iterative study explores the possibilities of interseting wildlife corridors through a typical building in various configurations.
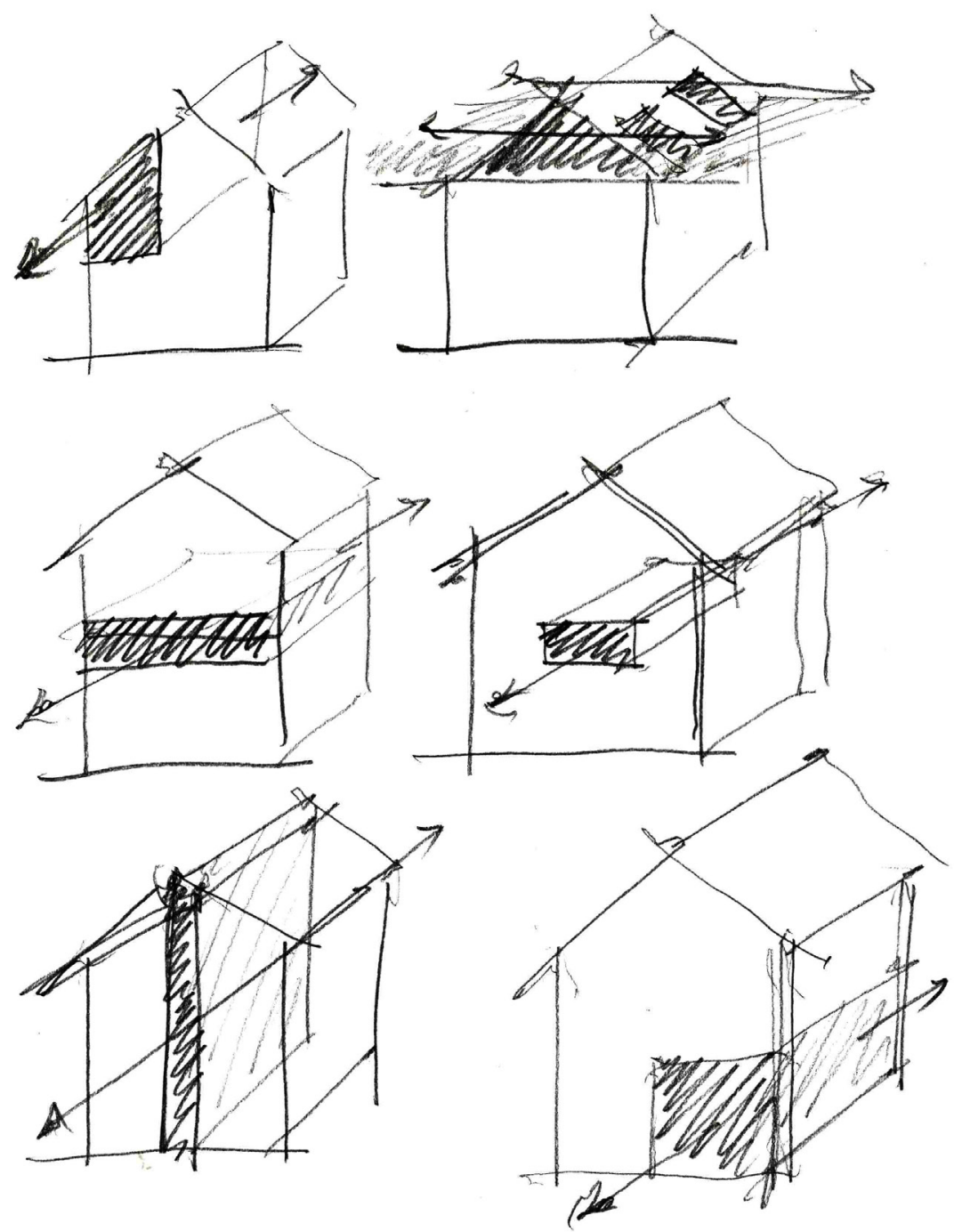

b.

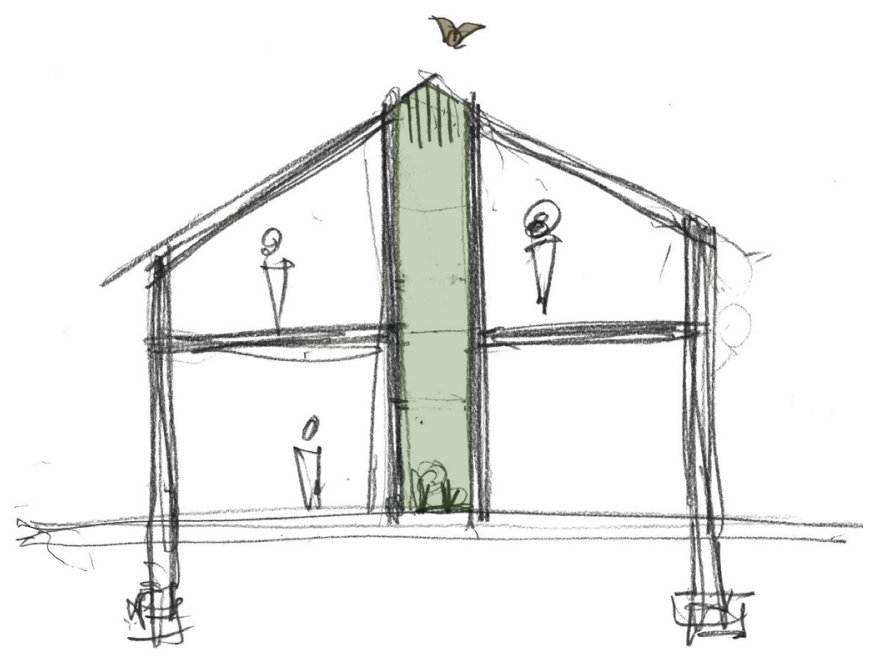


a.
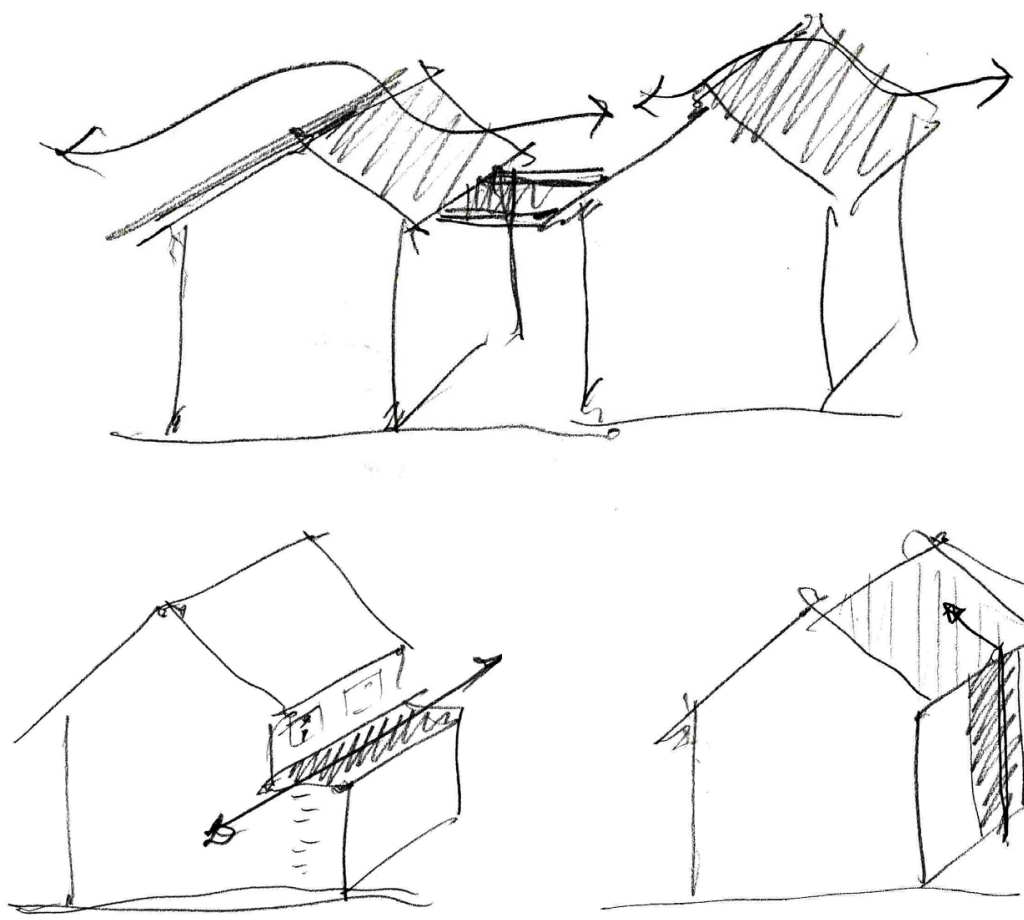

Fig A.3-4. Surface.

These studies explore how wildlife circulation pathways can form on the surface of various portions of a building.

b.

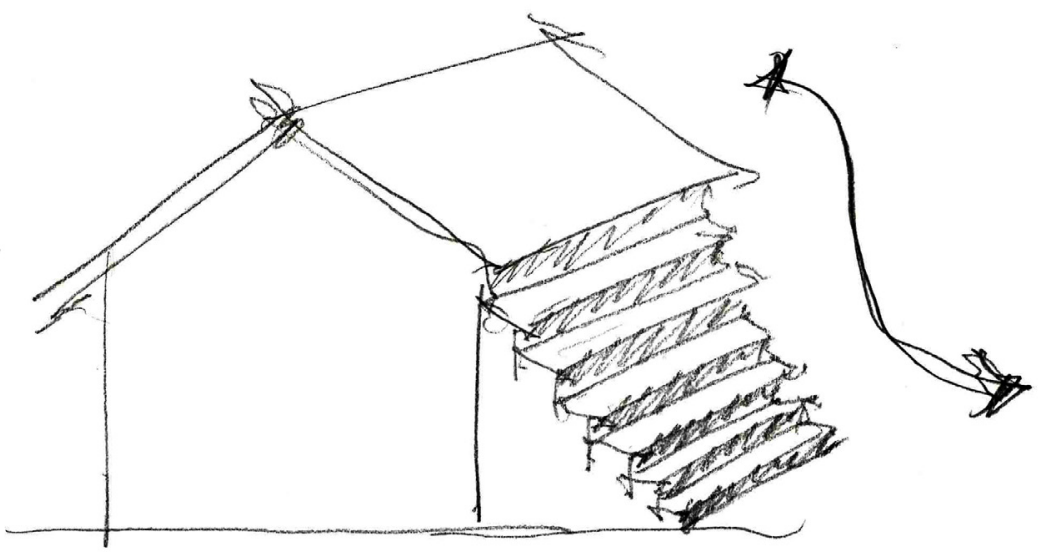




\section{Fig A.3-5. Pan-species Environment.}

This sketch attempts to envision the mutation of a common home into a module that contains habitat and circulation strategies for wildlife within its architectural framework.

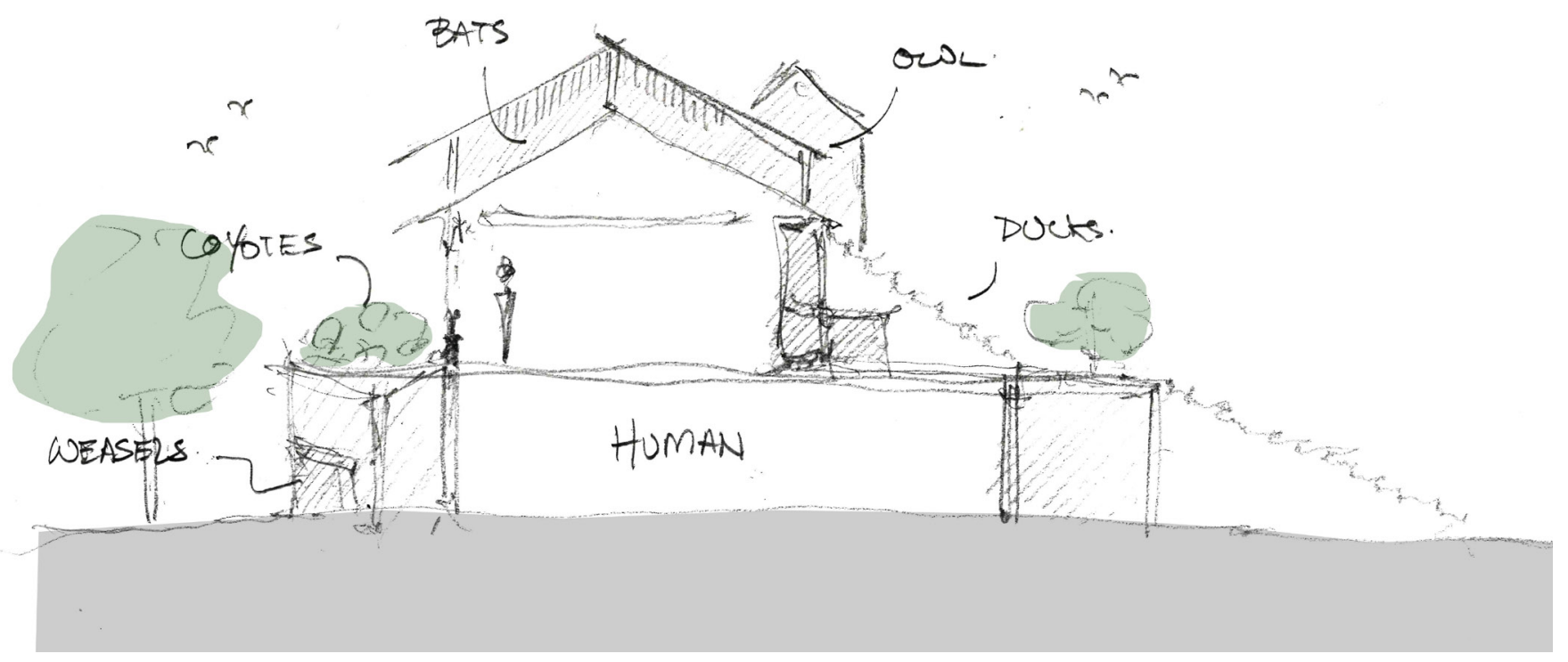




\section{A. 4}

\section{Photographs}

Fig A.4-1.

Canada Goose at Dundas and Bay.

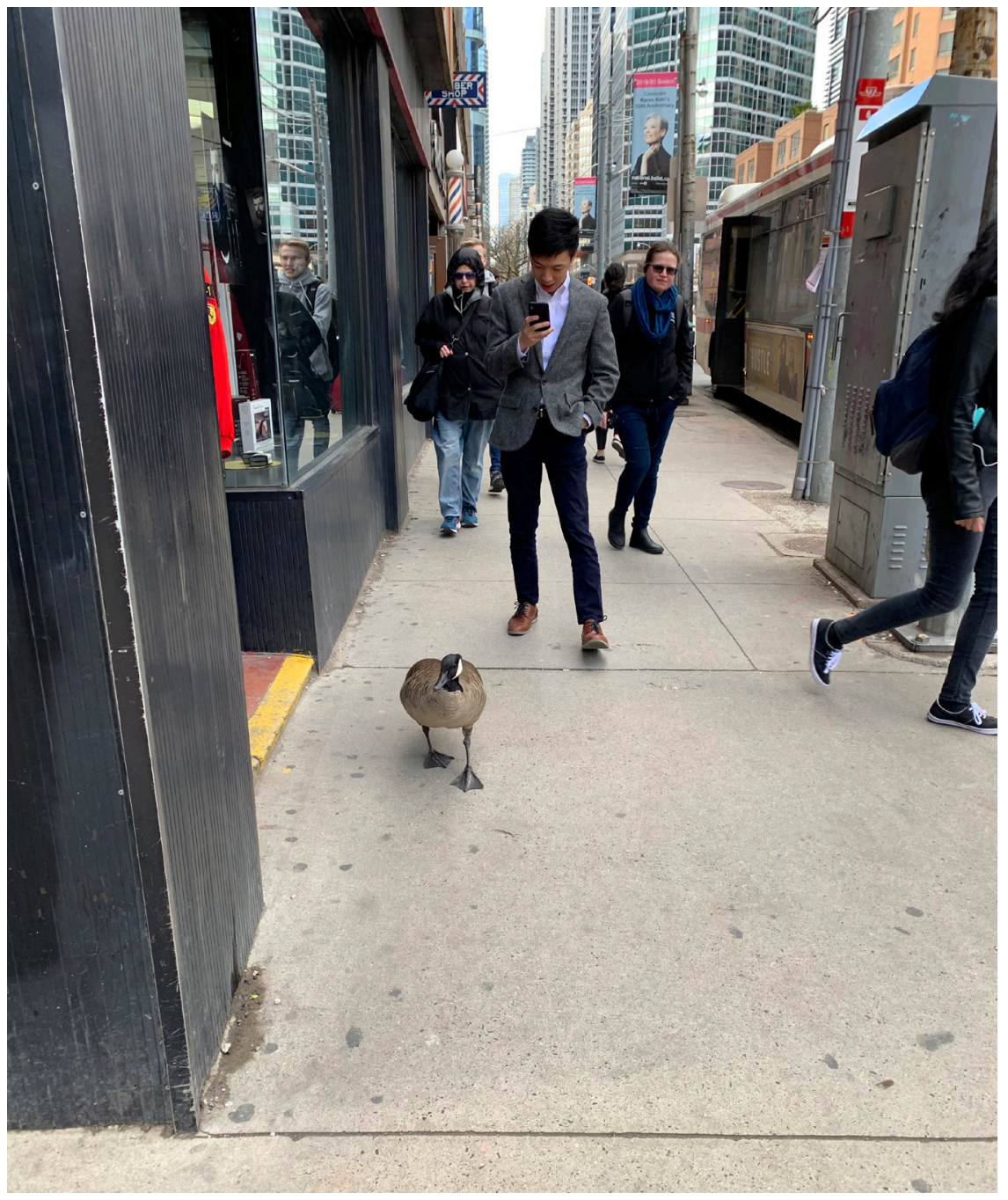


Fig A.4-2.

Bickford Centre, as seen from Christie Pits Park to the north. The building's chimney is among the tallest structures in the neighbourhood. For this reason, it is incorporated as a landmark element in the design.

a.

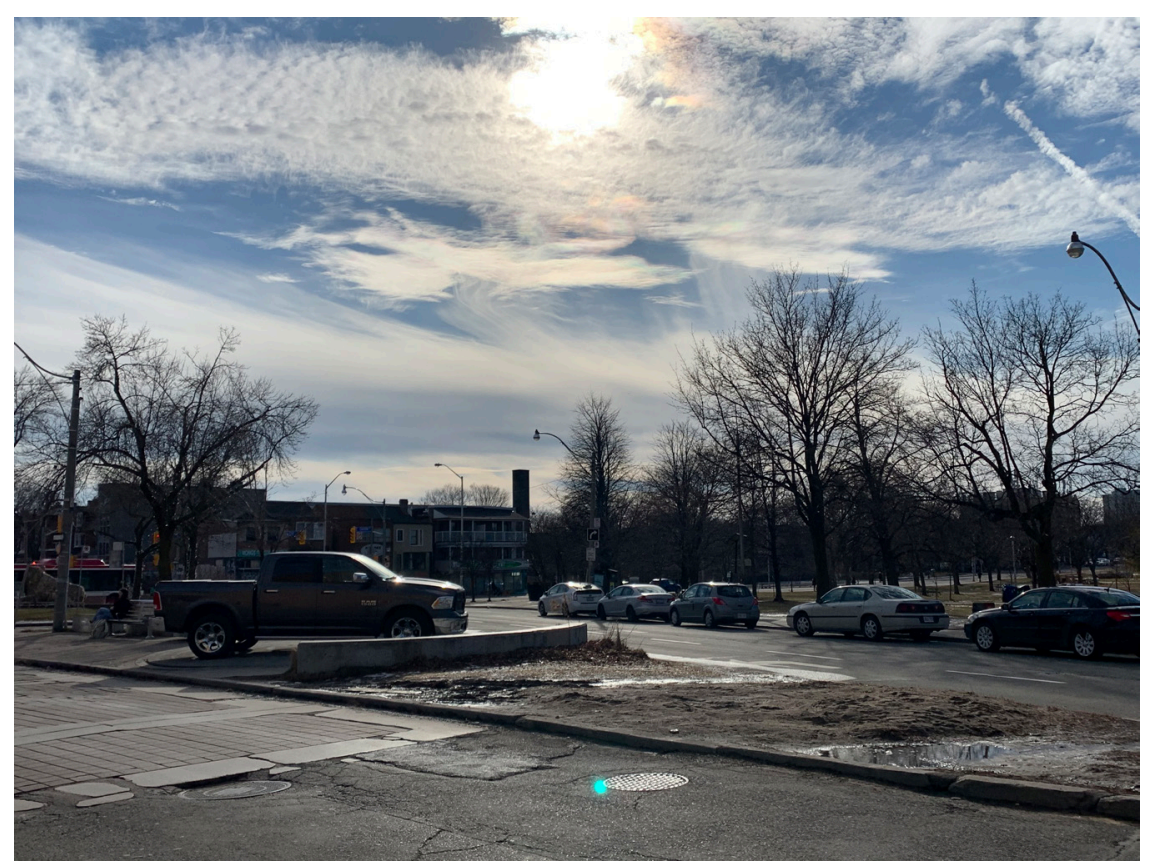

b.

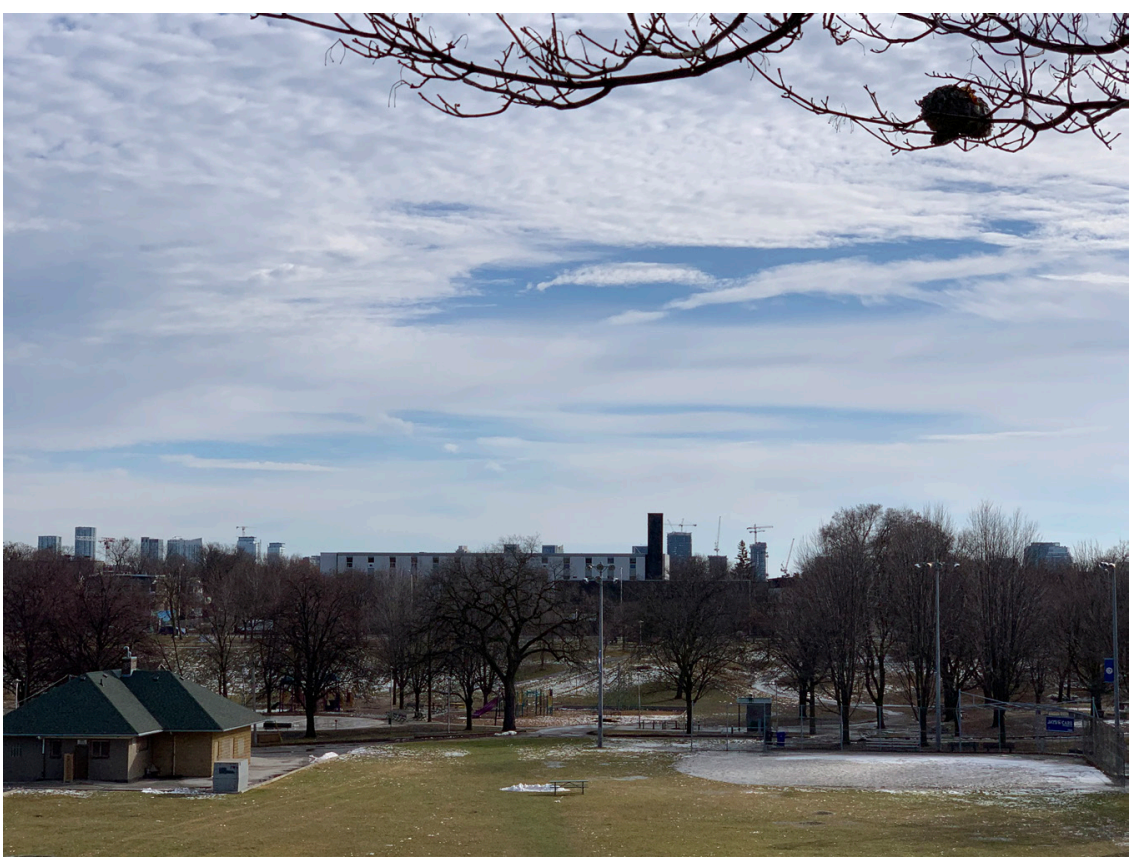




\section{Fig A.4-3. Bickford Centre.}

These are site photographs of the entrance plaza and greenspace in the area of Bickford Centre adjacent to Bloor Street.

The photographs on the next page depict the underpass that connects the entry area with the interior courtyard and exits at Bickford Park on the other side of the building.

b.

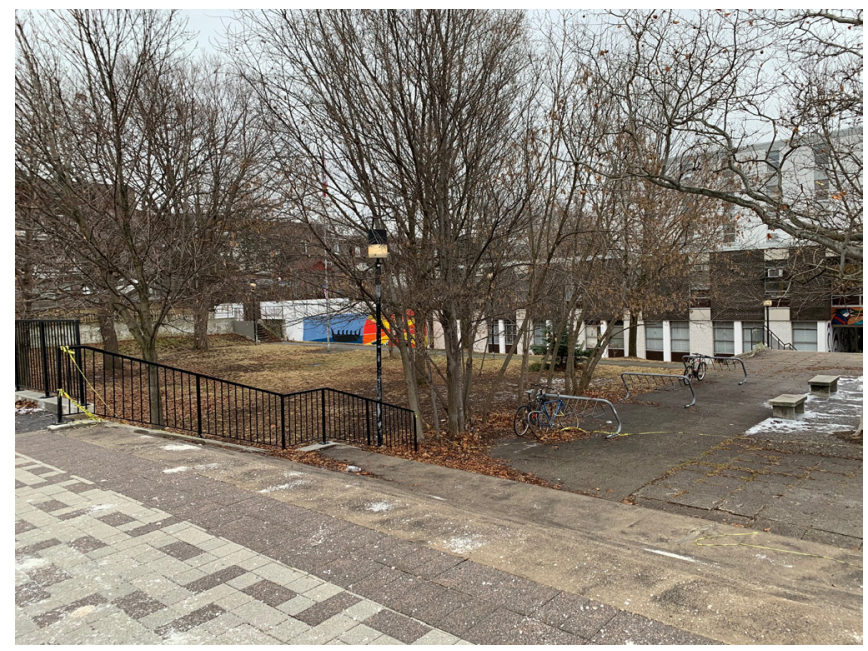

d.

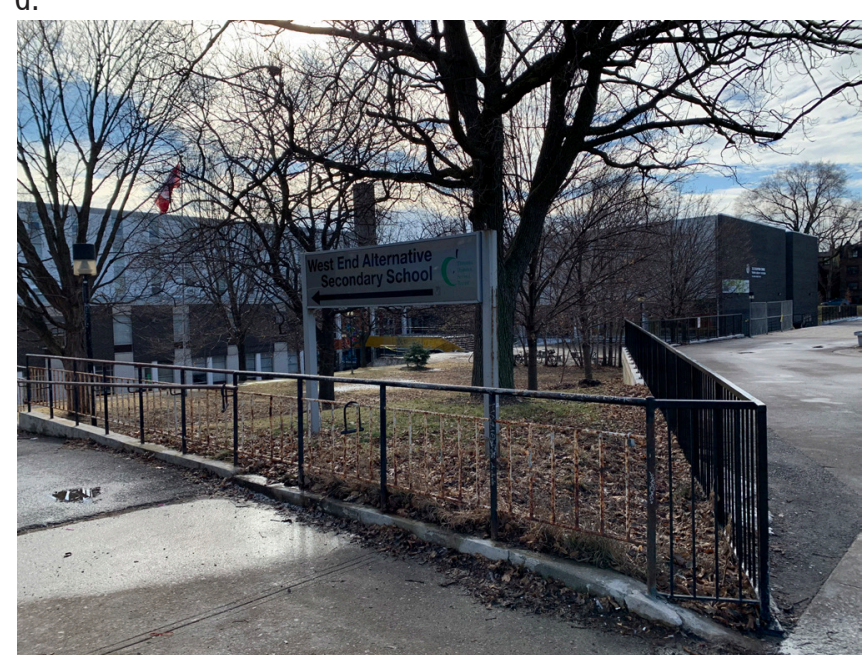

a.

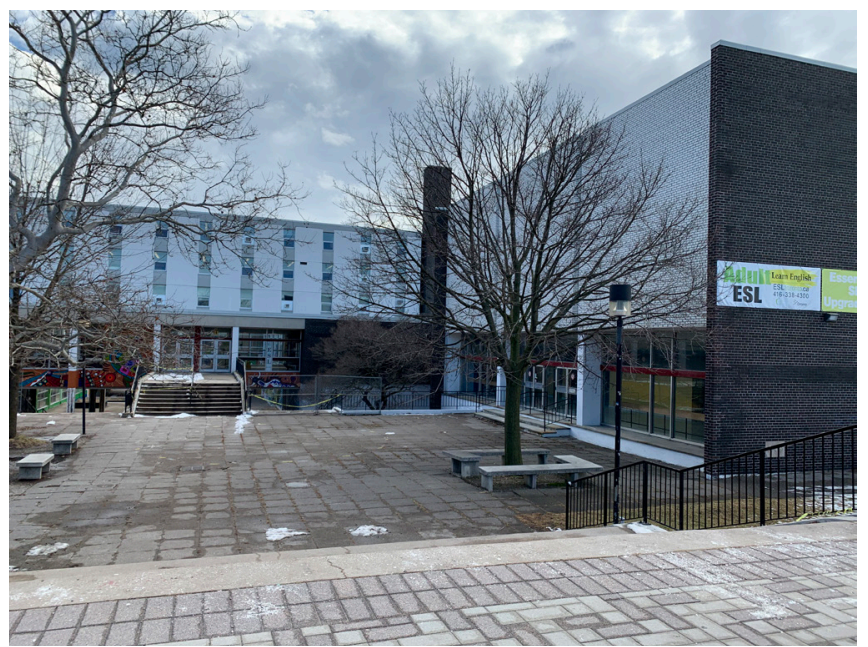

c.

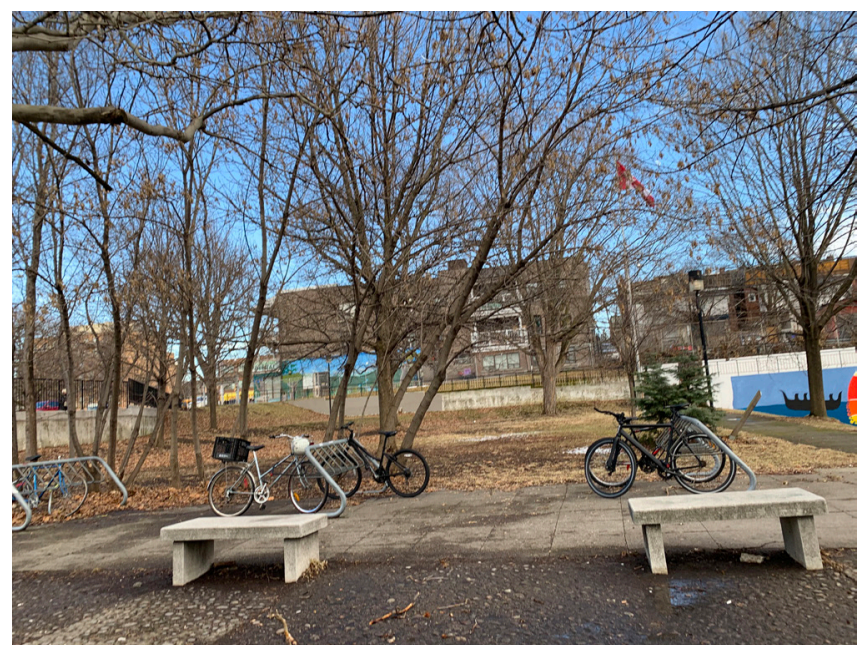

e.

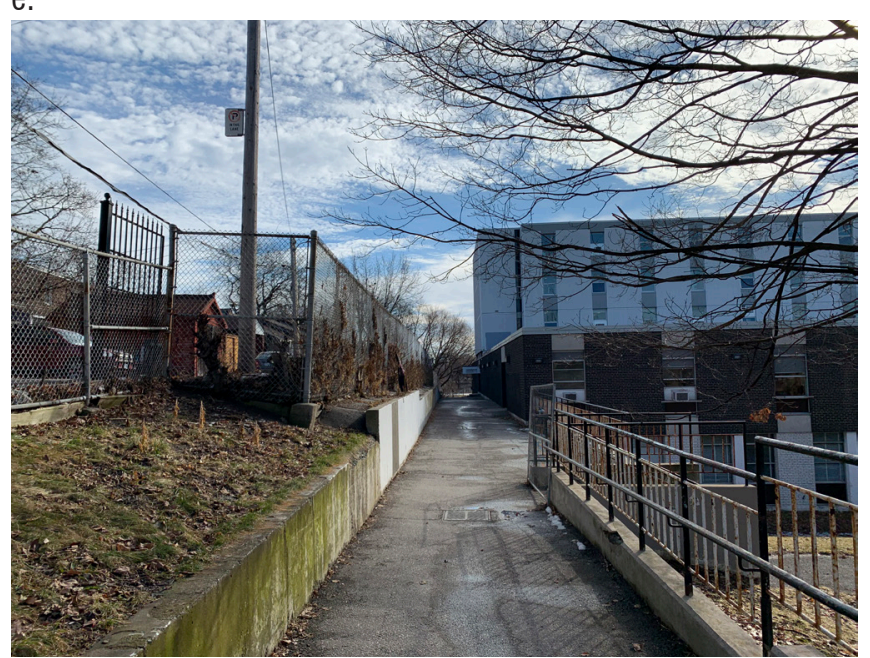



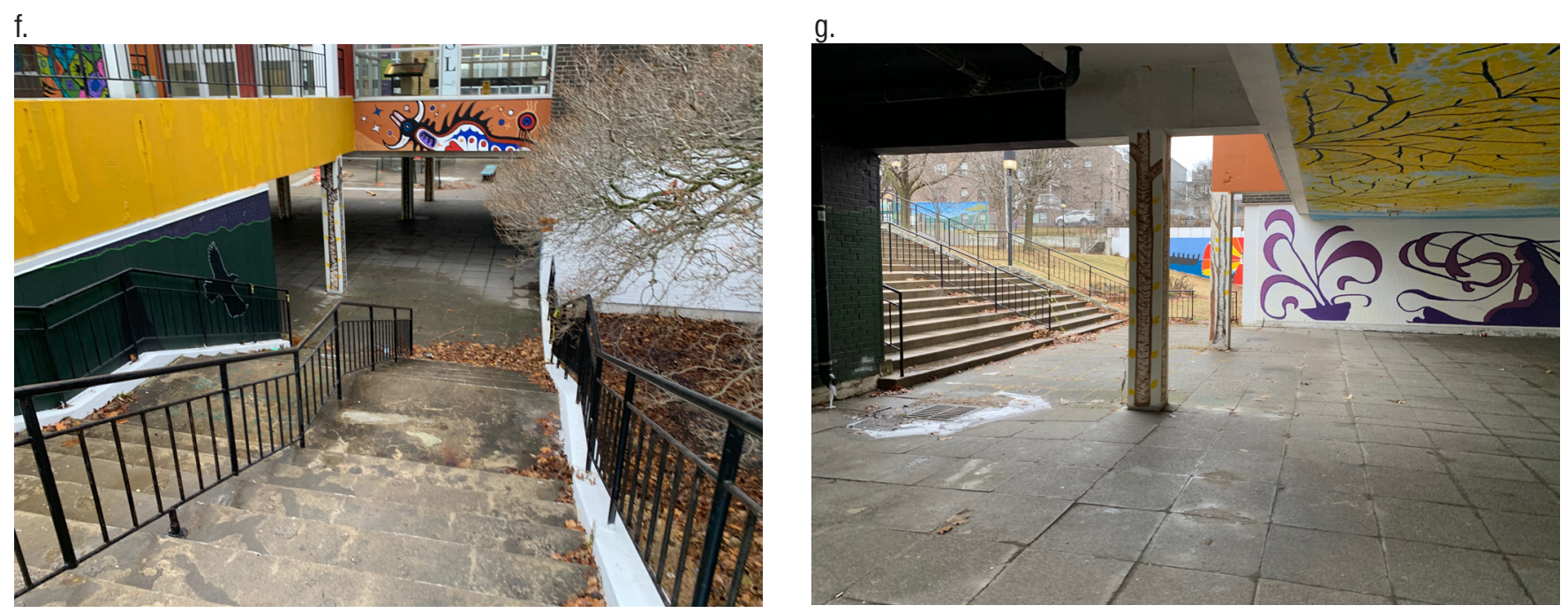

h.
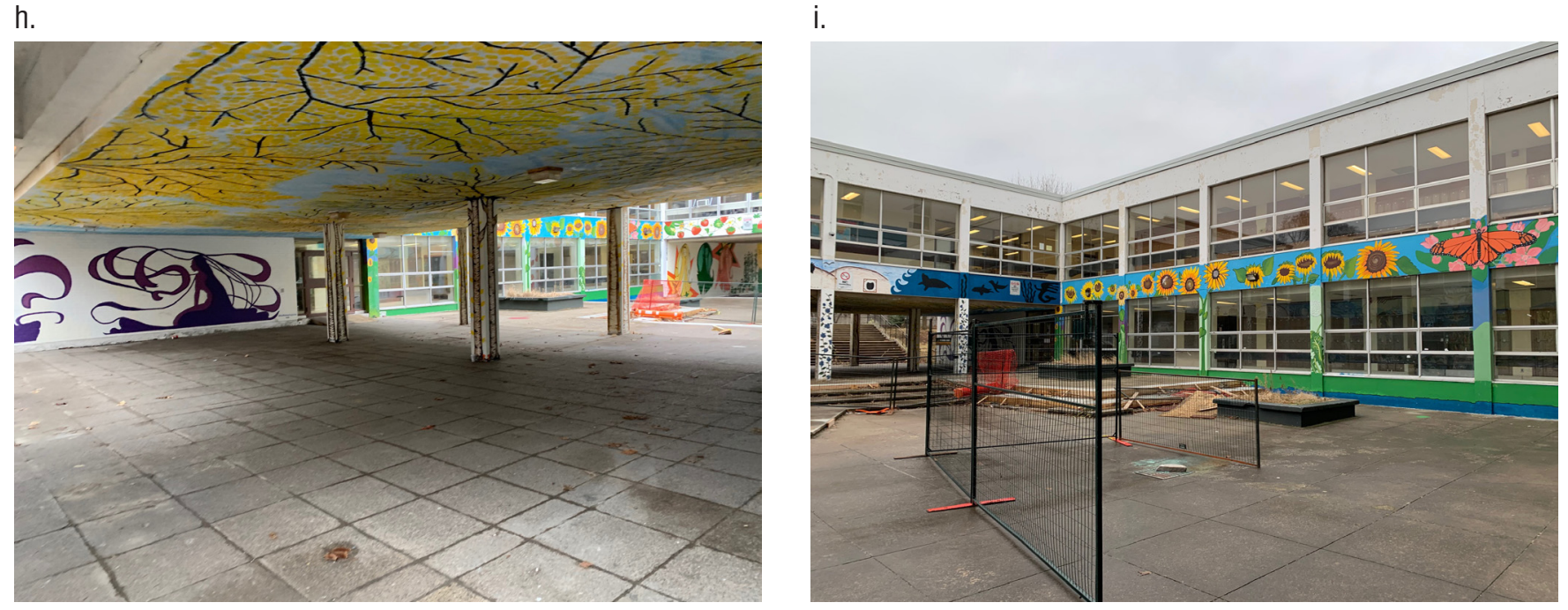

k.
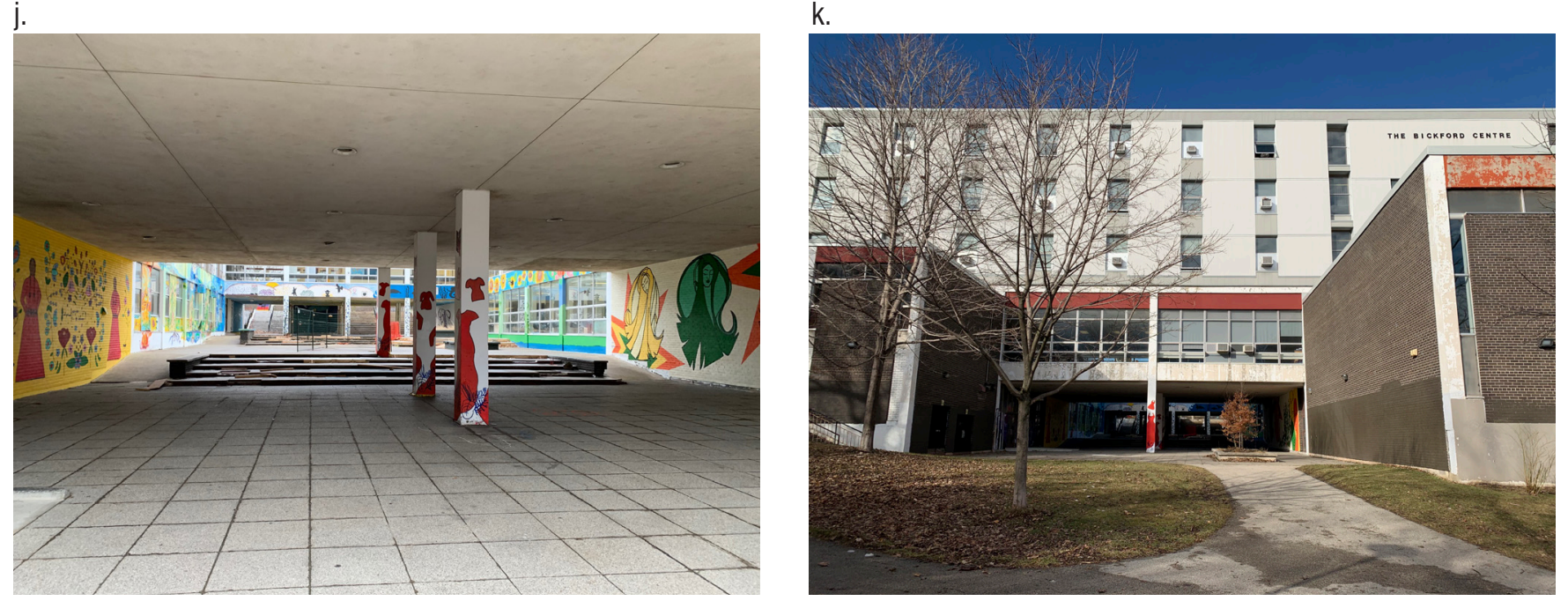
Fig A.4-4. Bickford Park.

These are site photographs of Bickford Park, which is depressed a few metres below street level. This creates sloped areas often used for tobogganing in winter.

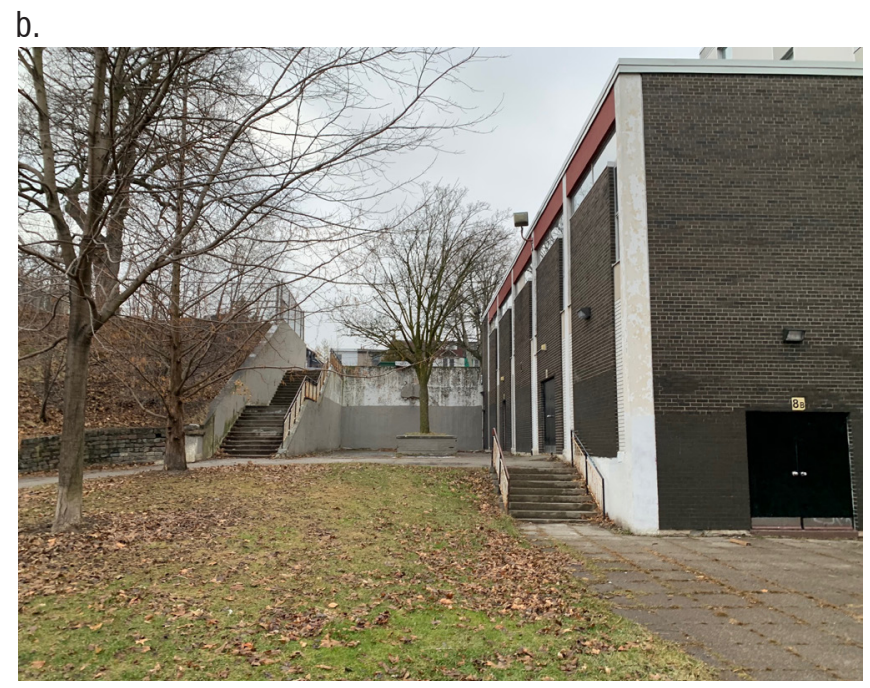

d.

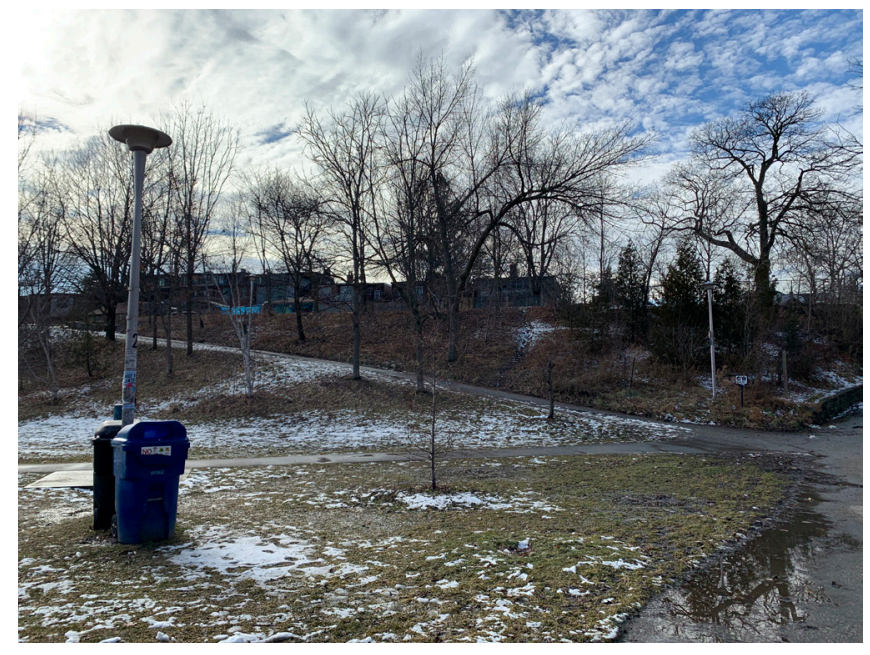

a.

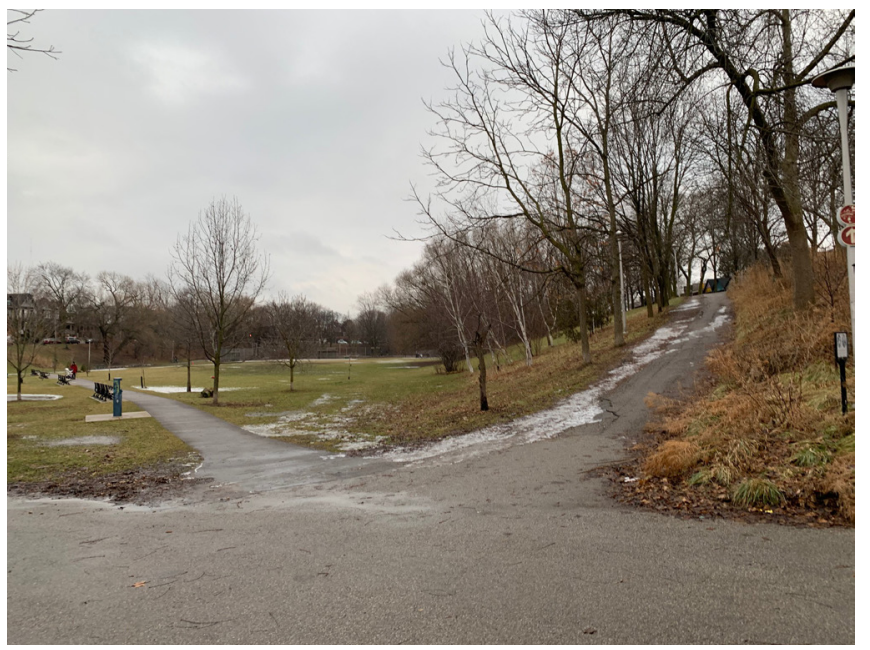

C.

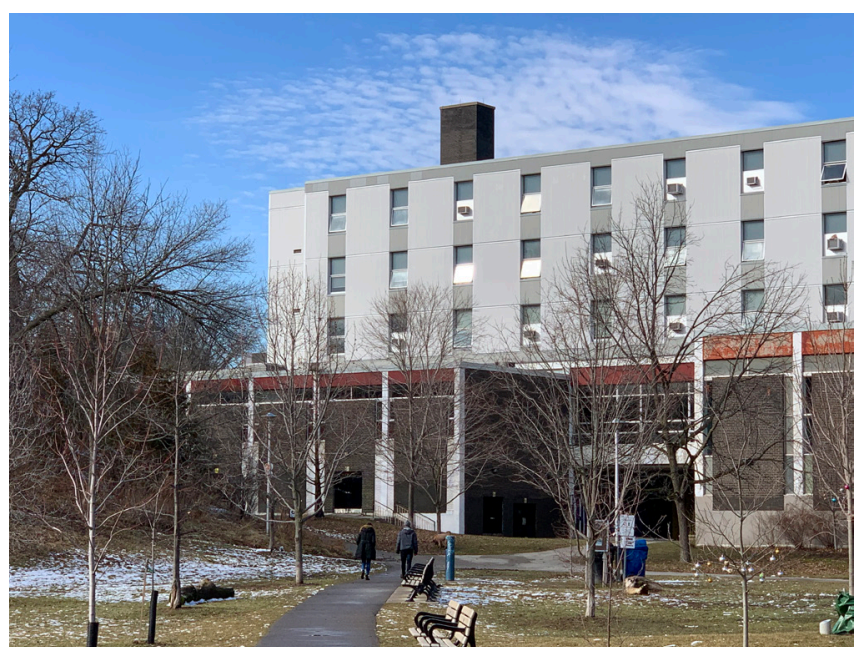

e.

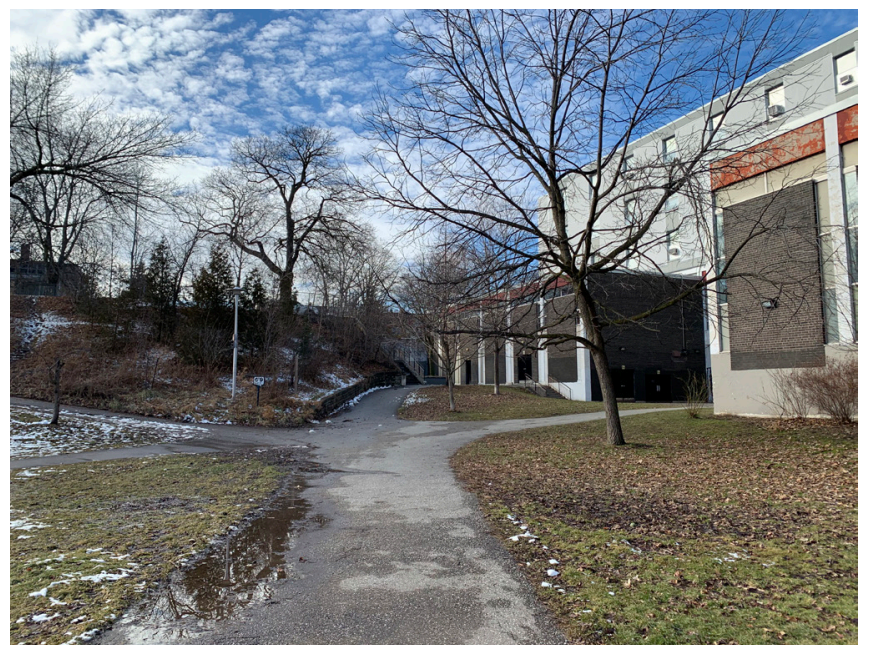


f.
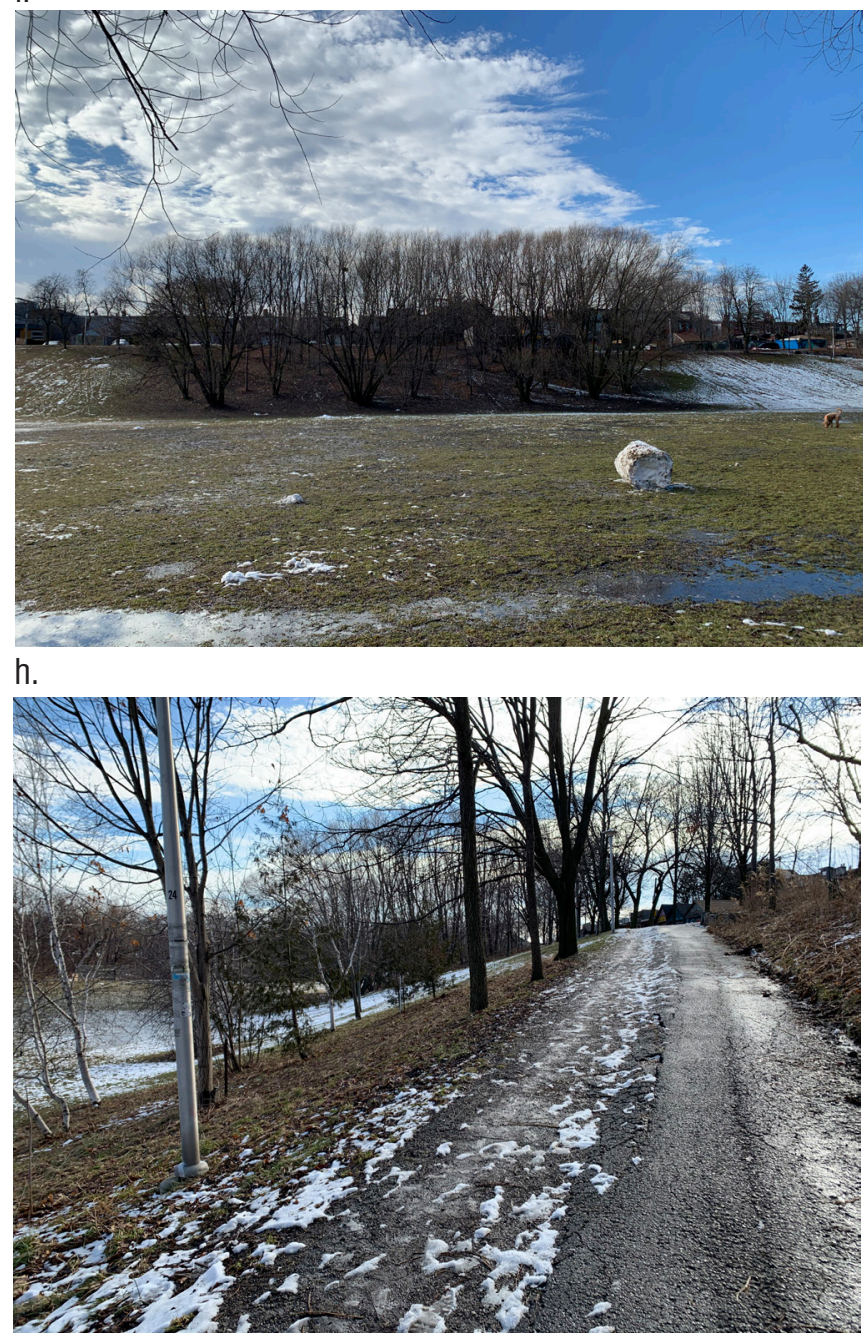

j.

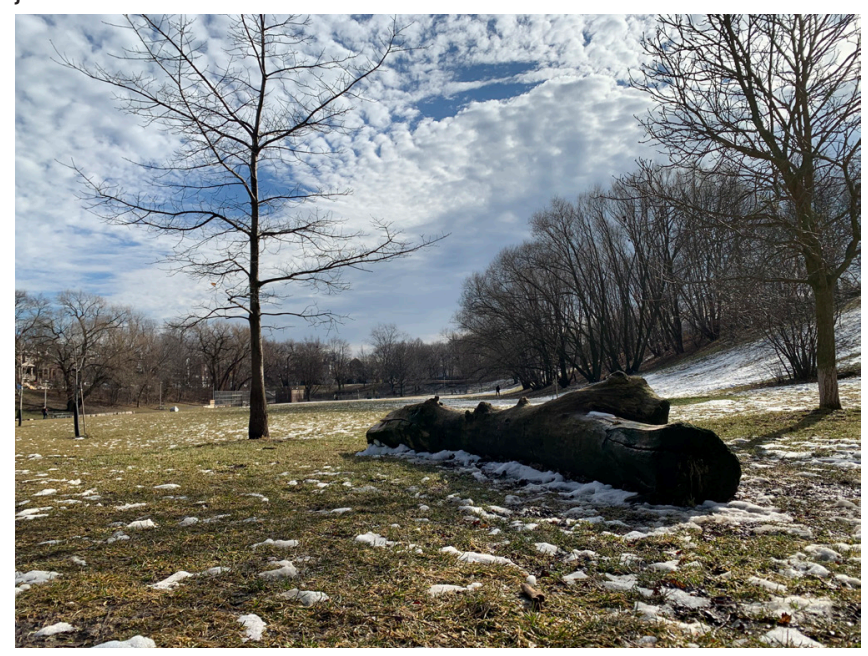

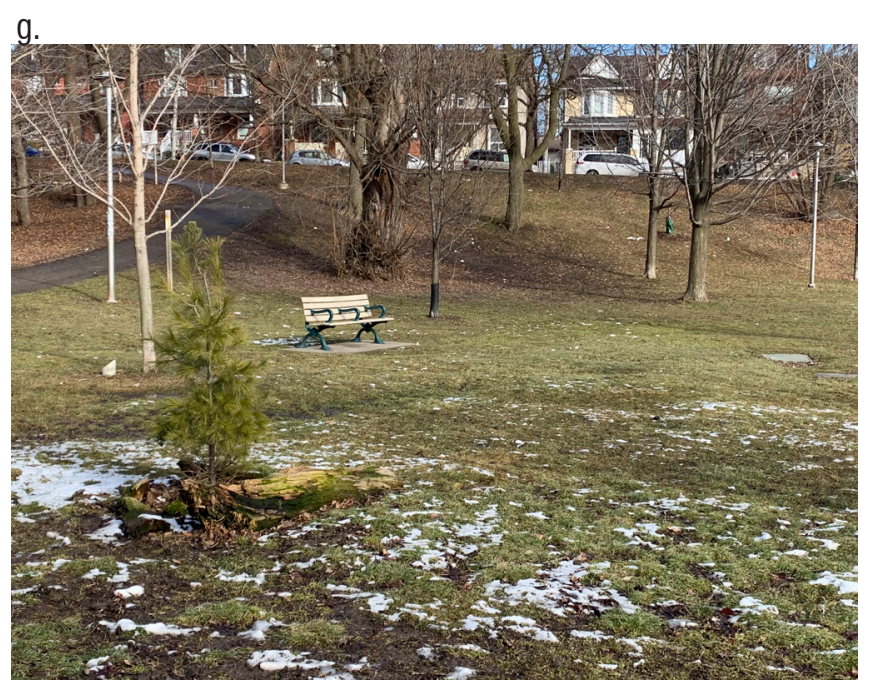

i.

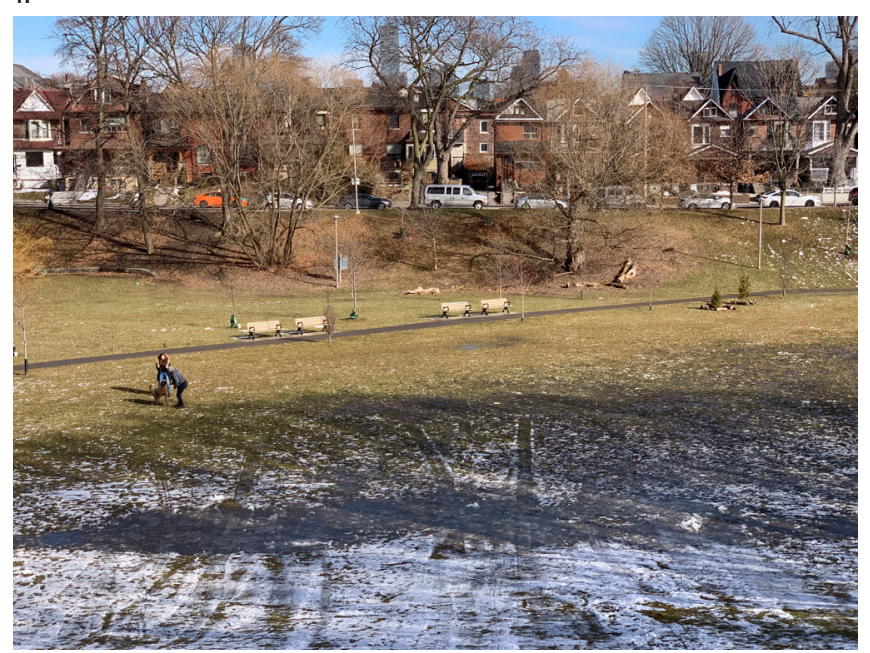

k.

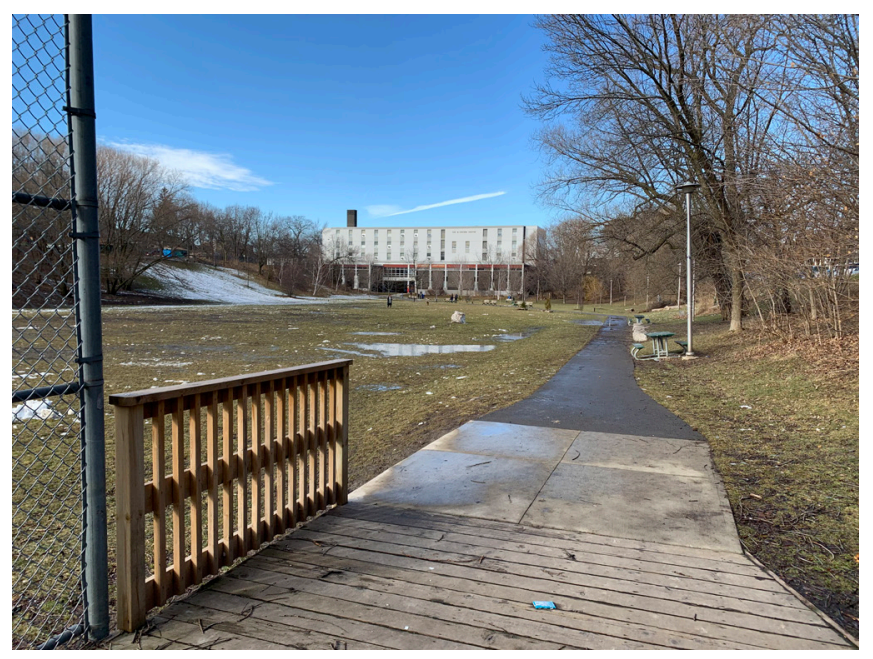




\section{A.5}

\section{Physical Models}

Fig A.5-1. Bat Roost Prototype.

This 1:1 model is built of various wooden parts which are glued and screwed together. Wooden dowels allow for the face and roof of the box to be removed for demonstration purposes. The interior is lined with a plastic mesh that bats can cling to. Alternatively, grooves in the wood would serve this purpose as well. These need to be hung at a height of about 15 feet, facing south to obtain heat during the day. This particular model is meant as a demonstration prototype that comes apart. Otherwise, the application of caulking to create a water-proof environment would allow this to be used as a functional bat roost.

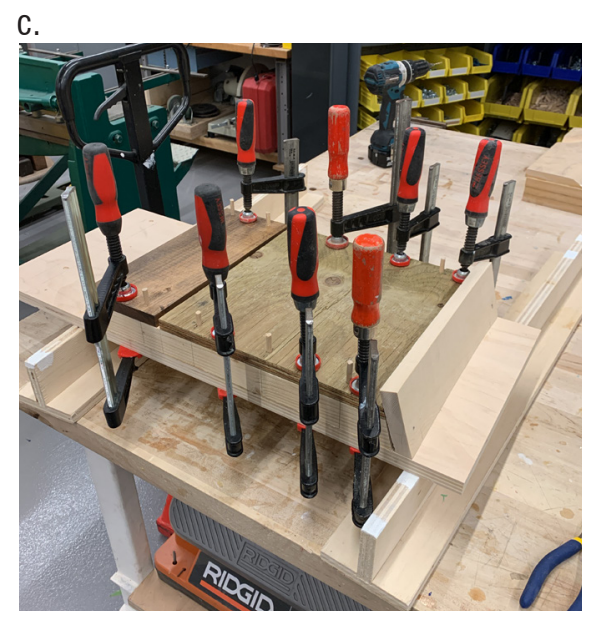

a.

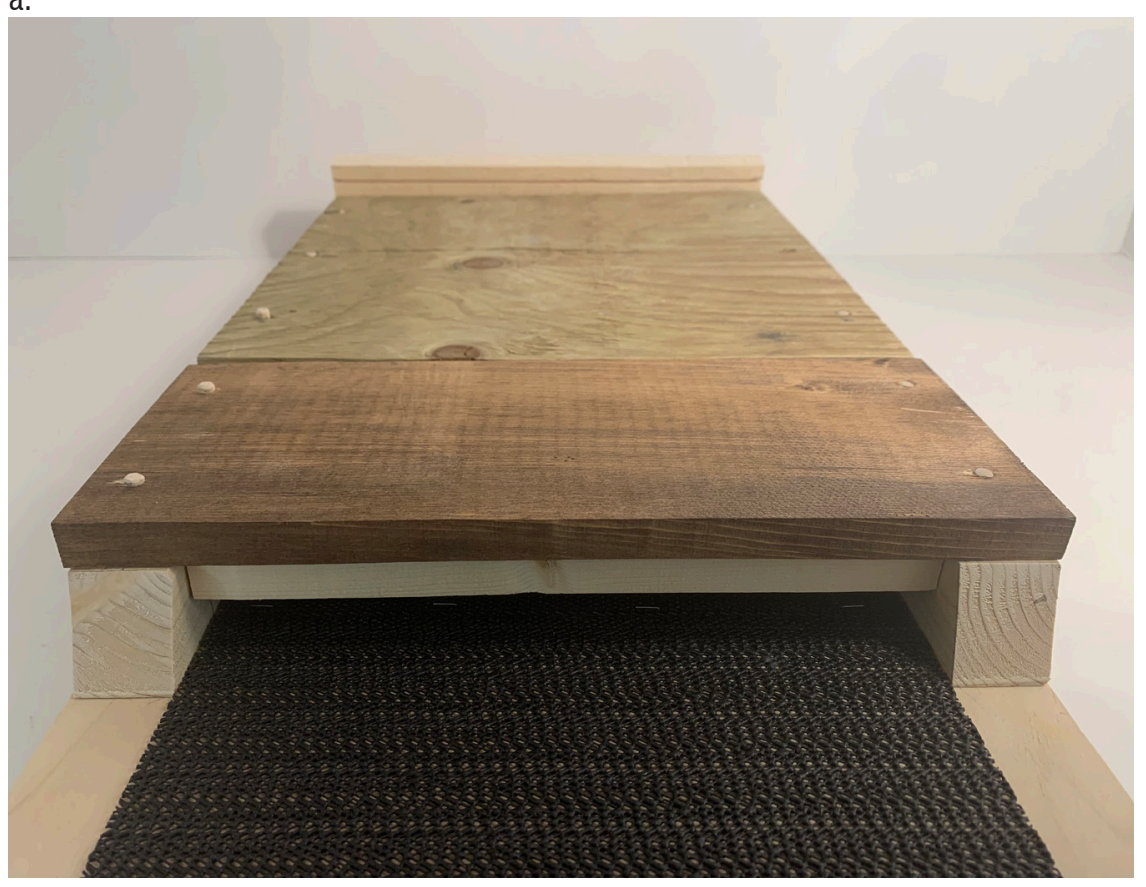

b.

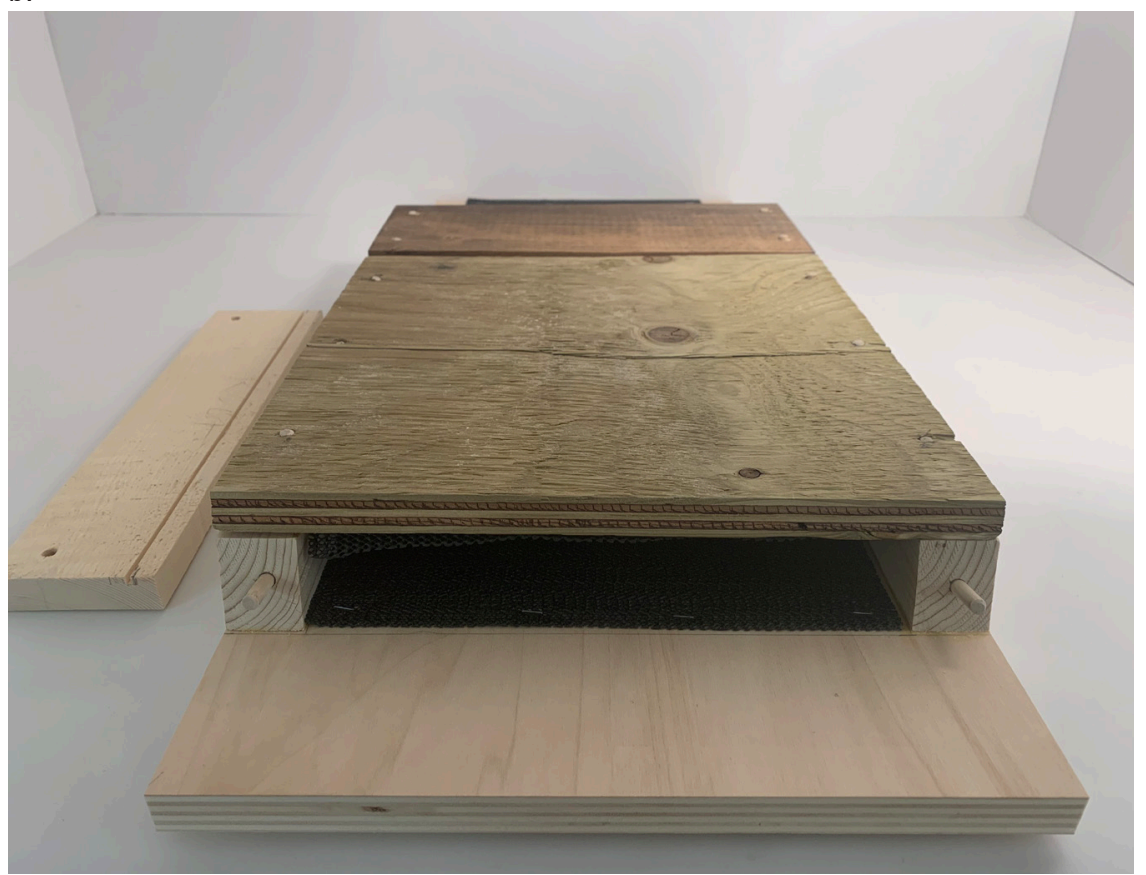


d.

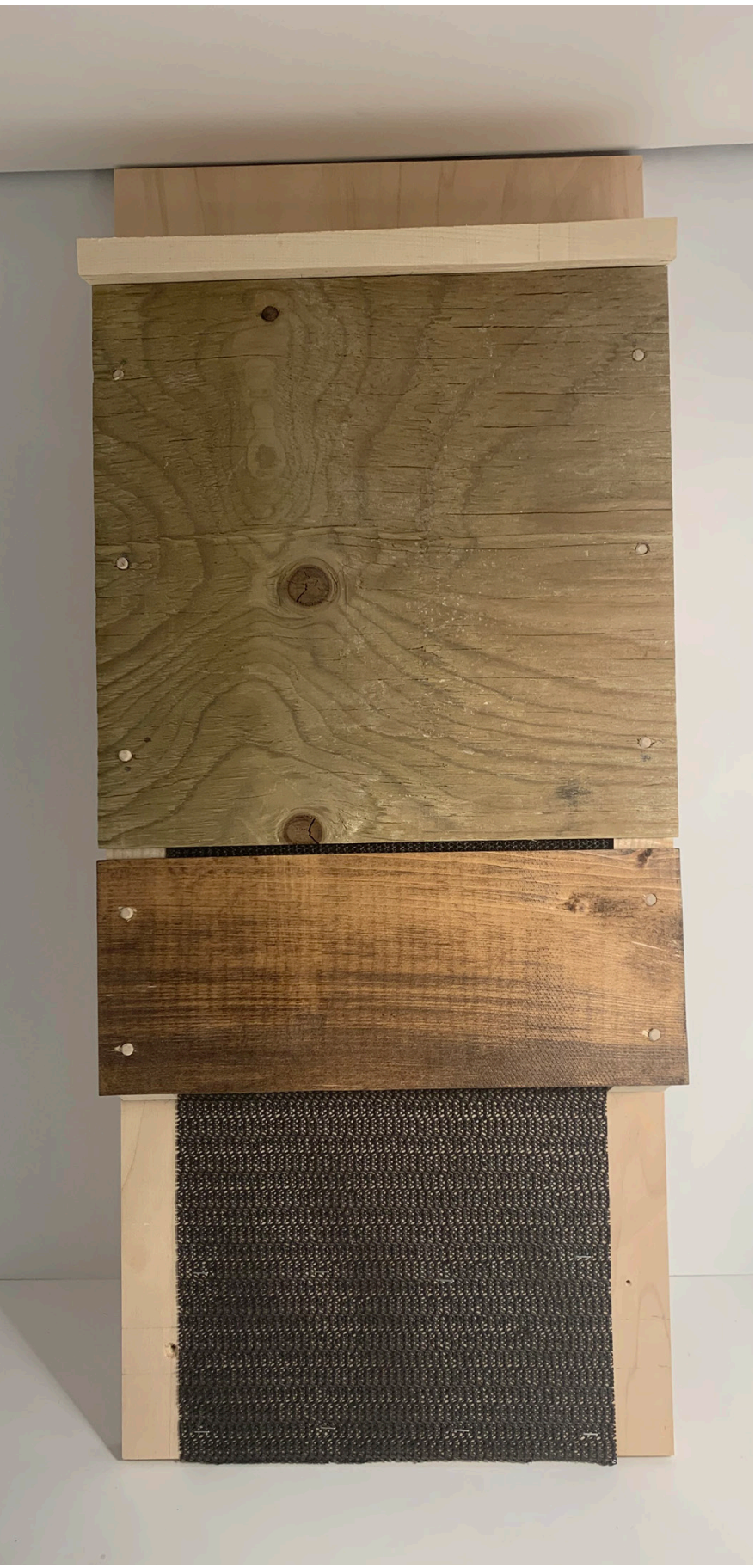

e.

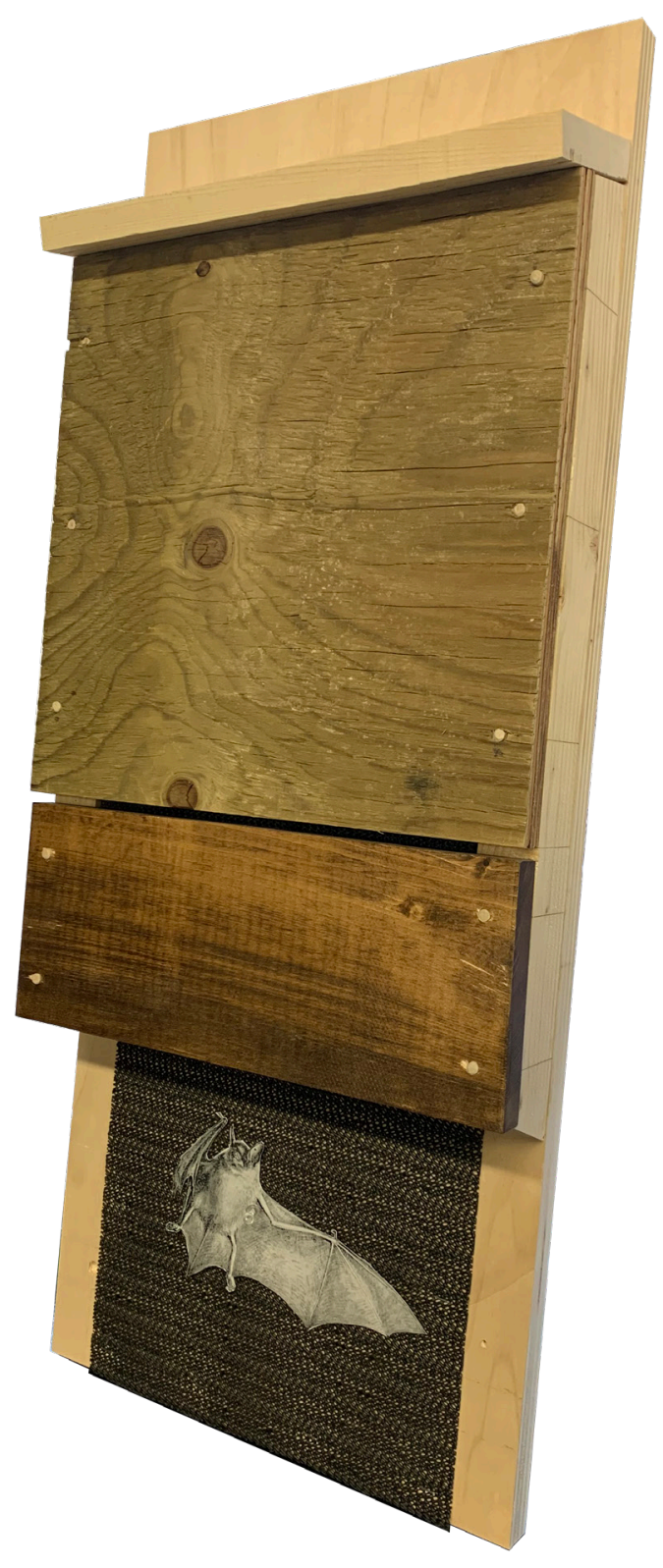


Fig A.5-2. Classroom Pod in the Heterogeneous Space.

Study model, 1:100 scale.

a.

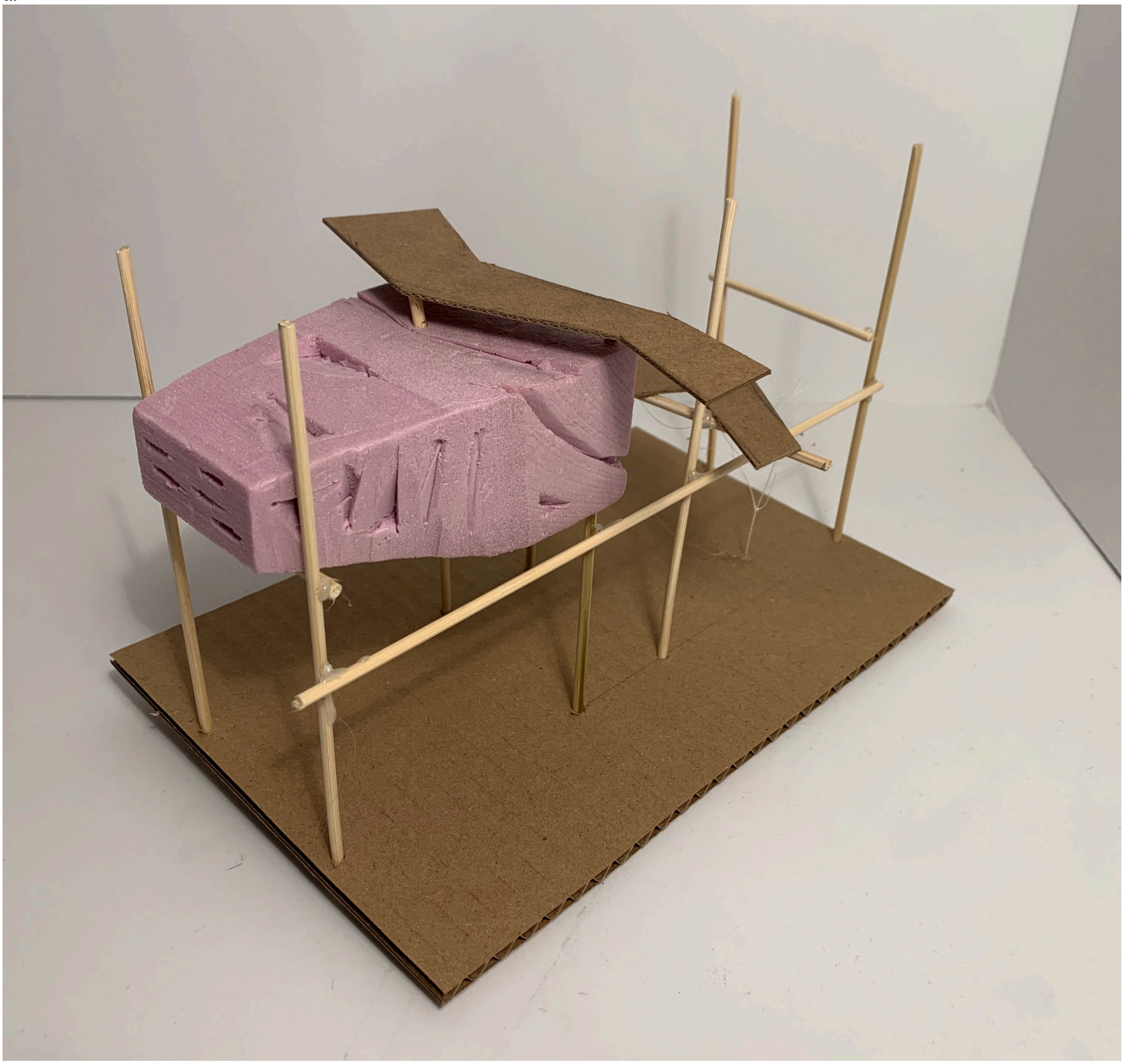


b.

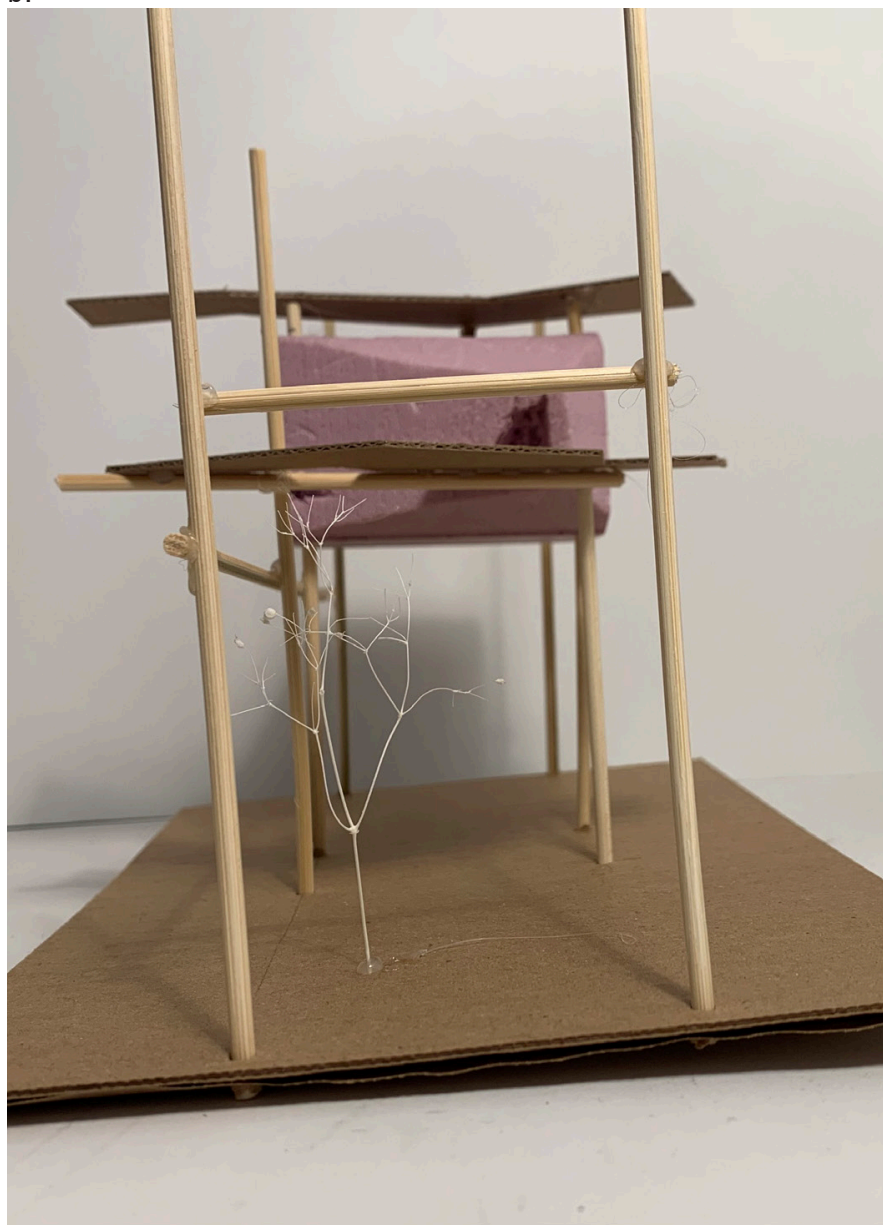

C.

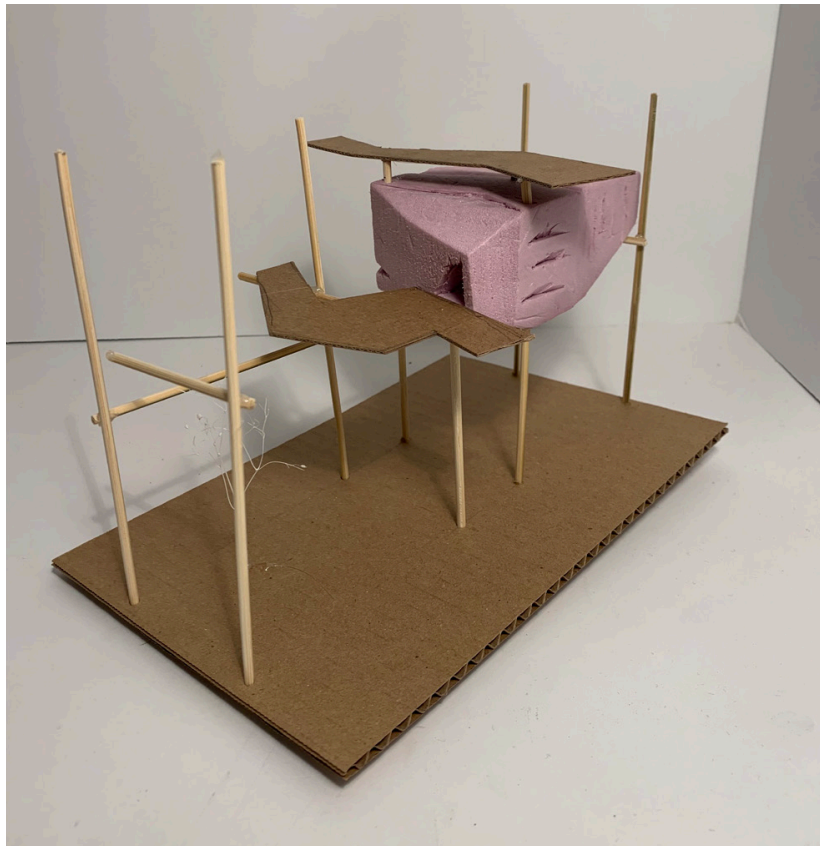




\section{Synanthropic Centre (DD)}

\section{Fig A.6-1. Shared Space.}

Floating pods connected by elevated and vegetated platforms. Vertical circulation shafts frame the two opposite ends.

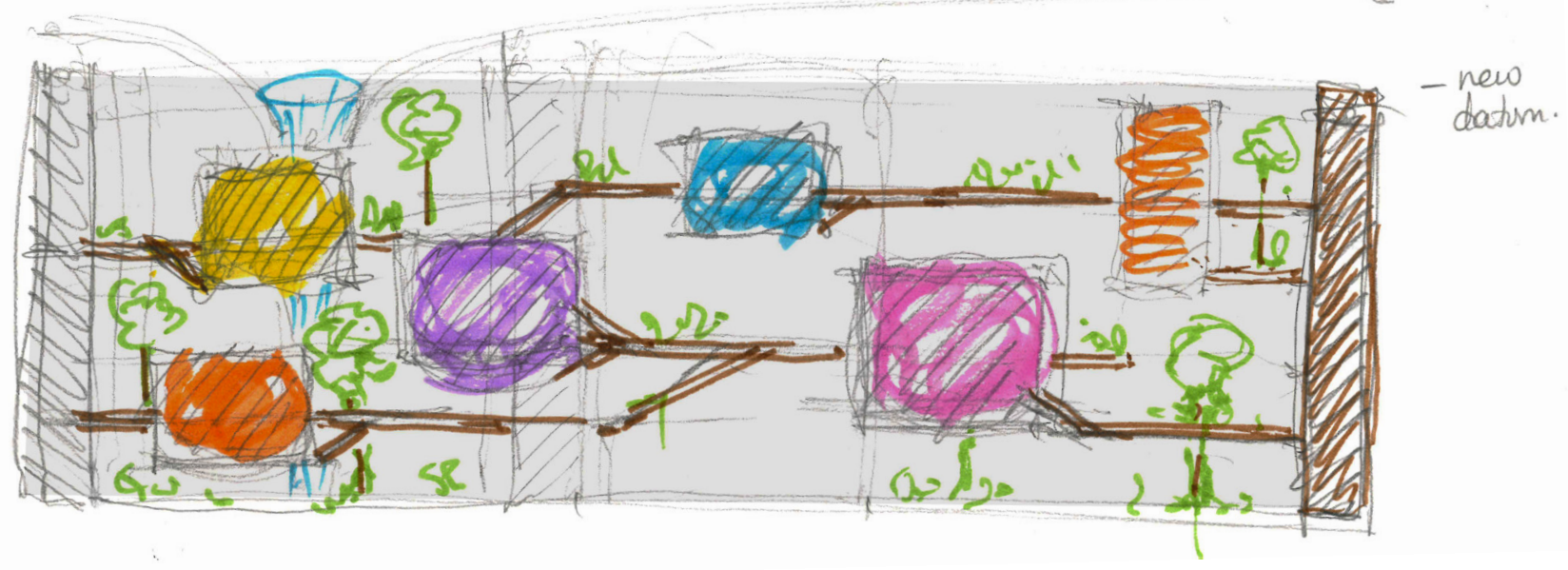




\section{Fig A.6-2. View from Bloor Street.}

Patterned glass protects birds while providing partial view into the interior space. The emerging aesthetic is similar to a biological cell or a nebula - a murky body that contains key organelles (classrooms) within a network of connective fibres, surrounded by a flurry of activity.

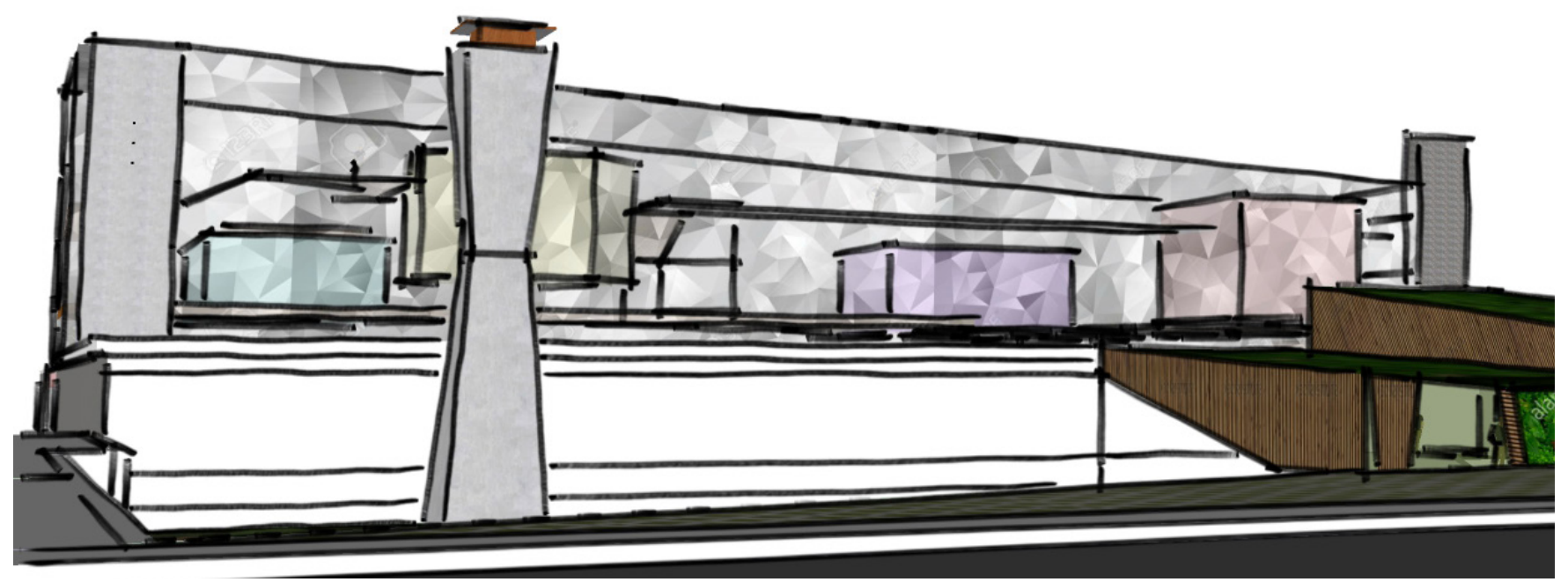

Fig A.6-3. Elevation.

The chimney remains as a vertical landmark while the rest of the building is redeveloped by this drastically different architectural language.

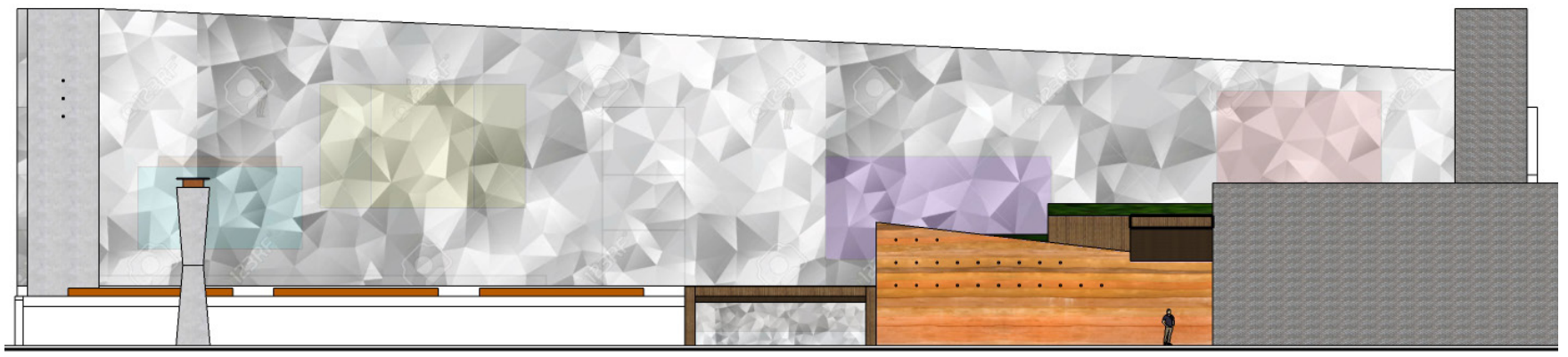




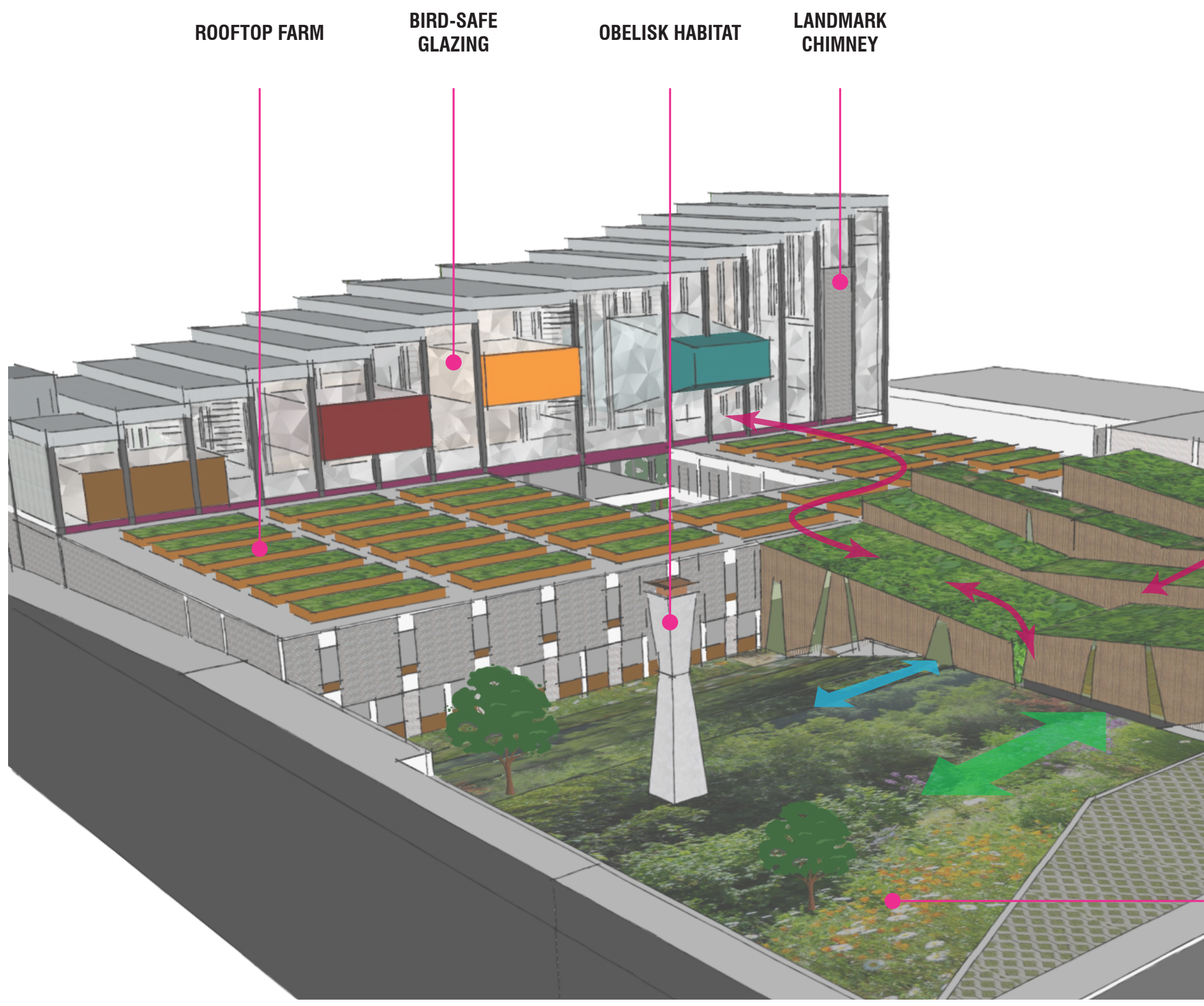




\section{Fig A.6-4. Overall Scheme (Milestone II).}

This early variation aimed to use a landscape vernacular to define the redesigned portions of the building. These formations allow animals to negotiate this hybrid built landscape. Other programs such as farming activity was incorporated into the overall scheme.

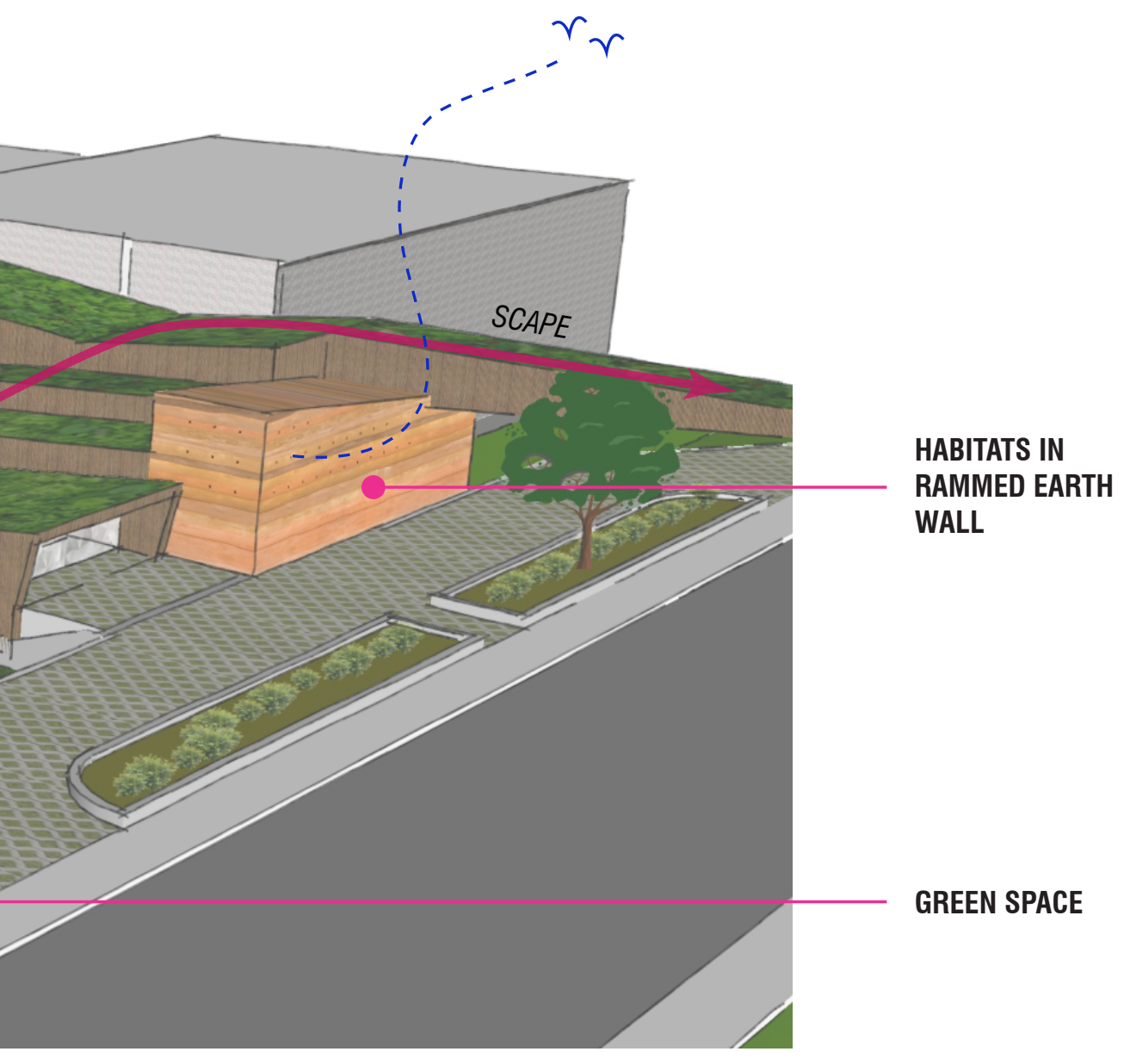


Fig A.6-5. Facade System: horizontal louvers, sliding glass, and storage compartments (Milestone III).

This design followed the column grid of the existing building to create enclosed compartments that can house sliding glass panels. During warmer weather, the operable windows slide open, allowing birds and other animals to move into the building while passing between the horizontal slats.

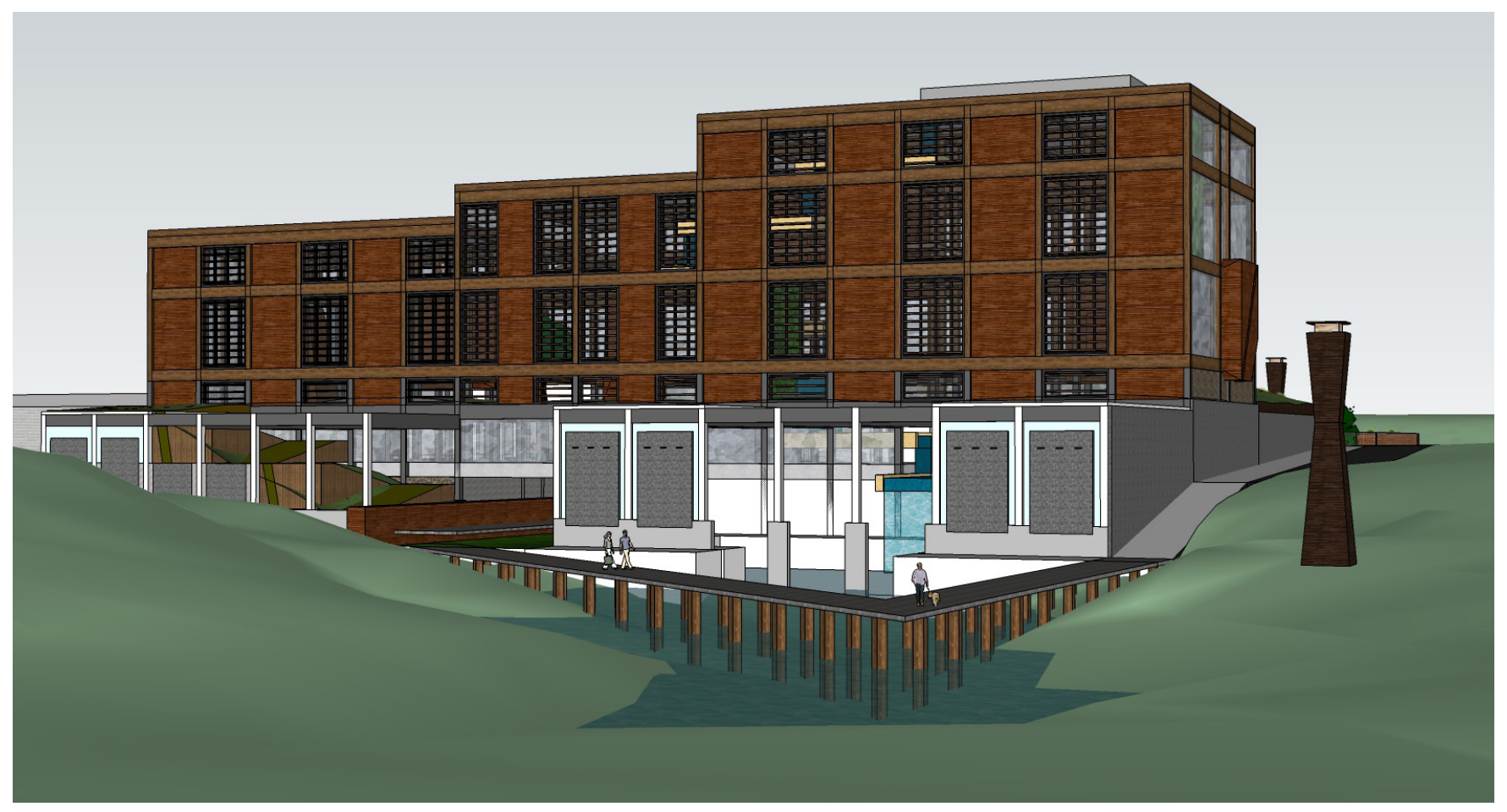


Fig A.6-6. View from Bloor Street (Milestone III).

This middle-stage design incorporated a new lobby addition that was attached to the threatre. In this scheme, the passage to the underpass was much narrower; the adjacent greenspace was not enclosed and therefore not as protected.

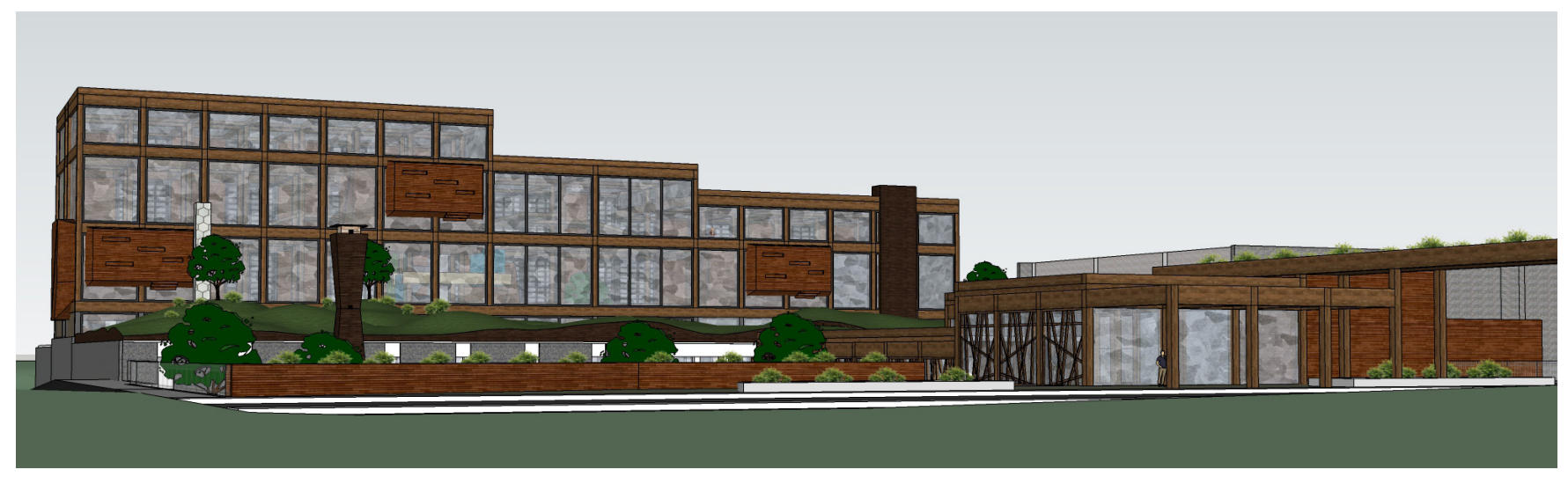

Fig A.6-7. Entrance Lobby Elevation (Milestone III).

This preliminary idea for the facade explored the design of a forestlike arrangement of wooden slats; these adhere to the spacing requirements of bird-friendly design.

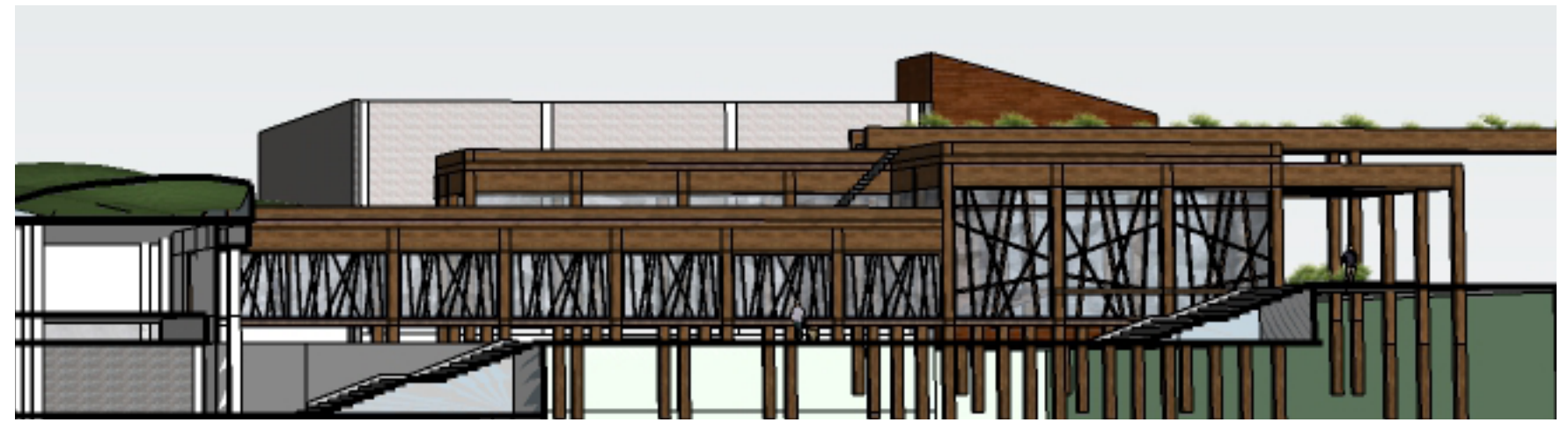




\section{Fig A.6-8. Process investigation of the facade.}

Vertical wooden slats create an organic contour in contrast to the orthagonal geometry of the building.

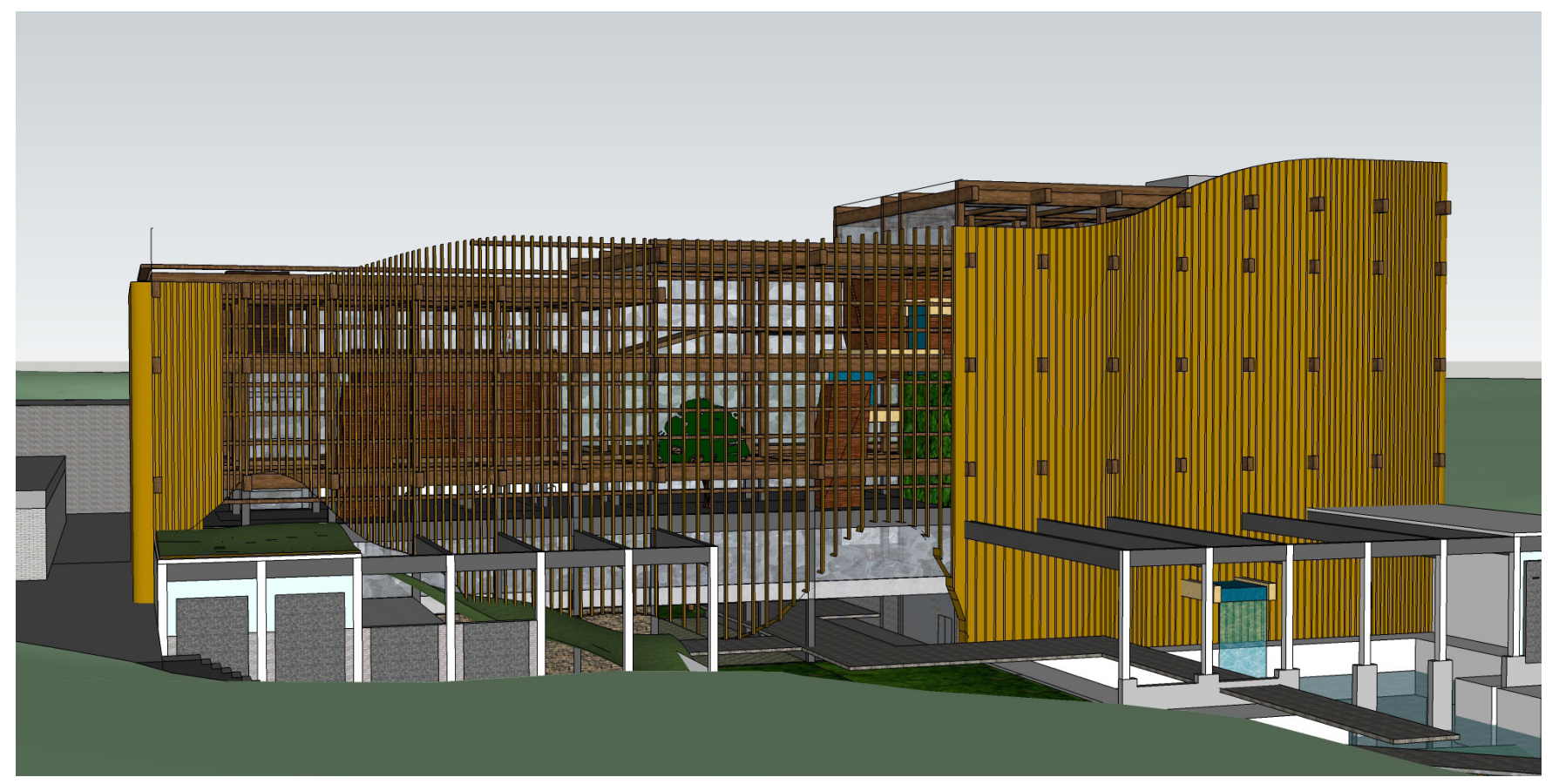




\section{Fig A.6-9. Bloor Street Elevation.}

The facade of undulating wooden slats consists of voids and dips to create openings for entrances and viewing areas.

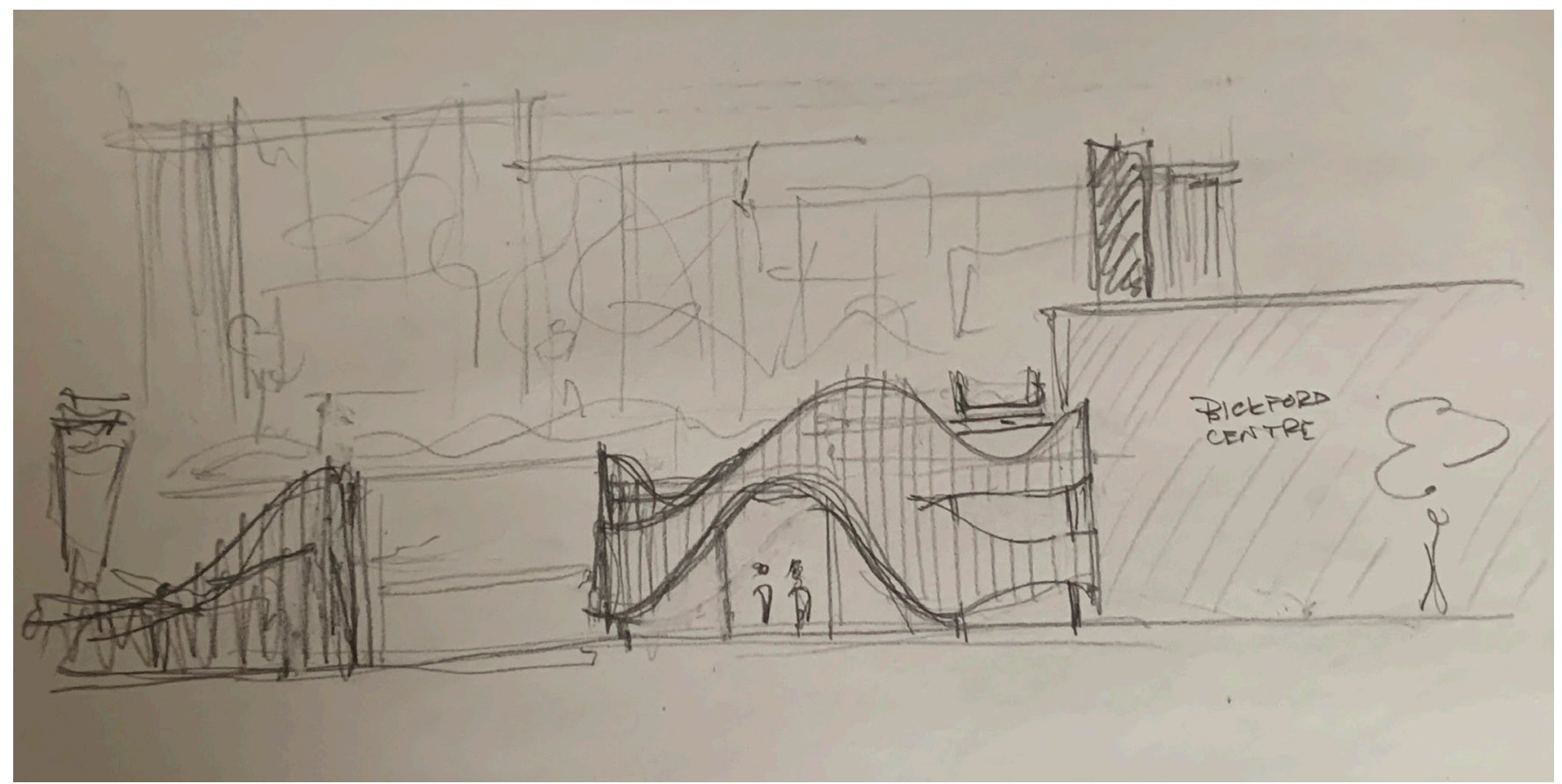




\section{Fig A.6-10. Animal Vestibule Section.}

An insulated door allows animals to enter the compartment. A slide then ensures that they slip downwards in order to deter animals from nesting in this space. The animals then exit on the other side.

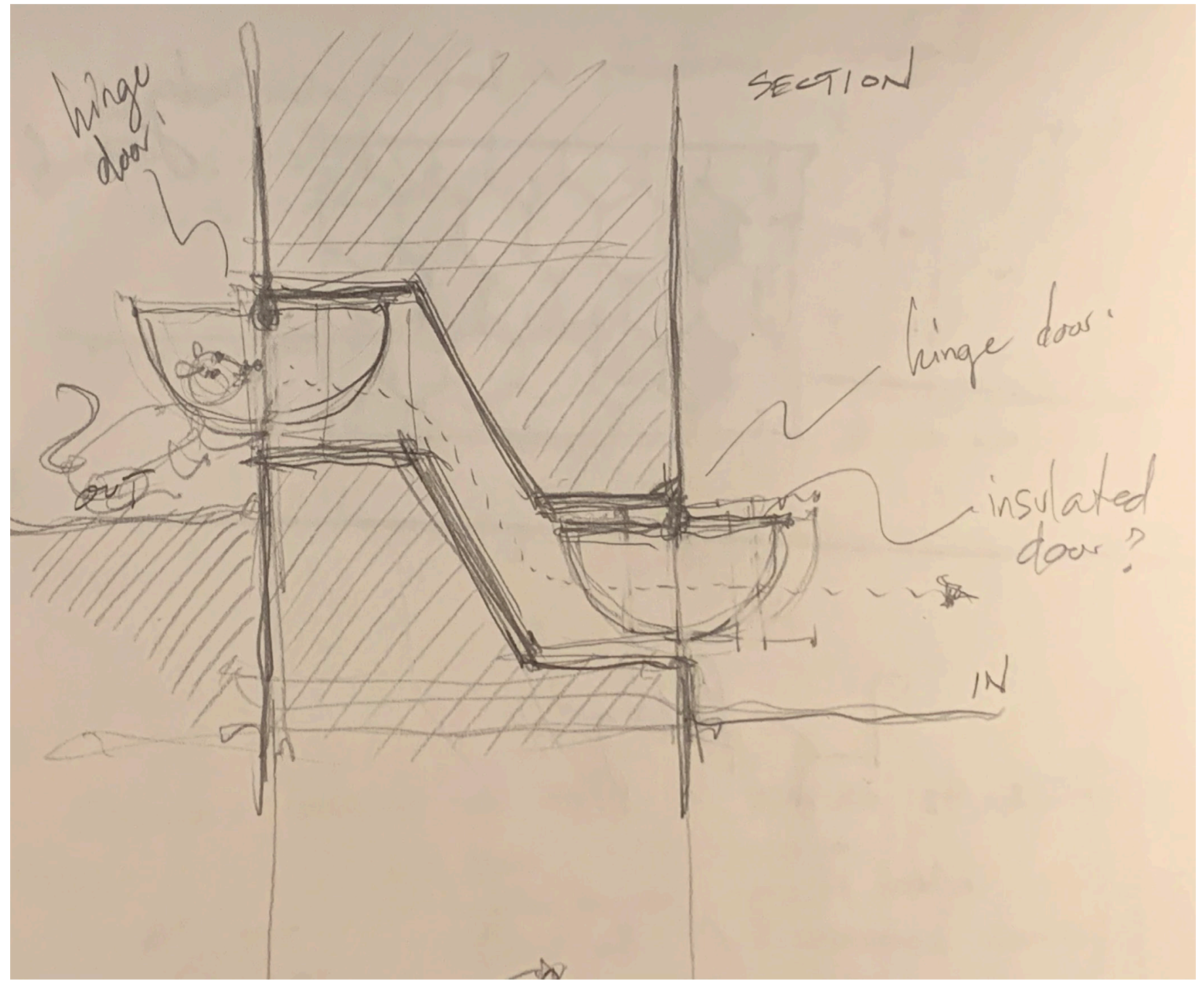




\section{Fig A.6-11. Animal Vestibule.}

Two such vestibule slides are placed side-by-side in order to allow animals to pass through the wall in both directions.

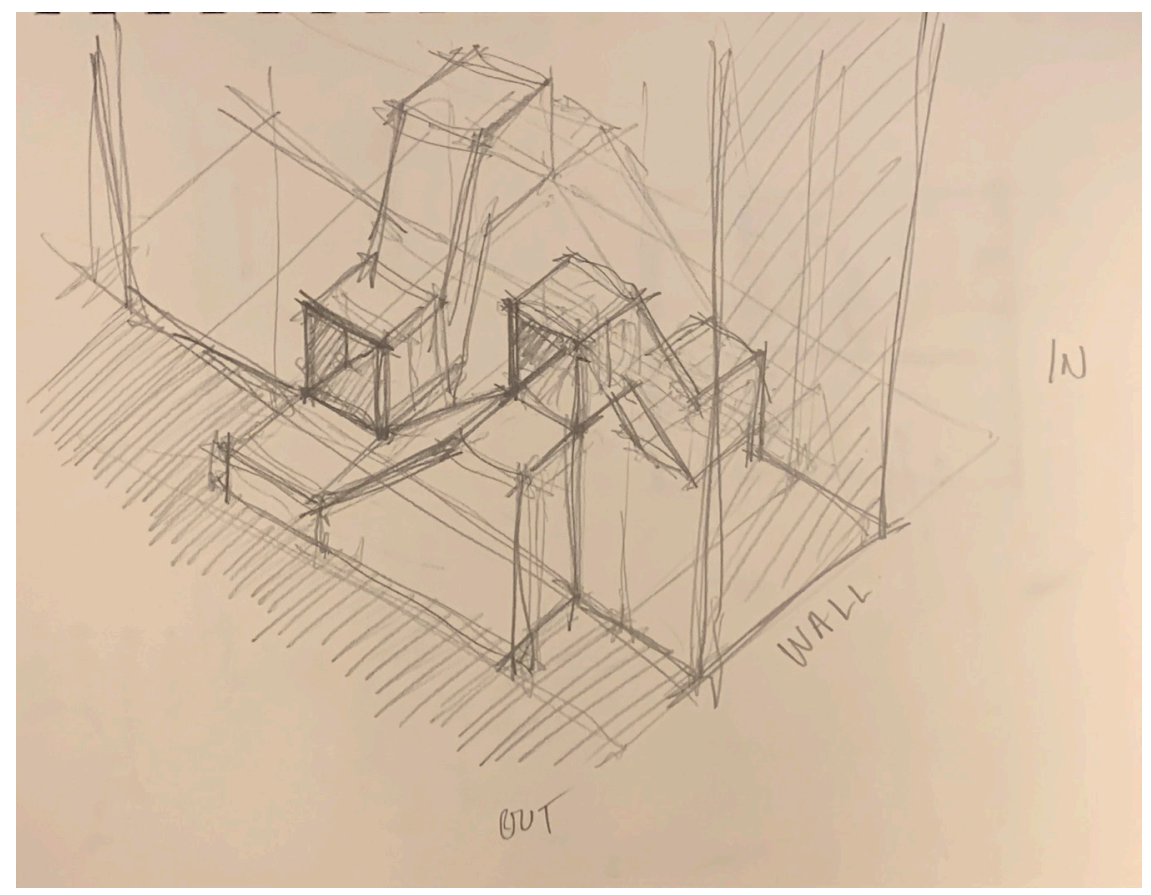

Fig A.6-12. Animal Vestibule at the Synanthropic Centre.

Animal vestibules are located at the perimeter of the heterogeneous space.

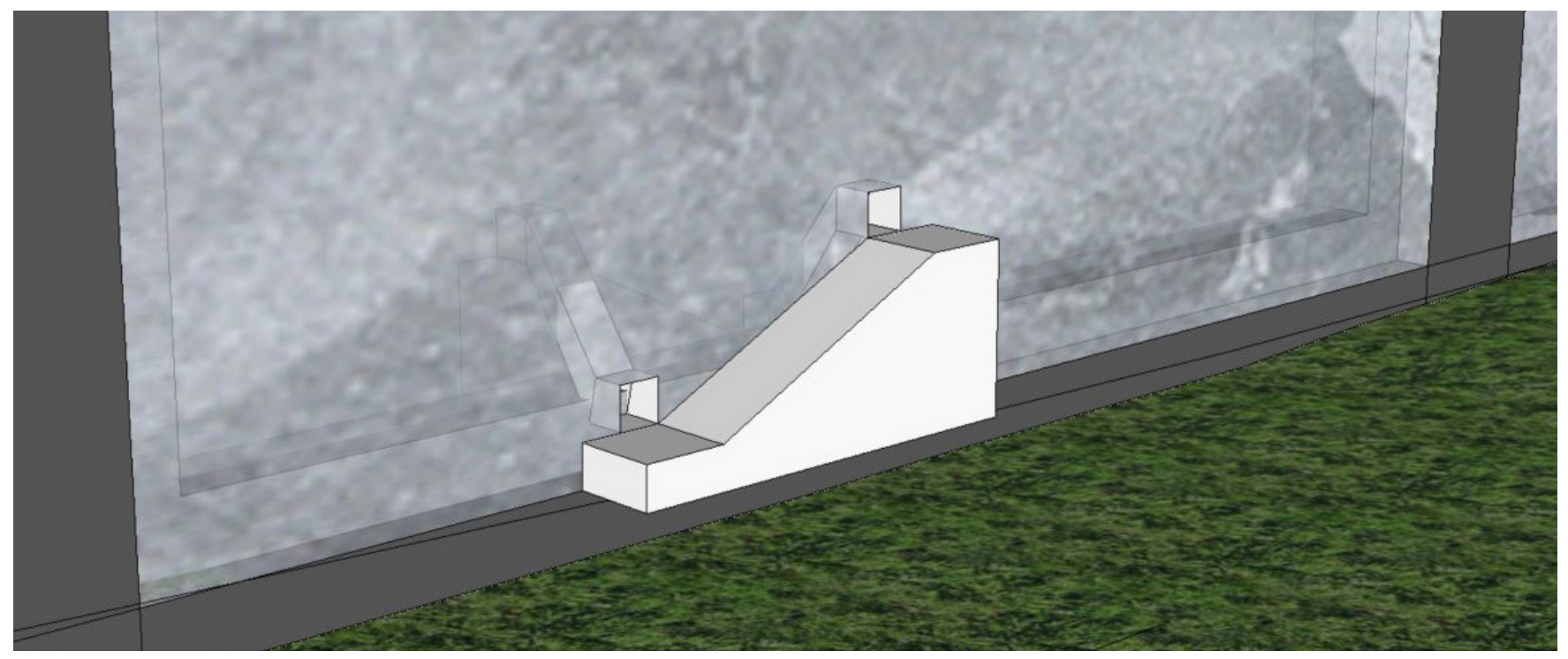


Fig A.6-13. Final Design - Entry from Bloor Street.

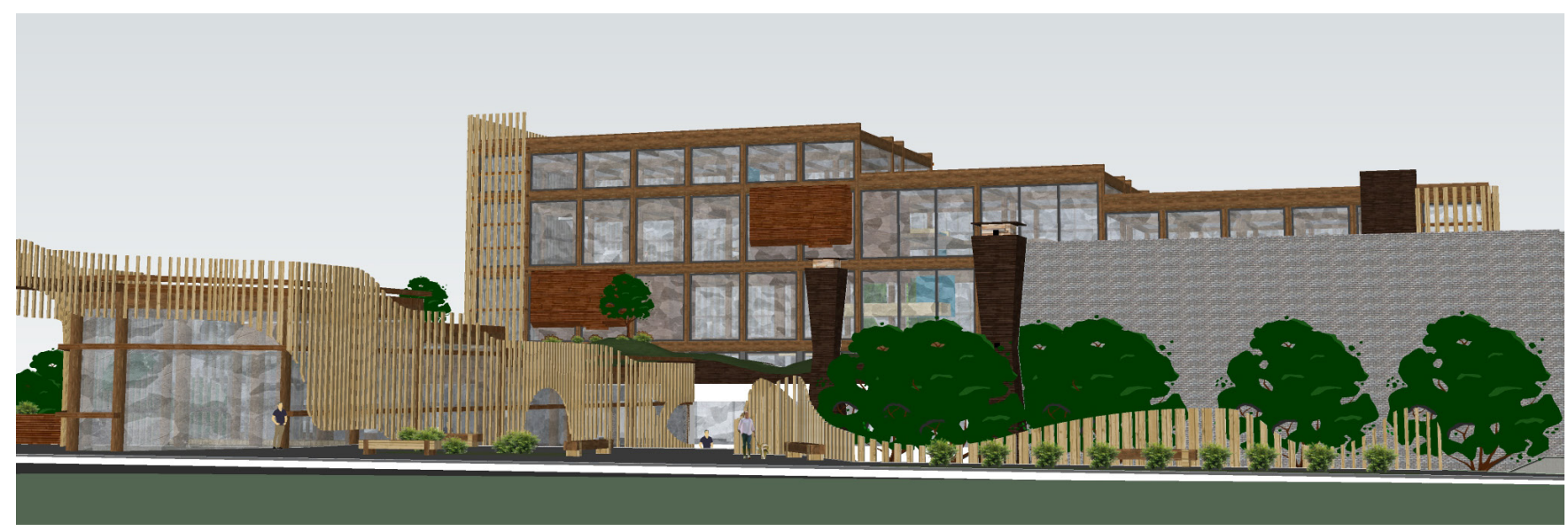

Fig A.6-14. Final Design - Sunken Garden.

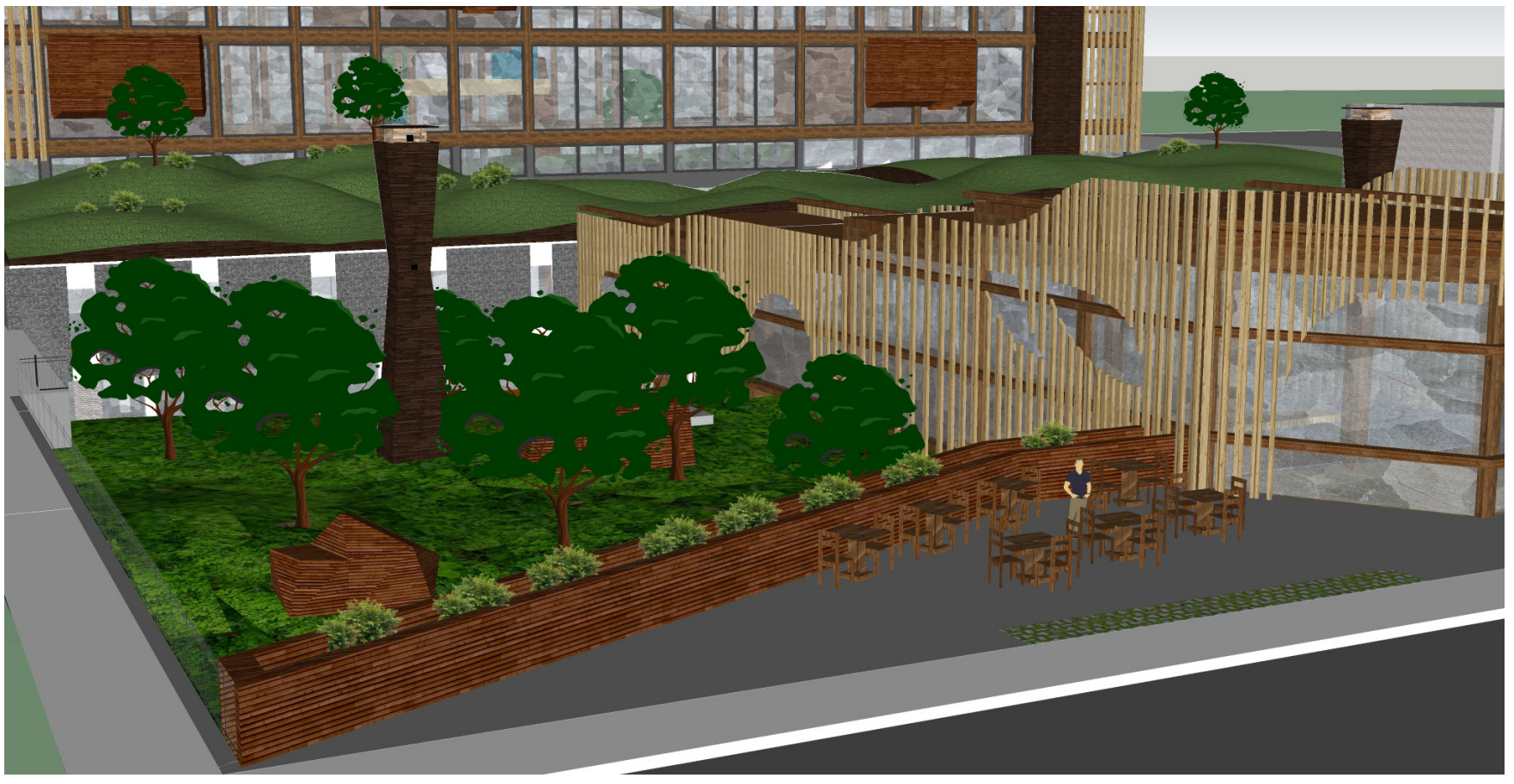


Fig A.6-15. Final Design - Entrance Lobby.

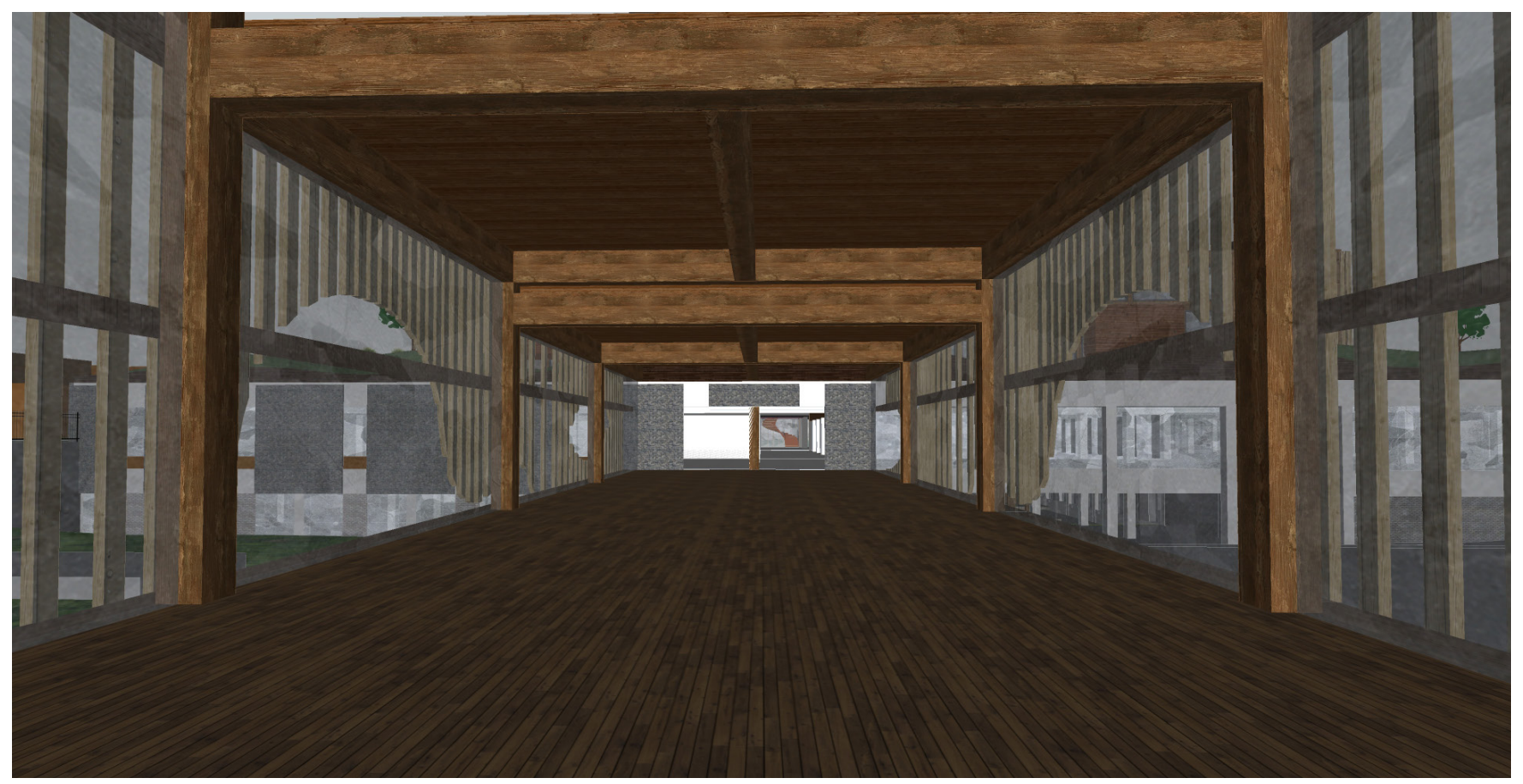


BIBLIOGRAPHY 
Ábrán, Ágota, and Iulia Hurducaş. 'Assessing Nature: Between Zones of Exploitation and Protection'. Studia Universitatis Babes-Bolyai: Sociologia; Cluj-Napoca 63, no. 1 (June 2018): 7-10,134. http://dx.doi.org.ezproxy.lib. ryerson.ca/10.2478/subbs-2018-0001.

Adams, Clark E., Kieran J. Lindsey, and Sara J. Ash. Urban Wildlife Management. Boca Raton: Taylor \& Francis, 2006.

Admin. 'Saigon House'. Dezign Ark (Beta), 13 January 2019. https://dezignark.com/blog/saigon-house/.

Ahern, Jack, Elisabeth Leduc, and Mary Lee York. Biodiversity Planning and Design: Sustainable Practices. Land and Community Design Case Studies. Washington: Island Press, 2006.

Aldhous, Peter. 'We Are Killing Species at 1000 Times the Natural Rate'. New Scientist. Accessed 17 March 2020. https://www.newscientist.com/article/dn25645-we-are-killing-species-at-1000-times-the-natural-rate/.

Almas, Andrew, and Tenley Conway. 'The Role of Native Species in Urban Forest Planning and Practice: A Case Study of Carolinian Canada'. ResearchGate, March 2016. https://www.researchgate.net/publication/301269917 The role of native species in urban forest planning and practice A case study of Carolinian Canada/ figures?lo=1.

AndersonWildlife. 'How to Get Raccoons out of Your Chimney'. Anderson Wildlife Control (blog), 27 April 2016. https://www.andersonwildlifecontrolllc.com/how-to-get-raccoons-out-of-your-chimney/.

Andrew, Scottie. 'The Internet Is Going Crazy over a "salmon Cannon" That Shoots Fish over a Dam - CNN'. CNN, 12 August 2019. https://www.cnn.com/2019/08/12/us/salmon-cannon-twitter-trnd/index.html.

Armstrong, Rachel. Soft Living Architecture: An Alternative View of Bio-Informed Practice. London, UK ; New York, NY, USA: Bloomsbury Visual Arts,an imprint of Bloomsbury Publishing Plc, 2018.

Avis, Rob. 'Verge Permaculture - Permaculture for Professionals, Innovators and Entrepreneurs'. Accessed 18 January 2020. https://vergepermaculture.ca/.

Backhouse, Frances. Owls of North America. Richmond Hill, ON: Firefly Books, 2008.

Baldwin, Eric. 'Standing Out: 8 Extruded Brick Pattern Details'. Architizer, 12 September 2017. https://architizer. com/blog/inspiration/collections/facing-brick-extrusion/.

Bastolla, Ugo, Miguel A. Fortuna, Alberto Pascual-García, Antonio Ferrera, Bartolo Luque, and Jordi Bascompte. 'The Architecture of Mutualistic Networks Minimizes Competition and Increases Biodiversity'. Nature; London 458, no. 7241 (23 April 2009): 1018-20. http://dx.doi.org.ezproxy.lib.ryerson.ca/10.1038/nature07950. 
Bateman, Chris. '5 Lost Rivers That Run under Toronto'. BlogTO, 10 February 2014. https://www.blogto.com/ city/2014/02/5 lost rivers that run under toronto/.

- - - 'A Brief History of the Lake Iroquois Shoreline in Toronto' BlogTO, 14 July 2012. https://www.blogto.com/ city/2012/07/a brief history of the lake iroquois shoreline in toronto/.

———. 'About Owls.' Owl Research Institute. Accessed 12 April 2020. https://www.owlresearchinstitute.org/owls-1.

_-_. 'About Tommy Thompson Park'. Tommy Thompson Park (blog), 22 January 2016. https://tommythompsonpark.ca/about/.

_-_. 'Barn Owl: Breeding Facts'. The RSPB. Accessed 5 March 2020. https://www.rspb.org.uk/birds-and-wildlife/ wildlife-guides/bird-a-z/barn-owl/breeding/.

_-_. 'Barn Owl Nests and Eggs'. The Barn Owl Trust (blog). Accessed 26 January 2020. https://www.barnowltrust.org.uk/sitemap/galleries/barn-owl-nests-eggs/.

_-_. 'Barn Owls in Spring - Nesting'. The Barn Owl Trust (blog). Accessed 5 March 2020. https://www.barnowltrust.org.uk/barn-owl-facts/barn-owl-nesting/.

Beetz, Andrea, Kerstin Uvnäs-Moberg, Henri Julius, and Kurt Kotrschal. 'Psychosocial and Psychophysiological Effects of Human-Animal Interactions: The Possible Role of Oxytocin'. Frontiers in Psychology 3 (9 July 2012): 15. https://doi.org/10.3389/fpsyg.2012.00234.

Begon, Michael, Robert Warren Howarth, and Colin R. Townsend. Essentials of Ecology. 4th edition. Hoboken, NJ: John Wiley \& Sons, Inc, 2014.

Berman, Marc G., John Jonides, and Stephen Kaplan. 'The Cognitive Benefits of Interacting With Nature'. Psychological Science 19, no. 12 (1 December 2008): 1207-12. https://doi.org/10.1111/j.1467-9280.2008.02225.x.

- - - 'Bickford Centre Theatre'. TripAdvisor. Accessed 19 January 2020. http://www.tripadvisor.ca/ShowUserReviews-g155019-d12217392-r464641814-Bickford Centre Theatre-Toronto Ontario.html.

Bies, Laura. 'Wildlife Habitat Fragmentation - Fact Sheet'. Bethesda, Maryland: The Wildlife Society, n.d. wildlife. org/policy.

_- - 'Bird-Friendly Building Design'. National Standard of Canada. Canadian Standards Association, May 2019. https://www.scc.ca/en/standardsdb/standards/29805.

- - - 'Bird-Friendly Building Design: Coming to a City Near You!' American Bird Conservancy, 9 September 2019. https://abcbirds.org/blog/bird-friendly-design-coming-soon/.

_- - 'Bird-Friendly Guidelines'. City of Toronto. City of Toronto, 7 September 2017. Toronto, Ontario, Canada. https://www.toronto.ca/city-government/planning-development/official-plan-guidelines/design-guidelines/ bird-friendly-guidelines/. 
- - - 'Bird-Safe Building Design Taking Flight', 2 August 2013. https://www.mysanantonio.com/lifestyle/ home-garden/article/Bird-safe-building-design-taking-flight-4703245.php.

——_. 'Bird Friendly Buildings in Toronto - I See Dead Birds Everywhere'. Urban Toronto, 4 July 2013. https://urbantoronto.ca/forum/threads/bird-friendly-buildings-in-toronto-i-see-dead-birds-everywhere.19833/.

Blakemore, Erin. 'This Pattern Is Made of 2,100 Dead Birds'. Smithsonian Magazine. Accessed 6 April 2020. https:// www.smithsonianmag.com/smart-news/pattern-made-2100-dead-birds-180958379/.

Boeri, Stefano. 'Urban Forestry Manifesto'. Stefano Boeri Architetti (blog). Accessed 20 April 2020. https://www. stefanoboeriarchitetti.net/en/urban-forestry/.

Boyle, Rebecca. 'Wind Turbines Kill More Than 600,000 Bats A Year. What Should We Do?' Popular Science, 19 November 2013. https://www.popsci.com/blog-network/eek-squad/wind-turbines-kill-more-600000-bats-yearwhat-should-we-do/.

Bradley, Sarah. 'Major Increase in Torontonians Biking to Work: Up to 34\% in Some Neighbourhoods. Cycle Toronto, 1 December 2017. https://www.cycleto.ca/news/major-increase-torontonians-biking-work-34-some-neighbourhoods.

Brulliard, Karin. 'One Tall Building. One Dark and Stormy Night. 395 Dead Birds' The Washington Post, 15 May 2017. https://www.washingtonpost.com/news/animalia/wp/2017/05/10/one-tall-building-one-dark-and-stormynight-395-dead-birds/?fbclid=IwAR0L08bFzw7q7N x-B penZGcFrZ1Kvy0LeUlPJ9nPSRSCyQ2sRkGAIZXNo.

Burley, Robert, Anne Michaels, Michael Mitchell, Alissa York, George Elliott Clarke, Wayne C. Reeves, and Leanne Simpson. An Enduring Wilderness: Toronto's Natural Parklands. Toronto, Ontario, Canada: ECW Press, 2017.

Burnett, J. A., and Candace Sherk Savage, eds. On the Brink: Endangered Species in Canada. Saskatoon: Western Producer Prairie Books, 1989.

Burton, John A., ed. The Atlas of Endangered Species. London: Apple Press, 2000.

- - - Butchering Bird. World's Deadliest. Accessed 4 April 2020. https://www.youtube.com/watch?v=okQYO10MT3c\&fbclid=IwAR2FIZtAisiVwAaNYdsdfQ-UBM6JmivOoISA9rVdSdILAPBeVCD3hG9umVw.

Campbell, Georgie. 'Human Impact'. Pinterest. Accessed 19 January 2020. https://www.pinterest.ca/ $\operatorname{pin} / 300615343852413735 /$.

Camps, Marc Arenas. 'How Many Species Live on Earth?’ All You Need is Biology, 20 May 2018. https://allyouneedisbiology.wordpress.com/2018/05/20/.

Castillo, Nancy. 'FAQ - What Happens to the Poop in a Birdhouse or Nest?' The Zen Birdfeeder, 5 July 2012. https://wildbirdsunlimited.typepad.com/the zen birdfeeder/2012/07/faq-what-happens-to-the-poop-in-a-birdhouse-or-nest.html. 
- - - 'Capital Facts for Toronto, Canada'. World's Capital Cities, 11 April 2019. https://www.worldscapitalcities. com/capital-facts-for-toronto-canada/.

_- - 'Carolinian Canada'. Carolinian Canada. Accessed 20 March 2020. https://caroliniancanada.ca/.

- - . 'Carolinian Species \& Habitats - Forests'. Accessed 2 April 2020. https://caroliniancanada.ca/legacy/SpeciesHabitats Forests.htm?fbclid=IwAR2zBD97TSDYyoaJoxfHX0rqgTiaMGtxm3o5SM6jl-ChZxWck5RrkSWtIWI.

- - - 'Carolinian Species \& Habitats - Other Rare Species'. Accessed 3 April 2020. https://caroliniancanada.ca/ legacy/SpeciesHabitats OtherRareSpecies.htm.

CBC News. 'Toronto Website Calculates Personal Carbon Footprint'. CBC, 26 February 2008. https://www.cbc.ca/ news/canada/toronto/toronto-website-calculates-personal-carbon-footprint-1.772007.

CBC Radio. “'You Forget You're in a Building," Says Israeli-Canadian Architect of Giant Airport Waterfall'. CBC, 30 April 2019. https://www.cbc.ca/radio/asithappens/as-it-happens-tuesday-edition-1.5116850/you-forget-you-re-ina-building-says-israeli-canadian-architect-of-giant-airport-waterfall-1.5112380.

Chappel, Bill, and Colin Dwyer. 'Raccoon Is Rescued Atop Building In Minnesota, After Capturing Fans Worldwide'. NPR, 14 June 2018. https://www.npr.org/2018/06/13/619491657/raccoon-is-trapped-in-minnesota-after-capturing-fans-worldwide.

Cheung, Adrian, Julia Whalen, Victoria Valido · CBC News · Posted: Jul 15, 2019 6:00 AM ET | Last Updated: July 15, and 2019. 'Is Toronto the Raccoon Capital of Canada?' CBC, 15 July 2019. https://www.cbc.ca/news/canada/ toronto/is-toronto-raccoon-capital-canada-1.5208580.

'Cities'. 16:9. Planet Earth II. United Kingdom: BBC One, 2016.

- - - 'Conservation'. Toronto and Region Conservation Authority (TRCA) (blog). Accessed 20 January 2020. https://trca.ca/conservation/.

——- 'Conservation Breeding and Reintroduction'. Toronto Zoo. Accessed 11 April 2020. http://www.torontozoo. $\underline{\text { com/tz/els. }}$

Cosma, Ana. 'Architecture for Animals'. Arch2O, 21 September 2015. https://www.arch2o.com/architecture-for-animals/.

Curl, James Stevens, and Susan Wilson. 'Ouroboros, Uroboros'. In A Dictionary of Architecture and Land-

scape Architecture. Oxford University Press, 2015. https://www.oxfordreference.com/view/10.1093/ acref/9780199674985.001.0001/acref-9780199674985-e-5835.

Czerniak, Julia, ed. CASE: Downsview Park Toronto. CASE Series. Munich ; New York : Cambridge, Mass: Prestel ; Harvard University, Graduate School of Design, 2001.

Daley, Jim. 'Silent Skies: Billions of North American Birds Have Vanished'. Scientific American. Accessed 6 April 2020. https://www.scientificamerican.com/article/silent-skies-billions-of-north-american-birds-have-vanished/. 
——_. 'Daredevil Raccoon Scales 9 Floors of New Jersey Building'. YouTube. Accessed 16 April 2020. https://www. youtube.com/watch?v=fItgbnuC-1E.

Dawicki, Shelley. 'The Great Flood of New York’. Woods Hole Oceanographic Institution (blog), 10 June 2005. https://www.whoi.edu/oceanus/feature/the-great-flood-of-new-york/.

Dawkins, Richard. The Selfish Gene. New York: Oxford University Press, 1976.

Dean, Joanna, Christabelle Sethna, Darcy Ingram, and Sherry H. Olson, eds. Animal Metropolis: Histories of Human-Animal Relations in Urban Canada. Canadian History and Environment Series, no. 8. Calgary, Alberta, Canada: University of Calgary Press, 2017.

———. 'Decomposer'. In Wikipedia, 19 January 2020. https://en.wikipedia.org/w/index.php?title=Decomposer\&oldid $=936457222$.

———. 'Definition of Scape'. www.dictionary.com. Accessed 18 January 2020. https://www.dictionary.com/browse/ scape.

'Deserts'. 16:9. Planet Earth II. United Kingdom: BBC One, 2016.

Devall, Bill, and George Sessions. Deep Ecology. Salt Lake City: Gibbs Smith, Publishers/ Peregrine SmithBooks, 1985.

Diaz, Jesus. 'Graphic Clear Shows Human Pressure on Earth Reaching Critical Levels'. Gizmodo UK, 16 January 2015. https://www.gizmodo.co.uk/2015/01/graphic-clear-shows-human-pressure-on-earth-reaching-critical-levels/.

———. 'Discovery Walks'. City of Toronto, 17 November 2017. https://www.toronto.ca/services-payments/ streets-parking-transportation/walking-in-toronto/walking-tours/etobicoke-walking-tours/.

- - - 'Discovery Walks: Don Valley Hills \& Dales'. City of Toronto. Accessed 19 January 2020. https://www. toronto.ca/wp-content/uploads/2017/11/99ff-Discovery-Walk-Don-Valley-Hills-Dales-route-map.pdf.

——_. 'Discovery Walks: Garrison Creek'. City of Toronto. Accessed 19 January 2020. https://www.toronto.ca/ wp-content/uploads/2017/11/9a94-Discovery-Walk-Garrison-Creek-route-map.pdf.

Domm, Jeff. Lorimer Field Guide to 225 Ontario Birds. Toronto, ON: Lorimer, 2012.

Downer, Ann. Wild Animal Neighbors: Sharing Our Urban World. Minneapolis, UNITED STATES: Lerner Publishing Group, 2013. http://ebookcentral.proquest.com/lib/ryerson/detail.action?docID=5481592.

———. 'DTAH'. DTAH. Accessed 8 August 2019. https://dtah.com/work/lower-don-valley.

_-_. 'Elevator B | Hive City’. Archello. Accessed 8 April 2020. https://archello.com/project/elevator-b. 
Elmqvist, Thomas, Michail Fragkias, Julie Goodness, Burak Güneralp, Peter J. Marcotullio, Robert I. McDonald, Susan Parnell, et al., eds. Urbanization, Biodiversity and Ecosystem Services: Challenges and Opportunities. Dordrecht: Springer Netherlands, 2013. https://doi.org/10.1007/978-94-007-7088-1.

_- - 'Endangered Ontario: Little Brown Bat'. YouTube, 8 September 2017. https://www.youtube.com/watch?v=MXqF R374Q.

———. 'Endangered Species Reserve Fund'. Toronto Zoo. Accessed 11 April 2020. http://www.torontozoo.com/tz/ reserve.

———. 'Energy Flow and Primary Productivity'. Khan Academy. Accessed 8 February 2020. https://www.khanacademy.org/science/high-school-biology/hs-ecology/trophic-levels/a/energy-flow-and-primary-productivity.

Everard, Mark. The Business of Biodiversity. Southampton, UK ; Billerica, MA: WIT Press, 2009.

———. 'Facade'. BirdSafe. Accessed 17 January 2020. https://birdsafe.ca/birdsafe-consulting-service/.

- - - 'The Facts'. Wildlife Collision Prevention Program. Accessed 2 April 2020. https://www.wildlifecollisions. ca/thefacts.htm?fbclid=IwAR3g3LI3YRbRcaMRXgHfQZocT4faG1UfZmkcRCWlVrFCc3lwzXDKKRHHcU0.

- - - 'Far from Special: Humanity's Tiny DNA Differences Are “average” in Animal Kingdom'. Phys.org, 21 May 2018. https://phys.org/news/2018-05-special-humanity-tiny-dna-differences.html.

Fenton, M. Brock. Just Bats. Toronto: University of Toronto Press, 1983.

- - - 'First Peoples, 9000 BCE to 1600 CE - The History of Toronto: An 11,000-Year Journey - Virtual Exhibits | City of Toronto'. City of Toronto. Accessed 3 April 2020. https://web.archive.org/web/20150416111209/https:// www1.toronto.ca/wps/portal/contentonly?vgnextoid=dd058d577e312410VgnVCM10000071d60f89RCRD.

Fischer, Nan. 'What Is Permaculture? And How to Apply It to Your Garden'. Nature’s Path, 7 August 2018. https:// www.naturespath.com/en-ca/blog/what-is-permaculture/.

———. 'Food Chains \& Food Webs'. Khan Academy. Accessed 23 January 2020. https://www.khanacademy.org/ science/biology/ecology/intro-to-ecosystems/a/food-chains-food-webs.

- - - 'Ford Calumet Environmental Center'. Architizer. Accessed 28 March 2020. https://architizer.com/projects/ ford-calumet-environmental-center/.

Forte, Leah, Jonathan Kitchen, Sharon Lam, Dani Magsumbol, and Clara Shipman. 'Wildlife in the City: Designing Bird-Friendly Roofs in Toronto. Toronto: University of Toronto, n.d.

Frisch, Karl von, and Otto von Frisch. Animal Architecture. 1st ed. New York: Harcourt Brace Jovanovich, 1974.

Fuller, Richard A, Katherine N Irvine, Patrick Devine-Wright, Philip H Warren, and Kevin J Gaston. 'Psychological Benefits of Greenspace Increase with Biodiversity'. Biology Letters 3, no. 4 (22 August 2007): 390-94. https://doi. org/10.1098/rsbl.2007.0149. 
Garrard, Georgia E., Nicholas S. G. Williams, Luis Mata, Jordan Thomas, and Sarah A. Bekessy. 'Biodiversity Sensitive Urban Design'. Conservation Letters 11, no. 2 (2018): e12411. https://doi.org/10.1111/conl.12411.

———. 'Garrison Creek Demonstration Project'. Brown + Storey Architects, 1995. http://www.brownandstorey. com/project/garrison-creek-study/.

- - - 'The Garrison Creek Discovery Walk. BlogTO. Accessed 20 January 2020. https://www.blogto.com/ city/2010/11/the garrison creek discovery walk/.

Gehrt, Stanley D., Seth P. D. Riley, and Brian L. Cypher, eds. Urban Carnivores: Ecology, Conflict, and Conservation. Baltimore: Johns Hopkins University Press, 2010.

Ghisoni, A. A4A : Architecture for Animals. Siracusa, Italy: LetteraVentidue Edizioni srl, 2014.

Gill, Don, and Penelope Bonnett. Nature in the Urban Landscape: A Study of City Ecosystems. Baltimore: York Press, 1973.

Gissen, David. Subnature: Architecture's Other Environments: Atmospheres, Matter, Life. 1st ed. New York: Princeton Architectural Press, 2009.

———. 'Glacial Lake Iroquois'. In Wikipedia, 23 January 2020. https://en.wikipedia.org/w/index.php?title=Glacial Lake Iroquois\&oldid=937253700.

Gould, James L., and Carol Grant Gould. Animal Architects: Building and the Evolution of Intelligence. New York: Basic Books, 2012.

Grady, Wayne. Toronto the Wild: Field Notes of an Urban Naturalist. Toronto: Macfarlane, Watler \& Ross, 1995.

'Grasslands'. 16:9. Planet Earth II. United Kingdom: BBC One, 2016.

- - - 'Growing at a Slower Pace, World Population Is Expected to Reach 9.7 Billion in 2050 and Could Peak at Nearly 11 Billion around 2100'. United Nations Department of Economic and Social Affairs, 17 June 2019. https:// www.un.org/development/desa/en/news/population/world-population-prospects-2019.html.

Grinde, Bjørn, and Grete Grindal Patil. 'Biophilia: Does Visual Contact with Nature Impact on Health and Well-Being?' International Journal of Environmental Research and Public Health 6, no. 9 (31 August 2009): $2332-43$. https://doi.org/10.3390/ijerph6092332.

Grooten, M., and R.E.A. Almond. 'Living Planet Report - 2018: Aiming Higher'. Gland, Switzerland: WWF, 2018. https://wwf.panda.org/knowledge hub/all publications/living planet report 2018/.

Gunawan, Sarah. 'Synanthropic Suburbia. University of Waterloo, 2015. https://uwspace.uwaterloo.ca/handle/10012/9765.

Hadidian, John, and Humane Society of the United States. Wild Neighbors: The Humane Approach to Living with Wildlife. Washington, D.C: Humane Society Press, 2007. 
Hall, Thomas. 'Canadian Artist to Create Bird-Friendly Solar Panels for Buildings'. Canadian Geographic, 30 April 2014. https://www.canadiangeographic.ca/article/canadian-artist-create-bird-friendly-solar-panels-buildings.

Han, Ke-Tsung. 'An Exploration of Relationships Among the Responses to Natural Scenes: Scenic Beauty, Preference, and Restoration'. Environment and Behavior 42, no. 2 (March 2010): 243-70. https://doi. org/10.1177/0013916509333875.

Hancocks, David. Animals and Architecture. Excursions into Architecture. London: H. Evelyn, 1971.

Harrison, Ariane Lourie, ed. Architectural Theories of the Environment: Posthuman Territory. 1 edition. Routledge, 2013.

Heerwagen, Judith, and Gordon Orians. 'Adaptations to Windowlessness: A Study of the Use of Visual Decor in Windowed and Windowless Offices'. Environment and Behavior 18, no. 5 (September 1986): 623-39. https://doi. org/10.1177/0013916586185003.

Heinrich, Bernd, and George A. Bartholomew. 'The Ecology of the African Dung Beetle'. Scientific American 241, no. 5 (November 1979): 146-56. https://doi.org/10.1038/scientificamerican1179-146.

- - - 'Here's What Happens to Urban Animals When Their Habitats Disappear'. CityLab. Accessed 2 April 2020. https://www.citylab.com/environment/2017/11/where-do-urban-animals-go-when-their-habitats-disappear/546002/?fbclid=IwAR169bwU/3fej1w73-4-jnqpmaWtr0LymmXUhTcrebxe6uir6CKv1HPiqP0.

Horrocks, Julia, and Darren Browne. 'Links to Conservation Resources'. The Barbados Sea Turtle Project. Accessed 22 January 2020. http://www.barbadosseaturtles.org/pages/links/index.html.

———. 'How to Choose the Best Barn Owl Nestbox Design'. YouTube, 9 October 2017. https://www.youtube.com/ watch? $=$ zr8qLyAFl k.

—_- 'How Wildlife Bridges over Highways Make Animals—and People_Safer'. Accessed 28 March 2020.

https://www.nationalgeographic.com/animals/2019/04/wildlife-overpasses-underpasses-make-animals-people-saferl.

Howard, Alfredo. 'Bird-Friendly Building Design'. Accessed 17 January 2020. https://www.readkong.com/page/ bird-friendly-building-design-bird-friendly-building-design-4548563.

Huijser, Marcel, John Duffield, Anthony Clevenger, Robert Ament, and Pat McGowen. 'Cost-Benefit Analyses of Mitigation Measures Aimed at Reducing Collisions with Large Ungulates in the United States and Canada: A Decision Support Tool'. Ecology and Society 14, no. 2 (8 September 2009). https://doi.org/10.5751/ES-03000-140215.

Hurn, Samantha. Humans and Other Animals: Cross-Cultural Perspectives Onhuman-Animal Interactions. Anthropology, Culture, and Society. London : New York: Pluto Press ; distributed in the United States of America exclusively by Palgrave Macmillan, 2012.

Ingraham, Catherine T. Architecture, Animal, Human: The Asymmetrical Condition. London, UNITED KINGDOM: Routledge, 2006. http://ebookcentral.proquest.com/lib/ryerson/detail.action?docID=254453. 
- - - 'Inside the Amazon Spheres: The Plants, the Architecture, and a Transforming City'. Curbed Seattle. Accessed 19 April 2020. https://seattle.curbed.com/2018/1/30/16947838/amazon-spheres-seattle-architecture-photos. International), BirdLife International (BirdLife. 'IUCN Red List of Threatened Species: Loggerhead Shrike'. IUCN Red List of Threatened Species, 1 October 2017. https://www.iucnredlist.org/en.

'Islands'. 16:9. Planet Earth II. United Kingdom: BBC One, 2016.

_- - 'The IUCN Red List of Threatened Species'. IUCN Red List of Threatened Species. Accessed 16 April 2020. https://www.iucnredlist.org/en.

Jackson, Laura E. 'The Relationship of Urban Design to Human Health and Condition'. Landscape and Urban Planning 64, no. 4 (August 2003): 191-200. https://doi.org/10.1016/S0169-2046(02)00230-X.

Jacobs, Duncan. 'Carpe Noctem'. Pinterest. Accessed 10 January 2020. https://www.pinterest.ca/ pin/241294492514895861/.

Johnson, Steve. 'WWF Living Planet Report'. Synergist, 31 October 2016. https://www.synergist.co.uk/info-hub/ blog/2016/october/wwf-living-planet-report.

Joyce, Christopher. 'Building For Birds: Architects Aim For Safer Skies'. NPR, 9 August 2012. https://www.npr. org/2012/08/09/157792377/building-for-birds-architects-aim-for-safer-skies.

'Jungles'. 16:9. Planet Earth II. United Kingdom: BBC One, 2016.

Kadinsky, Sergey. 'Garrison Creek, Toronto'. Hidden Waters Blog (blog), 14 March 2016. https://hiddenwatersblog. wordpress.com/2016/03/14/garrison-creek-toronto/.

Kaufman, Kenn. 'Barn Owl'. Audubon, 13 November 2014. https://www.audubon.org/field-guide/bird/barn-owl.

Kellert, Stephen R. Birthright: People and Nature in the Modern World. New Haven: Yale University Press, 2012.

Kellert, Stephen R., and Edward O. Wilson, eds. The Biophilia Hypothesis. Washington, D.C: Island Press, 1993.

King, Jason. 'Toronto Lost Rivers'. Hidden Hydrology (blog), 11 July 2017. http://www.hiddenhydrology.org/toronto-lost-rivers/.

Krzycka, Liliana, and Rafal Pieszko. 'Architecture for Animals: Cities for People and Animals'. Future Architecture. Accessed 11 January 2020. http://futurearchitectureplatform.org/projects/142c61c7-2029-4dd5-a895d367ae870a 83/.

Landau, Diana, and Shelley Stump. Living with Wildlife: How to Enjoy, Cope with, and Protect North America's Wild Creatures around Your Home and Theirs. San Francisco: Sierra Club Books, 1994.

Lee, Tracy, Anthony Clevenger, and Robert Ament. 'Highway Wildlife Mitigation Opportunities for The Trans-Canada Highway in the Bow River Valley'. Calgary, Alberta, Canada, August 2012. 
- - - 'Little Brown Bat'. Canadian Wildlife Federation. Accessed 15 April 2020. https://cwf-fcf.org/en/resources/ encyclopedias/fauna/mammals/little-brown-bat.html.

- - - 'Little Brown Bat Stretches and Yawns before Taking a Nap' YouTube, 9 April 2011. https://www.youtube. com/watch?v=AxExwByOb9c.

-——. 'Living Planet Report - 2018: Aiming Higher - Summary'. Gland, Switzerland: WWF, n.d. https://wwf. panda.org/knowledge hub/all_publications/living_planet_report_2018/.

- - - 'Living Planet Report Canada'. WWF-Canada. Accessed 2 April 2020. http://www.wwf.ca/about us/lprc/.

_-_. 'Living Planet Report Canada: A National Look at Wildlife Loss - Report'. Toronto: WWF-Canada, 2017. http://www.wwf.ca/about us/lprc/.

- - - 'Living Planet Report Canada: A National Look at Wildlife Loss - Summary'. Toronto: WWF-Canada, 2017. http://www.wwf.ca/about us/lprc/.

——_. 'Loggerhead Shrike'. The Cornell Lab. Accessed 11 April 2020. https://www.allaboutbirds.org/guide/Loggerhead Shrike/lifehistory.

——_. 'Loggerhead Shrike - Request for Information'. Accessed 11 April 2020. http://people.eku.edu/ritchisong/ shrike.html.

- - - 'Loggerhead Shrike Identification, All About Birds, Cornell Lab of Ornithology'. All About Birds. Accessed 11 April 2020. https://www.allaboutbirds.org/guide/Loggerhead Shrike/id.

Lubell, Sam. 'How to Keep Buildings From Killing Hundreds of Millions of Birds a Year'. Wired, 1 November 2016. https://www.wired.com/2016/11/keep-buildings-killing-hundreds-millions-birds-year/.

Mackay, Richard. The Atlas of Endangered Species. Rev. and Updated. Berkeley: University of California Press, 2009.

Magazine, Hakai. 'Fish in Tubes'. Hakai Magazine. Accessed 28 March 2020. https://www.hakaimagazine.com/article-short/fish-in-tubes/.

Mashegoane, Paul, and ContributorBusiness Leader. 'Population Explosion'. HuffPost, 01:47 400AD. https://www. huffpost.com/entry/population-explosion_b 9837278.

Mayntz, Melissa. 'Where Birds Go At Night, Anyway?' The Spruce, 17 January 2020. https://www.thespruce.com/ where-birds-go-at-night-386443.

Mazis, Glen A. Humans, Animals, Machines: Blurring Boundaries. Albany: SUNY Press, 2008.

Meghna, G. 'Food Chain: Definition, Components and Types'. Zoology Notes (blog), 20 October 2016. http://www. notesonzoology.com/food-chain/food-chain-definition-components-and-types-ecology/3570.

Mies, Rob. 'How to Build a Bat House'. YouTube, 19 September 2014. https://www.youtube.com/ watch?v=V8CheVXf7YY. 
Milius, Susan. 'Stop Blaming Cats: As Many as 988 Million Birds Die Annually in Window Collisions. - The Washington Post'. The Washington Post, 3 February 2014. https://www.washingtonpost.com/national/health-science/ stop-blaming-cats-as-many-as-988-million-birds-die-annually-in-window-collisions/2014/02/03/9837fe80-886611e3-916e-e01534b1e132_story.html.

Mogelgaard, Kathleen. Helping People, Saving Biodiversity: An Overview of Integrated Approaches to Conservation and Development. Occasional Paper (Population Action International). Washington, DC: Population Action International, 2003.

Monbiot, George. Feral: Rewilding the Land, the Sea, and Human Life. Penguin Canada, 2014.

'Mountains'. 16:9. Planet Earth II. United Kingdom: BBC One, 2016.

- - - 'NBRS Architecture-Designed Research and Learning Institute for Taronga Zoo Completed'. ArchitectureAU. Accessed 5 March 2020. https://architectureau.com/articles/nbrs-architecture-designed-research-and-learning-institute-for-taronga-zoo-completed/.

———. 'Nesting Boxes For Birds'. Bird Brick Houses. Accessed 30 March 2020. https://www.birdbrickhouses.co.uk/ brick-nesting-boxes/nesting-boxes/.

- - - 'Nocturnal Flight Calls Increase Building Collisions among Migrating Birds | The University Record'. Accessed 2 April 2020. https://record.umich.edu/articles/nocturnal-flight-calls-increase-building-collisions-among-migrating-birds/?fbclid=IwAR1i-fpDoIZI0zSJ3u1Zi1nSju2XtBtaxM3ShFWNTJdUIE6xZqjZRjhzp E.

Norsworthy, Scott. Waterfall Building, Arthur Erickson. 23 August 2011. Photo. https://www.flickr.com/photos/ scottnorsworthy/6306535135/.

Northrop, Robert. 'Urban Natural Areas \#2 - Habitat Fragmentation Series of Blogs on Ecological Managment of Urban Natural Areas.' University of Florida, 16 December 2019. http://blogs.ifas.ufl.edu/hillsboroughco/2019/12/16/urban-natural-areas-2-habitat-fragmentation/.

- - - 'NYC Sky Condo - New York City Farm Tower'. Archilovers, 6 June 2015. https://www.archilovers.com/ projects/157848/nyc-sky-condo.html.

O’Neil, Lauren. 'Hundreds of Baby Seagulls Rescued after Jumping from Hot Roof in Toronto' blogTO, 28 June 2018. https://www.blogto.com/city/2018/06/hundreds-baby-seagulls-rescued-after-jumping-hot-roof-toronto/.

———. 'On The Line'. Toronto District School Board. Accessed 19 January 2020. https://www.tdsb.on.ca/ Adult-Learners/Skills-Development/On-The-Line.

_- - 'Ontario Bat Guide’. Ontario Nature (blog), 31 October 2018. https://ontarionature.org/ontario-bat-guide/. ——_. 'Our DNA Is 99.9\% the Same as the Person next to Us — and We're Surprisingly Similar to a Lot of Other 
Living Things'. Business Insider, 3 April 2018. https://www.businessinsider.com/comparing-genetic-similarity-between-humans-and-other-things-2016-5.

Parks Canada. 'Bats and White-Nose Syndrome'. YouTube, 7 June 2016. https://www.youtube.com/ watch?v=MQtrDxJRhOU.

- - - 'Permaculture'. In Wikipedia, 4 March 2020. https://en.wikipedia.org/w/index.php?title=Permaculture\&ol$\underline{\operatorname{did}=943884028}$.

Polo, Marco. 'Environment as Process'. Canadian Architect, n.d., 14-19.

_-_. 'Protecting Sea Turtles'. Accessed 22 January 2020. http://www.barbadosseaturtles.org/pages/faqs/index. $\underline{\text { html. }}$

Primack, Richard B. Essentials of Conservation Biology. Sixth edition. Sunderland, Massachusetts, U.S.A: Sinauer Associates, Inc., Publishers, 2014.

- - - 'A Quote by David Attenborough'. Good Reads. Accessed 18 April 2020. https://www.goodreads.com/ quotes/3243300-no-one-will-protect-what-they-don-t-care-about-and.

——_. 'Rabies Info'. Bat World Sanctuary. Accessed 16 April 2020. https://batworld.org/rabies-info/.

_- - 'Raccoon'. Online Etymology Dictionary. Accessed 16 April 2020. https://www.etymonline.com/word/raccoon.

———. 'Raccoon Facts'. Nature, 7 February 2012. https://www.pbs.org/wnet/nature/raccoon-nation-raccoon-factsheet/7553/.

Ramsey, Lydia, and Samantha Lee. 'Humans Share Almost All of Our DNA with Cats, Cattle and Mice'. The Independent, 6 April 2018. https://www.independent.co.uk/news/science/human-dna-share-cats-cattle-mice-same-genetics-code-a8292111.html.

Ramsey, Matthew. 'For the Love of Birds: Saving Species at UBC Is a Campus-Wide Initiative'. UBC News, 26 April 2019. https://news.ubc.ca/2019/04/26/for-the-love-of-birds-saving-species-at-ubc-is-a-campus-wide-initiative/.

Ravenscroft, Tom. 'Eight Buildings That Incorporate Waterfalls'. Dezeen, 21 March 2019. https://www.dezeen. com/2019/03/21/buildings-waterfall-architecture/.

-_- 'Reports'. Toronto Ravine Revitalization Study (blog), 15 April 2016. https://torontoravines.org/reports/.

- - - 'Rescuers Rush to Save Birds That Hit NASCAR Hall of Fame, as Theories Emerge on Cause'. charlotteobserver. Accessed 6 April 2020. https://www.charlotteobserver.com/news/local/article236350023.html.

_- - 'Rewilding the Gardiner Expressway'. Rewilding the Gardiner Expressway. Accessed 2 April 2020. https:// rewildingthegardiner.com/. 
Richard, Bryan. The Ultimate Guide to Wildlife of North America: Fact and Photo Filled Practical Guide. 2011th ed. New York: Parragon, n.d.

Ritchie, Hannah, and Max Roser. 'Land Use'. Our World in Data, September 2019. https://ourworldindata.org/landuse.

Roberts, Alice. Evolution: The Human Story, 2nd Edition. Revised edition. New York: DK, 2018.

Robertson, Chrisanne. 'Animal Rights Group PETA Awards Aqua Tower for Bird-Friendly Design'. Pinterest. Accessed 17 January 2020. https://www.pinterest.ca/pin/81064862013479725/.

Rosenberg, Kenneth V., Adriaan M. Dokter, Peter J. Blancher, John R. Sauer, Adam C. Smith, Paul A. Smith, Jessica C. Stanton, et al. 'Decline of the North American Avifauna'. Science 366, no. 6461 (4 October 2019): 120-24. https:// doi.org/10.1126/science.aaw1313.

Roser, Max. 'Future Population Growth'. Our World in Data, 9 May 2013. https://ourworldindata.org/future-population-growth.

———. 'Save Our Sea Turtles -’. Accessed 22 January 2020. http://sos-tobago.org/.

Sandilands, A. P., and Ross D. James. Nonpasserines: Shorebirds through Woodpeckers. Birds of Ontario : Habitat Requirements, Limiting Factors,and Status. Vancouver: UBC Press, 2010.

Semeniuk, Ivan. 'As Canada's Habitats Disappear, Conservation Needs to Start on Our Doorstep'. The Globe and Mail, 21 June 2019. https://www.theglobeandmail.com/canada/article-biodiversity-doesnt-stop-at-the-city-limits-and-conservation-needs/.

Shriya, S. 'Food Chains, Food Webs and Trophic Levels. Zoology Notes (blog), 11 January 2017. http://www. notesonzoology.com/food-chain/food-chains-food-webs-and-trophic-levels-environment/6583.

_- - 'Sir David Attenborough's Best Quotes'. Eco-Age, 5 December 2018. https://eco-age.com/news/david-attenboroughs-best-quotes.

Skinner, Justin. 'AT ISSUE: Sprucing up Bickford Centre'. Toronto.com, 6 May 2011. https://www.toronto.com/ news-story/63850-at-issue-sprucing-up-bickford-centre/.

———. 'SLA - Urbanity | Strategy | Landscape'. Accessed 27 March 2020. https://www.sla.dk/en/.

Spivack, Caroline. 'State Bird-Friendly Buildings Bill Hits Roadblock as City Mulls Design Solutions'. Curbed NY, 21 November 2019. https://ny.curbed.com/2019/11/21/20975012/new-york-bird-friendly-buildings-veto-andrewcuomo.

Staff, TreeHugger, TreeHugger Staff, and TreeHugger Staff. 'Buildings Kill A Billion Birds A Year; Its Time To Stop This Carnage. Fast Company, 27 April 2011. https://www.fastcompany.com/1750228/buildings-kill-billion-birdsyear-its-time-stop-carnage. 
———. 'The State of Canada's Birds'. NABCI Canada, 2019. http://nabci.net/resources/state-of-canadasbirds-2019/.

- _ - 'The State of the World's Sea Turtles'. The State of the World's Sea Turtles. Accessed 22 January 2020. https://www.seaturtlestatus.org.

Steffen, Will, Wendy Broadgate, Lisa Deutsch, Owen Gaffney, and Cornelia Ludwig. 'The Trajectory of the Anthropocene: The Great Acceleration'. The Anthropocene Review 2, no. 1 (April 2015): 81-98. https://doi. org/10.1177/2053019614564785.

———. 'Striped Skunk'. Canadian Wildlife Federation. Accessed 17 April 2020. https://cwf-fcf.org/en/resources/ encyclopedias/fauna/mammals/striped-skunk-1.html.

- - - 'Studio Gang Projects - Ford Calumet Environmental Center'. Accessed 27 March 2020. https://studiogang. com/project/ford-calumet-environmental-center.

Uy, Stephanie. 'For the Birds! A Rooftop Bird Garden (in Toronto)'. M.Arch., Carleton University (Canada), 2013. http://search.proquest.com/docview/1437151060/abstract/E2CDF1F91174F38PQ/1.

Vartan, Starre. 'Wildlife Bridges over Highways Make Animals and People Safer'. Animals, 16 April 2019. https:// www.nationalgeographic.com/animals/2019/04/wildlife-overpasses-underpasses-make-animals-people-safer/.

- - - 'Vertical Forest'. Stefano Boeri Architetti. Accessed 18 January 2020. https://www.stefanoboeriarchitetti. $\underline{\text { net/en/project/vertical-forest/. }}$

Villazon, Luis. 'How Many Species Have Yet to Be Discovered?' Science Focus: The Home of BBC Science Focus Magazine, 2016. https://www.sciencefocus.com/nature/how-many-species-have-yet-to-be-discovered/.

Villegas, Tim. 'We Posted an Image about Inclusion on Facebook and Everybody Freaked out. This Is Why'. Think Inclusive (blog), 11 July 2017. https://www.thinkinclusive.us/inclusion-exclusion-segregation-integration-different/.

Vincent, Donovan. 'Why Our Ravines Are the City below Toronto'. The Star, 7 August 2016. https://www.thestar. com/news/gta/2016/08/07/why-our-ravines-are-the-city-below-toronto.html.

- - - 'We Live in a Very Special Ecosystem — and It Needs Our Help'. thestar.com, 2 August 2019. https://www. thestar.com/life/homes/2019/08/02/residents-of-the-gta-live-in-a-very-special-ecosystem-and-it-needs-our-help. html. 
Weppner, Hannah. 'Response 4: Art on Campus'. Hannah's Place and Space (blog), 4 October 2015. http://hannahsplaceandspace.weebly.com/5/category/all.

Wernick, Jane. 'What Can Transform a Raod into a Place?' ARC Solutions. Accessed 30 March 2020. https:// arc-solutions.org/new-methods/.

———. 'Why Do Some Species Thrive in Cities?' YouTube, 27 March 2015. https://www.youtube.com/ watch?v=4LDGzXpei8k.

Wood, Chris. 'On Nature’s Death Row: Ontario's Vanished “Carolinian” Forest'. The Tyee. The Tyee, 4 February 2016. http://thetyee.ca/News/2016/02/04/Ontario-Carolinian-Forest/.

———. 'World Population Clock: 7.8 Billion People (2020)'. Worldometer. Accessed 25 January 2020. https://www. worldometers.info/world-population/.

Yamchomsuan, Phuchong. 'The Banyan Tree Skyscraper Was Designed To Support Humans And Wildlife'. Architecture Magazine. eVolo, 11 July 2016. http://www.evolo.us/the-banyan-tree-skyscraper-was-designed-to-supporthumans-and-wildlife/.

Zwan, Adam van der. 'Ottawa Working towards Guidelines to Keep Birds from Colliding with Glass Buildings'. Capital Current: Covering Ottawa Communities, 2019. https://capitalcurrent.ca/ottawa-working-towards-guidelines-to-keep-birds-from-colliding-with-glass-buildings/. 

(c) Simon Sharon Gordon, 2020 